Biblioteca di Studi Slavistici

$-41-$ 
DiRETTORE RESPONSABILE

Laura Salmon (Università di Genova)

SEGRETERIA DI REDAZIONE

Maria Bidovec (Università di Napoli "L'Orientale")

REDAZIONE

Rosanna Benacchio (Università di Padova)

Maria Cristina Bragone (Università di Pavia)

Giuseppe Dell'Agata (Università di Pisa)

Claudia Olivieri (Università di Catania)

Francesca Romoli (Università di Pisa)

Laura Rossi (Università di Milano)

Comitato SCIENTIFICO INTERNAZIONALE

Maria Di Salvo (Università di Milano)

Alexander Etkind (European University Institute)

Lazar Fleishman (Stanford University)

Marcello Garzaniti (Università di Firenze)

Lucyna Gebert (Università di Roma "La Sapienza")

Harvey Goldblatt (Yale University)

Mark Lipoveckij (University of Colorado-Boulder)

Jordan Ljuckanov (Bălgarska Akademija na Naukite)

Roland Marti (Universität des Saarlandes)

Michael Moser (Universität Wien)

Ivo Pospíšil (Masarykova univerzita)

Krassimir Stantchev (Università Roma Tre) 


\section{La lirica di Vasyl' Stus}

Modernismo e intertestualità poetica nell'Ucraina del secondo Novecento

Alessandro Achilli

Firenze University Press

2018 
La lirica di Vasyl' Stus : modernismo e intertestualità poetica nell'Ucraina del secondo Novecento / Alessandro Achilli. - Firenze : Firenze University Press, 2018. (Biblioteca di Studi Slavistici ; 41)

http://digital.casalini.it/9788864538143

ISBN 978-88-6453-813-6 (print)

ISBN 978-88-6453-814-3 (online PDF)

ISBN 978-88-6453-815-0 (online EPUB)

La collana Biblioteca di Studi Slavistici, $(<\mathrm{http} / /$ www.fupress.com/collane/biblioteca-di-studislavistici/47>), fondata per iniziativa dell'Associazione Italiana degli Slavisti, opera in sinergia con la rivista Studi Slavistici ( $<$ http://fupress.com/riviste/studi-slavistici/17 $>)$.

Editing e progetto grafico: Alberto Alberti.

Questo volume è stato pubblicato grazie al contributo della School of Languages, Literatures, Cultures and Linguistics della Monash University, Australia.

In copertina: Vasyl' Stus, KGB, 1980 (Wikimedia Commons)

\section{Certificazione scientifica delle Opere}

Tutti i volumi pubblicati sono soggetti ad un processo di referaggio esterno di cui sono responsabili il Consiglio editoriale della FUP e i Consigli scientifici delle singole collane. Le opere pubblicate nel catalogo della FUP sono valutate e approvate dal Consiglio editoriale della casa editrice. Per una descrizione più analitica del processo di referaggio si rimanda ai documenti ufficiali pubblicati sul catalogo on-line della casa editrice (www.fupress.com).

Consiglio editoriale Firenze University Press

A. Dolfi (Presidente), M. Boddi, A. Bucelli, R. Casalbuoni, M. Garzaniti, M.C. Grisolia, P. Guarnieri, R. Lanfredini, A. Lenzi, P. Lo Nostro, G. Mari, A. Mariani, P.M. Mariano, S. Marinai, R. Minuti, P. Nanni, G. Nigro, A. Perulli, M.C. Torricelli.

La presente opera è rilasciata nei termini della licenza Creative Commons Attribution 4.0 International (CC BY 4.0: http://creativecommons.org/licenses/by/4.0/legalcode).

This book is printed on acid-free paper

CC 2018 Firenze University Press

Università degli Studi di Firenze

Firenze University Press

via Cittadella, 7, 50144 Firenze, Italy

www.fupress.com

Printed in Italy 
A Giulia 

Questo lavoro è il frutto di anni di letture, esperienze e discussioni. Senza il sostegno e la pazienza della mia famiglia ciò non sarebbe stato possibile. Ringrazio Giovanna Brogi per il suo costante supporto, i suoi stimoli e la sua fiducia. Ringrazio Marko Pavlyshyn per avermi sostenuto in momenti cruciali del mio percorso e per le possibilità che mi ha dato. Last but not least, sono grato a Maria Grazia Bartolini e Marco Puleri, che ho il privilegio di considerare amici prima che colleghi. 



\section{Indice}

$\begin{array}{ll}\text { Introduzione } & \text { XI }\end{array}$

Capitolo primo Vasyl' Stus, il suo tempo e la ricezione della sua opera 1

Capitolo secondo $\quad$ Stus lettore e critico

$\begin{array}{lll}\text { Capitolo terzo } & \text { La lirica giovanile } & 63\end{array}$

$\begin{array}{lll}\text { Capitolo quarto } & \text { La lirica mediana } & 109\end{array}$

$\begin{array}{lll}\text { Capitolo quinto } & \text { La poesia della maturità } & 201\end{array}$

Capitolo sesto Modernismo e intertestualità modernista nell'universo poetico stusiano $\quad 323$

$\begin{array}{ll}\text { Riflessioni conclusive } & 335\end{array}$

$\begin{array}{ll}\text { Bibliografia } & 337\end{array}$

$\begin{array}{ll}\text { Abstract } & 370\end{array}$ 



\section{Introduzione}

\section{Osservazioni generali}

Questo lavoro nasce dall'esigenza di una lettura approfondita dell'opera di Vasyl' Stus (1938-1985), una delle voci più importanti della poesia ucraina della tarda età sovietica. Da alcuni considerato come il maggiore poeta ucraino del Novecento (Finnin 2014; Zabuzhko 1995: 271), Stus ha lasciato in eredità al pubblico e alla critica un'opera ampia, complessa, sfaccettata, profondamente intellettuale e sorprendentemente inattuale sullo sfondo del contesto storicosociale da cui essa è in buona parta scaturita, ossia gli anni della Stagnazione brežneviana. Certamente debitrice del clima di relativa apertura culturale del Disgelo post-staliniano, la poesia stusiana si è ritrovata a condividere le attenzioni di lettori e studiosi con la figura del suo autore, assurto a eroe nazionale in concomitanza con la rinascita dell'Ucraina indipendente. Ciò ha condotto a un frequente appiattimento dell'interpretazione della lirica di Stus al mero dato biografico, con particolare riferimento all'ultimo periodo della vita del poeta, segnato da oltre vent'anni di prigionia e confino a causa del suo operato in difesa della cultura ucraina, della libertà di parola e di espressione artistica e dei diritti umani in Unione Sovietica. Una lettura acritica della poesia di Stus si è in molti casi accompagnata a una sacralizzazione della sua figura a scapito di un approccio al testo puramente letterario. Come ha scritto di recente Marko Pavlyshyn, uno dei pochi critici a essersi occupato dell'opera stusiana al di fuori dell'Ucraina, "[h]ow Stus might be viewed relative to Rilke or Pasternak was of less interest than what he could teach the inhabitants of post-Soviet Ukraine through the example of his life" (Pavlyshyn 2010: 602). Questo studio cercherà di colmare almeno in parte la lacuna correttamente e provocatoriamente evidenziata da Pavlyshyn.

Necessaria ai fini di una prima risposta agli interrogativi sollevati da Pavlyshyn sarà tuttavia una trattazione adeguata della poesia stusiana nel suo complesso, a tutt'oggi non ancora disponibile. Obiettivo delle pagine che seguono sarà dunque una ricostruzione integrale del percorso poetico di Stus dagli esordi tra gli anni Cinquanta e Sessanta alla fine degli anni Settanta. Si cercherà di mostrare la straordinaria varietà tematica e stilistica della poesia stusiana nel suo insieme, individuandone in ogni sua fase le caratteristiche 
precipue. Si metterà in evidenza allo stesso tempo l'intenso dialogo intercorso tra la lirica stusiana e i modelli che sembrano averla maggiormente influenzata. Da un'iniziale panoramica degli interessi letterari di Stus, poeta e studioso, così come dallo sviluppo del suo fare poetico, emergerà l'importanza per la sua formazione di tre tradizioni nello specifico, ovvero la letteratura ucraina, russa e tedesca.

La prima di esse si configura come un fondamentale elemento di identificazione culturale per un poeta appartenente a una civiltà letteraria non sostenuta da una statualità e dunque naturalmente incline a concedere ai suoi scrittori l'oneroso status di colonne portanti dell'identità nazionale ${ }^{1}$.

Non meno significativo si rivelerà per Stus il costante riferimento alla letteratura russa, nella sua percezione straniera e vicina allo stesso tempo. Poeta ucraino e ucrainofono, ma cresciuto e formatosi nel russofono Donbas urbano, Stus, come molti altri scrittori ucraini ritrovatisi in una simile situazione linguistico-culturale, si confrontò incessantemente con una letteratura, quella russa, allo stesso tempo familiare ed estranea, meno soggetta tanto a pressioni censorie, quanto alla necessità di farsi strumento politico di liberazione nazionale, dunque, almeno in parte, più libera. Si osserverà come alle frequenti dichiarazioni di interesse di Stus per la letteratura russa, e per la poesia russa nello specifico, corrisponda nella sua lirica un'effettiva interazione intertestuale con quest'ultima. Si cercherà dunque di mostrare come il libero e consapevole dialogo di Stus con la poesia russa si situi al polo opposto di quella "coercitive intertextuality" a lungo imposta alla cultura ucraina dalla dominazione imperiale e sovietica. La sostanziale mancanza di contributi critici su questo argomento sembra riecheggiare e confermare le ancora attuali considerazioni espresse da George G. Grabowicz nel 1992 sull'arretratezza degli studi comparatistici russo-ucraini, ora eloquentemente assenti, ora pesantemente viziati da vincoli dottrinali (Grabowicz 1992).

Ci si convincerà di come la lotta per l'indipendenza politica e culturale dell'Ucraina portata avanti da Stus non sia da confondere con la sua poesia, assolutamente esente da condizionamenti ideologici e, come correttamente osservato da Myroslav Shkandrij, libera da dinamiche di opposizione e complessi di inferiorità (Shkandrij 2001: 257). La consapevolezza della maturità del proprio fare poetico significò dunque per Stus la possibilità di confrontarsi alla pari con la tradizione letteraria russa, non più vissuta come un ingombrante fattore di oppressione, ma come uno stimolante interlocutore ${ }^{3}$.

1 Cfr. Rothe 2010. Sull'inevitabilità di un profondo e complesso legame tra poesia e politica - nel senso più ampio del termine - nelle civiltà letterarie dell'Europa orientale si veda anche Cavenagh 2009. 2006: 452

Dal titolo di una comunicazione di John Fizer del 1985, riportato in: Naydan

3 Sul complesso processo di emancipazione della cultura ucraina dalla "narrazione pan-russa' imperiale e sovietica cfr. tra gli altri Ilnytzkyj 2003. 
La letteratura di lingua tedesca, infine, rimase sin dagli anni degli studi universitari al centro delle passioni letterarie di Stus, uno dei massimi traduttori di poesia tedesca in ucraino. La sua profonda conoscenza della letteratura e nello specifico della poesia tedesca emergerà dalla discussione degli scritti critici e dell'epistolario di Stus.

Si avrà modo di osservare ampiamente come tra i nomi e le correnti più significativi per la formazione umana e letteraria di Stus spicchino in particolare quelli di Rainer Maria Rilke, Taras Ševčenko, Boris Pasternak, Johann Wolfgang Goethe, Marina Cvetaeva, Hryhorij Skovoroda e Mykola Zerov, nonché la tradizione dell'Espressionismo.

Nel primo capitolo, dopo alcuni cenni alla tormentata vicenda biografica di Stus, si discuteranno le caratteristiche distintive del contesto in cui egli si formò come scrittore, ovvero il complesso movimento di rinnovamento socio-culturale passato alla storia come šistdesjatnyctvo. Verranno discusse le particolarità della situazione ucraina nel più ampio contesto sovietico, nonché le principali tendenze della poesia ucraina nei primi decenni della seconda metà del Novecento, allargando lo sguardo anche alla produzione dell'emigrazione d'oltreoceano. Si passerà poi a una rassegna delle principali tendenze critiche che hanno segnato gli studi stusiani dalle loro origini a oggi, per mettere in evidenza come lo stato attuale degli studi, dopo le prime, importanti prove degli anni Ottanta e Novanta, non risulti all'altezza della complessità e del valore del suo oggetto di indagine.

$\mathrm{Nel}$ secondo capitolo si procederà a una disamina degli interessi letterari di Stus, con particolare attenzione dapprima agli scritti critici e poi all'epistolario. Si rifletterà sulle frequenti accuse di immaturità e inadeguatezza che Stus rivolse alla civiltà letteraria ucraina come sintomo della sua volontà di contribuire attivamente al suo ammodernamento. Emergeranno inoltre concrete dimostrazioni della sua profonda conoscenza degli autori con cui la sua lirica sembra avere intrattenuto un più intenso e proficuo confronto poetico.

Nei tre capitoli successivi si esaminerà da vicino l'opera stusiana nel suo percorso diacronico, secondo i principi descritti sopra: uno studio delle caratteristiche stilistiche, tematiche e compositive delle singole raccolte poetiche stusiane si affiancherà a una discussione del dialogo intertestuale che le plasma profondamente. Si inizierà dunque, nel terzo capitolo, dai versi giovanili dei tardi anni Cinquanta e dei primi anni Sessanta, segnati da un'irrefrenabile volontà di sperimentare svariati linguaggi e tradizioni. Si osserverà il peso del modello pasternakiano per il primo Stus, così come l'importanza nel suo palinsesto poetico di alcune vette della letteratura ucraina, quali Hryhorij Skovoroda (1722-1794), Taras Ševčenko (1814-1861) e Pavlo Tyčyna (1891-1967). Si prenderanno in esame sia i primi tentativi di organizzazione dell'ampio e variegato materiale poetico (Delo №13 / BE1339 e Kruhovert' ['Vortice']), sia le numerose liriche sparse.

Al centro del capitolo successivo saranno le due raccolte dei tardi anni Sessanta. Zymovi dereva ('Alberi d'inverno'), pubblicata in tamizdat nel 1970, è un'ideale sintesi dell'apprendistato poetico stusiano. L'attenzione verterà sull'accentuata polifonia della raccolta, anch'essa votata all'accostamento di un'ampia 
gamma di stili, e sulla comprensione della sua struttura compositiva, con particolare attenzione alla prima parte. Si osserverà anche la crescente importanza dei nomi di Marina Cvetaeva e Rainer Maria Rilke per la determinazione del complesso intertestuale della poesia di Stus. Si avrà quindi modo di notare le profonde differenze che intercorrono tra Zymovi dereva e Veselyj cvyntar ('L'allegro cimitero'), composta solo pochi mesi più tardi, ma incentrata sul tentativo di creare un linguaggio poetico (relativamente) unitario e monologico.

Il quinto capitolo affronterà le due raccolte dello Stus maturo. La prima di esse, Ćas tvorčosti / Dichtenszeit ('Il tempo dell'arte / Dichtenszeit'), è fortemente segnata dai dolorosi eventi intercorsi nella vicenda biografica del poeta nel 1972. Si rifletterà sulla correttezza di una possibile lettura dell'opera in chiave diaristica, nonché sul rapporto tra la prima parte della raccolta, costituita da liriche stusiane originali, e quella che, anche sulla base del titolo stesso dell'opera, è considerata la sua seconda parte, composta esclusivamente da traduzioni di poesie goethiane. Sulla base di alcuni esempi tratti da queste ultime si cercherà di comprendere le caratteristiche principali del lavoro di Stus sulla lirica di Goethe e il rapporto tra gli universi poetici dei due scrittori.

L'analisi della lirica di Stus sarà coronata, nella seconda parte del quinto capitolo, da quello che è comunemente ritenuto il suo capolavoro, ossia la raccolta Palimpsesty ('Palinsesti') della seconda metà degli anni Settanta, nella quale sono confluite numerose liriche tratte dalle raccolte precedenti, nonché suggestioni e ispirazioni stilistiche e tematiche provenienti da svariati episodi della storia della letteratura. Non si mancherà di ragionare, inoltre, sui punti di contatto e di divergenza nelle scelte compositive alla base rispettivamente di Čas tvorčosti / Dichtenszeit e Palimpsesty.

$\mathrm{Al}$ centro del sesto e ultimo capitolo sarà invece una sintesi delle tendenze emerse dai close-reading e dalle generalizzazioni emerse nelle numerose pagine precedenti, con il duplice obiettivo di una piena comprensione del dialogo di Stus con gli scrittori più significativi per la sua poesia, da una parte, e di una sua collocazione nel complesso panorama della letteratura occidentale novecentesca, dall'altra. Al centro della discussione sarà la possibilità di situare l'esperienza poetica stusiana nell'ambito del Modernismo europeo, anche in virtù dell'importanza che il dialogo con poeti ascrivibili alla tradizione modernista quali Rilke, Pasternak e Cvetaeva assume nella sua configurazione.

Per quanto riguarda le citazioni delle liriche di Stus si farà riferimento con le sigle $T$ e $Z T$, seguite dal numero del volume e della pagina, alle due edizioni delle opere stusiane al momento disponibili, rispettivamente Tvory (1994-1998) e Zibrannja tvoriv (2007-2009). L'edizione di quest'ultima è purtroppo ferma a quattro tomi sui dodici previsti, nei quali sono presentate rispettivamente la poesia giovanile sino a Kruhovert' e le liriche sparse degli anni Sessanta, Čas tvorčosti / Dichtenszeit, le liriche sparse degli anni Settanta e Palimpsesty. Per una discussione delle due edizioni si rimanda alla panoramica sullo status quaestionis degli studi stusiani.

Tutte le traduzioni, salvo ove diversamente indicato, sono da ritenersi di chi scrive. 


\section{Metodologia e terminologia}

Nel corso della trattazione si farà ampiamente uso di termini e concetti tanto comunemente in uso nella critica letteraria, quanto semanticamente e scientificamente instabili e, dunque, passibili di continue reinterpretazioni.

Primo di essi è lirica. In sintonia con le caratteristiche profonde dell'arte stusiana e con gli sviluppi più recenti degli studi sul linguaggio poetico, si è scelto di utilizzare i termini lirica e poesia come sinonimi. Com'è stato osservato di recente, infatti,

[...] lyric has become an umbrella term for most versified literature (except for the epic and verse drama) and has thus become a synonym of 'poetry' [...]: in fact no distinction between 'the lyric', 'poetry' and 'poems' seems to be appropriate any longer $[\ldots]^{4}$.

Particolarmente frequente sarà l'uso del termine io lirico. Introdotta per la prima volta in ambito tedesco all'inizio del secolo scorso, questa categoria ha indubbiamente beneficiato della svolta antibiografica e testualista tipica della più autorevole e innovativa Literaturwissenschaft novecentesca. Ora potente espressione di un'incontenibile soggettività (Hamburger 1977), ora puro espediente linguistico di organizzazione del discorso ${ }^{5}$, il concetto di io lirico, come è noto, si è affermato nella critica post-positivista come necessario strumento di delimitazione tra lo spazio biografico dell'autore e la testualità. Esso, tuttavia, non è ancora riuscito a imporsi come consueto strumento interpretativo per il lettore non specializzato, generalmente propenso all'equazione tra la prima persona singolare della lirica e la personalità del poeta che l'ha composta. Non sono inoltre mancati recenti tentativi di estromissione dell'io lirico dalla pratica critica nel panorama di un armamentario interpretativo ancora più complesso e articolato ${ }^{6}$.

Nel caso della civiltà letteraria ucraina, l'identificazione spontanea dell'io con lo scrittore, in molti casi parzialmente giustificata da un frequente sostrato

4 Wolf 2005: 23. Si veda anche l'ormai classico Culler 1988, più attento all'intrinseca problematicità dei termini lirica e poesia e alle contraddizioni che hanno segnato il loro utilizzo nel corso del Novecento. La distanza cronologica tra i due contributi sembra tuttavia confermare l'affermarsi della sinonimia tra i due termini nella pratica scientifica e nella riflessione metacritica. Si veda anche, infine, la breve introduzione a un recente numero monografico della rivista "Journal of Literary Theory", interamente dedicato alla teoria della lirica (Hillebrandt et al. 2017).

5 Si veda la rassegna bibliografica in Charpa 1985: 149-153. Cfr. anche Schlaffer 1995. Lo studioso tedesco parla di "pseudopragmatica" della lirica (49) e nega l'“espressività" dell'io lirico. Si vedano anche i recenti Burdorf 2017 e Stahl 2017.

6 Cfr. ad esempio Schönert 1999, incentrato sulle aporie legate all'utilizzo della categoria dell'io lirico in uno schema che preveda anche per l'analisi del testo poetico, in conformità con la narratologia, la presenza di un autore implicito. Si veda a questo proposito la nota seguente. Per un approccio analogo in ambito slavistico si veda, tra gli altri, Grübel 1987. 
storico-biografico nel formarsi dell'emozionalità lirica, è a tutt'oggi predominante nella critica. Solidi studi sulla natura del principio soggettivo della lirica nella critica ucraina sono infatti pressoché inesistenti ${ }^{7}$. Ciò ha portato a una persistente situazione di inadeguatezza nel trattamento della specificità letteraria del testo in quanto tale, al di là dei frequenti e in certi casi evidenti legami di quest'ultimo con la realtà extratestuale. La confusione tra l'io lirico della poesia stusiana e Vasyl' Stus, come si è già accennato e come si avrà modo di approfondire analizzando le principali tendenze degli studi stusiani, ha rappresentato e tuttora rappresenta una delle tendenze maggiormente limitanti per un reale approfondimento critico dei testi in questione.

Come si è accennato, le circostanze che hanno accompagnato la creazione della poesia stusiana matura degli anni Settanta hanno favorito in molti casi un'acritica sovrapposizione tra l'universo lirico in cui il soggetto è immerso e il dato biografico dell'autore, segnato dalle condizioni inumane dell'incarcerazione e dell'esilio. Il lettore, sia critico che amatoriale, ha ignorato di frequente che il 'mondo' rappresentato nel e dal testo poetico è un mondo di finzione, che non può essere identificato tout court con il vissuto di chi l'ha creato. Si ricordino a questo proposito alcune osservazioni di Samuel R. Levin dal suo fondamentale contributo del 1976 sulla natura del testo poetico:

I imagine myself in (a world). The illocutionary force of this utterance is one of the poet's transporting himself or projecting himself into a world of his imagining, a world which he is free to make as different from our world as he pleases. It is a world that cannot be reached by ship or plane, and is thus one which would ordinarily be closed to us. It is a world which only the poet, or the transported image of himself, can know, and which we can discover only from his account of it ${ }^{8}$.

Nelle pagine a seguire ci si riferirà dunque all'io lirico stusiano come al fulcro nevralgico di un testo in cui al principio di soggettività spetta un ruolo di primissimo piano, senza che questo ne escluda o ne neghi la possibile ispirazione autobiografica di base, non di rado oggettivamente inconfutabile ${ }^{9}$. La centralità

7 Ciò risulta particolarmente evidente da un confronto con lo status quaestionis nelle vicine culture letterarie di Russia e Polonia. Per quanto riguarda gli studi sull'io lirico in area polacca si veda la bibliografia indicata in: Marinelli 2002: 239; per la scuola russa cfr., tra gli altri, Weststeijn 2000 e Brojtman 1997.

8 Levin 1976: 154. Si noti come Levin tenda a identificare inaspettatamente l'autore e l'io lirico.

9 Per un approccio inclusivo all'io lirico, che, ribadendone innanzitutto il carattere euristico, non ne neghi a priori i legami con l'autore, senza per questo vedere in essi l'elemento di maggiore interesse per l'analisi testuale, cfr. Stephens 1982 e il più recente Fuchs 2009. Non si farà qui invece riferimento alla figura dell'autore implicito, ideale collegamento tra l'io lirico e l'autore. A proposito dell'autore implicito nel testo poetico cfr. Levin 1998: 465. 
dell'io nell'universo lirico stusiano sembra inoltre giustificare l'utilizzo convenzionale dei termini io lirico e soggetto come sinonimi che si adotterà nell'analisi.

Si avrà modo di osservare come il soggetto stusiano si ritrovi apparentemente scisso tra le sfere dell' 'io' e del 'tu'. La seconda persona singolare a cui l'io lirico stusiano si rivolge con insistenza e a tratti con ossessione, al di là dei pochi casi in cui esso è identificabile con un ente esterno, è da interpretarsi nei termini di un espediente atto a realizzare l'analisi del sé che il soggetto porta avanti lungo tutto il percorso poetico. Non si tratta di lacerazione, dunque, ma di rispecchiamento e potenziamento dell' io ${ }^{10}$.

Nell'introduzione a una delle maggiori pubblicazioni degli ultimi anni incentrata su vecchi e nuovi problemi dell'interpretazione della lirica, Eva MüllerZettelmann e Margarete Rubik hanno scritto:

While with the 'emotional school' of lyric criticism the concentration is on the life of the author or reader, for the formalist approach the non-referential interplay of phenomena within the text becomes a focus of contemplation. What is missing is attention to the speech-dependence and fictionality of what is evoked $[\ldots]^{11}$.

In sintonia con un evidente avvicinamento alla narratologia della strumentazione teorica relativa alla poesia, la critica degli ultimi decenni appare dunque sempre più propensa a una rivalutazione del potenziale narrativo di un linguaggio, quale quello della lirica in senso stretto, tradizionalmente ritenuto adiegetico, in opposizione, innanzitutto, a generi ormai meno produttivi come la ballata e il poema ${ }^{12}$.

10 Le ricerche sul 'tu lirico' sono ben distanti dal potersi dire concluse. Spesso toccato rapidamente nei contributi sull'io lirico, il 'tu lirico' è stato oggetto di almeno due monografie, di ambito rispettivamente americanistico (Grabher 1989) e romanistico-comparatistico (Coenen-Mennemeier 2004). Mentre Grabher vede nell'io lirico un narcisistico rispecchiamento dell'io, Coenen-Mennemeier vi legge una sua possibilità di fuga dalla gabbia dell'egotismo. Si vedrà come l'approccio di Grabher sia molto più adatto a descrivere il 'tu lirico' stusiano di quello di Coenen-Mennemeier. Si ricordi anche il contribuito di Ursula Oomen del 1975 sulla comunicazione poetica, incentrato sulla "multiplication of roles" (63) che distingue chiaramente la lirica dal testo in prosa. Si pensi anche, tuttavia, alla letteratura dedicata al "lyric address", concetto più ampio del 'tu lirico' stricto sensu, per cui si rimanda a Waters 2003 e Culler 2015: 186-243.

11 Müller-Zettelmann, Rubik 2005: 8. Il corsivo è mio (AA).

12 Cfr. Hühn 2005: 140: "This paper is based on the assumption that lyric poems generally share the fundamental constituents of story and discourse as well as the narrative act with narrative fiction in that they likewise feature a sequence of incidents (usually of a mental kind), mediate and shape it from a specific perspective and present it from a particular point of time vis-à-vis the sequence of incidents." Per un approccio critico nei confronti dell'accostamento di lirica e narratività cfr. Culler 2015. 
Confortati da questa tendenza, osservabile anche in ambito slavistico ${ }^{13}$, utilizzeremo nei capitoli a venire il termine narrazione lirica in riferimento ai componimenti in cui il vissuto dell'io lirico è organizzato in forma più esplicitamente narrativa.

Ampio utilizzo sarà fatto inoltre dei concetti di poetologia, poesia poetologi$c a$ e poesia metapoetica. Il consenso critico attorno all'utilizzo di questi termini è molto basso e si possono osservare notevoli divergenze tra le varie consuetudini d'uso nazionali. La tradizione nostrana non è effettivamente avvezza ai primi due termini sopraccitati, stabilmente impiantati nella scuola critica di lingua tedesca e, in misura minore, in quella russa e anglosassone. Nelle pagine a venire essi serviranno a descrivere versi o interi componimenti in cui l'io lirico, più $o$ meno esplicitamente raffigurato nei panni del Poeta, descrive la sua vocazione e il suo dono artistico. Parlando di poesia metapoetica ci si riferirà invece alla riflessione sulla poesia, sulle sue possibilità espressive e sui suoi limiti, quale essa emerge dalla poesia stessa. Indubbiamente vicine e anche complementari, la lirica poetologica e la lirica metapoetica si distinguono per l'oggetto privilegiato della loro attenzione, 1' 'uomo' nel primo caso, il linguaggio poetico nel secondo ${ }^{14}$.

13 Si veda anche il seminale Herrnstein Smith 1971. La questione, che non può non portare a riflettere ulteriormente sul problema dell'io lirico e della sua conformazione, è stata abbondantemente discussa anche in ambito slavistico. Se nel 1984 Klaus Dieter Seemann, basandosi su precedenti contributi di studiosi polacchi in primo luogo (A. Okopień-Sławińska, J. Sławiński), si era cautamente arrestato sulla soglia del passaggio da una concezione a-narrativa della lirica al modello oggi probabilmente dominante (cfr. Seemann 1984), Menno Kraan, agli inizi degli anni Novanta, si è spinto decisamente in avanti. Si veda Kraan 1991: 203: "I think lyric texts are fictional, in the same way as dramatic and narrative texts are." Si vedano, inoltre, le interessanti osservazioni dello studioso olandese a proposito dell'io lirico. Ricollegandosi al termine comunemente in uso nella critica russa, ossia "eroe lirico" (liričeskij geroj), Kraan ne ha proposto un'utile ridefinizione. Cfr. ivi: 221-222: "Like Ginzburg [Lidija - AA], I do not think that it is possible to apply this concept with respect to just a single poem. In this respect one should, indeed, think of a cycle of poems or of a certain sequence of poems which have in common a particular theme. Indeed, it is very well possible to apply this concept to the complete works of a poet. [...] the lyric hero can be regarded as the greatest common denominator of all lyric subjects to be found in a certain, limited amount of lyric texts." Per una rassegna dell'approccio 'classico' alla presunta atemporalità e alla conseguente anarratività della lirica si veda anche, in ambito slavistico, Seemann 1988.

14 Nella critica, così anche come nella riflessione metacritica, i due termini che riteniamo qui opportuno mantenere separati sono spesso confusi. Si veda, ad esempio, Müller-Zettelmann 2005: 132: "Metalyric poems refer to lyric inspiration, to the poetic creative process, to the social task of literary creation, or to the intended reader's response." Sandra Pott, nel suo ampio studio sulla lirica poetologica tedesca del 2004, ha invece operato una condivisibile distinzione tra la "lirica sul poeta" (Dichtergedicht) e la "lirica sulla lirica" (Gedichte über Dichtung), considerandole tuttavia come due sottogeneri della lirica poetologica. Cfr. Pott 2004: 10-22. 
Lo studio del dialogo tra la poesia stusiana e gli autori con cui essa sembra aver maggiormente interagito si baserà sulla tassonomia genettiana dell'intertestualità. Fondamentale risulterà dunque il concetti di ipotesto (Genette 1982: 11):

J'entends par là toute relation unissant un texte B (que j'appellerai hypertexte) à un texte antérieur (que j'appellerai, bien sûr, hypotexte) sur lequel il se greffe d'une manière qui n'est pas celle du commentaire.

Ci si servirà poi dello sfuggente e sostanzialmente indefinibile concetto di stile, intendendo con esso la scelta di un determinato tipo di linguaggio poetico nella costruzione di ogni singola lirica nell'insieme degli elementi che la compongono, dal registro linguistico, alla forma metrica, dall'imagery all'intonazione ${ }^{15}$. Il lavoro attivo dell'autore (implicito) sullo stile del testo poetico si concretizza in alcuni casi, come si vedrà, in vere e proprie stilizzazioni di determinati linguaggi tradizionali. Con quest'ultimo termine si rimanda alla classica idea bachtiniana della dialogicità della parola artistica (prosastica) nei confronti del discorso altrui, sostenendone convintamente un' applicazione anche alla sfera della poesia ${ }^{16}$. Come precisato da Bachtin,

стилизация предполагает стиль, т. е. предполагает, что та совокупность стилистических приемов, которую она воспроизводит, имела когда-то прямую и непосредственную интенциональность, выражала последнюю смысловую истанцию ${ }^{17}$.

Per una riflessione consapevole circa il posizionamento dell'esperienza poetica stusiana nel contesto del panorama letterario novecentesco è infine necessario soffermarsi brevemente sui termini modernismo e postmodernismo, dei quali si farà ripetutamente uso nelle pagine a venire. Dal punto di vista della storia letteraria e culturale dell'Occidente la parabola poetica di Stus si colloca infatti negli anni della nascita e dello sviluppo dell'esperienza postmodernista.

L'impossibilità di fornire una definizione pienamente convincente e onnicomprensiva del termine postmodernismo è, com'è noto, parte integrante dell'essenza

15 Per una panoramica degli studi sullo stile dall'Ottocento a oggi si veda Compagnon 1998: 195-230. Se ne ricordi la conclusione, in: ivi: 230: “Trois aspects du style sont ainsi revenus au premier plan, ou n'ont jamais été vraiment éliminés. Il semble qu'ils soient inévitables et indépassables. Ils ont en tout cas résisté victorieusement aux assauts que la théorie leur a livrés : - le style est une variation formelle sur un contenu (plus ou moins) stable ; - le style est un ensemble de traits caractéristiques d'une œuvre permettant d'en identifier et d'en reconnaître (plus intuitivement qu'analytiquement) l'auteur ; - le style est un choix (corsivo mio - AA) entre plusieurs 'écritures'. Seul le style comme norme, prescription ou canon passe mal, et n'a pas été réhabilité. Mais à part cela, le style existe bel et bien."

16 Cfr. Bachtin 2000: II, 81-86. A proposito di Bachtin e la lirica si veda KulcsárSzábo 2016.

17 Ivi: 85. Cfr. anche, in ambito slavistico, Mayenowa 1979. 
stessa di quest'ultimo. Già nel 1985 Ihab Hassan, uno dei suoi padri fondatori, autore della seminale monografia The Dismemberment of Orpheus: Towards a Postmodern Literature del 1971, riassumeva:

Postmodernism once more - that breach has begun to yawn! I return to it by way of pluralism, which itself has become the irritable condition of postmodern discourse, consuming many pages of both critical and uncritical inquiry ${ }^{18}$.

A proposito delle civiltà letterarie dello spazio sovietico e poi ex-sovietico, il termine postmodernismo è generalmente utilizzato a proposito della cultura $\mathrm{e}$ della letteratura dei tardi anni Ottanta e dei due decenni successivi sino al giorno d'oggi, con un notevole scarto temporale rispetto all'Europa occidentale e al mondo anglo-americano ${ }^{19}$. Pochi, seppur convincenti, sono stati i tentativi di leggere i fenomeni più innovativi delle letterature sovietiche degli anni Sessanta, nello specifico della letteratura russa, secondo il prisma del Postmodernismo, permettendone di conseguenza una piena integrazione nella coeva vicenda culturale e letteraria europea ${ }^{20}$. Per quanto riguarda la letteratura ucraina precedente all'ultimo decennio dell'era sovietica, si è significativamente parlato di Postmodernismo solamente in riferimento alla produzione poetica dell'emigrazione americana e, nello specifico, alla sua fase più tarda ${ }^{21}$.

La complessità del fenomeno modernista, non meno sfuggente, variegato e indefinibile del Postmodernismo che idealmente lo segue, ne rende altrettanto impossibile una definizione unitaria e onnicomprensiva. In un suo scritto sull'ar-

18 Hassan 1987: 17. Simili ammonimenti a non farsi illudere dal miraggio di una qualsiasi interpretazione univoca del fenomeno postmodernista erano stati espressi due anni prima da eminenti studiosi della questione, quali Hans Bertens (Bertens 1986) e Brian McHale (McHale 1986). Una delle migliori panoramiche dell'idea letteraria e culturale di postmoderno è la monografia di Hans Bertens The Idea of the Postmodern: A History (Bertens 1995), incentrata sull'intrinseca contraddittorietà dei termini 'postmoderno' e 'Postmodernismo' e sulla straordinaria produttività che da essa deriva (Bertens 1995: 3-36). Insostituibili per profondità intellettuale e chiarezza espositiva sono anche le pagine di Andreas Huyssen del 1984 (Huyssen 1984).

19 Cfr. Hundorova 2013: 73-77. Per quanto riguarda la letteratura russa, la critica ha fornito interpretazioni del termine anche molto discordanti tra loro sia per quanto riguarda il significato del termine, sia per la cronologia dei fenomeni culturali a esso riconducibili. Cfr. Possamai 2000.

20 Si vedano il pionieristico lavoro di Raoul Eshelman (Eshelman 1997), dedicato essenzialmente alla prosa, e la dissertazione della sua allieva Gesine Dornblüth (Dornblüth 1999) sulla poesia giovanile di Andrej Voznesenskij. Il primo tentativo in questo senso si deve, sempre nell'ambito della slavistica tedesca, a Herta Schmid, autrice di un articolo sul 'dramma postmodernista russo' pubblicata in una delle pietre miliari della letteratura critica dedicata al Postmodernismo, la miscellanea a cura di Douwe Fokkema e Hans Bertens del 1986, risultato di un importante simposio a Utrecht di due anni prima (Schmid 1986 e Fokkema, Bertens 1986).

21 Bartolini 2012. Sul Postmodernismo ucraino si vedano, tra gli altri, Hundorova 2013 e Chernetsky 2007. 
gomento, parte di un'ampia miscellanea risultato del lavoro di sessantacinque studiosi (Eysteinsson, Liska 2007), Edward Możejko ha sottolineato la sostanziale coesistenza di un'interpretazione 'storicistica' del termine, relativa alle principali tendenze della letteratura europea e angloamericana dalla fine dell'Ottocento alla seconda guerra mondiale, con un'interpretazione 'concettuale', pronta ad accettare la sopravvivenza del Modernismo nei decenni a venire ${ }^{22}$. L'inclusione della poesia stusiana nel paradigma modernista che si propone e si cercherà di dimostrare in questa sede si inserisce chiaramente nel secondo filone critico.

Nell'ampia - e in buona parte contraddittoria - bibliografia sulla storia dei processi culturali e letterari della civiltà occidentale novecentesca, riassumibili nella dialettica tra Modernismo e Postmodernismo ${ }^{23}$, uno dei pochi elementi di distinzione delle due tendenze generalmente accettati è individuabile nel trattamento della figura del soggetto e dell'idea, anche habermasiana, di soggettività ${ }^{24}$. Come ha osservato Matei Călinescu,

Modernity in the broadest sense, as it has asserted itself historically, is reflected in the irreconciliable opposition between the sets of values corresponding to the objectified, socially measurable time of capitalist civilization (time as a more or less precious commodity, bought and sold on the market), and the personal, subjective, imaginative durée, the private time created by the unfolding of the self. The latter identity of time and self constitutes the foundation of modernist culture $^{25}$.

Alla base del superamento del Modernismo da parte della nuova estetica e della nuova poetica sarebbe così il dissolvimento del modernistico principio centralizzante di un io che riflette su se stesso, in grado di conservare con estrema fatica la propria integrità e identità nella contrapposizione più o meno marcata con una realtà esterna e interna più o meno ostile. Come ha scritto Ástráđur Ey-

22 Cfr. Możejko 2007. Si veda anche Flaker 1979 per una precisazione sull'utilizzo del termine modernismo nelle diverse culture slave.

23 È stato messo in evidenza come la pervasività dell'idea di postmoderno e Postmodernismo nella cultura contemporanea non possa che condizionare inevitabilmente la lettura di ciò che dovrebbe costituire il suo opposto, oppure, alternativamente, il suo presupposto, ovvero il moderno e il Modernismo. L'autonomia di quest'ultimo è sempre più messa in discussione da una visione totalizzante (e dunque paradossalmente 'anti-postmodernista') che fa del postmoderno un sinonimo per la cultura 'post-realista' novecentesca nella sua interezza. Cfr. Schwartz 1997 e Eysteinsson 1990: 103-142.

24 Cfr. Habermas 1981: 6: "Modernist culture has come to penetrate the values of everyday life. The life-world is infected by modernism. Because of the forces of modernism, the principle of unlimited self-realization, the demand for authentic self-experience and the subjectivism of a hyper-stimulated sensitivity have come to be dominant." Cfr. anche Sheppard 1993: 23-25. Sulla straordinaria multiformità dell'io tra Classicità, Modernismo e Postmodernismo cfr. Fülleborn 1988. Cfr. anche Krings 2005: 1-39 e 239-250.

25 Calinescu 1987: 5. 
steinsson, è proprio la rivolta del soggetto contro la realtà a porsi come fattore unificante della weltanschuung modernista ${ }^{26}$.

Si avrà ampiamente modo di osservare come la centralità del principio soggettivo sia elemento fondante dell'universo poetico stusiano, nonché come esso si imponga più marcatamente nell'evoluzione dalla poesia giovanile alla produzione matura. Allo stesso tempo si evidenzieranno le occasionali incursioni nella poetica postmoderna che la lirica stusiana non manca di presentare nel suo percorso.

26 Cfr. Eysteinsson 1990: 28: "[W] and that of extreme subjectivity have in common (and this overweighs whatever may separate them) is a revolt against the traditional relation of the subject to the outside world." Sull'auto-riflessività come elemento costitutivo della soggettività modernista cfr. Becker, Kiesel 2007: 17. 


\section{Capitolo primo. Vasyl' Stus, il suo tempo e la ricezione della sua opera}

\section{Cenni biografici}

Vasyl' Stus nacque nella regione di Vinnycja, nell'Ucraina occidentale, il 6 gennaio del 1938. La coincidenza dell'evento con la Vigilia del Natale ortodosso avrebbe in seguito contribuito al consolidamento del culto martirologico stusiano. Due anni più tardi la famiglia Stus si ritrovò nel Donbas, dove il padre del futuro poeta, Semen Dem"janovyč, si era dovuto rifugiare in seguito a un donos, una denuncia politica, nonché a causa delle pesanti condizioni in cui versava la regione in seguito al holodomor, la grande carestia del 1932-1933.

Nel 1954 il giovane Vasyl', fallito il tentativo di iscrizione alla facoltà di giornalismo dell'Università di Kiev, iniziò gli studi umanistici presso l'Istituto pedagogico di Stalino, l'odierna Donec'k. Nella sua biografia del padre (Stus 2005: 80-99), Dmytro Stus ha sottolineato la fondamentale importanza di questi anni per la formazione culturale del giovane aspirante scrittore. Negli sconvolgimenti dei primi mesi e anni dell'era post-staliniana, infatti, il piccolo ma vivace universo culturale di Donec'k godeva di una libertà intellettuale relativamente maggiore rispetto a Kiev. Ciò valeva in particolare per la ristretta cerchia degli ucrainofoni e ucrainofili che si trovavano a vivere e operare nell'ambito di una realtà urbana quasi interamente russificata. Sia Dmytro Stus che gli amici di gioventù del poeta hanno insistito in particolare sulla grande cultura e umanità di Tymofij Duchovnyj, docente di letterature straniere, che avrebbe aperto al poeta le porte di un approccio critico al testo non deformato dai dogmi del realismo socialista, rendendogli disponibile la sua imponente biblioteca (cfr. Ovsijenko 2013: 108). Agli anni degli studi universitari risalgono anche le prime serie prove letterarie del giovane Stus.

Terminati gli studi nel 1959 e con le prime esperienze poetiche già alle spalle, Stus si cimentò per due mesi con l'insegnamento della lingua e letteratura ucraina nella regione di Kirovohrad, oggi Kropyvnyc'kyj, che egli stesso definì 1'“Ucraina vera, non il Donbas", probabilmente in riferimento alla predominanza linguistica dell'ucraino nella regione ${ }^{1}$. Si noti come questa affermazione non cor-

T I.1, 42: “Стужілий за справжньою (не донецькою) Україною, поїхав учителювати на Кіровоградщину, поблизу Гайворона." 'Provando nostalgia per la vera Ucraina (non quella di Donec'k), andai a insegnare nella regione di Kirovohrad, vicino a Hajvoron.' 
risponda in realtà alla grande importanza che la specificità culturale del Donbas ebbe per la formazione umana e culturale del giovane Stus. Alla fine del 1959 l'aspirante scrittore vide tre delle sue liriche pubblicate sulla prestigiosa "Literaturna hazeta", in seguito rinominata "Literaturna Ukrajina", il principale giornale letterario della Repubblica Sovietica Ucraina. La pubblicazione era introdotta da un breve elogio al giovane autore da parte di Andrij Malyško (1912-1970), uno dei massimi esponenti della poesia ucraina sovietica dell'epoca.

Presto chiamato alle armi, dapprima nei luoghi skovorodiani della Poltavščyna e quindi nella lontana regione di Čeljabinsk, Stus dovette attendere il 1961 per fare ritorno a Donec'k con l'intenzione di dedicare tutto se stesso al perfezionamento delle sue già notevoli conoscenze umanistiche e alla scrittura. Nell'ultimo mese dell'anno riprese l'attività didattica a Horlivka, nel Donbas, dove avrebbe insegnato ucraino per poco più di un anno.

Dopo qualche mese di attività di redattore della sezione letteraria della neonata versione in lingua ucraina del giornale di Donec'k "Socialističeskij Donbass", riuscì finalmente a coronare il suo sogno. Nel novembre del 1963 fu infatti ammesso al corso di dottorato in teoria della letteratura presso l'Istituto di Letteratura Ševčenko dell'Accademia delle Scienze di Kiev. Il passaggio dalla provincia alla capitale diede al giovane autore la possibilità di inserirsi in un ambiente intellettuale in pieno fermento. Sotto la guida di Mykola Šamota (1916-1984), letterato ultraconservatore e acerrimo nemico di ogni deviazione dall'ortodossia, ma allo stesso tempo in grado di riconoscere il merito tra i giovani studiosi (cfr. Orač 1993: 67-75), Stus iniziò a lavorare a una tesi dottorale sulle "fonti dell'emozionalità del testo letterario". Per quasi due anni Stus poté godere degli stimoli di un'atmosfera culturale straordinariamente intensa, figlia delle speranze di un Disgelo destinato a durare meno di un decennio. Ai primi mesi della sua nuova vita kieviana risalgono i lavori preparatori a Kruhovert', la prima raccolta poetica stusiana, sintesi e vetrina di più di un lustro di esponenziale crescita artistica.

Nel settembre del 1965, in seguito a una forte ondata di repressioni ai danni di numerosi esponenti dell'intelligencija indipendente ucraina, un gruppo di giovani letterati, storici e artisti tra i quali lo stesso Stus organizzò una pacifica protesta durante la prima kieviana del film Tini zabutych predkiv (Le ombre degli avi dimenticati) di Sergej Paradžanov. Fu la fine della prima, complessivamente tranquilla parte della vita del poeta. Espulso dall'Istituto di Letteratura dell'Accademia delle Scienze, dovette accontentarsi di lavori saltuari e non degni della sua cultura e delle sue capacità intellettuali, nonché rinunciare definitivamente alle speranze di pubblicare i primi frutti del suo ingegno poetico. Pochi mesi più tardi si sposò con Valentyna Popeljuch, conosciuta a Kiev, e divenne padre di Dmytro.

Per sei anni e mezzo la sua vita fu scissa tra la necessità di lavorare per mantenere la famiglia e il non meno impellente bisogno di dedicarsi alla scrittura e alle traduzioni. Giunto nel 1970 alla terza raccolta (Veselyj cvyntar), diffusa in samizdat, mentre la seconda (Zymovi dereva) era stata pubblicata in Occidente lo stesso anno a sua insaputa, Stus, come molti altri intellettuali ucraini, fu arrestato 
il 12 gennaio del $1972^{2}$. In carcerazione preventiva per nove mesi sino alla condanna, duranti i quali la sua poesia raggiunse definitivamente la maturità poetica con Čas tvorčosti / Dichtenszeit, si vide comminare cinque anni di reclusione in un campo di lavoro e tre anni di confino per attività antisovietica. Scontò la prima parte della pena in Mordovia e la seconda nella Kolyma, raggiungendo in questo periodo l'apogeo della sua evoluzione artistica con i celeberrimi Palimpsesty. Nel 1977 il massimo editore dell'emigrazione ucraina, "Sučasnist"”, pubblicò una raccolta di liriche stusiane trafugate fuori dai confini dell'Unione Sovietica dal titolo Sviča v svičadi ('La candela nello specchio'), a cura di Marko Carynnyk e Wolfram Burghardt. Tornato a Kiev nel 1979, Stus prese parte attivamente alla fondazione della sezione ucraina del "Gruppo di Helsinki" (Ukrajins'ka hel'sins 'ka hrupa), un importante raggruppamento di attivisti dei diritti umani originatosi a Mosca nel 19763. L'anno seguente il suo impegno politico gli costò un secondo, fatale arresto. Dopo cinque anni in condizioni degradanti, morì in circostanze oscure nel settembre del 1985, già in epoca gorbačëviana. L'anno successivo vide la luce in Occidente la prima edizione di Palimpsesty, a cura della dissidente Nadija Svitlyčna (1936-2006) e con una prefazione di Jurij Ševel'ov (George Y. Shevelov, 1908-2002).

Quattro anni più tardi, le ceneri di Stus e dei compagni di reclusione Jurij Lytvyn e Oleksa Tychyj furono trasportate a Kiev, dove si tenne una seconda cerimonia funebre in loro onore, che i testimoni descrivono come un evento di portata impressionante (cfr. Pidhirnyj 2002: 52-116 e Stus 2005: 10-41). Nel 1990 Stus venne riabilitato e l'anno seguente fu pubblicata la prima raccolta di poesie stusiane per il lettore ucraino, dal titolo Doroha bolju ('La strada del dolore'), a cura di Mychajlyna Kocjubyns'ka (1931-2011). Contestualmente gli fu anche conferito il premio Ševčenko, massimo riconoscimento del paese per il contributo allo sviluppo della cultura nazionale. L'ingresso di Stus nel pantheon nazionale era ormai ufficialmente sancito.

\section{Il contesto culturale e letterario}

La maturazione umana e artistica di Stus e i suoi primi passi nella poesia coincidono con il periodo storico e culturale del Disgelo, di cui di recente si è sottolineato in vari contesti il carattere complesso e contraddittorio ${ }^{4}$. Frutto, come è

2 Nella prima metà dell'anno furono arrestati circa cento esponenti della cultura ucraina anticonformista. Cfr. Berdychovs'ka 2004: 25.

3 Sul breve periodo di libertà tra la fine della prima condanna e il secondo arresto si vedano le memorie della dissidente Svitlana Kyryčenko (1935-2016), pubblicate sulla rivista "Dnipro" nel 1998 e recentemente riedite in volume (Kyryčenko 2016).

4 Sulla necessità di uno studio più approfondito della politica culturale sovietica negli anni Cinquanta ha di recente posto l'attenzione Katerina Clark, una studiosa di lunga data del periodo. Clark ha messo in evidenza come alcune delle questioni cen- 
noto, della morte di Stalin e dell'iniziale distensione dei primi anni chruščëviani, il Disgelo presenta nella situazione sociale e letteraria dell'Ucraina tra gli anni Cinquanta e gli anni Sessanta un carattere ancora più sfaccettato che nell'ambito russo a cui esso è più comunemente associato. Così come in altre repubbliche socialiste sovietiche, principalmente nei paesi baltici e nella Transcaucasia, la volontà di riconquistare almeno in parte gli spazi espressivi negati negli anni precedenti si è infatti accompagnata in Ucraina a una decisa riaffermazione delle componenti nazionali dell'arte e della cultura. La necessità di gettarsi alle spalle con il proprio lavoro gli aspetti più opprimenti della politica culturale sovietica, giunta probabilmente all'apice del suo oscurantismo negli anni bui dello strapotere ždanoviano, non poté che realizzarsi tra Dnister e Dnipro anche mediante una spontanea e sincera riscoperta dell' 'ucrainicità', riscontrabile a livello superficiale in una spiccata attenzione per il colorito nazionale e a livello più profondo in un ritrovato dialogo con la tradizione letteraria ucraina. In virtù di questa forte attenzione alla riconquista e alla riattivazione del proprio retaggio culturale, la cultura ucraina, così come le altre culture 'minori' a essa tipologicamente vicine nel contesto sovietico, si distingue dalla vicina più prossima, quella russa, ma anche da quella polacca, che per i letterati di Kiev e Leopoli rappresentava sempre più nettamente un modello da seguire.

La riappropriazione di questo patrimonio letterario e linguistico minacciato, in certi casi espressamente proibito o travisato, si esplicò su più fronti. Il recupero delle potenzialità di una lingua degna di questo nome, né dialetto del russo, né semplice appannaggio del folclore e della cultura popolare, nonostante l'estrema importanza di queste due componenti nella riflessione di quegli anni, portò a un potenziamento del suo potere comunicativo. Da ciò derivano, ad esempio, due momenti essenziali dell'azione culturale di questi anni: la creazione di neologismi (cfr. Šmilo 2006), a livello intra-linguistico, e il forte interesse per la traduzione, a livello letterario e interculturale, ma anche linguistico. Non a caso alcuni dei grandi maestri della cultura di questi anni, come Hryhorij Kočur (1908-1994) e Mykola Lukaš (1919-1988), sono entrati nella storia della lette-

trali del dibattito letterario della metà del decennio, prima fra tutte la nota questione della "sincerità" nella letteratura sollevata da Vladimir Pomerancev nel suo articolo pubblicato su "Novyj mir" nel 1953, avessero degli inaspettati precedenti negli anni immediatamente anteriori e, addirittura, nel secondo oscuro lustro degli anni Trenta (sulle tempestose reazioni provocate dall'articolo di Pomerancev cfr. Kozlov 2013: 44-87). Ciò indurrebbe a ripensare la tesi tradizionale che attribuisce al Disgelo un carattere rivoluzionario di assoluta contrapposizione agli anni che lo hanno anticipato, dando maggiore rilievo agli aspetti di continuità intrinseci alla cultura sovietica, da una parte, e alla persistenza di spinte conservatrici e tardo-staliniane dopo il 1953, dall'altra. Cfr. Clark 2013. Polly Jones, autrice di notevoli studi sulla questione, ha invece messo in evidenza il tentativo delle autorità di mantenere un equilibrio tra tendenze reazionarie e pressioni innovative per mantenere lo status quo, evitando sia evidenti derive ideologiche, sia i malumori derivanti da un ulteriore irrigidimento dei principi culturali dell'età di Stalin. Cfr. Jones 2013. Sull'effettiva complessità delle dinamiche socio-culturali del Disgelo, con particolare riferimento all'istituto censorio, si veda anche Zalambani 2009: 58. 
ratura ucraina principalmente grazie alle loro titaniche imprese nel campo della traduzione poetica da numerose lingue, epoche e culture di Oriente e Occidente (Stricha 2006: 251-280).

Questo necessario, fisiologico ritorno a un passato lacerato è spiegabile nei termini di un parziale sfasamento storico della storia intellettuale ucraina rispetto alle civiltà dell'Europa occidentale. Le limitazioni da essa subite in decenni e secoli di oppressione politica, linguistica e artistica si sono imposte nel contesto di una civiltà letteraria intrinsecamente europea (cfr. Brogi Bercoff, Pavlyshyn, Plokhy 2017). La riconquista del patrimonio nazionale caratteristica del Disgelo ucraino nella sua fase iniziale è dunque da considerarsi un fenomeno innanzitutto culturale, una naturale maturazione dello straordinario sviluppo della lingua e della letteratura iniziato negli anni Venti e brutalmente stroncato nel decennio seguente.

Questa rinascita sembra configurarsi come il 'normale' esito di una congiuntura socio-culturale relativamente favorevole, non necessariamente politico nel senso che questo termine avrebbe assunto a partire dalla metà degli anni Sessanta, quando si sarebbe cominciato a parlare di Dissidenza. Nella sua prefazione a una raccolta di studi di Mychajlyna Kocjubyns'ka, principale curatrice dell'archivio stusiano e instancabile propagatrice della sua opera sino alla morte sopraggiunta nel 2011, Tamara Hundorova ha sottolineato la naturalezza della fusione di "universale" e "nazionale", ovvero "moderno" e "tradizionale", nelle weltanschauung e nelle poetiche degli esponenti di quel rinnovamento etico ed estetico noto come šistdesjatnyctvo e figlio della cultura del Disgelo. La studiosa ha significativamente definito il fenomeno come "neopopulismo" (neonarodnyctvo; Hundorova 2004: 8). Nella sua interpretazione lo šistdesjatnyctvo si configurerebbe dunque come un superamento, temporaneo nell'ottica degli sviluppi degli anni Ottanta e Novanta, della tradizionale contrapposizione tra i due fronti opposti del Populismo e del Modernismo, centrale alla storia della civiltà letteraria ucraina dal tardo Ottocento in poi ${ }^{5}$.

Allo stesso tempo, come sembra emergere dall'analisi della stessa Hundorova e come più ampiamente documentato da altri studiosi, la cultura degli šistdesjatnyky è non meno profondamente figlia del suo tempo e parte integrante della storia della cultura sovietica. Benjamin Tromly ha evidenziato l'importanza e la complessità dei rapporti tra i giovani scrittori e artisti ucraini degli anni Sessanta e i loro colleghi moscoviti (Tromly 2009), anticipando alcuni risultati del ben più ampio lavoro di Simone Attilio Bellezza in corso di pubblicazione ${ }^{6}$. Discutendo i risultati delle ricerche degli storici ucraini e nordamericani sul Disgelo e la dissidenza a Kiev e nelle altre città dell'Ucraina sovietica, prima fra tutti la seminale monografia di Heorhij Kas'janov del 1995 (Kas'janov 1995), Bellezza ha assunto come punto di partenza metodologico la seguente affermazione:

5 Sul tradizionale contrasto tra populismo e modernismo nella letteratura ucraina moderna cfr. Pavlychko 1996.

6 Ringrazio vivamente l'autore per avermi fornito una copia del manoscritto del suo lavoro, ora in corso di stampa. 
From this point of view, the shistdesiatnytstvo was an evolutionary stage (and not one particularly rich of consequences or success, at that) of the history of the movement of national liberation. Such an interpretation is the outcome of a not casual (but perhaps unconscious) underestimation of the Soviet content of the shistdesiatnytstvo. It is my opinion that it is impossible to properly understand the shistdesiatnytstvo without taking into account that it was also the product of Soviet culture, which for more than three decades had influenced Ukrainian culture, radically transforming it $^{7}$.

Come ben dimostra lo storico italiano sulla base di testimonianze inedite e interviste ai protagonisti di quella stagione culturale, almeno nella fase iniziale del rinnovamento post-staliniano l'intelligencija ucraina progressista non poteva che percepire se stessa come protagonista di un processo di crescita e ammodernamento sociale e letterario di un'Ucraina parte integrante della più ampia realtà sovietica. Ciò conferma l'idea di un 'nazionalismo' culturale prima che storico-politico, volto alla conoscenza di un passato da riscoprire e non necessariamente orientato verso la (ri)creazione di una statualità. Come si vedrà a proposito dei gusti letterari di Stus, la devozione alla causa nazionale ucraina non escluderà in nessun caso un forte interesse per la letteratura russa e una costante volontà di stare al passo con gli sviluppi di quest'ultima e di farne proprie le tendenze innovatrici.

Per quanto riguarda il recupero da parte degli šistdesjatnyky di intere porzioni di patrimonio nazionale in precedenza negato e perseguitato, è da evidenziare sicuramente il ritorno alla ribalta della cosiddetta "Rinascita fucilata" (Rozstriljane Vidrodžennja). Questo termine, citazione dal titolo di un'antologia di scrittori ucraini degli anni Venti pubblicata da Jurij Lavrinenko (1905-1987) nel 1959, indica la fiorente e variegata cultura letteraria ucraina dei primi anni dell'età sovietica. In parte riabilitati negli anni Cinquanta, in parte diffusi in $s a$ mizdat, i fautori del definitivo riavvicinamento delle lettere ucraine alla cultura europea dopo le limitazioni dell' età imperiale sono da considerarsi un precedente fondamentale per gli šistdesjatnyky (cfr. Najenko 2010: 347-411). La continuità della civiltà letteraria ucraina nei decenni a cavallo della metà del secolo si realizzò anche mediante la collaborazione tra i giovani debuttanti e i 'grandi classici viventi', entrati nel mondo delle lettere all'incirca nel periodo della Rivoluzione o nei primi anni dell'affermazione dell'Unione sovietica. Avendo messo la loro fama e la loro penna al servizio della causa e del potere comunista, ma senza per questo aver completamente abdicato alla loro genuina ispirazione ${ }^{8}$, alcuni dei massimi poeti e scrittori dell'Ucraina sovietica quali Maksym Ryl's'kyj (1895-1964), Mykola Bažan (1904-1983) e Leonid Pervomajs'kyj (1908-1973) diedero un importante contributo all'ingresso delle nuove leve nel mondo della

\footnotetext{
$7 \quad$ Bellezza (in stampa). Cfr. anche Yekelchyk 2015.

8 Il caso più eclatante di drammatica sovietizzazione di un poeta di primissimo ordine è indubbiamente quello di Pavlo Tyčyna (1891-1967), alla cui triste sorte Stus avrebbe dedicato il lungo saggio Fenomen doby (Schodžennja na Holhofu slavy) del
} 1969-1970. 
letteratura. L'appoggio dei poeti nati tra la fine dell'Ottocento e l'inizio del Novecento ai loro successori è inoltre coinciso con la cosiddetta "terza fioritura" di questi ultimi, dopo l'esordio tra gli anni Dieci e gli anni Venti e una generale 'ricollocazione' stilistico-tematica all'inizio dell'era staliniana. Ola Hnatiuk ha evidenziato il ruolo particolare di alcuni scrittori nella difesa degli šistdesjatnyky, come il pluri-premiato Oles' Hončar (1918-1995), tra i più significativi prosatori ucraini dell'epoca, nonché l'effettiva convenienza per le autorità di un possibile e auspicato incanalamento della produzione artistica giovanile nel solco dell'ufficialità (Hnatiuk 2010: 21). Bellezza ha indagato a fondo le complesse dinamiche delle scelte della nomenklatura in fatto di politica culturale, costantemente oscillante tra permissivismo di convenienza e repressione.

Il fermento creativo dei giovani intellettuali si concretizzò a Kiev tra il 1959 e il 1960 con la formazione del Klub tvorčoji molodi (KTM, 'Club dei giovani artisti'), significativamente in seno al Komsomol. Sopravvissuto sino agli inizi del 1964, il KTM costituiva un punto di aggregazione e propagazione della cultura per poeti, critici e artisti alle prime armi o con alcuni anni di esperienza creativa alle spalle. Tra questi ultimi spicca il nome di Lina Kostenko (1930), che aveva debuttato intorno alla metà del decennio precedente con una poesia sorprendentemente innovativa, incentrata in buona parte sul mondo interiore dell'io lirico ${ }^{10}$. Figure di primo piano del KTM furono anche il critico Ivan Dzjuba (1931), la 'mente' dello šistdesjatnyctvo, e il poeta Vasyl' Symonenko (1936-1963), i cui versi sinceri e calorosi cantavano la verità, la giovinezza e l'amore per la patria, significativamente tanto ucraina quanto, almeno in una prima fase, sovietica ${ }^{11}$.

$9 \quad$ Pervomajs'kyj arrivò in seguito (in anni in cui la relativa libertà artistica del Disgelo si era già consumata, a dire il vero) a tematizzare nella sua poesia il ringiovanimento da lui sperimentato anche grazie all'ondata di fresca creatività dei nuovi talenti, nonché il suo ruolo di maître per la loro scuola poetica. Si vedano i versi conclusivi di Uroky poeziji ('Lezioni di poesia'), poesia eponima della raccolta pervomajs'kiana del 1968, in Pervomajs'kyj 1985: I, 396-397: “Буду вчитись у вас, / Але вчитиму й вас: / Як треба любити / Цю землю й це небо, / Не лякатися щастя, / Не зрікатися біди, / І як від вчорашнього - / Відмовлятись від себе, / Щоб собою / Завтрашнім / Стать назавжди." "Imparerò da voi, / Ma vi farò studiare: / Come si deve amare / Questa Terra e questo cielo, / La felicità non temere, / La disgrazia non rinnegare, / E come fosse di ieri - / Se stessi rifiutare / Per divenire / Per sempre / Il sé di domani'.

10 Si veda la seconda strofa di una breve lirica tratta dalla prima raccolta di Lina Kostenko, Prominnja zemli ('I raggi della terra') del 1957, in: Kostenko 1969: 50: “Я в людей попрошу тільки віри / в кожне слово почуте від мене, / в кожний погляд очей моїх сірих, / в кожну ласку рук нестудених...” “Alle persone chiederò solo fede / in ogni parola da me detta, / in ogni sguardo degli occhi miei grigi, / in ogni carezza delle mani calorose...'

11 Cfr. Symonenko 2012: 276: “Люди - прекрасні. / Земля, мов казка. / Кращого сонця ніде нема. / Загруз я по серце / У землю в’язко. / Вона мене цупко трима. / І хочеться / бути дужим, / І хочеться так любить, / Щоб навіть каміння байдуже / Захотіло ожити / I жить! / [...].” 'Le persone son bellissime. / La terra come una fiaba. / Non c'è in nessun luogo un sole migliore. / Son sprofondato fino al cuore / nella terra pesante. / Lei mi tiene stretto. / E ho voglia / di esser forte, / e voglio amare, / per- 
I primi tre anni del nuovo decennio videro l'uscita ufficiale di raccolte poetiche fondamentali per la storia della poesia ucraina degli anni Sessanta, come Mandrivky sercja ('I viaggi del cuore') di Lina Kostenko, Atomni preljudy ('Preludi atomici') di Mykola Vinhranovs'kyj (1936-2004), Sonjašnyk ('Girasole') di Ivan Drač (1936-2018) e Tyša i hrim ('Il silenzio e il tuono') di Vasyl' Symonenko. Se la poesia di Vinhranovs'kyj è nota per il suo anelito filantropico e il suo pathos patriottico ${ }^{12}$, Drač è passato alla storia per il suo roboante metaforismo ${ }^{13}$, che non esclude, beninteso, il motivo dell'amore per l'umanità ${ }^{14}$.

La parentesi complessivamente felice di quella manciata di anni non era tuttavia destinata a durare. Gli eventi moscoviti del dicembre del 1962, allorché Nikita Chruščëv si espresse con dure invettive in occasione della sua visita alla mostra di arte contemporanea sulla Piazza del Maneggio, e le conseguenti, devastanti accuse di formalismo e astrattismo, erano sintomi di un brusco cambio di clima e di un nuovo irrigidimento nella politica culturale sovietica. In un contesto, inoltre, di tradizionale chiusura e rigore censorio nei confronti della cultura delle repubbliche, naturalmente considerate a rischio di derive nazionalistiche.

Il $K T M$ dovette chiudere i battenti all'inizio del 1964, dopo alcuni mesi di tensione tra i suoi membri e le autorità. Fu in questo clima che Vasyl' Stus giunse a Kiev per iniziare gli studi dottorali. La sostanziale rottura dell'equilibrio tra gli šistdesjatnyky e la cultura di partito sovietica si accompagnò a un profondo rafforzamento dei legami personali tra le giovani leve della cultura ucraina. Il punto di ritrovo di scrittori e artisti si spostò dal KTM all'appartamento del critico e poeta Ivan Svitlyčnyj (1929-1992), una delle personalità più vicine a Stus negli anni a venire. Nonostante il passaggio da una forma legale di aggregazione a una parziale clandestinità e il progressivo restringimento delle possibilità di pubblicare (o, nel caso degli artisti, come Alla Hors'ka e Opanas Zalyvacha, di realizzare opere plastiche), l'accoglienza della capitale nei confronti del giovane letterato di Donec'k non poteva certo dirsi carente di stimoli culturali. All'Istituto di Letteratura dell'Accademia delle Scienze l'ortodossia marxista-leninista

ché anche la pietra apatica / si ravvivi / e viva! / [...]' Si noti il raffinato sottotesto orfico di questi versi solo apparentemente ingenui, sapientemente costruiti sull'interazione tra la tematica vitalistica e la piena padronanza degli strumenti del linguaggio poetico.

12 Cfr. Vinhranovs'kyj 2013: 131: “Нi! Цей народ із крові і землі / Я не віддам нікому і нізащо! / Він мій, він я, він - світ в моїм чолі, / Тому життя його і ймення не пропащi!." 'No! Questo popolo di sangue e terra / non lo darò per niente e per nessuno! / È mio, è me, è mondo su di me, / la sua vita e il suo nome non sono perduti!'

13 Cfr. Drač 1962: 57: “Зацвіте автострада доспілими гронами, / Змиє коси рожеві в пахучім любистку зоря! / 3 твого чистого ставу між лататтям та оріонами / Ти лебідкою плинеш у безкресі мої моря." 'Fiorirà l'autostrada di gemme mature, / Laverà le trecce rose nel levistico odoroso l'aurora! / Dal tuo specchio d'acqua limpido tra ninfee e Orioni / nuoterai come cigno nei miei mari sconfinati.'

14 Ivi: 67: “Це - спрага людяності, і краси, і змоги. / Я нею сповнений. Мене пече щоднини / Жагуча спрага щастя для людини. / Тривоги людства — це мої тривоги”. 'Ѐ sete di umanità, bellezza e abilità. / Ne sono pieno. Mi brucia tutti i giorni / la sete di felicità per gli uomini. / Le pene dell'uomo - sono le mie.' 
di Mykola Šamota ${ }^{15}$ veniva compensata dalle conversazioni con Mychajlyna Kocjubyns'ka, allora giovane ricercatrice di teoria della letteratura, mentre le conoscenze al di fuori dell'ambito strettamente accademico consentivano a Stus un fecondo arricchimento umano e conoscitivo.

La situazione mutò bruscamente meno di due anni dopo l'arrivo di Stus a Kiev. Gli arresti del 1965 e la protesta nel settembre dello stesso anno, che costò a Stus e ad altri giovani intellettuali la carriera letteraria e accademica, non erano che la punta dell'iceberg di un processo di 'controriforma' in corso ormai da mesi. L'epoca del Disgelo era ormai definitivamente tramontata e si apriva la stagione della lunga Stagnazione, destinata a durare più di vent'anni. Per quanto riguarda la storia della letteratura ucraina, una delle conseguenze più notevoli del distacco degli scrittori innovatori dal sistema fu il potenziamento del samizdat (ucr. samvydav), fenomeno di portata già significativa nel decennio precedente ${ }^{16}$. La necessità per i letterati di ricorrere all'auto-produzione creava un circolo vizioso nei rapporti tra l'intelligencija indipendente e il potere, dal momento che la reazione di quest'ultimo alla scoperta di nuove pubblicazioni clandestine generava ulteriori repressioni. Queste, a loro volta, rendevano impellente il bisogno di darne testimonianza scritta, sia per il lettore non indifferente in patria, sia per la comunità internazionale. La diffusione di opere di carattere storico-politico non precludeva, naturalmente, il fiorire della letteratura, nel contesto di una globale riduzione degli spazi editoriali ufficiali, sempre più asfittici e anacronistici.

15 Si veda uno stralcio da una recensione dell'influente connazionale Leonid Novyčenko (1914-1996), un uomo 'per tutte le stagioni' in grado di rimanere autorevole e apprezzato sia nell'Ucraina sovietica che nei primi anni dell'Ucraina indipendente, a una pubblicazione di Šamota in russo. Si tratta, significativamente, dell'anno 1961, ovvero del presunto picco di 'liberalità' del regime sovietico nel campo delle arti: Novičenko 1961: 216: “Коммунистическая партия и народность советской литературы как её главнейшие, определяющие принципы и качества - центральная тема книги М. Шамоты. [...] Так, говоря о сказавшейся в творчестве отдельных литераторов тенденции к бескрылому бытописательству, к выдвижению на первый план серенькой, тусклой фигуры 'не героя', в отношении которой художник по существу отказывается от ясных идейных и моральных оценок, - автор убедительно показывает, как несовместимы подобные тенеденции со всем духом советской литературы и питающими ее эстетическими взглядами социалистического общества.” Evidente è la distanza tra la concezione šamotiana della letteratura, brillantemente espressa da Novyčenko, e l'estetica pluralista e adogmatica dello šistdesjatnyctvo. Il conservatorismo di Šamota emerge in tutta la sua profondità dal confronto con le istanze più progressiste della critica degli stessi anni. Si veda, ad esempio, da un articolo di Boris Rubin sulla poesia di Evgenij Evtušenko, Rubin 1963: 20: "Но борьба с догматическим мышлением, с условностями, навыками и предрассудками, доставшимися нам в наследство от прежних времен, не случайно получила наиболее наглядное проявление в творчестве молодых."

16 Sul samvydav ucraino si veda la monografia di Oles' Obertas (Obertas 2010). Sul samizdat sovietico come complesso fenomeno culturale e letterario si veda la recente monografia di Valentina Parisi (Parisi 2014). 
Come sottolineato da Hnatiuk, le autorità sovietiche furono abili nel creare una profonda divisione in seno al campo degli šistdesjatnyky, anche in virtù del fatto che tra di essi non mancassero convinti comunisti e membri del partito, come Symonenko e Ivan Dzjuba (Hnatiuk 2010: 30-38). Forse la massima autorità tra i giovani uomini di cultura, Dzjuba cedette alle minacciose pressioni dall'alto e fece pubblica ammenda. Una simile sorte toccò al poeta Ivan Drač. La reazione degli ex-sodali fu in certi casi molto dura. Stus indirizzò a Dzjuba, autore del celeberrimo libello Internacionalizm čy rusyfikacija? (Internazionalismo o russificazione?), vero e proprio 'bestseller' del samizdat presto tradotto in numerose lingue, uno sdegnato J'accuse, doloroso simbolo della fine di un'epoca. Dopo il 1965, il gruppo degli šistdesjatnyky si ritrovò dunque gravemente lacerato. La tappa successiva della repressione brežneviana prese l'avvio nel 1972, quando un centinaio di intellettuali, fra cui lo stesso Stus, furono arrestati e condannati a diversi anni di reclusione e confino. Due anni prima era stata uccisa Alla Hors'ka (1929-1970), artista molto vicina a Stus e ai membri del KTM. Gli scrittori e gli artisti del vecchio fronte culturale del Disgelo erano così divisi fra una grossa fetta di vittime del sistema penitenziario, come Stus e Ivan Svitlyčnyj, chi aveva scelto di mantenere i propri privilegi accettando l'inclusione nel sistema, come Drač, chi si trovava formalmente in libertà, ma era privo della possibilità di pubblicare e seguire pienamente la propria vocazione, come Lina Kostenko, e, infine, chi era già stato eliminato fisicamente, come Alla Hors'ka.

Negli anni successivi al 1965 e, soprattutto, negli anni Settanta si sviluppò quell'ampio e variegato fenomeno noto con il nome di Dissidenza. L'evidente e giustificata politicizzazione del discorso intellettuale, in buona parte condotto tramite samizdat e tamizdat, non vanificò in alcun modo lo sviluppo e la piena maturazione della fioritura poetica iniziata nel decennio precedente. È proprio nel corso degli anni Settanta, infatti, che videro la luce i due capolavori di Stus, Čas tvorčosti / Dichtenszeit e Palimpsesty, ma anche, ad esempio, la lirica carceraria di Ivan Svitlyčnyj raccolta nei Gratovani sonety ('Sonetti con le grate'), pubblicati a Monaco da "Sučasnist" " nel 1977. La formazione di una rete di dissidenti ucraini, sparsi sull'intero territorio dell'Unione Sovietica in seguito al frazionamento causato dalle condanne, culminò nel 1976 nella formazione del Gruppo Ucraino di Helsinki, con l'obiettivo di perseguire le impressionanti violazioni dei diritti umani e nazionali nell'URSS. Stus, come si è visto, vi aderì nel 1979, nel corso dei pochi mesi trascorsi a Kiev tra la fine della prima condanna e la seconda condanna. Nello stesso periodo il poeta fu costantemente impegnato nella redazione della versione più ampia di Palimpsesty, la cosiddetta Kyjivs'ka versija, che non poté portare a termine a causa dell'arresto. La preoccupazione politica non provocò dunque in lui alcun calo dell'interesse per l'attività letteraria. Come osservato da Oxana Pachlovska, "una letteratura come 'alternativa alle barricate"" (dal titolo di una nota poesia di Lina Kostenko - AA) non comportò né la politicizzazione della cultura, né l'estetizzazione della politica"17.

17 Pachl'ovs'ka 2000: 76: “Тому в контексті шістдесятників література як 'альтернатива барикад' (Ліна Костенко) не означає ні політизації культури, ні 
Sebbene una politicizzazione della cultura degli anni Sessanta e Settanta non possa in realtà essere completamente negata, secondo una tendenza ricorrente in vari momenti della storia della civiltà letteraria ucraina e giustificata da evidenti ragioni storiche, il caso di Stus è un ottimo esempio di 'immunità' della letteratura all'asservimento alla causa politica. Non mancherà infatti l'occasione di osservare come la presenza della tematica politica nella lirica stusiana non significhi affatto una svalutazione di quest'ultima in senso 'utilitaristico'.

Come si avrà modo di approfondire in seguito, tra gli aspetti più spinosi per l'interprete dell'opera stusiana e lo storico della sua ricezione spicca infatti il problema del presunto carattere politico della sua poesia nel più ampio contesto dello šistdesjatnyctvo. Il passaggio di molti degli esponenti del movimento culturale degli anni Sessanta alla Dissidenza nella seconda metà del decennio e nei tre lustri successivi, nonché la presenza oggettiva di motivi storico-politici in alcune delle opere degli šistdesjatnyky, hanno infatti favorito una limitante lettura in chiave pubblicistica di buona parte della loro produzione letteraria.

La complessa questione della collocazione dell'opera stusiana nel contesto dello šistdesjatnyctvo riflette il più ampio problema della possibilità di una definizione di quest'ultimo come movimento. Le profonde divergenze nei percorsi umani e artistici delle personalità che sono state ricondotte sotto questa etichetta, anche con significative differenze tra gli studiosi nella scelta dei nomi, rende infatti alquanto difficile una caratterizzazione unitaria del fenomeno ${ }^{18}$. Indubbia e fondamentale per tutti i nomi a esso accostabili è sicuramente la volontà di contribuire a un rinnovamento globale della cultura ucraina dopo tre decenni di stalinismo.

Vicini ad alcuni šistdesjatnyky, ma di qualche anno più giovani e più distaccati dalla politica, i poeti riconducibili alla "Scuola di Kiev" (Kyjivs'ka škola) sono considerati i veri rappresentanti di una concezione della parola poetica come esperienza libera da ogni condizionamento esterno nell'Ucraina tardo-sovietica. Nella prefazione a una recente antologia dei quattro originari componenti della scuola (Mykola Vorobjov [1941], Vasyl'Holoborod'ko [1945], Mychajlo Hryhoriv [1947-2016], Viktor Kordun [1946-2005]), Volodymyr Morenec' ha sottolineato, rifacendosi a parole di Viktor Kordun, 'l'assenza presso i 'kieviani' di retorica social-politica, polemica ideologica, didattica, volontà di edificare, di qualsivoglia moralismo"19. Secondo Morenec', in riferimento ai poeti della "Scuola di

естетизації політики." Si veda anche il più recente Pachlovska 2017.

18 Per una sintetica panoramica della varietà degli approcci alla definizione dello šistdesjatnyctvo si vedano i frammenti di un dibattito sul tema tenutosi presso l'Istituto di Letteratura Ševčenko dell'Accedemia delle Scienze ucraina del 1997, pubblicati lo stesso anno sull'organo dell'Istituto "Slovo i čas" (Šistdesjatnyctvo jak javyšče, joho vytoky j naslidky 1997). Pienamente condivisibili sono le conseguenti considerazioni di Vitalij Dončyk (ivi: 45), che ha invitato gli studiosi a concentrarsi maggiormente sulle differenze tra le scritture e le personalità di ciascun šistdesjatnyk.

19 Morenec' 2013: 8: “Що мав на увазі В. Кордун? Він мав на увазі відсутність у 'киян' соціально-політичної риторики, ідеологічної полемічності, дидактики, повчальності, будь-якого моралізаторства, що є правдою.” Il riferimento di Morenec' è a un articolo di Viktor Kordun del 1997 (Kordun 1997). 
Kiev" si potrebbe dunque parlare di "poesia pura", contrapponendo così implicitamente la loro esperienza artistica a quella 'ibrida' degli sistdesjatnyky. Ė inoltre il caso di sottolineare ulteriormente come entrambe le etichette šistdesjatnyctvo e "Scuola di Kiev" facciano riferimento a scrittori anche molto diversi tra loro per orientamento stilistico. Ad accomunare i "kieviani" sembrano infatti essere state considerazioni di carattere storico-politico relative al loro isolamento dalla vita letteraria ufficiale dell'Ucraina sovietica brežneviana, piuttosto che una vera e propria vicinanza estetica ${ }^{20}$.

Sia nella loro auto-percezione dell'epoca, sia nella successiva ricostruzione storico-letteraria, gli šistdesjatnyky e i "kieviani” risultano uniti dalla comune contrapposizione alla letteratura sovietica ufficiale di orientamento conservatore. Si tratta anche in questo caso, in realtà, di un'etichetta piuttosto complessa, con cui ci si può riferire a tendenze e scrittori molto diversi tra di loro. Sotto quest'ampio comune denominatore si possono infatti riunire sia gli scrittori interamente asserviti all'estetica del realismo socialista (si pensi, ad esempio, all'ancora attivo Ivan Le [1895-1978]), sia quei letterati non indifferenti ai processi di rinnovamento introdotti dal Disgelo, ma distanti dallo šistdesjatnyctvo e in ultima analisi parte integrante della storia della letteratura sovietica ucraina e transnazionale, come il già citato Oles' Hončar. Non si dimentichi, infatti, come la letteratura ucraina di quegli anni sia inscindibile dal più ampio contesto sovietico, sia per quanto riguarda le tendenze innovatrici, sia per quelle del campo opposto.

Una panoramica complessiva della letteratura ucraina tra anni Sessanta e anni Settanta deve inoltre travalicare le rigide frontiere dell'Ucraina sovietica per comprendere anche quell'interessante fetta di produzione culturale realizzata dagli scrittori dell'emigrazione di oltreoceano. Negli stessi anni in cui si realizzò la rivoluzione culturale dello šistdesjatnyctvo, si consumò negli Stati Uniti la parabola del "Gruppo di New York". Costituito prevalentemente da poeti e intellettuali nati in Ucraina occidentale ed emigrati nella fase finale della Guerra, prima in Germania e poi negli Stati Uniti, i newyorchesi debuttarono tra il 1953 e il 1956, dunque con un leggero anticipo rispetto agli šistdesjatnyky. Nell'opera di poeti quali Jurij Tarnavs'kyj/Yuriy Tarnawsky (1934), Bohdan Bojčuk/Boichuk (1927-2017) e Bohdan Rubčak/Rubchak (1935-2018), liberi di 'creare' al di là di qualsivoglia pressione ideologica e finalità politica, nonché più direttamente sottoposti all'influenza delle letterature occidentali, sembrano finalmente giungere a compimento sia la piena evoluzione di quel 'puro' Modernismo che la letteratura ucraina aveva faticato a permettersi, sia il conseguente passaggio al Postmodernismo, in sintonia con la coeva cultura letteraria europea e americana (cfr. Bartolini 2012). La poesia dei newyorchesi si configurerebbe dunque come realizzazione di quelle potenzialità che $\mathrm{i}$ coetanei scrittori dell'Ucraina continentale, con i quali ebbero anche per un breve periodo contatti epistolari (ivi: 45-53), non poterono realizzare integralmente per evidenti ragioni. La critica ha tuttavia cercato di mettere in evidenza le similarità tra la poetica del "Gruppo di New York" e la "Scuola di Kiev" come rappresentanti di una cultura letteraria

20 Sulla polifonia stilistica dei "kieviani” cfr. Pastuch 2010. 
libera dal condizionamento politico, ancora una volta in contrapposizione allo šistdesjatnyctvo ${ }^{21}$. Si avrà modo di riflettere sulla problematicità di una simile schematizzazione in riferimento alla figura di Stus.

\section{Stus e la poesia stusiana nello specchio della critica}

Con la pubblicazione in Occidente di Zymovi dereva (1970), Sviča v svičadi (1977) e Palimpsesty (1986) si gettarono le basi per lo studio dell'opera stusiana, campo di ricerca noto in ucraino con il termine stusoznavstvo. Il paradosso che si è tuttavia costretti a riconoscere con rammarico è il seguente: dopo una fase di intensiva germogliazione della critica stusiana, principalmente a opera di studiosi dell'emigrazione di oltreoceano, i frutti sono comparsi a fatica, in ritardo e con risultati spesso deludenti. Sono pochi gli studi degli ultimi vent'anni che abbiano raggiunto lo spessore critico dei primi saggi sulla poesia stusiana pubblicati tra gli anni Ottanta e i primi anni Novanta. Da questi ultimi è naturalmente opportuno iniziare la rassegna.

Al 1987 risale una fondamentale raccolta di articoli, testimonianze e scritti di varia natura su Stus, corredata da lettere e note di carattere diaristico del poeta. Edita tra Stati Uniti e Canada, quest'opera riunisce lavori di anni diversi, alcuni dei quali altrimenti difficilmente reperibili (Zinkevyč, Francuženko 1987). Di enorme impatto per la fondazione e il (mancato?) sviluppo degli studi stusiani sono state innanzitutto le pagine di Bohdan Rubčak (Rubčak 1987) e Jurij Ševel'ov (Ševel'ov 1987).

Rubčak, poeta e critico già membro del "Gruppo di New York", affrontò per primo l'imprescindibile tema del rapporto tra l'opera stusiana e la tradizione poetica, sia occidentale che ucraina. L'importanza del dialogo con la letteratura per lo sviluppo della poesia stusiana spinse Rubčak a parlare della sua "organica letterarietà" (Rubčak 1987: 322). Al centro della sua attenzione sono due dei nomi più importanti per la costruzione della genealogia poetica di Stus, quelli di Rainer Maria Rilke e Taras Ševčenko. L'autore delle Duineser Elegien esercitò secondo Rubčak un' "influenza sistem(at)ica" sulla poesia stusiana dai versi giovanili a Palimpsesty, tanto a livello tematico (il rapporto dell'io lirico con la morte, alcune immagini ricorrenti come lo specchio e il precipizio), quanto stilistico (la tonalità confessionale di una lirica che si fa preghiera). Seppur meno identificabile nell'opera stusiana matura, anche la poesia pasternakiana, secondo una più che condivisibile opinione di Rubčak, influenzò Stus "sistem(at)icamente", soprattutto per quanto riguarda il ritmo sincopato della frase poetica e la personificazione dell'elemento naturale. Tra gli influssi "non sistem(at)ici" indi-

21 Morenec' 2013. Mykola Il'nyc'kyj ha invece cercato di sottolineare gli elementi condivisi nella poetica degli šistdesjatnyky e degli scrittori del Gruppo di New York insistendo sulla comune ricerca della novità espressiva e sul libero fluire del principio creativo. Cfr. Il'nyc'kyj 1996. 
viduabili nella lirica stusiana Rubčak cita diversi poeti ucraini, tra cui i grandi, immancabili classici novecenteschi Pavlo Tyčyna, Maksym Ryl's'kyj e Mykola Bažan, nonché Jevhen Plužnyk (1898-1936) e Oleh Zujevs'kyj (1920-1996). Rubčak si spinge fino ad affermare che "in generale il lettore può avere l'impressione che sotto lo pseudonimo 'Vasyl' Stus' scrivano diversi poeti" 22 . Come si avrà modo di osservare ampiamente, sarebbe molto difficile negare la validità di questa osservazione. Rubčak passa dunque a considerare il rapporto di Stus con Taras Ševčenko, padre delle lettere ucraine moderne. Più che un modello di riferimento, l'autore del Kobzar è per Stus un "padre spirituale" (ivi: 320). Secondo Rubčak, l'elemento fondamentale dell'universo poetico ševčenkiano ereditato dalla poesia di Stus sarebbe l'ipertrofia dell'io. Anche in questo caso la correttezza del punto di vista di Rubčak è sotto gli occhi di ogni lettore. La seconda parte del lungo saggio di Rubčak è invece dedicata a una disamina della lirica stusiana matura in chiave dialettica. Lo studioso nota la "riunificazione" dell'io lirico con se stesso e con l'universo, dopo una fase di sdoppiamento e alienazione segnata da venature esistenzialiste, coincidente con un percorso analogo nell'opera rilkiana. Per una discussione critica di questa interpretazione, sostanzialmente riduttiva, si rimanda alle pagine su Palimpsesty e all'ultimo capitolo.

Il secondo lungo saggio contenuto nella miscellanea curata da Osyp Zinkevyč e Mykola Francuženko, a firma del grande linguista, filologo e critico Jurij Ševel'ov, si mostra per molti aspetti complementare alle pagine di Bohdan Rubčak. A inaugurare la riflessione, dopo una lunga constatazione delle oggettive difficoltà legate allo svolgimento di un discorso scientifico nell'ambito di un panorama testologico "preistorico", è in questo caso la straordinaria varietà stilistica della poesia stusiana. Trovandosi costretto a rinunciare all'agognato obiettivo di una "collocazione di Stus nella lirica contemporanea ucraina e mondiale" (Ševel'ov 1987: 370), Ševel'ov sceglie di soffermarsi sulle diverse tendenze stilistiche di un poeta per il quale traspare la sua sentita (e autorevole) ammirazione. Evidenti sono per Ševel'ov i punti di contatto tra la lirica stusiana e l'Esistenzialismo, così come la sua vicinanza all'Espressionismo e all'Ermetismo. In ultima analisi Ševel'ov riconduce il pluristilismo di Palimpsesty a due macrofiloni, identificabili nei termini di una ricerca "poetistica", da una parte, e di una spiccata prosaicità a essa opposta, dall'altra. Di grande interesse sono, inoltre, le considerazioni di Ševel'ov sul lessico stusiano, ricco di neologismi, dalle quali traspare l'inconfondibile acume filologico dello studioso. Nonostante il richiamo a Hryhorij Skovoroda per quanto riguarda l'indubbia propensione dell'io lirico stusiano all'osservazione e alla conoscenza di sé e la definizione degli elementi ševčenkiani in Stus come "l'aria spirituale che lo circonda e in cui egli vive" ${ }^{23}$, Ševel'ov è restio ad accordare un particolare rilievo alle influenze

22 Rubčak 1987: 319: “Взагалі, в читача може скластися враження, що під псевдонімом 'Василь Стус' пише кілька поетів.”

23 Ševel'ov 1987: 397: “Шевченківське в Стуса - не вплив і не наслідування, його цитати не з книжки взяті. Це те духовне повітря, що його оточує, що в ньому він живе." 
intertestuali di altri autori sulla poesia di Palimpsesty: "In sintesi: di influssi letterari Stus ne ebbe, ma non determinarono la sua opera. Quello di Ševčenko non fu un influsso, - fu un'identificazione"24. Che in ciò il punto di vista di Ševel'ov diverga da quello di Rubčak è piuttosto evidente. In conclusione, lo studioso riflette sul contributo di Stus alla storia della poesia "carceraria" ucraina, osservando come i versi di Palimpsesty "superino i limiti della storia della letteratura carceraria, i limiti della storia della letteratura ucraina e appartengano dunque alla letteratura mondiale" 25

Oltre ai saggi di Rubčak e di Ševel'ov, la raccolta include altri quattro articoli di carattere letterario. Tre di essi affrontano l'opera stusiana principalmente nel contesto della letteratura ucraina classica e moderna ${ }^{26}$. Il breve studio del comparatista Leonid Rudnytzky si sofferma invece sui rapporti di Stus e della sua opera con la letteratura tedesca ${ }^{27}$. Oltre a fornire un'agile panoramica degli ampi interessi dell'autore nell'ambito della letteratura di lingua tedesca, il saggio di Rudnytzky cerca di offrire nello spazio di poche pagine un'interpretazione globale della presenza di Goethe e Rilke nell'opera stusiana, considerando anche le poche traduzioni stusiane allora disponibili. La principale debolezza del contributo di Rudnytzky sembra risiedere nella sua volontà di ricondurre Stus e l'autore delle Duineser Elegien sotto etichette interpretative troppo rigide, che mal si adattano alla verietà di stili e visioni del mondo che emerge dai loro rispettivi universi poetici. Secondo il critico,

Rilke fu il più grande poeta-panteista religioso nella storia dell'umanità. Stus, invece, si teneva sempre su posizioni prettamente cristiane. [...] I motivi della poesia rilkiana sono sparsi nella poesia di Stus, ma in essa sono tutti cristianizzati. Stus, per così dire, ha incarnato Rilke nella tradizione ucraina ${ }^{28}$.

24 Ivi: 399: "У підсумку: літературні впливи в Стуса були, але вони не визначали його творчости. Шевченків був не вплив, - було ототожнення."

25 Ivi: 400: "Вони проривають межі історії тюремної літератури, межі історії української літератури, вони належать до літератури світової.”

26 Leonid Pljušč (Pljušč 1987) mise in evidenza prima di chiunque altro i manifesti legami di Stus con Skovoroda e Śevčenko. Ostap Tarnavs'kyj (Tarnavs'kyj 1987) si soffermò principalmente sui nessi tra la poesia stusiana e il modernismo ucraino, mentre Ljudmyla Voljans'ka (Voljans'ka [1985]) toccò svariati nessi intertestuali tra Stus e diverse generazioni della letteratura ucraina, con particolare riguardo agli aspetti religiosi e patriottici.

${ }^{27}$ Rudnyc'kyj 1987. L'articolo era stato pubblicato in tedesco l'anno precedente sulle pagine del monacense "Jahrbuch der Ukrainekunde."

28 Ivi: 362: "Рільке був найбільш релігійним поетом-пантеїстом в історії людства. Стус, натоміст завжди стояв на суто християнських позиціях. [...] Мотиви з поезії Рільке порозкидані в поезії Стуса, але тут усі вони схристиянізовані. Стус, так би мовити, втілив Рільке в українську традицію." 
La distinzione individuata da Rudnytzky della "religiosità" dei due poeti sulla base di una mera "cristianizzazione" di Rilke da parte di Stus è, come si potrà osservare, indubbiamente schematica e riduttiva.

Per vedere una nuova pietra miliare lo stusoznavstvo ai suoi albori dovette attendere cinque anni. Mentre nell'Ucraina degli ultimi mesi del regime sovietico veniva pubblicata la prima antologia poetica stusiana e, di conseguenza, uscivano sulle riviste letterarie i primi contributi critici, si tenne in Australia un'importante giornata di studi dedicata a Stus, i cui atti videro la luce l'anno seguente (Pavlyshyn 1992a). Vi parteciparono cinque relatori, provenienti sia dall'Ucraina ancora sovietica che dagli ambienti della diaspora australiana. Nella prefazione alla breve raccolta di saggi Marko Pavlyshyn, organizzatore dell'incontro e curatore della pubblicazione, espresse a chiare parole un'“energica [volontà] di protestare contro la 'ševčenkizzazione' di Stus” 29 .

Sia nel variegato universo dell'emigrazione che nell'Ucraina 'continentale', infatti, la "santificazione" di Stus, ovvero la sua elevazione a figura di culto nazionale, era ormai un processo inarrestabile. Ne sono un ottimo esempio queste parole di Mykola Žulyns'kyj, tutt'oggi direttore dello stesso Istituto di Letteratura dell'Accademia delle Scienze ucraina da cui Stus era stato espulso nel 1965, in una pubblicazione del 1990 dedicata ai grandi scomparsi della letteratura ucraina del Novecento:

Questo costante ritorno a sé, questo conflitto interiore, questa orgogliosa lotta senza compromessi per poter rimanere un artista, perché qualsiasi compromesso, checché se ne dica, avrebbe potuto alleviare la sua sorte, questo continuo guardarsi indietro con la speranza di trovare una giustificazione a ciò che è accaduto e accettarlo, per avere la possibilità di sopravvivere e creare, ricorda un Golgota poetico, sul quale Stus è salito per crocifiggere se stesso sulla croce del dolore e sul sacrificio. Il dolore per il tragico destino del popolo ucraino e il sacrificio in nome di un avvenire storico più sereno per la natia Ucraina ${ }^{30}$.

Queste righe, nelle quali un fondamentale elemento dell'immaginario poetico stusiano come l'avvicinamento della sofferenza dell'io al modello cristologico si decontestualizza, trasformandosi da immagine poetica a prosa critica, hanno determinato il tono di gran parte dello stusoznavstvo a venire sino al giorno d'oggi.

29 Ivi: x (“енергійно протестувати проти шевченкізації Стуса.”)

30 Žulyns'kyj 1990: 431: “Оце повсякчасне повернення в себе, внутрішній конфлікт з самим собою, безкомпромісним і гордим в боротьбі за збереження себе як митця, бо ж певний компроміс, як не кажіть, а міг би полегшити його долю, оце постійне озирання назад із надією виправдати, що сталося, і змиритися 3 ним, щоб вижити і творити, нагадує поетичну Голгофу, на яку сходив Стус, і на якій він замірився прикувати себе на хресті скорботи і жертовності. Скорботи, вирощенної на осмисленні трагічної долі українського народу, і жертовності в ім'я щасливішого історичного майбуття рідної України.” Di segno diametralmente opposto è invece un coevo pregevole articolo a firma di Jaroslav Mel'nyk, incentrato sulla complessa immagine dell'Ucraina nella lirica stusiana. Cfr. Mel'nyk 1990. 
Si inizia così a delineare la contrapposizione tra Stus come eroe, da una parte, e Stus "come testo" dall'altra, come recita il titolo della conferenza e dell'antologia di studi pubblicatata a Melbourne. Il primo articolo della raccolta, dopo la programmatica prefazione di Pavlyshyn, gettò le basi per un dibattito sulla collocazione dell'autore di Palimpsesty nella storia della letteratura del Novecento. Tamara Hundorova, dichiarando di voler guardare all'opera di Stus da una prospettiva postmodernista (Hundorova 1992: 5), giunge alla conclusione che Stus, "ritrovandosi al confine tra l'alto modernismo e il postmodernismo, rimase in buona misura modernista, conservando l'individualismo e la soggettività modernisti" ${ }^{31}$. La studiosa, nel corso di una trentina di pagine di non facile lettura, si serve del concetto di žertvoslovo, con una buona dose di approssimazione traducibile come "martirologio", per esprimere la consapevole testualità della poesia stusiana, non messa volutamente in risalto come nell'estetica del Postmoderno, ma ugualmente testimone di un'intenzionale separazione tra il discorso poetico come discorso, da una parte, e l'autore, dall'altra. Evitando così un'ingenua identificazione tra l'io lirico e il poeta, viene messa in rilievo la teatralità insita nella poesia in quanto atto comunicativo. Ciò non esclude un doveroso riconoscimento della modernistica centralità della soggettività nell'universo poetico di Stus.

Rimandando alla parte conclusiva di questo lavoro per una più profonda discussione critica del problema della collocazione di Stus nella storia della poesia contemporanea, è opportuno notare sin da ora come l'approccio di Hundorova sia stato immediatamente contestato in una recensione agli atti del convegno di Melbourne. Bohdan Bojčuk vi nega nettamente l'ipotesi del modernismo di Stus, ricollegandosi implicitamente - e inaspettatamente, per un poeta del Gruppo di New York - all'interpretazione 'patriottica' della sua poesia, nell'ottica di una sostanziale subordinazione dell'opera al vissuto storico dell'autore:

Certamente Stus non era un modernista. Per quanto riguarda il suo stile, era un poeta tradizionale, che a tratti infrangeva i confini della poetica tradizionale con immagini originali [...]. Stus non era una 'persona alienata' nel senso esistenziale [di questo termine]. Era 'alienato' fisicamente, cioè isolato dalla famiglia, dagli amici, dal suo popolo. [...] Ho, infine, delle difficoltà con l'affermazione di Tamara Hundorova a proposito del fatto che i dissidenti abbiano creato 'una cultura modernista-avanguardistica'. Con la sola eccezione di Ihor Kalynec', i dissidenti non hanno creato e non creano alcunché del genere. I concetti di 'avanguardia' e 'modernismo' si riferiscono all'estetica e non alla politica ${ }^{32}$.

31 Ivi: 17: “Стус, перебуваючи на грані високого модернізму і постмодернізму, все ж таки лишався більшою мірою модерністом, оберігаючи модерністський індивідуалізм і суб'єктивізм.”

32 Bojčuk 1993: 115: “Звичайно, модерністом Стус не був. Якщо йдеться про стиль, то був він традиційним поетом, який денеде розпикав рамки традиційної поетики оригінальними образами [...] Не був Стус 'відчуженою людиною' в екзистенціяльному сенсі. Він був 'відчужений' фізично, тобто ізольований від родини, друзів і свого народу. [...] Маю ще, накінець, проблему з твер- 
È evidente come in queste righe sia in realtà lo stesso Bojčuk a confondere l'estetica con la politica e la personalità di Vasyl' Stus con la sua opera ${ }^{33}$.

Il secondo articolo di Stus jak tekst, a firma del curatore della raccolta Marko Pavlyshyn, esordisce precisando l'eccezionalità di Stus nel panorama della poesia ucraina degli anni Sessanta e Settanta, al cui interno la sua lirica non può che distinguersi nettamente da un "semplice (ma comunque grande) Symonenko, o un Karavans'kyj, o un Krasivs'kyj” (Pavlyshyn 1992b: 34). Pavlyshyn ribadisce inoltre le oggettive difficoltà legate a uno studio dell'opera stusiana di livello pienamente scientifico sullo sfondo della tradizionale trasformazione dei poeti in portatori di "postulati ideologici" nella cultura ucraina, nonché all'interno di una situazione culturale postmodernista ormai definitivamente liberatasi da sistemi assiologici precedentemente ritenuti incrollabili.

La seconda parte del contributo di Pavlyshyn si concentra su un'analisi della spazialità dell'universo poetico stusiano, che lo studioso riconduce alla contrapposizione tra il "quadrato, emblema della terrestrità e della sofferenza, e il cerchio, simbol[o] di un'esistenza elevata (fisicamente o psicologicamente) 'al di sopra' della dolorosa quotidianità del mondo"34. Nonostante le inevitabili semplificazioni che uno schema di questo tipo impone a un linguaggio per sua natura non riconducibile a compartimenti stagni come quello lirico, il prisma di

дженням Тамари Гундорової, що дисиденти, мовляв, творили 'модерністськоавангардистську культуру’. 3 єдиним винятком Ігоря Калинця дисиденти такого не творили й не творять. Поняття 'авангард', ‘модернізм' відносяться, все-таки, до естетики, а не політики."

33 Simili affermazioni furono espresse dal sodale di Bojčuk Jurij Tarnavs'kyj, otto anni dopo la recensione in questione. Tarnavs'kyj arrivò ad affermare che l'attenzione dedicata a Stus da studiosi ucraini formatisi in Occidente era in piena contraddizione con la loro dichiarata volontà di riscoprire il Modernismo ucraino, secondo Tarnavs'kyj da loro completamente ignorato (Tarnavs'kyj 2000). La critica tarnavs'kiana agli studi letterari dell'Ucraina contemporanea è passibile di una doppia lettura. Dalle sue parole sembrano emergere alternativamente un'accusa nei confronti delle predominanti letture in chiave patriottica e populistica dell'opera stusiana, dunque nei confronti di una sostanziale incomprensione di quest'ultima, oppure, con maggiore probablità, una provocatoria negazione assoluta del suo valore estetico nei confronti delle conquiste del Modernismo occidentale. Indipendentemente da quale sia il significato esatto da attribuire alle (volutamente?) ambigue considerazioni di Jurij Tarnavs'kyj, è interessante osservare come in risposta al suo scritto e in difesa degli šistdesjatnyky si sia immediatamente schierato lo stesso Bohdan Bojčuk, solo pochi anni prima strenuo oppositore dell'interpretazione di Stus in chiave modernista proposta da Tamara Hundorova. L'inaspettata riabilitazione bojčukiana dello šistdesjatnyctvo, forse spiegabile anche nei termini di un deteriorato rapporto personale con Tarnavs'kyi, si limita tuttavia ai nomi di Lina Kostenko, Mykola Vinhranovs'kyj e Ivan Drač, più difficilmente accostabili alle tensioni moderniste, mentre di Stus non è fatta in questo caso alcuna menzione. Cfr. Bojčuk 2000.

34 Pavlyshyn 1992b: 40: “Якщо квадрат - емблема приземлености й терпіння, то круг символізує буття, що піднесене (чи фізично, чи психологічно) 'понад' болючу щоденність світу.” 
lettura di Pavlyshyn si rivela indubbiamente produttivo per la poesia stusiana di Palimpsesty, così come per quella della giovinezza. A proposito di quest'ultima, è doveroso citare alcune righe dal paragrafo conclusivo dello studio, vicino per molti aspetti all'impostazione di questo lavoro:

Forse verrà un tempo in cui potremo guardare all'opera di Stus così come vorremmo: considerando il primo periodo della sua opera come un museo postmodernista di temi, stili, citazioni e parodie, vedendovi semplicemente la letterarietà della letteratura, [guardando] invece al periodo tardo come a qualcosa di barocco, denso, giocoso: come alla conclusione di un brillante kitsch nell'esecuzione di un poeta di rara maestria tecnica ${ }^{35}$.

Il carattere volutamente provocatorio, dissacratorio, forse addirittura rivoluzionario di una simile affermazione, ricca di stimolanti spunti interpretativi e accostabile alle considerazioni di Tamara Hundorova precedentemente discusse, sarà sottoposto ad attento esame in questo lavoro.

Il saggio successivo affronta il delicato problema della memoria nella poesia stusiana, come si avrà modo di osservare motivo fondamentale di Palimpsesty. Anna Berehuljak vi osserva con acutezza l'alternanza di un'affannosa ricerca del ricordo, garante di identità e conservazione, e di una consapevole rimozione, a sua volta unica possibilità di sopravvivenza (Berehuljak 1992). Mentre il quarto contributo del volume propone un'interpretazione globale della poesia stusiana come "pratica spirituale" in risposta alle avversità della realtà (Sarževs'kyj 1992), fornendo dunque un punto di vista in parte opposto ai tre articoli precedenti, il quinto, e ultimo, a firma di Petro Savčak (Peter Sawczak), affronta lo spinoso problema della ricezione dell'opera e della figura di Stus in chiave meta-critica (Savčak 1992). Il titolo dell'intervento ("La poetica della responsabilità e la responsabilità della critica: per una decanonizzazione della personalità artistica $\mathrm{e}$ dell'opera di Vasyl' Stus") mostra una chiara comunanza di orizzonti con le posizioni di Hundorova e Pavlyshyn. Il plaidoyer di Savčak per una rimozione di Stus (e di Ševčenko) dall'iconostasi delle lettere ucraine, al fine di consentire 'finalmente' un approccio critico scientifico alle loro rispettive opere, sarebbe stato tuttavia destinato a un sostanziale fallimento.

La raccolta di studi curata da Marko Pavlyshyn, come si è potuto osservare, ha ripetutamente sollevato la questione del possibile accostamento della poetica stusiana alla sensibilità postmodernista. Gli unici due brevi articoli a oggi disponibili interamente dedicati alla questione del rapporto di Stus con il postmodernismo, a firma di Mykola Najenko e Anna Bila, due dei critici più autorevoli dell'Ucraina contemporanea, si concentrano prevalentemente su questioni di intertestualità, ricollegandosi a quella tradizione critica che vede l'essenza del

35 Ivi: 51: “Може, колись прийде час, коли ми зможемо подивитись на Стуса так, як нам би кортіло: розглянути ранній період його творчости як постмодерністичний музей тем, стилів, цитат і пародій, і побачити в ньому просто літературність літератури, а пізній період — як бароковий, насичений, грайливий: як завершення блискучого кічу у виконанні поета рідкісної технічної вправности." 
postmodernismo letterario nell'accentuazione della citazionalità. Najenko ha in questo senso parlato di pisljamodernizm in riferimento al postšistdesjatnyctvo stusiano. Lascia piuttosto perplessi, per quanto riguarda l'insistenza sul carattere ideologico della letteratura postmoderna, la seguente affermazione dello studioso: "La letteratura (in particolare quella postmodernista) inizia sempre da una grande idea (oggettivo-sociale o soggettivo-personale) e da una nuova forma artistica precedentemente sconosciuta. Stus possedeva l'una e l'altra cosa" ${ }^{36}$.

Bila ha invece fornito un'elencazione di intertesti ševčenkiani, rilkiani e goethiani a (dubbia) dimostrazione del postmodernismo stusiano (Bila 2010). Entrambi gli studiosi hanno inoltre correttamente sottolineato l'intrinseca postmodernità del titolo "Palimpsesty" ${ }^{37}$.

Dopo le due fondamentali pubblicazioni del 1987 e del 1992 il baricentro dei lavori intorno all'eredità stusiana si spostò sul settore filologico-testuale ed editoriale. L'immane lavoro di Mychajlyna Kocjubyns'ka, Dmytro Stus e altri studiosi legati all'Istituto di Letteratura Sevčenko dell'Accademia delle Scienze ucraina portò alla pubblicazione nel corso di sei anni (1994-1999) della prima edizione accademica delle opere del poeta. I sei volumi in questione resero finalmente accessibili al lettore il lascito stusiano in una quantità e qualità editoriale assolutamente impensabili fino a pochissimi anni prima. Le raccolte poetiche, prima di allora disponibili soltanto parzialmente e in singole edizioni, vi si affiancano agli scritti in prosa, ancora sostanzialmente inesplorati, e all'intensa e preziosissima produzione epistolare. La titanica fatica dei curatori della raccolta per la compilazione e la pubblicazione dell'archivio stusiano non ha significato, beninteso, una definitiva soluzione del problema. Le note di lettura di Stus, ad esempio, sono state pubblicate più tardi e solo in piccola parte (Stus 2002b, 2008a), così come non si può dire terminato il lavoro su Palimpsesty, che attende ancora la ricostruzione della terza parte.

Alla prima metà degli anni Novanta risalgono anche le due prime monografie dedicate alla figura e all'opera di Stus. Nel 1992 venne pubblicata una breve, ma per lo stato delle conoscenze dell'epoca indubbiamente fondamentale rassegna biografica, a firma di Dmytro Stus, figlio allora ventiseienne del poeta (Stus 1992). Frutto dei primi lavori di raccolta e descrizione dell'archivio stusiano e tesi di laurea in letteratura ucraina, Žyttja i tvorčist'Vasylja Stusa mostra chiaramente i primi segni di quella scissione interiore tra la volontà di opporsi al processo di sacralizzazione della figura del padre per il bene della ricerca letteraria e la tentazione di contribuire attivamente a questo stesso processo che ha caratterizzato la vita e l'attività scientifica e divulgativa del figlio di Stus. Se nella prima pagina, infatti, Dmytro Stus osserva con rammarico che "l'impegno politico ha di nuo-

36 Najenko 2008: 41: “Література (зокрема й постмодерністська) починається завжди з великої (об'єктивно-суспільної чи суб'єктивно-особистісної) ідеї та 3 нової, малознаної досі, художньої форми. У В. Стуса було і те, й інше.”

37 Per una riflessione sulle profonde radici dell'idea di palinsesto come resistenza della cultura all'oblio e alla cancellazione e del significato profondo del palinsesto nella postmodernità cfr. Shallcross, Nycz 2011. 
vo avuto la meglio sulla poesia" 38 , non si può in seguito che constatare come sia stato egli stesso a portare avanti un discorso non esente dalla retorica patriottica. D'altro canto, l'insistenza del giovane Dmytro sullo "spirito aristocratico della poesia" come movente della curiosità artistica del padre, in connessione con le figure di Goethe, Rilke e Pasternak, sembra voler invitare il lettore a una riflessione letteraria degna di questo nome ${ }^{39}$.

L'anno seguente vide invece la luce un'opera altrettanto breve contenente le prime considerazioni meta-critiche a proposito della giovane, ma già variegata ricezione dell'opera stusiana (Bedryk 1993). L'autore, il giovane poeta e critico Jurij Bedryk, dopo aver richiamato l'attenzione del lettore sulla netta distinzione operata da Stus tra problemi estetici e problemi politico-sociali, vi mette in evidenza il carattere elitario e aristocratico del lascito personale e letterario dello scrittore. Insistendo sulla sua incondizionata adesione all'esistenzialismo cristiano, che significherebbe la sua sostanziale opposizione a Ševčenko, Bedryk si schiera apertamente con i fautori dell'approccio testualista, sulla scia della pubblicazione australiana dell'anno precedente, da lui per ovvie ragioni cronologiche non letta e dunque non citata. Il libro si chiude con un esplicito invito a una lettura più approfondita della lirica stusiana: "E per quanto possa essere amaro ammetterlo, non possiamo non farlo: la causa della crescente popolarità della poesia di Stus è da ritrovarsi in grande misura al di fuori della poesia stessa" ${ }^{40}$.

Lo stesso anno vide anche la pubblicazione di una cospicua raccolta di testimonianze su Stus (Orač 1993), che andavano ad arricchire il panorama memorialistico di Vasyl'Stus v žytti, tvorčosti, spohadach ta ocinkach sučasnykiv (Zinkevyč, Francuženko 1987). Presentando al grande pubblico più di quaranta interventi su Stus, molti dei quali inediti, nonché le lettere alla poetessa Vira Vovk (1926), “Ne vidljubyv svoju tryvohu rannju... ” rappresenta indubbiamente un importante contributo alla conoscenza della personalità del poeta, dagli anni giovanili a Donec'k sino alla detenzione e alla morte a Kučino. Particolarmente interessanti per lo studioso dell'opera stusiana sono, ad esempio, le attestazioni relative ai gusti di Stus in fatto di letteratura.

Per l'uscita di un nuovo significativo tassello dello stusoznavstvo in lenta e incostante crescita si dovette attendere il 1997, quando fu discussa all'Università dell'Alberta la prima tesi di dottorato su Stus scritta al di fuori dei confini dell'Ucraina. Il lavoro di Natalja Burjanyk, già autrice di un interessante artico-

38 Stus 1992: “Сумно, але політична заангажованість знову перемогла поезію.”

39 Ibidem: "Побіжно завважимо, що 1979-1980 pp. поет так визначав свої дороговкази: 'Для мене існує лиш три поети: Гете, Рільке і Пастернак'. Отож аристократичність духу поезії, іiі щирість важили вже в той період для Василя Стуса чи не найбільше.”

40 Bedryk 1993: 68. "I як би не було гірко не визнавати, але не визнати цього ми не маємо права: причина зростаючої популярності поезії Стуса опинилася великою мірою поза самою цією поезією." Allo stesso periodo risale anche la breve rassegna bibliografica in polacco di Bohdan Huk, ugualmente segnata da un buon grado di scetticismo nei confronti dei più recenti sviluppi del seppur giovane stusoznavstvo. Cfr. Huk 1992. 
lo sulla simbologia dello specchio e della candela nella lirica stusiana pubblicato in Ucraina pochi anni prima (Burjanyk 1993), offre una lettura competente dell'opera tarda attraverso il prisma della storia della poesia carceraria in chiave comparatistica (Burjanyk 1997). Spaziando inoltre dall'analisi degli elementi esistenzialisti nella pratica poetica stusiana agli influssi delle filosofie orientali, la studiosa fornisce numerosi spunti interpretativi originali relativi al tema della morte, che nel suo approccio critico costituisce il nocciolo dell'universo lirico di Čas tvorčosti / Dichtenszeit e Palimpsesty. Tra i pregi del lavoro di Burjanyk è sicuramente da annoverare la sostanziale estraneità al filone 'patriottico' dello stusoznavstvo, più propenso a una continua constatazione dell'amore del poeta per la patria che a un vero studio del suo lascito poetico.

Proprio quest'ultima tendenza si mostra dominante nell'ambito del crescente interesse per Stus nella critica ucraina. Mentre la sua figura viene sostanzialmente dimenticata nei centri di ricerca e nelle riviste della diaspora ucraina d'oltreoce$\mathrm{ano}^{41}$, a Kiev, Donec' $\mathrm{k}$ e in altre città ucraine si assiste a un vero e proprio boom degli studi stusiani. Nella città dove il poeta crebbe e iniziò gli studi, Donec'k, venne inaugurata la tradizione delle conferenze a lui dedicate, l'ultima delle quali si è tenuta nell'autunno del 2013. Nella capitale si intensificava la pubblicazione di articoli di argomento stusiano sulla rivista "Slovo i čas", organo dell' Istituto di Letteratura Ševčenko, mentre in tutto il paese giovani letterati intraprendevano gli studi dottorali con progetti di ricerca dedicati all'autore di Palimpsesty. Eppure, nonostante il saldo dello stusoznavstvo abbia segnato negli anni notevoli prestazioni a livello quantitativo, non si può dire lo stesso per quanto riguarda la qualità dei contributi. Come notato nel 2010 da Marko Pavlyshyn in un articolo sulla ricezione di Stus dall'eloquente titolo Martyrology and Literary Scholarship (Pavlyshyn 2010), l'insistenza sull'intrinseca "ucrainicità" di Stus e, soprattutto, sul suo percorso politico e personale, è frutto di una sorta di inerzia epistemologica del mondo culturale ucraino:

The biographical and martyrological reading of Stus offered an alternative drawn from the well-established tradition of Ukrainian nativism. From this perspective Stus's stature within his culture was secured by his significance relative to the special conditions of that culture and required no external verification. How Stus might be viewed relative to Rilke or Pasternak was of less interest than what he could teach the inhabitants of post-Soviet Ukraine through the example of his life (ivi: 602).

41 Un'importante eccezione è costituita da due ottimi articoli di Natalia Pylypiuk del 2002 (Pylypiuk 2002a e Pylypiuk 2002b), il primo dei quali affronta l'importante questione del rapporto tra la poesia stusiana e l'opera di Hryhorij Skovoroda. Il fatto che essi siano stati sostanzialmente ignorati dalla critica ucraina, forse 'soltanto' in quanto scritti in inglese (come confermatomi in una conversazione con la studiosa), esemplifica magistralmente lo stato di difficoltà in cui versano a tutt'oggi gli studi letterari ucraini in Ucraina, nonostante gli indubbi progressi dell'ultimo quinquennio. 
La fusione di biografismo e didatticismo messa in evidenza da Pavlyshyn si è realizzata e continua tuttora a realizzarsi nei termini di una sostanziale negazione della letterarietà del testo stusiano, nel senso jakobsoniano del termine, $\mathrm{e}$ di una sua implacabile soggezione al dato esterno, ora politico, ora più semplicemente personale. Che la lirica stusiana, così come quella dei suoi sodali e colleghi di penna Lina Kostenko e Ivan Svitlyčnyj, sia e debba essere innanzitutto un modello di comportamento per i giovani ucraini, invece che un testo letterario, è stato espresso a chiare lettere in un articolo dei secondi anni Novanta, a firma di Alla e Jurij Bondarenko, che altro non rappresenta se non un buon esempio di una tendenza diffusa e comunemente accettata. Pubblicato su una rivista di taglio pedagogico-letterario, il contributo in questione si spinge fino ad affermazioni al limite della logica e dell'accettabilità: "I poeti degli anni Sessanta erano rappresentanti del Ventesimo secolo. Per questo rivolgevano la loro attenzione principalmente alla raffigurazione del carattere repressivo del regime dell'Unione Sovietica"42.

La degradazione del testo poetico a mera testimonianza di un vissuto personale, probabilmente in parte comprensibile nel caso di una biografia dolorosa ed 'esemplare' come quella di Vasyl' Stus, ma decisamente non accettabile nell'ambito degli studi letterari, non ha mancato di segnare anche alcune delle poche monografie sul poeta a oggi disponibili, basate su dissertazioni dottorali discusse in Ucraina tra la fine degli anni Novanta e l'inizio del nuovo millennio, come i lavori di Oleh Raryc'kyj (Raryc'kyj 2002) e Hanna Vivat (Vivat 2003).

Per dare il benvenuto a una nuova pubblicazione di rilievo si dovette attendere il 2005, quando l'editore kieviano "Fakt" diede alle stampe una nuova monografia a firma del figlio Dmytro, a tredici anni di distanza dalla sua prova precedente. Il legame tra i due scritti, così come il radicale cambiamento metodologico di base, è suggerito dal titolo, apparentemente simile a quello del 1992 (Žyttja i tvorčist' Vasylja Stusa), ma in realtà profondamente differente. In Vasyl' Stus: žyttja jak tvorčist' ('Vasyl' Stus: una vita che è poesia') viene ripetutamente ed esplicitamente dichiarata la volontà di sostenere l'approccio biografico-martirologico alla figura stusiana a scapito del testo:

Proprio in riferimento a questi cambiamenti nell'odierna civiltà [nel paragrafo precedente si parla di globalizzazione - $\mathrm{AA}$ ] diventa sempre più attuale non tanto l'opera, quanto la biografia vissuta di Vasyl' Stus, grazie alla quale è come se l'Est ucraino si riavvicinasse all'Ovest, mentre l'idea nazionale si manifesta nell'atteggiamento anarchico individuale ${ }^{43}$.

42 Bondarenko, Bondarenko 1996: 54: “Поети-шістдесятники були представниками XX століття. Тому основну увагу вони приділяли змалюванню репресивного характеру режиму Радянського Союзу.”

43 Stus 2005: 54: “Саме з огдялу на ці зміни в сучасній нам цивілізації сьогодні дедалі більш актуальною стає навіть не так творчість, як життєва біографія Василя Стуса, якою український схід ніби зближується із заходом, а державницька ідея виявляє себе через анархічну індивідуальну поведінку.” 
Un'impostazione di questo tipo, ancorché non esente da palesi contraddizioni intellettuali e logiche ${ }^{44}$, non impedisce all'ampia monografia di rappresentare un importantissimo passo avanti nella conoscenza globale di Vasyl' Stus e della sua opera. La presentazione di materiali d'archivio inediti, come alcuni brani dei taccuini di lettura degli anni Cinquanta e le note diaristiche degli anni Sessanta, nonché una ricostruzione precisa e di ampio respiro dei diversi contesti socio-culturali in cui si svolsero la crescita e la maturazione di Stus sino all'arresto, costituiscono elementi di sicuro e inestimabile valore. Un indubbio merito di Dmytro Stus è l'importanza da lui attribuita alla fase donec'kiana della vita e della formazione professionale del padre, nel corso della quale si posero le basi esistenziali e letterarie per gli anni a venire del futuro autore di Palimpsesty.

Contemporaneo all'uscita di Žyttja jak tvorčist' fu l'inizio della pubblicazione della seconda edizione delle opere di Stus. Originatosi con l'intento di colmare le lacune della raccolta degli anni Novanta, il nuovo progetto mirava all'inclusione nel corpus stusiano delle varianti delle liriche non riprodotte in precedenza per questioni di spazio, nonché alla correzione degli errori inevitabilmente infiltratisi nei sei tomi di Tvory, risultato, come si è notato in precedenza, di un'autentica fatica di Ercole filologica. I lavori al nuovo Zibrannja tvoriv si sono purtroppo interrotti dopo l'uscita nel 2009 del quarto dei dodici libri previsti. La ragione di questo fallimento sarebbe da ricercarsi nelle difficoltà economiche in cui versava la casa editrice "Fakt" 45 , poi fallita, ma è difficile non interpretarlo emblematicamente alla luce delle aporie del mercato culturale ucraino a vent'anni dall'indipendenza. La nuova edizione non ha inoltre inspiegabilmente corretto alcuni gravi errori testuali già riscontrabili in Tvory.

Per quanto riguarda l'ultimo decennio è difficile parlare di pubblicazioni di rilievo. Una felice eccezione è costituita dalla tesi di dottorato di Olena Rosins'ka, pubblicata come monografia nel 2010 (Rosins'ka 2010). Nonostante un'apparente adesione di intenti allo stusoznavstvo di marca tradizionalista, ovvero all'ossessivo svisceramento del carattere immancabilmente "nazionale" del testo stusiano, il contributo della studiosa di Donec'k si rivela fondato e innovativo. Al centro dell'attenzione di Rosins'ka figurano la complessa simbologia numerale della poesia stusiana e le immagini più frequenti e fondative del suo universo poetico, nonché la ricezione da parte del poeta della filosofia esistenzialista francese e tedesca.

L'evento più significativo degli ultimi anni è la pubblicazione di una corposa raccolta di memorie sul poeta (Ovsijenko 2013), la quarta dagli anni Ottanta, notevole per la raffinata veste editoriale e la portata dei materiali. Si tratta principalmente di scritti già noti ma di difficile reperibilità, anche se non mancano testimonianze nuove. Che quasi trent'anni dopo la morte di Stus l'attenzione degli stusoznavci si concentri ancora maggiormente sul versante biografico è indicativo della pressante necessità di uno svecchiamento degli studi su Palimpsesty e le opere che hanno preceduto il capolavoro.

44 Cfr. ivi: 193: “В українському соціумі ця незбагненна потреба мати іконостас мучеників часом набирає потворних форм."

45 Come confermatomi in un colloquio con Dmytro Stus nel dicembre del 2012. 
Decisamente scarsi, sia quantitativamente che qualitativamente, risultano inoltre gli scritti incentrati sul dialogo tra Stus e i poeti e le correnti letterarie e culturali che lo hanno maggiormente influenzato.

Il problema dei rapporti tra le personalità artistiche di Stus e Pasternak è stato messo in evidenza sin dai primordi dello stusoznavstvo. Bohdan Rubčak, nel sovraccitato fondamentale articolo del 1983, ha mostrato alcuni intertesti pasternakiani nella poesia stusiana, nello specifico per quanto riguarda la lirica giovanile (Rubčak 1987: 317, 326). Nell'unico breve studio interamente dedicato alla questione, Marharyta Jehorčenko ha sottolineato la necessità di considerare la ricezione stusiana di Pasternak nel più ampio contesto del dialogo di quest'ultimo con Cvetaeva e Rilke (Jehorčenko 2008a: 83). Secondo la giovane studiosa kieviana, in sintonia con Rubčak, il "testo pasternakiano" è un elemento costitutivo dell'universo poetico di Stus. Il contributo di Jehorčenko si limita tuttavia a un elenco dei brani dell'epistolario stusiano riguardanti la figura e l'opera di Pasternak.

L'unico breve studio sul rapporto tra Stus e Marina Cvetaeva, dovuto anche in questo caso a Marharyta Jehorčenko, ha correttamente evidenziato il carattere fondamentale della poetologia di entrambi gli autori per la definizione dei loro rispettivi universi poetici, così come le notevoli comunanze tra questi ultimi (Jehorčenko 2008b). La studiosa ha insistito prevalentemente sulle somiglianze tra le affermazioni contenute nella prosa cvetaeviana e nell'epistolario stusiano a proposito della natura dell'ispirazione poetica e sull'importanza per entrambi delle figure di Rilke e Pasternak come modelli e interlocutori.

La questione del rapporto tra Stus e Rilke, ufficialmente 'riscoperto' come tanti autori negli anni del Disgelo, è stata invece oggetto di discussione sin dagli esordi della critica stusiana. A ciò hanno sicuramente contribuito le affermazioni stesse del poeta ucraino e il suo ampio lascito di traduzioni di lirica rilkiana. Le basi per una discussione della presenza di Rilke nella lirica stusiana sono state poste, anche in questo caso, da Bohdan Rubčak, che ha ricondotto all'ispirazione rilkiana la frequenza di immagini come l'abisso e lo specchio e la generale tonalità confessionale nella lirica di Stus. Pochi, tuttavia, sono stati i progressi in questo ambito di ricerca nei trent'anni che hanno seguito la prima pubblicazione dell'articolo di Rubčak. Nonostante la ricezione stusiana di Rilke sia stata inquadrata nel più ampio contesto della rilkiana ucraina ${ }^{46} \mathrm{e}$ sia stato condotto un notevole studio traduttologico e comparativo delle versioni stusiane delle Duineser Elegien e dei Sonette an Orpheus (Kravčenko 2008), resta ancora da riflettere sul significato profondo della presenza della poesia di Rilke nella lirica di Stus.

Mentre la questione del rapporto di Stus con la poetica espressionista e l'Espressionismo tedesco, come si vedrà alquanto significativi nel suo palinsesto po-

46 Cfr. Kravčenko 2002 e Kravčenko 2005. L'articolo del 2003 a firma della stessa studiosa, nonostante il titolo lasci presumere un'analisi comparativa delle poetiche di Stus e Rilke, si riduce alla consueta accentuazione dell'intrinseco "carattere nazionale" della poesia stusiana. Cfr. Kravčenko 2003. Si veda anche Nalyvajko 1995. Sulle oscillanti dinamiche della ricezione di Rilke in Russia e in Unione Sovietica si veda Brodsky 1983. 
etico, non è ancora stata affrontata adeguatamente, maggiore è stata la risonanza della vicinanza del poeta alla filosofia esistenzialista. Le origini della discussione sugli aspetti esistenzialisti dell'opera stusiana e sui possibili nessi intertestuali tra quest'ultima e gli scritti di filosofi francesi e tedeschi riconducibili alla sensibilità esistenzialista nelle sue svariate concretizzazioni risalgono ancora una volta al seminale studio stusiano di Jurij Ševel'ov. La questione è stata ampiamente dibattuta dalla critica da punti di vista e con conclusioni molto differenti tra loro. Se, nella biografia del padre, Dmytro Stus ha affermato che intorno al 1970 il futuro autore di Palimpsesty avrebbe definitivamente superato la fase esistenzialista del periodo precedente (Stus 2004: 7), alcuni studi degli ultimi anni hanno cercato di mostrare come Stus sia stato lungo tutto il suo cammino umano e letterario un filosofo esistenzialista mancato, vuoi per le condizioni storiche in cui egli si trovò a vivere e operare, vuoi per la sua innata e inguaribile tendenza a esprimere un sistema di pensiero in forma di poesia ${ }^{47}$. La discussione ha tuttavia privilegiato in molti casi i presunti "atteggiamenti esistenziali" della personalità stusiana rispetto a un'analisi puntuale dei punti di contatto della sua produzione poetica con il linguaggio della filosofia esistenzialista.

Numericamente più consistenti, ma non esaustivi, risultano i contributi sul dialogo tra Stus e la letteratura ucraina. Lo studio del suo fondamentale rapporto poetico con Ševčenko, messo inizialmente in evidenza negli scritti di Ševel'ov e Rubčak, si è generalmente fermato a una constatazione delle similarità nei loro tormentati percorsi biografici. Anche un critico affermato come Hryhorij Syvokin' (1931-2014) non resistette alla tentazione di ridurre la complessa questione dell'incontro tra i due poeti al presunto carattere profetico del loro operato. Lo studioso affermò infatti che l'argomento non può sostanzialmente essere affrontato dal punto di vista letterario, in quanto il suo baricentro semantico e assiologico risiederebbe piuttosto nella sacralità del loro "Destino" 4 .

Decisamente più adeguato alla problematicità dell'argomento risulta l'approccio della studiosa di Donec'k Anna Bila, che ha toccato con rapidità ma efficacemente il tema del rapporto tra Stus e Ševčenko in un breve scritto dedicato a un'altra questione cruciale, ossia la presenza del filosofo ucraino settecentesco Hryhorij Skovoroda nel panorama intellettuale e intertestuale dell'arte stusiana. Bila ha individuato nell'insegnamento skovorodiano un modello 'etico' per l'io

47 Si vedano Iščenko 2015, Poljuha 2011 e Kraljuk 2010. Anche gli ottimi studi di Jurij Bedryk e Olena Rosins'ka hanno messo in evidenza i legami tra l'opera di Stus e la riflessione esistenzialista in senso ampio. Rosins'ka si è particolarmente soffermata su i punti di contatto tra Stus e Jaspers. Cfr. Rosins'ka 2009: 9-42 e Bedryk 1993. Una lettura della lirica stusiana in rapporto all'esistenzialismo cristiano è stata tentata da Viktor Marinčak, ma il suo approccio risulta poco convincente a causa di una forzatura nei confronti della letterarietà del testo intrinseca alle sue premesse di fondo, volte a una lettura necessariamente assiologica del testo poetico (Marinčak 2013).

48 Syvokin' 2001: 6: “У такий спосіб тема ‘Василь Стус і Шевченко’ виходить на вищий рівень ії̈ осмислення, де важить не так суголосся чи, навпаки, одмінність поетичного голосу і словесної фактури написаних віршів, як ії величність Доля, віру в яку і довіру до якої свято сповідував Стус, не страхаючись іiі, навіть злої.” 
lirico di Stus e il suo universo poetico, da non confondere con il significato in primo luogo 'emozionale' che vi riveste la componente ševčenkiana. Gli elementi riconducibili alla tradizione di Ševčenko sono inoltre correttamente indicati da Bila come uno dei tasselli di un mosaico intertestuale ampio e variegato (Bila 2007).

Il maggior contributo sul ruolo dell'eredità del grande filosofo ucraino settecentesco per l'opera di Stus, è il già menzionato articolo di Natalia Pylypiuk del 2002, che ha messo in rilievo la possibile origine skovorodiana dell'ansia di rigenerazione di cui è pervaso l'io lirico stusiano, dalla studiosa ricondotto al mito di Narciso ${ }^{49}$.

Altri brevi saggi hanno toccato rapidamente questioni come il rapporto tra Stus e il secondo scrittore nazionale Ivan Franko (1856-1916; cfr. Tarnašyns'ka 2008 e Vivat 2008) e, in misura ancora minore, il ruolo della poesia del primo Novecento nella sua formazione letteraria. Interessante, seppur fermo a uno stadio iniziale, il tentativo di Anna Bila (Bila 2008) di collocare lo Stus dei primi anni in un'ideale "terza generazione" del Simbolismo ucraino, sulle orme di poeti come Pavlo Tyčyna, Volodymyr Svidzins'kyj (1885-1941) e Bohdan-Ihor Antonyč (1909-1937), nonostante il notevole scarto temporale tra essi e Stus.

A fornire un'evidente conferma della complessità del lascito poetico stusiano è la sua sostanziale assenza nelle recenti panoramiche della poesia ucraina del secondo Novecento e nei contributi dedicati ai singoli movimenti.

Si veda ad esempio lo studio di Anatolij Hryzun sulla "poesia suggestiva" nella letteratura del Novecento ucraino, nel quale a un'iniziale dichiarazione sull'importanza dell'analisi della lirica stusiana per una trattazione completa della questione fa seguito una sostanziale omissione di Stus dal corpus preso in esame (Hryzun 2011). Una fortunata eccezione è invece costituita dall'ormai classica monografia di Eleonora Solovej del 1999 sulla "lirica filosofica" ucraina, in cui l'esperienza poetica stusiana è riportata sotto il cappello esistenzialista dell'“autenticità dell'essere", di cui sarebbe piena realizzazione (Solovej 1999: 153-190).

A dare adito a interpretazioni contrastanti e a essere di sovente passata sotto silenzio è la collocazione della figura di Stus nel mondo culturale ucraino degli anni Sessanta e Settanta. La sua stessa appartenenza allo šistdesjatnyctvo non sembra essere accettata da tutti gli studiosi ${ }^{50}$. La raccolta di studi dedicati alle massime personalità del movimento a firma di Ljudmyla Tarnašyns'ka (Tarnašyns'ka 2010), uno dei pochissimi titoli disponibili che possa essere considerato come una monografia sullo šistdesjatnyctvo, non contiene un capitolo dedicato integralmente all'autore di Palimpsesty, che deve accontentarsi di sporadiche menzioni in connessione con Lina Kostenko, Ivan Svitlyčnyj, Jevhen

\footnotetext{
49 Cfr. Pylypiuk 2002a. Sull'argomento si veda anche Bordukova 1998.

50 Si veda l'intervento di Mykola Najenko, in: Stusivs 'ki čytannja 1998: 28: “B. Стус - не шістдесятник, він постшістдесятник і тому в нього намітився новий відхід від традиційності, але причетність до ней його не полишало." 'Stus non è uno šistdesjatnyk, è un post-šistdesjatnyk, e per questo si nota in lui un nuovo modo di allontanarsi dalla tradizione, senza per questo abbandonarla.'
} 
Sverstjuk (1928-2014) e le altre figure più univocamente ascrivibili alla corrente principe degli anni Sessanta.

Si noti a questo proposito come negli anni Novanta non siano mancate radicali voci di protesta contro lo šistdesjatnyctvo tout court da parte di intellettuali delusi dall'ascesa al potere di alcuni esponenti del movimento. Vasyl' Ivaško propose in questo contesto una netta separazione tra l'esperienza intellettuale stusiana e lo šistdesjatnyctvo, giudicando tendenziosa l'assimilazione della raffinata opera poetica di Stus da parte di una cultura a suo avviso meramente populista:

Come tutti i miti politici contemporanei, anche il mito di Stus è un mezzo piuttosto efficace di lotta politica. Una risposta alla domanda su chi, come e perché lo utilizzi è ovvia: il mito del poeta serve a coloro che detengono ora il potere politico, cioè la generazione 'degli anni Sessanta'. [...] Il vero Stus inizia laddove finisce lo Stus-šistdesjatnyk $k^{51}$.

In alternativa a una sua classificazione nell' ambito dello šistdesjatnyctvo, altri studiosi hanno ipotizzato un' inclusione di Stus nel più ampio contesto della poesia "alternativa" dei tardi anni Sessanta e Settanta, spesso ricondotta alla già menzionata "Scuola di Kiev"52. Nella definizione di quest'ultima, riconducibile in ultima analisi a una concezione della poesia come arte pura, libera da qualsivoglia condizionamento sociale e politico, sembrano concorrere due tendenze opposte. Alcuni specialisti, rifacendosi a una dichiarazione di Viktor Kordun (Kordun 1997), sottolineano la necessità di limitare il campo di utilizzo di questa etichetta ai quattro rappresentanti originari del movimento, ovvero lo stesso Kordun, Mykola Vorobjov, Mychajlo Hryhoriv e Vasyl' Holoborod'ko. In quest'ottica è concepita la monografia di Ljudmyla Dudarenko del 2009 (Dudarenko 2009). Un altro gruppo di critici sostiene al contrario la possibilità di un utilizzo più largo del termine, che si presterebbe ad accogliere anche quei poeti accostabili per sensibilità artistica e vicinanza umana alla summenzionata 'quadriga'. Miglior esempio di questo approccio indubbiamente produttivo, è la monumentale monografia di Taras Pastuch del 2010, vera e propria miniera di interpretazioni sulle peculiarità stilistiche del-

51 Ivaško 1994: 107-112 passim: “Як і всі сучасні політичні міфи, міф про Стуса - доволі ефективний засіб політичної боротьби. Відповідь на питання про те, хто, як і навіщо його використовує - очевидна: міф про поета потрібен тим, хто нині утримує політичну владу, тобто поколінню 'шістдесятників'. [...] Справжній Стус починається там, де закінчується Стус-“шістдесятник'.” Simile il punto di vista di Jurij Gudz', in: Gudz' 1994. Si veda sull'argomento un contributo metacritico di Jaroslav Poliščuk (Poliščuk 2011a). Per una critica del "mito stusiano" si veda anche l'ormai classico Rjabčuk 1999.

52 Tra i primi studiosi a evidenziare correttamente la vicinanza estetica di Stus ai poeti kieviani è da menzionare Mykola Il'nyc'kyj, che, come Najenko, considera Stus un post-šistdesjatnyk (Il'nyc'kyj 1999) Nella postfazione a una raccolta di liriche di Mykola Vorobjov, Mykola Dmytrenko ha addirittura enfaticamente posto il nome di Vasyl' Stus all'inizio di un elenco dei membri del gruppo che si limita, in realtà, a tre soli nomi: Stus, Vorobjov e Holoborod'ko (Dmytrenko 2007: 626). 
la poesia ucraina del secondo Novecento (Pastuch 2010). Questa interpretazione meno rigida del concetto di "Scuola di Kiev" ha permesso la discussione del lascito letterario di poeti quali Vasyl' Ruban (1942-2017), Stanislav Vyšens'kyj (19442018) e, soprattutto, Ihor Kalynec' (1939) in una prospettiva finalizzata a ottenere un quadro complesso della poesia ucraina della tarda età sovietica. L'esclusione di Stus da questo interessante progetto appare sintomatica delle profonde difficoltà legate a una schematizzazione della straordinaria tavolozza stilistica stusiana, così come di una più generale e più che comprensibile aporia epistemologica nella caratterizzazione del suo contributo alla letteratura ucraina novecentesca.

Nella più recente, più ampia e ponderata seconda monografia di Ljudmyla Tarnašyns'ka sugli anni Sessanta, l'ormai comunemente affermatasi contrapposizione tra il movimento degli šistdesjatnyky e i "kieviani" 53 è stemperata a favore di un approccio più ampio e meno dogmatico alla cultura dell'epoca come frutto dell'interazione di personalità e orientamenti estetici diversi (Tarnašyns'ka 2013: 590). La studiosa ha evidenziato a questo proposito la spiccata autonomia di Stus, nonché di Ihor Kalynec', all'interno di uno šistdesjatnyctvo inteso come fenomeno storico-generazionale e non come riduttiva etichetta tematico-stilistica (ivi: 583).

Diverso è, infine, l'approccio proposto da Halyna Rajbedjuk in una monografia concepita come un manuale universitario (Rajbedjuk 2012). Servendosi del concetto di "poeti-dissidenti" (poety-dysydenty), la studiosa odessita ha potuto oltrepassare i confini generazionali, geografici e stilistici avvicinando scrittori quali Stus, Svitlyčnyj, Ihor Kalynec', Mykola Rudenko (1920-2004), Taras Mel'nyčuk (1939-1995) e Stepan Sapeljak (1951-2012) sulla base della loro comune esperienza politica e delle repressioni da loro subite. I rischi legati a una scelta metodologica di questo tipo sono evidenti. L'elenco dei poeti ucraini vittime delle molteplici ondate di recrudescenza del controllo sovietico sugli intellettuali nella seconda metà del Novecento non si limita certo ai sei nomi selezionati da Rajbedjuk ${ }^{54}$, mentre non sono chiare le ragioni intrinsecamente letterarie ed estetiche alla base della sua scelta.

Nel corso di una trentina d'anni lo stusoznavstvo ha prodotto, come si è potuto osservare, una quantità notevole di studi, diversi tra loro per qualità, obiettivi e scelte metodologiche. Nonostante molti aspetti del lascito poetico stusiano siano stati affrontati portando anche a risultati notevoli, rimangono da valutare più ampiamente sia il rapporto tra la poesia stusiana e le sue fonti, sia la collocazione di Stus nel panorama letterario del secondo Novecentesco ucraino ed europeo. Questo lavoro cercherà di fornire alcune risposte a questi interrogativi.

53 Contrapposizione decisamente marcata proprio dai "kieviani", come ben risulta dalla ricostruzione della storia della "Scuola di Kiev" a firma dello stesso Viktor Kordun. Cfr. Kordun 1997.

54 Nell'antologia Poety iz-za grat ('Poeti da dietro le sbarre'), pubblicata nel 2012 dalla casa editrice engagée "Smoloskyp", figurano i nomi di più di sessanta poeti repressi, anche molto distanti tra loro per decennio di nascita e valore letterario, tra i quali, naturalmente, Vasyl' Stus. Cfr. Holub 2012. Alcune liriche e testi in prosa di Stus sono inoltre confluiti in una recente antologia di scrittori e intellettuali dissidenti ucraini della tarda età sovietica, a metà strada tra politica e letteratura (Sinčenko, Stus, Finberg 2018). 



\section{Capitolo secondo. Stus lettore e critico}

\section{Gli scritti critici}

La tensione intellettuale di un poeta lettore e studioso di letteratura si è concretizzata in quasi trent'anni di note di lettura, scritti analitici e approfondite disamine di fatti culturali disseminate nello spazio dell'epistolario stusiano. A emergere da una visione d'insieme del lascito interpretativo di Stus è indubbiamente la sorprendente varietà delle metodologie critiche di volta in volta adottate, a testimonianza della pluralità di tradizioni e modelli culturali alla base della sua opera. Altrettanto degna di nota è l'ampiezza del materiale di studio, che spazia dagli scrittori ucraini, alla letteratura russa, imprescindibile per uno scrittore del Novecento ucraino, alle letterature occidentali e, in misura minore, extraeuropee.

Come testimoniato da un compagno di studi degli anni di Donec'k, il giovane Stus aveva il permesso di accedere al fondo speciale della biblioteca regionale, probabilmente in virtù delle sue eccezionali doti di apprendista letterato (Kulyk 2008: 43). Ciò gli garantiva la possibilità di una conoscenza particolarmente approfondita dei testi e della critica.

Il primo scritto critico stusiano di cui si è a conoscenza risale al 1957, ossia ai tempi degli studi universitari a Stalino (Donec'k), ed è dedicato a un'opera allora fresca di pubblicazione, la raccolta poetica Trojandy j vynohrad ('Le rose e l'uva'), momento centrale della cosiddetta "terza fioritura" (tretje cvitinnja) di Maksym Ryl's'kyj. Non si può negare come lo Stus appena diciottenne di Poezija tret'oji vesny ('La poesia della terza primavera') non fosse immune da stereotipi ascrivibili tanto alla tradizione populista ucraina, quanto alla retorica sovietica: "Ryl's'kyj è orgoglioso delle conquiste del suo tempo, che si immagina come un tenero uccello-aeroplano che si innalza al di sopra della terra. Il cuore del poeta è colmo di amore per la Patria natia, che dà stimoli all'artista e forza all'operaio".

I frequenti rimandi alla poesia di altri illustri rappresentanti della letteratura ucraina, dal secondo vate nazionale Ivan Franko al bardo sovietico Volodymyr

1 T IV, 160: "Рильський пишається досягненням своєї доби, яку він уявляє собі в образі милого птаха-літака, що гордо зринає над землею. Серце поета сповнене любові до рідної Вітчизни, що дає наснаження творцю, силу робітникові." 
Sosjura (1898-1965), mostrano l'agilità del giovane letterato nello spaziare tra varie generazioni di scrittori patri. L'insistenza sul motivo del lavoro e della dignità umana che da esso deriva, basato sull'oggettiva importanza che esso ricopre nell'universo lirico ryl's' kiano $^{2}$, sembra rimandare sia al mitologema sovietico della fatica dell'uomo, sia a motivi di scrittori come Franko ${ }^{3}$ e Antonyč ć $^{4}$ "La tensione umanistica della raccolta è di ordine superiore. Il poeta celebra il sonoro canto dell'uomo, per il quale la creatività artistica e il lavoro sono inseparabili" 5 - scrive Stus, avvicinando nello stile naïf di uno studente del terzo anno tradizioni di origine ben lontana tra loro e anticipando problematiche importanti della propria futura auto-percezione di artista.

Alla prima metà degli anni Sessanta risalgono le prime serie prove di un poeta ansioso di farsi strada professionalmente anche nel campo della critica letteraria. In Naj budem ščyri ('Siamo sinceri!') e Na poetyčnomu turniri ('Al torneo di poesia'), entrambi risalenti al 1964, Stus si cimenta con la letteratura ucraina contemporanea, al centro dei suoi interessi in connessione con il tema della tesi di dottorato sulle fonti dell'emozionalità del testo letterario. Non si può accusare il giovane studioso e scrittore di eccessiva indulgenza nei confronti dei compagni di penna, anche più anziani e affermati di lui. L'incipit di Naj budem ščyri, pubblicato sulla prestigiosa rivista "Dnipro" nel febbraio del 1965, suona come un atto d'accusa nei confronti di una poesia non all'altezza delle aspettative, pallida e vuota dopo le prove di Ivan Franko, a un verso del quale è ispirato il titolo dello scritto, di Lesja Ukrajinka (1871-1913), tra le figure più venerate del pantheon delle lettere ucraine, e di Vladimir Majakovskij. La stessa scelta dei modelli a cui paragonare ex negativo i contemporanei mostra la convergenza del canone nazionale e di quello russo-sovietico nell'orizzonte letterario di Stus, dottorando all'Istituto di Letteratura dell'Accademia delle Scienze e dunque inserito a pieno titolo, per il momento, nel sistema culturale ufficiale ucraino-sovietico. Nel se-

2 Si veda ad esempio da Bahrjanyj večir dohoriv... ('Si consumava la sera purpurea...') del 1963-64, in: Ryl's'kyj 2005: 11-12: “Спокійна творчості тривога, / В мовчанні зімкнені уста / Ледь-ледь окреслена мета / Знов серце манить у дорогу.” 'La tranquilla cura del creare, / Labbra serrate nel silenzio, / Una meta appena definita / Di nuovo il cuore richiama alla strada.'

3 Si veda l'ultima quartina di Pisnja i pracja ('Il canto e il lavoro') dal ciclo frankiano Poet del 1883, in: Franko 1951: 49: “Пісня і праця. Великі дві силі! / Їм до скону бажаю служить; / череп розбитий — як ляжу в могилі, / ними лиш зможу й для правнуків жить." 'Canto e lavoro. Che due grandi forze! / Fino alla morte io voglio servirle; / col cranio rotto sarò nella tomba, / solo con loro ai posteri sarò.'

4 Si pensi alla strofa finale di Ekstatyčnyj vos'mystrof ('Otto strofe estatiche') del 1935, in: Antonyč 2012: 202: “І сонце заходу, і літо й липи мрійні, / змінливість вічну світу ввечорі і вранці, / я прославляю невгомонний труд в олійні, / горіння душ, екстазу тіл і хміль кохання." 'E il sole del tramonto, l'estate e i tigli in sogno, / l'eterno mutare del mondo la sera e il mattino, / benedico il lavoro incessante del torchio, / le anime che bruciano, i corpi in estasi e l'ebbrezza d'amore.'

5 T IV, 162: "Гуманістичний струмінь збірки - вищого порядку. Поет співає гучну пісню людині, для якої творчість і праця — неподільні.” 
condo paragrafo del corposo articolo l'opinione dell'autore viene espressa con una sincerità in perfetta sintonia con il titolo: "Purtroppo, a molti dei nostri poeti manca proprio un'elevata statura intellettuale"6. Il J'accuse stusiano a proposito della povertà non solo intellettuale della poesia ucraina del tardo Disgelo viene quindi argomentato mediante concetti di stampo tipicamente sovietico: "Si sono fatte prove disperate di elevare quel livello, di superare quel pericoloso distacco della poesia dalla vita, dalle necessità e dagli interessi del nostro contemporaneo"7.

Il lessico utilizzato da Stus sembra qui infatti ricalcare le parole d'ordine della critica sovietica, acerrima nemica di ogni deviazione dalla "vita" e dalla "contemporaneità". La necessità di un innalzamento del livello artistico della lirica degli anni a venire sembra derivare non da ultimo da un presunto innalzamento del livello culturale del lettore: "Il poeta deve costantemente tenere in conto il livello del lettore. E questo livello è diventato incomparabilmente più alto. Scrivere per un lettore di questo tipo risulta essere una prova sempre più complessa".

Dietro a quest'affermazione si cela il riconoscimento degli effetti positivi delle politiche culturali degli anni del Disgelo - ormai avviato a una rapida fine - sulla produzione artistica sovietica. Complicato, nell'ottica stusiana, è il raggiungimento di un corretto rapporto con la tradizione: "La nostra era tecnologica crea la propria estetica, e la tradizione le si rivela a volte d'impaccio. [...] La forza della poesia risiede proprio nel fatto che in essa si conserva intatta la concretezza della realtà circostante, con la sua bellezza, la sua saggezza e la sua etica"10.

6 Ivi: 173: “На жаль, багатьом нашим поетам бракує саме глибокої інтелектуальної позначеності."

7 Ivi: 174: “Робилися також відчайдушні спроби піднести той рівень, подолати той небезпечний відрив поезії від життя, від потреб та інтересів нашого сучасника."

8 Si veda, ad esempio, Michajlov, Čudakov 1960: 40: "В наши дни с особенной силой звучит требование к поэту - быть подлинно современным. Без этого он способен родить лишь 'отклик в воздухе пустом'. Иными словами, сегодня в сферу его поэзии не могут не войти многие сложные представления, характеризующие современность.” Si veda anche Grinberg 1966: “В. Луговской и А. Твардовский не только 'доводили до сведения' читателей свое отношение к тому или иному факту, но создавали картину современной жизни. И этим смелым решением самых острых, насущных вопросов действительности (решением, а не перечислением, не упоминанием, не иллюстрированием!) была и осталась сильна и наша лирика второй половины 50-х — первой половины 60-х годов.” Si noti la chiara volontà dell'autore di distinguere la storia della poesia sovietica dell'ultimo decennio da quella dell'età staliniana.

9 T IV, 175: "Поет мусить постійно враховувати рівень читача. А цей рівень став незрівнянно вищим. Писати для такого читача - стає все важчим і вачжим письменницьким іспитом."

10 Ivi: 176: "Наш технічний час витворює нову естетику, а традиція стає їй часом на заваді. [...] Сила поезії саме в тому, що в ній зберігається нерозщеплена конкретність навколишньої реальності, де і $є$ своя краса, і своя мудрість, і своя етика." 
L'idea che la tradizione - o meglio una tradizione ridotta alle sue manifestazioni vuote e superficiali - rappresenti un pericolo per lo sviluppo delle lettere ucraine non smetterà di preoccupare Stus anche negli anni seguenti. Altrettanto problematico è per il futuro autore di Palimpesty il ruolo della componente pubblicistica nella poesia contemporanea, della cui necessità egli non sembra inizialmente dubitare:

Ci servono poesie pubblicistiche di buon livello, combattive. [...] Gli elementi pubblicistici nella nostra poesia sono allo stesso tempo la negazione della vecchia estetica dei versificatori da strapazzo, che elevano la banale capacità di illustrare al rango di poesia, e, dall'altra parte, mostrano l'impotenza dei poeti davanti al loro tema, ancora poco chiaro ${ }^{11}$.

Dopo una disamina dei pregi e dei difetti della poesia ucraina degli ultimi mesi sulla base di numerose citazioni, Stus conclude con una previsione ottimistica sui successi a venire. L'obiettivo da raggiungere, a cui la lirica contemporanea sembra lentamente avvicinarsi, è ancora una volta quello di una "appropriazione estetica dell'oggetto reale, del fatto reale della vita nella loro essenza interiore, e non nella varietà dei suoi rapporti col mondo esterno" ${ }^{12}$. È indicativo, tuttavia, che i primi esempi di questa tendenza siano tratti innanzitutto da letterature straniere: Neruda, Hikmet e Różewicz. Solo dopo vengono, in ordine di età, nomi ucraini: Franko, Ryl's'kyj, Mysyk (1907-1983), Bažan e poi Drač, Korotyč (1936) e Symonenko. La necessità di guardare a modelli stranieri per migliorare la qualità della poesia nazionale sembra essere per Stus imprescindibile ${ }^{13}$. A emergere dalla lettura di Naj budem ščyri è l'immagine di un giovane studioso armato di solide conoscenze e passione critica, scisso tra gli obblighi verso l'ufficialità letteraria sovietica, il discorso nazionale del modello populista ucraino e la modernità della vocazione personale, che gli impedisce di cedere integralmente al peso delle altre due ingombranti componenti del suo background. È significativo che gli assunti teorici contenuti in questo saggio non trovino sostanzialmente riscontro nella coeva lirica stusiana, a possibile conferma della presenza di un sostrato concettuale esterno, non pienamente interiorizzato, nella sua ideazione e realizzazione.

11 Ivi: 182: “Нам потрібні хороші, бойові публіцистичні вірші. [...] Публіцистичність у нашій поезії - це одночасно заперечення старої домашньої естетики віршомазів, які ілюстраторство возводять у ранг поезії, $\mathrm{i}-3$ другого боку — це вияв безсилості поетів перед естетичним подоланням своєї, іще неясної теми."

12 Ivi: 189: "Процес естетичного освоєння самого реального предмета, реального факту життя у їх внутрішній сутності, а не в численних зовнішніх відношеннях, - цей процес усе активніше торує собі дорогу в поезію.”

13 Ivi: 190: “Необхідність гармоніювати стильовий 'букет' нашої літератури вимагає ширшого засвоєння художніх здобутків інших народів світу." 'La necessità di armonizzare il bouquet stilistico della nostra letteratura esige un più ampio adattamento delle conquiste degli altri popoli del mondo.' 
Da Na poetyčnomu turniri, recensione dell'almanacco Den 'poeziji del 1963 pubblicata su "Dnipro" nell'ottobre del 1964, emerge un panorama della poesia ucraina contemporanea non meno disilluso. In entrambi gli scritti le concilianti dichiarazioni di fiducia nel futuro delle lettere patrie - a cui il giovane critico sa di non poter rinunciare - non nascondono infatti la distanza di Stus dai suoi colleghi di penna. La principale lacuna della produzione poetica nazionale degli ultimi mesi è ora da lui individuata nella debolezza estetica di gran parte delle liriche $^{14}$. La tendenza a una vuota modernizzazione del linguaggio mediante l'inserimento di immagini tratte dal repertorio della contemporaneità che Stus osserva in molti poeti dell'epoca è dal suo punto di vista nient'altro che una moda sterile e controproducente ${ }^{15}$. Anche in queste pagine Stus ricollega la mancanza di una riproduzione convincente delle manifestazioni del mondo circostante a un riferimento alla tradizione come forma 'vuota'. Ciò si tradurrebbe nella mancanza di un rinnovamento profondo del linguaggio poetico. I versi in lode di Kiev di un poeta oggi sostanzialmente dimenticato come Jevhen Bandurenko (1919-1972) sono paragonati da Stus alla poesia di Petro Hulak-Artemovs'kyj (1813-1873), rappresentante del tardo Illuminismo ucraino. Che un accostamento simile non sia da intendersi in senso lusinghiero è dichiarato esplicitamente dallo stesso Stus ${ }^{16}$. A risultare carente nella poesia ucraina contemporanea, vittima di un romanticismo di maniera, è la concretezza, che il critico identifica invece, ad esempio, nella lirica del russo Evgenij Vinokurov (1925-1993) ${ }^{17}$. La necessità di guardare agli sviluppi delle lettere russe come modello per gli scrittori ucraini sarà un motivo inaspettatamente ricorrente nell'epistolario stusiano. Tra i connazionali della sua generazione Stus distingue Vasyl' Holoborod'ko, futuro membro della "Scuola di Kiev", di sette anni più giovane e fresco della prima pubblicazione,

14 Ivi: 166: "I тут ми підходимо до найболючішого питання нашої поезії міри естетичності багатьох віршів, їх художньої внутрішньої цілісності.” 'Е giungiamo così all'aspetto più dolente della nostra poesia: la qualità estetica di molte liriche, la loro intrinseca integrità artistica.'

15 Ibidem: “Зовнішній осучаснений антураж, збагачений на ракети, космодроми, антиречовину, Пікассо, кібернетику чи галактики, не може врятувати слабкого і малоестетичного в своїй суті вірша.” 'Un'esteriorità modernizzata, arricchita di razzi, cosmodromi, antimateria, Picasso, cibernetica e galassie non è in grado di salvare una poesia di per sé debole e povera esteticamente.'

16 Ivi: 170: “Такі вірші міг писати рівно сто років тому Гулак-Артемовський. Але вони не зробили йому честі." 'Poesie così poteva scriverle giusto HulakArtemovs'kyj cent'anni fa. Ma non gli facevano certo onore.'

17 Ibidem: “От та конкретність, що частково притаманна російському поетові $€$. Винокурову, ще й досі є вакантним місцем нашої поезії. Романтичність стає на перешкоді дальшому розвитку нашої поезії. Більше того: в сьогоднішньому романтизмі $\epsilon$ багато консервативного - і в формі, і в змісті." 'Proprio quella concretezza in parte tipica del poeta russo Evgenij Vinokurov è quello che manca tuttora alla nostra poesia. Il romanticismo ostacola il suo ulteriore sviluppo. E non è tutto: nel romanticismo di oggi c'è molto conservatorismo - sia nella forma che nel contenuto.' 
dimostrando di saper riconoscere il vero talento nel mare degli aspiranti poeti non destinati a entrare nella storia della letteratura ${ }^{18}$.

La complessità della posizione di Stus come critico negli anni degli studi dottorali è ben testimoniata dalle sue pagine sul romanzo autobiografico $\mathrm{Na}$ kalynovim mosti ('Sul ponte dei viburni') di Petro Panč (1891-1978), scrittore già attivo negli euforici anni Venti e in seguito pienamente inserito nell'establishment letterario sovietico ${ }^{19}$. La necessità per Stus di bilanciarsi tra indipendenza intellettuale e inevitabili cessioni alla retorica sovietica a lui richiesta è evidente in alcuni passi dello scritto in questione, dal titolo Rozdumy nad perežytym ('Riflessioni sul vissuto'), pubblicato nel 1966 con lo pseudonimo B. Doroš sull'organo del Komsomol "Molod' Ukrajiny":

La secolare oppressione dello zarismo e l'arretratezza economica e politica dell'Impero russo non poterono che riflettersi sul movimento di liberazione. La varietà degli istituti socioeconomici decretata da Lenin apriva le porte a una corrispondente varietà di partiti, programmi e conformazioni future. Ciascuna di queste opzioni necessitava forze umane e, per di più, vite umane ${ }^{20}$.

Dalla discussione delle pagine di Panč relative alla definitiva affermazione del sistema sovietico nelle campagne ucraine emerge la difficoltà di Stus nel mantenimento del necessario equilibrio tra la fedeltà alla narrazione storica ufficiale, da una parte, e il punto di vista nazionale, dall'altra, imprescindibile per uno šistdesjatnyk sempre più consapevole delle ingenti perdite inflitte alla cultura ucraina negli ultimi quarant'anni:

Lo scrittore, diciamo, raffigura un villaggio in cui è stata introdotta la radio e parla degli stupefacenti cambiamenti vissuti dai contadini nelle condizioni della realtà sovietica. [...] La lotta per l'ulteriore introduzione e il consolidamento della rivoluzione veniva portata avanti in tutte le sfere. E lo scrittore rende ciò molto bene, soltanto a tratti cadendo in un eccessivo schematismo ${ }^{21}$.

18 Ivi: 171: “Зовсім недавно прохопився В. Голобородько, поет здорового ліро-епічного хисту.” 'Da pochissimo si è fatto sentire Vasyl' Holoborod'ko, poeta con una sana tensione lirico-epica.'

19 La voce dedicata a Panč nell' Encyclopedia of Ukraine, a firma di Ivan Košelyvec', si conclude con un laconico invito a un deciso ridimensionamento della figura dello scrittore, vincitore del premio Ševčenko nel 1965. Si veda Kubijovyč 1993: 764: "Panch's realistic style, free of any leaning toward formalism, and his loyalty to the Soviet regime earned him a place among those who had contributed nothing new to literature, but who were nevertheless hailed as the founding creators of Ukrainian soviet prose."

20 T IV, 192: "Віковий гніт царату, економічна й політична відсталість колишньої Російської імперії не могли не відбитися й на визвольному русі. Строкатість соціально-економічних укладів, відзначена В. І. Леніним, викликала таку ж строкатість партій, програм, образів майбутнього. Кожен із варіантів майбутнього потребував людських сил, ба й людських життів.”

21 Ivi: 193: "Письменник, скажімо, зображує радіофіковане село і говорить про разючі зміни, яких зазнали селяни в умовах радянської дійсності. [...] 
Očyma humanista ('Con gli occhi di un umanista'), dedicato alla figura e alle opere di Heinrich Böll, che avrebbe in seguito cercato di far conoscere la tragica sorte di Stus agli intellettuali e agli attivisti per i diritti umani in Europa, reca numerose tracce di retorica sovietica che sembrerebbero indicare la volontà di Stus di pubblicare lo studio, rimasto tuttavia inedito fino agli anni Novanta: "[L]'autore diventa sempre più profondo e di ampi orizzonti, si fa più concreto il suo sentimento umanistico, si rafforzano i conflitti con l'oscura realtà della Germania Occidentale"22.

Si può al contrario ipotizzare che l'insistenza sulla critica bölliana all'ordine politico e sociale della Germania Federale del dopoguerra offra a Stus la possibilità di esprimere indirettamente il proprio punto di vista sull'Unione Sovietica: "Böll convince il lettore che un simile livellamento della personalità umana sia socialmente molto pericoloso: produce una scissione radioattiva dell'anima, una sua degradazione spirituale, la degradazione morale dell'umanità'²3.

Nella seconda metà degli anni Sessanta, in seguito all'espulsione dall'Istituto di Letteratura Ševčenko, le poche pubblicazioni critiche di Stus poterono trovare spazio sulle riviste letterarie solo se celate dietro a uno pseudonimo, con l'unica eccezione di una recensione a uno studio monografico dell'amica Kocjubyns'ka, uscita su "Žovten"” nel settembre del 1968. Risalgono a questi anni pagine su Mykola Bažan e García Lorca, nonché due brevi scritti su Goethe e Rilke, poeti destinati a rimanere al centro degli interessi letterari di Stus sino alla morte. In Velykij z najbil'šych ('Grande tra i maggiori'), premessa a una selezione di traduzioni goethiane approntate da Stus insieme a Leonid Čerevatenko (1938-2014) e pubblicate sul numero di Luglio di "Dnipro" del 1967, in occasione del centotrentacinquesimo anniversario della morte dell'autore del Faust, Stus, dietro lo pseudonimo V. Petryk, condensa in poche righe una panoramica della (scarsa) conoscenza di Goethe in Ucraina ${ }^{24}$. Anche in

Боротьба за дальше провадження й ствердження революції велась на всіх ділянках. I письменник це все добре передає, тільки подекуди впадаючи в надмірний схематизм."

22 Ivi: 203: “[А]втор стає все глибшим і об’ємнішим, конкретнішає його почуття гуманізму, посилюються конфлікти з похмурою дійсністю Західної Німеччини.”

23 Ivi: 206: “Белль переконує читача, що подібна нівеляція людської особистості соціально дуже небезпечна, оскільки вона продукує радіоактивний розпад душі, іiі духовну деградацію, моральну деградацію людства."

${ }_{24}$ Sulla presenza di Goethe nella civiltà letteraria ucraina sin dal terzo decennio dell'Ottocento si veda l'agile e informativa monografia di Wolodymyr Zyla (Zyla 1989), nonché Bojko-Blochyn 1981. Entrambi i contributi ignorano l'episodio delle traduzioni di Stus, giunte ai lettori solamente nella prima metà degli anni Novanta. Sulla goethiana russa del Novecento, molto probabilmente non meno nota a Stus di quella ucraina, si veda Jakuševa 2004, nonché il classico Žirmunskij 1937 per l'Ottocento. Si noti, inoltre, l'importanza del dialogo con la tradizione goethiana per gli altri poeti che hanno maggiormente segnato il percorso personale e artistico stusiano. Su Goethe e Pasternak, autore di una delle più apprezzate traduzioni novecentesche del Faust e poeta 'tipologicamente' vicino al genio di Weimar, si veda Lavrent'eva 2010. A proposito del 
questo caso il giovane studioso si trova costretto a inevitabili concessioni alla narrazione ufficiale: "Grande umanista, considerava forse suo obiettivo principale la lotta contro le tenebre" 25 .

I pochi paragrafi dedicati a Rilke, mai pubblicati prima degli anni Novanta, si rivelano più liberi da condizionamenti ideologici di ogni origine. Spicca una considerazione di Stus sull'arretratezza dello sviluppo della lingua ucraina: "Tradurre Rilke è molto difficile. Le sue poesie possono trasformarsi solo in lingue molto sviluppate"26. Questo abbozzo critico è interessante sia in quanto testimonianza dell'ottima conoscenza della lirica di Rilke da parte di Stus già nella seconda metà degli anni Sessanta e dei suoi esordi come traduttore rilkiano, sia come ulteriore manifestazione della maturità critica di un ancora giovane studioso, attento ai problemi della lingua letteraria ucraina e desideroso di contribuire alla causa del suo perfezionamento.

Di più ampio respiro è Hnivnyj poet doby ('Un irato poeta dell'epoca'), lo studio su Brecht pubblicato sulle pagine di "Žovten"” del settembre del 1968 per presentare una raccolta di traduzioni dell'autore della Dreigroschenoper, che risalirebbe ancora agli anni degli studi dottorali. Dedicandosi a uno scrittore comunista fautore di un sistema teatrale opposto all'estetica del realismo socialista, Stus guarda alla produzione brechtiana attraverso un prisma variegato e contraddittorio memore dell'estetica e della personalità dello stesso Brecht. La retorica comunista si tinge così di venature esistenzialiste e spunti di identificazione tra il proprio vissuto e il modello brechtiano, che Stus sente di dover difendere dalle accuse di decadentismo e deviazioni ideologiche ripetutamente mosse a Brecht dall'establishment culturale sovietico ${ }^{27}$ : "In questa viva massa di carne è iniettata dalla siringa fascista, come un grumo, una sola idea - distruggere l'Unione Sovietica" 28 - scrive Stus a proposito della Germania nazista alle soglie della guerra, da cui Brecht era emigrato nel 1933. Nella caratterizzazione dello scrittore è tuttavia difficile non cogliere note personali intrise di lessico esistenzialista: "Brecht comprende l'estremismo della propria posizione, si rende conto del fatto che il "mondo asociale" lo priva delle manifestazioni umane, ma sa che il

complesso rapporto tra i due giganti della letteratura tedesca Rilke e Goethe, segnato da alterne fasi di allontanamenti e riavvicinamenti del primo al secondo, cfr. Mason 1958 e Steiner 1991. Poco studiata risulta ancora ancora la ricezione goethiana della fervente germanofila Cvetaeva. Cfr. a questo proposito Kuznecova 2002.

25 T IV, 239: "Великий гуманіст, він чи не найважливішою метою свого життя вважав боротьбу з темрявою."

26 Ibidem: "Перекладати Рільке дуже важко. Його поезії можуть трансформуватися тільки в дуже розвинені мови."

${ }_{27}$ Cfr. Autant-Mathieu 1999. Notevole è la presenza di Brecht sulle pagine di un periodico simbolo della cultura del Disgelo quale "Inostrannaja literatura", in particolare per quanto riguarda i primi anni dell'era post-staliniana.

28 T IV, 248: "В цю живу купу м'яса фашистським шприцом ввігнано, як друзку, одну думку — знищити Радянський Союз.” 
ritrovarsi in una situazione estrema, in una situazione-limite, non dà mai la possibilità di essere pienamente buoni e pienamente giusti" ${ }^{29}$.

Gli ammonimenti brechtiano-stusiani al lettore sui pericoli del fascismo e sulla necessità di impedire un suo possibile ritorno sono anche in questo caso interpretabili su due piani: in riferimento all'età di Brecht e alla Germania degli anni Trenta, così come, esopicamente, a proposito delle tendenze neostaliniane degli anni brežneviani. Non a caso lo studio stusiano si chiude con una citazione dalla celeberrima lirica brechtiana An die Nachgeborenen ${ }^{30}$ ('A coloro che verranno'), il cui significato rivoluzionario in relazione al presente dell'epoca di Stus è sapientemente mascherato dalla conciliante frase conclusiva dell'autore del saggio: "Così scriveva Brecht. E il suo geniale talento poetico, la sua opera ci redarguiscono: quei tempi non devono ripetersi" 31.

Alla fine degli anni Sessanta e ai primi mesi del nuovo decennio risalgono i capolavori critici di Stus. Isolato dal mondo della cultura ufficiale e sempre più sicuro del proprio talento poetico, Stus saluta gli anni Settanta sotto il segno di un'esplosione di creatività artistica che si concretizza nelle due raccolte Zymovi dereva e Veselyj cvyntar, nonché in alcune pagine sulla poesia ucraina del Novecento che avrebbero dovuto attendere gli ultimi due lustri del secolo per essere pubblicate e trovare la loro meritata collocazione nella storia della critica letteraria ucraina. Si tratta in primo luogo di Fenomen Doby ('Un fenomeno dell'epoca'), dedicato a Pavlo Tyčyna, Znykome rozcvitannja ('Fioritura che svanisce'), a proposito dell'allora semisconosciuta poesia del tardo-simbolista Volodymyr Svidzins'kyj, ma anche del più breve saggio dedicato al giovane poeta Viktor Kordun. Se la critica stusiana degli anni precedenti era in parte 'inquinata' dalla necessità di accogliere almeno superficialmente stereotipi e frasi fatte della linea ufficiale sovietica, gli studi dello Stus del periodo immediatamente precedente all'arresto, ormai solo con la propria libertà conoscitiva, si rivelano immuni all'influenza dell'ideologia e dell'estetica di stato. Pienamente conscio dell'impossibilità di una pubblicazione al di là del samizdat, Stus può sfidare dall'interno gli asfittici dogmi degli studi letterari sovietici proponendo a se stesso e ai pochi,

29 Ivi: 243: “Брехт усвідомлює крайність своєї позиції, віддає собі звіт у тому, що 'асоціальний світ' обкрадає його людські прояви, але знає, що перебування в крайній, межовій ситуації не дає ніколи змоги бути зовсім добрим і зосвім справедливим."

30 Brecht 1988: XII, 86: "Ich wäre gerne auch weise. / In den alten Büchern steht, was weise ist. / Sich aus dem Streit der Welt halten und die kurze Zeit / Ohne Furcht verbringen. / Auch ohne Gewalt auskommen, / Böses mit Gutem vergelten, / Seine Wünsche nicht erfüllen, sondern vergessen / Gilt für Weise. / Alles das kann ich nicht: / Wirklich, ich lebe in finsteren Zeiten!." 'Farei volentieri anche il saggio. / Nei vecchi libri si dice cos'è saggio. / Astrarsi da tutto ciò che è vano e il poco tempo / Passare non temendo. / Cavarsela senza sangue, / Ripagare il male con il bene, / Quello che vuoi non ottenerlo, ma dimenticalo, / Così fanno i saggi. / Ma io così non ce la faccio: / Viviamo veramente in tempi bui!'

31 T IV, 249: “Так писав Брехт. I його геніальний поетичний талант, його творчість перестерігають нас: ті часи не повинні повторитись.” 
fidati lettori-sodali alcuni esempi di un approccio alla lettura altamente personale. Ciò non esclude, tuttavia, un sorprendente livello di polifonia all'interno degli scritti in questione. La sconcertante diversità degli orizzonti ideologici e concettuali di Fenomen Doby e Znykome rozcvitannja è il frutto delle scissioni dello stesso Stus, lacerato tra due divergenti pulsioni intellettuali: il modello populistico della tradizione ucraina, da una parte, e la volontà di superare i confini culturali nazionali in un'ottica modernistica paneuropea, ricollegandosi così alla lezione dimenticata del Modernismo ucraino stesso, dall'altra. Che a un livello più ampio queste due tensioni apparentemente opposte siano in realtà complementari nella loro interazione come propellenti della storia della civiltà letteraria ucraina nella sua specificità è stato ampiamente dibattuto e dimostrato dalla critica (Pavlyčko 1999, Morenec' 2002 e Hundorova 2009).

Al centro di Fenomen doby, composto tra il 1968 e il 1971 e approntato da Stus in dodici copie autoprodotte, è il percorso esemplare di Pavlo Tyčyna come pefetta realizzazione del modello culturale sovietico. Il primo paragrafo del più lungo contributo critico stusiano inizia significativamente con il pronome di prima persona singolare ${ }^{32}$, esplicitando così immediatamente la prospettiva individuale da cui verrà condotta l'analisi, in chiara contrapposizione alla rigorosa impersonalità del literaturovedenie sovietico. Voce più alta della poesia ucraina dei tardi anni Dieci, scomparso solamente pochi mesi primi e onorato nel pantheon culturale sovietico, Tyčyna si è trasformato secondo Stus in una "mummia vivente", un "manichino". Il tragico contrasto tra la "degenerazione" della figura di Tyčyna dai tardi anni Venti in poi, tra paura e ricerca di ricchezza e benessere, e i suoi esordi come poeta libero nel decennio precedente sono laconicamente espressi dalla prima, breve frase del secondo capitolo dello studio: "Gli era stata destinata la sorte di un genio" 33 . Stus passa dunque a una rassegna della storia dell'intelligencija ucraina delle generazioni precedenti a Tyčyna, il cui principale errore storico è secondo lui da ritrovarsi in una smodata necessità di autoaffermazione, di “conservazione dell'antichità perduta". La letteratura ucraina dell'età imperiale è per lo Stus autore di Fenomen Doby un fenomeno culturale radicalmente opposto al modernismo europeo. Paragonando a una "fatica di Sisifo" 34 il destino dell'intellettuale ucraino, Stus constata la necessità per quest'ultimo di creare "in contrapposizione alla realtà, in un mondo a lui assolutamente vietato"35. La

32 Ivi: 259: “Я бачив його двічі.” 'Lo vidi due volte.'

33 Ivi: 260: "Йому судилася доля генія."

34 Il sottotesto camusiano di questa affermazione sembra ricollegarsi all'epigrafe a Fenomen doby, in: ivi: 259: “Кожен митець, що хоче бути в суспільстві знаменитий, мусить знати, що знаменитий буде ні він, а хтось інший із його ім'ям. Він урешті-решт від нього вислизне і, можливо, колись уб'є в ньому справжнього митця. Альбер Камю." 'Ogni artista che voglia essere noto alla società deve sapere che a essere famoso non sarà lui, bensì qualcun altro con il suo stesso nome. Alla fine quest'ultimo scivolerà via da lui e, probabilmente, un giorno ucciderà il vero artista in lui. Albert Camus.'

35 Ivi: 262: “Специфіка українського митця в тому, що в кращому разі він змушений цю реальність нести на своїх плечах, а в гіршому, і значно частіше, 
fortuna di Tyčyna consistette proprio nella consonanza tra la propria missione e la storia, venendo così a costituire un unicum nella vicenda culturale ucraina. Dopo aver analizzato dal punto di vista del rapporto tra l'io lirico e la realtà circostante Sonjačni klarnety ('Clarinetti solari'), il capolavoro giovanile di Tyčyna del 1918, e aver fornito al lettore una sintetica rassegna della sua ricezione tra gli anni Venti e gli anni Trenta, Stus si avvicina alla svolta concettuale alla base delle lunghe pagine che seguono:

Far derivare l'autore di Sonjačni klarnety esclusivamente da Kocjubyns'kyj, Gor'kij e Majakovskij significa impoverire le poesie di Tyčyna, in larga misura privarlo della sua base nazionale, rendere più difficoltosa la comprensione del carattere innovativo del suo talento e, in ultima analisi, la comprensione del poeta stesso ${ }^{36}$.

L'urgenza di approfondire gli aspetti nazionali della figura e dell'opera tyčyniana si traduce per Stus in una lunga riflessione sulla storia ucraina dei primi anni del Novecento, che viene a prendere il posto delle considerazioni di carattere puramente letterario che avevano occupato i paragrafi precedenti. Nel corso della discussione Stus menziona un nome fondamentale della cultura ucraina di inizio secolo, la cui importanza per la concezione di Fenomen doby è più che evidente, ossia Serhij Jefremov (1876-1939). L'approccio critico dell'autore dell'Istorija ukrajins 'koho pys'menstva ('Storia delle lettere ucraine') del 1911, riconducibile a un'idea conservatrice della letteratura come "riflesso e incarnazione dell'anima e della vita del popolo" (cfr. Hrabovyč 1976: 54), sembra ora imporsi attivamente nel progetto stusiano. La storia nazionale diventa il metro di misura dell'evoluzione (o, meglio, dell'involuzione) artistica tyčyniana. Il rimando al modello jefremoviano è evidente:

Ma Tyčyna di ciò [le dissonanze stilistiche della raccolta Zamisc' sonetiv $i$ oktav ('Invece di sonetti e ottave') - AA] non si cura: la vita del popolo è ben più ampia dei canoni estetici, e i dilemmi 'arte oppure vita' per il poeta non sono mai esistiti. Aveva il solenne diritto - da vero cantore del popolo - di rimproverare gli esteti $[\ldots]^{37}$.

- існувати всупереч реальності, в абсолютно забороненому для себе світі." "La specificità dell'artista ucraino consiste nel fatto che nel migliore dei casi deve portare la realtà sulle proprie spalle, mentre nel peggiore, il che accade sensibilmente più spesso, si trova a esistere in contrasto con la realtà, in un mondo a lui completamente proibito.'

36 Ivi: 276: "Виводити автора Соняшних кларнетів виключно 3 Коцюбинського, Горького і Маяковського значить збіднити світ поезій Тичини, значною мірою позбавити його національного грунту, утруднити розуміння новаторського таланту поета, i, зрештою, розуміння самого поета.”

37 Ivi: 286: “Але Тичина про те не дбає: життя народу значно ширше за естетичні канони, а дилеми - життя чи 'тільки мистецство' для поета ніколи не існували. Він мав високе право - справді народного співця - дорікати чистим естетам $[\ldots] . "$ 
L'inscindibile nesso tra il poeta e il suo popolo è chiaramente mostrato dal processo di corruzione che ha riguardato entrambi con l'affermarsi del potere e della cultura sovietica: "La sua tragedia ha riflesso la tragedia del suo popolo. E per questo egli è parte della storia del suo popolo [...]"38. È significativo, infine, come l'ultima frase del lungo saggio dedicato a Tyčyna ricordi la conclusione dello studio su Brecht: "Il destino di Tyčyna accusa e mette in guardia"39.

Radicalmente opposto è l'orizzonte concettuale di Znykome rozcvitannja, composto tra il 1970 e il 1971 e dedicato a Volodymyr Svidzins'kyj, una delle massime voci del Modernismo poetico ucraino della prima metà del Novecento. Nell'affrontare un poeta che conobbe una sorte ben diversa da quella di Tyčyna, Stus astrae l'oggetto della sua analisi dalle circostanze storico-geografiche in cui Svidzins'kyj si ritrovò a vivere e scrivere per concentrarsi sulla figura del $\mathrm{Po}$ eta da un punto di vista universale. Svidzins'kyj, bruciato vivo dal NKVD nei pressi di Charkiv nel 1941, è, come emerge dalla prima frase del testo, il "poeta per eccellenza" (ivi: 346). Limitandosi a definire Svidzins'kyj il "vero homo sapiens della poesia ucraina" e a menzionare "l'era incancrenita del culto della personalità staliniano" e i piani quinquennali, Stus sceglie di non offrire al lettore altri punti di riferimento storico-geografici. Al centro della sua attenzione è ora l'arte poetica in sé, con il suo potenziale distruttivo nei confronti dell'esistenza umana: "Originatasi come una sorta di consolazione e di salvezza dalle sfortune dell'esistenza, l'arte ci fa suoi prigionieri, privandoci sempre di più della vita"

Lo smascheramento della passione poetica svidzins'kiana si rivela così la risposta all'impellente necessità di Stus di espiare il proprio peccato poetico di fronte al lettore. Non potendo resistere al richiamo di una musa che è in realtà una sirena, il poeta pecca, tradisce se stesso in quanto figlio di un popolo sofferente. Descrivendo la fuga di Svidzins'kyj nella propria interiorità, Stus sembra anticipare la poetica della propria produzione lirica degli anni Settanta: "Per il fuggitivo, per il poeta è diventato una gioia contemplare in solitudine il proprio illegale diamante. Ma che stupendo peccato fermarsi di fronte a se stessi! La vita è diventata una peccaminosa auto-contemplazione, una contrapposizione a se stessi, un guardare se stessi $[\ldots]^{\prime 41}$.

L'atteggiamento di Stus nei confronti di Svidzins'kyj, e dunque implicitamente anche di se stesso come poeta sempre più 'svidzins'kiano', si sviluppa nelle pagine di Znykome rozcvitannja sotto il segno di una sorprendente contraddittorietà. L'obbligo morale per l'uomo di pagare il proprio tributo di gratitudi-

38 Ivi: 344: “Його трагедія відбила трагедію його рідного народу. I вже тому він є часткою свого народу [...]."

39 Ivi: 345: “Доля Тичини звинувачує і застерігає.”

40 Ibidem: "Виникле як своєрідня відрада і порятунок від злигоднів існування, мистецтво забирає нас у свій полон, все далі й далі відмежовуючи від життя."

41 Ivi: 348: “А втеклому, поетові стало радісно розглядати на самоті свій незаконний діамант. Який же то прекрасний гріх - зупинятися якраз навпроти самого себе! Життя стало гріховним розгляданням себе, самопротистоянням, самоспогляданням [...].” 
ne alla Terra di cui è figlio ${ }^{42}$ si infrange contro la corruzione intellettuale della modernità ${ }^{43}$. La risposta di Svidzins'kyj al proprio peccaminoso abbandono alla poesia sembra consistere per Stus nell'amore per il mondo, nello specifico per la sfera della natura:

Se dovessimo ricercare il centro compositivo della costruzione del mondo nella poesia di Svidzins'kyj, dovremmo concludere che esso risiede nell'amore per il mondo. In un amore come il suo, diventato sinonimo dell'esistenza, il suo secondo nome. Vivere è amare. E amare significa cedere al potere extra-umano (cioè incomprensibile all'intelletto umano) dell' armonia delle forze naturali ${ }^{44}$.

La riabilitazione della poesia dopo 1'attacco in stile tardo-tolstojano alla sua azione corruttrice si è così compiuta. La complessità della concezione modernista dell'arte, votata a una sua esaltazione non immune da dolorose crisi iconoclastiche, si incontra qui con la tentazione postmoderna del distacco dal mondo nella sfera di una parola opaca, non più referenziale.

La distanza che intercorre tra Fenomen doby, fedele alla tradizione critica nazional-storicistica di marca tardo-ottocentesca, e Znykome rozcvitannja, scisso a sua volta tra una fragile condanna dell'arte in nome dell'azione politica e la sua apoteosi, è ora più che evidente. Entrambe le pulsioni concettuali e stilistiche alla base dei due scritti risultano essere parti integranti della cultura di Stus, formatosi come studioso e scrittore al crocevia di tendenze letterarie diverse e in un complesso equilibrio tra loro. La multiformità della sua prosa critica si ritroverà trasposta nella sua poesia, il suo più importante contributo alla storia della civiltà letteraria ucraina ed europea.

Agli stessi mesi risalgono anche le pagine di Stus sul contemporaneo Viktor Kordun. La caratterizzazione stusiana della poesia di uno dei quattro rappresentanti storici della "Scuola di Kiev" ricorda per molti aspetti il ritratto dell'opera svidzins'kiana di Znykome rozcvitannja. Stus mette in evidenza l'individualismo dell'universo lirico di Kordun e la sua assoluta incompatibilità con la realtà circostante, ovvero con il mondo dell'Unione Sovietica degli anni brežneviani. Il lettore non digiuno di poesia stusiana non potrà inoltre mancare di osservare le numerose coincidenze tra la descrizione che Stus dà in queste pagine della weltanschauung e del linguaggio korduniano e alcune delle immagini più ricorrenti

42 Ivi: 352: “Людина завжди мусить відчувати єдиний обов’язок - бути вдячним сином землі." "L'uomo deve sentire sempre un unico obbligo - essere un grato figlio della terra.'

43 Ibidem: "Розум перетворився на ракову пухлину нашої духовної конституції." 'La ragione si è trasformata in un tumore maligno della nostra costituzione spirituale.'

44 Ibidem: "Коли відшукати композиційний центр поетичної світобудови Свідзінського, то він - у любові до світу. В такій любові, яка стала синонімом існування, його другою назвою. Жити - любити. А любити - значить піддатися владі позалюдської (тобто незбагненної людським розумом) гармонії природніх стихій." 
nella stessa produzione poetica dell'autore del saggio: "Il mondo si è trasformato in un ammasso di densa, amorfa, sciolta, indeterminata tristezza globale. Il cielo è caduto sulla terra, si è dissolto in essa, hanno cioè cessato di esistere sia il cielo che la terra, sia la superficie che l'aria, sia le persone che la società [...]"'55. Significative, e confortate dalla menzione del nome di Ortega y Gasset, sono allo stesso tempo le implicazioni di marca esistenzialista che Stus riscontra nella poesia di Kordun. Queste ultime lo inducono a trasporre le tematiche del testo in questione a un'analisi della contemporaneità decisamente extraletteraria:

La seconda significativa negazione della normalità del mondo sociale è la massificazione dell'esistenza, l'impossibilità di essere autonomi in un mondo meccanizzato, dove tutto è livellato e ricondotto alla misura dell'impersonalità. Proprio questa perdita delle antinomie, soprattutto etiche, modifica il consueto sistema sociale nella sua interezza; questa perdita testimonia della decadenza della vitalità biologica, come dice Ortega y Gasset ${ }^{46}$.

L'io lirico di Kordun, come quello di Svidzins'kyj e dello stesso Stus, sembra essere costretto a scegliere tra due diverse forme di alienazione: "[R]esta da fuggire all'indietro in se stessi, ermetizzarsi, oppure, pieni di biasimo per il terribile peccato di possedere il proprio volto, ricercare la spersonalizzazione di sé, fuggire da se stessi, abbassarsi sul fondo del tunnel sotterraneo dell'ontogenesi [... ${ }^{347}$.

Stus arriva addirittura a citare un verso di una propria lirica, tratta da Veselyj cvyntar: "Da che cosa è suscitato nel poeta questo sentimento di una catastrofe globale? Come lo chiarifica a se stesso? [...] Innanzitutto, è una reazione alla

45 Ivi: 362: “Світ перетворився на стоплену, згусклу, аморфну, неозначену грудку глобальної печалі. Небо впало на землю, розчинилося в ній, тобто не стало ні землі ні неба, ні тверді ні повітря, ні людини ні суспільства [...].” Lo stesso Stus è consapevole della vicinanza tra una simile interpretazione della lirica korduniana e la propria poesia. Si veda dalla lettera alla poetessa Vira Vovk del 29-05-1970, in: T VI.2, 65: “Десь недавно закінчив статтю про Віктора Кордуна. Власне, вийшов ніби коментар до автора, хоч потерпаю, що й самокоментар. Стаття - без замовлень і без спрямувань - у який певний журнал." "Росо tempo fa ho finito un articolo su Viktor Kordun. A dire il vero è venuto fuori una sorta di commento all'autore, anche se temo che sia anche un auto-commento. Un articolo non commissionato e non destinato a una rivista specifica.'

46 Ivi: 364: “Другим істотним запереченням нормальності соціального світу $\epsilon$ омасовленість існування, неможливість розокремленого буття в машинізованому світі, де все знівельовано й підведено під масштаб імперсональності. Саме ця втрата антиномій, особливо ж етичних, переінакшує всю звичну систему соціального буття, вона, ця втрата, свідчить про занепад біологічної вітальності, кажучи словами Ортеги-і-Гассета.”

47 Ibidem: “[З]алишається або втікати назад у себе, герметизуватися, або, сповненим нарікання на страшний гріх мати власне обличчя, прагнути вже й самому знеособитись, утекти од себе, спуститись на саме дно онтогенетичної штольні $[\ldots] . "$ 
lunga e minacciosa storia dell'umanità, che, si può dire, ci allontana da noi stessi: [...] sembra che ci stiamo trasformando nell'archivio di noi stessi"48.

È evidente la consonanza tra la caratterizzazione stusiana dell'universo poetico di Kordun, scrittore come lo stesso Stus impossibilitato a far conoscere al più ampio pubblico la propria opera, e il vissuto dell'io lirico della propria poesia: "Sembra che ti trasformi nell'archivio di te stesso"49.

Come nella sua poesia, anche nella prosa critica Stus si rivela dunque un instancabile sperimentatore di linguaggi e modalità di analisi diverse. Ad avvicinare tra loro i saggi stusiani sulla letteratura, in particolare quelli scritti intorno al 1970 e dedicati alla poesia ucraina, è il continuo dialogo con la produzione poetica personale e la propria esperienza di intellettuale, negli anni del passaggio a una contrapposizione con il regime e il sistema culturale sovietico sempre più marcata e consapevole.

Alla fine degli anni Sessanta risale anche un breve scritto dal titolo Dvoje sliv čytačevi ('Due parole al lettore'), pubblicato come prefazione all'edizione in tamizdat di Zymovi dereva. Cercando di condensare in poche righe la propria (ideale) genealogia letteraria, Stus insiste sulla matrice nazionale del proprio battesimo poetico e umano: "Le prime lezioni di poesia sono della mamma. [...] Ševčenko nella culla non lo si dimentica" ${ }^{50}$. Anche nella descrizione delle preferenze letterarie degli anni della prima maturità Stus si sforza di mettere in risalto la componente ucraina della propria formazione. Per quanto riguarda gli anni Cinquanta spiccano i nomi dei classici sovietici Maksym Ryl's'kyj e Mykola Bažan, curiosamente accostati a Émile Verhaeren, mentre tra i poeti più amati al momento della scrittura del breve saggio Stus menziona, oltre a Goethe e Rilke e a Volodymyr Svidzins'kyj, i contemporanei Vasyl' Holoborod'ko, Mykola Vinhranovs'kyj e Leonid Kysel'ov (1946-1968). Non mancano inoltre importanti voci della poesia italiana, quali Ungaretti e Quasimodo. L'ultima frase dello scritto segna il ritorno alla tradizione nazionale: "Uno dei miei migliori amici è Skovoroda" 51 .

Agli anni Settanta (cfr. Stus 2008b) datano inoltre alcuni appunti di lettura su Guerra e pace, costruiti come un vero e proprio dialogo con il romanzo tolstojano, da Stus in un'altra occasione definito come la migliore lettura della sua vita $^{52}$. Ampie citazioni dall'opus magnum di Tolstoj si alternano a considerazio-

48 Ivi: 363: “Чим же викликане це відчуття поетом глобальної катастрофи? Як він з'ясовує іiї для себе? [...] Передусім, це реакція на загрозливо довготривалу людську історію, що ніби віддяляє нас од себе: [...] ми ніби перетворюємось на власний архів."

49 T I.1, 159: “Ти ніби перетворюєшся на власний архів.”

50 Ivi: "Перші уроки поезії — мамині. [...] Шевченко над колискою — це не забувається."

51 Ibidem: "Один 3 найкращих друзів - Сковорода."

52 Dalla lettera alla moglie e al figlio del 14-09-1981, in: T VI.1, 395: “Дуже мені хотілося б поговорити з тобою про 'Війну і мир' (нічого кращого, здається, я не читав у житті!)" "Vorrei molto parlare con te di Guerra e pace (non credo di aver letto niente di meglio in vita mia!)' 
ni di Stus profondamente intrise di scetticismo e irrazionalismo. Si vedano le riflessioni di Stus in seguito alla rilettura dell'episodio della battaglia di Austerlitz e del ferimento del principe Andrej:

La ricerca del senso della vita è in buona sostanza il tentativo di raggiungere ciò che per la ragione è irraggiungibile. L'uomo nasce per vivere. Il suo significato individuale è nell'esistenza stessa, nell'essere un'arteria di ciò che vive, il verbo delle forze vitali che agiscono in e attraverso di lui. Per l'esistenza dell'uomo nel mondo la ragione non serve. La ragione, come la lingua, è il limite superato del nostro sistema nervoso centrale, originatasi per le necessità della comunicazione sociale. [...] È un surrogato dell'anima, che è il suo alter ego; trovandosi accanto agli istinti vitali dell'uomo, la ragione li modifica e li indebolisce, nutrendosi della loro energia ${ }^{53}$.

La varietà di metodologie e approcci al testo dimostrata dalla penna di Stus lettore e critico, nonché l'evidente progressiva liberazione dagli obblighi nei confronti dell'ideologia sovietica che si ritrovano inevitabilmente nei suoi primi scritti, rendono la prosa saggistica stusiana un capitolo della sua produzione di sicuro interesse e di fondamentale importanza per la comprensione della sua poesia.

\section{La letteratura nell'epistolario stusiano}

A partire dal 1972, l'anno del primo arresto, la riflessione critica stusiana è relegata alla sola scrittura epistolare. La prima edizione delle opere stusiane presenta al lettore circa centocinquanta lettere ad amici e conoscenti e oltre duecentotrenta lettere ai familiari. Le prime risalgono agli anni dal 1959 al 1980 e le seconde, con la sola eccezione di un breve messaggio ai genitori del 1970, al periodo compreso tra i mesi della carcerazione preventiva nel 1972 e il 1985, l'anno della morte. La discussione di opere della letteratura ucraina, russa ed europea dell'immediato presente e del passato occupa una parte fondamentale dell'epistolario di Stus, in particolare, ma non solo, per quanto riguarda le lettere alla moglie e al figlio degli ultimi anni. Il corpus epistolare stusiano presenta una serie di costanti che permette di trarre alcu-

53 Stus 2008a: 11: “По суті, відшукування смислу життя — це проба досягти того, що для розуму недосяжне. Людина народжується в житті, щоб жити, іiі індивідуальний живий смисл - у самому існуванні, тобто, бути судиною живого, глаголом вітальних сил, що діють через неї і нею. Для існування людини в світі ій розуму не потрібно. Розум, як і мова, - це подоланий рубіж нервового центру, викликаний потребами суспільних комунікацій. [...] Сурогат душі, яка $є$ його alter ego, він, сусідуючи з вітальними інстинктами людини, виінакшує їх і прислабляє, оскільки живиться енергією їхніх воль." 
ne considerazioni di carattere generale fondamentali per la comprensione dei suoi interessi letterari.

Evidente è in primo luogo la complessità della ricezione stusiana della letteratura ucraina ${ }^{54}$. Stus si mostra particolarmente esigente nei confronti della civiltà letteraria di cui vuole essere parte integrante; nel contesto della Stagnazione ciò non può che tradursi in un costante senso di delusione e frustrazione. La letteratura ucraina sovietica ufficiale, soprattutto se paragonata alle letterature dei paesi del Patto di Varsavia, pure - in misura maggiore o minore - sottoposte alle norme del realismo socialista, sembra a Stus destinata all'immobilità, a una consapevole e incurabile negazione del proprio potenziale creativo. Si veda dalla lettera alla moglie del 26 febbraio 1976: "Sto già pensando alla gioia che mi darà abbonarmi ai giornali e ai periodici polacchi per liberarmi definitivamente da questa triste occupazione: leggere i periodici ucraini. Ho ricevuto il primo numero di 'Žovten" - 1'ho guardato, che povertà intellettuale, che prosa insulsa, che poesie, che articoli" 55 .

Non esente da dubbi e insoddisfazioni è, inaspettatamente, anche il rapporto di Stus con la letteratura ucraina classica:

Sto leggendo le poesie di Lesja [Ukrajinka-AA] (il primo tomo della raccolta in dodici tomi) - non la leggevo da molto tempo, ma non ne sono particolarmente entusiasta. [...] È interessante osservare come sia difficile per i nostri poeti smuovere la realtà che si portano addosso, come sia difficile per loro sentirsi non sorretti da questa realtà, che è parte di loro, ma ostacolati, limitati, costretti. Soltanto Ševčenko ha saputo spezzare queste catene, agli altri è toccato seguire la corrente, avanzare nella palude. Sembra che anche Lesja non abbia saputo

54 Sotto questo aspetto le lettere stusiane sono accostabili alla scrittura saggistica ed epistolare dell'amico Ivan Svitlyčnyj, forse il massimo interlocutore di Stus negli anni kieviani, non solamente dal punto di vista culturale. Sulla critica e l'epistolario di Svitlyčnyj cfr. Zahorujko 2012: 64.

55 T VI.1, 215: “Я вже думаю, якя то буде відрада - передплачувати польські газети й журнали, аби остаточно звільнитися од невеселого заняття читати українську періодику. Одержав 'Жовтень' № 1 - побачив, яка біднота інтелектуалька, яка проза ница, які вірші, які статті”. Si veda anche dalla lettera alla moglie del 8-12-1974, in: T: VI.1: 107: “Коли дивлюся українську пресу (до речі, від 'Вітчизни' на наступний рік відмовився), коли порівнюю її з пресою балтійською (з неї часом мені деякі шмати перекладають), то впевнююся, що черговий напад інтернаціонального виховання окошився на нас i, здається, переважно на нас. I вже не хотілося б читиати і 'Літературної України', яка кожного разу лише псує настрій і нічого не додає до того, що вже знане кількома минулими літами." 'Quando guardo la stampa ucraina (a proposito, ho disdetto l'abbonamento a 'Vitčyzna' per l'anno prossimo), quando la paragono con la stampa baltica (me ne traducono a volte dei brani), mi convinco sempre di più che l'ennesimo attacco di educazione internazionalista si sia abbattuto su di noi, principalmente su di noi, direi. E allora non ho più voglia di leggere la 'Literaturna Ukrajina', che ogni volta altro non fa che rovinarmi l'umore e non aggiunge nulla di nuovo a quanto già sappiamo da qualche anno.' 
evitare questa sorte. Nonostante la sua indipendenza dalle condizioni esterne fosse molto maggiore che per gli altri. Il mondo delle astrazioni e della poetica populistica, nello spirito di Pleščeev ${ }^{56}$.

La problematicità intrinseca alla civiltà letteraria ucraina in quanto terreno di scontro tra la parola e l'inerzia della storia, già affrontata da Stus nel saggio svidzins'kiano, è per lui una condizione strutturale, superabile soltanto eccezionalmente e grazie a un talento straordinario, come nel caso di Ševčenko.

Negli anni Ottanta Stus sembra addirittura avvicinarsi a un rifiuto incondizionato della tradizione letteraria ucraina in toto:

La lingua del popolo, tu, purtroppo, non la puoi sentire. [...]Allora, ecco: leggi i vecchi autori (tutti quei Kvitka-Osnov'janenko, Storoženko, Marko Vovčok, Nečuj-Levyc'kyj - è quasi tutta prosa noiosa, poco interessante, povera di contenuti - [...] sono arrabbiato con l'Eneide [di Ivan Kotljarevs'kyj, 17691938 - AA], molto arrabbiato. Non ho mai amato il suo humour, ma l'ho letta - e solo per la lingua. [...] Il romanzo di Hončar mi sembra di averlo visto ancora a Kiev, ma non mi ci sono messo, non credo nella sua prosa (oh, la prosa ucraina - tutta come i racconti di una vecchietta su com'era da ragazza!). [...] Mi sembra che l'Ucraina sia tutta femmina. Sì, è una musa poco maschia, non cavalleresca; la sua tristezza è femminile. La sua forza è femminile. Il suo coraggio è altrettanto femminile. E gli uomini? ${ }^{57}$

56 Lettera alla moglie del 8-03-1876, in: ivi: 222: “Тепер читаю поезію Лесі (перший том із 12-томовика) - давно іï не читав, але захвату особливого не маю. [...] Цікаво бачити, як тяжко бути нашому поетові — рухати реальність на собі, як тяжко чути не допомогу цієї рідної реальності, а заваду, стрим, обтяження. Один Шевченко виламався 3 цих пут, решті довелося йти в річищі, в баговинні. Леся, здається, не уникла цієї долі. Хоч незалежність ії од умов - значно більша за інших. Світ абстракцій і народницької - в дусі Плещеєва - поетики." Si noti la somiglianza tra queste righe e le considerazioni scaturite dall'analisi della figura di Pavlo Tyčyna in Fenomen doby.

57 Lettera alla moglie e al figlio del 1-06-1981, in: ivi: 373: “Що стосується народної мови, то ти іiі, на жаль, не чуєш [...]. Отож, і тут: читай старих авторів (усіх тих Квіток-Основ'яненків, Стороженка, Марка Вовчка, Нечуя-Левицького — майже вся ця проза нудна, нецікава, бідна змістом — [...] Я злий на 'Енеїду', дуже злий, ніколи не любив їі гумору, але читав — i тільки для мови. ...] Роман Гончара, я, здається, бачив ще в Києві, але не накидався, бо не вірю в його прозу (ой, та українська проза - вся схожа на бабусину розповідь, як вона дівкою була!). [...] Мені здається, що Україна - вся жіноча, жіночна. [...] Справді, це муза безчоловіча, безлицарна; туга іiі - жіноча. Сила ii - жіноча. Мужність iii - жіноча так само. А що ж чоловіки?” Il giovane Stus dei primi anni Sessanta, complice anche l'atmosfera culturale indubbiamente più consona alla pubblicazione di opere valide, si era dimostrato più accomodante nei confronti della prosa ucraina contemporanea. Si veda dalla lettera all'amico Anatolij Lazorenko del 28-07-1962, in: T VI.2, 25: “Стельмах правдами і кривдами написав роман 'Правда і кривда', про котрий можна сказати: багато галасу даремно. Чудовий роман АнтоненкаДавидовича 'За ширмою', чудовий Є. Гуцало 'Люди серед людей’ (автор - 
La metafora stusiana della carente "virilità" della cultura ucraina ricorda l'accusa di "incompletezza” (nepovnota) che Dmytro Čyževs'kyj (1894-1977) aveva audacemente lanciato alla letteratura ucraina moderna venticinque anni prima nella sua fondamentale Istorija ukrajins 'koji literatury. Evidente è a questo punto la necessità di non appiattire l'interesse per la cultura nazionale nell'ambito dello šistdesjatnyctvo e della Dissidenza a una mera esaltazione acritica del retaggio nazionale. Come notato da Jaroslav Poliščuk,

l'Occidente attraeva il poeta per la sua capacità di rifarsi alla tradizione, costruendo sulla sua base una serie di grandi letterature. [...] Stus considerava dunque il superamento di quelle barriere artificiali, risultato dell'esperienza coloniale, dell'isolamento e del provincialismo ucraino che ne derivavano il compito più importante della cultura ucraina ${ }^{58}$.

Fondamentale nel patrimonio epistolare stusiano è la ricorrenza di alcuni nomi della letteratura europea che accompagnano la crescita poetica e umana di Stus dagli anni Sessanta alla detenzione a Kučino. Indubbio protagonista della personale storia letteraria dell'autore di Palimpsesty è Rainer Maria Rilke. La discussione delle proprie traduzioni dei Sonette an Orpheus e delle Duineser Elegien occupa gran parte delle lettere di Stus alla moglie tra gli anni Settanta e gli anni Ottanta. La prima menzione di Rilke nell'epistolario stusiano risale al 1964, dunque ai mesi degli studi dottorali, negli anni della riscoperta del poeta dopo circa tre decenni di oblio in Unione Sovietica ${ }^{59}$. In una lettera all'amico letterato Jurij Badz'o (1936-2018), il giovane Stus, a Donec'k dai genitori per le vacanze estive, si lamenta dell'impossibilità di reperire una copia delle opere rilkiane e ne richiede con insistenza l'invio ${ }^{60}$. Nella lettera successiva, indiriz-

хлопчина з 37 року)." 'Stel'mach tra giustizie e ingiustizie ha scritto il romanzo Giustizia e ingiustizia, sul quale si può dire: tanto rumore per nulla. Stupendo il romanzo di Antonenko-Davydovyč Dietro il paravento, stupendo Gente tra la gente di Je. Hucalo (l'autore è un ragazzo del '37).'

58 Poliščuk 2011b: 278: “Захід видавався поетові привабливий тим, що давав досконалі приклади плекання традиції і на цьому грунті найчастіше народжувались великі літератури. [...] Отже, ламання штучних, витворених колоніальним досвідом та, як наслідок його, самоізоляцією, українським хуторянством, бар'єрів Василь Стус вважав стратегічним завданням українства." Sulla necessità per Stus di un approccio multiculturale alla propria missione di poeta si veda anche il breve ma interessante contributo di Valentyna Narivs'ka, incentrato sull'intrinseca fusione del retaggio occidentale, ucraino e russo nella coscienza artistica di Stus (Narivskaja 2011).

59 Si ricordi il seminale articolo su Rilke del 1962 a firma di Vladimir Admoni sulle pagine di "Voprosy literatury" (Admoni 1962).

60 Lettera a Jurij Badz'o del 29-07-1964, in: T VI.2, 34: “Вчора був у книгарні іноземної книги. Рільке там немає. Дуже тебе прошу: коли є змога, то дістань. [...] Дуже було б добре, аби ти мені не вислав гонорару, а придбав би Рільке. На Бога, Юрку! Вік молитимусь на тебе." 'Ieri sono stato alla libreria straniera. Rilke non c'è. Ti prego tantissimo: se ne hai la possibilità trovamelo. [...] Sarebbe ottimo se 
zata all'amico di Donec'k Viktor Didkivs'kyj e datata 13 novembre, Stus afferma di possedere tre tomi delle opere di Rilke e di considerare quest'ultimo un "dio" 61 . Gli inizi della sua attività poetica in senso professionale, dopo gli esordi dei tardi anni Cinquanta, nonché la formazione alla ricerca offertagli dal corso di dottorato, si trovano così a coincidere con i primi segni di un fortissimo interesse per la poesia rilkiana, che non sarebbe sostanzialmente calato per tutto il ventennio seguente. Se alla traduzione delle Duineser Elegien Stus lavora già nei mesi precedenti all'arresto del 1972, al centro dei suoi interessi negli anni della detenzione in Mordovia, ovvero dalla fine del 1972 all'inizio del 1977, si trovano i Sonette an Orpheus ${ }^{62}$, nonché, in secondo luogo, ancora le stesse Elegien. Il tema principale delle lettere alla moglie di questi anni è proprio la discussione delle traduzioni rilkiane, che Stus invia a Valentyna Popeljuch ricevendo a sua volta da quest'ultima i testi originali, le proprie prove precedenti all'incarceramento, i suggerimenti di conoscenti e maestri come Jurij Badz'o e Hryhorij Kočur, nonché le altre traduzioni di Rilke in ucraino e in russo a lui non disponibili in Mordovia ${ }^{63}$. Fondamentale per Stus è innanzitutto il confronto con le coeve traduzioni rilkiane di Mykola Bažan, pubblicate a partire dalla fine del 1973 su "Vsesvit" e in seguito in volume:

Servus, miei cari! Che bella fatica che mi è toccata - starmene seduto davanti alla traduzioni di Bažan da Rilke, registrando le mie sconfitte (sono tantine) e le mie vittorie (molte meno). Anche prima pensavo che l'unico partner ucraino

tu invece che mandarmi l'onorario mi comprassi Rilke. Per favore, Jurko! Ti adorerò per sempre.'

61 Ivi: 35: "Книжок гарних - до біса. Нема як зразу всі читати. Я ж маю 3 томи Рільке. Бог!' 'Di bei libri ne ho un sacco. Non si possono leggere tutti subito. E poi ho tre tomi di Rilke! Un dio!'

62 Già alla fine del 1974 Stus dichiara di aver provvisoriamente terminato la traduzione della prima parte dei Sonette an Orpheus. Cfr. la lettera alla moglie del 8-121974, in: T VI.1, 107: "Вчора закінчив останній сонет із першої частини Рільке. Отже, всі 26 сонетів переклав - деякі близько до того, що хочу, кілька - якраз те зробив, чого прагнув, а чимало - таких, над якими ще працюватиму, аби хоч наблизитися до вартісного рівня." 'Ieri ho finito l'ultimo sonetto della prima parte di Rilke. Dunque, ho tradotto tutti i ventisei sonetti - alcuni all'incirca come volevo, altri proprio come desideravo, mentre su parecchi dovrò ancora lavorare per avvicinarmi almeno a un livello accettabile.'

63 Si veda dalla lettera alla moglie del 23/24-09-1974, in: ivi: 97: “Юрко досить добре пише про сонети Рільке, добре й про вади моїх перекладів. Не 3 усім я можу погодитися (особливо ж - про 1 сонет), але багато мені стає в пригоді. Справа в тому, що чимало вад я знаю й сам, але в мене немає потрібної тривалості вдумування." “Jurko scrive molte bene dei sonetti di Rilke e anche dei difetti delle mie traduzioni. Non riesco a essere d'accordo con tutto (soprattutto per quanto riguarda il primo sonetto), ma molte cose mi tornano utili. Il fatto è che molti dei miei difetti li ho presenti bene anch'io, ma non ho la necessaria costanza nella concentrazione.' 
di Rainer Maria fosse Bažan: il suo universo poetico è forse quello più vicino a quello "da ricreare", come dicono i dottorandi ${ }^{4}$.

Durante il primo lustro degli anni Ottanta sono le Duineser Elegien a tornare in primo piano. Purtroppo la quasi totalità della produzione poetica originale e traduttoria stusiana di questo periodo non è mai uscita dalle segrete del KGB ed è con buone probabilità andata perduta per sempre. Nelle lettere dei secondi anni Settanta, nonostante il costante interesse di Stus per la sua opera, non mancano esternazioni di stanchezza e delusione, relative alla figura dell'autore piuttosto che alla sua poesia:

Negli ultimi tempi ho osservato in me che più leggo e più lavoro su Rilke, più lui mi delude, mi delude il suo pane troppo soffiato, troppo nobile, con poco grano (sentimento già noto: un tempo fu lo stesso, psicologicamente "saturo" di Pasternak, per molti anni - intorno alla metà degli anni Sessanta - provai per lui rifiuto, effetto collaterale della "saturazione"). [...] Insomma, un leone servito in stile rococò. Non so perché, ma un Rilke così mi irrita, è troppo poco virile, troppo femmineo, e a un uomo questo non sta bene, nemmeno a un originale come lui ${ }^{65}$.

64 Dalla lettera alla moglie e al figlio del 7-12-1973, in: ivi: 57: “Сервус, рідні мої! Маю прекрасну мороку — сидіти над Бажановими перекладами Рільке, фіксуючи власні втрати (їх багатенько) і набутки (їх куди менше). Я вже давніше думав, що єдиний український партнер Райнера Марії - Бажан, чия власна сфера поетична чи не найближча до пошукованої, як кажуть дисертанти.” Un'analisi comparativa delle traduzioni di Stus e Bažan è stata proposta da Lesja Kravčenko nella sua monografia dedicata a Stus traduttore di Rilke (Kravčenko 2008).

65 Dalla lettera ai familiari del 6/10-05-1984, in: T VI.1, 466: “Останнім часом я спостеріг за собою: що більше читаю і працюю над Рільке - то більше розчарування в ньому, в його надто пухкому, надто панському, надто не-житньому хлібі (знайоме відчуття: колись так само, психологічно 'переситившись' Пастернаком, я на довші літа - це було десь у 2. половині 60-х рр. - відчув до нього нехіть, синоніми супутників 'пересичення'). [...] Одне слово, лев, поданий стилістикою рококо. Не знаю, чому, але такий Рільке мене дратує, надто він не вірильний, надто жіночний, а це мужчині не пасує — навіть такому оригіналові, як він.” Si veda anche dalla lettera alla moglie e al figlio del 1-08-1982, in: ivi: 427: “Здається, трохи він мені вже стає докучливий - Рільке. Надто вже він безплотний, надто - не від життя, сказав би я ще - грішний чистотою своєю в світі по страшній війні 1914-18 pp., про яку йому не ходило, здається." 'Mi sembra che mi sia diventato un po' irritante Rilke. È troppo etereo, troppo distaccato dalla vita, direi anche - colpevole della sua purezza in questo mondo dopo la terribile guerra 14-18, del quale non si era curato, mi pare.' Si noti come queste esternazioni facciano in realtà seguito all'invio e al commento di alcune traduzioni rilkiane, tra cui, significativamente, l'Elegie an Marina Zwetajewa-Efron. Sull'apoliticità di Rilke il giudizio di Stus è troppo tranciante. Si veda a questo proposito il lavoro di Egon Schwarz dedicata al contraddittorio discorso politico rilkiano (Schwarz 2000). Si noti, al di là del dichiarato disamore di Stus per Rilke, l'iniziale insistenza sulla continuità delle sue letture e della sua attività di traduttore delle opere rilkiane. 
Queste dichiarazioni non inficiano minimamente l'estrema importanza del dialogo con la tradizione rilkiana lungo tutto l'arco dell'esperienza poetica di Stus dalla metà degli anni Sessanta agli anni Ottanta ${ }^{66}$. Particolarmente opportuna si mostra così la possibilità di uno sguardo alla produzione degli anni Settanta, Palimpsesty in particolare, attraverso il prisma del costante confronto di Stus con il modello rilkiano da lui quotidianamente vissuto mediante l'esperienza traduttiva. Nonostante l'impossibilità di conoscere l'ultima raccolta stusiana, Ptach duši ('L'uccello dell'anima'), confiscata a Kučino e mai restituita alla famiglia e molto probabilmente distrutta, si può agevolmente ipotizzare una prosecuzione dell'incontro poetico tra Stus e Rilke sulla base del titolo stesso dell'opera, dietro al quale non è difficile cogliere un rimando all'apertura della seconda delle Duineser Elegien:

Jeder Engel ist schrecklich und dennoch, weh mir, ansing ich euch, fast tödliche Vögel der Seele, wissend um euch ${ }^{67}$.

Sebbene la sua presenza nell'epistolario stusiano sia decisamente inferiore a quella di Rilke, sarebbe Goethe, secondo le parole dello stesso Stus, ad aver rappresentato per lui il principale punto di riferimento letterario. Nella lettera alla moglie e al figlio del 15 aprile 1982 Stus scrive: "Vorrei consigliargli [al figlio Dmytro, allora sedicenne - AA] di leggere Dichtung und Wahrheit [Poesia e verità $-\mathrm{AA}][\ldots]$. Ma ho sempre rimpianto di essermene innamorato a diciotto o diciannove anni e non prima. Non conosco un autore più saggio. Non penso di averne letto uno"68.

Protagonista del già menzionato breve saggio Velykyj z najbil 'šych del 1967, Goethe è nominato da Stus al primo posto tra i suoi autori amati nella sua prima

66 Si veda, in parziale contrasto con le esternazioni appena menzionate di pochi anni più tarde, da una lettera (disponibile solamente nella traduzione ucraina) all'amica tedesca Christine Bremer del 23-07-1979, in: T VI.1, 173: “Даруй мені, моя сестро, я надто довго не озивався. Отримав усі Твої подарунки й листи, ч. 57 я отримав також. Але 'Worpswede' не мав. Я дуже радію, що мій чудовий ангел Райнер Марія Рільке у його висловах і картинах є тут. Шкода, мій світ $є$ інший від того, в якому жив Рільке. Моя душа шукає не тільки краси, але й прагне вищих сфер, справедливості і правди. Тут криються всі проблеми мого життя." 'Perdonami, sorella, troppo a lungo non mi sono fatto sentire. Ho ricevuto tutti i Tuoi doni e le tue lettere, anche la numero 57. Ma non ho avuto Worpswede. Sono molto lieto che ci sia il mio stupendo angelo Rainer Maria Rilke nelle sue dichiarazioni e nelle sue immagini. Peccato, il mio mondo è diverso da quello in cui viveva Rilke. La mia anima ricerca non soltanto la bellezza, ma anche le alte sfere, la giustizia e la verità. In questo si racchiudono tutti i problemi della mia vita.'

67 Rilke 1996: II, 205. 'Ogni angelo è terribile, ma lo stesso / vi canto, uccelli dell'anima quasi mortali / sapendo di voi.'

68 T VI.1, 421: “Хотів би порадити йому прочитати 'Dichtung und Wahrheit' [...]. Але я завжди шкодував, що Гете я полюбив у 18-19 років, а не раніше. Мудрішого автора я не знаю. Може, і не читав у житті." 
lettera conservatasi, rivolta a Viktor Didkivs'kyj e risalente all'estate del 1959: "Sono contento di aver preso con me i miei amati, Goethe e Verhaeren, Oles' e Ryl's'kyj, Słowacki e Éluard, il buon Radharkrishnan e Winckelmann, il virtuoso Rāmāyaṇa e la virtuosa Selma Lagerlöf"69.

In posizione d'onore nel complesso di un innegabile sfoggio di erudizione da parte di un neolaureato in lettere appena ventenne, in compagnia di autori di diverse epoche e provenienze molti dei quali sarebbero presto scomparsi dall'orizzonte degli interessi stusiani, Goethe sembra dunque accompagnare Stus sin dagli esordi del suo cammino letterario. Della sua fondamentale presenza nell'universo poetico e personale di Stus nei mesi della carcerazione preventiva del 1972 e almeno per tutto l'anno successivo si parlerà ampiamente analizzando la seconda parte di Čas tvorčosti / Dichtenszeit.

La preferenza accordata da Stus a Goethe su qualunque altro scrittore è esplicitamente affermata in una lettera al figlio del 15 gennaio 1984:

Mi conforta sapere che ti sei immerso nella lettura di Pasternak. È un genio. Impara i suoi versi a memoria, ripetili tra te e te, con ogni umore, per sentire con la bocca e osservare che si tratta di un genio. Che maestro dell'anima! Che meraviglia la sua lirica amorosa, la sua lirica paesaggistica, la sua lirica personale. Credo che per me ci siano tre poeti: Goethe (il più grande di tutti, ma in traduzione non lo sentirai), Rilke e Pasternak ${ }^{70}$.

Ai due numi tutelari stusiani già discussi, rispettivamente ai vertici della lirica di lingua tedesca tra Settecento e Ottocento e nel primo Novecento, si accompagna dunque il nome dell'autore di Sestra moja žizn' e Doktor Živago. Nella già citata prefazione alla raccolta Zymovi dereva Stus scrive: "Dopo il servizio militare [1959-1962 - AA] era già tempo di poesia. Era l'epoca di Pasternak e di un amore incautamente grande nei suoi confronti. Me ne liberai solo intorno al 1965-1966. Ora più di tutti amo Goethe, Svidzins'kyj e Rilke"71.

Come si avrà modo di osservare in seguito, la presenza di Pasternak nella poesia del giovane Stus è decisamente evidente. Più nascosta e quantitativamente meno significativa essa risulta a proposito della produzione stusiana dai secondi

69 Lettera a Viktor Didkivs'kyj dell'agosto-settembre 1959, in: T VI.2: 5, “Я радий, що я взяв своїх коханих, моїх - Гете і Верхарна, Олеся і Рильського, Словацького і Елюара, доброго Радхакришнана і Вінкельмана, цнотливу Рамаяну і цнотливу Сельму Лагерльоф."

70 T VI.1, 454: “Втішила мене згадка, що Ти зачитуєшся Б.Л. Пастернаком. Це - геній. Вчи його вірші напам'ять, повторюй про себе - під кожен настрій, аби розжувати, розчовпати, що це геній. Який він майстер - душі! Яка чудова його любовна, пейзажна лірика, лірика особистості. Для мене, мабуть, є три поети: Гете (це - най-більший із усіх, але 3 перекладів Ти його не відчуєш), Рільке і Пастернак."

71 T I.1, 42: “Післяармійський час був уже часом поезії. Це була епоха Пастернака - i необачно велика любов до нього. Звільнився — тільки десь 19651966 рр. Найбільше нині люблю Гете, Свідзінського, Рільке.” 
anni Sessanta in poi, in sintonia con le parole dello stesso Stus. Nell'epistolario con i famigliari degli anni Settanta e Ottanta il rapporto di Stus con Pasternak si rivela ambiguo come nel caso di Rilke, al quale è spesso accostato anche in ragione dei rapporti umani e artistici dei due poeti, culminati nella corrispondenza a tre con Marina Cvetaeva del 1926. Pasternak, vincitore del Nobel per la letteratura del 1958, è per Stus ora un genio, come nella summenzionata lettera del gennaio del 1984, ora una vittima del proprio talento:

Mi fa molto piacere che Dmytro si sia appassionato alle poesie di Pasternak. [...] Consiglierei a Dmytro di imparare a memoria alcune poesie di Pasternak, come A Elena ("Ja b i napečatnym slovom ne pobrezgoval"), Improvizacija ("Ja klavišej staju kormil s ruki"), Ural vpervye ("Bez rodovspomogatel'nicy, vo mrake, bez pamjati"), le poesie dal romanzo: Gefsimanskij sad e Noč, Gamlet ("Zal utich. Ja vyšel na podmostki"). [...] Sono molto interessanti le sue poesie paesaggistiche ("Rassvet raskolychnet sveču"; "Ty v vetre, vetkoj probujuščem") e le poesie amorose ("Pomešaj mne, poprobuj"; "Moj stol ne stol'širok!") - sono straordinariamente emozionali. [...] Forse più in là scriverò a Dmytro una lettera sul mio Pasternak - tutt'ora mi ricordo molte sue cose e lo cito spesso. Pensavo: con che gioia leggerei la prosa di Pasternak Vozdušnye puti, M., "Sovetskij pisatel"”, 1982, in particolare Ochrannaja gramota! [...] Questo libro mi aveva sconvolto - circa venticinque anni fa, quando lo lessi per la prima volta. E poi è dedicato a R. M. Rilke, il poeta che aveva ispirato Pasternak all'impresa di scriverlo $[\ldots]^{72}$.

A dire il vero è un po' un peccato che sia Rilke, sia Pasternak a volte siano un po' "affettati", volendosi mostrare più saggi di quanto non siano, senza togliersi il trucco teatrale dal volto. $\mathrm{E}$ a un uomo, a mio parere, non sta bene far l'attore. Mi ricordo quando nel 1978, mentre andavo a seppellire mio papà, presi quelle lettere ("Voprosy literatury", 1978, N. 3-5?) e come mi parsero

${ }^{72}$ Si veda dalla lettera ai familiari del 4-03-1984: “Дуже мені приємно, що Дмитро захопився віршами Пастернака. [...] Порадив би Дмитрові вивчити напам'ять такі вірші Пастернака, як 'Елене' (Я б и напечатным словом не побрезговал), Импровизация ('Я клавишей стаю кормил с руки'), Урал впервые ('Без родовспомогательницы, во мраке, без памяти'), вірші з роману: 'Гефсиманский сад’ і 'Ночь', 'Гамлет' ('Зал утих. Я вышел на подмостки'). [...] Цікаві дуже у нього пейзажні вірші (Рассвет расколыхнет свечу; Ты в ветре, веткой пробующем), любовні вірші (Помешай мне, попробуй; Мой стол не столь широк) - вони надзвичайно емоційні. [...] Я, може, згодом напишу Дмитрові листа про мого Пастернака - досі з нього багато пам’ятаю і часто цитую. Думаю собі: з якою радістю я прочитав би книгу прози Б. Пастернака 'Воздушные пути', М., Советский писатель, 1982, особливо 'Охранную грамоту'! [...] Ця книга потрясла мене - десь 25 років тому, коли я її вперше прочитав. До всього ця книга присвячена Р.М. Рільке, поетові, що надихнув Пастернака на подвиг — ії написати [...]." 
peccaminose, false, non autentiche, soprattutto sullo sfondo della mia pena un padre gravemente ammalato ${ }^{73}$.

La profonda conoscenza e l'instancabile interesse di Stus per Rilke e Pasternak, al di là delle dichiarazioni polemiche contenute in alcune delle sue tarde lettere, inducono a ipotizzare un equivalente coinvolgimento per l'opera poetica di Marina Cvetaeva. Legata a entrambi da profondi legami umani e artistici, Cvetaeva è da annoverare tra i poeti più influenti per la poesia sovietica più o meno non allineata degli anni Sessanta, Settanta e Ottanta ${ }^{74}$. Già ampiamente diffusa mediante il samizdat ${ }^{75}$, un'ampia selezione della poesia cvetaeviana vide una prima pubblicazione ufficiale in Unione Sovietica nel 1961, nell'ambito della prestigiosa collana "Biblioteka poeta" (cfr. Gladkova, Mnuchin 1982). Menzionata da Stus per la prima volta in una lettera del 1964 al poeta Ihor Nyžnyk (1935-2013) insieme a Pasternak e ad altri scrittori russi, ucraini e stranieri ${ }^{76}$, Cvetaeva occupa un posto di particolare rilievo nel tardo epistolario stusiano. L'oscillazione dei giudizi di Stus su Rilke e Pasternak nelle lettere degli anni Ottanta non risparmia neanche la poetessa moscovita. Dopo aver richiesto al figlio Dmytro e a Mychajlyna Kocjubyns'ka l'invio di alcuni testi cvetaeviani, Stus dedica non poco spazio della sua corrispondenza a una loro analisi. Al centro della sua attenzione è Poema konca del 1925. Nella lettera alla moglie e al figlio del 10 agosto del 1981, la discussione di questo capolavoro cvetaeviano è introdotta da un'esplicita e perentoria dichiarazione

73 Si tratta della stessa lettera: “Трохи, правда, біда — в тому, що і Рільке, і Пастернак часом 'жеманяться', побільшуючи своєї мудрості, не змиваючи з лиця театрального гриму. А мужчині, як на мене, акторствувати не подобає. Згадую, як 1978 р., їдучи ховати тата, я взяв ці листи (Вопросы литературы, 1978, № 3-5?) - i які вони видалися мені грішними, удаваними, мімічними - особливо на фоні моєї біди - тяжко хворого тата."

74 Cfr. Ginzburg 1987: 331: “Основоное положение молодых и относительно молодых поэтов состоит еще в том, что слишком трудно выбраться из семантического круга, очерченного поэзией, пришедшей на смену символизму. Особенно всепроникающей четверкой: Пастернак, Мандельштам, Ахматова, Цветаева."

75 Cfr. Surikova 2013: 9: “Возрастающий интерес к культуре прошлого можно назвать одной из главных тенденций неофициального культурного движения 1960-1980 гг. Стихи почти не издававшихся поэтов Серебряного века становятся значимой частью самиздата, что совпало и с борьбой за 'возвращение имен' в официальных кругах: в 1955-1965 гг. выходят сборники С. Есенина, И. Бунина, В. Хлебникова, М. Цветаевой.”

76 Dalla lettera a Ihor Nyžnyk del 22-03-1964, in: T VI.2, 32: “Читай Пастернака, Цветаєву, С. Незвала, але читай, будучи Нижником. [...] Вознесенського не читай, крім 'Сигулды'. Гарний Підпалий [...]”. 'Leggi Pasternak, Cvetaeva, Nezval, ma leggi, dato che sei Nyžnyk. Voznesenskij non leggerlo, tranne Sigulda. È bello Pidpalyj [...]' Volodymyr Pidpalyj (1936-1973) è stato uno dei massimi rappresentanti in Ucraina della cosiddetta "lirica quieta" (tycha liryka) degli anni Sessanta e Settanta. 
di delusione: "Non sono molto entusiasta di quest'opera" 77 . Quest'ultima viene tuttavia immediatamente contraddetta da un'effettiva negazione dello scetticismo inizialmente dichiarato: " $[\mathrm{M}] \mathrm{i}$ piace molto il suo stile, l'energia della scrittura - un testo molto elastico, muscoloso"78. L'elogio stusiano della poesia cvetaeviana si concretizza in una lunga disanima delle peculiarità formali di Poema konca, a partire del quale Stus si concede alcune divagazioni sulla personalità artistica di Marina Cvetaeva, il linguaggio poetico in sé e la storia della lirica russa, nelle quali non è assente una tendenza all'identificazione dell'esperienza umana e artistica della poetessa con la propria:

Mi piace l'ampiezza dei sentimenti nella Cvetaeva - è come un fiume di montagna. [...] Scrivere così è l'apice della maestria (è forse geniale). È un'arte già cristallizzata - come il sale marino a riva. È un montaggio. Un ottimo montaggio. [...] - persone così forti, come la Cvetaeva (persone dallo spirito eccezionale) sanno vivere nella tragedia - con dignità. [...] Pensi che abbia capito tutto? No. Ma non è sempre colpa mia (è anche colpa dell'autrice - a volte scrive in modo oscuro. Ma non è un male che scriva in modo oscuro. L'importante è che abbia esposto la grandezza del desiderio, del sentimento, della forza dello spirito umano - una forza incontenibile che prima di lei non c'era nella letteratura russa (forse nel primo Majakovskij, soprattutto nel Trinadcatyj apostol, o in Pasternak). [...] L'essenza principale di Marina è che è una rivoluzionaria, come dev'essere un vero poeta ${ }^{79}$.

L'avvicinamento della figura cvetaeviana e della sua poetica alla propria situazione è esplicitata in una lettera dell'anno successivo. Stus scrive alla moglie e al figlio della totale consonanza tra la concezione cvetaeviana del poeta e della sua missione espressa nel saggio Iskusstvo pri svete sovesti ${ }^{80}$ e la propria

77 T VI.1, 380: “Я не дуже в захваті од цього твору.”

78 Ibidem: “[М]ені подобається її стиль, енергія письма — дуже пружний i м'язистий текст."

79 Ibidem: "Мені подобається широта почуттів у Цветаєвої — як гірська річка. [...] Писати так — то верх майстерності (можливо, й геніально). Це вже кристалізоване мистецтво - як морська сіль на березі. Це - монтаж. Гарний монтаж. [...] - такі могутні люди, як Цветаєва (люди виняткового духу) вміють жити в трагедії - гідно. [...] Думав, що я все в ній збагнув? Ні. Але то - не всюди моя вина (є вина й автора - часом тьмяно писала). I не біда, що тьмяно - писала. Головне - виявила велич прагнення, почуття, сили людського духу — такої сили скаженої, якої до неї в російській літературі не було (хіба у Маяковського-раннього, особливо 'Тринадцятого апостола' чи Пастернака). [...] Суть же головна Марини: що це революціонерка, як і належить бути справжньому поетові."

${ }^{80}$ Nella concezione cvetaeviana di Iskusstvo pri svete sovesti la poesia è il superamento delle contraddizioni che riguardano il resto del reale, la realizzazione della sintesi dei contrari che tormentano il poeta nella sua esistenza terrena, anzi nel suo esilio terreno. Il saggio alterna passaggi in cui al poeta è assegnato un ruolo attivo, quello di fautore dell'"eticità" e della "spiritualità" dell'arte, a momenti in cui egli è descritto 
esperienza $^{81}$. Ora ridimensionata ${ }^{82}$,ora ai vertici della poesia mondiale ${ }^{83}$, Marina Cvetaeva si colloca tra gli indiscussi protagonisti degli interessi letterari dello Stus degli ultimi anni. Dalle pagine che seguono emergerà la fondamentale importanza del dialogo con la tradizione cvetaeviana per la poesia stusiana già a partire dagli anni Sessanta.

La grande confidenza di Stus con la letteratura occidentale nel suo complesso è evidente ${ }^{84}$. Dal suo epistolario, da alcuni suoi scritti di carattere pubblicistico e memorialistico, come le note diaristiche pubblicate dal figlio Dmytro nella sua autobiografia del padre, così come dal suo lascito traduttorio, emerge dunque con chiarezza l'importanza rivestita nella sua formazione artistica e umana da tre tradizioni nello specifico: la letteratura ucraina, russa e tedesca. Il carattere fondamentale del confronto con la civiltà letteraria patria per un poeta e intellettuale esponente di una cultura politicamente oppressa da più di due secoli non può in alcun modo essere sottovalutato. Dalla volontà stessa

come un esecutore solamente passivo della stichija, la forza degli elementi naturali. Per un approfondimento su Iskusstvo pri svete sovesti si veda Stock 2005.

81 Dalla lettera alla moglie e al figlio del 14/15-11-1982, in: T VI.1, 430: “Сидів, читаючи прегарні нотатки Марини Цветаєвої 'Искусство при свете совести' (Литературное обозрение, № 10, 82) і думав про вас. [...] Здається, підписався б під кожним ії словом, де вона провадить про поета і його місію.” 'Ero seduto a leggere gli stupendi appunti di Marina Cvetaeva Iskusstvo pri svete sovesti ('Literaturnoe obozrenie' 10,1982 ) e pensavo a voi. [...] Credo che sottoscriverei ogni sua singola parola a proposito del poeta e della sua missione.'

82 Dalla lettera alla moglie e al figlio del 26-01-1982, in: ivi: 411: "Вiрші Пастернака, що ти, Валю, вислала — я не в захваті од них. [...] Так само і Цветаєва дратує, коли мудрує з формою (кокетерії починаються іiї - вона хотіла дивувати 'по-жіночому' і в віршах).” “Le poesie di Pasternak che mi hai mandato, Valja, non mi entusiasmano. [...] Allo stesso modo anche la Cvetaeva mi irrita quando fa la ricercata con la forma (cominciano le sue civetterie - voleva fare la primadonna anche in poesia.'

83 Dalla stessa lettera: “Дмитрику, ти пишеш про Лесю Українку, про іiї 'Лісову пісню’. Про все це я міг би багато провадити. I про те, що Леся почала писати, коли наша література була вкрай бідна, як і мова [...] На свій час вона була для України могутньою поеткою. А сьогодні читати ії не дуже втішно. Бо ми вже розпанькані на могутніших, зріліших віршах Лорки чи Цветаєвої чи Еліота.” 'Dmytryk, scrivi di Lesja Ukrajinka e della sua Lisova pisnja ['Il canto del bosco' - AA]. Di questo potrei parlare a lungo. E anche del fatto che Lesja iniziò a scrivere quando la nostra letteratura era estremamente povera, così come la nostra lingua. [...] Ai suoi tempi era per l'Ucraina una grande poetessa. Ma oggi leggerla non è un grande piacere. Perché siamo viziati dai versi più potenti e più maturi di Lorca, della Cvetaeva o di Eliot.'

84 Dall'epistolario emerge inoltre il desiderio di Stus di approfondire le sue conoscenze della letteratura extra-europea. Spicca la sua curiosità nei confronti della cultura giapponese, come dimostra la sua conoscenza di Yasunari Kawabata e Kenzaburō Ōe. Si vedano a questo proposito le lettere alla moglie del 3/4-12-1975 e del 15-01-1984. Per uno studio degli “orientalismi” stusiani cfr. Burjanyk 1997 e Punina 2012. 
di contribuire alla fuoriuscita della letteratura ucraina da un'inevitabile condizione di temporanea "minorità" impostale dalla storia, che Stus condivide con la cultura dello šistdesjatnyctvo nel suo complesso, derivano le sue frequenti critiche a molti scrittori connazionali del presente e del passato. La necessità di traghettare il potenziale artistico e culturale ucraino al di fuori dello stato di emergenza dettato dal contesto sovietico sembra essere al centro delle preoccupazioni etiche ed estetiche di Stus. Nella pratica artistica, ciò non può che tradursi in un fare poetico libero da qualsivoglia dettato esteriore di natura sociale e politica, ossia, come si potrà osservare, in un riallacciamento alla tradizione del Modernismo europeo.

La partecipazione attiva di Stus allo sviluppo della civiltà letteraria ucraina non esclude un suo stretto legame con la cultura russa. Seppur non identificabile con una tradizione patria, la letteratura russa non può che costituire per Stus, nato nell'ucrainofona Ucraina occidentale e cresciuto nell'ormai quasi completamente russificato Donbas urbano, uno spazio intermedio tra identità e alterità. La cultura e la letteratura russa sono per Stus al contempo proprie ed estranee, ma sicuramente conosciute alla perfezione e inesauribile fonte di interesse e curiosità ${ }^{85}$. La letteratura russa sembra a tratti costituire per Stus un modello da imitare, in virtù delle minori limitazioni imposte alla cultura dominante rispetto alle culture 'secondarie', in età imperiale come in età sovietica ${ }^{86}$. L'importanza

85 In una lettera del 1965-66 al segretario del Partito Comunista Ucraino Petro Šelest (1908-1996) Stus definisce "nostri” alcuni poeti russi (cit. in: Stus 2004: 270): "В мистецтві ми відстали на десятиліття, ми відкинені назад. Ми регресуємо далі. А геніальні наші митці, такі як Пастернак, Цвєтаєва, Мандельштам відомі більше за кордоном, ніж у себе на Батьківщині." 'Nell'arte siamo fermi da decenni, siamo scaraventati all'indietro. E continuiamo a regredire. E i nostri artisti geniali, come Pasternak, Cvetaeva e Mandel'štam, sono più conosciuti all'estero che in patria.'

${ }_{86}$ Si veda, a questo proposito, un'interessante nota diaristica riportata in: ivi: 227: “2.12.1970p. Читав учора Анну Ахматову ('Реквієм’), дивувався її високому, нагірному стражданню, успокоєнності. Вона сприймає страждання як Господню кару й вивищується над ним, залишаючись аристократкою, людиною, відданою красі. Будь-хто з наших літераторів зайшовся б криком 'рятуйте', прокльонами, а на гірший випадок - рятувався б через власну етичну смерть, пішов би в 'услужение'. Подумав, що М. Рильський, один з більших аристократів наших, валявся після 1930 р. попідтинню, а потім заплатив совістю й самоповагою - за добробут. Інші, як І. Драч, починали з плати на вихід у світ. Це наші потворства, долюдський період України.” '2-12-1970. Ieri ho letto Anna Achmatova (Requiem) e mi hanno sorpreso la sua elevata e nobile sofferenza, la sua tranquillità. Vive la sofferenza come una punizione divina e si eleva al di sopra di essa, rimanendo nella sua nobiltà, votata alla Bellezza. Chiunque dei nostri letterati si sarebbe messo a gridare 'aiuto', a inveire, nel peggiore dei casi si sarebbe salvato morendo eticamente, sarebbe andato a fare il servo. Pensavo al fatto che Maksym Ryl's'kyj, uno dei nostri più grandi aristocratici, era in mezzo a una strada dopo il 1930, poi si è comprato il benessere con la coscienza e il rispetto di sé. Altri, come Ivan Drač, hanno cominciato pagando per avere un posto là fuori. Sono le nostre mostruosità, il periodo pre-umano dell'Ucraina.' 
della letteratura russa nella strutturazione del palinsesto stusiano, già evidenziata dal suo profondo interesse per le figure di Pasternak e Cvetaeva, non può dunque essere in alcun modo minimizzata ${ }^{87}$.

La terza principale componente della genealogia letteraria stusiana, la letteratura tedesca, è probabilmente riconducibile non da ultimo all'importanza dello studio della lingua tedesca nel sistema educativo sovietico. Gli inizi dell'instancabile interesse di Stus per la lingua e la letteratura di Goethe e Schiller sono databili al periodo degli studi universitari a Stalino/Donec'k. Raggiungendo i suoi vertici con le traduzioni di Goethe e Rilke e il dialogo intertestuale con la loro poesia, la conoscenza stusiana della letteratura tedesca si esplica significativamente nell'adattamento in ucraino di un nutrito numero di autori dall'età premoderna alla contemporaneità. Il corpus traduttorio stusiano a noi giunto si basa infatti principalmente su testi tedeschi, annoverando liriche di poeti barocchi e tardo-barocchi (Christian Hoffmann von Hoffmannswaldau, Christian Weise, Johann Christian Günther), espressionisti e post-espressionisti (Wilhelm Klemm, Albert Ehrenstein, Gottfried Benn, Erich Kästner) ed esponenti di primo piano del secondo Novecento, come Ingeborg Bachmann, Paul Celan, Hans Magnus Enzensberger e Johannes Bobrowski. A questo elenco si sommano le traduzioni ucraine del Leben des Galilei (Vita di Galileo) brechtiano e del ro-

87 In una lettera dal carcere del febbraio 1972 a Jurij Smolyč (1900-1976), presidente dell'Unione degli Scrittori Ucraini, Stus scrive (cit in: Stus 2004: 304): “Як поет, я все більше і більше тяжів до психологічної поезї - мого генералізованого світо- і самосприймання і усвідомлення. Світ Рільке, Еліота, Заболоцького і Бажана, італійських 'герметиків' — ось те, що, може, на 95\% визначало найвласніший напрям моєї поезіi." "Come poeta ho teso sempre di più verso la poesia psicologica - la mia percezione e coscienza generalizzata di sé e del mondo. Il mondo di Rilke, Eliot, Zabolockij e Bažan, degli ermetici italiani: ecco chi ha segnato forse per un $95 \%$ il vettore più profondo della mia poesia'. L'elevazione di Nikolaj Zabolockij a figura determinante per la formazione del proprio universo poetico non sembra trovare altri riscontri nel lascito stusiano, se non per la sua traduzione del bozzetto lirico zabolockiano Vozvraščenie s raboty. Nella lettera alla moglie del 3-01-1976 Stus riflette invece sulla propria vicinanza al simbolismo blokiano e scrive della propria recente scoperta della poesia di Ivan Bunin. Si veda T VI.1, 206: "А ще трапилася мені нагода - прочитати Блока в злецькому бідному виданні (200 стор. тексту). Чотирирічна розлука з ним виявилася — при зустрічі — тяжчою, ніж я думав. Виявляється, чимало мотивів, духових спроб (без слів) живе в мені - оглушено живе, впевнено. Я мав майже радість - таку, як позаторішня моя келійна зустріч з Буніним і ‘богинею с козьим лицом' [...].” 'Ho avuto anche l'occasione di leggere Blok in una povera edizione da quattro soldi (200 pagine). Al momento dell'incontro quattro anni di separazione si sono fatti sentire, più di quanto pensassi. Mi sono reso conto che non pochi motivi e non poche prove spirituali (non a parole) vivono in me, in sordina, certamente. Che gioia, quasi come con l'incontro di due anni fa nella mia cella con Bunin e "la dea dal volto caprino" [...].' Stus si riferisce quasi sicuramente alla lirica buniniana Boginja del 1916. Si veda la tesi di dottorato di Tetjana Mychajlova per una discussione più approfondita dell'interesse di Stus per la lirica buniniana (Mychajlova 2016: 111-125). 
manzo breve ottocentesco Mozart auf der Reise nach Prag (Mozart in viaggio verso Praga) di Eduard Mörike.

La familiarità di Stus con la poesia di lingua tedesca nel suo complesso, nonché la presenza di alcune traduzioni di poeti espressionisti nel suo lascito traduttorio, inducono a ipotizzare una sua approfondita conoscenza dell'Espressionismo tedesco ${ }^{88}$. Sebbene lo stesso Stus, con grande modestia, dichiari in una lettera ad Anna-Halja Horbatsch (1924-2011) di conoscere la poesia tedesca del Novecento "molto approssimativamente" - tra i nomi citati di Stus spicca quello del sommo poeta dell'Espressionismo Georg Trakl (1887-1914) ${ }^{89}$ - l'eviden-

88 L'Espressionismo tedesco, non a caso con una prevalenza della sua declinazione battagliera e utopistica della seconda metà degli anni Dieci (per una buona panoramica sull'Espressionismo cfr. Rötzer 1976), iniziò a diffondersi in Russia e più tardi in Unione Sovietica già negli anni pre-rivoluzionari, principalmente a livello traduttorio e inter-testuale e vi consolidò la propria presenza nei primi anni Venti a livello critico. Sulla circolazione della lirica espressionista in Russia tra gli anni Dieci e gli anni Venti si veda Belentschikow 1994. Si ricordi in questo contesto l'attiva partecipazione di Anatolij Lunačarskij alla diffusione dell'Espressionismo in Unione Sovietica. Cfr. anche Pestova 2004: 163: "Началом научного осмысления немецкоязычного экспрессионизма в России следует считать, по всей видимости, 1923 г.” Nello stesso anno Pasternak iniziò a lavorare alla traduzione russa di diversi poeti espressionisti, tra cui Georg Heym. Cfr. a proposito Čubrakova 2012 e Polivanov, Charer 1995. La studiosa vi sottolinea correttamente la lontananza tra gli universi poetici di Pasternak e degli Espressionisti. Le traduzioni pasternakiane, la cui conoscenza da parte di Stus è possibile ma non sicura, potrebbero fungere da ulteriore conferma della presenza della lirica espressionista tedesca tra le fonti stusiane. Per quanto riguarda la conoscenza dell'Espressionismo nell'Ucraina sovietica, si ricordino gli sforzi di Osval'd Burghardt/Jurij Klen (1891-1947), autore nel 1925 dell'articolo Ekspresionizm u nimec'kij literaturi (sulla critica di Burghardt/Klen cfr. Žovtani 2007), e la miscellanea del 1929 a cura di Stepan Savčenko Ekspresionizm ta espresionisty. Literatura, maljarstvo, muzyka sučasnoji Nimeččyny. A proposito dell'inevitabile ambiguità della ricezione sovietica del retaggio espressionista si veda un articolo del 1961, a firma di Natal'ja Pavlova, che ben riflette le difficoltà dell'accettazione di un'estetica completamente opposta al realismo socialista (pur, ben inteso, in pieno Disgelo), ma al contempo carica di potenziali rivoluzionari e antiborghesi. Cfr. Pavlova 1961: 129-141 passim: “Своеобразие экспрессионистического обобщения состояло в чрезвычайно субъективном, абстрактном восприятии мира. В отличие от реализма, исходившего из настойчивого изучения жизненного материала, экспрессионисты шли в своей концепции современности от субъективной гипотезы. [...] Разумеется, далеко не всегда эта современная демократическая традиция непосредственно связана с достижениями левого экспрессионизма 10-х - начала 20-х годов. И все же именно здесь - во вмещающем широкие проблемы времени лиризме - стоит искать его оставшееся жить наследие. Оно - в широте лирического начала, в активном чувстве лиричной причастности событиями мира, в умении всюду и всегда донести до читателя свой авторский голос, свою тревогу за жизнь и судьбу человечества."

89 Dalla lettera a Anna-Halja Horbatsch del 4-04-1977, in: T VI.2, 98: "I3 книжок мені дуже ходить про німецьких філософів 20 ст. (Ясперс, Гайдеггер, 
za di un significativo filone espressionista nella sua poesia induce a dubitare di questa affermazione. Si riscontreranno più avanti casi di oggettiva sovrapposizione tra il testo stusiano e un presunto ipotesto derivante dall'Espressionismo tedesco, accanto a più frequenti esempi di semplice consonanza tra il linguaggio poetico di Stus e l'immaginario espressionista, non necessariamente frutto di un concreto dialogo intertestuale.

Stus tradusse anche alcuni poeti francesi, una lirica di Rudyard Kipling ${ }^{90}$, alcune poesie di Ungaretti, Federico García Lorca, Tadeusz Różewicz, Tadeusz Kubiak e autori cechi, slovacchi, bielorussi e di lingua ebraica. Dal russo si sono conservate traduzioni di Bunin, Brjusov, Zabolockij e Cvetaeva (Nepodražaemo lžët žizn'), anche se nell'epistolario Stus menziona la propria traduzione della pasternakiana Zimnjaja noč’ dagli Stichi Jurija Živago ${ }^{91}$.

Dall'epistolario emerge inoltre l'interesse di Stus per la filosofia esistenzialista riscontrabile con diversa intensità in tutte le fasi del suo percorso poetico. In una delle sue ultime lettere Stus definisce Albert Camus il suo "prosatore preferito" "92, dopo averlo ripetutamente menzionato negli anni precedenti ${ }^{93}$. Lo scrittore Michail Chejfec (1934), compagno di reclusione di Stus in Mordovia, ha testimoniato tra gli altri dell'eccellente conoscenza di Stus dell'opera camusiana ${ }^{94}$.

Al 1964 risale invece un'univoca attestazione del precoce interesse del giovane poeta e studioso per l'Esistenzialismo non solo francese: "L'anno scorso di notti insonne ce ne sono state. Adesso è lo stesso. Mi tormento con il libro di T.

деякі “франкфуртці“, Клагес), але дорога їм сюди, певне, видасться далекою. Так само - дуже цікаво мені мати поезію 20 ст. німецькомовну - Тракля, Бенна, Бахман, Целяна, Фріде - іх я знаю дуже приблизно." 'Per quanto riguarda i libri terrei molto ai filosofi tedeschi del Novecento (Jaspers, Heidegger, alcuni "francofortesi", Klages), ma sicuramente faranno fatica ad arrivare qui. Mi interessa anche avere la poesia tedesca del Novecento - Trakl, Benn, Bachmann, Celan, Fried - li conosco molto approssimativamente.'

90 Per una discussione della traduzione stusiana di If si veda Veretelnyk 2016.

91 Cfr. la lettera alla moglie del 1-08-1984.

92 Dalla lettera alla moglie e al figlio del 15-01-1984, in: T VI, 455: “Дуже хочу, аби ти прочитав и полюбив Альбера Кам'ю - це найлюбленіший мій прозаїк особливо 'Посторонний' і оповідання-нариси." 'Voglio molto che tu legga Albert Camus - è il mio prosatore preferito - soprattutto Lo Straniero e gli scritti a metà tra saggistica e narrativa'. Sull'importanza di Camus per gli šistdesjatnyky cfr. Pachlovska 2017.

93 Si vedano le lettere alla moglie del 19-11-1973, del 22/30-09-1976, del 23-031981, del 10-08-1981 e del 4-04-1983, nonché la lettera ai genitori del 1-10-1975. Nella lettera a Ivan Svitlyčnyj del 16-02-1970 (T VI.2, 63) Stus ringrazia l'amico per aver presumibilmente ricevuto da lui un'edizione di Camus: “Дуже дякую тобі за Камю.” 'Ti ringrazio molto per Camus'.

94 Chejfec 1983: 29: “Я не встречал более тонкого знатока творчества Камю - он прочел и проанализировал все написанное французом (помню, что меньше остального ему нравилась знаменитая 'Чума').” 
Schwarz Da Schopenhauer a Heidegger, con Le parole di Sartre ('Novyj mir', 10), mi tormento con qualunque cosa mi capiti sotto mano"95.

Si ricordi, inoltre, come gli anni della formazione intellettuale di Stus coincidano con l'ingresso ufficiale dell'Esistenzialismo laico francese in Unione Sovietica, in precedenza ufficialmente rifiutato dall'establishment culturale sovietico ${ }^{96}$.

95 Dalla lettera a Viktor Didkivs'kyj del 3-11-1964, in: T VI.2, 35: “Торік були ж такі безсонні ночі. Тепер - такі ж. Катую себе книгою Т. Шварца 'От Шопенгауэра к Хейдеггеру’, катую ‘Словами' Сартра, катую чим тільки можу.”

96 Nel 1953 era stata pubblicata in una miscellanea sovietica di scritti di intellettuali francesi engagé in traduzione russa una sintesi di L'existentialisme n'est pas un humanisme del dirigente comunista Jean Kanapa, scritto nel 1947 in risposta al noto pamphlet sartriano dell'anno precedente. Il titolo della versione russa dello scritto di Kanapa, nel quale vengono accusati di ogni nefandezza Sarte e Jaspers, Berdjaev e Marcel, Kierkegaard e Šestov, è ancora più eloquente dell'originale francese: Ekzistencializm - vrag gumanizma. Cfr. Kanapa 1953. Già nel 1954 Sartre iniziò il suo avvicinamento al marxismo e si svolse inoltre il suo primo viaggio in Unione Sovietica. Cfr. Smirnova 2013: 125: "На самом деле систематическое изучение французской философии началось в СССР в конце 1950-х гг. [...] В 1966 г. в издательстве 'Мысль' вышел сборник 'Современный экзистенциализм. Критические очерки' [...]” Un buon esempio dell'ambiguità della ricezione sovietica dell'Esistenzialismo francese e dell'opera di Albert Camus anche negli anni Sessanta è fornito da Karpušin 1967: 129-133 passim: “Следует однако отметить, что гносеологическое обоснование философии абсурда, которое предлагает Камю, не беспочвенно. [...] Нельзя сказать, что Камю не видел социальный смысл абсурдности мира.” Lo studioso parla di “мелкобуржуазный этический индивидуализм” a proposito dell'esistenzialismo camusiano, per poi aggiungere: "Прежде всего отметим, что отстаивание принципа индивидуализма для многих западных мыслителей было формой выражения антифашистских убеждений.” Nella lettera alla moglie e al figlio del 16-04-1973 Stus afferma di aver ricevuto la miscellanea Sovremennaja buržuaznaja filosofija, pubblicata a Mosca nel 1972 a cura di A. Bogomolov, e di considerarla un "manuale non male" (“досить незлий підручник”). L'opera non è naturalmente esente da pesanti condizionamenti ideologici. Nel capitolo dedicato all'Esistenzialismo tedesco, a firma di due autorità come lo stesso Bogomolov e Piama Gajdenko, si legge: “Экзистенциализм как философское направление, отразившее глубокий кризис современного капиталистического общества, его науки, искусства, культуры вообще, отразившее тот факт, что эксплуататорское общество действительно враждебно человеку. Однако черты, присущие антагонистическим общественным формациям и прежде всего коммунизму, он приписывает обществу как таковому, а тем самым отвергает возможность преобразить общество на новых, социалистических и коммунистических началах" (Bogomolov 1972: 516). 


\section{Capitolo terzo. La lirica giovanile}

\section{I versi dell'esordio}

La sezione di apertura del primo tomo della raccolta stusiana $Z T$ raccoglie i versi composti dal giovane poeta tra il 1955 e il 1961 e non inclusi successivamente in alcuna opera unitaria ${ }^{1}$. I curatori del tomo dichiarano di non aver presentato gli juvenilia stusiani nella loro interezza, ma di aver cercato di proporre al lettore "la parte più interessante di questo materiale variegato e incompiuto", pur nel tentativo di ricreare un corpus quanto più ampio possibile. Sono riportati più di ottanta componimenti, a cui si aggiungono le varianti consultabili nell'apparato critico. Le prime prove di questa fase iniziale risalgono, dunque, all'epoca degli studi universitari presso l'Istituto pedagogico di Stalino/Donec'k, mentre le poesie degli anni a cavallo fra i due decenni si situano prevalentemente nel periodo del servizio militare.

L'amplissima gamma di stili, motivi e tonalità di questi versi, non insolita per il debutto di un poeta, testimonia la grande varietà delle letture del loro autore, lasciando aperto uno spiraglio sui diversi percorsi poetici che lo Stus maturo avrebbe in seguito potuto intraprendere. Pur trattandosi di primi esperimenti, non si può negare a queste poesie, o almeno a buona parte di esse, un intrinseco valore estetico, frutto della rapida maturazione artistica e culturale di un giovane che ha chiaramente scelto di dedicare la propria vita alla letteratura. Le note del futuro Stus ermetico degli anni Settanta trovano qui diverse anticipazioni, in una pluralità di orizzonti estetici che sarebbe rimasta una caratteristica costante della produzione stusiana almeno fino a Palimpsesty. Non è possibile individuare un'unica cifra stilistica e tematica per questi versi, ma si può cercare di riconoscere l'insieme di tradizioni letterarie a cui sono ispirati e di cui si fanno prosecutori. Sembra lecito affermare che il cammino poetico di Stus inizi all'insegna di una sintesi di romantico pathos amoroso e civile, da una parte, e di moderna sensibilità espressionista, dall'altra. La tradizione poetica ucraina di marca ottocentesca si fonde così con il richiamo della modernità europea, inaugurando una

1 A proposito delle complesse questioni testuali relative al primo Stus si rimanda all'apparato critico di ZT (I, 508-515).

2 Ivi: 508. 
tendenza che sarebbe rimasta, tra significative oscillazioni e ovvi aggiustamenti stilistici, un chiaro 'marchio di fabbrica' della parola poetica stusiana.

Nelle poesie dei primi anni dell'apertura post-staliniana i miti patrii di Ševčenko e Skovoroda convivono a livello tematico con evidenti, seppur non numerosi, rimandi alla tradizione vitalistica tyčyniana e pasternakiana nella rappresentazione dell'io, immerso nell'inebriante vortice degli eventi naturali. Spiccano allo stesso tempo quegli stilemi espressionistici che dagli anni Cinquanta sarebbero poi giunti sino alla poesia matura di un ventennio più tardi.

La lirica del primo Stus non è esente inoltre da ascendenze simbolisticodecadenti, come mostra, ad esempio, Son (nona) ('Sogno [Nona]'), la poesia di apertura della raccolta, frutto dei turbamenti amorosi e delle fresche memorie letterarie di un autore appena diciassettenne:
Струнка, білява, з синіми очима, Неначе лебідь, з хвилі вдалині
(В вечірній тиші ми лише одні), -
Мені вона привидилась вві сні.
I я завмер, милуючись плечима, Не бачачи обличчя. Раптом крик, Надтріснутий, і немічний, і милий, Мене ж покинули тоді останні сили, А образ... образ, ніби привид, зник ${ }^{3}$.

Intensa musicalità, atmosfera rarefatta e ipnotica confusione delle sfere del sogno e della realtà spingerebbero a relegare questo forse primo componimento di Stus nel solco di un semplice decadentismo epigonale. Sembrano tuttavia profilarsi in questi versi due elementi centrali del suo universo poetico: la concentrazione sull'io, qui schiacciato prima dall'apparizione e poi dalla sparizione dell'immagine, ancora ben lontana dall'ossessivo incentrarsi sul sé che avrebbe caratterizzato la poesia a venire, e il motivo dell'urlo $(k r y k)$, qui quasi svenevole, più tardi connotato in chiave chiaramente espressionista.

Netto è il contrasto tra Son (nona) e la poesia che la segue, per la quale gli editori non hanno né riscontrato, né ipotizzato una datazione:

\footnotetext{
Спить долина, ніжним сяйвом

оповита. [...]

Опочинь. Нехай воскресне

Віра в сяйві всеблагім.

Гей, мандрівниче, спинися

І по втомі вечеровій

Пий із келиха міцного,
}

3 Ivi: 41 . 'Snella, chiara, occhi blu, / come un cigno dall'onda in lontananza / (nel silenzio della sera siamo soli), - / mi apparve in sogno. // Impietrii, ammirandone le spalle, / non vedendone il volto. Di colpo - un urlo, / Tremante, debole, tenero, / mi lasciarono le ultime forze, / e l'immagine... l'immagine, un fantasma, svanì.' 
Життєдайну силу пий.

$[\ldots]$

Втома. Ніч. У самотині

На безлюдді бродять тіні,

На безлюдді тіні бродять,

Сосни стомлено скриплять.

$[\ldots]^{4}$

La lirica reca una dedica a "H.S.", dietro al quale, anche in riferimento al contenuto del testo e ad altri numerosi componimenti del periodo, non è difficile individuare l'immagine mitizzata di Hryhorij Skovoroda, filosofo e scrittore spirituale, una delle figure più importanti del Settecento ucraino. Anche solamente dai pochi versi citati si può notare con facilità la stretta compresenza di spunti stilistici e tematici anche molto distanti tra loro. A immagini tipiche della tradizione folklorica, il cui coronamento è la personificazione dei pini, si fonde un inno al creato certamente non alieno al folklore, ma qui inevitabilmente ridotto a una sua moderna, schillerianamente "sentimentale" riproposizione. La figura romantica del filosofo vagante è immersa in un paesaggio notturno modernamente inquietante, dove le ombre che vagano nella solitudine di un deserto umano anticipano l'ossessione stusiana per questa immagine, che tanto spazio avrebbe trovato nelle raccolte a venire. Il verbo brodyty (vagare) ${ }^{5}$ sembra poi contrapporsi in senso negativo, trasmettendo un forte senso di inquietudine, all'idea teleologicamente connotata del cammino (šljach) e della strada (doroha), termini frequentissimi nel lessico stusiano, qui non direttamente espressi, ma evocati dalla figura-modello di Skovoroda recepita in chiave stereotipata.

Questi due motivi saranno invece ampiamente ripresi nelle due parti di Vstup do poemy "Skovoroda" ('Introduzione al poema "Skovoroda"), la cui datazione non è indicata, ma di cui si può presumere una buona vicinanza cronologica con la lirica appena analizzata. Tuttavia, gli spunti perturbanti sono qui affievoliti a favore di un romanticismo di maniera decisamente accentuato, insistendo su elementi fondamentali della poesia popolare e ševčenkiana:

[...] На степних курганах

Уже з'явився промінь. Золотий.

[...]

А в небі, мов проміння, лунко плине

Все вище и вище - пісня солов 'їна ${ }^{6}$.

4 Ivi: 43. 'Dorme la valle, di tenero bagliore / avvolta. [...] / Riposa. Che risorga / la fede nella luce di Dio. / Ehi, viaggiatore, fermati / e stanco della sera / bevi dall'alto calice, / la forza che ristora bevi. / [...] Stanchezza. Notte. Nella solitudine / tra nessuno vagano le ombre, tra nessuno le ombre vagano, / i pini cigolano esausti.'

Sul cliché del filosofo-errante nella ricezione della biografia skovorodiana, a discapito dei periodi più 'strutturati' dell'esistenza del filosofo settecentesco, cfr. Bartolini 2010: 28.

6 ZT I, 45-47. '[...] Sui sepolcri della steppa / è già apparso un raggio. D'oro. // [...] Nel cielo, come un raggio, alto si diffonde / sempre più in alto - dell'usignolo il canto.' 
L'irrequieta sete di conoscenza del filosofo settecentesco, e dell'io lirico che sembra perseguirne le tracce, si concretizza nella frequente ripetizione, a tratti quasi tautologica, del topos della strada, che sembra aprire all'ignoto di un universo soprannaturale:

Похмурі тіні нишком підійшли

До шляху — вже хвилюється дорога,

И прохолода розтає волога.

$[\ldots]$

Замріяно дорога майорить

І манить око, і за обрії вабить,

Де силует видніє. [...]

Al mito skovorodiano è legata anche un'altra lirica, dal titolo Skovoroda. Chvylevi treny ('Skovoroda. Lamenti momentanei'), in cui il tono romantico tra elegia e invettiva sostiene la tematica nazionale della schiavitù dell'Ucraina e della conseguente tragica necessità di lottare per la patria:

В коротких зойках стишеного болю,

В снах одержимого - в них має голубінь -

Нам не розкрить незнаність одкровінь,

Нам не спинить незнаності сваволю.

$[\ldots]$

Поміж народами ми лиш каріатиди.

Котрому предкові подяку воздаю?

$[\ldots]$

Коли ж збереться наше агора,

Скликаючи на прю, скликаючи до волі?

$[\ldots]^{8}$

L'aspetto più interessante di questi versi, probabilmente obsoleti per la sensibilità di un lettore europeo contemporaneo, risiede nella comparsa di due lessemi-motivi chiave dell'immaginario stusiano, che troveranno pieno sviluppo ed elaborazione nella poesia della maturità: bil' (dolore) e svavolja (arbitrio). Il primo, come in questo caso, molto spesso legato al motivo dell'urlo (zojk, kryk); il secondo in relazione al fato (dolja) e alla libertà (volja $)^{9}$.

7 Ibidem. 'Cupe ombre abbassatesi piano / sul cammino - già ondeggia la strada / e la frescura si disperde umida. // [...] Sognante appare la strada / e ammalia l'occhio, / lo invita all'orizzonte, / dove ecco una figura. [...]' Si noti la ripresa 'smorzata' del motivo delle ombre dalla lirica precedente.

8 Ivi: 52-53. 'Tra brevi urla di dolor smorzato, / Nei sogni d'un ossesso - lì è l'azzurro - / Non riveleremo le rivelazioni, / dell'ignoranza non fermerem l'arbitrio. / [...] Tra i popoli siam solo cariatidi. / A quale avo di ciò rendere grazie? / [...] Quando sarà per noi un'agorà, / a chiamare a lotta, a libertà? [...]'

$9 \quad$ Sull'importanza fondamentale di questi motivi nell'immaginario ševčenkiano, nonché sulla loro vastità semantica, si vedano rispettivamente Nachlik 2008 e Dzjuba 2008. 
Il titolo di questa lirica introduce inoltre il motivo di origine probabilmente goethiana dell'attimo ( $m y t$ ', più raramente chvylja, come in questo caso), molto frequente nel periodo giovanile della produzione di Stus. L'attimo è connotato ora positivamente, come fulminea esplosione di energia vitale e conoscitiva, ora, più spesso, negativamente, come metafora di fretta e immaturità infantili.

Si veda il netto contrasto tra questi due esempi:

Спіши пізнати мить! Енергії стебло

Вже затужавіло, прокляло, проросло.

Тож виплекай його, моя земля кохана,

Що покоління в болях пронесло -

$[\ldots]^{10}$

[...]

Хай гнів буя! Напевно так належить.

Його тремтливо-пристрасні вогні

Тобі окреслять молодечі дні

I мить, що губить, зраджує й бентежить ${ }^{11}$.

Sull'accostamento delle costanti tematiche del cammino, della strada, del dolore, dell'attimo e della patria è basata gran parte della poesia stusiana di orientamento romantico e patriottico di questo periodo. L'Ucraina è talvolta rappresentata per sineddoche, ma anche metaforicamente, come una strada da intraprendere:

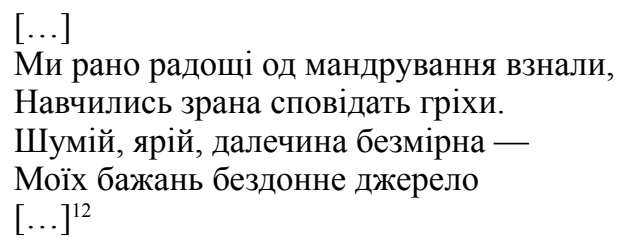

A questa impostazione stilistico-tematica sono riconducibili numerose altre liriche, unite dal motivo tradizionale della sofferenza dell'Ucraina in catene e della rabbia dell'io lirico per la propria impotenza nei confronti della patria oppressa.

Tra i primi testi della sezione è riportata una breve lirica di tonalità decisamente differente, per la quale è lecito supporre un sostrato pasternakiano e tyčyniano:

10 ZT I, 55. 'Corri a conoscere l'attimo! Il tronco della forza / è rigido, è secco, sta invecchiando. / Crescilo, terra mia amata, / che una generazione ha portato tra le doglie.'

11 Ivi: 63. 'Che la rabbia esploda! Così dev'essere. / I fuochi suoi tremanti di passione / designeranno i giorni giovanili / e l'attimo, che perde, tradisce e fa soffrire.'

12 Ivi: 55. 'Presto conoscemmo del vagabondar le gioie, / subito imparammo i peccati a confessare. / Risuona, infuria, o infinita lontananza - / dei desideri miei fonte senza fondo.' 
Ій-богу, добрий вітер!

Весна пливе у гомінких струмках,

Блищить и день, і ніч, і капелюх і дах.

Усе всміхається, підноситься, радіє...

Блажен, проживший вік, хто так і не уміє

читати мудрості скрижалі по складах ${ }^{13}$.

L'incontenibile vitalità della natura, messa in movimento da un vento gioiosamente inarrestabile di inconfondibile tyčyniana memoria, contagia anche i frutti del lavoro dell'uomo, come un cappello e un tetto, abolendo ogni distinzione tra le sfere non più opposte dell' 'alto' e del 'basso', così come tra il creato e i prodotti della creatività umana. Ciò risulta in piena sintonia con la concezione pasternakiana dell'unitarietà dell'universo in ogni sua manifestazione. La luminosità delle cose ne rende impossibile una piena, dunque limitante comprensione, lasciando il soggetto eternamente alla ricerca dell'inesauribile significato della vita.

Sebbene il peso di questa tendenza sia tra le poesie note come "versi giovanili" meno rilevante dal punto di vista puramente numerico del filone romanticopatriottico, non ne mancano ulteriori esempi:

В хаосі зглиблених світів,

Де вічна круговерть,

Нема неплинного в житті

$[\ldots]^{14}$

Tuttavia, il primaverile moto perpetuo delle cose, che nella lirica precedente era fonte di gioia ed euforia, è qui immediatamente identificato come "caos". Si noti la netta contrapposizione tra la beatitudine derivante dall'impossibilità di comprendere il mondo in Jij-bohu, dobryj viter! e l'angoscia dei "mondi interpretati" in questo caso. I versi successivi, che è necessario citare nella loro interezza, ben mostrano come il modello vitalistico pasternakiano e tyčyniano sia solamente una delle numerose componenti dell'universo lirico di Stus:

Неплинна тільки смерть.

В хаосі зглиблених світів, Де вічність - тільки тінь,

Котру уздрівши, ти хотів

Життя пізнать глибінь.

В хаосі зглиблених світів,

Ти тільки метеор,

Що в хвилі зринувсь і згорів

13 Ivi: 49. 'Eh sì, è buono il vento! / Nuota la primavera tra flutti fragorosi, / risplende il giorno, la notte, il cappello, il tetto. / Tutto sorride, s'innalza, è felice... / Beato chi, dopo lunga vita, non legge ancora / sillabando le tavole della saggezza.'

14 Ivi: 87. 'Nel caos dei mondi conosciuti, / dov'eterno è il vortice, / nient'è immobile sulla terra. [...]' 
В суворій тайні зорь.

І що в тій тайні - пізнать

Заказано тобі,

Дано нести важку печать

І зринути в ганьбі.

Тобі не чути одкровінь,

Коли у віщий час

Загомонить прадавня тлінь

I зрине порух, зрине рінь ${ }^{15}$.

Il valore dell'eternità è negato attraverso il suo accostamento all'ombra ${ }^{16}$, elemento inquietante, negazione dell'esistenza e del movimento, a cui l'io lirico reagisce con un impeto gnoseologico che sarà frustrato. Nella fusione tipicamente stusiana dei poli del tu e dell'io, che si rivelerà un elemento centrale del suo universo poetico simultaneamente dialogico e monologico, il soggetto è ontologicamente impossibilitato all'azione conoscitiva. Non può conoscere, non può crescere, non può né vivere, né risorgere dalla sua "vita-in-morte", come dirà in seguito l'io lirico stusiano maturo degli anni Settanta. Inizia a profilarsi in questi versi con inattesa chiarezza lo Stus ermetico di Čas tvorčosti / Dichtenszeit e Palimpsesty, che convive qui con una varietà di riferimenti e modelli letterari più ampia che nei periodi successivi.

Sembrano potersi identificare in questa lirica i germi del precoce dialogo di Stus con alcuni dei poeti che maggiormente lo avrebbero accompagnato nei due decenni a venire: Pasternak, come si è visto, Rilke e Cvetaeva. I mondi conosciuti e conoscibili che aprono le prime tre quartine paiono alludere apertamente a due notissimi versi della prima delle Duineser Elegien rilkiane: "dass wir nicht sehr zu Haus sind / in der gedeuteten Welt" ${ }^{17}$. La meteora del decimo verso, invece, potrebbe costituire un rimando alla cometa della prima lirica del trittico cvetaeviano Poety ${ }^{18}$, anche in virtù del fatto che l'io lirico di $V$ chaosi zhlyblenych svitiv raffigura se stesso indubbiamente nelle vesti di un poeta:

15 Ibidem. 'Immobile è solo la morte. / Nel caos dei mondi conosciuti, / l'eternità è solo un'ombra, / dopo averla vista, tu volevi / della vita conoscere il profondo. / Nel caos dei mondi conosciuti / sei solo una meteora, / in un istante apparsa e bruciata / nel mistero profondo delle stelle. / $\mathrm{E}$ in quel mistero - conoscere / ti è proibito, / devi portare grave il marchio / e incedere nell'onta. / Non udirai rivelazioni, / nel momento in cui / le antiche ceneri parleranno, / ed ecco muoversi, ed ecco la pietra'.

16 Sulla connotazione negativa dell'eternità (vičnist') come cattiva infinità nella lirica stusiana, in contrapposizione alla gloria dell'immortalità, cfr. Babenko 2006: 41.

17 Rilke 1996: II, 201. 'che non ci sentiamo molto a casa / nel mondo interpretato.' Sulla gedeutete Welt rilkiana si veda Walisch 2012.

18 Su Poety si vedano Hasty 1996: 110-133 e Bartolini 2005. Per una prima ed evidente rielaborazione del trittico cvetaeviano nella poesia ucraino si veda il sonetto Meteor ('Meteora') di Bohdan-Ihor Antonyč, dalla prima raccolta del poeta galiziano, uscita nel 1931, dunque circa otto anni dopo la scrittura della lirica di Marina Cvetaeva. Si veda Antonyč 2012: 49: ““Де батьківщина, де твоя, скажи. / Якої син планети чи комети, / які твій лет міжсвітній має мети, / де перед мандрами давніш ти жив? // 
$[\ldots]$

Ибо путь комет - поэтов путь.

Развеянные звенья

причинности - вот связь его!

$[\ldots]^{19}$

Tuttavia, è evidente come la potente cometa modernista del poeta di Marina Cvetaeva si sia postmodernamente frantumata per cadere sulla terra sotto forma di meteora, perdendo la capacità di cogliere il mistero. Comincia così a delinearsi la complessa poetologia stusiana, lacerata tra i richiami modernisti all'onniscenza del poeta, la tradizione romantica patria del bardo in grado di indicare al popolo il cammino da compiere verso la resurrezione spirituale e nazionale e la postmoderna disgregazione di entrambi i miti. Significativa è la rima tra odkrovin' e tlin', rivelazioni da una parte, ceneri mortuarie e decomposizione dall'altra, nonché il rimando del secondo termine all'ombra, tin', come si è già avuto modo di osservare vera e propria ossessione espressionista dell'immaginario stusiano. Rimane da comprendere la vera natura dell'incapacità di comprendere che affligge l'io lirico, a cui è vietata la penetrazione nel mistero. Non è chiaro, infatti, se la causa di questa proibizione sia storica, momentanea o intrinseca, ontologica. L'ambiguità fra nichilismo assoluto e invettiva contro le catene del presente storico sarebbe rimasta una caratteristica costante dell'universo poetico di Stus, di cui questa lirica si rivela un primo, forse inaspettato gioiello. Il dialogo con il trittico Poety di Marina Cvetaeva sembra inoltre proseguire nella raffigurazione dell'io lirico oppresso dal marchio della vergogna per la propria inettitudine. Tuttavia, rispetto all'ipotetico modello cvetaeviano la prospettiva appare anche in questo caso capovolta. Il poeta non è più un reietto della società ${ }^{20}$, nel senso che non è su questo che si focalizza la lirica: il poeta è tragicamente colpevole nei confronti di se stesso e della propria vocazione. Non sa, non può essere né profeta né conoscitore ed è dunque condannato alla sofferenza. L'ambiguità della conclusione della liri-

\footnotetext{
Міжзірний волокито та бродяго, / в безкраю безвість пущений в крутіж, / сліпучий, ярий спижу, що гориш / на вежі світа полум'яним стягом. // Незбагнений в рахунку астрономів, / уроджений в височині німій, / навіщо в низині шукаєш дому, // на власнім гробі кам'яна статує?' / - ‘Поете, не журись. Упадок мій / жар мого серця від зими врятує'." “'Dov'è la patria tua, dillo, dov'è? / Di che pianeta o cometa sei figlio, / che fini ha il volo tuo tra i mondi, / prima dei viaggi tuoi dove vivevi? // Barbone e vagabondo interstellare, / nell'ignoto dell'infinito in vortice, / bronzo accecante, che splendi rilucente / sulla torre del mondo vessillo di fiamma. // Incompreso nei conti degli astronomi, / nato nel silenzio delle altezze, / perché tu cerchi casa quaggiù in basso, // $\mathrm{o}$ statua di pietra sulla stessa tua tomba?"" / - "Poeta, non c'è da star tristi. Cadendo / io salvo dal gelo il caldo del cuore."'

19 Cvetaeva 2004: 607-608.

20 Ivi: 609: “Что же мне делать, слепцу и пасынку, / В мире, где каждый и отч и зряч."
} 
ca, nella quale sembra delinearsi la possibilità di una rinascita, non lascia comunque profilarsi alcuna speranza per l'io lirico, solipsisticamente rinchiuso nel labirinto di una ricerca senza sbocchi.

Il ripensamento del paradigma vitalistico pasternakiano, dal quale abbiamo preso le mosse per l'analisi di V chaosi zhlyblenych svitiv, sembra caratterizzare anche un altro breve componimento, tra gli ultimi dei versi giovanili che compongono la sezione in proposito:

Серце - не губка. Його не вижмеш.

Тільки - тільки не вірш.

Буває гірше -

Кров'ю напишеш,

А вірша не вийшло,

Збляк той вірш ${ }^{21}$.

Il riferimento al primo componimento del trittico Vesna, contenuto in Poverch bar'erov, oltre che al noto episodio della scrittura della sua ultima lirica con il sangue da parte di Sergej Esenin prossimo al suicidio, è evidente:

Поэзия! Греческой губкой в присосках

Будь ты, и меж зелени клейкой

Тебя б положил я на мокрую доску

Зеленой садовой скамейки.

Расти себе пышные брыжжи и фижмы,

Вбирай облака и овраги,

А ночью, поэзия, я тебя выжму

Во здравие жадной бумаги ${ }^{22}$.

L'opacità semantica dell'intera lirica, costruita su di una contraddittoria auto-negazione tra la prima parte e la seconda, non può non essere letta nei termini di un ripensamento della concezione pasternakiana del poeta e della poesia. Se il futuro autore di Doktor Živago fa di questi versi un manifesto sulla poesia come assorbimento e riproposizione della realtà nella sua estenuante vorticosità $^{23}$, Stus affida al proprio io lirico il compito di negare sostanzialmente il valore conoscitivo e auto-conoscitivo della poesia. Le difficoltà interpretative legate alla lettura del secondo verso, nel quale la poesia sembra riferirsi sia al cuore, che alla spugna, vengono ulteriormente complicate dall'identificazione al quar-

21 ZT I, 127. 'Il cuore - non è una spugna. Non lo strizzi. / Solo - solo non il verso. / C'è di peggio - / Scrivi col sangue, / ma il verso non viene, / è sbiadito il verso.'

22 Pasternak 2003-2005: I, 90. Si veda anche dallo scritto giovanile Neskol'ko položenij (1918, 1922): “Современные течения вообразили, что искусство как фонтан, тогда как оно - губка. Они решили, что искусство должно бить, тогда как оно должно всасывать и насыщаться." (Pasternak 2003-2005: V, 24).

23 Sulla lirica poetologica e metapoetica pasternakiana si vedano Erlich 1959, Zelinsky 1974, Zelinsky 1975 e Gorelik 2011. 
to verso tra la scrittura e il sangue, a sua volta riconducibile al cuore del primo verso. Come nel caso del dialogo polemico con il ciclo cvetaeviano Poety, si ha a che fare anche qui con il rifiuto da parte dell'io lirico stusiano della figura onnipotente del poeta centrale all'estetica modernista che quest'ultima aveva ereditato dalla tradizione precedente, quella romantica in primo luogo. Tuttavia, l'elemento più interessante di questo aspetto della poesia giovanile di Stus è la sua intrinseca contraddittorietà con l'effettiva pratica poetica stusiana dai tardi anni Cinquanta fino alla fine degli anni Settanta, nella quale una concezione 'forte' del poeta e della sua pratica risultano oggettivamente innegabili, mettendo in evidenza quella lotta intestina tra impostazione modernista e tensioni postmoderne così tipica dell'arte stusiana. Ritornando al dialogo poetico con Pasternak, si può presumere che l'immagine della scrittura con il sangue possa essere letta come un'ulteriore polemica con il poeta russo e la sua carriera letteraria sovietica, probabilmente contrapposta alle perdite, gli esili e gli abbandoni sofferti dalla letteratura ucraina. In generale, traspare da questi versi una negazione del modello pasternakiano letto in chiave romantica, in chiara contrapposizione al rifiuto del romanticismo dello stesso Pasternak, espresso sia a livello teorico come dichiarazione di poetica, che nella poesia stessa ${ }^{24}$. Infine, è il caso di ribadire ulteriormente il carattere paradossale di questa lirica nel suo complesso, inquadrabile nell'ampia tradizione otto-novecentesca della poesia che nega se stessa a livello tematico, svolgendosi concretamente intorno al tema della negazione di sé25. Tipica di questa tendenza sembra essere una forte musicalità diretta verso un'accentuazione del significante a scapito del significato assolutamente coerente con la tematica in questione. Si noti in questi versi, inoltre, il potere quasi ipnotico della ripetizione delle fricative sibilanti.

Il dialogo 'critico' con Pasternak sembra permeare anche un'altra lirica di questa sezione, votata a un poco convincente inno nichilistico all'abbandono del sé e della propria vocazione:

24 Si veda un noto brano della prima autobiografia pasternakiana Ochrannaja gramota, in: Pasternak 2003-2005: III, 226: “Время и общность влияний роднили меня с Маяковским. У нас имелись совпаденья. [...] От их пошлости его надо было уберечь. Не умея назвать этого, я решил отказаться от того, что к ним приводило. Я отказался от романтической манеры. Так получилась неромантическая поэтика 'Поверх барьеров'. Но над романтической манерой, которую я отныне возбранял себе, крылось целое мировосприятье. Это было понимание жизни как жизни поэта." Sul complesso romanticismo pasternakiano si vedano France 1979 e Djurčinov 1979. Si ricordi il "non-romanticismo" dell'atteggiamento dell'io lirico in Složa vesla, una delle poesie più celebri della pasternakiana Sestra moja - žizn', in: Pasternak 2003-2005: I, 127: “Лодка колотится в сонной груди, / Ивы нависли, целуют в ключицы, / В локти, в уключицы - о погоди, / Это ведь может со всяким случиься!"

25 Si pensi alle evocazioni dell'inesprimibile e del silenzio frequenti e fondamentali nella storia della lirica russa, da Žukovskij (Nevyrazimoe) a Tjutčev (Silentium!) sino almeno a Mandel'štam (Silentium). 
[...] Я думав в житті поєднати прозорість ясного неба

3 душею разом. Та хмари над світлим чолом зійшлись.

Кінчилося. Вийшло. Доста. Віри уже не треба.

Не треба тривожить спогадів.

Спочинь. Забудься. Спинись ${ }^{26}$.

La serie di imperativi che corona la lirica è un'eloquente manifestazione del ripiegamento del soggetto su se stesso tipico della poesia stusiana, che avrebbe trovato piena espansione nella fase matura. L'incapacità di unire il cielo e l'anima è nuovamente interpretabile nei termini di un rifiuto del modello pasternakiano, basato sulla fusione tra il soggetto e la realtà circostante, qui agognata, inizialmente creduta possibile, forse in passato sfiorata, ma nel presente non realizzabile. La discesa delle nuvole sulla candida fronte del soggetto è invece un timido esempio di quella imagery espressionista sempre più pervasiva nelle poesie giovanili e in seguito nelle fasi più tarde della lirica di Stus. Si veda dalla poesia che in $Z T$ segue il testo appena discusso:

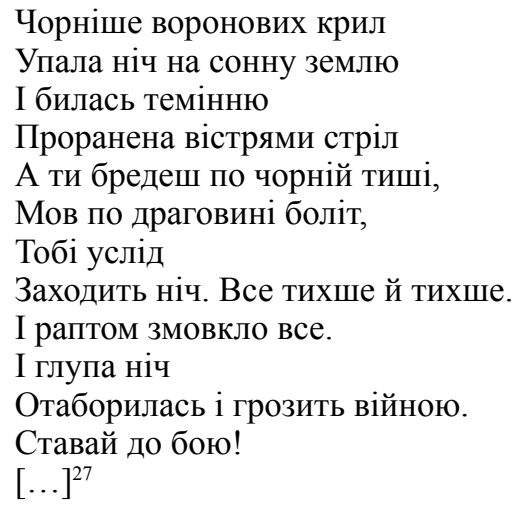

L'inquietante scenario notturno, interamente giocato sulle variazioni cromatiche del nero e sulle gradazioni acustiche del silenzio, segnato dall'incombente minaccia di guerra e morte, testimonia della presenza di un filone espressionista nella tavolozza stilistico-tematica del giovane Stus, destinata, come si vedrà, a svilupparsi nelle raccolte degli anni successivi ${ }^{28}$.

Numerosi sono gli esempi di questo repertorio di immagini:

26 ZT I, 130. 'Pensavo nella vita di unire la trasparenza del cielo chiaro / insieme all'anima. Le nuvole scesero sulla fronte lucente. / È finito. È andato. Basta. Non serve più la fede. / Non serve agitare i ricordi. / Riposa. Dimentica. Arrestati.'

27 Ivi: 131. 'Più nera delle ali corvine / è calata la notte sulla terra / e ha sbattuto con l'oscurità / ferita dalle punte delle frecce. / E tu vaghi nel silenzio nero, / come in un pantano di paludi, / dietro di te / viene la notte. / Sempre più piano. / Di colpo tutto tace. / Stupida la notte / si è accampata e minaccia la guerra. / Scendi in battaglia! / [...]'

28 Sul carattere intrinsecamente espressionista di un'imagery di questo tipo cfr. Schneider 1961: 12. 


\section{[...] А ніч протарашить тишу \\ Зойком чи схлипом \\ I думи кошлаті вишикує, \\ Обхлюпа й одхлине... \\ О божевілля, живлене \\ Сонцем! Снігом! \\ [...] раптом вирветься \\ Червоним осонням, \\ Червоною стрічкою мітяться \\ Кола агоній ${ }^{29}$.}

La passività del soggetto schiacciato dalla notte, la descrizione sinestetica della sua potenza, l'invocazione alla follia, l'insistenza anaforica sul colore rosso e la raffigurazione finale dell'agonia, che occupa quindi i trenta versi conclusivi della lirica, sono elementi univocamente accostabili alla sensibilità espressionista ${ }^{30}$.

$\mathrm{Nel}$ contesto ucraino dello šistdesjatnyctvo, il retaggio espressionista può tingersi di venature marcatamente romantiche, rendendo versi come "Stavaj do boju" passibili di una doppia lettura: in chiave 'puramente' espressionista, da una parte, e come esortazione di spirito romantico-patriottico, dall'altra. Come già osservato, queste due componenti del patrimonio culturale stusiano sono spesso inscindibili tra loro, soprattutto nella fase giovanile in esame. Si veda, ad esempio, un altro frammento:

[...] Напевно, має бути,

Щоб день змінився і загусла ніч,

I $з$ мороку тривожних протиріч

Ти поставав, стражданнями розкутий ${ }^{31}$.

Qui il lessico e il repertorio di immagini di stampo espressionista sono chiaramente subordinati alla concezione romantica del poeta liberatore, in piena contraddizione con i versi 'antipasternakiani' e 'antiromantici' di [V chaosi

${ }^{29}$ ZT I, 111. '[...] E la notte a colpi porterà il silenzio / con un urlo o con un singulto / e i pensieri arruffati porrà in fila, / infradicerà e scaraventerà... / Oh follia, nutrita / di sole! di neve! / [...] all'improvviso si spezzerà / alla luce rossa del sole, / come una striscia rossa / punteranno i cerchi delle agonie.'

30 Si veda l'accostamento dei motivi del rosso della sera, dell'angoscia, dell'avanzare della notte e della malattia nella prima e nell'ultima strofa di Der Gewitterabend ('La sera del temporale') di Georg Trakl, in: Trakl 2012: 17: "O die roten Abendstunden! / Flimmernd schwankt am offenen Fenster / Weinlaub wirr ins Blau gewunden. / Drinnen nisten Angstgespenster. // [...] // Kranken kreischen im Spitale, / Bläulich schwirrt der Nacht Gefieder. / Glitzernd braust mit einem Male / Regen auf die Dächer nieder." 'O le rosse ore della sera! / Tremolano alla finestra / I tralci intrecciati nel blu. / Dentro ad essi i fantasmi dell'ansia. // [...] // Strillano i malati all'ospedale, / Bluastre frusciano le piume della notte. / Scroscia luccicante all'improvviso / La pioggia giù sui tetti.'

31 ZT I, 115. 'Sicuramente, così dev'essere, / che il giorno cambi e s'addensi la notte, / e dal buio d'angosciose contraddizioni / tu ti alzi, dai dolori liberato.' 
zhlyblenych svitiv] e [Serce - ne hubka. Joho ne vyžmeš]. Una raffigurazione romantica del poeta si riscontra anche in altre liriche di questo periodo, non particolarmente interessanti dal punto di vista estetico, ma decisamente significative per la ricostruzione del complesso ritratto letterario del giovane Stus. Se ne vadano due esempi ben rappresentativi:

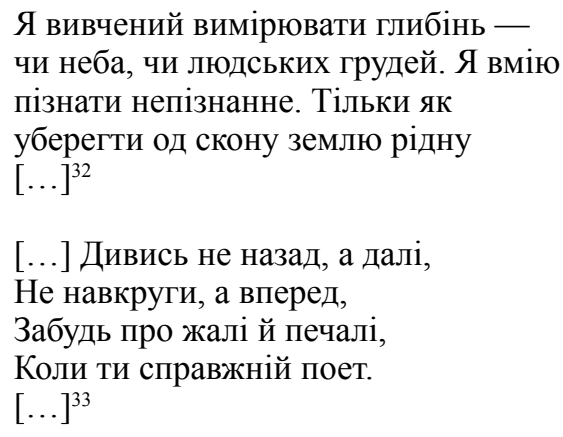

In connessione con la tematica patriottica, il poeta può 'romanticamente' assurgere a vate, (ri)conquistando la capacità di penetrare nelle profondità dell'animo umano e dell'universo. Il vero poeta è ora un deciso e pragmatico combattente immerso nel concreto della realtà storica del suo tempo e, contemporaneamente, una mitica figura in grado di ergersi al di là degli angusti limiti delle possibilità umane.

L'accostamento di una poetologia tradizionale, incentrata sull'(auto)esaltazione del cantore e del potere rigeneratore della parola, a un moderno e ancora più postmoderno ridimensionamento di questo paradigma mitico si inserisce pienamente nel carattere binario dell'universo poetico stusiano, costantemente segnato da contraddittorie rappresentazioni del sé e del suo rapporto con la realtà. La versatilità del linguaggio del primo Stus, d'altro canto, testimonia della sua indubbia precoce maturità artistica, della sua instancabile volontà di sperimentare con linguaggi molto diversi tra loro per poterli pienamente assimilare, nonché, con uno sguardo in avanti alla sua evoluzione poetica, della presenza in nuce di quasi tutti gli elementi centrali alla sua lirica delle raccolte che ne avrebbero in seguito decretato la grandezza.

\section{Delo №13 / BE1339}

Il titolo Delo №13/BE1339 si riferisce originariamente a una raccolta dei migliori versi dell'anno 1962, edita autonomamente dall'autore in samizdat. L'i-

32 Ivi: 91 . 'So misurare le profondità - / del cielo, del cuore dell'uomo. So / conoscere l'inconoscibile. Solo come / salvare dalla fine la mia terra. / [...]'

33 Ivi: 113. 'Guarda avanti, non indietro, / non intorno, sempre dritto, / dolore e tristezza dimentica / se sei un vero poeta.' 
ronico nome della fittizia casa editrice dell'opera è Sampyšsamčyt ('Scrivituleggitu'), alquanto rappresentativo della situazione letteraria del giovane Stus, in questo momento, come osservato dal figlio Dmytro, "massimamente scontento delle sue condizioni di vita" (Stus 2005: 134). Secondo lo studioso, "la mancata accettazione delle sue opere da parte degli scrittori più anziani, tradottasi in varie sconfitte letterarie, legati ai suoi esperimenti con la forma, rese Stus ermetico, costringendolo a nascondersi dal mondo e a chiudersi nel proprio guscio"34. Nei tre anni successivi Stus avrebbe ampliato la raccolta, venticinque liriche della quale sarebbero state incluse nel 1963 nell'esperimento seguente, Kruhovert'. ZT presenta quindici poesie, composte tra il 1958 e il 1965.

La tematica nazionale è fondamentale in questo gruppo di liriche. Si veda, nella sua interezza, la prima, incentrata sulla rappresentazione del rapporto tra l'io lirico e la realtà a lui circostante, inconfondibilmente connotata in senso nazionale:

Стольний граде!

Стволовий надрізе!

Ліхтарі як спалахи ракет.

Зібгана душа спішить урізатись

На мосту Патона - в парапет.

Спить - не спить Дніпро, завжди гостинний,

Зречена душа - без крил — летить

За биками, за човнами и за кпинами...

Свій пролитий полишае слід.

Не сльозою зійде - а фонтаном

Над водою. Не сльозою, сплеском,

Мов бар'єром від життя віддалена.

Ця, остання - 3 крутояру стежка.

Ніг нема. Ні рук. Одні долоні.

Лишь долоні голі - замість рук.

У нічні, зазорені холодні

Хвилі - так, як по дощі на брук.

Стольний граде! Стволовий надрізе!

3 мосту в воду - кулі не жалять.

Бо на власний зойк ребром нанижуться,

Заковтнувнши хвилю, наче кляп ${ }^{35}$.

34 Ibidem. Cfr. anche ZT I, 516.

35 Ivi: 139. 'Capitale! Ritaglio di fucile! / I lampioni - come lampi di un missile. / L'anima piegata corre a sbattere / sul ponte di Paton - sul parapetto. // Dorme - non dorme lo Dnipro, sempre amico, / l'anima ferita - senz'ali - vola / oltre piedritti, barche, derisioni... / seminata qua e là la propria traccia lascia. // Non come lacrima scenderà come fontana / sopra l'acqua. Non come lacrima - come zampillo, / come da una barriera dalla vita separata. / Questo, ultimo - ripido sentiero. // Niente gambe. Né mani. Solo palmi. / Solo palmi nudi - invece di mani. / Nelle notturne, sospette, fredde / onde - così, come dopo la pioggia lo sterrato. / Capitale! Ritaglio di fucile! / Dal ponte nell'acqua - 
Molto ampia è la gamma di spunti stilistici e tematici di questa lirica. Riprendendo alcuni motivi tradizionali, come la potenza di Kiev e la fraternità dei suoi abitanti con lo Dnipro, questi versi ricompongono elementi consueti dell'immaginario ucraino in un disegno prettamente moderno e modernistico. La dissonanza tra l'io lirico e la realtà penetra all'interno dell'io lirico stesso, privato della corporalità e ridotto a pura anima. Quest'ultima appare a sua volta paradossalmente de-materializzata, priva delle ali che la contraddistinguono, ma ugualmente capace di spiccare il volo, di allontanarsi dalla materialità di un mondo a lei ostile, identificabile sia nell'Ucraina sovietica del tardo Disgelo, che nella condition humaine in assoluto. Dopo le altisonanti, contemporaneamente settecentesche e futuristiche esclamazioni del primo verso, di chiara matrice avanguardista è il secondo, mentre il terzo è riconducibile a una sensibilità nuovamente espressionista. La seconda quartina potrebbe invece alludere al Son (Sogno) ševčenkiano, in cui l'io lirico sogna di volare sopra l'Ucraina e altre regioni dell'Impero osservandone la desolante realtà ${ }^{36}$. La lacrima del decimo e dell'undicesimo verso, così come il distacco dell'anima dall'interezza dell'io, sono altrettanto accostabili all'imprescindibile modello ševčenkiano ${ }^{37}$. Allo stesso tempo, l'immagine dello sradicamento dell'anima dal corpo e del suo totale assottigliamento è altresì accostabile all'universo poetico di Marina Cvetaeva. In Poema Vozducha del 1927 l'io lirico cvetaeviano compie un percorso di progressiva liberazione dalle catene della corporalità e dell'attaccamento alla terra ${ }^{38}$ che si riverbera nel testo stusiano, radicalizzandosi, nella riduzione del "corpo dell'anima" a puro palmo. Nella strofa finale una imagery nuovamente avanguardistica chiude una lirica, come si è vista, straordinariamente densa di ispirazioni, venature stilistiche e spunti te-

le pallottole non pungono. / Al proprio grido la costola infileranno, / inghiottita l'onda, come un bavaglio.'

36 Ševčenko 2003: I, 267: “Лечу и прощаюся з землею: / Прощай світе, прощай, земле, / неприязний краю, / Мої муки, мої люті / В хмарі заховаю. / А ти, моя Україно, / Безталанна вдово, / Я до тебе літатиму / 3 хмари на розмову.” Si veda dalla traduzione di Giovanna Brogi e Oxana Pachlovska, in: Brogi, Pachlovska 2015: 197: "E io volo dietro a lei, sempre dietro / Volo e dalla terra mi congedo. / Addio mondo, addio terra, / Paese ostile, / I miei tormenti, i miei mali / In una nuvola nascondo. / E tu, mia Ucraina, / Vedova infelice, / da te io volerò / per parlarti dalla nuvola."

37 Ševčenko 2003: I, 268: “Душе моя убогая, / Чого марне плачеш? / Чого тобі шкода? Хіба ти не бачиш? / Хіба ти не чуєш людського плачу? / то глянь, подивися; а я полечу / Високо, високо, за синії хмари." Brogi, Pachlovska 2015: 197: "Povera anima mia, / Perché tal pianto vano, / Che mai tanto t'angoscia? Non vedi forse, / Forse non senti degli uomini il pianto? / Ascolta e guarda ancora - e io volerò / In alto, oltre le nuvole azzurre."

38 Cvetaeva 1990: 579: “Слава тебе, допустившему бреши: / Больше не вешу. / Слава тебе, обвалившему крышу: Больше не слышу. / Солнцепричастная, больше не щурюсь. / Дух - не дышу уж! / Твердое тело есть мертвое тело, / Оттяготело." Su Poema Vozducha si veda Gasparov 1995. Si noti come Poema Vozducha non sia presente nelle prime due selezioni di liriche e poemi di Marina Cvetaeva edite in Unione Sovietica, rispettivamente nel 1961 e nel 1965. Sulla "fuga dalla terra" dell'io lirico cvetaeviano si veda inoltre Vitins 1977. 
matici, ottima esemplificazione della ricchezza del palinsesto poetico stusiano. Si noti inoltre come anche in [Stol'nyj hrade! Stvolovyj nadrize!] sia evidente un profondo strato semantico poetologico: allontanandosi dalla terra il soggetto è in grado di lasciare sulla superficie di quest'ultima una traccia concreta di se stesso (“Свій пролитий пролишає слід”), ossia nient'altro che la propria parola poetica.

Ben diversa risulta la seconda lirica del ciclo, dal titolo Z cycklu "Umovyvo$d y$ " ('Dal ciclo "Deduzioni"'). Se il nucleo concettuale rimane quello della riflessione lirica sui rapporti tra il soggetto e la realtà, la risposta che il soggetto stesso sembra qui dare è quella di una sostanziale adesione alla realtà, in evidente opposizione al suo rifiuto nella poesia precedente:

Що таке білий світ?

$[\ldots]$, то що таке людськість?

Хіба це не ти і я?

Хіба це не таємниче ми

(завжди більше за нас обох, це ж бо колодязь вічності).

А коли так, коли людськість — це величезне ми, то що тоді я в цім світі?

Хіба це не земля, не зорі, не далекі галактики, хіба це не мій народ, не рідне моє Поділля, не коханий Донбас, [...] СВІТ - ЛЮДСТВО - ЛЮДИНА ЛЮДИНА, ЛЮДСТВО - СВІТ хіба не в цій коловерті висока мудрість сущого на землі? ${ }^{39}$

In versi per i quali la problematica definizione di poesia filosofica è direttamente proposta dal titolo della lirica stessa, marcata da un uso intensivo dei parallelismi sintattici e dal carattere spiccatamente colloquiale del registro linguistico, forse discordante con l'impianto generale del componimento, la risposta dell'io lirico alla domanda sulla possibilità di un'intesa tra lui stesso, il noi e il tutto sembra essere positiva. Tra il singolo, la collettività e la natura stessa della loro esistenza esiste un'armonia di fondo, seppur definita nei termini di un "turbine". Gli stereotipi nazionali mostrano un'Ucraina solida e unita, di cui l'io lirico, qui innegabilmente modellato sull'autore, coglie e incarna l'unitarietà al di là delle

39 ZT I, 140-141. 'Cos'è il mondo? / [...], ma allora cos'è 1'umanità? / Non siamo forse io e te? / Non è forse quel misterioso noi / (sempre più di me e di te, / è il pozzo dell'eternità). / E se è così, / se l'umanità è un enorme noi, / ma allora cosa sono io in questo mondo? / Non è forse la terra, / le stelle, le galassie lontane, / non è forse il mio popolo, / il mio natio Podillja, / l'amato Donbas, / [...] IL MONDO - L'UMANITÀ - LA PERSONA - / LA PERSONA - L'UMANITÀ - IL MONDO - / non è forse in questo turbine / la grande saggezza di ciò che esiste sulla terra?' 
apparenti differenze culturali tra occidente e oriente del paese. Che questi versi possano apparire 'stridenti' nel panorama generale della poesia stusiana - o dei suoi momenti più noti - è evidente. D'altro canto la loro tonalità ingenua, colloquiale, a tratti esaltata è un elemento tipico di numerosi versi di questa raccolta, all'interno della quale l'elemento ermetico-espressionista individuato nei versi giovanili e in seguito tratto distintivo dello Stus maturo cede di frequente il passo a un linguaggio poetico più consonante al gusto di šistdesjatnyky 'canonici' come Vasyl' Symonenko e Mykola Vinhranovs'kyj ${ }^{40}$.

Si veda a questo proposito il bozzetto Kyjivs'kjy žebrak ('Un mendicante di Kiev') del 1963:

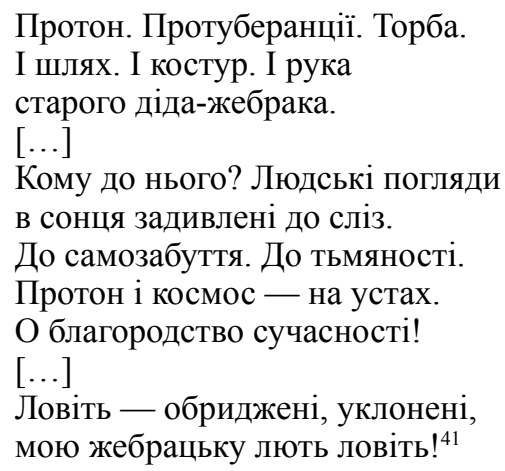

Il futuro autore di Palimpsesty si mostra qui perfettamente consono alla moda del suo tempo, con una poesia ardita sia dal punto di vista tematico, sia per quanto riguarda la sperimentazione linguistica. La critica alla realtà contemporanea che emerge da questi versi è espressa in un linguaggio aspro, ruvido, basato sull'accostamento di campi semantici e piani lessicali ben distanti tra loro. In questo Kyjivs'kyj žebrak rappresenta un contributo stusiano alla poetica più diffusa nello šistdesjatnyctvo non solo ucraino, mostrando una delle numerose strade che che il giovane Stus avrebbe potuto intraprendere. Inoltre, nelle poco numerose prove dell' autore principiante con il linguaggio poetico predominante nel suo tempo, è anche lecito ipotizzare un'altra forma di confronto con il modello pasternakiano, indubbiamente presente nella poetica della lirica innovatrice degli

40 Si veda una simile organica fusione dell'individuo, nonché del poeta, con il popolo e la terra nella lirica giovanile di Mykola Vinhranovs'kyj, in Vinhranovs'kyj 2013: 131: “Нi! Цей народ із крові і землі / Я не віддам нікому і нізащо! / Він мій, він я, він - світ в моїм чолі, / Тому життя його і ймення не пропащі!” 'No! Questo popolo di sangue e terra / Non lascerò per nulla e per nessuno! / Lui è mio, è me, è la luce che ho sulla fronte, / Per questo la sua vita e il suo nome sono eterni!'

${ }^{41}$ ZT I, 148. 'Un protone. Protuberanze. Una borsa. / E il cammino. Un bastone. E la mano / di un vecchio nonno poveretto. / [...] A ch'importa di lui? Gli sguardi umani / guardano il cielo fino alle lacrime. / Si dimenticano di sé. Fino alle tenebre. / Un protone e il cosmo - sulle labbra. / Oh, la nobiltà del giorno d'oggi! / [...] Prendete - offesi, piegati, / la mia ira di povero prendete!' 
anni Sessanta. Nell'utilizzo di parole 'esotiche' come proton e protuberanciji di fianco a termini della sfera quotidiana come torba (borsa) è evidente la lezione avanguardista probabilmente filtrata attraverso il prisma pasternakiano, autore naturalmente attuale per tutta la poesia sovietica negli anni prima, dopo e durante il Disgelo. Lo stesso si può dire per la disposizione del protone e del cosmo intero sulle labbra (dei passanti? del mendicante? del poeta?) nella parte centrale della lirica. Allo stesso tempo, il paradigma romantico non manca di plasmare la conclusione del bozzetto urbano, mostrando, ancora una volta, il grande interesse della poesia stusiana giovanile dal punto di vista storico-letterario al di là del valore estetico più o meno marcato del singolo componimento.

Come già accennato, la tematica nazionale occupa un ruolo di primo piano nell'immaginario di Delo №13. Il motivo ševčenkiano dell'amore e odio per l’Ucraina, incapace di riconquistare il diritto a essere se stessa, è molto produttivo in questa fase $\mathrm{e}$ sarà destinato a non abbandonare la poesia stusiana fino alle vette di Palimpsesty. Si veda dalla lirica che in ZT conclude la breve raccolta (1961-1964):

Немало люблячих тебе, народе мій!

А я не можу й слова проронити,

А я не можу підійти и звіритись.

Освідчуватися не вмію. [... $]^{42}$

Il tono probabilmente ironico di questa quartina convive agevolmente con gli strali romantici di una lirica contemporanea ormai antologica, in quanto alcune sue parti saranno recuperate in Palimpsesty:

О краю мій, коли тобі проститься

крик передсмертний і важка сльоза

розстріляних, замучених, забитих

по соловках, сибірах, магаданах ${ }^{43}$

Il ridondante pathos civile di questo incipit segna la lunga lirica fino alla sua conclusione:

[...] Гірко

3 сльозами на очах радіть нащадкам, які колись очистяться од скверни і злочинів, у світі найстрашніших: вбивати правду — правдою ${ }^{44}$.

42 Ivi: 159 . 'Non pochi ti amano, popolo mio! / Ma io non riesco a dire una parola, / non posso avvicinarmi e confidarmi. / Non so dichiararmi.'

43 Ivi: 152. 'Paese mio, quando ti saranno perdonati / il grido di morte e la lacrima grave / dei fucilati, torturati, uccisi / in solovki, siberie, magadan?'

44 Ibidem. 'Amaro / con le lacrime agli occhi gioir dei discendenti, / che un giorno saran dall'obbrobrio puliti / e dalle infamie, al mondo le peggiori: / la verità - con la verità uccidere.' 
È forse lecito leggere questi versi così apparentemente 'inattuali' come un esercizio poetico sul "millenarismo" ševčenkiano (cfr. Grabowicz 1982: 123), riconoscendo in quest'ultimo un punto di riferimento imprescindibile per la poesia ucraina almeno fino agli anni Sessanta e Settanta. Ciò non singifica, tuttavia identificare Stus come un novello Ševčenko novecentesco, come non di rado accade nella critica ucraina. Al contrario, questa tendenza della sua lirica risulta essere 'solamente' un importante tassello del variopinto mosaico di ispirazioni e punti di riferimento che il giovane Stus, più o meno consapevolmente, ora forse per inerzia, ora per volontà sperimentatrice sceglie per sé nella costruzione del proprio percorso artistico. Soltanto in questi termini si può spiegare l'accostamento così apparentemente sorprendente di fonti ben distanti nel dipanarsi del suo linguaggio poetico, in particolare per quanto riguarda il periodo giovanile.

Non troverebbe altre spiegazioni la vicinanza cronologica altrimenti paradossale di liriche come O kraju mij, koly tobi prostyt’sja e Pljaž na mori:

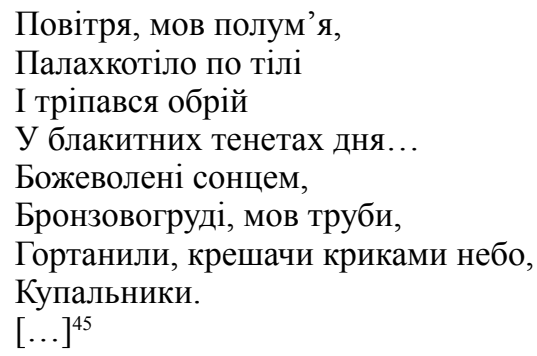

È evidente come nella sensibilità poetica e negli interessi letterari del giovane Stus nei primi anni kieviani, il periodo in cui il poeta ormai non più principiante era anche un dottorando dell'Istituto di Letteratura dell'Accademia delle Scienze, la sperimentazione sul linguaggio delle avanguardie non escluda la riproposizione del modello romantico e tardoromantico.

L'insistenza nel lessico stusiano su immagini 'convenzionali' come doroha, šljach e put' è in quest'ottica interpretabile anche dal punto di vista metapoetico. Si vedano a proposito alcuni brani della lirica più lunga della sezione:

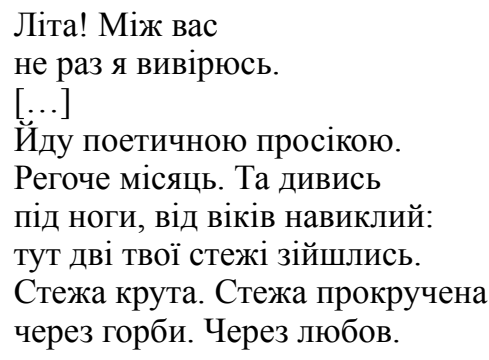

45 Ivi: 154. 'L'aria, come fiamma / bruciava sul corpo / e vibrava l'orizzonte / nelle azzurre reti del giorno... / Impazziti per il sole, / di bronzo i petti, come trombe, / urlavano, / e scintillava di grida il cielo, / i bagnanti.' 


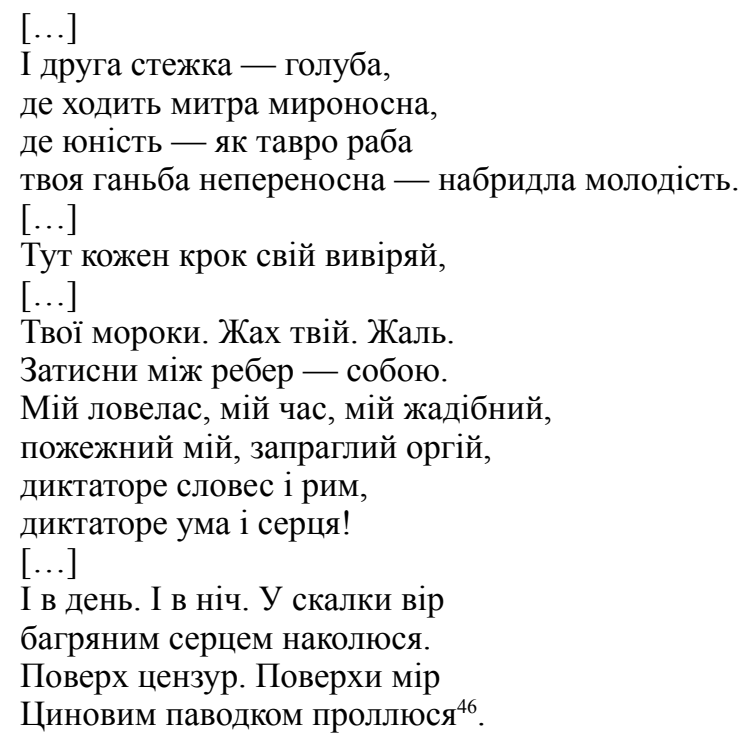

Che questi versi siano interpretabili come un'auto-riflessione dell'io lirico sulla propria natura di poeta sembra essere fuori dubbio. La decisione di essere poeta è stata maturata e irrevocabilmente presa. Il cammino poetico è iniziato e si prospetta sotto il segno della dualità, che appare adesso, almeno momentaneamente, superata. La strada da percorrere è insidiosa e inquietante, mentre il soggetto è afflitto dalla piaga di una lacaniana vergogna insopportabile (si ricordi la lirica $V$ chaosi zhlyblenych svitiv nei versi giovanili sparsi). Particolarmente interessante risulta l'apostrofe al tempo, accusato di essere un "dittatore". Dietro a questa affermazione è forse possibile leggere una dichiarazione dell'io lirico a proposito del carattere necessariamente attuale della propria poesia o quanto meno di parte di essa. È a causa dei dettami del tempo che la poesia metapoeticamente intesa dal soggetto non può essere solamente 'pura', ritrovandosi a tratti nella condizione di doversi macchiare della colpa di rispondere ai richiami della contemporaneità. Questa lettura sembra essere corroborata dalla conclusione della lunga lirica e dal riferimento alla censura, sineddoche dell'azione

46 Ivi: 142-144 passim. 'Anni! Tra voi / più d'una volta mi proverò. / [...] / Vado per un sentiero poetico. / Ride la luna. Ma guarda / sotto i piedi, dopo secoli di abitudine: / i tuoi due cammini si sono qui uniti. / Il cammino erto. Il cammino tortuoso / tra i poggi. Nell'amore. / [...] / E l'altro cammino - azzurro, / dove va la mitra della pace, / e la gioventù - come un marchio di schiavo / insopportabile la tua onta - / la giovinezza ha insozzato. $[\ldots] /$ Metti alla prova ogni tuo passo, / [...] / Le tue ansie. Il tuo terrore. La tua tristezza. / Spingila tra le costole - con te stesso. / Mio tentatore, mio tempo, mio avido, / mio smanioso, che chiedi orgie, / dittator di poetici verbi e rime, / dittatore della mente e il cuore! / [...] / E di notte. E di giorno. / Nelle rocce delle fedi / col cuore purpureo mi inciderò. / Al di sopra delle censure. Al di sopra delle misure / come una piena di piombo mi verserò.' 
del tempo sulla poesia, nonché memore a livello fonico di Poverch bar'erov, la seconda raccolta lirica pasternakiana. Che il cammino poetico sia costellato di paure e tormenti è chiaro all'io lirico, altrettanto sicuro della propria potenza e della propria capacità di abbattere gli argini che limitano il libero fluire della parola. Anche in questo caso, come per $V$ chaosi zhlyblenych svitiv è ipotizzabile la presenza del trittico cvetaeviano Poety come ipotesto (Cvetaeva 2004: 609):

[...] Что же мне делать, ребром и промыслом,

Певчей! — как провод! загар! сибирь!

По наваждениям своим - как по мосту!

С их невесомостью

В мире гирь.

Что же мне делать, певцу и первенцу,

В мире, где найчернейшии - cep!

Где вдохновенье хранят, как в термосе!

С этой безмерностью

В мире мер.

Si notino le coincidenze lessicali e le prossimità semantiche tra i due ultimi versi della lirica stusiana e rispettivamente il terzo e il quarto verso del brano del testo cvetaeviano citato ("Poverchy mir / cynovym pavodkom prolljusja" - corsivo mio, AA). L'assimilazione della propria ispirazione poetica a un'esondazione per la sua capacità catarticamente distruttiva avvicina l'auto-rappresentazione dell'io lirico stusiano al Poeta di Marina Cvetaeva. Tuttavia, nel testo stusiano è assente l'idea di una contrapposizione tra l'io e la folla nella tradizione del Poèt i tolpa puškiniano. Questa differenza è probabilmente riconducibile alla forte persistenza nella civiltà letteraria ucraina novecentesca dell'idea del carattere popolare e nazionale del poeta, ossia della consonanza della sua ispirazione e della sua missione con il destino del proprio popolo. L'io lirico stusiano si contrappone qui alla storia, non al popolo, divergendo nettamente dall'immagine cvetaeviana del poeta, isolato tra gli uomini, in grado di trovare un linguaggio comune soltanto con un altro poeta ${ }^{47}$. Alla tematica nazionale, a cui nell'opera stusiana si collega generalmente il "noi", sono inoltre riconducibili anche le "rocce di fedi" del quartultimo verso, in cui il poeta decide con fermezza di incidere se stesso. La lontananza assiologica della lirica stusiana in questione dal modello cvetaeviano, la cui importanza come magistero poetico si rivela comunque fondamentale, è sotto questo aspetto più che evidente.

47 L'unico "noi" che l'io lirico cvetaeviano ammette è la comunità ideale dei poeti. Si veda ancora da Poety, in: ibidem: "Поэты мы и в рифму с париями, / но выступив из берегов, / мы бога у богинь оспариваем / И девственницу у богов!” Si noti anche l'insistenza sul motivo della fuoriuscita dei poeti dagli argini dell'umanità. Si veda anche da un'altra nota lirica di Posle Rossii, seconda parte del trittico Dvoe ispirato alla relazione epistolare tra Cvetaeva e Pasternak, in: ivi: 650: "Не суждено, чтоб сильный с сильным / Соединились в мире сем." 
A completamento della descrizione della tavolozza stilistica di Delo №13/ $B E 1339$ resta da citare il filone di ispirazione folklorica. Si vedano alcuni versi da Rannij promin'('Primo raggio'), una lirica del 1958, dunque cronologicamente anteriore ai componimenti finora analizzati:

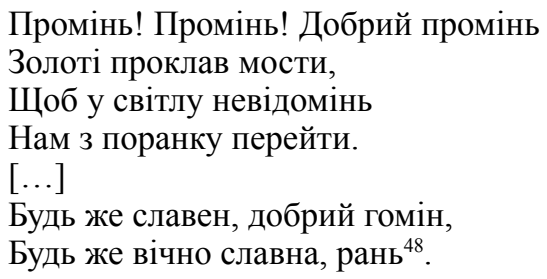

La personificazione e l'evocazione degli eventi atmosferici, l'impersonalità della situazione lirica e le ripetizioni, nonché probabilmente lo stesso ritmo trocaico, sono chiari marcatori della stilizzazione folklorica di questi versi. Nel complesso dell'opera poetica stusiana questa tendenza stilistico-espressiva, alquanto diffusa nella lirica ucraina a Stus contemporanea (cfr. Pastuch 2010: 160163), rimane indubbiamente in secondo piano, nonostante la grande attenzione dedicatale dalla critica (cfr. Myšanyč 2001).

Resta infine da sottolineare come la tendenza di marca espressionista sia meno rappresentata in questa raccolta, così come nella più ampia e coeva Kruhovert', nella quale, come si è visto, sono confluite molte liriche di Delo №13/BE1339. I fruttuosi germi della lirica espressionista stusiana, come si è potuto osservare a proposito dei versi sparsi giovanili, avrebbero trovato piena maturazione solamente nelle raccolte più tarde.

\section{Kruhovert'}

Se Delo №13/BE1339 è un'opera concepita e realizzata sotto forma di samizdat, Kruhovert'è il primo tentativo stusiano di pubblicazione ufficiale. Proposta alla casa editrice Molod' nel 1964, la raccolta venne stroncata da una lettura editoriale negativa l'anno successivo, che ne bloccò qualsiasi prospettiva di stampa. La critica sfavorevole seguì, non a caso, l'azione di protesta dei giovani intellettuali kieviani presso il cineteatro "Ukrajina" del 1965, ideale suggello della fine del Disgelo in Ucraina e punto di inizio della quasi ventennale contrapposizione di Stus al sistema. Il manoscritto consegnato alla casa editrice è andato perduto. Una sua parziale, complessa ricostruzione è stata effettuata seguendo la lettura editoriale di Mykola Nahnybida sulla base di diversi originali, alcuni dei

48 ZT I, 146. 'Raggio! Raggio! Oh buon raggio / D'oro i ponti hai innalzato, / così che noi nel chiaro ignoto / al mattin andar possiamo. / [...] Gloria a te, oh voce buona, / Gloria eterna a te, oh mattino.' Nevidomin' è un neologismo stusiano. Cfr. Olifirenko 2003: 45. 
quali restituiti alla famiglia di Stus soltanto nel corso degli anni Novanta (cfr. ZT I, 519). Non è stato tuttavia possibile ricreare la raccolta nella sua struttura originale, organizzata in tre sezioni, intitolate Roževe pivkolo ('Il semicerchio rosa'), Bil'-Bilyj den' ('Dolore - giorno bianco') e Kruhovert'. In ZT la seconda e la terza parte dell'opera sono riunite in un'unica sezione. I curatori hanno individuato nel principio cronologico il fattore compositivo fondamentale dell'opera. La prima parte comprende liriche precedenti al servizio militare; la seconda, nella versione originale, riuniva versi composti nei tre anni trascorsi nell'esercito, mentre l'ultima risaliva ai mesi successivi al ritorno in Ucraina. Allo stato attuale delle ricerche la prima parte consta di sedici testi, mentre la somma dei testi ricostruiti per la seconda e la terza ammonta a venticinque.

La poesia con cui il giovane Stus intende presentarsi al pubblico è principalmente ascrivibile al filone vitalistico della sua prima produzione, come testimonia anche il titolo della raccolta stessa. La tendenza all'uniformità stilistica e tematica di Kruhovert', almeno a una prima lettura, sembra contrastare fortemente con la suggestiva varietà di ispirazione dei versi sparsi degli anni precedenti. L'assunto vitalistico si fonde con la tematica amorosa e le ascendenze folkloristiche dando vita a una poesia che in molti casi ha poco in comune con i futuri capolavori. Almeno quattordici delle sedici liriche della prima parte e diciannove delle liriche della seconda (che comprende anche la terza del progetto originale) parte della raccolta sono assimilabili a questa tendenza. Si può dunque osservare un certo grado di evoluzione all'interno dell'opera, ovvero un leggero ampliamento del repertorio tematico-stilistico. Che ciò possa essere spiegato semplicemente in riferimento alla composizione e disposizione del testo su base cronologica è poco probabile: come si è visto e come non si smetterà di osservare nel corso dell'analisi, l'opera stusiana nel suo complesso è caratterizzata dalla convivenza di tendenze anche molto distanti tra loro in ciascuna delle sue fasi di sviluppo. Stilemi e motivi dominanti nella produzione matura sono già presenti in nuce nei versi giovanili. Allo stesso tempo, le caratteristiche peculiari della poesia degli inizi non scompaiono completamente nell'evoluzione dell'arte stusiana, trovandosi rilegate a una posizione subordinata. È dunque lecito parlare di prevalenza di un certo motivo o stilema in una determinata fase, ma non si possono ignorare i profondi legami tra tutte le fasi del percorso poetico dell'autore dagli esordi ai tardi anni Settanta.

La lirica inaugurale della prima parte, Roževe pivkolo, è programmaticamente intitolata Radist '('Allegria') e introduce la tonalità dominante dell'intera sezione:

\author{
ГОМОНИ! ГОМОНИ! \\ Із струмком, із промінням ранковим, \\ В вітровім шелестінні, у хмар миготінні яснім, \\ 3 тихим плюскотом хвиль, \\ Із прибоєм ланів колосковим - \\ Гомони! Гомони! Так як вітер, як промінь, як грім. \\ Гомони! Гомони!
}

Не вщухай ані миті, ні хвилі.

Бийся крильцями в небі, поглядом голубій. 
$[\ldots]$

Там, де бджіл золоте колихання,

Зупинись і замрійся. Та кроки свої не спини.

Добра радість буття! Добра щедрість людського кохання.

$[\ldots]^{49}$

Tipicamente stusiana è in questi versi l'apostrofe al sé attraverso l'uso dell'imperativo. L'io lirico esorta se stesso all'unione con la natura, a un ritorno rousseauiano alla sua primigenia armonia. Anche nel caso di Radist'non è da escludere una lettura in chiave poetologica. La voce che il soggetto invita se stesso a intonare è quella della natura in ogni sua manifestazione, dalla leggerezza del vento alla potenza del tuono. Come si è già avuto modo di comprendere, la poesia stusiana dei primi anni è effettivamente descrivibile nei termini di un vasto repertorio di cadenze e tonalità, anche in forte contrasto tra loro. La particolarità di Kruhovert' risiede nella sua sostanziale 'monotonia', in netta opposizione all'assunto metapoetico di questi versi. Si noti l'apparente contraddizione tra la necessità di non arrestare i propri passi e quella di fermarsi per darsi ai sogni. Un'interpretazione in chiave poetologica cancella ogni traccia di alogicità da questo verso, il cui significato è innanzitutto un'auto-esortazione a proseguire senza indugi lungo il cammino poetico intrapreso. La tradizione in cui questa lirica si innesta è evidentemente quella dei Sonjačni klarnety di Pavlo Tyčyna e di Sestra moja - žizn' di Boris Pasternak. Radist' è indubbiamente accostabile alla terza lirica del capolavoro tyčyniano, Haji šumljat' ('Rumoreggiano i prati', 1913):

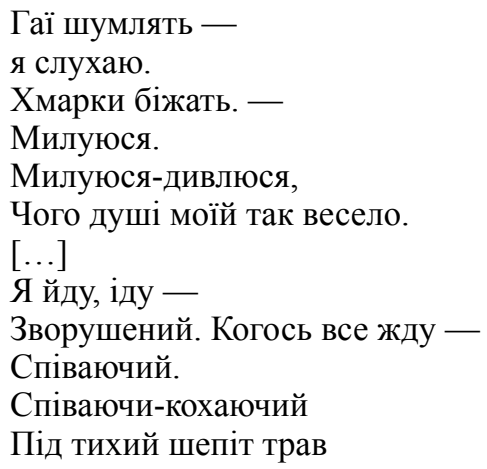

49 Ivi: 163 . 'VOCIA! VOCIA! / Con il torrente, con il raggio mattutino, / nel fruscio del vento, / nel lampeggiare chiaro delle nuvole, / con lo scroscio silenzioso delle onde, / con la risacca delle spighe dei campi - / Vocia! Vocia! Così come il vento, come il raggio, come il tuono. / Vocia! Vocia! // Non esitare né un attimo né un istante. / Sbatti con le ali nel cielo, fatti azzurro con lo sguardo. / [...] // Lì, dov'è l'ondeggiare dorato delle api, / fermati e sogna. E i passi tuoi non fermare. / Oh, buon'allegria dell'essere! Oh, generosità dell'amore umano. [...]' Come risulta dall'apparato critico di $Z T$, la lirica fu pubblicata sulla "Literaturna hazeta" nel 1959, in una versione leggermente diversa da quella del testo definitivo (ivi: 436). 
голублячий.

Щось мріє гай -

Над річкою.

Ген неба край - Як золото.

Мов золото - поколото,

Горить-тремтить ріка,

Як музика ${ }^{50}$.

L'interazione tra il soggetto e il mondo naturale a più livelli sensoriali si unisce in entrambe le liriche all'insistenza sul carattere sia passivo-ricettivo, sia attivo-produttivo dell'io lirico. Il cammino è marcato dalla gioia dell' armonia tra il micro- e il macrocosmo, la cui fusione è evidenziata, ad esempio, dall'acquisizione del colore azzurro del cielo da parte del soggetto in entrambe le poesie. A questa 'naturalizzazione' dell'io corrisponde in Tyčyna la capacità del prato di sognare, caratteristica che, invece, l'io lirico stusiano riserva solamente, e in modalità potenziale, a se stesso. Rispetto al presunto modello tyčyniano, il testo stusiano risulta artisticamente meno maturo per la sua ridondanza, così come per l'ingenua, 'prosastica' serie di esclamazioni che la attraversa. La concentrazione dell'io lirico su di sé, elemento fondante dell'universo poetico di Stus, distingue Radist' dalla tendenza tyčyniana a una più spiccata compenetrazione tra il soggetto e la realtà ${ }^{51}$.

Il sottotesto tyčyniano sembra fondersi con quello pasternakiano a esso contemporaneo $^{52}$. La gioia è un elemento centrale di Sestra moja - žizn', legata, esattamente come in Radist', all'indissolubile nesso tra l'amore per la donna, la creazione artistica e l'estasi vorticosa della partecipazione del soggetto al turbinio degli eventi naturali. Si veda da Naša groza: "Куда мне радость деть мою? / В стихи, в графленую осьмину?” (Pasternak 2003-2005: I, 135) Nella maggiore raccolta pasternakiana si profila inoltre, sebbene solo a tratti, un an-

50 Tyčyna 1971: 36-37. 'Rumoreggiano i prati - / Io ascolto. / Corrono le nuvolette. - / Io Ammiro. / Ammiro-e-guardo, / perché l'anima mia è così allegra. // [...] / Cammino, cammino - / agitato. / Aspetto qualcuno - / cantando. / Cantando-amando / sotto il bisbiglio leggero dell'erba / facendomi azzurro. / Sogna qualcosa il prato - / vicino al fiume. / L'orizzonte laggiù - / è come l'oro. / Come l'oro / frantumato. / S'infiamma-trema il fiume, / come musica.'

51 Si vedano ancora due liriche di Sonjačni klarnety: Ne Zevs, ne Pan ('Né Zeus, né Pan', 1918), in: ivi: 63: “Прокинувсь я — і я вже Ти: / Над мною, підо мною / Горять світи, біжать світи / Музичною рікою.” ('Mi son svegliato - e son già tu: / sopra di me, sotto di me / bruciano i mondi, corrono i mondi / come fiume di musica.'); Cvit v mojemu serci... ("Un fiore nel mio cuore...", 1917), in: ivi: 49: “Світ в моєму серці, / Мрій танок, світанок. / Ти той світ, мій друже, / Зоряний світанок. / Я твої очиці, / Зорі, зорениці - / Славлю як світанок!' ('Il mondo nel mio cuore, / dei sogni la danza, / l'aurora. / Tu sei quel mondo, amico mio, / L'aurora stellata. / Io gli occhi tuoi cari, / le tue stelle, le stelline tue - / lodo come aurora!').

52 Uno studio contrastivo delle poetiche tyčyniane e pasternakiane negli anni a cavallo della Rivoluzione è uno dei maggiori desiderata della comparatistica russoucraina di ambito novecentesco. 
nullamento della distinzione tra gioia creativa e amorosa, da una parte, e dolore dall'altra, risultato, quest'ultimo, della potentissima esplosione di sentimenti ed emozioni creative (ivi: 133):

\section{Чьи стихи настолько нашумели, Что и гром их болью изумлен? \\ Надо быть в бреду по меньшей мере, Чтобы дать согласье быть землей.}

In Radist' il dolore è assente, forse appena percettibile nell'esortazione a "sbattere con le ali nel cielo" che il soggetto lirico rivolge a se stesso. Elemento fondante dell'universo lirico stusiano maturo ${ }^{53}$, il dolore è in esso solitamente ben distinto dalla gioia, nonché assolutamente predominante.

In un'altra lirica di Roževe pivkolo, tuttavia, si può osservare un'oscillazione tra i due poli del tutto accostabile al modello pasternakiano:

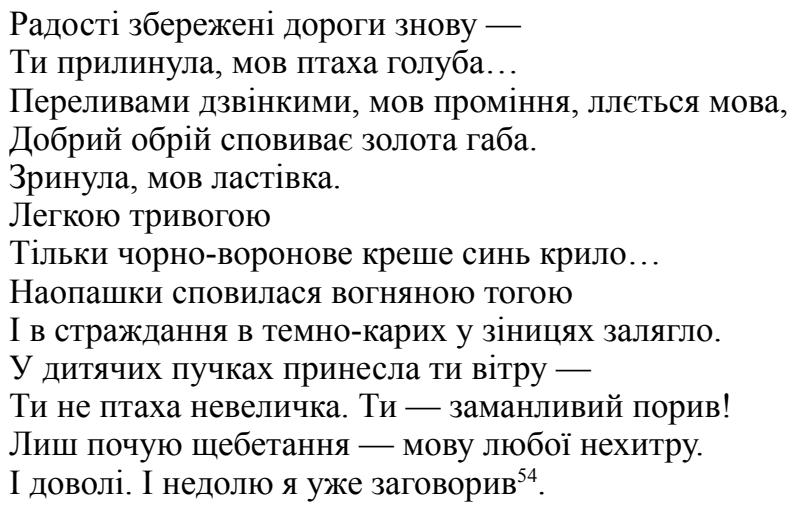

Nella figura della donna, e nella sua influenza sul poeta, la gioia e il dolore risultano inscindibili. Altrettanto inscindibili sembrano essere il sentimento amoroso e il fluire della lingua, ovvero della poesia. L'aspetto rassicurante, armonioso e ispiratore dell'amore, e dell'impulso artistico che questo risveglia, è indissolubile dal suo potenziale funesto. La tavolozza stusiana si serve qui dell'azzurro e dell'oro di simbolistica memoria, così come del nero inquietante dell'imagery espressionista, fornendo un esempio di poesia ermetica piuttosto insolito, come si è accennato, per l'immagine che il giovane poeta vuole comunicare al letto-

53 Cfr. Čorna 1999.

54 ZT I, 174. 'Ancora sono intatte le strade della gioia - / ti sei avvicinata, come un uccello azzurro... / Con rintocchi sonori, come raggi, scorre la lingua, / l'orizzonte buono è avvolto da un'onda d'oro. / Ti sei sollevata, come una rondine. Con angoscia leggera / Solo corvina infiamma l'azzurro un'ala... / S'è avvolta sulle spalle come toga di fuoco / E la sofferenza è ferma nelle pupille scure. / Con dita di bambino hai portato il vento - / Tu - non sei un uccellino. Sei - un impeto che ammalia! / Appena sento il cinguettio - la lingua ingenua dell'amata. / Basta. E ho già detto la malasorte.' 
re con Kruhovert'. Che anche in questo caso il significato profondo della lirica sia la totale adesione dell'io lirico alla propria vocazione poetica, latrice tanto di gioia creativa quanto degli imprevedibili capricci della sorte, è evidente. Tuttavia, sembra che anche in questo caso l'assunto di fondo della raccolta sia confermato: nonostante il cammino poetico sia erto e insidioso l'io lirico pronuncia consapevolmente la propria Bejahung al destino di poeta, come chiaramente indicato dall'ultimo verso della poesia in questione.

La prepotente necessità di dar voce alla parola che ineluttabilmente prorompe dalla propria coscienza poetica è tematizzata anche da un'altra lirica della sezione:

[...] Стільки правди в горлі, стільки мук -

Не переповідати до рання.

Вечір, мов сліпий, кістляві руки

Простяга услід мені. Я йду,

І чатують тіні по сліду,

Мовчки стережуть мене, мов круки.

Вже припавши до землі, причах,

Притомившись, вечір. От і маеш:

Сам сліпий, ти в ніч глуху ступаєш.

Хлюпає любов в твоїх очах ${ }^{55}$.

La situazione dell'io lirico è sospesa tra pericolo e certezza, tra minaccia e salvezza. La sera, inquietante e mortifera, si rivela traboccante d'amore. I rischi da cui essa sembra proteggere il soggetto sembrano essere legati in realtà alla parola poetica, per dare sfogo alla quale l'io lirico è costretto ad aspettare le luci del mattino. La poesia, identificata qui come tormentosa verità, risulta dunque associata alla rovina. Negli ultimi due versi il soggetto sembra rivolgersi ancora alla sera, invocata nella strofa precedente e nei due versi anteposti, ma si può supporre anche che si tratti di un'apostrofe dell'io lirico a se stesso. In questo caso sarebbe il poeta a essere traboccante d'amore, allargando così la caratterizzazione della poesia all'amore stesso, oltre che alla verità e alla sofferenza. La cecità concorrerebbe così alla raffigurazione tradizionale del bardo, incapace di vedere la realtà apparente a vantaggio della possibilità di cogliere l'essenza profonda delle cose. Si può ipotizzare anche in questo caso un modello pasternakiano. I primi versi qui riportati sembrano infatti echeggiare la quartina iniziale di una nota poesia da Vtoroe roždenie, la raccolta del ritorno alla lirica del Pasternak maturo dopo la crisi creativa dei secondi anni Venti (Pasternak 2003-2005: II, 80):

55 Ivi: 173 . '[...] Così tanta verità nella gola, così tanta pena - / fino al mattino tutto non dirai. // La sera, come un cieco, le mani ossute / allunga dietro a me. Io vado, / e dietro le ombre mi attanagliano, / silenziose mi custodiscono, come corvi. // Ormai a terra, smorzatoti, / la stanchezza, la sera. Ed ecco: / cieco, incedi nella notte sorda. / L'amore si frange nei tuoi occhi.' 
О знал бы я, что так бывает,

Когда пускался на дебют,

Что строчки с кровью - убивают,

Нахлынут горлом и убьют!

Si noti in entrambi i testi la pericolosa collocazione fisica della parola poetica nella gola del poeta, esposto ai rischi di un'ispirazione in grado di metterne a repentaglio l'incolumità.

Il richiamo più o meno esplicito all'opera pasternakiana, sia sotto forma di citazioni che, più in profondità, a livello di dialogo tra universi poetici, svolge un ruolo importante in Kruhovert'. Il riferimento a Pasternak si attua a tratti con una chiarezza che lascia poco spazio al dubbio, come emerge nettamente dalla prima di strofa di un'altra lirica della prima sezione della raccolta:

О слова не зрони! Немов закляття, слово

Коли бентежний струм нам пульс перетина!

В гучнім акорді рветься і струна -

Вона не забринить, не обізветься знову ${ }^{56}$.

È evidente in questi versi il rimando a una delle liriche di Sestra moja-žizn' (Pasternak 2003-2005: I, 156):

Давай ронять слова,

Как сад — янтарь и цедру,

Рассеянно и щедро,

Едва, едва, едва.

Stus sembra qui voler direttamente contrapporre una propria dichiarazione di poetica al modello pasternakiano universalmente noto e indubbiamente autorevole. Se il giovane Pasternak delle raccolte a cavallo degli anni della Rivoluzione tematizza più volte e con evidente provocazione la "casualità" della scrittura poetica $^{57}$, in assoluta sintonia con la concezione dei rapporti tra realtà testuale e poesia che si dipana nella sua opera, Stus si rifà a un'idea della parola intimamente correlata con la tradizione ucraina per lui irrinunciabile. Nella lirica pasternakiana delle prime raccolte, l'intrinseca poeticità della realtà in ogni sua manifestazione fa sì che tutto sia poesia e che dunque il singolo componimento altro non rispecchi che una minuscola, casuale particella del tutto, identificabile ancora una volta con la poesia stessa (cfr. Jakobson 1935). Nell'opera del giovane Stus questa concezione, a tratti ripresa e fatta propria, si accosta al modello sacramentale del Verbo profetico e poetico ereditato dalla tradizione romantica

56 ZT I, 169. 'Non disperdere le parole! Come un incantesimo è la parola, / quando una corrente agitata ci attraverso il battito! / Nell'accordo fragoroso si spezz'anche la corda - / Non vibrerà, più non risuonerà.'

57 Pasternak 2003-2005: I, 162: “И чем случайней, тем вернее, / Слагаются стихи навзрыд." 
e patriottica delle lettere ucraine. La parola poetica è così connotata in termini sacri e magici (zakljattja) e la necessità per il poeta di accostarsi a essa con cautela e consapevolezza è messa in evidenza dalla possibilità, in caso contrario, di una sua perdita, simboleggiata dalla spezzatura della corda.

Una ripresa del modello pasternakiano al livello della raffigurazione della realtà in cui l'io lirico si ritrova immerso è evidente nelle frequenti personificazioni degli elementi naturali. Si veda Mandry ('Viaggio'):

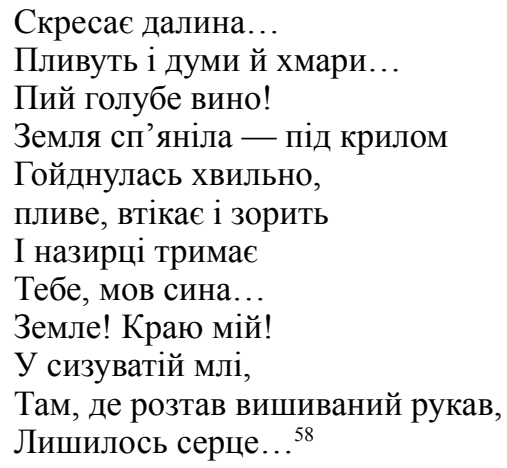

La corrispondenza tra il soggetto e la terra, accomunati dall'ebbrezza per l'inizio della primavera e lo scioglimento del ghiaccio, è rafforzata nella seconda parte della breve lirica dallo sguardo della terra stessa, intensamente rivolto al soggetto, qui, come spesso nella lirica stusiana, sdoppiato tra i poli dell'io e del tu. L'ubriachezza della terra e dell'io lirico è riconducibile all'immaginario pasternakiano ${ }^{59}$, di cui anche in questo caso, tuttavia, si registra una chiara distorsione. La terra, nella lirica di Pasternak prevalentemente a-storica e a-geografica ${ }^{60}$, si identifica qui con l'Ucraina, la patria, raffigurata metonimicamente con le tipiche camicie rica-

58 ZT I, 172. 'Si sveglia lo spazio lontano... / Nuotano i pensieri e le nuvole... / Bevi l'azzurro vino! / La terra è ubriaca - sotto l'ala / si dondola, agitata / nuota, fugge e guarda / e tiene d'occhio / te, come un figlio... / Terra! Paese mio! / Nella nebbia grigiazzurra, / lì, della manica è sciolto il ricamo, / lì, è rimasto il cuore.'

59 Si veda, ad esempio, la terza strofa di Pro domo, una lirica del 1914, inclusa nella versione originale della raccolta Poverch bar'erov del 1916, ma scartata in seguito durante la rielaborazione e riedizione della stessa nel 1928, in: Pasternak 2003-2005: I, 366: "В час, когда из сада остро тянет тенью, / Пьяной, как пространства, мировой, как скок / Степи под седлом, - я весь - на иждивенье / У огня в колонной воспаленных строк.” ̇̇ difficile stabilire se Stus potesse effettivamente conoscere questa lirica. Si noti in questi versi la correlazione tra lo spazio, l'io lirico e la sua vocazione poetica, in corrispondenza con un topos ben rappresentato, come si è potuto vedere, nell'opera stusiana.

60 La dichiarata storicità dell'ispirazione di Sestra moja - žizn' e la sua strutturazione come un viaggio lungo le stazioni di una linea ferroviaria ben definita, non inficiano, d'altro canto, il carattere mitico e atemporale della narrazione lirica che si dipana nella raccolta. 
mate del suo artigianato tradizionale (vy̌̌yvanky). Il gusto probabilmente kitsch $^{61}$ di questi versi mostra ancora una volta la concorrenza di ispirazioni e modelli letterari che segna la fase giovanile della produzione stusiana, a tratti ancora distante dalla maturità delle opere dei tardi anni Sessanta e degli anni Settanta. Tuttavia, il patetismo degli stereotipi nazionali, riscontrabile anche in altre liriche di Roževe pivkolo $^{62}$, continuerà a marcare parte della lirica stusiana anche negli anni a venire.

La seconda e la terza parte di Kruhovert', composte rispettivamente durante e dopo il servizio militare, non si discostano sostanzialmente dalla prima per tematiche e tonalità stilistiche, anche se è effettivamente osservabile un maggior grado di varietà e differenziazione a entrambi i livelli. L'attenzione dell'io lirico ai propri vissuti interiori e alle esperienze amorose si accompagna ai tradizionali motivi patri ${ }^{63}$, al folklore ${ }^{64}$, agli inni alla natura ${ }^{65}$ e alla giovinezza ${ }^{66}$. A tratti l'istanza narrativa si rafforza a tal punto da avvicinare la poesia alla prosa, come avviene nel caso dei bozzetti di costume inclusi nella raccolta ${ }^{67}$. Può avvenire che

${ }^{61}$ Stus e la sua poesia non figurano nella monografia di Tamara Hundorova sul kitsch nella cultura ucraina. Le vyshyvanky di questi versi potrebbero essere accostate al "kitsch nostalgico" che la studiosa osserva nelle pieghe del romanzo in versi Marusja Čuraj di Lina Kostenko (1979). Cfr. Hundorova 2008: 234.

62 Si veda da Veresneva zemlja ('Terra di settembre'), in: ZT I, 175: “[...] O, Вкраїно моя осіння! / Чом забракло мені уміння / Звеселити серце твое? / Голубінь моя, голубінь! / Розтривого моя і муко! / [...] / Земле рідна! Тобі одній / Я волів би служить до скону! / [...].” “[...] Oh, Ucraina mia d'autunno! / Perché non ho saputo / rallegrare il cuore tuo? / Mia azzurra, azzurra mia! / Angoscia mia, tormento! / [...] / Terra natia! Solo te / vorrei servir fino alla morte! / [...]' La lirica è preceduta da un'eloquente citazione da Ivan Franko: “Земле моя, / всеплодющая мати!” 'Terra mia, / oh madre sempre fertile!'

63 Ivi: 204: “Земле рідна! / Я виросту! Я піднесусь! / Я зможу тебе уберегти!” 'Terra natia! / Crescerò! Mi innalzerò! / Riuscirò / a proteggerti!'

64 Ivi: 192: “Запорожець - нелинь-дуб / Край борів отаборився. / Дідьком гнаний, вітер нісся, / Шарпав крону, в дупла дув.” 'Il cosacco - quercia eterna - al margine del bosco s'è accampato. / Da un demone spinto, il vento correva, / degli alberi le cime scuoteva, nelle cavità soffiava.'

65 Ivi: 182: “Дерева, вітром підбиті, / Пещені літом і сонцем, / Піднявши вгору долоні, / Пнуться до неба. Зайшлися / У ритуальному танці." 'Alberi, battuti dal vento, / carezzati dall'estate e dal sole, / sollevati hanno i palmi, / si ergono al cielo. / Han dato il via / a una danza rituale.'

66 Ivi: 203: “Я можу неба вимірять глибінь, / Як людські груди виміряють кулями. / Пізнать непізнане, / Щоб потому / Його навіки заховати в землю... / Мені життям даровано безсмертя / І вічну молодість. / Я виростав. 3 землі. / I син землі, / Не можу зупинитись." 'So misurare le profondità del cielo, / come il petto dell'uomo si misura a pallottole. / Conoscere ciò che non si sa, / per poi / conservarlo nella terra. / La vita mi ha regalato l'immortalità / e l'eterna giovinezza. / Sono cresciuto. Dalla terra. / E della terra figlio, / non posso fermarmi.'

67 Ivi: 211: “Робітники сіли обідати, / примостившись у цеховому подвір'і. / Хто — на лаві, хто - на жорстві, / а хто - так-таки на землі в холодочку.” “Gli operai sedettero a mangiare, / mettendosi nel cortile della fabbrica. / Chi in panchina, chi sulle pietre, / chi, alla fine, a terra nel freddo.' 
all'interno della stessa lirica si riscontri una notevole e inaspettata mescolanza stilistica, come mostrano le due lunghe parti della lirica seguente:

Я чую - зараз зірвусь. Риданням поночі.

I перетягну горло, мов жгутом,

Затисненим в кулак промінням місячним.

Затихни. Все одно поганий друг -

Твій крик самотній.

[...] Раптом

набухле серце підійде під груди,

ти - між землею і його биттям

Затиснений, і вдаришся, мов птаха,

Заломиш груддям рятівне коло.

Земля моя! Красо моя! Вкраїно!

Віддаленів твій обрій. Відгримів.

Ти ніби й є. Але тебе немає.

$[\ldots]$

На дальнім березі - високі тіні.

Високі сосни. І високий крик

I полум'я промовистий язик

Тріпоче полотном,

Палахкотіє

Від жовтого до ярого і до

блакитно-синього. $[\ldots]^{68}$

L'immaginario di matrice espressionista, raro in Kruhovert', apre la lirica per cedere poi inaspettatamente il posto a un'invocazione alla patria ispirata al pathos romantico. A quest'ultima segue dunque, all'inizio della seconda parte, una nuova serie di immagini riconducibili alla sensibilità espressionista, all'interno della quale alcuni dei lessemi più frequenti del vocabolario stusiano (bereh, tin', sosna, kryk, palachkotity; si noti anche l'aggettivo samotnij nella prima parte) si fondono con la raffigurazione dei colori della bandiera nazionale ucraina, vietata in epoca sovietica. Ė qui dunque esemplarmente mostrata la confluenza di ispirazioni distanti e distinte nella formazione del linguaggio poetico del giovane Stus. È inoltre lecito osservare in questi versi una significativa anticipazione di quello che sarebbe diventato nel decennio seguente il cupo immaginario stusiano par excellence, sviluppato fino all'ossessione nei versi di Čas tvorčosti e Palimpsesty.

68 Ivi: 187-188. 'Lo sento - mi spezzerò. Col singhiozzo nel buio. / E strozzerò la gola, come con una fune, / da un raggio di luna stretta nel pugno. / Taci! Non è comunque un buon amico / il tuo urlo solitario. // [...] / Di colpo il cuore gonfio scenderà nel petto, / tu - tra la terra e il suo battito / stretto sbatterai, come un uccello, / romperai contro i massi l'ala che salva. / Terra mia! Bellezza mia! Oh Ucraina! / S'è allontanato il tuo orizzonte. Più non tuona. / Come se tu ci fossi. Ma non ci sei. / [...] // Sulla riva distante - alte ombre. / Alti pini. E un alto grido / e della fiamma la lingua precisa / trema come una tela, brucia / dal giallo fino a splendere, / fino all'azzurro-blu. [...]' 
Per quanto riguarda il dialogo con la tradizione pasternakiana, si vedano alcuni versi da Slovo ('La parola'):

Ми дуже часто од душі,

од серця мовим...

А слово може задушить.

Чи стане слово,

Неначе кістка - не дихнуть,

Не продихнути.

[...]

В словах не вихлюпни з грудей

Ти серця свого,

Котре під горло підійде

І мучить довго.

$[\ldots]^{69}$

È evidente un altro rimando a [O znal by ja, čto tak byvaet], la cui presenza come ipotesto è già stata osservata nella prima parte. Se al centro del testo pasternakiano si trova incontestabilmente la figura dell'artista, Slovo sembra avere per tema la condizione umana tout court, che non esclude, beninteso, una sua reinterpretazione in chiave poetologica. Le coincidenze lessicali fra le due liriche, costruite a partire dell'immagine della parola che strozza il parlante occludendogli la gola, così come fra di esse e la poesia discussa precedentemente, sono palesi. Una conferma del legame diretto tra i due testi sembra giungere anche dall'analisi di due delle sette varianti del testo stusiano, entrambe classificate dai curatori del primo tomo di ZT come brogliacci (ZT I, 460-461). Si veda dalla prima delle due versioni in seguito profondamente rielaborate:

[...] Забудь, что ти колись кричав

В надсаднім тоні,

Що хтось бажання розіп'яв

на Рубіконі -

ми в кожнім покрику гучнім,

У кожнім слові

$<$ і в крику пристрасті однім>

згубить готові

свої радіння і жалі,

свої тривоги.

$[\ldots]^{70}$

69 Ivi: 206. 'Spesso coll'anima / dal profondo del cuore parliamo... / Ma la parola può soffocare. / Si mette una parola, / come un ossicino - non respiri, / ti manca il fiato. / [...] / Nelle parole non rovesciar dal petto / il cuore tuo, / che in gola andrà / e ti tormenta a lungo. / [...]'

70 Ibidem. '[...] Dimentica che un tempo tu gridavi / forsennato, / che qualcuno i desideri aveva crocefisso / sul Rubicone - / in ogni grido acuto / in ogni parola / <e 
Il riferimento funebre al mondo classico può essere accostato alla tragica terza strofa di [O znal by ja, čto tak byvaet]:

Но старость — это Рим, который

Взамен турусов и колес

не читки требует с актера,

А полной гибели всерьез ${ }^{71}$.

La strofa conclusiva della lirica di Pasternak, infine, è altrettanto vicina ai motivi del testo stusiano che avrebbe ispirato trent'anni più tardi:

Когда строку диктует чувство,

Оно на сцену шлет раба,

И тут кончается искусство,

И дышат почва и судьба ${ }^{72}$.

Comune agli universi poetici di Stus e Pasternak e alla loro poesia poetologica è la volontà, ben percepibile nei due testi in questione, ma spesso costretta a scontrarsi con l'opposta tentazione della torre d'avorio, di (ri)avvicinare la figura dell'artista all'uomo comune. Ciò emerge con chiarezza dall'ultima quartina pasternakiana, in cui il Poeta sembra perdere le proprie peculiarità ritornando a essere 'semplicemente', e tragicamente, un uomo, così come dalla poesia stusiana in questione nel suo complesso, aperta da un pronome personale di prima persona che sembra rappresentare l'umanità nel suo insieme e non solamente i poeti.

Si noti, infine, la parziale coincidenza dei due testi a livello metrico, con l'alternanza di tetrametri e dimetri giambici in Slovo e il mantenimento del classico tetrametro giambico nel testo russo dell'ex-avanguardista Pasternak.

La doppia presenza ipotestuale di [O znal by ja, čto tak byvaet] in Kruhovert' mostra la produttività nella lirica giovanile stusiana del modello pasternakiano nella sua interezza, dalla febbricitante vitalità giovanile di Sestra moja - žizn' alla malinconica, elegiaca riflessività di Vtoroe roždenie.

Il riferimento alla poesia di Pasternak non sembra tuttavia esaurire l'ispirazione alla base di Slovo. La necessità di "contenere il proprio cuore" che l'io riconosce come fondamentale per un rapporto corretto con la parola può infatti essere messa in collegamento con la tradizione skovorodiana, sicuramente nota al giovane Stus dopo la pubblicazione delle opere complete del filosofo settecentesco nel 1961. L'evento, reso possibile dall'apertura culturale del Disgelo, fu di enorme importanza per la crescita culturale degli šistdesjatnyky. Frequente è negli scritti di Skovoroda l'invito a custodire (Храни) e preservare (Береги) il proprio cuore (cfr. Bartolini 2010: 65-67), inteso come sede della facoltà intellettiva, da mettere al riparo dagli attacchi del Maligno. Nel testo stusiano questo topos di derivazione esicastica subi-

nel solo grido della passione $>$ / a perdere siam pronti / le gioie e i dolori, / le nostre angosce. / [...]'

71 Pasternak 2003-2005: II, 80.

72 Ibidem. 
sce un duplice evidente processo di 'laicizzazione' e poetologizzazione, che non toglie validità al riconoscimento della probabile radice skovorodiana della ricorrenza.

Si avrà inoltre modo di constatare l'enorme importanza del motivo del cuore in tutta la poesia stusiana dagli esordi qui analizzati a Palimpsesty.

\section{Versi sparsi degli anni Sessanta}

Il primo tomo di $Z T$ presenta infine più di un centinaio di versi sparsi scritti in diversi momenti del decennio, alcuni dei quali precedentemente inediti. La varietà tematica e stilistica riscontrata nell'insieme della produzione giovanile stusiana, più evidente nei versi sparsi giovanili e attenuata nelle due raccolte composte dall'autore, caratterizza anche questo gruppo di liriche. Da esse emergono con chiarezza entrambi i principali filoni della poesia stusiana nella sua fase di formazione: da una parte, l'ispirazione modernista, che si concretizza a livello di immaginario in una scrittura di matrice ermetico-espressionista e a livello tematico nell'interrogazione dell'io; dall'altra, la ripresa della tematica nazionale e patriottica, elaborata ora in chiave patetica tardo-romantica, ora in chiave pseudo-naturalistica mediante bozzetti di vita rurale. La poesia stusiana dei primi anni potrebbe così essere paragonata, con una metafora tynjanoviana, a un campo di battaglia tra queste due opposte tendenze. Per poter proclamare un vincitore, il lettore e il critico dell'opera di Stus dovranno aspettare i capolavori del decennio seguente.

Come nel caso dei versi sparsi dei primi anni, anche per queste liriche, che arrivano ad abbracciare la fine del decennio, sarebbe erroneo voler attribuire la tendenza tradizionalista ai primi anni e la svolta modernista alla conclusione del periodo. I due linguaggi convivono, si intersecano e si scontrano nel corso dell'intero periodo. Si veda una delle prime liriche della sezione, la cui datazione è ipotizzata dai curatori dell'edizione al primo lustro del decennio:

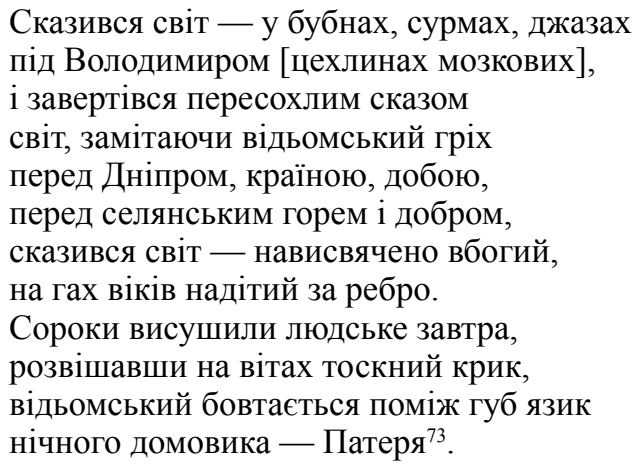

73 ZT I, 221. 'Si è infuriato il mondo - nei tamburelli, nelle surma, nei jazz, / in Zechlin cerebrali sotto Volodymyr, / s'è messo a ruotare di rabbia prosciugata / il mondo, spazzando il peccato stregonesco / davanti allo Dnipro, all'epoca, al paese, / 
Emerge chiaramente da questi versi l'accostamento del motivo urbano kieviano, legato al discorso nazionale e autobiografico e allargato anche al mondo rurale, all'immaginario apocalittico espressionista extra-storico e sovranazionale. La rabbia del mondo, da intendersi nel senso patologico del termine, trascende la situazione contingente del "paese" e dell' "epoca" in un minaccioso scenario di rovina che arriva ad abbracciare la storia umana nella sua interezza, rappresentata da quell'"amo dei secoli" a cui il microcosmo della realtà contemporanea è appeso dolorosamente per la costola. Ricorrono qui elementi tipici dell'immaginario stusiano come il grido ( $k r y k)$ e gli uccelli mortiferi (qui gazze, soroky) ${ }^{74}$. L'interesse di una lirica come [Skazyvsja svit - u bubnach, surmach, džazach] per lo studio dello sviluppo della poetica stusiana risiede proprio nel fragile equilibrio tra contingenza e universalità, i due poli opposti del linguaggio e dell'arsenale tematico del poeta. A distinguere questi versi dalla maggior parte dei testi del corpus poetico stusiano è, d'altro canto, l'assenza di riferimenti diretti alla presenza dell'io lirico, solitamente assoluto centro di gravità dell'universo poetico, qui, al contrario, risucchiato dal vortice di rabbia del mondo.

Da questo punto di vista, più consona al generale ego-centrismo della migliore poesia stusiana è una breve lirica in parte non dissimile da [Skazyvsja svit -u bubnach, surmach, džazach], ma presumibilmente databile alla seconda metà del decennio (ZT I, 518) e ancora più vicina alla sensibilità poetica dello Stus maturo:

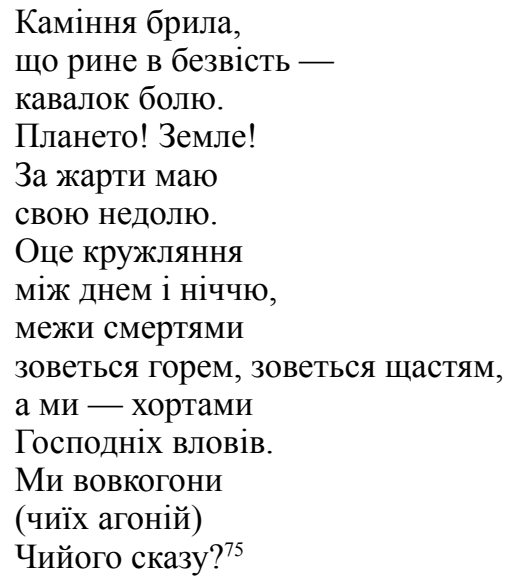

al dolore e alla gioia contadina, / s'è arrabbiato il mondo - povero come un santo, / all'amo dei secoli attaccato per la costola. / Le gazze hanno asciugato il domani umano, / appendendo ai rami un grido di tristezza, / stregonesca si agita tra le labbra la lingua / del folletto di casa notturno - Pater.'

74 L'ipotesi di un sottotesto ševčenkiano per questo verso non trova conferma. Nell'insieme degli scritti ucraini di Ševčenko la gazza si incontra solamente tre volte e sempre con una connotazione chiaramente positiva, in quanto è legata alla donna e alla giovinezza. Cfr. Ilnytzkyj, Hawryschyn 2000: III, 1677-1678. Per un primo studio sull'imagery del mondo animale in Ševčenko cfr. Brogi Bercoff 2011.

75 ZT I, 223. 'Un frammento di pietra / che cade nel nulla - / un pezzo di dolore. / Pianeta! Terra! / Uno scherzo mi pare / la mia cattiva sorte. / Questo ruotare / tra la 
La metafora del "pezzo di dolore", che tornerà in una delle più celebri e antologizzate liriche stusiane degli anni Settanta, è qui ascrivibile sia all'io lirico che alla terra, sostanzialmente identificati nella loro comune abulia. La degradazione della propria mala sorte, termine ševčenkiano per eccellenza, a scherzo sembra qui significare la sottomissione dei destini dell'io a quelli dell'umanità, in un'ottica 'umanistica' che nell'opera dello Stus maturo andrà progressivamente sgretolandosi. In questo momento l'io si trova ancora in comunione con coloro che condividono la sua stessa strada, fatta di incertezza, pericoli, decadimento, alle dipendenze di una divinità imperscrutabile e indifferente. La prima persona singolare è pienamente armonizzata con la prima persona plurale, come spesso nella poesia dello šistdesjatnyctvo, nella speranza che il fragile io possa trovare riparo nella comunità.

Questa tendenza è messa in evidenza anche da un'altra lirica, composta presumibilmente in contemporanea o subito dopo [Kaminnja bryla] ${ }^{76}$ :

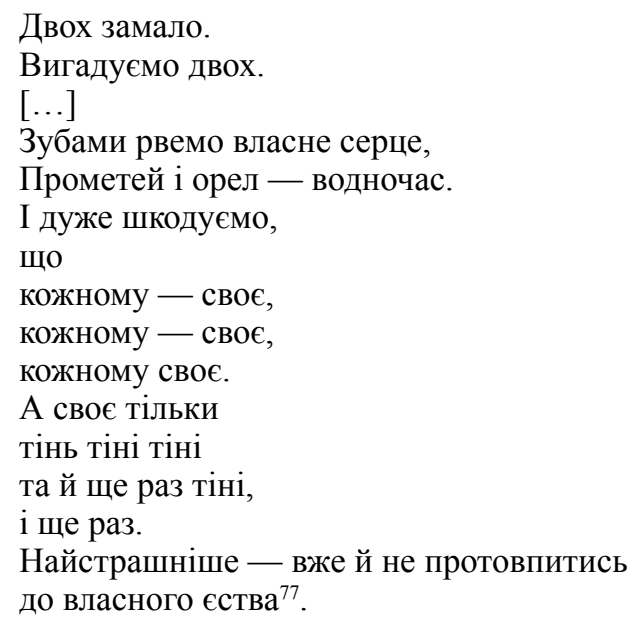

La situazione dell'io è qui sospesa tra una tanto angosciosa quanto paradossalmente rassicurante appartenenza a un "noi" e il riconoscimento di una ormai postmoderna perdita del sé. La persistenza della centralità del principio soggettivo, tuttavia, rende impossibile l'accettazione della propria impenetrabilità. Si pongono qui, dunque, le basi di quello Stus postmoderno che non smetterà di convivere sia con uno Stus moderno/modernista, 'assediando' a tratti la preva-

notte e il giorno, / tra le morti / si chiama pena, si chiama felicità, / e noi - levrieri / della caccia del Signore. / Noi, segugi / (delle agonie di chi?) / della rabbia di chi?'

76 Ivi: 528.

77 Ivi: 224. 'Due - troppo poco. / Pensiamone due. / [...] / Coi denti strappiamo il nostro cuore, / Prometeo e l'aquila allo stesso tempo. / E ci dispiace molto, / che / a ciascuno - il proprio, / a ciascuno - il proprio, / a ciascuno - il proprio. / E il proprio - è solo / l'ombra dell'ombra di un'ombra / e ancora di un'altra ombra, / e ancora. Il più terribile - / è non riuscir più a entrare / nel proprio essere.' 
lenza di quest'ultimo, sia, in misura sempre minore, con uno Stus romanticotradizionale. Si osserva qui, inoltre, l'uso straniante del genitivo moltiplicato destinato a giocare un ruolo fondamentale nel linguaggio poetico delle raccolte mature. "L'ombra dell'ombra dell'ombra" è la paradossale reductio ad nihilum di qualcosa già di per sé privo di materialità e consistenza ontologica. Tuttavia, la lirica è giocata proprio sull'ambiguità tra la perdita dell'essere dell'io e la sua 'semplice' inaccessibilità da parte del soggetto. Come si avrà modo di osservare a più riprese e più approfonditamente a proposito delle opere degli anni Settanta, l'oscillazione tra un mantenimento in chiave modernista del valore fondativo e conoscitivo del soggetto nella sua esperienza di se stesso e della realtà circostante, da una parte, e la sua negazione postmodernista, dall'altra, costituisce una delle costanti distintive dell'universo poetico stusiano maturo. Si noti, inoltre, la persistenza in Dvoch zamalo dell'immaginario espressionista, qui ritrovabile nell'immagine dell'uomo che strappa con i denti il proprio cuore. È invece completamente assente da questi versi qualsivoglia riferimento all'Ucraina e ai motivi patriottici a lei connessi, in sintonia con la tendenza alla desituazionalizzazione del linguaggio lirico di buona parte della poesia degli anni successivi.

Si vedano, parzialmente in contrasto con quanto si è osservato a proposito di Dvoch zamalo, alcuni frammenti di una lunga lirica databile alla metà del decennio:

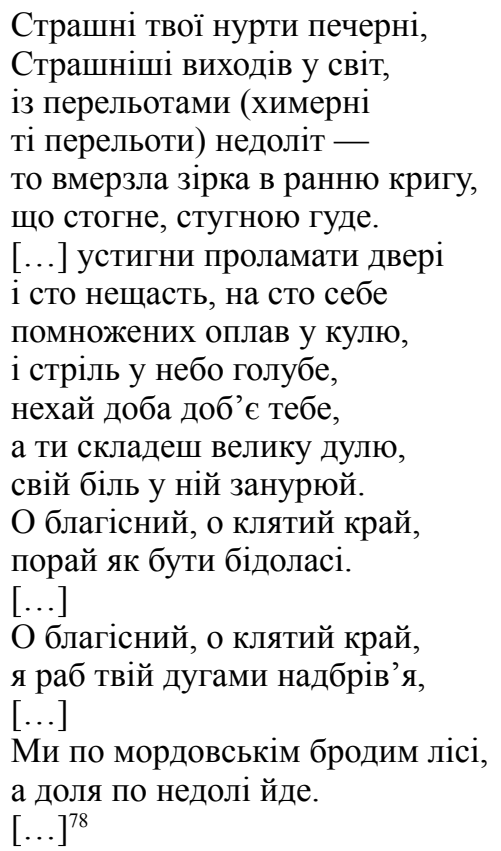

78 Ivi: 226-227. 'Tremende le caverne dei tuoi vortici, / più dell'andar nel mondo, / coi lunghi voli (chimerici / quei voli) la caduta - / una stella gelata nel ghiaccio precoce, / che geme, risuona rimbombando. / [...] rompi in fretta le porte / e le cento infelicità, 
La lirica inizia sulla nota dell'ermetismo espressionista che caratterizzerà la maggior e miglior parte della sua produzione matura, per mostrare in seguito un ulteriore esempio di fusione di linguaggi poetici distinti. L'analisi del sé che il soggetto intraprende, d'ora in avanti definitivamente momento centrale della poesia stusiana, constata l'inquietante insondabilità delle oscure profondità dell'io, incapace di conoscere e accettare se stesso. La skovorodiana umanistica conoscenza di sé (samopiznannja) è tanto ossessivamente ricercata, quanto dolorosamente impraticabile. Il contatto con l'altro, grazie al quale, come sembra emergere dal secondo verso, si è momentaneamente ipotizzato un possibile sollievo dalla fatica del proprio essere, si rivela 'esistenzialisticamente' impossibile, chimerico. La stella immobilizzata nel ghiaccio del quinto verso, simbolo della negazione di qualsivoglia movimento o evoluzione, è pienamente riconducibile all'immaginario espressionista ${ }^{79}$. Gli imperativi che l'io lirico rivolge a se stesso, come si è già potuto osservare, ricollegabili alla vana volontà di comprendere e perfezionare la propria natura, si uniscono qui alla ripetizione della parola "cento" $" 80$, colonna portante della numerologia stusiana, in particolare nella poesia matura. Raggiunta la metà della lunga poesia, l'ormai 'consueta' tonalità ermetico-esistenzial-espressionista si ritrova a fondersi ancora una volta con il motivo nazionale. L'evocazione del potere dell '“epoca" sul debole io e l'invocazione al paese odiato e amato modificano sensibilmente l'ideale collocazione estetica e storico-letteraria del testo, ponendolo (facendolo retrocedere?), come molte liriche stusiane contemporanee, al confine tra modernità europea e (obsoleta) tradizione patria. La 'situazionalità' di Strašni tvoji nurty pečerni è ulteriormente evidenziata dal riferimento al "bosco della Mordovia" verso la conclusione della lirica, quasi anticipazione profetica del destino dell'autore una decina di anni più tardi. L'assimilazione della vicenda personale a quella nazionale tramite la prima persona plurale è inoltre rafforzata dalla ripresa stereotipata della coppia dolja/nedolja, come si è già sottolineato, motivo ševčenkiano per eccellenza.

L'oscillazione tra l'io e il noi, tra la poesia pura e la poesia 'nazionale', tra la modernità e la tradizione contraddistingue la lirica di Stus degli anni Sessanta nella sua interezza. Tra le liriche sparse la tematica ucraina gioca un ruolo nu-

cento volte / fondile in una pallottola, / e spara nel cielo azzurro, / che l'epoca ti finisca, / e ci sarà un grande frutto, / e vi infilerai il tuo dolore. / Oh benedetto, oh maledetto paese, / fai vivere un poveretto. / [...] Oh maledetto, oh benedetto paese, / sono tuo schiavo, ho le sopracciglia ad arco, / [...] / noi per il bosco della Mordovia vaghiamo, / e la sorte per la malasorte va. / [...]'

79 Si veda dalla poesia in prosa Winternacht ('Notte d'inverno') di Georg Trakl, in: Trak1 2012: 71: "Frost und Rauch. Ein weißes Sternenhemd verbrennt die tragenden Schultern und Gottes Geier zerfleischen dein metallenes Herz. // O der steinerne Hügel. Stille schmilzt und vergessen der kühle Leib im silbernen Schnee hin. // Schwarz ist der Schlaf. Das Ohr folgt lange den Pfaden der Sterne im Eis." 'Gelo e fumo. Una bianca camicia di stelle brucia le spalle e gli avvoltoi di Dio dilaniano il tuo cuore di ferro. // Ecco il colle di ferro. Obliato, silente il corpo gelido si scioglie nella neve d'argento. // Nero è il sonno. Lento segue l'orecchio i sentieri delle stelle nel ghiaccio.'

80 Cfr. Rosins'ka 2010: 97-106. 
mericamente rilevante nelle diverse declinazioni che essa può assumere: riferimenti alle figure-guida di Ševčenko ${ }^{81}$ e Skovoroda ${ }^{82}$, riflessioni sulla storia patria recente $^{83}$ e contemporanea ${ }^{84}$, mitizzazione dell'Ucraina e del ruolo profetico del poeta nello spinoso cammino verso la sua auspicata rinascita ${ }^{85}$, ricordi d'infanzia $^{86}$ e bozzetti di costume ${ }^{87}$.

La tematica nazionale può essere sviluppata con un linguaggio di chiara memoria pasternakiana:

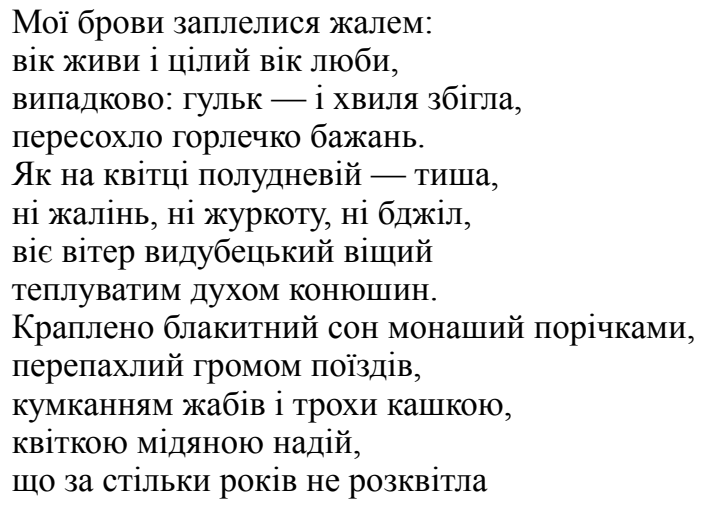

81 ZT I, 352: Taras na zaslanni ('Taras in esilio'): “Світ перейду — і упаду / десь на чужій стерні. / Вже свого краю не знайду, / не попращаюсь." 'Il mondo attraverserò - e cadrò / su qualche campo straniero. / Il mio paese già non troverò, / a lui addio non dirò.'

82 Ivi: 252: Holos Skovorody ('La voce di Skovoroda'): “Я світ утікав. Втікав од себе. / Втікав у себе. В нетрі. У лісі.” 'Ho fuggito il mondo. Ho fuggito me stesso. / Sono fuggito in me. Nel fitto. Nel bosco.'

83 Ivi: 275: "Тридцять сьомий - неначе жарт. / Як кавалок у горлі. / Від країв набігає пожар / У тюремному коридорі.” "Il Trentasette, come uno scherzo. / Come un nodo in gola. / Dai confini irrompe un incendio / nella prigione in corridoio.'

84 Ivi: 340: "Безпашпортний і закріпачений, / сліпий, колгоспний мій народ! / Катований, але не страчений, / рабований, але не втрачений." 'Senza documenti, servo della gleba, / cieco, popolo mio dei kolchoz! / Tormentato, ma non perduto, / schiavizzato, ma non perduto.'

85 Ivi: 329: “Там - Україна. За снігами - там, / лівіше серця. 3 горя молодого / душі мурашник скоро сточить щоглу / та попливем. Бо там - моя мета, / як на хресті розп'ята самота.” 'Là - l'Ucraina. Oltre le nevi, là, / più a sinistra del cuore. Dal giovane dolore / il formicaio dell'anima ergerà l'albero maestro / e partiremo. Perch'è là - la mia meta, / la solitudine come in croce crocefissa.'

86 Ivi: 361: "Бо сплинув вік. I мариться село, / Де руки діда, схрещені в могилі. / Рахнівка. Гайсин. Голубе Поділля." 'Ё passato il tempo. E vedo il villaggio, / le mani del nonno, incrociate nella tomba. / Rachnivka. Hajsyn. L'azzurro Podillja.'

87 Ivi: 215: "Несуть в руках, пропахлих кізяками, / у грудкуватих земляних руках, / тихіше, як за пазухою камінь, / дорідний житній хліб у колосках." 'Portano con mani che sanno di concime / con le mani callose della terra, / in silenzio, come una pietra dietro al seno, il pane abbondante nelle spighe.' 


\begin{abstract}
на пахучих дніпрових вітрах, із світання золотого виткана, із чаїних вересків Дніпра. Цибулина. Горобина. Степ. Дарниця ховає гострі ребра, і збігає Україна стежкою, у руці тримаючи сомбреро ${ }^{88}$.
\end{abstract}

Il brusco accostamento di sfere lessicali distanti tra loro, le ardite consonanze tra barbarismi esotici (sombrero) e parole del vocabolario ucraino e la raffigurazione dell'estenuante instabilità del creato nella sua interazione con l'io lirico sono elementi di chiara derivazione avanguardistica, probabilmente filtrate attraverso la lezione di Pasternak ${ }^{89}$. Tipiche di questa tradizione sono anche l'esasperazione della sinestesia e l'ingrandimento macroscopico del dettaglio. Inconfondibilmente pasternakiana è l'umidità che lega le diverse parti del creato in un fremente, unico corpo ${ }^{90}$, qui il sogno dell'io lirico che arriva ad abbracciare l'esistente nelle sue più svariate manifestazioni, per poi giungere, tuttavia, alle rive dello Dnipro. Nell'ambiguità stessa degli elementi naturali e dei frutti del lavoro dell'uomo che penetrano il sogno del soggetto, il tuono dei treni e il gracidare dei rospi, tanto astratti quanto riconducibili al paesaggio kieviano, è tuttavia ben esemplificata l'ambiguità di fondo di questa poesia, scissa, ancora una volta, tra l'universalità e il particolare, la 'purezza' dell'evocazione lirica e la contingenza della storia. Se i versi più 'pasternakiani' sembrano collocare la raffigurazione lirica in un cronotopo non connotato geograficamente e storicamente, la parte finale della poesia, così come il riferimento al "vento di Vydubyči", situa inequivocabilmente la rappresentazione in un contesto ben definito, quello ucraino e kieviano, in cui le speranze sono tanto insistenti quanto fugaci. Il fiorellino giallo in così tanti anni non è ancora fiorito: il sogno del Disgelo non si

88 Ivi: 278: 'Le sopracciglia intrecciate di tristezza: / vivi, ama la vita, / a caso: / un attimo, ed è passata l'onda, / è secca la gola dei desideri. / Come su di un fiore il pomeriggio - il silenzio, / né lamenti, né sciabordii, né api, / soffia il vento di Vydubyči / presago dello spirito tiepido del trifoglio. / È gocciolato il sogno azzurro monastico di ribes, / intriso dell'odore del tuono dei treni, / del gracidio dei rospi e un po' di zuppa, / del fiorellino ramato delle speranze, / che così tanti anni non fiorisce / agli odorosi venti dello Dnepr, / intessuto dell'aurora dorata, / delle grida dei gabbiani dello Dnepr. / Bulbo. Sorbo. Steppa. / Darnycja con le sue costole acute / e corre l'Ucraina sul sentiero, / col sombrero in mano.'

89 Si pensi, ad esempio, alla prima strofa di Ivaka dalla seconda edizione di Poverch bar'erov (Pasternak 2003-2005: I, 92, 444): “Кокошник нахлобучила / Из низок ливня - паросль. / Футляр дымится тучею, / В ветвях горит стеклярус.” Sul rapporto di Pasternak con le Avanguardie si vedano, tra gli altri, Flejšman 1979 e Locher 1981.

90 Sull'umidità come principio fondante del cosmo pasternakiano si vedano lo scritto cvetaeviano del 1923 Svetovoj liven' e Frank 1962. Per lo stesso motivo in Stus cfr. Pylypiuk 2002a: 186-196. 
è avverato ${ }^{91}$. Il modello di Pasternak ha dunque trovato anche in questo caso un adattamento, una 'ricollocazione' in un contesto storico chiaro e riconoscibile.

Si noti, inoltre, come l'accostamento del vento al "tuono dei treni" possa far ipotizzare un ulteriore sottotesto tyčyniano. La vicinanza cronologica e poetica della lirica del giovane Tyčyna al coevo paradigma pasternakiano, come si è già più volte osservato, è molto produttiva per il giovane Stus. Si pensi a Viter z Ukrajiny ('Vento d'Ucraina'):

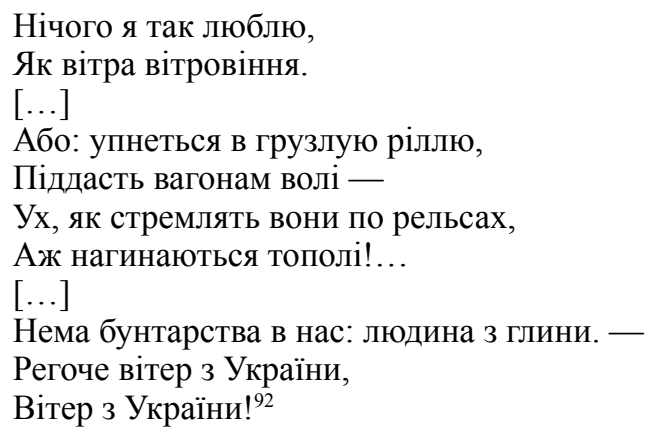

Nel testo stusiano, diviso dal possibile modello tyčyniano da circa quarant'anni, il vento sembra aver rallentato, avvicinandosi all'immobilità dell'uomo ucraino e sovietico immortalata dalla lirica di Tyčyna. Si noti in entrambi i testi la vicinanza del campo semantico del vento a quello ferroviario - fondamentale in Pasternak - e, in generale, la fusione dei tre piani dell'umanità, della tecnica e della natura.

Nei testi degli anni Sessanta la poesia stusiana persegue l'amplificazione della singola immagine poetica, della singola area semantica e del singolo procedimento in quanto fine a se stesso, come esercizio di stile di un giovane poeta ancora alla ricerca del proprio 'marchio di fabbrica'. Liriche degli stessi anni, come si è visto, possono essere attribuite a linguaggi e visioni del mondo distanti tra loro, in particolare, ovviamente, se si tratta di testi non destinati a essere inclusi in una raccolta. Così, i germi dell'universo poetico di Palimpsesty possono convivere con versi ascrivibili a tradizioni molto differenti. Si confrontino Narodžennja ('Nascita') e [Ty mertvyj. Mertvyj ty. Žyvyj - i napivmertvyj] (['Sei morto. Morto sei. Vivo - e mezzo morto]'). La prima è databile all'inizio del decennio o alla fine degli anni Cinquanta (ZT I, 491), mentre le numerose redazioni della seconda, chiara anticipazione della lirica matura, testimoniano del faticoso lavoro di limatura del testo durato probabilmente per anni (ivi: 504). Si veda Narodžennja:

91 I curatori non propongo tuttavia un'ipotesi di datazione per questa lirica.

92 Tyčyna 1971: I, 104. 'Niente amo tanto / quanto il vento che è ventoso. / [...] / Si infila nei campi grevi, / dà la forza ai treni in corsa - / oh, come corrono sulle rotaie, / anche i pini gli si inchinano!... / [...] / Non siamo ribelli, noi: gente d'argilla. / Ride il vento d'Ucraina, / il vento d'Ucraina!' 
Рятуйте мене, хто навколо!

Згоряю!

Диміють вже скроні,

Горю!

Даруйте,

Як яро

Мов золотом брязну об площу,

сполощу

Юнацькою кров'ю зорю!

Сто сонць почорніло в очах!

Сто лиць, мов вуглин, почорнілих.

Душа, мов черінь,

Од вогню очамріла,

Пожежно важка

Голова-головешка.

Рятуйте - пожар!

Поспішіть. Бо Земля згорить

В хижому полум'і! ${ }^{93}$

Il soggetto mostra qui con giovanile ardore la pienezza e la potenza del proprio io, talmente carico di energia e vitalità da mettere a repentaglio se stesso e il mondo circostante. Non c'è differenza tra l'io lirico e la Terra: la fiamma del primo, nell'istante della nascita, contagia la seconda, assoggettata alla potenza creatrice del Poeta. Elementi tipici del lessico e dell'immaginario della poesia stusiana matura, come il fuoco e il numerale cento, sono qui deputati a rappresentare la forza del soggetto e non il suo dissolvimento, come più spesso nel periodo successivo. Anche questi versi sono ascrivibili al filone di ispirazione avanguardista dell'opera giovanile dell'autore. L'incendio dell'io è accostabile, ad esempio, al famoso "požar serdca" del majakovskiano Oblako v štanach, nel quale all'eruzione della personalità del soggetto seguono il divampare della sua fiamma tra lo stupore e il panico degli astanti (Majakovskij 1968: I, 103-105 passim):

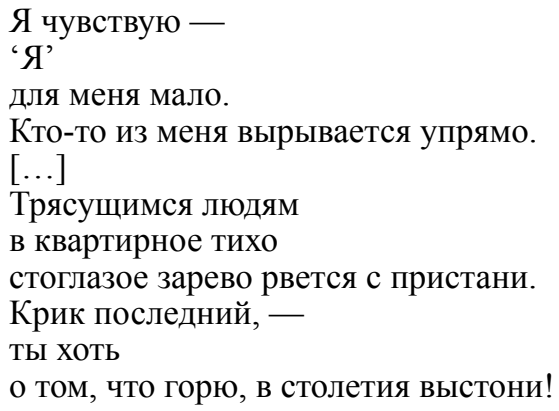

93 ZT I, 358. 'Salvatemi, gente! / Brucio! / Già fumano le tempie, / brucio! / Ammirate, / con che splendore, / come fossi d'oro sbatto sulla terra, / lucido / di sangue giovane la stella! / Cento soli ora neri negli occhi! / Cento volti, come carbone, ora neri. / L'anima, come un forno, / è impazzita di fuoco, / pesante d'incendio / la mia testolina. / Salvatemi - un incendio! / Fate in fretta. Brucia la terra / di una fiamma rapace.' 
Si noti, inoltre, la coincidenza tra i cento soli stusiani anneriti negli occhi e il bagliore d'incendio dai cento occhi nel poema di Majakovskij. In entrambi i testi l'unitarietà dell'io non è messa in discussione, ma ribadita e rafforzata nella necessità di fuoriuscire dagli angusti confini del corpo nell'irrefrenabile slancio della sua energia.

Di altra natura è invece la situazione dell'io in [Ty mertvyj. Mertvyj ty. Žyvyj - i napivmertvyj]:

Ти мертвий. Мертвий ти. Живий - i напівмертвий.

Між світом цим і потойбічним світом зупинений, вагаєшся збагнуть, де світло, темінь - де.

$[\ldots]$

Як зерна в зерні, як алмаз в алмазі, як крик проваллю відданої жертви, немов північне сяйво царсвту тіней так ти мені ввижаєшся не раз.

...то був двійник, найближчий варіант від твого голосу. [...]

Це він, подумав я. Це той, що ніс Овідія на Соловецький острів цю самострату й самопорятунок. І ось тепер - роздвоївся усмерть.

...дар перевтілення — то Божий дар: грудьми припасти до планети, болем з землею злютуватись і навік позбавитися права самосмерті ${ }^{94}$.

L'indefinitezza del soggetto è sintomo della sua inconsistenza. La sua inanità lo rende impossibilitato a comprendere e incapace di agire. La perdita dell'unicità del sé minaccia l'io, privandolo dell'identità, causando quella confusione tra l'io e il tu centrale all'immagine del soggetto nella poesia stusiana. In questa lirica la distinzione tra l'io e il tu in quanto non-io è ulteriormente complicata dall'ambiguità intrinseca al polo del tu stesso, attribuibile ora al soggetto lirico,

94 ZT I, 396-397: 'Sei morto. Morto sei. Vivo - e mezzo morto. / Tra questo mondo e il mondo ultraterreno / fermo, esiti a capire, / dov'è la luce, la tenebra - dov'è. $/ /[\ldots] / /$ Come un seme nel seme, come un diamante nel diamante, / come il grido di una vittima ceduta all'abisso, / come l'aurora boreale al regno delle ombre - / così tu mi appari di frequente. // ...era il doppio, la versione più vicina / della tua voce. [...] // È lui, pensai. E quello che ha portato / Ovidio alle Solovki - / sua rovina, sua salvezza. // ...il dono della reincarnazione - è un dono divino: / cadere di petto sul pianeta, con dolore / arrabbiarsi con la terra e per sempre / privarsi del diritto di morire.' 
ora al suo doppio ${ }^{95}$, ora a colui "che portò Ovidio alle Solovki", dietro al quale non è difficile riconoscere la figura di Mykola Zerov (1890-1937). Capostipite negli anni Venti della scuola poetica neoclassica kieviana (cfr. Simonek 1992), Zerov ha introdotto nella poesia ucraina nomi, opere, stili e correnti fino ad allora sconosciuti o accessibili solamente in altre lingue. La sostanziale identificazione di sé con Zerov proclamata dal debole io lirico di questi versi è leggibile in chiave metapoetica. Accettando in questo caso la validità di un accostamento tra l'io lirico e l'autore, nelle vesti di Kulturvermittler, si può interpretare questa dichiarazione di consanguineità come indicazione della volontà stusiana di proseguire sulle tracce di Zerov nel cammino di avvicinamento della cultura ucraina al linguaggio dell'arte occidentale nella sua interezza, dal mondo classico alla contemporaneità. Tuttavia, questo momento positivo convive con la consapevolezza della natura intrinsecamente suicida del Poeta in Ucraina ${ }^{96}$, da una parte, così come della postmoderna perdita di ogni certezza e unicità dell'io, dall'altra. La conclusione della lirica, scissa tra l'elogio della volontà di portare avanti la tradizione (qui espressa come "reincarnazione", perevtilennja) e il riconoscimento della vanità di ogni affermazione dell'io, affonda il testo in un cortocircuito semantico prettamente postmoderno. Il neologismo samosmert', tipico del lessico stusiano, sembra indicare il compimento e l'integrazione della personalità nella morte. Non è da escludere che in questa identificazione della morte 'vera' con la vita nella pienezza del suo significato e della sua individualità sia da intravedere una delle prime dimostrazioni delle frequentazioni stusiani con l'opera di Rilke, al cui interno il mito della "morte autentica" occupa un posto di primissimo pia-

95 Sulla produttività e multiformità del motivo del Doppio nella poesia sovietica degli anni Sessanta, Settanta e Ottanta cfr. Pen 1994.

96 Si ricordino a questo proposito Fenomen doby e Znykome rozcvitannja nella loro complementarietà. Per quanto riguarda il dialogo di questi versi con la tradizione ucraina, si noti come come l'accostamento del seme di grano al diamante sia riscontrabile nel dialogo skovorodiano Razgovor, nazyvaemyj alfavit, ili bukvar' mira. Si veda Skovoroda 2011: 683: "Правда, что дружеская бесьда есть возок, путника облегчающій. А тъм он лучше, когда катится на Колесах Пророческих. // О КОЛЕСА! О сладчайшая Въчносте! // Щаслив! Кто взор свой приобучил к свђтозарному твоему блистанїю. Сей почаще взглядывает и вкушает от тебе. // Вот точная манна! А Зерно Ея, мЂлкое, как Корїяндр, разными любителям своим прїятностьми вкус услаждает. Как дражайшїй Алмаз, мечет в очи молнїю разнаго цвьта." Si tratta, al di là del singolo riferimento testuale, di due lessemi-mitologemi fondamentali nell'immaginario di Skovoroda. Una imagery simile, anche se la menzione del diamante è in questo caso solo indiretta, sembra permeare anche il sonetto $V$ Donbasi ('Nel Donbas') di Mykola Zerov. Se ne vedano le due terzine, in: Zerov 1990: I, 55: "I вгору брались ми крізь глід і терен, / Не зводячи очей з огнистих зерен, / Просипаних на кристалічну синь. // В крайнебі гасли просмуги янтарні, / А проти нас крізь млу і далечінь / Займалось дві зорі на солеварні." 'In alto ci spingemmo tra prugnoli e biancospini, / Gli occhi non distolti dal fuoco delle gemme / Sparse sull'azzurro cristallino. // All'orizzonte si smorzavan striature d'ambra, / Di fronte a noi tra la nebbia e la distanza / Due stelle muoversi nella salina.' 
no: "O Herr, gib jedem seinen eignen Tod. / Sterben, das aus jenem Leben geht, / darin er Liebe hatte, Sinn und Not $^{97}$."

A rimanere inalterati sono il dolore ( $\mathrm{bil}^{\prime}$ '), la rabbia e la contrapposizione al mondo, in totale opposizione all'identificazione tra l'io e la terra di Narodžennja. In bilico tra affermazione e negazione del soggetto, lo Stus di [Ty mertvyj. Mertvyj ty. Žyvyj - i napivmertvyj] dimostra la maturità poetica del decennio a venire, aprendo nuovamente una finestra sull'universo poetico di Čas tvorčosti / Dichtenszeit e Palimpsesty. Si noti il motivo dell'abisso (qui provallja, altrove anche bezdna), fondamentale nell'universo lirico stusiano, nonché, con esiti e significati beninteso distinti tra loro, nell'immaginario di alcuni dei suoi più importanti punti di riferimento, quali lo stesso Rilke e Skovoroda.

Tra le caratteristiche più significative della produzione giovanile stusiana nel suo complesso è inoltre da mettere ulteriormente in rilievo l'alternanza di una predominante concezione negativa del rapporto dell'io lirico con la realtà circostante con il modello a essa opposto. Seppur meno rappresentativa a livello quantitativo, la raffigurazione dell'armonia tra il soggetto e il mondo in cui egli si trova immerso è non meno significativa. La coesistenza dei due modelli è un'ulteriore dimostrazione del carattere sperimentale della prima poesia stusiana, fatta di "maschere" che il poeta alterna nel lungo processo di costruzione del proprio io lirico e di raffinamento del proprio linguaggio poetico, qui ancora scissi tra spinte opposte e suggestioni anche ben poco compatibili tra loro (cfr. Rubčak 1980). Così, il messianesimo à la Ševčenko può convivere con il titanismo majakovskiano:

[...] Щоб мільйоново запліднити вас, я прострілю вас палицею-стеком.

$[\ldots]$

Вагітний світ впаде мені до ніг, запліднений моєю пліттю-злістю, а потім Землю одружу на Місяці, а потім всесвіт одружу понівечений ${ }^{98}$.

$97 \quad$ Si tratta di una celebre terzina da Buch von der Armut und vom Tode (Il libro della povertà e della morte), terza parte di Das Stunden-Buch (1903), in: Rilke 1996: I, 236. 'Oh Signore, dai a ciascuno la sua morte. / Il morire, che viene da quel vivere, / in cui c'è amore, c'è senso e c'è bisogno.'

98 ZT I, 274. '[...] Per fecondarvi a milioni, / vi sparerò con il frustino. / [...] / Il mondo gravido cadrà ai miei piedi, / fecondo della mia furia, / la Terra poi alla Luna sposerò, / spossato l'universo sposerò.' 



\section{Capitolo quarto. La lirica mediana}

\section{Zymovi dereva}

Zymovi dereva ('Alberi d'inverno') è la prima raccolta stusiana pubblicata a stampa. Le complesse vicende editoriali dell'opera mostrano il forte interesse di Stus per quest'ampia selezione della sua opera poetica giovanile, oltre a esemplificare con chiarezza la difficile situazione culturale dell'Ucraina sovietica nei tardi anni Sessanta. L'edizione stusiana di riferimento sarà in questo caso $T$, in quanto l'interruzione dei lavori a $Z T$ non ha consentito una recente ripubblicazione dell'opera nella sua interezza. La scrupolosa ma sintetica ricostruzione della storia testuale di Zymovi dereva nell'apparato critico del primo dei due volumi che compongono il primo tomo di $T$ (T I.1, 353-363) consente di comprenderne con facilità il ruolo fondamentale all'interno dell'evoluzione artistica e umana del giovane Stus. Tre anni dopo l'espulsione dall'Istituto di Letteratura Ševčenko dell'Accademia delle Scienze, Stus cerca di tirare le somme di più di dieci anni di apprendistato poetico con una corposa antologia del proprio lavoro, nutrendo forse la speranza di poter rientrare nel mondo letterario da cui è stato escluso nel 1965. La proposta del manoscritto alla casa editrice "Molod" nel maggio del 1968 si traduce dapprima in due letture editoriali favorevoli, a firma di Ivan Drač e Jevhen Adel'hejm (1907-1982), personalità indubbiamente influenti e autorevoli nell'universo culturale dell'epoca. Tuttavia, Zymovi dereva viene ugualmente rifiutata dalla casa editrice, in un momento di forte recrudescenza del controllo e della pressione sulla vita socio-culturale nel paese. Due anni dopo, all'inizio del nuovo decennio, l'opera esce a insaputa dell'autore per i tipi dell'oscura casa editrice di Bruxelles "Literatura i mystectvo", anche se fonti più recenti ipotizzano che si tratti invece di un'edizione londinese (cfr. Stus 2005: 217). La mancata accettazione del manoscritto a Kiev nel 1968 non aveva scoraggiato Stus dalla prosecuzione del lavoro sul testo, in previsione, con ottime probabilità, di una sua pubblicazione in samizdat. Nell'archivio dell'Istituto di Letteratura Ševčenko sono oggi custoditi più di dieci progetti di revisione dell'opera, nonché, oltre a sue diverse copie approntate in samizdat, il manoscritto che si può considerare definitivo ${ }^{1}$. Quest'ul-

1 Il curatore del tomo sottolinea come il termine "manoscritto" (rukopys) sia qui da intendere in modo convenzionale, trattandosi di un testo composto di materiali scritti a mano, dattiloscritti e misti. 
timo è il frutto delle rielaborazioni del testo del 1968 effettuate nel corso dei due anni successivi, principalmente sulla base dei suggerimenti forniti a Stus dalle due sovracitate letture editoriali, in particolare da quella di Drač. Questa versione del testo sembra rispecchiare pienamente la volontà dell'autore e sarebbe dunque da considerarsi autorizzata. L'edizione a stampa uscita all'estero si discosta dal testo originale per una serie di imperfezioni grafiche e ortografiche, ma soprattutto per la presenza della già citata prefazione autoriale dal titolo Dvoje sliv čytačevi, tra gli scritti in prosa più noti dell'opera stusiana, assente nel testo originale. Degna di nota è anche l'esistenza di un esemplare a stampa donato al traduttore e critico Hryhorij Kočur, che si distingue dall'originale e dalle sue copie in samizdat per la mancanza della suddivisione del testo in tre capitoli.

Nella sua versione definitiva, Zymovi dereva comprende centoquindici liriche, composte in un arco di tempo molto vasto, dal 1957 al 1969. La scelta dell'autore di non seguire l'ordine cronologico nella disposizione dei testi nell'opera, unito all'abbandono del principio ciclico che dominava in buona parte la versione del 1968, rende alquanto difficoltosa la comprensione della logica interna dell'opera, nella quale esperimenti giovanili ancora piuttosto deboli si accostano ad anticipazioni del miglior Stus degli anni a venire. Nel complesso, sembra legittimo affermare che in questa raccolta la vena vitalistica predominante nella prima opera stusiana sia ancora in grado di controbilanciare il linguaggio oscuro, in entrambi i significati del termine, che segna gran parte della poesia degli anni Settanta. Ciò è particolarmente significativo se si tengono in conto due fattori: il lavoro dell'autore sulla selezione delle liriche, da una parte, e le difficoltà della sua situazione pubblica e professionale nei tre anni in cui la raccolta venne realizzata, dall'altra. Stus sceglie di privilegiare quel versante della sua ispirazione poetica più legato alla raffigurazione in chiave avanguardistica della natura e alla rielaborazione artistica della realtà quotidiana e dei motivi di origine autobiografica, così come alla tematica ucraina, a parziale discapito della sua attrazione per il linguaggio espressionista e i motivi 'apocalittici' a esso legati. Ciò non significa, tuttavia, che questi non trovino spazio nelle pagine di Zymovi dereva, ma è innegabile che non ne rappresentino l'aspetto dominante.

L'analisi della raccolta si concentrerà sulla prima parte, composta da trentadue liriche, dalla cui ampia gamma stilistica e tematica emerge con forza la varietà degli interessi letterari del giovane Stus e la sua maestria nell'accostare linguaggi anche molto diversi tra loro, creando un insieme testuale che si regge sull' equilibrio solo a prima vista paradossale tra discordanza e omogeneità.

La lirica introduttiva alla raccolta sembra determinare, come di consueto, la tonalità dell'opera nel suo insieme:

Куріють вигаслі багаття, собаки виють до зірок, а в річці місяць, мов латаття, доріс до повні і розмок. [...] 
Самотність аркою провисла

над райські кущі в пригри снів.

Шукай по них щасливі числа,

так, як раніше ти умів:

той день, як від земної тверді

найперше сонце відійшло,

і той, що мітить знаком смерті

ще нерозгадане число.

А ти іще посередині,

ще посередині твоє.

Отож, радій вечірній днині,

допоки в ребрах серце б'є².

Risalente all'ottobre del 1967, la prima lirica di Zymovi dereva è tra le ultime a essere stata scritta. La prima strofa, così come la seconda qui omessa, sembra preludere a una lirica incentrata sulla raffigurazione del paesaggio naturale, all'interno della quale la presenza dell'io lirico sembra ridursi all'attività fenomenologica della percezione del mondo circostante. Le strofe seguenti mostrano invece come sia il soggetto stesso a ritrovarsi al centro del testo, in un'ottica auto-riflessiva prettamente poetologica. L'io raffigura l'evoluzione, o meglio l'involuzione della propria capacità conoscitiva e creatrice, che sembra aver perso nel presente il dono della penetrazione nell'ignoto e nel misterioso. In chiave orfica, la parola poetica appare inscindibilmente legata alla sfera della morte. Solo l'accettazione della totalità dell'essere nella fusione dell'apparente separazione tra vita e morte permette al poeta la comprensione del mondo. Risulta così evidente come non ci sia contraddizione tra il giorno e la sua caratterizzazione come "serale" al penultimo verso. All'occhio del poeta ogni cosa supera la contrapposizione con il proprio contrario, rivelando l'intrinseca unitarietà del tutto. Tuttavia, per raggiungere e conservare questo stato di empatia con la natura profonda del mondo il poeta deve compiere un percorso di skovorodiana memoria all'insegna della solitudine e dell' ascolto di se stesso, come mostra il richiamo al simbolo del cuore nell'ultimo verso.

Non è difficile osservare come alla base dell'ispirazione di questa lirica si trovino diversi modelli poetici, nonostante il testo, in virtù del ripiegamento dell'io lirico su se stesso nella seconda parte, si riveli inconfondibilmente 'stusiano'. La descrizione del proprio stato esistenziale e il dialogo dell'io con se

2 T I.1, 43. 'Fumano i falò spenti, / i cani abbaiano alle stelle, / nel fiume la luna, come una ninfea, / è piena e si è bagnata. // [...]// La solitudine si è inarcata / sugli arbusti del paradiso, / accompagnando i sogni. / Cerca tra loro cifre felici, / come sapevi fare prima: // quel giorno, quando dalla terra / la prima volta uscì il sole, / e quello che mira con un segno di morte / una cifra indecifrata ancora. // Ma tu sei ancora nel mezzo, / ancora nel mezzo è ciò che è tuo. / Gioisci così al giorno serale, / finché nel petto ti batte il cuore.' 
stesso anticipano una tendenza tipica della poesia stusiana matura, all'interno della quale, come già più volte evidenziato, risulta fondamentale l'uso estensivo dell'imperativo rivolto a un "tu" che altro non è che l'io stesso. Un posto importante sembra spettare all'ultimo sostantivo della lirica, quel "cuore" (serce) che tornerà nel testo successivo di Zymovi dereva. Tra le ricorrenze fondamentali del lessico skovorodiano (serdce, cfr. Skovoroda Online Concordance) e ševčenkiano, il "cuore" (Herz) gioca un ruolo altrettanto di primo piano anche nella tarda poesia rilkiana (cfr. Görner 2002). Se in questi versi il cuore sembra in primo luogo una semplice metonimia della vita, è evidente che alla coscienza dell'autore non poteva non essere ben presente la sua importanza nelle rispettive tradizioni poetiche di Rilke e Skovoroda, due degli autori più importanti nel percorso della sua maturazione letteraria.

Si noti la continuità tra [Kurijut'vyhasli bahattja] e le prime due strofe della lunga lirica seguente:

Сине небо обрієм пролилося.

Лиловіє Труханів острів.

I Дніпро у моїх очах, катери і автомобілі.

I не розхлюпати себе,

I не витримати,

за тамбережні гони

серця не виплескати.

Гримить радіо. Надсадне тріщать сороки.

Натужно здіймається автобус угору.

А ти відкритий — для всіх чотирьох вітрів,

відкритий, як шлюз,

3 котрого

не витікає вода ${ }^{3}$.

La vicinanza tra le due liriche in questione esemplifica ottimamente tanto la coesione della raccolta, laboriosamente costruita da Stus nel corso di tre anni, quanto, ancora una volta, la ricorrenza di determinati motivi e stilemi in momenti diversi del cammino umano e letterario del poeta. [Syve nebo obrijem prolylosja], infatti, risale al $1964^{4}$, tre anni prima di [Kurijut'vyhasli bahattja]. Nel lasso di tempo che separa la composizione dei due testi la vita di Stus è radicalmente cambiata, segnando il suo destino per i due decenni a venire. Le proteste del 1965, la conseguente espulsione dal dottorato e l'inizio della Dissidenza hanno

3 T I.1, 44. 'Il cielo grigio si è versato all'orizzonte. / Si fa lilla l'isola di Truchan. / E lo Dnipro negli occhi miei, / le barche e le automobili. / E non disperdere se stessi, / e non trattenere, / correndo all'altra riva / il cuore non rovesciare. // Tuona la radio. Tese stridono le gazze. / Con sforzo si solleva in alto l'autobus. / E tu ti apri - a tutt'i quattro venti, / aperto, come una chiusa, dalla quale / non scorre acqua.'

4 L'apparato critico di $T$ non riporta inoltre varianti per la prima strofa del testo, da ritenersi, dunque, già concepita nella sua versione definitiva nel 1964 . 
posto le basi per la 'seconda parte' della biografia stusiana, quella del 'martire' dell'Ucraina moderna. Tuttavia, questa esperienza non sembra lasciare, almeno per il momento, una traccia evidente nell'opera del poeta, come mostra la chiara vicinanza dei due testi in esame. Ciò sembra valere come argomento a favore di una più cauta sovrapposizione tra il "testo stusiano" e la biografia eroicizzante del dissidente ed eroe nazionale Vasyl' Stus. Le liriche composte dopo il 1965 non riflettono infatti necessariamente lo sgretolarsi del percorso iniziato dal poeta negli anni precedenti, volto alla realizzazione del proprio straordinario potenziale creativo e scientifico.

È facile notare come nelle due liriche in esame il focus si restringa da un'iniziale descrizione del paesaggio all'auto-analisi dell'io lirico, con un successivo restringimento al proprio cuore. Anche in [Syve nebo obrijem prolylosja] la caratterizzazione che il soggetto da di se stesso è costruita sulla base dell'accostamento ossimorico di parole in contrasto tra loro. Alla ricerca di un equilibrio tra chiusura e apertura, concentrazione sul sé e ricettività verso il mondo, l'io lirico arriva a identificarsi integralmente con il cuore, attribuendo dunque a quest'ultimo un peso specifico decisamente maggiore rispetto alla lirica precedente. $\mathrm{Nel}$ superamento poetico di ogni apparente contraddizione, il soggetto può e deve ritrovare il proprio posto nel mondo, qui significativamente ridotto al paesaggio naturale e urbano di Kiev. Nella fusione dell'elemento naturale con la traccia dell'uomo nello spazio kieviano è rappresentato un modello produttivo di risoluzione dei contrasti che marcano l'esistenza dell'uomo pensante. Notevole è, dunque, la differenza tra l'ottica 'localista' di questi versi del 1964 e la versione universalizzante della più tarda [Kurijut'vyhasli bahattja].

La stessa tematica è ripresa con una tonalità diversa nella lirica seguente, la terza, dunque, della prima parte di Zymovi dereva:

О що то - єдність душ? О що то - щирість?

Довіра? Приязнь? Що то є любов?

То рівновага звички. Скам'яніле здивовання, подовжене в віки.

... і і тільки те? а вглиблення чуття?

а самороздаровування - замість

самозбереження? а крик добра -

ці щедрі іскри самопрозрівання?

[...]

(пізнання меж, які нас віддаляли

од себе!).

О наломи гіркоти,

що трудять груди! Ти - нелюдина,

[...].

Ти варіант.

Невчасний гість. 3 запізненням зустрів

тебе твій вік. А ти прийшов зарання,

i, доростаючи, лиш серцем покривив. 


\section{I чим ти став? I чим ти можеш стати? \\ ...хіба ти не один? Не сам один? \\ [...] Чистота твого чола}

така потрібна в пів на третю ранку 5 .

Con un linguaggio ricco di elementi tipicamente stusiani, come i diversi neologismi basati sulla radice samo-, si dipana in questo testo del 1968 un'enfatica indagine di gusto esistenzialistico sulla natura dei sentimenti umani. Come nel caso delle due liriche precedenti, anche in questi versi al centro dell'attenzione del soggetto è il labile confine tra l'io e il non-io, tra l'arroccamento nel sé e la dispersione nell'altro. Ugualmente in sintonia con [Kurijut'vyhasli bahattja] e [Syve nebo obrijem prolylosja] è lo spostamento da un'ottica universale alla concentrazione dell' io lirico su se stesso, ulteriormente e nuovamente ridotto, infine, al proprio cuore. L'interessante contrasto stilistico tra il patetismo delle domande retoriche nella prima parte, l'angoscia del dialogo del soggetto con se stesso e l'autoironia della pointe dei due versi conclusivi, nei quali un possibile richiamo all'episodio biblico del tradimento di Pietro al canto del gallo sembra 'svalutato' nell'impossibilità di una sua attualizzazione nel presente, induce a considerare questa lirica un esperimento sulla molteplicità dei linguaggi poetici. Che il pastiche sia consapevole sembra emergere altresì dai versi qui citati prima del distico finale, nei quali la riflessione del soggetto sulla propria interiorità sembra allargarsi alla sfera della letteratura - si pensi all'inizale menzione della sincerità, tema fondamentale nella riflessione culturale del Disgelo - e della storia. L'io lirico non può che constatare poetologicamente l'inattualità della propria voce e il nefasto effetto su di essa della contemporaneità, che la costringe ad assumere tonalità forzate e a lei estranee. [O ščo to - jednist' duš? $O$ ščo to - ̌šcyrist'] è inoltre un'evidente testimonianza dell'interesse di Stus per la filosofia esistenzialista qui prevalentemente trattata, tuttavia, come uno dei possibili linguaggi poetici su cui il giovane scrittore si sta cimentando.

A dimostrazione del carattere volutamente eterogeneo del materiale poetico di Zymovi dereva è da considerarsi la scelta di fare seguire al trittico che si è appena analizzato una lirica giovanile, datata 1961-1964, di carattere autobiografico, incentrata sull'esperienza del servizio militare, la cui conclusione è ri-

$5 \quad$ T I.1, 46-47. 'Ma che cos'è - l'unità delle anime? Ma che cos'è - la sincerità? / La fiducia? L'amicizia? Che cos'è l'amore? / È l'equilibrio dell'abitudine. Impietrito / stupore, prolungato nei secoli. / ... e solo questo? e la profondità del sentimento? / e il donare se stessi - e non / conservarsi? e l'urlo del bene - / queste sincere scintille nel chiarire se stessi? / [...] / (la conoscenza dei limiti, che c'allontanano / da noi stessi). // Oh frantumi di amarezza, / che stancano il petto! Sei - non-del-tutto-uomo, / [...]. / Sei un'opzione. / Un ospite inatteso. In ritardo ti ha incontrato / il secolo. Sei arrivato troppo presto / e, crescendo, ti sei solo macchiato il cuore, / e che sei diventato? E che puoi diventare? / ...non sei forse solo? non sei tutto solo? / [ ...] / Il lindore della tua fronte / è così importante alle due e mezza di notte.' 
conducibile al filone metapoetico e poetologico produttivo in tutte le fasi della lirica stusiana:

[...] Оренбург. Шевченко.

І стільки тут у мене земляків -

аж до Печори. Справді бо - Вітчизна.

Заснеш - і волохаті, як клубки,

намотані віками, глухо бродять

плоскінні сни. І в горлі волохатіє.

Розповідай. Розповідай. Кажи ж! ${ }^{6}$

La natura del poeta risulta qui subordinata al riconoscimento del proprio posto nella tradizione patria, ma contemporaneamente frutto di un'allucinazione espressa con una metafora ascrivibile ancora una volta alla sensibilità espressionista, a ulteriore conferma del carattere 'sincretistico' dell'ispirazione e della poetologia stusiana giovanile.

Nei testi che seguono l'ampiezza dei modelli a cui guarda la sensibilità poetica del primo Stus è percepibile in tutta la sua varietà. In Bezsonnoji noči ('Di una notte insonne'), datata 1964, si assiste a un'inebriante fusione di elementi di matrice espressionista, puškinana, cvetaeviana, ševčenkiana, skovorodiana e futurista. Si veda il testo nella sua interezza:

Думи визбираю, мов зерня, ніби стернями колоски.

Колять сльози. Колючі сльози.

Остюками - в очах.

Ніч протовпиться, як п'яниця, по кімнаті, по стінах шастає.

І мовчить, і мовчить. Домовий

так ходив би. Мовчав би.

За вікном гуркотять літаки, ніби відьми - на шабаш.

Понад дахами, понад затихлими, понад притихлим Києвом — гуркотять.

Емігрантом. Їй-богу. Ліжко.

I на ковдрі - од вікон — грати.

6 Ivi: 49. '[...] Orenburg. Ševčenko. / E quanti connazionali ho qui con me - / fino alla Pečora. E certo, è la Patria. / Ti addormenterai - e lanosi, come batuffoli, / ammassati dai secoli, sordi vagano / i sogni di canapa. E come di lana la gola si stringe. / Racconta. Racconta. Dillo, su!' In una versione precedente del testo (ivi: 230) il verso conclusivo suona ancora più esplicitamente come un incitamento a non tacere la parola poetica: “Розповідай. Розповідай. Не мовкни.” 'Racconta. Racconta. Non tacere.' 
I подушка моя скуйовджена, і скуйовджена голова.

Що ви ловите, телевізорні

Збожеволілі антени - погорільці?

Що ви ловите - запалим ротом коміни почорнілі?

Вам повітря забракло? Диму

Розум спертий, як спирт, горить?

Другу ніч уже, другу - не спиться.

Жовкнуть у вікні ліктарі ${ }^{7}$.

Nel titolo stesso della lirica è evidente un richiamo alla tradizione degli Stichi, sočinënnye noč’ju vo vremja bessonnicy puškiniani, ai quali il testo stusiano è debitore nello specifico per quanto riguarda le sue due strofe conclusive ${ }^{8}$. Le domande che l'io lirico di Bezsonnoji noči rivolge alle antenne televisive e ai comignoli delle case kieviane sembrano infatti rimandare strutturalmente al dialogo tra il soggetto puškiniano e il "noioso sussurrio" di una lirica che Roman Jakobson sviscerò come modello di "poesia della grammatica" (Jakobson 1981). In entrambi i testi una serie di domande (quattro nella lirica di Stus, cinque nell'ipotesto di Puškin), costrette per ovvie ragioni a rimanere prive di una risposta, si arresta prima del distico finale, in cui il soggetto esprime apertamente la propria dipendenza dalla realtà esterna e la necessità di raggiungere uno stato di armonia con essa. Negli Stichi, sočinënnye noč ju vo vremja bessonnicy la rappresentazione del rapporto tra l'io e la realtà è affidata alla sfera uditiva (il rintoccare dell'orologio, il sussurrio), poiché il soggetto è immerso nell'o-

$7 \quad$ Ivi: 49. 'I pensieri scelgo come grani, / come spighe per i campi. / Pungono le lacrime. Lacrime pungenti. / Come barbe di grano - negli occhi. // La notte si spinge, come un ubriaco, / per la stanza, corre per le pareti. / E tace, e tace. Il fantasma della casa / così camminerebbe. E tacerebbe. // Oltre la finestra rombano gli aerei, / come streghe al sabba. / Sopra i tetti, / i tetti silenziosi, / sopra Kiev in silenzio - rombano. // Come un emigrante. Dio mio! Il letto. / E sulla coperta - del letto - una grata. / E il cuscino arruffato, / e la testa arruffata. / Cosa prendete, antenne / impazzite del televisore - che avete sofferto l'incendio? / Cosa prendete - con la bocca che casca - / comignoli anneriti? // Vi manca l'aria? Il fumo? / La mente oppressa, come alcool, brucia? / Per la seconda notte, già la seconda - non dormo. / Gialli son nella finestra i lampioni.'

8 Puškin 1949-1950: II, 118: “Мне не спится, нет огня, / всюду мрак и сон докучный; / Ход часов лишь однозвучный / Раздается близ меня, / Парки бабье лепетанье, / Спящей ночи трепетанье, / Жизни мышья беготня... / Что тревожишь ты меня? / Что ты значишь, скучный шепот? / Укоризна, или ропот / Мной утраченного дня? / От меня чего ты хочешь? / Ты зовешь или пророчишь? / Я понять тебя хочу, Смысла я в тебе ищу...” Distante dal linguaggio poetico di entrambi Puškin e Stus è invece l'“insonnia poetica" cvetaeviana, per un'analisi della quale si rimanda a El'nickaja 1994. 
scurità, mentre in Bezsonnoji noči essa avviene sinesteticamente ${ }^{9}$, attraverso il concorso del suono (il rombo degli aerei, l'implicito audio televisivo disturbato derivante dalle antenne "impazzite"), della vista (le impressioni esterne filtrate dalla finestra) e, indirettamente, dell'olfatto (il fumo dei comignoli). Gli elementi offerti dall'ipotesto puškiniano vengono ripensati in chiave novecentesca, mediante la trasformazione del 'classico' sussurrio nel rombo degli aerei e nell'audio della televisione, con la relativa iniezione nel repertorio lessicale e stilistico del testo di elementi legati alla sfera della tecnologia di derivazione avanguardistica. Lo strato puškiniano della lirica, dunque, è introdotto dal titolo e rielaborato nella parte finale.

La prima strofa, tuttavia, crea immediatamente un contrasto nell'orizzonte di attesa del lettore tra l'annunciato rimando a Puškin e l'evidente ripresa di Dumy moji, Dumy moji ('Pensieri miei, pensieri miei') di Ševčenko ${ }^{10}$ al primo verso. La manifesta coincidenza tra le parole iniziali dei due versi è accompagnata dal comune accostamento dei pensieri alle sfere semantiche della piccolezza e della fragilità (i grani e la polvere in un campo) ${ }^{11}$, dal dolore che essi causano nel soggetto che li concepisce e dalle lacrime che egli piange a causa loro. È probabilmente l'evocazione dell'area semantica del sonno al settimo verso a sancire definitivamente il nesso intertestuale tra le tre poesie, conferendo ai pensieri del soggetto la marca dell'insonnia che caratterizza primariamente l'io lirico stusiano e puškiniano.

La presenza ševčenkiana in [Dumy vyzbyraju, mov zernja] non si limita tuttavia alla sola [Dumy moji, dumy moji]. Il nesso tra l'insonnia e la chiusura del soggetto in uno spazio angusto, sineddoticamente rappresentato dalla parete, in [Dumy vyzbyraju, mov zernja] rimanda chiaramente a una breve lirica di Ševčenko del 1847, tra i primi frutti letterari del periodo della reclusione:

9 Sulla frequenza e l'importanza della sinestesia in Stus si veda Pustova 1998: 68.

10 Ševčenko 2003: I, 124: “Думи мої, думи мої, / Лихо мені з вами! / Нащо стали на папері, / Сумними рядами?... / Чом вас вітер не розвіяв, / В степу, як пилину? / Чом вас лихо не приспало, / Як свою дитину?... // Бо вас лихо на світ породило, / Поливали сльози... чом не затопили, / Не винесли в море, / не розмили в полі?... / [...]" 'Pensieri miei, pensieri miei, / Che sfortuna che ho con voi! / Perché state sulla carta / Tristi voi nei versi?.. / Perché non vi sparge il vento, / Particelle nella steppa? / Perché il male non vi culla / Come foste figli suoi?... // Perché il male vi ha messi al mondo, / Lacrime versate... Perché non affogate? / Dispersi nel mare, / Sparsi dentro a un campo... / [...]'. Si noti l'ambiguità intrinseca alla parola duma stessa, nella quale la sfera del pensiero e quella della creazione poetica si fondono inscindibilmente.

11 Si pensi anche all'importanza del lessema zerno (grano) nella prosa skovorodiana, a cui si è già accennato in precedenza. Nel dialogo Kol'co. Družeskij razgovor $o$ duševnom mirě si assiste a un accostamento dell'immagine del grano all'area semantica del pensiero. Si veda Skovoroda 2011: 576: “Зерно и съмя - помышленіе и мненіе." 
Не спалося, - а ніч, як море

(Хоч діялось не восени),

Так у неволі. До стіни

Не заговориш ні про горе,

Ні про младенческие сны.

Верчуся, світу дожидаю,

А за дверима про своє

Солдатськеє нежитіє

Два часовії розмовляють ${ }^{12}$.

Comune alle due liriche è l'impotenza del soggetto di fronte all'immensità e, nel caso del testo stusiano, dell'inquietante imprevedibilità della notte.

Il soggetto ševčenkiano di Dumy moji, dumy moji raffigura se stesso in questi versi inequivocabilmente nei panni di un poeta. Se da una parte la tematica poetologica, abbondantemente rappresentata nella lirica stusiana, può sembrare in questo caso trascurata o elaborata solo implicitamente, si può facilmente ipotizzare che l'epiteto di "emigrante" con cui il soggetto si definisce all'inizio della quarta strofa rimandi a Emigrant, una delle più celebri poesie poetologiche cvetaeviane. Nella prima strofa di quest'ultima non mancano di essere evocati i pensieri (dumy) come fonte di oppressione del soggetto-poeta-emigrante (Cvetaeva 2004: 585):

Здесь, меж вами: домами, деньгами, дымами,

Дамами, думами

Не слюбившись с вами, не сбившись с вами,

Неким -

Шуманом пронося под полой весну:

Выше! Из виду!

$[\ldots]$

Sia il primo testo ševčenkiano qui citato ("Нехай думка, як той ворон, / Літає та кряче, / А серденько соловейком / Щебече та плаче / Нишком люди не побачать, / То й не засміються...”, in: Ševčenko 2003: I, 126), sia il testo cvetaeviano (“Соловьиным тремоло на весу — / Некий — избранный”, in: Cvetaeva 2004: 585) riprendono, inoltre, la tradizionale caratterizzazione del poeta come usignolo, 'novecentescamente' assente dalla lirica stusiana. Comune ai tre testi (e, indirettamente, anche al Puškin di Poèt $i$ tolpa), dunque, è la concezione del poeta come essere 'altro', incompreso dalla massa, reietto, ma superiore. Si noti, infine, la possibile corrispondenza tra l'anagramma dumy/ dymu nell'incipit e nella conclusione di Bezsonnoji noči e nei primi due versi di Emigrant, a metà tra paronomasia e metafora. Come anticipato, Bezsonnoji noči

12 Ševčenko 2003: II, 21. 'Non dormivo e la notte - come un mare / (Ma non correva allora l'autunno), / Così è in prigionia. Alla parete / Né del dolore parlerai, né dei mladenčeskie sny. / Mi rigiro, attendendo la luce / E oltre la porta parlando di sé / E la vita da soldati che vita non è / Due guardie stanno a chiacchierare.' 
presenta, inoltre, ascendenze di matrice espressionista nella raffigurazione della notte nella seconda strofa e un utilizzo del linguaggio della tecnologia memore della lezione futurista.

Si ha dunque a che fare con un meccanismo intertestuale decisamente complesso, nel quale i rimandi tra l'ipertesto e i suoi diversi ipotesti si sommano alle corrispondenze tra gli ipotesti stessi, messe in evidenza dal loro accostamento nell'ipertesto. Il concomitante riuso di fonti puškiniane, ševčenkiane e cvetaeviane e, probabilmente, skovorodiane, oltre a dimostrare l'indubbia e evidente familiarità di Stus con gli universi poetici di questi autori, è una perfetta esemplificazione di "intertestualità costruttiva", ossia basata sul dialogo con testi non interconnessi tra loro, ma inequivocabilmente legati da convergenze di immagini, parole, suoni e sottotesti (cfr. Smirnov 1985: 22 e Zholkovsky 1988).

In apparente contrasto con Bezsonnoji noči è la lirica seguente, Lisova idyli$j a$, datata 1965 e ulteriore esempio del dialogo di Stus con il magistero poetico pasternakiano, nonostante il titolo richiami immediatamente Lisova pisnja, capolavoro di Lesja Ukrajinka. Si veda la prima quartina:

Шишки горять, як кремові цукерки,

і пересохлий травень залюбки

тополь патрошить повстяні чемерки,

одягнені, здавалось, на віки ${ }^{13}$.

L'antropomorfizzazione degli elementi della flora, tipica della tradizione 'magico-naturalistica' della poesia ucraina novecentesca da Volodymyr Svidzins'kyj a Bohdan-Ihor Antonyč, si unisce qui alla fusione avanguardistico-pasternakiana della sfera naturale (le pigne) con quella del byt (le 'gozzaniane' caramelle alla crema), con le conseguenti dissonanze a livello lessicale ${ }^{14}$. Il verso finale ("He спатимуть лиш сосни на поляні, вижалюючись") ${ }^{15}$ ricollega inaspettatamente [Šyšky horjat', jak kremovi cukerky] a Bezsonnoji noči, permettendo così l'identificazione tra i pini e l'io lirico. La solitudine di quest'ultimo è evidenziata anche graficamente dal distacco dell'ultimo verso dal resto del testo.

La stessa ispirazione è alla base della lirica seguente, datata 1962, anch'essa composta da una serie di quartine, di cui l'ultima presenta il quarto verso in posizione staccata, come una strofa a sé stante. Il quadro che si compone davanti agli occhi del lettore è quello di una natura allo stremo delle forze, lacerata dall'ardore della canicola estiva, come in Sestra moja - žizn' di Pasternak ${ }^{16}$ :

13 T I.1, 50. 'Le pigne bruciano, come caramelle alla crema, / e volentieri il maggio riarso / toglie dei pioppi le vesti di feltro, / indossate, diresti, per sempre.'

14 Cfr. Pasternak 2003-2005: I, 119: “Души не взорвать, как селитрой залежь, / не вырыть, как заступом клад."

15 T I.1, 51. 'Non dormiranno solo i pini nella radura, pieni di lamento.'

16 Pasternak 2003-2005: I, 125: “Мой друг, ты спросишь, кто велит, / Чтоб жглась юродивого речь? / В природе лип, в природе плит, / В природе лета было жечь." 


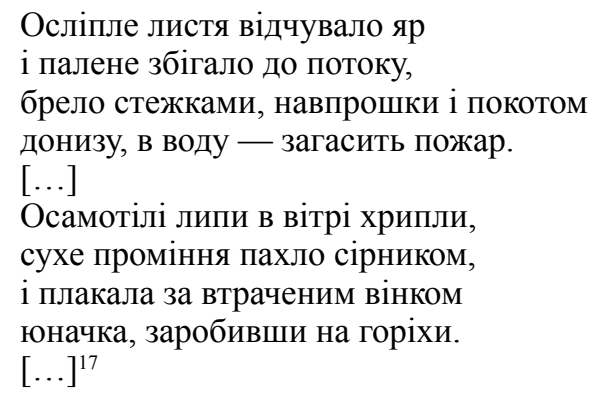

La raffigurazione della corsa sfrenata della natura estiva verso l'apparente salvezza dell'autunno, tanto liberazione dall'arsura del sole, quanto addormentamento momentaneo delle forze vitali, si unisce qui a reminiscenze della tradizione romantica ucraina nella figura della giovane donna dolente, a sua volta non estranea all'immaginario pasternakiano. Il motivo ševčenkiano della pokrytka, la fanciulla sedotta e abbandonata, sembra fondersi con la Donna che l'io lirico di Pasternak confessa trovarsi al cuore della propria ispirazione ${ }^{18}$. Si noti la ripresa stusiana del riferimento ai tigli (lypy), presenti anche nel brano pasternakiano da Sestra moja - žizn' qui ipotizzato come possibile ipotesto. La chiusura della lirica, asciutta come un haiku, non smentisce l'ambiguità intrinseca al testo nel suo insieme, lacerato tra suggestioni di vitalità e minaccia di morte che sembrano in realtà trascendere il probabile punto di partenza pasternakiano in chiave tragica: "Кружляє лист в передчутті біди"

La prima parte di Zymovi dereva non è esente da stridenti e ricercati contrasti stilistici, come nel caso delle tre liriche di Iz cyklu "Zabuttjam" ('Dal ciclo "Con l'oblio"'), il terzo componimento successivo a [Osliple lysta vidčuvalo jar], che segue due testi in cui viene sviluppato il tema del rapporto tra l'io e l'elemento naturale già noto dalle liriche immediatamente precedenti. La seconda e la terza lirica del ciclo sono datate alla fine del 1969. Il trittico inizia con la prosaica descrizione di una consueta scena domestica:

На роботі дружина.

У яслах - син.

Тиша.

Розкошуй. Поки години пік сиди. Втішайся ${ }^{20}$.

17 T I.1, 51. 'Il fogliame accecato sentiva il burrone, / quello bruciato correva al torrente, / vagava ai sentieri, in pianura e in collina, / in basso, all'acqua - a spegner l'incendio. / [...] / I tigli ora soli son rochi nel vento, / rinsecchito il raggio sembrava un cerino, / e piangeva la corona perduta, / la fanciulla, che di noci guadagnava.'

18 Pasternak 2003-2005: II, 88: “И так как с малых детских лет / Я ранен женской долей, / И след поэта - только след / Ее путей, не более, / И так как я лишь ей задет / И ей у нас раздолье, / То весь я рад сойти на нет / В революционной воле.”

19 T I.1, 51. 'Si avvita la foglia, che sente la disgrazia.'

20 Ivi: 53. 'Al lavoro la moglie. / All'asilo - il figlio. / Silenzio. / Godine. / Finch’è l'ora di punta - / stai seduto. / Gioisci.' 
La seconda strofa segna il passaggio dalla sfera della quotidianità alla trascendenza:

Постав розкладачку під соснами, ляж горілиць

і задивляйся в небо ${ }^{21}$.

La terza strofa e i due versi finali sono ormai completamente slegati dalla realtà quotidiana e tangibile, ora rifiutata:

Як ти довго випростуєшся з землі, білий світе!

Десятилітнє терпіння -

вмирання. $\mathrm{CoH}-$

визволення.

Визволення -

для сну.

Порожнеча щастя.

Дякую, Господи!22

La felicità sembra coincidere con l'astrazione dal giogo della gravità terrestre, qui contrapposta al "mondo" (bilyj svit). La morte, o meglio il lungo processo del morire, si assimilano alla liberazione e al sogno. Sembra lecito porre questa triade in relazione con l'attività poetica, a sua volta frutto dell'oblio della vita quotidiana (si ricordi il titolo del ciclo) e delle pastoie che questa comporta. La felicità altro non è che il vuoto, ossia il superamento della materialità della terra.

Più complessa risulta la costruzione della seconda lirica del trittico:

О, тим і дорога мені -

перегортаю сторінки книжок

іду в крамницю,

слухаю Бортнянського

про тебе дума.

Bce.

Ось річище.

Заглиблюйся. Помалу.

Випростуй плечі.

$21 \quad$ Ibidem. 'Metti la branda sotto i pini. / Sdraiati a testa in su / e guarda il cielo.'

22 Ibidem. 'Per quanto tempo ti sollevi dalla terra, / mondo! / Dieci anni di sopportazione - / di morte. Un sogno - / di liberazione. / La liberazione - / per il sogno. // Il vuoto della felicità. // Grazie, Signore!' 
Межи берегами -

задосить світу.

Але перспектива -

уже затвердла.

Сонце іде за ліс.

Віддати іншому свою любов -

то справжній егоїзм.

То вже наполовину бути мертвим.

Егоїстична - смерть.

Перегортаю сторінки книжок.

О, тим і дорога! $!^{23}$

La dinamica del passaggio tra la sfera concreta del reale all'astrazione è meno lineare che nella prima lirica. I riferimenti alla vita di tutti i giorni e la chiusura dell'io nella poesia si alternano qui al momento intermedio dell'amore, a metà strada tra la soffocante concretezza del terrestre e la purezza dell'elevazione. Particolarmente significativo risulta essere il doppio richiamo al libro, indizio del carattere letterario e possibilmente poetologico della riflessione. Nella terza strofa l'io lirico sembra contrapporsi al mondo, ma quest'ultimo penetra sino all'acqua che scorre tra le due sponde del torrente in cui il soggetto cerca conforto dalla quotidianità. Notevole è dunque la distanza dalla prima lirica, in cui il soggetto si assimilava sostanzialmente (e sorprendentemente) al mondo stesso. Anche nel caso di [O tym, i doroha meni] la liberazione dalla pesantezza della materia e della corporalità è rappresentata dal gesto del raddrizzamento, dall'elevazione al di sopra dell'orizzontalità delle cose della terra. Il distacco dalle catene del concreto sembra ora tuttavia meno raggiungibile, anche a causa del carattere cogente del sentimento amoroso.

Nella terza parte del breve ciclo il processo di astrazione del soggetto dalla realtà visibile è giunto all'apogeo:

Вчися чекати, друже,

вчися чекати.

Ластівки на електричних дротах,

${ }^{23}$ Ivi: 54 . 'Oh, per questo mi sei cara - / sfoglio le pagine dei libri / vado al negozio, / ascolto Bortnjans'kyj / il pensiero va a te. // E tutto. // Ecco il torrente: / immergiti. Poco alla volta / raddrizza le spalle. / Tra le sponde / c'è fin troppo mondo. // Ma la prospettiva / è già fissa ormai. // Il sole va dietro al bosco. // Dare a un altro il proprio amore - / è il vero egoismo. / È già esser morti per metà. // Egoista - è la morte. // Sfoglio le pagine dei libri. // Oh, per questo mi sei cara!' 
почорнілих од сині неба,

ще наслухують стумні струми землі.

Ще підсліплі вікна

за тисячі проминулих літ

не витворили своєї духовності.

Ще людська душа

дрижить, як море,

в незручній западині екзистенції.

Ще потерпає вівериця

битий горіх

брати з твоєї руки.

Зарано, друже,

власним піддатися пристрастям.

Тільки так,

вияви - самострати.

Кам'яній. Кам'яній. Кам'яній.

Тільки твердь знає самозбереження ${ }^{24}$.

Gli elementi del mondo concreto che ancora circondano l'io lirico, del quale si rivelano essere metafore, sono manifestazioni di una sfera dell'esistente a metà tra la terra e il cielo: rondini, fili elettrici, finestre. Le prime sono scisse tra il richiamo dell'alto e il richiamo della terra, del quale non si sono ancora del tutto liberate. Le finestre, allo stesso modo, non hanno ancora raggiunto lo stato di rarefazione auspicato. L'esistenza, con un linguaggio di possibile derivazione heideggeriana, altro non è che una buca, in cui l'uomo, caduto dal cielo a cui appartiene e al quale deve sforzarsi di elevarsi, si sente a disagio.

Si possono ipotizzare per la terza parte del ciclo Zabuttjam alcuni riferimenti all'immaginario lirico cvetaeviano, in particolare al trittico Sivilla del 1923 (su Sivilla cfr. Hasty 1996: 83-109) e al già citato Poema Vozducha di quattro anni più tardi. L'idea del ritrovamento del sé mediante l'ascesa e il conseguente superamento delle catene della gravità terrestre ${ }^{25}$ è al centro del poema del 1927, vera e propria summa dell'universo poetico cvetaeviano maturo. L'aspetto più interessante del presunto dialogo intertestuale tra [Včysja čekaty, druže] e Sivilla risiede nel senso volutamente ambiguo che in entrambe le liriche assume il termine tverd', che può indicare sia la volta celeste, sia la superficie terrestre e il campo

$24 \quad$ Ibidem. 'Impara ad attendere, amico, / impara ad attendere. // Le rondini sui fili elettrici, / anneriti dall'azzurro del cielo, / ascolteranno ancora gli opachi raggi della terra. // Ancora le finestre miopi / in mille anni trascorsi / non hanno creato spiritualità. / Ancora l'anima umana / trema, come il mare, / nella scomoda buca dell'esistenza. / Ancora si sforza lo scoiattolo / la noce rotta / di prender dalla tua mano. / È troppo presto, amico / per darti alle passioni. / Solo così: / mostrarsi - è uccidersi. / Impietrisci. Impietrisci. Impietrisci. / Solo la dura pietra sa conservarsi.'

25 Cvetaeva 1990: 579: “Слава тебе, допустившему бреши: / Больше не вешу. / Слава тебе, обвалившему крышу: / Больше не слышу. / Солнцепричастная, больше не щурюсь. / Дух - не дышу уж! / Твердое тело есть мертвое тело: / Оттяготело." 
semantico della durezza a esso etimologicamente connesso. Si vedano le prime due quartine della seconda parte del ciclo cvetaeviano (Cvetaeva 2004: 561):

Каменной глыбой серой,

С веком порвав родство.

Тело твое - пещера

Голоса твоего.

Недрами - в ночь, сквозь слепость

Век, слепотой бойниц.

Глухонемая крепость

Над пестротою жниц.

Le si confronti con la nona strofa del terzo componimento del trittico, dal nome Sivilla - mladencu (ivi: 562):

Но встанешь! То, что в мире смертью

Названо - паденье в твердь.

Nel primo dei due passi cvetaeviani la durezza della pietra è la manifestazione tattile e visiva della liberazione della Sibilla dalla vita umana sulla terra. Il suo impietrimento è nuovamente raffigurato nella strofa seguente attraverso l'immagine della fortezza sordomuta, dunque completamente avulsa dalla realtà circostante, con la quale non è in grado di comunicare. In Sivilla-mladencu, tuttavia, una caratterizzazione univocamente positiva dell'area semantica della durezza è resa problematica dall'utilizzo stesso dell'ambigua parola tverd', che può rimandare tanto alla sfera ctonia e celeste, dunque alla liberazione dalla vita umana sulla terra, quanto alla durezza, ovvero alla materialità dell'esistenza. In un testo in cui i poli convenzionali della negatività e della positività risultano inevitabilmente confusi e non nettamente separabili e tanto più nel caso di una parola intrinsecamente ambigua, in quanto legata alla figura mitica della Sibilla, l'adozione delle consuete categorie valutative sembra risultare impossibile. La Sibilla, che nella terza poesia si fa io lirico, è 'incarnazione' (se è possibile usare questo termine così concreto nel contesto della ricerca dell' astrazione rappresentata dalla Sibilla stessa) perfetta del mitizzato Poeta di Marina Cvetaeva.

Anche il soggetto stusiano persegue la conservazione del proprio io mediante la chiusura del sé all'universo circostante. Utilizzando la parola tverd' come astratto per indicare la durezza in sé, in modo meno ambiguo rispetto al modello cvetaeviano, l'io lirico di [Včysja čekaty, druže] identifica nell'impenetrabilità della pietra l'ideale supremo del rifiuto del mondo da parte del poeta. Si noti, inoltre, come in entrambi i testi ricorra l'area semantica della cecità, caratterizzata in senso inequivocabilmente positivo.

Il contrasto tra un'iniziale, apparente 'situazionalità' e l'effettivo svolgimento del testo sotto forma di "poesia pura" è un procedimento frequente in Zymovi dereva. La lirica che segue il trittico Zabuttjam, datata 1963, ne è un ulteriore esempio: 
Учора, як між сосон догоряв

мій день домашніх клопотів, я думав:

життя - занадто довге задля нас.

Червоні коні пристрасті давно

відцокотіли брест-литовським трактом.

Ось вийди в ніч - ніде тобі нікого,

лише й живого - шлюбна служба псів.

Вже сни, мої заблукані телята, не знають за собою чабана,

обпалених бажань чорніле поле

безмірне, як голодний спокій мій.

Лише кипить у ключ пораннє небо, усипане пітьмою гайворіння, і крику пересохлені фіолети нагадують про тисячі смертей.

Вже тлін протяв мою охлялу душу, не висвітлену спалахами років, а сто ще ненароджених нащадків мені й дихнути вільно не дають.

\section{$[\ldots]$}

Ти тут. Ти тільки тут. Ти тут. Ти тут на цілий світ! I поєдинчим болем обперся об натужні крони сосон. А стогін їхній, вічністю пропахлий, вивищує покари до покор ${ }^{26}$.

Ancora una volta è evidente come al centro del lavoro sulla parola poetica del giovane Stus siano propri la varietà dei registri linguistici e la stratificazione della tradizione letteraria. Straniante si rivela già il passaggio dal primo al secondo verso, ovvero da un incipit che, seppur nella pseudo-localizzazione temporale

${ }_{26}$ T I.1, 55-56. 'Ieri, mentre tra i pini si spegneva / il mio giorno di piccole faccende, pensavo: / la vita - è troppo lunga per noi. // I cavalli rossi della passione da molto / non sento sulla strada di Brest-Litovsk. / Ecco, esci nella notte - per te nessuno in nessun luogo, / anche solo vivo - il rito nuziale dei cani. // Già i sogni, i vitelli miei perduti, / non sanno tra di loro più il pastore, / dei bruciati desideri il campo / è infinito, come la pace mia affamata. // Solo bolle nella fonte il cielo mattutino, / disperso dalla tenebra dei corvi, / e dell'urlo le violette rinsecchite / ricordano di mille e mille morti. // Già ha la cenere penetrato l'anima mia esausta, / non illuminata dai bagliori degli anni, / e cento ancor non nati discendenti / respirare in pace non mi lasciano. // [...]// Sei qui. Sei solo qui. Sei qui. Sei qui - / in tutto il mondo! E col dolore solitario / ti sei appoggiato alle cime tese dei pini. / E il loro gemito, impregnato di eterno, / eleva le pene alla mitezza.' 
di un incerto "ieri", sembra rimandare al topos del vagabondaggio lirico nella natura al repentino abbassamento stilistico delle "faccende domestiche" in cui l'io lirico è immerso. Il terzo verso sembra poi voler riprendere ironicamente il filone della poesia speculativa, proponendo una riflessione tanto apparentemente banale e di poco valore, quanto opposta al locus communis della brevità dell'esistenza.

Anche la seconda strofa è marcata dal contrasto tra l'atemporale metaforicità del primo verso, nel quale l'avverbio davno elide per sua stessa natura i confini cronologici dell'evento, e il riferimento storico-geografico, denso di rimandi all'idea di un'Ucraina fugacemente libera e indipendente, la cui realtà appare ben distante dal presente e dalle angosce che lo accompagnano. Si crea, dunque, un cortocircuito tra la determinatezza storica della visione lirica che si sta dipanando e lo slegamento dai dati della concretezza tipico della poesia pura. A partire dal sesto verso il testo sembra proseguire in questa seconda direzione, abbandonando, o meglio lasciando sullo sfondo la possibile motivazione socio-politica a monte dei pensieri e degli incubi descritti. All'interno di questa porzione di testo riconducibile alla stessa sensibilità poetica sono tuttavia distinguibili diversi sotto-registri. Il "rito nuziale dei cani" al termine della seconda strofa, di per sé nobilitazione poetica di un avvenimento chiaramente basso, si scontra con le venature misticheggianti del verso precedente, a sua volta elevatosi al di sopra della contingenza storica del quinto verso. Maggiormente coesa risulta la terza strofa, in cui viene ripresa la metafora animalesca rielaborata due volte nella precedente. In un'unica lunga frase, maestosamente classica nell'eufonia delle sue due parti parallele, viene raffigurato l'universo interiore dell'io lirico, scisso tra una tranquillità ossimoricamente affamata, il bruciare dei desideri in un campo ševčenkianamente annerito ${ }^{27}$ e il libero fluire dei sogni.

La quarta strofa risalta nell'insieme del testo per l'assenza dell'io lirico, rivelandosi al contempo inconfondibilmente stusiana per l'accostamento di immagini e parole tipiche del suo linguaggio poetico come i corvi, già ševčenkiani, il grido, e le "mille morti". Il quadro dipinto in questi versi, nel quale riaffiora con potenza l'immaginario espressionista già ampiamente utilizzato nei versi giovanili non inclusi in Zymovi dereva, è interpretabile come prosecuzione dell'affresco interiore intrapreso nella quartina precedente, da un punto di vista lirico interno, che esclude soltanto apparentemente l'io lirico per concentrarsi sulla descrizione metaforica del suo vissuto. Dopo questa catabasi la prospettiva si sposta nuovamente all'esterno, come mostra il riferimento all'"anima mia esausta", nuovamente osservata in chiave auto-riflessiva da un io lirico che si guarda dal di fuori e conosce se stesso. Che le "mille morti" della quarta strofa si trovino dentro l'anima del soggetto è esplicitato dal verso successivo, dall'evocazione della decomposizione penetrata nel profondo dell'anima. Quest'ultima appare oscura, non illuminata, parzialmente in contrasto con i bagliori violetti rinsecchiti della quartina precedente. Nei due versi successivi, introdotti dal tipicamente stusiano numerale cento, l'angoscia del soggetto sembra essere messa in relazione con il

27 Ševčenko 2003: II, 143: “Ой, чого ти почорніло, зеленеє поле?” ‘Oh, perché ti sei annerito, o verde campo?' 
suo ruolo profetico di rinnovatore sociale e culturale: la responsabilità del poeta (ucraino), chiamato a espletare il suo compito messianico dalla tradizione, si scontra con la modernità e con la crisi assiologica che questa comporta. I discendenti condizionano l'io lirico, ma la loro nascita è almeno momentaneamente negata, impossibilitata da quelle condizioni storiche accennate nelle prime due strofe, e la consapevolezza di questa assenza toglie letteralmente il fiato al soggetto, ancora una volta lacerato tra $\mathrm{i}$ richiami del passato e la negazione del presente $\mathrm{e}$ del futuro. È qui evidente il richiamo di Stus al Poslanije ševčenkiano, nel cui titolo completo è esplicitato l'appello ai posteri a metà tra preghiera e profezia (cfr. Brogi Bercoff 2012 e Finnin 2011): I mertvym, $i$ žyvym, i nenarodžennym zemljakam mojim $v$ Ukrajini i ne v Ukrajini moje družnjeje poslanije (Ševčenko 2003: I, 348). Se nella dolente epistola ševčenkiana la possibilità di un dialogo ideale con le generazioni future non è esclusa a priori, ma al contrario appassionatamente ricercata, la lirica stusiana sembra allontare postmodernamente l'esistenza stessa di questo futuro ${ }^{28}$, in un contesto in cui l'io lirico stesso ha ormai perduto il pathos profetico del Romanticismo.

Nella sesta strofa, qui omessa, viene sviluppato il quadro dipanatosi nella quarta, che sfocia nel parossistico ripetersi della constatazione della propria presenza al mondo nel quintultimo verso: "Sei qui. Sei solo qui. Sei qui. Sei qui -". Il soggetto è solo in questo mondo, privato della possibilità di una trascendenza redentrice. Il suo dolore trova corrispondenza nella sofferenza dei pini, il cui gemito è, tuttavia, inaspettatamente "impregnato di eternità". Il richiamo a una realtà altra rispetto al presente e alla contingenza si impone alla fine della lirica, contrapponendosi nettamente alla sua precedente negazione. Il passaggio dalle "pene" alle "mitezze" nell'ultimo verso, facilitato dalla paronomasia tra i due sostantivi in ucraino (pokara - pokora), conferisce al testo nel suo insieme un'evidente nota di cristiana rassegnazione, la cui importanza ai fini di una lettura globale della lirica è ben evidenziata dalla sua marcata posizione finale.

Che sia proprio l'oscillare tra la dissonanza e la coesione stilistica a imporsi come cifra interpretativa della composizione di Zymovi dereva è ulteriormente confermato dal fatto che a [Učora, jak miž soson dohorjav] seguano due liriche connesse dal tema dell'infanzia, ma alquanto contrastanti sul piano stilistico. Se la prima di queste si ricollega alla parta finale della precedente per la tonalità elevata ${ }^{29}$, la seconda registra una notevole abbassamento stilistico, nonché un evidente pastiche:

28 Si pensi anche alla conclusione della celebre Grodek (2. Fassung) di Georg Trakl, frutto del trauma della partecipazione del poeta alla Prima guerra mondiale. Si veda Trakl 2012: 95: “O stolzere Trauer! Ihr ehernen Altäre, / Die heiße Flamme des Geistes nährt heute ein gewaltiger Schmerz, / Die ungebornen Enkel.” 'O tronfio lutto! O altari ferrei, / La calda fiamma dello spirito avvicina oggi un dolore violento, / I nipoti non nati.'

29 T I.1, 56: “Мені здалося - я живу завжди. / Неначе в сні було моє дитинство. / Неначе в казці я пройшов цей вік, / і мій вінок, де квітло двадцять весен, / уже пожовк, осипався, опав." "Mi è sembrato che io viva sempre. / Come se 
[...] Він із спецівки вийме хліба шмат і рідний степ ріднішає стократ ${ }^{30}$.

Segue dunque una serie di liriche incentrate sulla tematica amorosa scritti prevalentemente nella prima metà del decennio, nei quali uno stile ora colloquiale, ora romanticheggiante si tinge frequentemente dei colori avanguardistici della contemporaneità ${ }^{31}$, in sintonia con la poetica di gran parte della produzione dello šistdesjatnyctvo. Le sperimentazioni con il linguaggio dell'amore precedono un complesso gruppo di tre testi, unificati dalla data della loro stesura, l'ottobre del 1967. La prima e l'ultima lirica di questo possibile trittico sono segnate da chiare ascendenza pasternakiane, mentre il secondo si staglia al loro interno per una tematica e una tonalità decisamente distanti. Nella prima il motivo ševčenkiano della malasorte (nedolja) viene sviluppato attraverso alcuni richiami a Gamlet, una delle liriche di Jurij Živago che concludono l'omonimo romanzo:

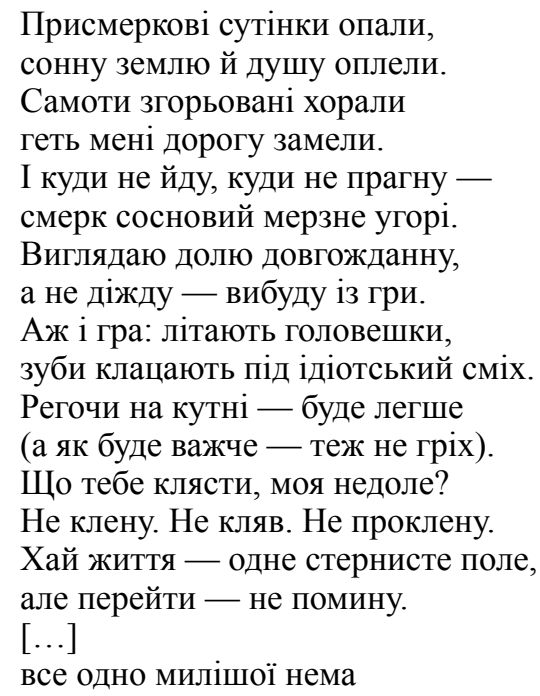

in un sogno fosse la mia infanzia. / Come se in una fiaba passassi questa età, / e la mia corona, dove fiorirono vent'anni, / già sia ingiallita, diradata, cada.'

30 Ivi: 57 . '[...] Dalla tuta prenderà un pezzo di pane - / e la steppa natia cento volte sarà ancor più natia.'

31 Ivi: 58. "Я знаю — / ми будем іще не раз бродити з тобою, / слухати ліс притихлий, / старих і мудрих сорок, / вирізняти гудки азотнотукового заводу, / чути постріли на мовчазному полігоні, / i, лячна, наслухатиме нас земля." 'Lo so - / vagheremo ancora io e te, / ad ascoltare il bosco quieto, / le gazze vecchie e sagge, / a distinguere i fischi della fabbrica di azoto, / a sentire gli spari al poligono silente, / e, paurosa, la terra starà a sentirci.’ Ivi: 59: “[...] I нам любові досі не затвердять / кербуди, коменданти, будівельники / і кубатура наших двох сердець? / Жалкі вітри всю наскрізь прошивають / цю амбразуру недовиконань." 'E l'amore ancora non ci approvano / amministratori, direttori, costruttori / e la cubatura dei nostri due cuori? / I venti pungenti penetreranno tutta / questa fessura di omissioni.' 
за оцю утрачену й ледачу,

за байдужу, осоружну, за

землю цю,

якою тільки й значу

і якою барвиться сльоза ${ }^{32}$.

Si veda dal testo pasternakiano (Pasternak 2003-2005: IV, 515):

Гул затих. Я вышел на подмостки.

$[\ldots]$

На меня наставлен сумрак ночи

Тысячью биноклей на оси.

Если только можно, Авва отче,

Чашу эту мимо пронеси.

[...]

Но продуман распорядок действий,

И неотвратим конец пути.

Я один, все тонет в фарисействие,

Жизнь прожить - не поле перейти.

La lirica stusiana riprende parzialmente il motivo teatrale su cui è basata Gamlet, innestandolo sul tradizionale tema del cammino da portare a termine, a sua volta accennato nell'ipotesto pasternakiano ${ }^{33}$. Comune a entrambi i testi è la solitudine dell'io lirico, impossibilitato a dialogare con gli altri uomini e da loro incompreso e condannato ${ }^{34}$. La senile rassegnazione del soggetto pasternakiano lascia il posto nell'ipertesto stusiano a una vitalistica accettazione dell'esistere nella sua globalità, al cui interno un posto predominante sembra spettare alla lotta e alla sofferenza. La dichiarazione d'amore alla terra con cui si chiu-

32 Ivi: 61 . 'Crepuscolari son calate le tenebre, / hanno avvolto la terra sonnolenta e l'anima. / I cori dolenti della solitudine / mi han cancellato via la strada. / E ovunque vada, ovunque voglia, / l'oscurità dei pini ghiaccia nell'alto. / Osservo la sorte tanto attesa, / se non saprò aspettare - lascerò la parte. / E che gioco: volano le teste, i denti stridono tra una risata idiota. Ridi in cima al palo - sarà più facile / (fosse più pesante non è peccato). / Perché maledirti, malasorte mia? / Non maledico. Non ho maledetto. Non maledirò. / Sia pure la vita solo un campo spinoso, / ma di passarlo - non tralascerò. $/[\ldots]$ / non c'è comunque nulla di più caro / di questa perduta e svogliata, / indifferente, orrida / terra, che sola mi dà un senso, / è per lei che si colora la mia lacrima.'

33 Sulla presenza di Gamlet nel corpus stusiano nel suo complesso cfr. Mychajlova 2016: 163-179.

34 È probabile anche un richiamo all'inizio del Poslanije ševčenkiano, di cui è però smorzata la tragicità. Si veda Ševčenko 2003: I, 348: “І смеркає, і світає, / День божий минає, / I знову люд потомлений / I все спочиває. / Тілько я, мов окаяний, / I день і ніч плачу / На розпуттях велелюдних, / I ніхто не бачить, / I не бачить, / I не знає — / Оглухли, не чують." "Albeggia e si fa sera, / Passa il giorno di Dio, / E ancora stanco è il popolo, / E riposa. / Solo io, come un reietto, / Piango notte e giorno / Ai crocicchi affollati / E nessuno vede, / Nessuno vede / E nessuno sa - / Assordati, non sentono.' 
de [Prysmerkovi sutinky opaly] non lascia dubbi sulle difficoltà dell'inquietante cammino da intraprendere, i cui contorni, come emerge dai primi versi, sono lontani dal potersi dire definiti.

La minaccia di morte univocamente legata alla vita, che la lirica di Stus riprende, rendendola ancora più inevitabile, dal modello di Pasternak, può essere letta nei termini della piena assunzione della responsabilità che al poeta deriva dal proprio sublime e inderogabile compito, per il quale, nel caso di entrambi gli autori, sono ovviamente possibili e in questo caso necessari rimandi alla realtà extratestuale della loro concreta esperienza storica: da un lato lo Stus dei tardi anni Sessanta, privato della possibilità di partecipare alla vita artistica e culturale, di per sé soffocata dalla sempre maggiore recrudescenza del neo-conservatorismo del post-Disgelo, dall'altro il Pasternak degli anni Cinquanta, scisso tra la dissidenza e la partecipazione all'establishment, la relativa possibilità di continuare a lavorare e il peso delle pressioni dall'alto. La riflessione poetica e metapoetica sulla funzione del poeta nella società totalitaria diventa così una tematica artistica che il giovane Stus rielabora sulla scia del modello di Pasternak, in evidente contrasto con l'annuncio del superamento dell'influenza pasternakiana proclamato in Dvoje sliv čytačevi.

Il tema della consapevolezza della propria eccezionalità in quanto poeta $\mathrm{e}$ del proprio conseguente distacco dall'umanità circostante è ripreso nella lirica seguente, la seconda di quello che si lascia facilmente interpretare come un trittico. Divenuta in seguito uno dei testi più celebri e antologizzati dell'intera produzione stusiana, [Otak žyvu, jak mavpa sered mavp] è intimamente legata a [Prysmerkovi sutinky opaly], anche per essere stata composta negli stessi giorni, nonostante le loro apparenti differenze:

Отак живу, як мавпа серед мавп чолом прогрішним із тавром зажури все б'юся об тверді камінні мури, як їхній раб, як раб, як ниций раб. Повз мене ходять мавпи чередою, у них хода поважна, нешвидка.

Сказитись, легше, аніж буть собою, бо ж ні зубила, ані молотка.

О Боже праведний, важка докука сліпорожденним розумом збагнуть: ти в цьому світі — лиш кавалок муки, отепрлий і розріджений, мов ртуть ${ }^{35}$.

35 T I.1, 62. 'Vivo così, come una scimmia tra le scimmie, / marchiato di tristezza sulla fronte peccatrice, / sbatto e sbatto su duri muri di pietra, / come il loro schiavo, uno schiavo, un povero schiavo. / Davanti a me passan le scimmie in fila, / il passo serio, non veloce. / Più facile impazzir ch'esser se stessi, / non ho scalpello, non ho martello. / O Signore Iddio, è una brutta seccatura - / capire con la mente nata cieca: / tu in questo mondo - solo un pezzo di tormento / inerte e rinsecchito, una palla di mercurio.' 
L'io lirico sembra inizialmente affermare la propria comunanza con la società, se così si può definire l'autocompiaciuto branco di scimmie che gli passa di fianco. In realtà, la comprensione dell'assurdità di questa esistenza e il conseguente disagio mostrano l'assoluto distacco del soggetto dalla compagine umana, che sembra essere all'origine dell' annichilimento della sua persona descritto nel distico conclusivo. Come spesso nell'intera opera stusiana, anche in questo caso non è possibile identificare esclusivamente nella contingenza storica o nella natura profonda dell'uomo le cause dell'alienazione e della sofferenza del soggetto pensante. È invece evidente come questa lirica testimoni delle origini profonde della metaforica stusiana relativa alla sfera semantica della reclusione (cfr. Burjanyk 1997), presente e produttiva già ben prima della reale incarcerazione dell'autore. Ciò dimostra ancora una volta come l'elemento biografico, generalmente ritenuto fondamentale per l'elaborazione dell'imagery stusiana, sia in realtà subordinato allo sviluppo intrinsecamente letterario della poesia stusiana stessa, definibile, almeno fino al 1972, come un campo di sperimentazione di tendenze estetiche anche molto distanti tra loro, all'interno del quale, anche in virtù dell'esperienza biografica dell'autore, sarebbe poi prevalsa la linea ermetica della fase matura. Che l'image$r y$ legata alla reclusione possa a livello più generale essere collegata alla condizione esistenziale dell'intellettuale nella società totalitaria è evidente, ma l'elemento storico non è necessariamente prevalente rispetto alla pura letterarietà dell' image$r y$ stessa. Si noti ancora la caratterizzazione che l'io lirico dà del proprio intelletto, "nato cieco". L'attributo della cecità sembra così acquisire ora una sfumatura chiaramente negativa, in contrapposizione all' effetto purificante che essa mostra in [Včysja čekaty, druže]. La sua mente fatica a comprendere il mondo degli uomini $\mathrm{e}$, dunque, anche il proprio ruolo nell'ambito di quest'ultimo. È tuttavia manifesto come la lirica nel suo insieme sia pervasa da una profonda ambiguità semantica. Da una parte, la contrapposizione del soggetto all'ordine delle cose nel consorzio umano lo fa apparire scisso, scarno, lo rende incapace di essere se stesso, oltre che, chiaramente, di sapersi integrare nella 'normalità'. Dall'altra, la contrapposizione stessa che sembra svilupparsi nel corso del testo sembra essere negata a priori dal primo verso, nel quale a essere postulata è al contrario l'identità tra l'io e la massa. Il soggetto si ritrova dunque paradossalmente lacerato al crocevia tra l'assimilazione in un consorzio umano alienato e la sua innata differenza da esso. Questa problematicità rende [Otak žyvu, jak mavpa sered mavp] profondamente sintomatica di una dualità inscindibile dalla struttura semantica della raccolta stessa e, più in generale, dell'universo poetico stusiano nella sua interezza.

Si veda l'ultima lirica dell'ideale trittico:

Справляю в лісі самоту.

Берези у воді по горло, мов риби, тріпаються, чорно в очах. I ластівка проворна вгорі прокреслює мету.

Справляю в лісі самоту. 


\begin{abstract}
Гривасті сосни, як пантери, спокійні в люті. Атмосфера гріха - в причаених печерах, ялин отіння - наче негри. А попри стежку день потух. $[\ldots]$
\end{abstract}

Не так живу? Не так росту? І відкриваю світ? - не так я? Прокльон - навзаєм віддяки? Ще не збагнув? Вони однакі.

Вода, як вурда переляку.

Справляю в лісі самоту ${ }^{36}$.

A prima vista molto distante dalla coeva lirica che la precede, [Spravljaju $v$ lisi samotu] sviluppa coerentemente la tematica della solitudine elaborata in [Prysmerkovi sutinky opaly] e [Otak žyvu, jak mavpa sered mavp]. Rappresentando la condizione del soggetto in uno stato di relativo equilibrio, la lirica si ricollega alla prima parte del trittico, in cui, come si è visto, la fiducia nelle proprie forze portava il poeta solitario a inneggiare alla terra e alla propria presenza su di essa. In questi versi l'io non è pienamente sicuro del proprio cammino, ma riesce a trovare una precaria armonia immergendosi nella natura e fondendosi con essa. Anche [Spravljaju v lisi samotu] si tinge di venature pasternakiane, conferendo coesione e circolarità al gruppo di tre poesie di cui si suppone l'unitarietà. Pur non mostrando vere e proprie citazioni come nel caso di [Prysmerkovi sutinky opaly], i primi versi del testo riprendono l'idea della fusione tra il soggetto e l'elemento naturale centrale all'universo poetico di Pasternak, nel quale l'interazione tra l'uomo, la flora e la fauna è alla base dell'estasi poetica che smuove e ricompone il tutto (cfr. Žolkovskij 2011: 10-24). Anche l'inaspettato paragone di sapore avanguardistico tra l'acqua e la "ricotta dello spavento" al penultimo verso è inquadrabile nella tradizione stilistica pasternakiana. Se però nella poesia pasternakiana 'classica' a dominare è un'inebriante sensazione di sfinimento creativo, la presenza del soggetto nella natura si risolve qui nel quadro di una momentanea fuga dal consorzio umano e dal demone della conoscenza di sé, che si traduce solitamente in angoscia e disperazione. Le perplessità dell'io lirico su se stesso e sul proprio incerto cammino prende il sopravvento sulla raffigurazione dell'elemento naturale, mostran-

${ }_{36}$ T I.1, 63. 'Compio solitudine nel bosco. / Le betulle nell'acqua alla gola, / come pesci, saltano nere / negli occhi. La rondine lesta / in alto segna la meta. // Compio nel bosco solitudine. // La criniera come pantere, i pini / tranquilli nella furia. Atmosfera / di peccato - nelle grotte racchiuse, / l'ombra degli abeti - come negri. / Lungo il cammino il giorno s'è spento. // [...] // Non vivo come devo? Non cresco come devo? / E scopro il mondo - non come devo? / Imprechi - al posto di dir grazie? / Non ho capito? Sono lo stesso. // L'acqua ricotta di spavento. // Compio nel bosco solitudine.' 
do chiaramente l'impostazione 'ego-centrica' che caratterizzerà la poesia stusiana matura, di cui si stanno ponendo le basi nella seconda metà degli anni Sessanta.

Avvicinandosi alla conclusione, la prima delle tre parti di Zymovi dereva fa seguire al trittico appena analizzato una serie di liriche molto diverse tra loro per tematiche e tonalità, composte prevalentemente nella prima metà del decennio. Alla lunga stilizzazione di una colloquiale lettera amorosa fanno seguito una rielaborazione poetica del linguaggio tipico dell'Esistenzialismo ${ }^{37}$, tre rielaborazioni di materiale folclorico e una lirica di argomento autobiografico ispirata al periodo del servizio militare.

Questa serie eterogenea è interrotta da una poesia tra le più celebri di Stus, con la quale ha inizio l'ultimo gruppo di testi della prima parte:
Утекти од себе геть світ за-очі, у небачене, нечуте, у немовлене, де нема ані осмут, ані радощів, де ніщо не збавлене, не здолане. Жив би там - безоко і безсердо, жив би так, як опадають вниз, поріднившись із земною твердю, до якої намертво приріс поглядом і серцем і думками (хто тебе такого віднайде?). Нерухомий і крихкий, як день, що зотлів і вижарів, і знов котиться з мулькавого поранку. Ти - Адам. Журба - твоя коханка, а земне тяжіння — то любов ${ }^{38}$.

Composti nel 1965, questi versi sono un'ulteriore e significativa testimonianza dell'interesse di Stus per il linguaggio della filosofia esistenzialista. Al centro di [Utekty od sebe het'svit za-oči] è l'idea stessa del soggetto, tema fondamentale della riflessione filosofico-letterario della modernità e postmodernità. La contraddittorietà intrinseca alla trattazione dell'io nella poesia stusiana, perfettamente esemplificata in questi versi, comporta un'apparente negazione dell'unitarietà del soggetto, alla quale non corrisponde tuttavia una sua effettiva

37 Ivi: 67: “Коли ти спробуєш себе перервати, / а я спробую перервати себе — / жодному з нас не вдасться / бути одночасно собою / і кимось іншим. / [...]" 'Quando proverai a strapparti / e io proverò a strappare me - / a nessuno di noi riuscirà / di essere insieme noi stessi / e qualcun altro. / [...]'

38 Ivi: 72. 'Scappar da sé, via, da qualunque parte, / nel non-visto, non-detto, nonsentito, / dove non c'è né gioia, né tristezza, / dove nulla è rovinato, nulla è vinto. / Lì vivrei, senz'occhi e senza cuore, / così vivrei, come cadendo giù, / ora fratello della terra dura, / a cui mi sono mortalmente unito / col cuore e coi pensieri / (chi ti troverebbe in questo stato?) / Immobile e fragile come la pietra, / immobile e fragile come il giorno, / bruciato e consumato, che di nuovo / si muove dal mattino che l'opprime. / Tu sei Adamo. La tristezza - la tua amata, / la gravità terrestre - è l'amore.' 
post-moderna disgregazione. Questo modello sarebbe rimasto dominante nel corso dell'intera produzione poetica stusiana matura. Se la prima quartina annuncia in maniera esplicita il paradossale desiderio del soggetto di liberarsi dalle pastoie della propria natura, la seconda strofa dimostra l'impossibilità del superamento del principio soggettivo. La ricerca di un chimerico io-senza-cuore annunciata nel quinto verso è 'umanisticamente' sconfessata dalla mortale unione del cuore stesso con la terra quattro versi più tardi. Lo stesso dicasi per la capacità del soggetto di percepire il mondo a livello sensoriale, il cui superamento è dapprima invocato ("Жив би там - безоко і безсердо") е successivamente riaffermato (“поглядом і серцем і думками”). Mentre nella prima strofa è la lingua stessa a segnalare l'auspicata e apparente vittoria del soggetto su di sé attraverso l'utilizzo in senso ottativo di un modo impersonale come l'infinito, la presenza inderogabile dell'io a se stesso viene pienamente riaffermata nel quinto e nel sesto verso dall'anafora del verbo vivere al congiuntivo singolare maschile. L'incertezza nell'attribuzione di questo verso a una persona, a causa della mancanza del pronome personale, è da ricollegarsi all'oscillazione tra l'io e il tu tipica, come si è ormai potuto ampiamente notare, di tutta la poesia stusiana incentrata sull'auto-analisi del soggetto. La mancata ricorrenza del pronome personale soggetto io nel testo di una lirica interamente incentrata sull'io stesso è compensata sia dall'evocazione di "sé" nel primo verso, sia, e soprattutto, dal triplice rimando alla seconda persona singolare nei versi successivi. Che un testo a prima vista 'negativo' sia in realtà una vera e propria affermazione di fedeltà alla vita nella sua totalità è dimostrato inoltre dal drastico ridursi delle negazioni a radice ne-/ $n i$ - nella seconda parte della lirica rispetto ai primi versi. Particolarmente degna di nota è la doppia valenza dell'area semantica della terra e della gravità terrestre al settimo ("поріднівшись із земною твердю") е al quindicesimo verso (“a земне тяжіння — то любов"). Nel primo caso è probabilmente il suo aspetto ctonio a prevalere: la progressiva fusione dell'io lirico con la terraferma sembra essere sinonimo del suo distacco da tutto ciò che è umano, cioè della sua morte. Nell'ultimo verso, al contrario, il richiamo della terra attraverso la gravità, citazione letterale del titolo della raccolta postuma Zemne tjažinnja ('La gravità terrestre') dello šistdesjatnyk Vasyl' Symonenko e di un verso all'interno della raccolta stessa, è identificato come forza amorosa, in pieno contrasto con la connotazione precedente. La disposizione della parola "amore" in fondo all'ultimo verso conferisce a quest'ultima un posto di primissimo rilievo nell'economia generale del testo, spostandone il baricentro semantico dal polo negativo a quello dell'affermazione dell'esistenza nell'interezza delle sue manifestazioni.

In questo senso anche [Utekty od sebe het'svit za-oči] sembra collocarsi in quel filone della poesia stusiana in sintonia con il magistero poetico pasternakiano, all'interno del quale l'idea dell'accettazione da parte dell'io lirico dell'esistenza sulla Terra nell'inscindibilità di amore e sofferenza gioca un ruolo fondamenta$\mathrm{l}^{39}$. Si noti, inoltre, come la pietrificazione del soggetto in [Utekty od sebe het'

39 Per la caratterizzazione dell'io lirico di [Utekty od sebe het'svit za-oči] come Adamo si può ipotizzare un ipotesto pasternakiano da Doktor Živago. Si veda da uno dei 
svit za-oči] rimandi chiaramente a [Včysja čekaty, druže], scritta quattro anni più tardi, ma antecedente nella composizione della raccolta, e dunque al possibile e complesso dialogo con il sostrato cvetaeviano in essa individuato.

Per l'immagine dell'auspicata caduta del soggetto sulla terra, sinonimo della sua fusione con essa e dunque della morte, si possono osservare inoltre alcune consonanze con la conclusione dell'ultima delle Duineser Elegien rilkiane, una delle opere che avrebbero più intensamente coinvolto Stus nel decennio a venire:

Aber erweckten sie uns, die unendlichen Toten, ein Gleichnis, siehe, sie zeigten vielleicht auf die Kätzchen der leeren

Hasel, die hängenden, oder

meinten den Regen, der fällt auf dunkles Erdreich im Frühjahr. -

Und wir, die an steigendes Glück

denken, empfänden die Rührung,

die uns beinah bestürzt,

wenn ein Glückliches fällt ${ }^{40}$.

L'identificazione tra morte, caduta e felicità con cui si conclude l'opus magnum rilkiano del 1922, alla cui traduzione e interpretazione Stus avrebbe dedicato tutto se stesso negli anni della reclusione e dell'esilio, sembra trovare un rispecchiamento tanto nell'imagery del sesto e del settimo verso di [Utekty od sebe het'svit za-oči], quanto nel significato profondo della lirica nel suo insieme, incentrata sul superamento delle contraddizioni tra vita e morte, individualità e consorzio umano.

Le ultime cinque poesie della prima parte di Zymovi dereva proseguono la sperimentazione con il linguaggio esistenzialista di [Utekty od sebe het'svit zaoči] e di altre liriche precedenti. In Veršnyk ('Cavaliere'), del 1969, la figura del poeta è elevata al rango di una trionfante divinità guerriera:
[...] I звитяжний лет
не перепинить радісний поет
коротким успіхом і довгим длянням.
Тобі не одірватись од тіні
(в ній проминуле вигадало нас).
Та уникаючи старих поразк,

\begin{abstract}
dialoghi tra Jurij e Lara a Jurjatin, in: Pasternak 2003-2005: IV, 400: “Мы с тобой как два первых человека Адам и Ева, которым нечем было прикрыться в начале мира, и мы теперь так же раздеты и бездомны в конце его. И мы с тобой последнее воспоминание обо всем том неисчислимо великом, что натворено на свете за многие тысячи лет между ними и нами, и в память этих исчезнувших чудес мы дышим, и любим, и плачем, и держимся друг за друга и друг к другу льнем.”

40 Rilke 1996: II, 234. 'Se trovassero per noi, gli infiniti morti, una metafora, / sarebbero, guarda, gli amenti dei vuoti / nocciòli, che pendono, oppurre / la pioggia, che cade sulla terra scura a primavera. - // E noi, che la felicità in salita / immaginiamo, sentiremmo la pace / sbalordente, / della gioia in caduta.'
\end{abstract}


перед новими стати ми повинні.

$[\ldots]^{41}$.

Una simile ispirazione sembra forgiare la lirica seguente, del 1968, il cui primo verso suona "Vyjdu v nič, pid sosnamy projdu" ('Esco nella notte, passerò sotto i pini'):

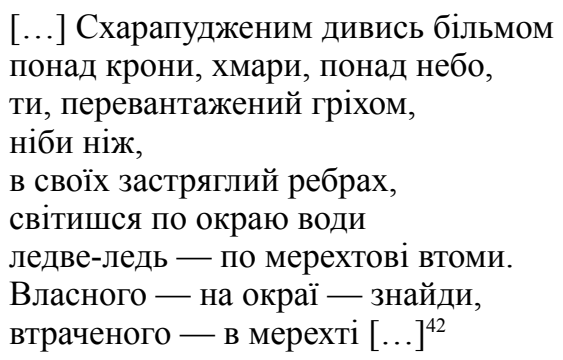

Il ripiegamento dell'io lirico sul proprio mondo interiore e sul cammino da compiere, centrali nella lirica stusiana dagli inizi alle vette degli anni Settanta, si sviluppa in questi versi in direzione dell'ambita fuga del soggetto dal proprio essere, anticipata in [Utekty od sebe het'svit za-oči], a causa dell'affanno che l'io stesso prova a causa del proprio peccato. Tuttavia, la saturazione di sé di cui il soggetto soffre non esclude la necessità della ricerca dell'io, che si può ritrovare "al margine", seguendo il tenue luccichio con cui ciò che è perduto richiama lo sguardo dell'errante. Apparentemente in bilico tra la negazione del valore dell'individualità e la sua affermazione, per sfociare dunque in un modernistico appello a una sua strenua difesa, questi versi esemplificano ottimamente la tematica fondamentale della parte conclusiva della prima sezione di Zymovi dereva. In essa si assiste infatti a un generale innalzamento della tonalità stilistica e della tematica dei componimenti rispetto alle costanti oscillazioni registrate in precedenza. I tre versi conclusivi, che ripropongono prepotentemente l'ispirazione espressionista trascurata nelle liriche precedenti e in generale meno rilevante nel panorama stilistico di Zymovi dereva, non sembrano contraddire questa tendenza:

$$
\begin{aligned}
& \text { Жально сяють божевільні зорі. } \\
& \text { І летить орда смертельно-хорих } \\
& \text { виплесків пекельних - кажанів }{ }^{43} \text {. }
\end{aligned}
$$

41 T I.1, 73. '[...] E il volo della vittoria / non fermerà il poeta gioioso / col successo breve e la lunga attesa. / Non puoi staccarti a forza dall'ombra / (in lei il passato ci ha trovati). / Ed evitando le vecchie sconfitte, / dobbiamo ergerci di fronte a nuove. / [...]'

${ }_{42}$ Ivi: 74. 'Col terrore negli occhi guarda / sopra le cime degli alberi, le nuvole, il cielo / tu, di peccato sovraccarico, / come un coltello, incastrato nelle tue stesse membra, / splendi al limite dell'acqua, / appena-appena - cercando stanchezze luccicanti. / Il proprio - al limite - trova, / il perduto - nel luccichio.'

43 Ibidem. 'Tristi risplendono le stelle impazzite. / E vola l'orda malata mortalmente / di bagliori infernali - pipistrelli.' 
Notevole è a questo proposito il caso del testo successivo, Potoky ('Torrenti'), una lunga lirica di oltre duecento versi composta di diverse parti di lunghezza differente separate tra loro dalla ripetizione della frase "velykyj hrich na serci ja nošu" ('un grande peccato porto sul cuore'). Rappresentando indubbiamente un ottimo esempio di dissonanza stilistica, Potoky si ricollega al testo precedente per l'importanza che vi assumono le tematiche del peccato ${ }^{44}$ e della necessità di accettare l'esistenza nella sua totalità. La stessa raffigurazione dell'immagine mitizzata e ševčenkiana della Madre con cui si apre la lirica contiene in sé tanto elementi decisamente prosaici, come i riferimenti ai terykony, cumuli di scorie minerarie tipici del paesaggio del Donbas, quanto momenti di astrazione dalla realtà concreta verso l'ermetismo di una poesia pura:

Ти все така ж, а я віддаленів.

За мною - кучугурами - розлуки -

час самовтрат...

(ще поповзом повзли

за тінню довженою, виростали

із самозмалення: німа рука

пограбілих тополь у надвечір’ї)

великий гріх на сериі я ношу

... розлуки рвав, як обривають жили

атланти териконів і тачок,

назбираного вугілля оклунки... (окраї землі -

тамтого світу в пекло провисання -

призналися відверто до душі $)^{45}$.

I "limiti della terra" in dialogo con l'anima dell'io lirico rimandano chiaramente ai "limiti" del testo procedente, fungendo da elementi coesivi nella costruzione della raccolta. Come nel caso di [Vyjdu v nič, pid sosnamy projdu], la possibilità che l'io lirico ha di ritrovare ora se stesso, ora il proprio posto nel mondo sembra dunque dipendere da una jaspersiana "situazione-limite" (cfr. Rosins'ka 2010: 163176). È la memoria a permettere qui il superamento della distanza spaziale e cronologica tra il soggetto e ciò che deve essere dolorosamente ricordato per consentire la comprensione dell' esistenza nella sua integralità. E che la ricordanza in sé sia proprio una situazione-limite è direttamente tematizzato qualche strofa più tardi:

44 Sulla concezione stusiana dell'onnipresenza e dell'ineluttabilità del peccato cfr. Jehorčenko 2002.

45 T I.1, 75. 'Sei sempre la stessa, e io sono distante. / Dietro di me - a mucchi distacchi - / il tempo delle perdite-di-sé... / (ancora strisciando strisciavamo / dietro a un'ombra allungata, crescevamo / dal rimpicciolimento-di-sé: la mano muta / dei pioppi intorpiditi al crepuscolo) // un grande peccato porto sul cuore // ... i distacchi ho strappato, come lacerano le vene / i titani dei terykony e dei carretti, / i fagotti del carbone raccolto, - / qualcosa ha strappato il petto... (i limiti della terra - / di quel mondo nell'inferno il dondolare - / si sono aperti sinceri all'anima).' 


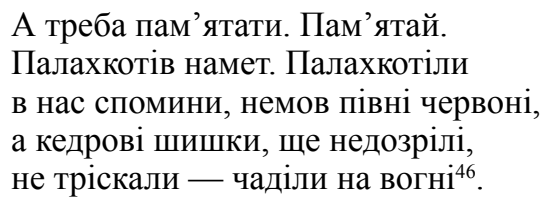

Spunti visionari si innestano nel vissuto infantile del soggetto dando vita a quei "torrenti" della memoria indicati dal titolo della poesia grazie ai quali la continuità, e dunque l'interezza del soggetto sono ancora una volta garantite. L'immaginario espressionista torna a imporsi nella strofa successiva:

І зорі в фіолетовому небі?

Ще ти казав: це колір божевілля

і судної доби.

$[\ldots]$

Земна півкуля брижилась од жару,

і півдуші ті спогади приспали,

і півсебе услід за сном пішло.

$[\ldots]^{47}$.

L'effetto ora devastante della memoria sull'io lirico, tentato dalla chiusura nella contingenza e dal rifiuto di riconoscere la continuità del sé nella storia, è paragonabile alla follia.

Ricollegando il testo alla concreta realtà storica del suo autore è possibile interpretare la tentazione del rifiuto della memoria nei termini della volontà da parte dell'intelligencija non allineata di abbandonare la storia pubblica e ritirarsi nel privato della torre d'avorio delle belle lettere (cfr. Kukulin 2011b). Che il dilemma dell'intellettuale impegnato si sarebbe posto con sempre maggior insistenza tanto nella concreta esperienza biografica di Vasyl' Stus negli anni a venire (Potoky, si ricordi, risale al 1969, quattro anni dopo la protesta del cineteatro "Ukrajina" e tre anni prima dell'arresto), quanto nella pratica interpretativa dei suoi lettori e studiosi sarà sempre più evidente via via che i "due Stus", poeta e dissidente, testo e martire, continueranno a intraprendere strade non necessariamente intersecate.

Si può notare come nello sviluppo della lirica l'alternanza tra la riflessione metaletteraria sulla memoria e la rielaborazione del ricordo stesso si tingano con maggiore intensità di venature apocalittiche di matrice espressionista, presen-

46 Ibidem. 'E si deve ricordare. Ricorda. / Bruciava la tenda. Bruciavano / in noi i ricordi, come galli rossi, / e le pigne non ancora mature / non scricchiolavano - fumavano al vento.'

47 Ibidem. 'E le stelle nel cielo violetto? / Hai detto: è il colore della follia / e dell'ora del giudizio. $[\ldots] /[\ldots] /$ Metà della terra si è rinsecchita per il caldo, / e metà dell'anima i ricordi hanno assopito, / e metà di sé è andata dietro al sonno. [...]' La caratterizzazione del colore violetto come manifestazione della follia va ad aggiungersi al suo precedente accostamento con la sfera della morte in [Učora, jak miž soson dohorjav], di sei anni precedente. 
tando diversi 'marcatori' tipici del linguaggio poetico stusiano. Si veda la strofa seguente all'ultima citata:

Ти мати. Тінь. І обернувшись тінню самонародження, ввійшля у тінь, і тінь запалюєш жданням своїм, і тінь круті гамує голосіння. Тінь підводиться. Гострішає. Чорніє ${ }^{48}$.

L'ossessione per l'ombra, già ampiamente documentata nelle poesie dei primi anni, arriva a inglobare addirittura la sacralità della figura della Madre, vero e proprio filo rosso della tradizione poetica ucraina. Alla base dell' adombramento sembra trovarsi il peccato, il vero e proprio leitmotiv di questo lungo testo. Nella seconda parte inconfondibili venature ševčenkiane si alternano a scene dialogiche:

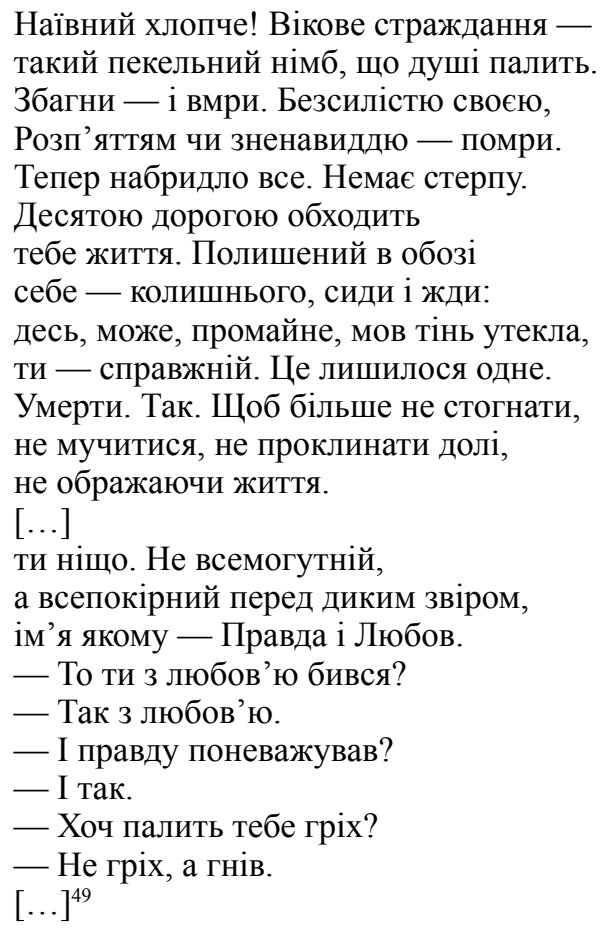

48 T I.1, 77. 'Sei madre. Ombra. E, rivelandoti ombra / della nascita-di-sé, sei entrata nell'ombra, / e l'ombra brucerai con la tua attesa, e l'ombra / calmerà gli alti lamenti. L'ombra / si sdoppia. Si fa pungente. Si fa nera.'

49 Ibidem. 'Ingenuo ragazzo! Secolare soffrire - / un' aureola infernale, che brucia l'anima. / Comprendi - e muori. Con la tua impotenza, / la crocifissione o l'odio - muori. / Tutto disgusta. Non c'è contegno. / Ti evita / la vita. Abbandonato nel convoglio / di te stesso - di un tempo, siedi e attendi: / in qualche luogo, forse, balenerà, come un'ombra fuggita, / l'autentico tu. Una cosa è rimasta. / Morire. Sì. Per non gemere più, / non 
La stridente disomogeneità tra l'inizio della strofa, in cui si condensano diversi elementi fondamentali del lessico e dell'immaginario stusiano maturo, la successiva ripresa del modello ševčenkiano e l'impressionante abbassamento stilistico della parte dialogica si colloca perfettamente nell'alveo della continua sperimentazione con i linguaggi di diverse tradizioni centrale al laboratorio poetico di Stus almeno fino alla fine degli anni Sessanta. Comune ai tre momenti individuati per questa porzione di testo è la presa di coscienza del restringimento dell'io, al quale viene contrapposto un ipotetico io 'altro', 'autentico', conoscibile solamente attraverso la morte. In questo modo, ciò che sembrerebbe a una prima lettura una postmoderna dichiarazione di commiato del soggetto da se stesso si rivela ancora una volta una riaffermazione del valore e della (seppur remota) possibilità di una soggettività autentica e attiva. Ciò è chiaramente confermato dal contesto assiologico in cui l'io si ritrova a scontare il proprio peccato. La permanenza della Verità e dell'Amore in un universo apparentemente privato di un significato trascendente colloca il testo stusiano in una prospettiva pre-postmoderna o tardo moderna/neomoderna, secondo la quale il perseguimento di un senso nascosto ma presente continua a porsi come la base dell'esistenza di un soggetto in costante ricerca. La prosecuzione del dialogo tra l'io e il suo interlocutore mette ancora maggiormente in evidenza questo assunto:
Скажи, пощо мені подарував
цей світ, якому я заприсягався
служити до скону. Нащо передрік
ці болі самозречення в хвилину, коли я вже самим собою став $?^{50}$

La complessa e dolorosa dinamica dei rapporti tra il soggetto e il mondo si fonda in un primo tempo sull'idea di una possibile influenza del primo sul secondo. L'io ha saputo realizzare momentaneamente la propria natura, dedicando se stesso alla causa del mondo, per poi scontrarsi con la comprensione della propria effettiva inanità. La nullità del soggetto è dunque un effetto secondario del suo scontro con la storia, non una sua componente ontologica originaria, in una prospettiva esistenziale umanisticamente basata, ancora una volta, sui tradizionali pilastri della Verità e dell'Amore. Pochi versi più tardi l'io lirico ribadisce la propria situazione al margine, ricollegandosi alle strofe precedenti:

tormentarsi, non maledire la sorte, / non offendendo la vita. [...] / [...]/ sei nulla. Non onnipotente, / ma umilissimo di fronte alla fiera selvaggia, / di nome - Verità e Amore. / - Ti sei battuto con l'amore? / - Sì, con l'amore. / - E hai trascurato la verità? / - Sì. / - Ti brucia almeno il peccato? - Non il peccato, ma sono arrabbiato. [...]'

50 Ibidem. 'Dimmi, perché mi hai donato / questo mondo, al quale ho giurato / di servir fino alla fine. Perché hai predetto / questi dolori di rinuncia nell'attimo / quand'ero già diventato me stesso?' 
[...] Краєм, скраєчку, на жебрах,

лиш прориваючись крізь грати заборон

(світ білий — заборонений!) $[\ldots]^{51}$

Il soggetto si raffigura come mendicante, incarcerato e reietto. Non è da escludere che per questi versi sia legittima una lettura in chiave poetologica ${ }^{52}$, anche se nell' auto-caratterizzazione dell'io lirico la componente pan-umana sembra qui avere il sopravvento sulla tentazione di una distinzione ontologica tra l'uomo e il poeta incontrata in altri casi. Questo sembra essere confermato dalla strofa successiva, la penultima del lungo componimento:

Так жив, як дякував. Вимолював. Просив.

А дякував за те, що народився,

що маю очі - бачити, що слух

епохою дарований, що серце

не билося б, коли б не двадцять літ,

перед тобою збіглих... Аж і гірко! ${ }^{53}$

Fondamentale è qui il collegamento tra la facoltà uditiva e la contingenza cronologica, dunque tra la sofferenza e la capacità di comprendere la propria posizione nel mondo. Nell'ultima strofa questa idea è ripresa e approfondita in rapporto alla tematica più profonda del testo, quella relativa al peccato:

Так від народження берем

правічний гріх собі на душу:

його покутувати змушені,

його ми вистраждати ревне повинні - спогадами, сном

[...]

Всі прогріхи минулих душ,

напевне ще від неоліту

ввійшли у серце оповите

гріховністю. $[\ldots]^{54}$

51 Ibidem. '[...] Al margine, al limite, elemosinando / solo insinuandomi tra le grate dei divieti / (il mondo - è proibito!). [...]'

52 Ancora una volta sarebbe accettabile in questo caso un rimando ai Poety cvetaeviani, la cui presenza a livello ipotestuale è già stata ipotizzata più volte: "Есть в мире лишние, добавочные, / Не вписанные в окоем. / (Нечислящимся в ваших справочниках, / им свалочная яма - дом).”

53 Ibidem. 'Così ho vissuto, come ho ringraziato. Ho supplicato. Ho chiesto / E ho ringraziato di esser nato / di avere gli occhi - per vedere, dell'udito - donato dall'epoca, che il cuore / non batterebbe, se non per i vent'anni / passati di fronte a te... Che amarezza!'

54 Ibidem. 'Così dalla nascita ci prendiamo / il peccato nell'anima: / dobbiamo scontarlo, / soffrirlo con pazienza dobbiamo - coi ricordi, il sogno / [...] / Tutti i peccati delle anime passate / ancora dal neolitico / sono entrate nel cuore avviluppato / di peccato. $[\ldots]$ ' 
La grande importanza del peccato per la creatività è il nucleo concettuale di questi versi. Due componenti irrinunciabili della capacità creativa, quali la memoria e la fantasia, sono qui identificati come gli strumenti necessari all'espiazione del peccato, confermando così l'ipotesi di una lettura poetologica della lirica avanzata a proposito della strofa precedente.

La prima, densa sezione di Zymovi dereva si conclude con un altro lungo ciclo e una breve lirica di chiusura accostabile alla sensibilità poetica del ciclo che la precede. Il primo testo, tra i più celebri dell'intera produzione stusiana, è intitolato Kostomarov u Saratovi (cykl) ('Kostomarov a Saratov [ciclo]') e risale agli anni 1965-1967. L'ispirazione e l'immaginario su cui il ciclo è costruito sono un'ulteriore prova della necessità di mantenere separato lo studio dell'evoluzione del linguaggio poetico stusiano dal dato biografico. Se, da una parte, l'ideazione e la stesura di Kostomarov u Saratovi non possono che trovare una prima spiegazione nelle vicende personali dell'autore e nella situazione socio-politica dell'Ucraina sovietica alla metà degli anni Sessanta, sarebbe fuorviante collegare questi versi univocamente al destino di Stus nel decennio seguente. Che una tentazione di questo tipo possa emergere dalla lettura della prima strofa è più che evidente:

За роком рік росте твоя тюрма,

за роком рік підмур'я в землю грузне,

і за твоїм жалінням заскорзулим,

за безголів'ям - просвітку нема ${ }^{55}$.

È tuttavia evidente, anche solo sulla base della cronologia, che l'imagery dell'incarcerazione qui sviluppata, seppur naturalmente carica di vividi riferimenti all'ondata di arresti del 1965, è da collocarsi a un livello di lettura intrinsecamente letterario e, in senso lato, 'culturale'. L'idea dell'intellettuale patriota carcerato è un topos del testo ucraino da Ševčenko e Ivan Franko in poi, in grado di esercitare produttivamente un potenziale di identificazione e ispirazione, contribuendo così al consolidarsi dell'identità culturale nazionale. In questo senso, il tema della prigionia di colui che potrebbe restituire all'Ucraina la sua autonomia culturale, creando di conseguenza i presupposti per la sua statualità, 'precede' idealmente il concreto episodio storico, in questo caso il confino dello storico Mykola/Nikolaj Kostomarov (1817-1885) a Saratov tra il 1847 e il 1855, a causa del suo coinvolgimento nella fondazione e nell'attività della "Confraternita cirillo-metodiana" (1845-1846), così come la serie di arresti di intellettuali non allineati nel 1965. Si vedano le altre tre strofe della prima delle sette parti del ciclo:

Живеш - i жди. Народжуйся - i жди.

Жди перед сконом. Жди у домовині.

Не назирай - літа збігають згінні

без цятки неба й кухлика води.

55 Ivi: 81 . 'Di anno in anno cresce la prigione, / di anno in anno il fondamento cede, / e dietro al tuo dolore rinsecchito, / alla tristezza tua - luce non v'è.' 
Ти весь - на бережечку самоти, присмотканий до туги, мов равлик, від вибухлої злості занепалий, не можеш межі болю осягти.

А світ весь витих, витух, відпалав, не вгамувавши вікової спраги.

Він висмоктав із тебе всю одвагу, лишив напризволяще і прокляв ${ }^{56}$.

Il linguaggio e la tematica di questi versi possono essere letti e compresi anche al di là del doloroso riferimento storico alla contemporaneità. Non è difficile cogliervi il nucleo fondamentale dell'immaginario stusiano, nonché una piena anticipazione della poesia matura di Čas tvorčosti e Palimpsesty. Il loro significato profondo trascende la loro possibile ispirazione contingente per raggiungere una dimensione esistenziale assoluta in piena sintonia con lo spaesamento del soggetto centrale alla tradizione novecentesca occidentale. L'io è solo, beckettianamente inerte e le sue energie vitali sono ormai consumate. In questo, tuttavia, si può intravedere un suo punto di contatto con il mondo, altrettanto prosciugato e privato della linfa. Il rapporto tra il soggetto e il mondo esterno si colloca, dunque, al crocevia tra uno stato di eterna belligeranza e una sorta di 'identità negativa' tra i due, basata sulla condivisione dei tratti della consunzione e dell'inaridimento. Il mondo è per il soggetto un boia a sua volta vittima di un'oscura forza mortifera. Nella sua solitudine, l'io condivide con i suoi simili un'esistenza in cui i confini tra la vita e la morte si sono annullati. Questa comunanza è messa in rilievo nelle due strofe che compongono la seconda parte del ciclo:

Живі - у домовині. Мертві — ні, хоча тюремним муром всіх притисло.

Прадавні роки, місяці і числа перебирають у живій труні.

Сомнамбулами бродять щонаймертві.

I так їм хочеться межи чужих кісток свій непомітний віднайти куток, щоб там боятися смерті ${ }^{57}$.

$56 \quad$ Ibidem. 'Vivi - e aspetta. Nasci - e aspetta. / Aspetta - prima della fine. Aspetta - nella tomba. / Non guardare - gli anni corrono schiavi / senza una scheggia di cielo e un sorso d'acqua. // Stai - sulla riva dello star soli, / incurvato come un arco, una lumaca, / esausto della rabbia che ti è esplosa, / del dolore non raggiungi il limite. // E il mondo s'è zittito, s'è sopito, s'è bruciato, / incontenibile la sete secolare. / Tutto il coraggio così ti ha risucchiato, / ti ha abbandonato e maledetto.'

57 Ibidem. 'I vivi - nella tomba. I morti - no, / anche se il muro carcerario ha stretto tutti. / Gli anni antichi, i mesi e le giornate / raccolgono in una bara viva. // Come sonnambuli vagano i più-morti. / E tanto vogliono tra ossa altrui / trovarsi un loro angolo appartato, / dove poter temer la morte.' 
La prigionia è sartraniamente condizione comune e condivisa dell'umanità. Ogni distinzione tra la situazione dei vivi e quella dei morti sembra essersi persa, in un'atemporalità che non prevede (più) riferimenti storici chiaramente identificabili. Viene così a crearsi un corto circuito interpretativo tra la necessità di 'situare' il testo, leggendolo alla luce della ben precisa indicazione fornita dal titolo, e la possibilità di porlo in una prospettiva esistenziale universale.

Nella prima strofa della terza parte viene portata avanti la caratterizzazione del mondo iniziata alla fine della prima parte:

Світ - тільки свист мигтючий. I провалля -

немов бездонне. Долі - не збагнеш.

Бездомний, хоч - то вжалюйся до жалю

(а жаль, немов провалля, теж - без меж) $)^{58}$.

In versi in cui l'ipnotico ordito del significante pare a tratti prendere il sopravvento sul significato, si assiste all'impossibilità per il soggetto di ordinare la realtà cogliendone i confini. Nell'insondabile profondità del suo nulla, il mondo è posto sullo stesso piano del dolore, di cui condivide la paradossale compresenza di infinitezza e inconsistenza. Alla base dell'incapacità del soggetto di comprendere è la natura del destino, inseparabile nella tradizione ucraina dal modello ševčenkiano, che fa sì che l'io si trovi "senza casa", ossia la condizione più tipica dell'immaginario novecentesco. In questa strofa, dunque, il soggetto attua implicitamente un disgiungimento tra sé e il mondo, precedentemente assimilati, come si è visto, nella condizione dell'arsura. La sua volontà di sottolineare la propria differenza e il proprio distacco dal mondo è ripresa nella quarta parte:

[...] Мій Боже, білий світ — це біле божевілля не варт твого зусілля, то й бідкатися встид ${ }^{59}$.

Nel corso della sesta parte il personaggio storico di Kostomarov sembra assumere tratti più concreti:

[...] Усе, чим жив, сьогодні трачу.

Все рвуть руками обома.

$[\ldots]$

квадрат — чотири на чотири -

i окрай чорного стола ${ }^{60}$.

58 Ibidem. 'Il mondo - solo un fischio balenante. Un burrone - / senza fondo. Il Destino - non capirai. / Senza casa, ma - lamentati al lamento / (e il lamento, come abisso, è sconfinato).'

59 Ibidem. '[...] Il mondo, oh Dio mio - / è tutto quanto folle - / non merita i tuoi sforzi, / non vale il mio lamento.'

60 Ivi: 84. '[...] Tutto ciò di cui vivevo ora lo perdo. / Strappano e strappano con ambo le mani. / [...] / un quadrato - quattro per quattro - / e il margine di un tavolo nero.' 
È così letteralmente anticipata la raffigurazione spaziale che il soggetto stusiano darà della propria situazione nella lirica degli anni Settanta. Nella seconda metà della sesta parte la 'localizzazione' esplicita della situazione lirica si sposta improvvisamente dal soggetto alla realtà nazionale, capovolgendo l'atemporalità dell'inizio del testo nel senso di una ripresa di motivi e stilemi tradizionali di marca ševčenkiana:

Якраз навпроти, на ослоні

сидить нужденна удова,

і на змозолених долонях -

солоні сльози, як жорства.

I так провадить: зглянься, сину,

руками горе, розведи,

бо як не стане України,

тоді не стане і біди.

$[\ldots]^{61}$

Nelle strofe rimanenti la prospettiva torna a concentrarsi sull'individualità del soggetto, reintroducendo in una prospettiva millenaristica elementi tipici del lessico poetico stusiano:

Єси ти сам - 3 собою врівень,

один на сотні поколінь

високим гнівом богорівен,

хай може, не ріка, а рінь,

важка занадто. Крик стоустий,

молінь столобих ти рука.

Ступай - майбутньому, назустріч,

і хай хода твоя легка

легкою буде. I не треба

жалких жалінь. I - задарма.

$[\ldots]^{62}$

La multiformità della rappresentazione dell'io lirico nel ciclo Kostomarov $u$ Saratovi non inficia la profonda unitarietà del testo, frutto del recupero e dell'accostamento di diversi mitologemi del testo culturale ucraino, a metà tra stretta localizzazione, da una parte, e innalzamento del singolare a universale, dall'altra.

${ }^{61}$ Ibidem. 'Proprio di fronte, dov'è la sbarra / sta seduta una povera vedova, / e sui palmi segnati dai calli - / lacrime salate come ghiaia. / E va dicendo: guarda, figlio mio, / con le mani allontana il dolore, / quando non ci sarà più l'Ucraina, / non ci sarà più la disgrazia. / [...]'

62 Ibidem. 'Sei tu solo - pari con te stesso, / uno su cento generazioni / di rabbia pari sei a un dio, / non fiume, ma pietrisco, / troppo greve. Di-cento-bocche un grido, / delle preghiere di-cento-fronti mano. / Incedi - incontro al futuro, / che il passo tuo leggero / lieve ti sia. E non servono / lamenti, lamentazioni inutili.' 
Sullo sfondo di Kostomarov u Saratovi, assume particolare rilievo la lirica conclusiva della prima parte della raccolta, scritta nel 1964, un anno prima dell'inizio del lavoro al ciclo stesso. La fiducia nella possibilità della redenzione invocata nella parte conclusiva del lungo testo sembra qui essere messa nuovamente in crisi:

Минає час моїх дитячих вір.

I я себе з тим часом проминаю.

I вже не віднайдусь. I вже не знаю,

А чи впізнав би на човні новім

Свій давній берег. Ні, напевно, ні.

Бо сам собі, відринутий від болю,

Пливу за днем, за часом, за собою

в новому необжитому човні.

$[\ldots]$

Ти сам пливеш, відринутий від себе.

І лиш за гребнем прозираеш гребінь ${ }^{63}$.

In un testo estremamente classico per forma - un sonetto inglese - e immaginario - la petrarchesca metafora della nave per la vita -, si assiste ancora una volta a una rielaborazione lirica sul linguaggio della filosofia esistenzialista e della sensibilità postmoderna. Il paradosso di un io a metà tra interezza e scissione, che dichiara di non saper ritrovare se stesso mentre riesce ad avere uno sguardo riflessivo sulla propria ricerca di sé, colloca [Mynaje čas mojich dytjačych vir] in una posizione mediana tra una soggettività modernamente integra, pur nella sua fragilità, e la sua postmoderna dissoluzione, qui annunciata, ma non effettivamente realizzata. Pur nel corso del distaccamento da sé, l'io non sembra rinunciare alla ricerca di se stesso, alla speranza del ritrovamento della propria individualità. Pare qui configurarsi, tuttavia, un'identificazione tra la fede del soggetto nella possibilità di un suo intervento sul mondo esterno, la cui perdita è annunciata nel primo verso, il dolore e la soggettività stessa. L'identità dell'io con se stesso è infatti messa in crisi dalla sfiducia, che fa sì che esso sia dapprima "distaccato dal dolore" e infine, con un evidente parallelismo, "distaccato da se stesso". Senza la sofferenza per la propria inanità l'io non è dunque più uguale a se stesso. Si anticipa qui implicitamente l'idea della disumanizzazione del soggetto più ampiamente sviluppata nel decennio seguente. La raffigurazione dell'integrità dell'io mediante la metafora della riva qui introdotta sarà ugualmente molto frequente nel lessico poetico dello Stus degli anni Settanta. Anche in questo caso, dunque,

63 Ibidem. 'Passa il tempo delle fedi mie infantili. / E passo io me stesso in questo tempo. / Più non mi ritroverò. E già non so, / se sulla barca nuova io vedrei / la vecchia riva mia. Certo che no. / Perché io solo, staccato dal dolore, / cerco il giorno e il tempo e me stesso / nella barca nuova, ancor inabitata. // [...] // Solo navighi, staccato da te stesso. / E dietro al crinale solo il crinale vedi.' 
non è possibile etichettare univocamente il testo a una ben precisa tendenza o corrente storico-letteraria e culturale, mentre si impone con chiarezza la necessità di coglierne le differenti venature anche nella loro apparente contraddittorietà.

Il primo capitolo di Zymovi dereva si mostra costruito all'insegna di una varietà stilistica e tematica molto marcata, con frequenti rimandi a vari livelli tra le liriche a garanzia dell'unitarietà della raccolta nel suo insieme. Nel secondo capitolo, al contrario, risulta preponderante la tematica nazionale, sviluppata ora in chiave folklorica, ora in chiave patetico-romantica, ora come bozzetto di costume o scena quotidiana. L'alta frequenza di queste ultime fa sì che molto spazio all'interno del capitolo sia dedicato alla sperimentazione con un registro linguistico basso, prosaico, in forte contrasto con i più rari, ma non assenti improvvisi innalzamenti stilistici che assicurano varietà e movimento anche a questo gruppo di testi. Particolare rilievo assumono anche il motivo amoroso, nella cui elaborazione si assiste a un'analoga alternanza di registri e intonazioni, e la rappresentazione della natura, raffigurata principalmente, secondo il titolo della raccolta, nei toni smorzati e austeri dell'inverno. Si tratta della sezione più lunga, composta da cinquantadue liriche.

Sullo sfondo delle liriche conclusive del primo capitolo, tra le quali spicca per lunghezza e potenza espressiva il ciclo Kostomarov u Saratovi, la poesia di apertura della seconda parte segna una notevole inversione di tendenza:

Добрий день, мій рядок кароокий, побратиме моїх безсонь!

Зупини іiі, мить високу,

для моїх молитовних долонь.

Сиве голубе, біль мій зичений, вечоровий і пелехатий, більше чутий, аніж помічений, більше мічений, ніж крилатий.

Слово, слово - достиглий смут мій!

Набираючий висоту, порятуй од важкої скрути і од радості порятуй, поки, круглі, цвітуть долоні, поки з серця ростуть пелюстки, поки думи, як дзвони довгі, і як дзвони, круглі такі,

та любов'ю мене, наче амфору, доливай, довіряй добру.

За розквітлу купальську папороть я пером і горбом віддарю ${ }^{64}$.

64 Ivi: 87. 'Buongiorno, verso mio dall'occhio scuro, / fratello delle insonnie mie! / Fermalo, l'alto attimo, / per i palmi miei in preghiera. // Colombo argenteo, dolore mio 
Anche in questo caso la data di composizione del testo è significativa. Scritta nell'aprile del 1966, dunque dopo i fatali eventi della metà del decennio, questa lirica metapoetica e poetologica testimonia massimamente dell'opportunità di mantenere separati il percorso biografico stusiano dall'interpretazione letteraria della sua lirica. La fiducia nella parola poetica libera l'io lirico dalla contingenza, elevandolo, nell'atemporalità delle "insonnie" già note al lettore, al di sopra dell'incostanza e della casualità della storia. L'evidente rimando al tema dell'attimo nel Faust goethiano al terzo verso si innesta in un gioioso universo privato intriso di mito, grazie al quale l'attimo viene a coincidere con il superamento della normale temporalità umana e l'ingresso nella sfera altra dell'arte. La parola poetica consente al soggetto il raggiungimento di un equilibrio, di un'autonomia dalle spinte centrifughe e destabilizzanti della sofferenza e della gioia. Dietro a questa stoica rassegnazione è certamente lecito intravedere il sostrato biografico di Stus, ma, allo stesso tempo, si ha una conferma dell'impossibilità di porre un segno di equivalenza tra l'immaginario poetico stusiano e le vicende 'esterne' dell'autore. L'assimilazione del soggetto all'elemento naturale può essere messa in connessione sia con la corrente magico-naturalistica della poesia ucraina da Svidzins'kyj ad Antonyč, sia con l'insegnamento goethiano sulla compartecipazione dell'uomo al modello evolutivo della pianta, al quale Stus si sarebbe dedicato attivamente nel decennio successivo. Alla trasformazione del soggetto in pianta non corrisponde dunque una sua disgregazione. Come testimonia l'ultimo verso, l'integrità dell'io è garantita dalla sua capacità e disponibilità a mettersi con tutto se stesso al servizio della parola poetica. Particolarmente interessante ai fini della comprensione della natura dell'io lirico e del rapporto tra quest'ultimo e l'autore implicito di [Dobryj den', mij rjadok karookyj] è altresì l'invocazione al dolore al quarto verso. Il dolore, dapprima apostrofato con tenerezza, è invocato con un termine che potrebbe significare sia "desiderato" che "preso in prestito". In virtù della sua collocazione all'inizio della seconda quartina, il dolore può essere messo in connessione con 1'“alto attimo" della strofa precedente, creando un nesso tra questi due elementi e la tematica centrale della lirica, ossia la poesia stessa e la capacità del soggetto di essere creatore. L'attimo del dolore è dunque ciò che rende la creazione poetica possibile, a condizione che l'io lirico sia in grado di arrestarlo e coglierne l'irripetibilità e la grandezza. Il dolore appare così distaccato dalla realtà concreta e intrinsecamente legato all'arte. Rielaborando il motivo del dolore in chiave metapoetica, Stus garantisce continuità tra il primo capitolo di Zymovi dereva e l'incipit del secondo, all'interno del quale, tuttavia, saranno altri motivi e altre tendenze stilistiche a prevalere.

agognato, / serale e arruffato, / più sentito che notato, segnato più che alato. // Parola, parola - tristezza mia matura! / Mentre sali verso l'alto, / salvami dal dolore, / e dalla gioia salvami, // mentre, rotondi, fioriscono i palmi, / mentre dal cuore nascono i petali, / mentre i pensieri, come lunghe campane, / e, come campane, rotondi, // tu, come un'anfora, d'amore / riempimi, affidami al bene. / Per la felce fiorita di Ivan Kupala / ricambierò con la penna e la schiena.' 
La tematica ucraina, come già anticipato, viene sviluppata in modalità differenti. Nei notissimi versi di [Sto rokiv, jak skonala Sič] del 1963 è il pathos romantico a dettare il tono delle sette quartine. Se ne vedano la prima e l'ultima:

Сто років, як сконала Січ.

Сибір. І соловецькі келії, і глупа облягає ніч пекельний край і крик пекельний.

$[\ldots]$

I радісним буремним громом спадають $з$ неба блискавиці, Тарасові провісні птиці слова шугають над Дніпром ${ }^{65}$.

Il nume tutelare ševčenkiano funge qui da garante della sopravvivenza dell' $U$ craina, nonché da giustificazione implicita del fare poesia per un io lirico che nel complesso della raccolta tende a rappresentarsi essenzialmente nelle vesti di poeta.

Nella lirica seguente, datata 1964, la coesione testuale è garantita dalla ripresa del numerale "cento", tipico, come si è visto, del lessico poetico stusiano, mentre alla tonalità abbassata corrisponde la constatazione della realtà disumana dell'Ucraina contemporanea:

Звіром вити, горілку пити - i не чаркою, поставцем, і добі підставляти спите вірнопідданого лице.

I не рюмсати на поріддя, коли твій гайдамацький рід ріжуть линвами на обіддя кілька сот божевільних літ. I не бештати, пане-брате, а триматися на землі!

Нею б до печінок пропахнути, в грунт вгрузаючи по коліна. $[\ldots]^{66}$

Al decadimento dell'Ucraina sembra poter rispondere solo il sobrio realismo dell'intellettuale, ora impegnato nel volo dell'ispirazione poetica, come in [Sto rokiv, jak skonala Sič], ora 'coi piedi per terra', come sembra emergere dagli ultimi due versi qui citati. La tematica poetologica è ripresa in Ostannij lyst

T I.1, 90. 'Cent'anni fa morì la Sič. / Siberia. Celle a Solovki, / stupida avvolge la notte / la terra d'inferno e infernale il grido. // [...] // E come un tuono allegro, tempestoso / cadono dal cielo le saette, / gli uccelli presaghi di Taras - / le parole aleggiano sul Dnepr.'

66 Ivi: 91. 'Come una bestia ululare, acquavite bere - e non in tazza, ma dalla brocca, / e all'epoca mostrare il volto ubriaco del suddito. / E non frignare sulla stirpe, / quando la stirpe tua di Hajdamaky / fanno a pezzi da cento e cento pazzi anni. / E non singhiozzare, fratello, ma sulla terra stare! / Impregnarsi di lei fino alle viscere, nel suolo suo sprofondar fino al ginocchio. [...]' 
Dovženka ('L'ultima lettera di Dovženko'), del 1964, in cui si assiste a una totale identificazione tra il soggetto e l'Ucraina:

Прозаїки, поети, патріоти!

Давно опазурились солов' одзьобились на нашій Україні.

А як не чути їх? Немає сил.

Столичний гамір заважкий мені.

I хочу вже на затишок, i, може,

на спокій хочеться на придеснянський,

і хочеться на мій селянський край.

Пустіть мене до себе. $[\ldots]^{67}$

La natura profonda dell'io di Dovženko può esplicitarsi solo ritrovando il contatto diretto con l'Ucraina natia. La prima quartina sembra inoltre contenere una sorta di autocritica della politicizzazione della poesia da parte di Stus, in relazione a un filone non completamente alieno, come si è potuto osservare, alla sua lirica. La presa di posizione a favore di un'arte libera da condizionamenti politici potrebbe certamente essere riferita anche e soprattutto a scrittori e a poeti allineati, fautori dell'estetica di stato, ma ciò non esclude l'evidente componente auto-riflessiva del testo in questione.

Un esempio dell'utilizzo di mescolanza di registri linguistici nell'elaborazione della tematica ucraina è dato da [Tysjačolitn'omu Kyjevu] del 1965:

Тисячолітньому Києву

закортіло омолодитися.

Раптом Київ відчув готелі, електрички, тролейбуси, поїзди, міст Патона і незграбні будинки Хрещатика.

Київ лизнув своїм язиком язичницьким і схили Зеленого театру почали проростати куницями, віверицями, буй-турами, зареготала, розганяючи Дніпрові хвилі, поганська Ярилова годова.

Київ астматичне закашлявся. [...]

Київ натужився і затих:

67 Ivi: 92. 'Prosatori, poeti, patrioti! / Da tempo si sono artigliati gli usignoli, / armati di becco nella nostra Ucraina. / E come non sentirli? Non ci si riesce. / Il frastuono della capitale è troppo forte. / Ho già voglia del mio posticino, forse, / della pace della Desna voglia ho già, / nel mio paese contadino voglio andare. / Lasciatemi andar a me stesso. [...]' 
де його в бісовій мамі

підняти оце збіговисько

новобудов, проспектів, магістралей

і високі черева

нерозроджених земляків своїх?

$[\ldots]^{68}$

In sintonia con il pluristilismo della lirica degli anni Sessanta e della "Scuola di Kiev", [Tysjačolitn'omu Kyjevu] fonde l'arsenale di linguaggi e motivi della contemporaneità, elevati a poesia in chiave (neo)avanguardista con l'ispirazione mitologicizzante, altrettanto fondamentale per la lirica dell'epoca (cfr. Pastuch 2010: 245-378), con la 'costante' ucraina della storia patria, come ben emerge dai due ultimi versi citati. L'astrazione in chiave mitologica si affianca così agilmente al dettaglio tecnico e al prosaismo.

Infine, la tematica nazionale può trovare sviluppo in chiave storico-folklorica, come nel caso di Hajdamac'ke, datata 1964-1965. Se ne veda l'ultima strofa:

Тож, чорний вороне, замовч і головоньки не мороч,

бо так накрячеш - що аби уже й добрався б до товариша...

а десь самотній упаду, а вмру — ніхто й не стулить очі...

А то - ще і хворим підберуть - i на Сибір відправлять маршем ${ }^{69}$.

Un posto importante nel panorama del secondo capitolo spetta anche alla lirica amorosa. Essa può concretizzarsi perseguendo un ideale modello alto, come nel caso di [Ja marno včyv hramatyku kochannja], del 1963, oppure imitando il linguaggio quotidiano, come nel caso di [Ne vidpovidaješ? Movčyš? Zacipylo?], datata 1964. Si veda il primo dei due testi nella sua interezza:

Я марно вчив граматику кохання,
граматику гріховних губ твоїх, а-
ти утікала і ховала сміх
межи зубів затиснений захланних.

68 Ivi: 105 . 'La millenaria Kiev / ha voluto ringiovanirsi. / All'improvviso ecco gli alberghi, / i treni elettrici, i filobus, i treni, / il ponte di Paton / e i goffi palazzi del Chreščatyk. / Ruvido asfalto / Kiev ha leccato / con la sua lingua pagana - / e i pendii del teatro Verde / han cominciato a riempirsi di martore, / scoiattoli, buj-tur, / s'è messa a ridere, agitando le onde del Dnepr, / la testa pagana di Jaryla. // Kiev si è messa a tossire asmatica. [...] // Kiev si è rattristita e zittita: / dove accidenti / erigere questa massa / di nuove case, viali, superstrade / e le alte pance / dei suoi non-nati connazionali?' Buj-Tur è un personaggio del folklore slavo orientale, fratello dell'Igor' Svjatoslavovič dello Slovo o Polku Igoreve. Jaryla è una divinità femminile del pantheon slavo, simboleggiante la fertilità. Si noti la citazione dal Poslanije ševčenkiano nell'ultimo verso.

69 Ivi: 110. 'Nero cavallo, taci e non romperti la testa, / tanto male porterai - che anche arrivar sol fin dal compagno... / in qualche luogo solo io cadrò, e perirò - nessun muoverà ciglio... / se no - anche malato - marciando in Siberia io andrò.' 


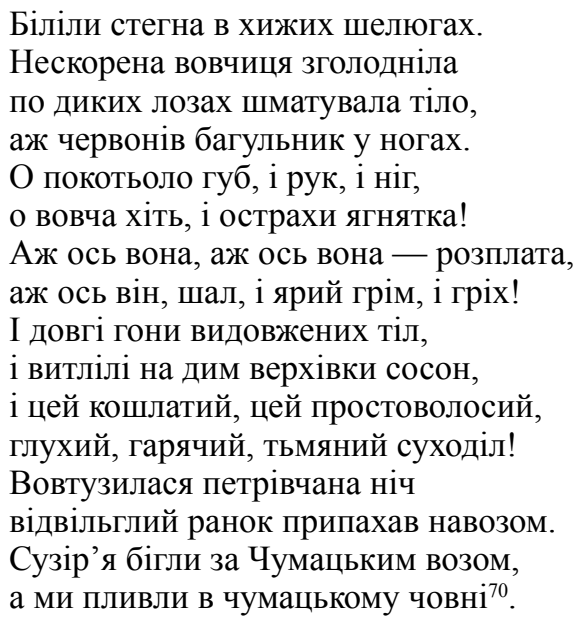

Nei due primi versi di questo capolavoro della poesia erotica stusiana, intriso di atemporale classicità, è facile cogliere un rimando al distico iniziale di una delle più note liriche di Osip Mandel'štam, Tristia, composta nel 1918 e inclusa nella raccolta eponima (Mandel'štam 1993-1997: I, 138):

Я изучил науку расставанья, в простоголовых жалобах ночных.

Il primo verso di [Ja marno včyv hramatyku kochannja] riprende il modello del probabile ipotesto mandel'štamiano sia a livello sintattico, sia dal punto di vista fonico, con la sola aggiunta di un avverbio di portata semantica negativa (marno) a bilanciare lo scarto dei due opposti "separazione" e "amore" nei due testi, rafforzandone e riconfermandone così l'affinità. Le due liriche sono inoltre accomunate dallo stesso metro, la pentapodia giambica, misura, tuttavia, tra le più comuni nel repertorio sillabo-tonico stusiano. Le somiglianze tra [Ja marno včyv hramatyku kochannja] e [Ja izučil nauku rasstavan'ja] sembrano però arrestarsi al distico iniziale. Se nella lirica mandel'štamiana l'incipit erotico si allarga nei versi successivi a un'ampia riflessione lirica sulla storia e la natura

70 Ivi: 113. 'Invano ho studiato dell'amore la grammatica, / grammatica delle labbra tue che peccano, - / sei scappata e hai nascosto le risa / strette tra i denti tuoi avari. / Bianchi erano i fianchi nei salici rapaci. / Indomita la lupa affamata / a pezzi tra gli arbusti faceva il corpo, / e rosso si fece ai piedi il rosmarino. / O cerchio di labbra, mani e gambe, / o voglia di lupo e paura d'agnello! / Ed eccola, eccola - la ricompensa, / eccola, l'eccitazione, e il forte tuono, ed il peccato! / E la frenesia dei lunghi corpi, / e le cime dei pini bruciate nel fumo, / e quest'arruffata, dai capelli sparsi, / sorda, bollente, opaca secca valle! / Era nervosa la notte di San Pietro, / il mattino sciolto odorava di letame. / Le stelle correvan dietro al carro dei Čumaky, / navigavamo noi assieme ai Čumaky.' Il termine čumaky si riferisce ai mercanti di sale e altri preziosi beni attivi in Ucraina dal Medioevo all'Ottocento. Si pensi ai numerosi dipinti di Ivan Ajvazovskij sul tema. 
umana, nel caso di Stus il motivo amoroso rimane centrale sino agli ultimi versi. È da notare come un recupero di Tristia non possa ad ogni modo prescindere dal profondo valore metapoetico della lirica stessa, esplicitamente annunciato nella seconda parte (ibidem):

Все было встарь, все повторится снова, и сладок нам лишь узнаванья миг.

Richiamandosi a questo testo, Stus sembra volere implicitamente sottolineare la centralità del lavoro intertestuale nella propria lirica, anticipando così l'ancora più esplicita dichiarazione di "intratestualità" al cuore del titolo del suo capolavoro Palimpsesty.

Sullo sfondo del maturo linguaggio di [Ja marno včyv hramatyku kochannja], frutto dell'ingegno di uno Stus appena venticinquenne, non può che colpire per la sua almeno apparente a-poeticità l'altro testo qui scelto come rappresentante della lirica amorosa stusiana del periodo di Zymovi dereva, composto un anno più tardi, nel 1964:

Не відповідаеш? Мовчиш? Заціпило?

Не можеш вибачити?

Клянеш?

Не можеш вивіритись розлуці?

Серцю - довіритися?

$[\ldots]$

Проклинаю. Цілую. Мовчки.

Задушився чеканням - мовчки.

Кулаками - в подушку ${ }^{71}$.

Lo sperimentale linguaggio sincopato di questo dialogo, ridotto alle sole repliche di uno dei due interlocutori, non può che confermare ulteriormente l'assoluta importanza della ricerca e della sperimentazione formale per il giovane Stus, più interessato al lavoro sui linguaggi poetici nella loro diversità che alla creazione di una cifra stilistica uniforme.

Allo stesso anno, il 1964, risale il testo che avrebbe dato il titolo alla raccolta nel suo insieme, Zymovi dereva, eccellente esempio della lirica stusiana a tema paesaggistico e naturale di questo periodo:

Згорнули руки - не викричатись

(як викричатись - без рук?).

Засніженим віттям витишитись

71 Ivi: 118. 'Non rispondi? Taci? Non riesci più a parlare? / Non puoi perdonare? / Maledici? / Non riesci a credere alla separazione? / Fidarti del cuore? // [...] // Maledico. Bacio. In silenzio. / Mi son strozzato di attesa - in silenzio. / Con i pugni - nel cuscino.' 


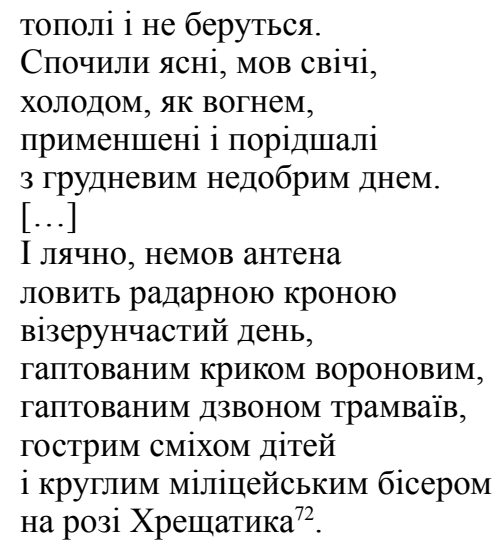

Bohdan Rubčak ha messo in evidenza il carattere intrinsecamente pasternakiano di questi versi, sia per quanto riguarda il ritmo sincopato, sia a livello figurativo, per l'antropomorfizzazione dell'elemento naturale (Rubčak 1987: 317). La raffigurazione simbolica del paesaggio invernale fonde infatti il motivo naturale a quello urbano. La loro unità è rappresentata dalla presenza dei corvi nella realtà cittadina di una Kiev fredda, inquietante, ma non priva di forza vitale. La compenetrazione tra la natura e la sfera della creatività umana e della contemporaneità è messa in evidenza dal linguaggio stesso, come mostra l'identificazione tra le cime degli alberi e i radar nella seconda parte, seconda una tendenza diffusa nella pratica poetica degli anni Sessanta. L'albero in questione, inoltre, è il pioppo, fondamentale simbolo di giovinezza e femminilità nel folclore ucraino, nonché protagonista di una delle più note ballate ševčenkiane. La tematica paesaggistica sembra dunque accostarsi a sua volta a quella amorosa, ampliando ulteriormente lo spettro semantico di questi versi, il cui peso all'interno dell'opera nel suo insieme è messo in rilievo dal fatto che la poesia dia il titolo alla raccolta stessa. Che il senso profondo di Zymovi dereva sia da ricercarsi proprio nella molteplicità dei suoi motivi e dei suoi linguaggi sembra dunque essere programmaticamente ribadito da questa lirica eponima.

Anche il secondo capitolo di Zymovi dereva presenta alcune liriche e singoli brani incentrati sulla situazione esistenziale dell' io lirico. Esse sono collocate tra $i$ testi numericamente più rilevanti, ovvero quelli riconducibili al discorso nazionale, nella varietà delle sue declinazioni, al motivo amoroso e alla raffigurazione dell'elemento naturale. La negazione della possibilità dell'io di identificarsi con se stesso si alterna, in sintonia con la pluralità di ispirazioni e linguaggi dell'opera, a una piena affermazione della soggettività. Si vedano, a esempio di que-

72 Ivi: 108 . 'Si son serrate le mani - come urlar tutto / (come urlar tutto - senza mani?) - / A tacere coi rami innevati / i pioppi non si mettono. / Han riposato chiari, come candele, / di freddo, come fuoco, / rimpiccioliti e radi / col giorno brutto di dicembre. / [...] / E con spavento, come un'antenna / riceve come cima di radar / il giorno arabescato, / ricamato di grido corvino, / ricamato col suono dei tram, / col riso acuto dei bambini / e la perlina dei poliziotti / in fondo al Chreščatyk.' 
ste due tendenze, [Vysamitniv den'. Vysmoktaly syly] del 1966 e alcuni versi da Medytacija del 1964, la lirica conclusiva della seconda parte:

Висамітнів день. Висмоктали сили, висотали біль.

Все тобі - чуже. Все тобі - немиле.

Все гірке тобі.

А немудре все! Хоч би дотягти, то бодай - до краю.

Світ - уже не світ. Ти - уже не ти.

(Хто із вас — конає?).

Хочеш — задушись. Можеш - утечи

сам од себе.

Скільки не волай, скільки не кричи, а - порожне небо.

Хто б тебе почув? Хто б тебе схотів зрозуміти?

Висохло перо. I мулькавий стіл слізьми - змитий ${ }^{73}$.

Il soggetto non è più in grado di costruire un legame con la realtà circostante, così come non riesce a riconoscere se stesso nelle forme del proprio io. Tuttavia, il parallelismo tra il mondo e l'io al sesto verso ("Svit - uže ne svit. Ty - uže ne ty") stabilisce anche in questo caso un'identità negativa tra i due poli in opposizione, dimostrandone la reale similarità, frutto della loro comune reazione all'alienante pressione della storia. Il mondo e l'io lirico condividono la perdita del legame con la propria natura, ritrovandosi al crocevia di identità e alienazione, continuità e lacerazione, senza che il logorio della contemporaneità possa realmente annientare la forza propulsiva del soggetto. Nonostante il settimo verso annunci la mancata coincidenza dell'io lirico con se stesso, la prospettiva che quest'ultimo si propone nel corso della seconda strofa è quella della possibilità di una fuga da sé. Ciò sembra implicare la permanenza dell'integrità dell'io al di là della sua apparente scissione. La sostanziale impossibilità di una definitiva rottura tra il soggetto e se stesso è messa in evidenza al nono e al decimo verso, anche attraverso l'enjambement che separa il verbo "fuggire" dal soggetto, così nuovamente 'racchiuso' in sé nell'unità di "sé" e "stesso". All'unitarietà dell' io fa da contraltare la sua assoluta solitudine, legata, come sembra emergere dall'immagine della penna essiccatasi al penultimo verso, alla sua difficile condizione di scrittore. La poesia rappresenta da una parte l'allontanamento dal consorzio

73 Ivi: 112 . 'Si è fatto solo il giorno. Han risucchiato le forze, / han centuplicato il dolore. / Tutto ti è - estraneo. Tutto ti è - fastidio. / Tutto amaro è per te. / E tutto stupido! Almeno raggiungere, / almeno fino all'orlo. / Il mondo - più non è il mondo. $\mathrm{Tu}$ - più non sei tu. / (Chi di voi - agonizza?) // Se vuoi - strozzati. Se puoi - fuggi / da te stesso. / Per quanto gridi, per quanto urli, - vuoto è il cielo. / Chi ti sentirebbe? Chi ti vorrebbe capire? / Si è seccata la penna. E il tavolo / di lacrime è lavato.' 
umano, dall'altra l'eterna lotta con e per l'ispirazione, venendo dunque a coincidere con il dolore del secondo verso, stusianamente "centuplicato". È inoltre evidente come nel verso conclusivo il discorso metapoetico non sia esplicitamente tematizzato, ma si realizzi al livello del significante. La forte attrazione paronomastica tra le due parole (sliz'my - zmytyj), confermata e sottolineata anche a livello semantico dalla comune appartenenza alla sfera dell'acqua, sembra porre jakobsonianamente al centro della conclusione della lirica il tratto precipuo della Poesia stessa, ovvero la sua concentrazione su di sé in quanto messaggio. Ciò è messo ulteriormente in risalto dalla posizione marcata di questo verso metapoetico alla fine del testo. Mettendo a nudo il principio della propria costruzione, la lirica ribadisce il proprio carattere autotematico, confermando la necessità di una lettura metapoetica e poetologica del testo nella sua interezza.

Si vedano anche alcuni brani di Medytacija ('Meditazione'):

Подвоєний, потроєний, посотий, ти меншаєш. Ти глибшаеш - i глухнеш. $[\ldots]$

Бажання приторговують тебе по часточці. Ти губишся між світу, що оповив дитинячість твою, сільский поріг, бабусині дарунки і матерні шершаві трудодні.

Маленька грудочка, ти йдеш в бездоння. $[\ldots]$

Як незбагненно серце вироста!

Хай очі п'ють - спивають. Вуха - чують і вичувають. Запахи — п'янять і вибирають; сонце рине в душу, безобрійний витворюючи світ!

I вже, загублений межі зірок проміж страждань ти звеселяеш смуту, проміж печалей - радість бадьориш (і вивіряеш спогадом майбутнє?)

О, скільки сподівань в душі гніздиться!

O, скільки в грудях золотих джмелів! Тож не спіши: іще цвістимуть скроні і заплітатиметься юний крок ${ }^{74}$.

74 Ivi: 131 . 'Sdoppiato, triplicato, centuplicato, / ti riduci. Ti fai profondo - ti fai sordo. / [...] // I desideri ti mercanteggiano / e ti fanno a pezzi. Ti perdi in mezzo al mondo, / che ha avvolto la tua infanzia, / la soglia del villaggio, i regali della nonna / e 
Ancora una volta è il contrasto stilistico tra i versi a imporsi al centro della lirica. La consueta riflessione esistenzialista sulle metamorfosi del sé e sul vacillare dell'identità si alterna alla raffigurazione della realtà contadina ucraina, accostando e fondendo le due principali tendenze stilistico-tematiche che hanno segnato nella loro alternanza lo svolgimento dei due primi capitoli di Zymovi dereva.

Per il terzultimo verso di Medytacija sono ipotizzabili due ipotesti, entrambi risalenti agli anni Dieci, di due scrittori indubbiamente uniti da un'inestinguibile tensione classicizzante: Opivdni ('A mezzogiorno'), poesia giovanile del classico sovietico Maksym Ryl'skyj, e Poslednij šmel' di Ivan Bunin, una delle liriche più note del futuro vincitore del Premio Nobel.

In Opivdni, come in Medytacija, l'io lirico si identifica integralmente con il bombo sotto il segno della pulsione creativa:

Мохнатий джміль із будяків червоних

спиває мед. Як соковито й повно

гуде і стелиться понад землею

ясного полудня віолончель.

Спочинь! На заступ вірний обіпрись

і слухай, і дивись, і не дивуйся.

Це ж ти сам вколо зеленню розлився, огудинням прослався по землі,

Це ти гудеш роями бджіл брунатних, $[\ldots]$

Заснули води і човни на водах,

Висять рої, як кетяги пахучі,

і навіть сонце, мов достиглий плід,

здається непорушним... Тільки ти

не дався чарам півдня й супокою,

бо, як сестра, схилилась над тобою

невтомна подруга, сувора творчість ${ }^{75}$.

le ruvide quote di tua madre. // Un piccolo mucchietto, vai nell'abisso. // [...] // Come cresce incomprensibilmente il cuore! // Che gli occhi bevano - sorbiscano. Le orecchie - sentano / e ascoltino. Gli odori - inebrino / e scelgano; il sole penetri nell'anima, / creando un mondo sconfinato! // E ormai, perso tra le stelle, / tra le sofferenze rallegri la tristezza, / tra le malinconie - risvegli la gioia / (e controlli il futuro col ricordo?) // Oh, quante speranze nell'anima si annidano! / Oh, quanti bombi d'oro nel petto! / Non affrettarti: fioriranno le tempie - / e si intreccerà il giovane passo.'

75 Ryl's'kyj 2005: 189. 'Villoso un bombo di rossi cardi / sorbisce il miele. Succoso, intenso / ronza e si stende sulla terra / violoncello del meriggio chiaro. // Riposa! Sulla vanga sicuro appoggiati / e ascolta, e guarda e non meravigliarti. / Sei tu stesso disperso nel verde tutt'intorno, / un virgulto sulla terra ormai famoso, / sei tu che ronzi a sciami di bombi bruni, / [...] // Dormono le acque e le barche sulle acque, / fermi gli sciami come grappoli odorosi, / e anche il sole, come un frutto maturo, / pare immobile... Solo tu / non cedi al richiamo di pace e meriggio, / perché su di te è, come sorella, / come amica indefessa, severa, l'arte.' 
Se in Medytacija i bombi che il soggetto riesce a percepire nel proprio cuore fungono da stimolo per il recupero della fiducia nella propria creatività, in Opivdni l'homo faber ha ormai decisamente superato la natura stessa, rispetto alla quale si sente superiore in virtù della propria instancabile attività. Rispetto al possibile ipotesto ryl's'kiano e alla hybris del suo io lirico, Medytacija mostra un soggetto attanagliato dal dubbio, ancora in cammino nella costruzione della propria identità umana e artistica. Si noti, a possibile conforma del legame genetico tra le due liriche, l'utilizzo in entrambe del verbo spyvaty in relazione all'interscambio tra l'entità agente e la natura, ora l'io lirico, ora il bombo nella loro interscambiabilità.

Si vedano ora la prima e l'ultima delle tre strofe di Poslednij šmel'(Bunin 1987: I, 334-335):

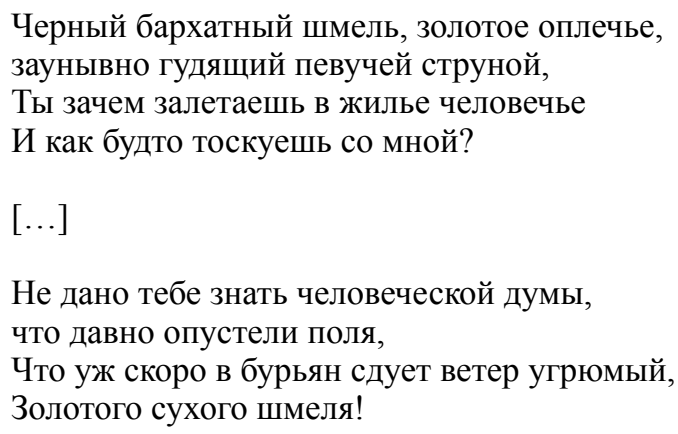

L'accostamento di Medytacija e Poslednij šmel' è giustificato dal grande apprezzamento espresso da Stus per la lirica buniniana, da lui ritenuta più interessante e originale della prosa dello stesso autore, generalmente considerata il suo principale contributo alla letteratura russa moderna. Nei classici versi di Poslednij šmel', nello specifico nella terza e ultima strofa, l'insetto è associato all'ingenua fiducia nel futuro, alla speranza, in perfetta sintonia con la caratterizzazione di sé che dà l'io lirico di Medytacija nell'ultima quartina del testo, con la quale si conclude, si ricordi, l'intero secondo capitolo della raccolta. È qui letteralmente ripresa anche la spontanea caratterizzazione dell' insetto come "dorato", presente nei versi di apertura e chiusura della poesia buniniana. Tuttavia, se in quest'ultima al centro della riflessione lirica sono il rapporto tra l'uomo e la natura e la fragilità del confine tra la vita e la morte, in Medytacija l'attenzione si rivolge esclusivamente all'interiorità dell'uomo, al "cuore" che ha raggiunto dimensioni incomprensibili per lo stesso soggetto che con esso si identifica.

Anche in questo caso, in sintonia con la compresenza dell'ipotesto ryl's'kiano a fianco di quello buniniano, è evidenziato come la realizzazione della natura del soggetto, del suo smisurato cuore, non possa che passare attraverso la creatività artistica. Il dispiegamento delle attività sensoriali descritto nella terzultima strofa di Medytacija è finalizzato alla creazione di un mondo sconfinato, in corrispondenza, dunque, con il cuore in cui il mondo stesso trova la sua origine. Il superamento dell'opposizione tra dolore e gioia, in sintonia con la totalità stili- 
stica e tematica di Zymovi dereva, sembra essere l'agognato risultato dell'azione creatrice e la garanzia del cammino auspicato nel verso conclusivo, in una prospettiva, ancora una volta, profondamente metapoetica e poetologica.

Medytacija è accostabile a un altro testo del secondo capitolo, composto nel 1965 e disposto tra le liriche iniziali, dal titolo Molodyj Gete ('Il giovane Goethe'). Se ne vedano gli ultimi versi:

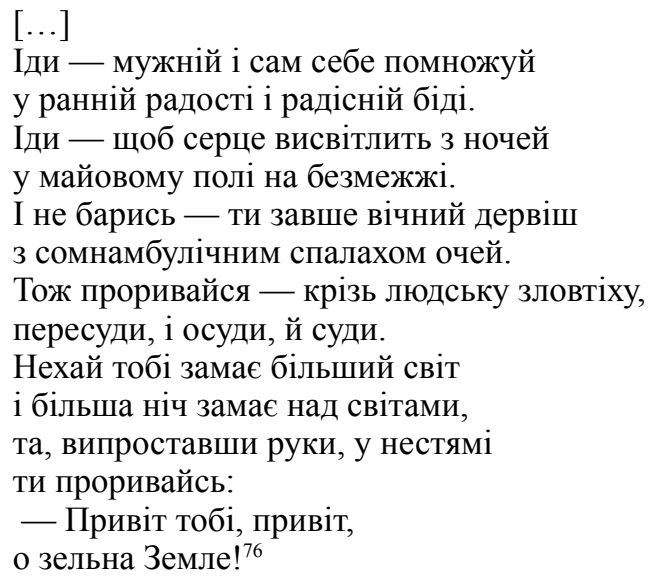

Importante testimonianza dell'interesse stusiano per l'autore del Werther già alla metà degli anni Sessanta, questi versi si ricollegano alla "meditazione" dell'anno precedente, creando un nesso significativo tra l'io lirico protagonista della raccolta e l'autore che all'inizio degli anni Ottanta Stus avrebbe definito come "il primo tra i suoi poeti". Il soggetto di Zymovi dereva, in equilibrio tra la constatazione della lacerazione del proprio io e l'affermazione della sua pienezza e vitalità, identifica qui la componente classica della propria auto-percezione con il modello del giovane Goethe, anticipando così la dinamica di biforcazione e fusione tra il sé e l'io lirico goethiano alla base di Čas tvorčosti / Dichtenszeit. La maturità del soggetto è inscindibile dalla sua accettazione e comprensione dell'universo nella sua interezza, composto tanto dall'elemento naturale, quanto dall'uomo e dalla sua imperfezione. La facoltà creatrice, inseparabile dalla figura di Goethe, risulta dall'unione dei due poli solo apparentemente opposti della passività nei confronti del tutto e dell'attività trasfigurante del poeta.

76 T I.1, 97. '[...] Va' - matura e moltiplica te stesso / nella gioia giovane e il dolore gioioso. / Va' - perché il cuore si rischiari dalle notti / sui campi di maggio sconfinati. / E non fermarti - sei l'eterno derviscio / col fulmine degli occhi. / Lanciati anche tu sul campo, all'acqua, / ai monti, alle stelle, al giovane riso. / Lanciati anche - attraverso il male umano, / le voci, i pregiudizi ed i giudizi. / Che il grande mondo ti si mostri / e la grande notte si mostri sopra i mondi, / e, allungando le braccia, sbigottito, / lanciati: / - Salve a te, salve, / o verde Terra!' 
Il terzo capitolo di Zymovi dereva, a differenza dei due precedenti dotato di un sottotitolo (Ranni poeziji ta eksperymenty - 'Prime poesie ed esperimenti'), è composto da trentuno liriche. Si noti, tuttavia, come siano presenti in esso anche testi scritti alla fine degli anni Sessanta, difficilmente, dunque, classificabili come giovanili. A distinguerlo dal primo e ad avvicinarlo al secondo capitolo è un buon grado di uniformità stilistica e tematica. Pur non mancando i consueti slittamenti ora verso l'alto ${ }^{77}$, ora verso il basso ${ }^{78}$, dalla composizione di questo gruppo di liriche non emergono i forti scarti stilistici che avevano segnato il primo capitolo. Questa relativa armonizzazione può essere ottenuta con un graduale adattamento dei versi alle estremità iniziali e finali delle liriche nei testi contigui, così come con una frequente mescolanza di registri alti e bassi nella maggior parte dei testi.

Particolarmente significativa alla luce della generale atmosfera vitalistica che il terzo capitolo offre nel suo complesso è la lirica conclusiva, tra le più citate e antologizzate dell'intero repertorio stusiano:

Не одлюби свою тривогу ранню, -

- той край, де обрію хвиляста каламуть,

де в надвечір'і вітровії тчуть

єдвабну сизь, не віддані ваганню.

Ходім. Нам є де йти - дороги неозорі,

ще сизуваті в прохолодній млі.

Нам є де йти — на хвилі, на землі -

шляхи - мов обрії — далекі і прозорі.

Шумуйте, весни - дні, ярійте, вечори,

поранки, шліть нам усмішки лукаві!

Вперед, керманичу! Хай юність догорить -

ми віддані життю і нам воздається в славі ${ }^{79}$.

77 Si vedano alcuni versi della parte centrale di [Otak $i$ vikuvaty] ('[E passar così gli anni]') del 1968, in: ivi: 149: “[...] Не нарікаю, Боже, / на іспити важкі: / одним стражденним дрожем / злютовано віки. / Та виболіти землю — / нам! Зберегти живе — / нам! Вивершити стелю — / нам! І Господь зове —/ нас! [...] / [...] / Наш шлях прослався вгору — / не вбік, а не вниз, а — ввись. / Ми добротою хорі, / до неба возмоглись, / Та наша Україна, / котра не знає грат, / а притиску, а кпини, / а помсти - й востократ. / [...]” '[...] Non mi lamento, oh Dio, / delle pesanti prove: / con un sol tremito sofferto / sono irati i secoli. / E soffrire la terra - / tocca a noi! Conservare ciò che vive - / tocca a noi! Coronare l'apice - / tocca a noi! E il Signore chiama - / noi! [...] / [...] / Il nostro cammino si è aperto in alto - / non di lato, non in basso, ma in su. / Noi, di bontà malati, / sin al ciel ci siam alzati. / Lì è l'Ucraina nostra, / che grate non sa, / e giogo, e irrisioni, / e vendette - e cento volte! / [...]'

78 Ivi: 148: “Дві дівчини / на трамвайній зупинці / жваво обговорюють / вчорашній день. / [...]" 'Due bambine / alla fermata del tram / discutono animate / la giornata di ieri. / [...]' La disposizione di queste due liriche in successione rappresenta uno dei rari casi di evidente discrepanza stilistica nel terzo capitolo.

79 Ivi: 152. 'Non smettere d'amar l'angoscia tua precoce, - / - quel paese, dove all'orizzonte è increspata la foschia, / dove la bora quando si fa sera tesse / senz'esitare lana grigiazzurra. / Usciamo. C'è dove andare. Le strade sconfinate, / ancora grigie 
Tra le prime liriche di Stus, datata 1958, [Ne odljuby svoju tryvohu rannju], frequentemente presentata come primo manifesto dell'indomita volontà di un convinto difensore della cultura patria, sembra mostrare in realtà echi della retorica sovietica. Come in Molodyj Gete, il soggetto è pronto a fondersi con la realtà circostante per poter così trovare la propria realizzazione. Tuttavia, rispetto alla lirica del 1965, [Ne odljuby svoju tryvohu rannju] evidenzia attraverso la frequente ripetizione della prima persona plurale il carattere collettivo di questa apertura alla totalità, rendendosi passibile di diverse letture. Un'interpretazione in chiave nazionale è sicuramente lecita, così come è legittimo leggervi semplicemente un'ingenua, ancorché non esente da influssi della cultura sovietica, esaltazione della giovinezza da parte di un poeta appena ventenne, in sintonia con i suoi scritti critici degli stessi anni. A favore di una lettura che privilegi la tematica nazionale gioca indubbiamente l'evocazione delle sfere del mare e della terra al settimo verso, memori dei colori tradizionali ucraini, così come la fiabesca evocazione di un paese fatato, amato e probabilmente irraggiungibile, coerente con il 'mito ucraino' della tradizione letteraria patria ripreso e portato avanti dallo stesso Stus. Indubbia, sulla base della datazione della lirica, è allo stesso tempo la necessità di situare $[\mathrm{Ne}$ odljuby svoju tryvohu rannju] nel contesto culturale tanto nazionale quanto sovietico e sovranazionale del Disgelo, in anni segnati dall'entusiasmo di una speranza di rinnovamento non ancora offuscata dalle repressioni dei primi anni Sessanta. Meno fondata, anche se non da escludere, sembra in questo caso un'interpretazione poetologica, a favore della quale si potrebbe citare con un buon grado di sicurezza solamente l'innato senso di angoscia che il soggetto dichiara di provare al primo verso, intendendolo nel senso di una precoce e inappagabile vocazione poetica.

Di chiara tematica poetologica è invece un sonetto all'inglese del 1965, di cui si vedano le ultime due quartine e il distico finale:

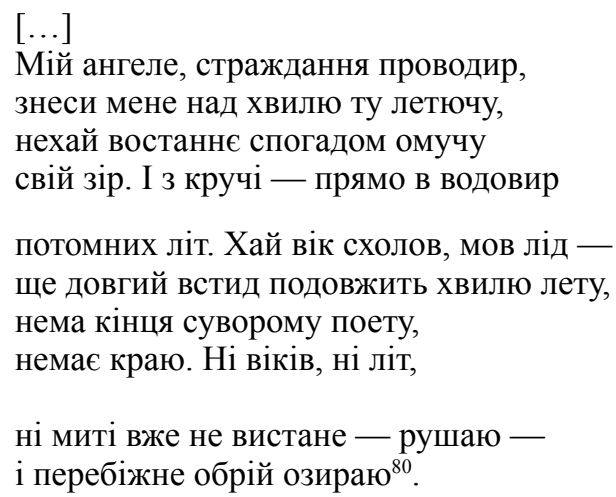

nella fresca nebbia. / C'è dove andare - sull'onda, sulla terra - / i cammini - gli orizzonti - lontani e luminosi. / Risuonate, primavere - giorni, splendete, sere, / mattini, mandate a noi sorrisi giocosi! / Avanti, timoniere! Che la gioventù al fuoco bruci - / alla vita donati, saremo in gloria compensati.'

80 Ivi: 137. '[...] Angelo mio, condottiero della sofferenza, / portami su quell'onda volante, / che alla fine col ricordo io tormenti / la mia vista. E dall'alta riva - dritto 
La prospettiva adottata in questi versi è quella dell'assoluto distacco del poeta dalla realtà circostante e della sua superiorità su di essa. La sua incontenibilità sembra ancora una volta modellata sul Poeta di Marina Cvetaeva, la cui sofferenza, come espresso dal distico conclusivo della terza lirica del più volte citato trittico Poety, deriva dal ritrovarsi con la propria "incommensurabilità in questo mondo di misure" ${ }^{81}$. Tuttavia, come nel primo e nel secondo dei componimenti del ciclo cvetaeviano, è qui la capacità del poeta di trionfare sulla piccolezza delle cose della terra a imporsi. La sofferenza e la vergogna, ugualmente riconducibili all'ipotesto cvetaeviano ${ }^{82}$, spingono il soggetto all'introspezione e all'unione con l'angelo, ovvero con l'ispirazione poetica, inscindibilmente connessa con il ricordo e l'interiorità. In un'ottica quasi interamente autotelica, che lascia spazio solo a una fugace osservazione dell'orizzonte, questi versi anticipano la chiusura del soggetto in se stesso che segnerà in gran parte Čas tvorčosti / Dichtenszeit e Palimpsesty.

Di grande interesse è, infine, una lirica del 1964 segnata da venature inconfondibilmente postmoderniste:

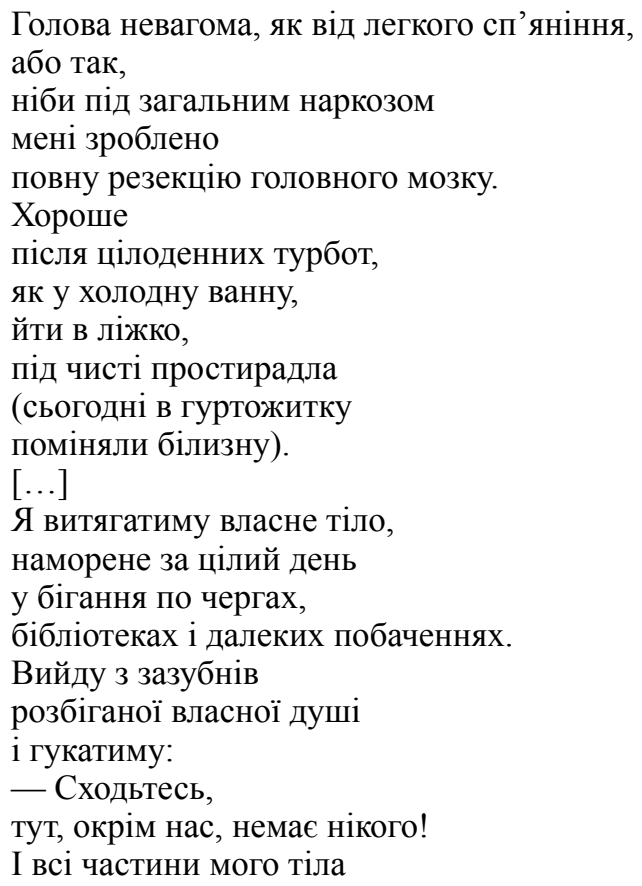

dentro al turbine // degli anni a venire. Che il secolo si geli, come il ghiaccio - / la lunga onta allunghi l'onda in volo, / non c'è fine al severo poeta, / non c'è confine. Né secoli, né anni, // né istanti basteranno - parto - / e di sfuggita osservo l'orizzonte.'

81 Cvetaeva 2004: 609: “С этой безмерностью / В мире мер?!”

82 Ivi: 608: “Есть в мире мнимые, невидимые: / (Знак: лепрозариумов крап!)

/ Есть в мире Иовы, что Иову / Завидовали бы - когда б." 


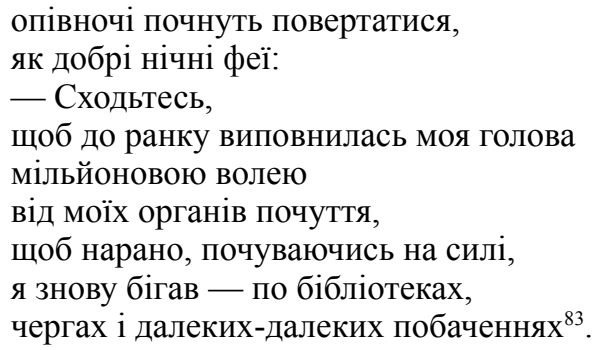

La concorrenza tra l'interezza dell'io e la sua disgregazione è chiaramente il nucleo semantico di questa sorprendente lirica. A questa duplicità sembra richiamarsi, a livello stilistico, l'alternanza tra un registro molto basso, colloquiale (“сьогодні в гуртожитку / поміняли білизну") е momenti di deciso innalzamento (l'anafora dell'appello alle parti del corpo, la "volontà a milioni"). Dal punto di vista tematico, il testo segue un andamento dialettico, secondo il quale all'iniziale presa di conoscenza della dispersione della propria fisicità, sfociata nella totale asportazione del cervello, segue la scelta del soggetto di ricostituire la totalità di anima e corpo del proprio io. La concreta realizzazione di questo progetto, in realtà, è solo annunciata per le ore notturne a venire. A livello grammaticale, la certezza che ciò avverrà è espressa dall'utilizzo dell'aspetto perfettivo del verbo "incominciare" (počaty).

Se l'inizio della lirica crea nel lettore odierno l'attesa di una 'consueta' presa di coscienza della disintegrazione dell'io, il suo svolgimento e la sua conclusione vanificano questa aspettativa, facendo ipotizzare, allo stesso tempo, un consapevole 'gioco' di Stus con motivi e linguaggi della poesia a lui contemporanea ascrivibile alla sensibilità postmodernista ${ }^{84}$. La dimensione ludica della narrazione lirica sembra essere ricalcata dall'accostamento delle parti del corpo del soggetto con delle fate, di cui è inoltre esplicitamente sottolineata la "bontà". Non può che colpire a questo proposito la perfetta coincidenza cronologica tra la composizione della lirica

83 T I.1, 146. 'La testa non pesa, / come per una leggera ebbrezza, / oppure / come se in anestesia totale / mi avessero fatto / una completa asportazione del cervello. / 亡̀ bello / dopo le preoccupazioni di una giornata / come in una vasca da bagno fredda, / andare a letto, / sotto le lenzuola fresche / (oggi allo studentato / hanno cambiato la biancheria). / [...] / Stenderò il mio corpo, / sfiancato da questa giornata / di corsa tra code, / biblioteche e lontani appuntamenti. / Uscirò dai vicoli ciechi / dell'anima mia in corsa / e griderò: - Venite, / qui, a parte noi, non c'è nessuno! / E tutte le parti del mio corpo / a mezzanotte inizieranno a ritornare, / come buone fatine della notte: / Venite! È già notte! / Sono solo, non c'è più nessuno. / Venite, / così fino al mattino la mia testa / si riempirà di volontà a milioni / dai miei organi di percezione / così al mattino, sentendomi in forma, / correrò di nuovo - tra biblioteche, / code e appuntamenti lontani-lontani.'

84 Se la scissione fisica e psicologia dell'io è a ragione accostabile alla sensibilità postmoderna, non si deve d'altro canto dimenticare che il motivo della disgregazione dell'unità corporea è ben rappresentato sin dalla lirica greca arcaica, senza che ciò debba necessariamente significare una lacerazione interiore dell'io. Per uno studio sull'argomento con esempi tratti a partire da Saffo fino al Romanticismo cfr. Böschenstein 1990. 
e la pubblicazione di opere come Idealizovana biohrafija ('Biografia idealizzata') e Spomyny ('Ricordi') del newyorchese Jurij Tarnavs'kyj, opere in cui l'ossessione per il dissolvimento della corporalità e dell'integrità del soggetto comincia ad assumere un ruolo di primo piano ${ }^{85}$. Tuttavia, al postmodernismo tarnavs'kiano non sembra corrispondere un simile esito nella lirica stusiana in questione. Il superamento della soggettività è solo momentaneo, passeggero, illusorio. Il controllo dell'io su se stesso può rapidamente essere ripristinato da un soggetto modernista che, con un paradosso, ha solo postmodernamente giocato con la propria rarefazione.

\section{Veselyj cuyntar}

La terza raccolta poetica di Stus fu pubblicata per la prima volta solo cinque anni dopo la sua morte. Composta tra il 1968 e il 1969, era rivolta per ovvie ragioni a un ristretto pubblico di amici, per i quali Stus approntò dodici esemplari dattiloscritti. Uno di essi è stato conservato da un amico del poeta, un altro è stato restituito dal KGB alla famiglia di Stus dopo la sua morte, mentre non si hanno tracce dei rimanenti dieci esemplari. L'archivio dell'Istituto di Letteratura Ševčenko conserva inoltre due brogliacci che mostrano alcune differenze a livello di quantità e disposizione dei testi. La versione definitiva della raccolta, la cui storia testuale risulta dunque alquanto meno complessa rispetto ai casi di Kruhovert', Zymovi dereva e Palimpsesty, consta di sessantadue liriche.

Sullo sfondo delle opere precedenti, Veselyj cvyntar ${ }^{86}$ si distingue per un buon grado di uniformità stilistica e tematica. Rispetto a Zymovi dereva, frutto della se-

85 Cfr. Bartolini 2012: 96-111. È tuttavia da escludere una conoscenza della poesia del Gruppo di New York da parte di Stus nel 1964. Essa appare invece molto probabile negli anni immediatamente successivi, in seguito agli scambi epistolari di Bohdan Rubčak e Bohdan Bojčuk con gli šistdesjatnyky nel 1965 e il viaggio di Vira Vovk in Ucraina nel 1966. L'unica testimonianza diretta della conoscenza di Stus dei poeti del Gruppo di New York, al di là dei suoi pluriennali contatti con Vira Vovk, risale alla metà degli anni Settanta. Si veda dalla lettera ai genitori del 13/17-06-1975, in: T VI.1, 147: “Одержав дуже приємного листа од Віри Вовк із Бразилії - вислала гарні відбитки двох композицій Ю. Соловія, відомого українського художника, що мешкає в Нью-Йорку. Там уся громада поетична міста - Віра, Тарнавський, Килина, Андієвська, Бойчук, Рубчак, Васильківська. Усі вони аполітичні митці, творять мистецтво, а не годять політикам." 'Ho ricevuto una bella lettera da Vira Vovk dal Brasile - mi ha mandato le copie di due composizioni di Jurij Solovij, un noto artista ucraino che abita a New York. Lì c'è tutta una comunità di poeti - Vira, Tarnavs'kyj, Kylyna, Andijevs'ka, Bojčuk, Rubčak, Vasyl'kivs'ka. Sono tutti artisti apolitici, fanno arte e non adulano i politici.'

86 Il titolo della raccolta sembra dialogare con diverse liriche di Vasyl'Symonenko. Si ricordi la prima quartina di una lirica del 1962 del poeta prematuramente scomparso (Symonenko 2012: 270: “Гранітні обеліски як медузи, / Повзли, повзли і вибилися 3 сил - / На цвинтарі розстріляних ілюзій / Уже немає місця для могил.” 'Granitici obelischi di meduse, / strisciavano, perdevano le forze - / Nel cimitero delle speranze 
lezione e composizione di liriche risalenti a periodi diversi della vicenda umana stusiana e testimoni di orientamenti letterari molto variegati, questa raccolta mostra chiaramente la volontà di Stus di concentrarsi su di un numero piuttosto ristretto di stilemi e nuclei tematici. La composizione di queste liriche si trova tuttavia a coincidere con la scrittura dei testi più tardi di Zymovi dereva, a testimonianza tanto dell'eccezionale importanza dei mesi finali degli anni Sessanta nella storia della poesia stusiana, quanto, ancora una volta, della poliedricità della sua ispirazione anche all'interno di un determinato periodo. Le concezioni artistiche alla base delle due raccolte si mostrano dunque opposte e complementari: estrema varietà e continua sperimentazione con diversi linguaggi nel caso di Zymovi dereva, concentrazione e restringimento stilistico-tematico nel caso di Veselyj cvyntar. Ciò non esclude, beninteso, che anche Veselyj cvyntar sia a tratti marcata da netti sbalzi stilistici e veri e propri esercizi di stile. Essi, tuttavia, non sembrano qui trovarsi al centro delle preoccupazioni artistiche di Stus, interessato piuttosto a una sostanziale rielaborazione in un registro medio-basso di motivi ascrivibili alla sensibilità esistenzialista, nel più ampio complesso della riflessione sulla storia contemporanea. Notevole, inoltre, è la tendenza, già osservabile in Zymovi dereva, alla costante ripresa di un numero ristretto di parole e immagini a cui sembra assegnata la funzione di 'puntellare' il testo, rinforzandone ulteriormente la coesione. Se in Zymovi dereva questa tecnica è principalmente riscontrabile in liriche contigue, a garanzia di un'unità testuale apparentemente non evidente ma profonda, in grado di costituire un contrappeso alla forte disomogeneità stilistica della raccolta, in Veselyj cvyntar essa si manifesta piuttosto al livello dell'opera nel suo insieme, disseminata di frequenti rimandi lessicali e tematici tra i singoli componimenti.

È inoltre il caso di notare come, pur con frequenti variazioni, circa un terzo delle sessantadue liriche che compongono la raccolta sia stato ripreso da Stus nella composizione di Palimpsesty, a testimonianza del carattere pienamente maturo di molti dei testi scritti alla fine degli anni Sessanta.

La prima lirica di Veselyj cvyntar, intitolata Nad osinnim ozerom ('Su di un lago in autunno'), si distingue nell'economia generale dell'opera per un'insistenza sul linguaggio espressionista tipico di altre fasi della produzione stusiana, che non troverà grande riscontro nelle poesie successive:

Цей став повісплений, осінній чорний став, як антрацит видінь і кремінь крику, виблискує Люципера очима.

П’янке бездоння лащиться до ніг.

Криваво рветься з нього вороння майбутнього. Летить крилатолезо

fucilate / Posto non c'è ormai per le tombe'), nonché Velykyj pochoron ('L'allegro funerale') dello stesso autore, anch'essa risalente al 1962. Symonenko è altresì autore di un ciclo dal titolo Mandrivka po cvyntarju: nyzka epitafij ('Viaggio al cimitero: una serie di epigrafi'), dalle spiccate tonalità grottesco-postmoderne. 


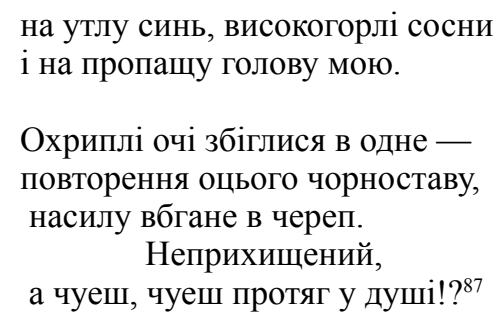

$\mathrm{Al}$ centro della lirica è la compenetrazione dell'io con la realtà in cui egli è immerso. L'inquietante, minaccioso bacino d'acqua davanti al quale il soggetto si ritrova è evidentemente antropomorfizzato. La sua prima caratterizzazione rimanda ai segni lasciati sul volto umano dal vaiolo, mentre nel secondo verso il suo colore nero è paragonato sinesteticamente alle sfere sensoriali della vista e dell'udito. La facoltà visiva è ripresa nel verso successivo attraverso l'accostamento del luccichio dello stagno agli occhi di Lucifero, metafora della diabolica attrazione dell'uomo per l'abisso. Nella strofa seguente è descritto invece l'avvicinamento fisico dell'inebriante abisso al soggetto umano. Quest'ultimo appare immerso in una totalità che riunisce il cielo, la natura e l'uomo nella sottomissione al principio diabolico. Il cielo e l'uomo risultano accomunati da un senso di debolezza e instabilità, che li rende vittima dell'azione distruttiva della realtà demoniaca. Nella terza strofa si assiste così al trasferimento, alla 'ripetizione' dell'abisso sul volto del soggetto, privato degli occhi, ridotti a una sola oscura profondità dal contatto con l'annichilente elemento esterno. Si noti, inoltre, come gli occhi stessi del soggetto, segnati dalla raucedine, riproponessero anche prima della loro effettiva trasformazione in stagno la caratterizzazione sinestetica di quest'ultimo al secondo verso ("антрацит видінь і кремінь крику"). Al soggetto non è dunque (più) garantita la possibilità di un'autonomia ontologica e, di conseguenza, gnoseologica. L'azione devastante del mondo esteriore sulla sua integrità lo priva della possibilità di essere se stesso e conoscere la realtà osservandola e percependola sensorialmente. Negli ultimi due versi sembra essere almeno provvisoriamente ripristinata l'individualità di cui l'io si è visto privato nelle strofe precedenti. Al soggetto, heideggerianamente indifeso, abbandonato, insicuro, è tuttavia concessa un'anima, parola con cui significativamente si conclude questa intensa, densa lirica iniziale.

L'oscillazione tra il disintegrarsi della personalità e la sua sopravvivenza, asse centrale dell'immaginario poetico stusiano, è rielaborata nella lirica seguente, dal titolo Vertep ('Il teatro delle marionette'), la cui tonalità, ben distinta dagli stilemi espressionisti di Nad osinnim ozerom, si rivelerà fondamentale per la raccolta nel suo complesso:

${ }_{87}$ T I.1, 154. 'Questo stagno sfregiato, nero stagno d'autunno, / antracite di visioni e selce di grido, / brilla degli occhi di Lucifero. // Un abisso mi si struscia ai piedi. // Sanguinosi se ne staccano i corvi / del futuro. Vola con lama alata sul blu sbiadito, i pini dall'alta gola / e la mia testa rovinata. // Gli occhi rauchi si sono fusi - / ripetono quel nero stagno, / a forza infilato dentro il cranio. Indifeso, / lo senti, lo senti lo spiffero nell'anima!?' 


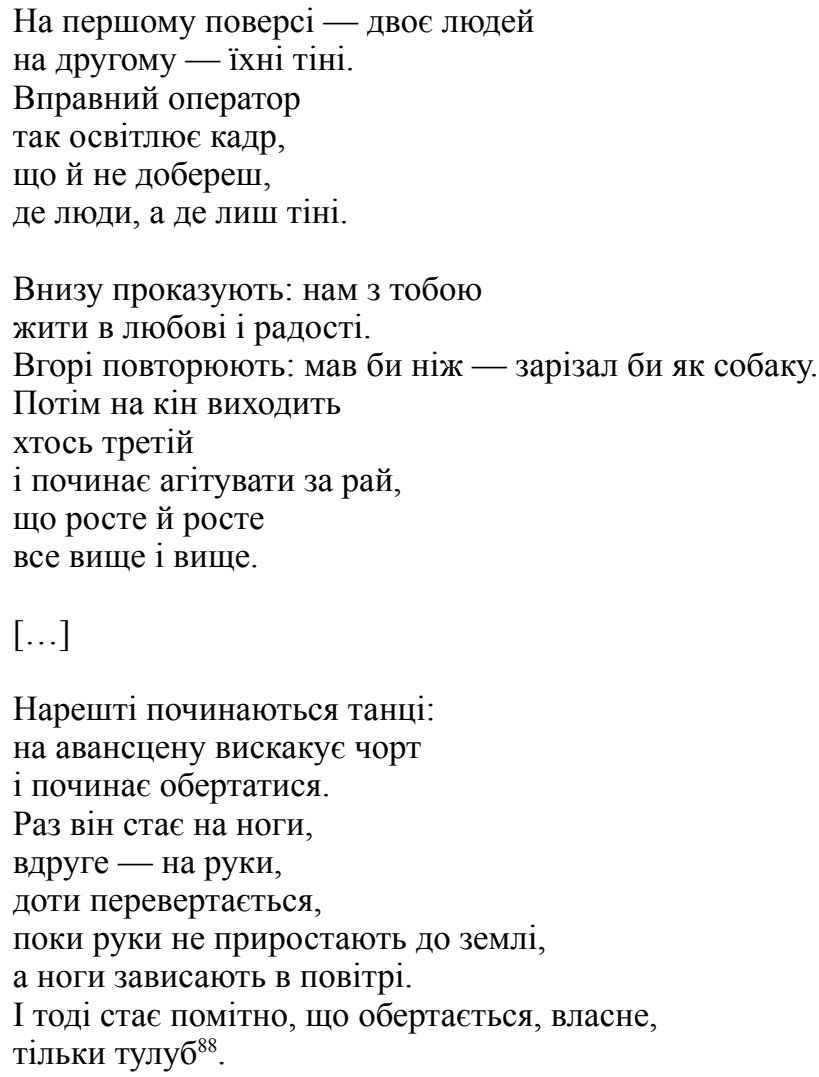

La storia e la contemporaneità hanno ridotto l'uomo a un manichino. In quella che è la sua opera maggiormente segnata dal riferimento alla concreta realtà storico-sociale, Stus si serve del linguaggio sovietico e dei realia del suo tempo per raffigurare il mondo in cui è immerso come la scena di un dramma assurdo e tragicomico. All'origine della confusione tra l'uomo e la sua ombra, dunque ancora una volta dell'oscuramento e della messa in discussione della personalità umana nella sua integralità, è in questo caso un'entità riconoscibile e ben definita, un "operatore" tecnico in grado di regolare metaforicamente la luce che concede alle persone il dono della loro individualità. È evidente come in questo caso il rimando extra-letterario alla realtà dell'Unione Sovietica brežneviana sia

${ }^{88}$ Ibidem. 'Al primo piano - due persone / al secondo le loro ombre. / Il tecnico, abile, / illumina la scena così / che non distingui / le persone dalle ombre. // Di sotto dicono: io e te / dobbiam vivere con gioia e con amore. / In alto ripetono: avessi un coltello / ti farei a pezzi come un cane. / Poi sulla scena entra / un terzo / a far pubblicità al paradiso, / che cresce e cresce / sempre più in alto. // [...] // Alla fine cominciano le danze: / sull'avanscena salta fuori il diavolo / e inizia a dimenarsi. / Una volta si mette sui piedi, / un'altra sulle mani, / continua a rigirarsi, / finché le mani non gli si fanno terra / con le gambe in arie. / E allora è chiaro: / a dimenarsi, in realtà, / è solo il tronco.' 
inevitabile, anche se ciò non esclude una possibile lettura in chiave puramente letteraria di questa lirica, così come dell'intera raccolta, accostabile con facilità a diverse tendenze artistiche novecentesche, dalle avanguardie, alla Neoavanguardia, al Teatro dell'Assurdo. Un'interpretazione che non escluda il concreto riferimento alla storia sembra giustificato dalla seconda strofa, nella quale non mancano elementi chiaramente riconducibili alla cultura verbale sovietica, come il verbo ahituvaty. Il motivo cristiano del paradiso, legato alla tematica delle rappresentazioni sacre della tradizione del vertep, è qui rivalutato e rielaborato in chiave sovietica sotto l'occhio sarcastico dell'io lirico. L'apparizione del diavolo nell'ultima strofa, memore degli occhi di Lucifero in Nad osinnim ozerom, dalla quale Vertep è decisamente distante dal punto di vista stilistico, ruba la scena a quello che era rimasto dell'uomo-marionetta nei versi iniziali. Si tratta, tuttavia, di un diavolo 'meschino', grottesco, ridicolo, privo di identità e personalità e impossibilitato a progredire come l'uomo che si è trovato a sostituire sul palcoscenico del mondo. In uno stile piano, quasi prosastico, ma segnato dal frequente ricorso a uno degli elementi più caratteristici del linguaggio poetico, il parallelismo, Stus dà inizio all'elaborazione della tematica annunciata dal titolo della raccolta, identificabile nell'assurdo e nel grottesco della contemporaneità, momentaneamente messa da parte nella lirica introduttiva.

A quest'ultima, in apparente opposizione a Vertep, sembra ricollegarsi la terza poesia della raccolta:

Мені здається, що живу не я, а інший хтось живе за мене в світі в моїй подобі.

Ні очей, ні вух, ні ніг, ні рота. Очужілий

в своєму тілі. I, кавалок болю, $\mathrm{i}$, самозамкнений, у тьмущій тьмі завис.

Ти, народившись, виголів лишень, а не приріс до тіла. Не дійшов своєї плоті. Тільки перехожий межисвітів, ворушишся на споді чужого існування.

Сто ночей попереду і сто ночей позаду, а межи ними - лялечка німа: розпечена, аж біля з самоболю, як цятка пекла, лаконічний крик усесвіту, маленький шротик сонця, зчужілий і заблуканий у тілі.

Ти ждеш іще народження для себе, а смерть ввійшла у тебе вже давно ${ }^{89}$.

89 Ivi: 155 . 'Mi sembra che non sono io che vivo, / ma qualcun altro è al posto mio nel mondo / con le mie sembianze. / Senz'occhi, senza orecchi, / né mani, gambe, né bocca. Alienato / nel proprio corpo. Un pezzo di dolore, / e, chiuso-in-se-stesso, / 
Tra le liriche più famose dell'intera produzione stusiana. [Meni zdajet'sja, ščo žyvu ne ja] è accostabile a entrambi i testi che la precedono in Veselyj cvyntar. Dal punto di vista stilistico si ricollega chiaramente a Nad osinnim ozerom, contrapponendosi all'andamento prosastico di Vertep, rispetto alla quale abbandona inoltre la tematica storico-nazionale. Tematicamente si riallaccia ad ambedue, venendo a formare con essi un trittico incentrato sul problema per eccellenza della sensibilità poetica moderna, ovvero il vacillare dell'identità individuale. Come nel caso del primo componimento della raccolta e di numerose altre poesie stusiane, anche in [Meni zdajet'sja, šč žyvu ne ja] si assiste a un'oscillazione tra il polo della negazione di sé da parte dell'io lirico e il polo opposto della sua effettiva affermazione. Il carattere incerto e ipotetico della disgregazione dell'io è affermato dall'io stesso all'inizio del testo, attraverso l'utilizzo del verbo "sembrare'. L'apparente dissociazione dell'io sembra confermata da un approfondimento delle caratteristiche del Doppelgänger che ha preso il posto del soggetto nel suo corpo, se è ancora possibile parlare di un corpo, e nel mondo. La mancanza di occhi, orecchie, mani e bocca avvicina la figura del doppio al diavolo di Vertep, con il quale condivide anche la posizione oscillante, espressa dall'utilizzo in entrambi i testi del verbo zavysaty ("essere appeso"). L'io lirico di [Meni zdajet 'sja, $\check{S} \check{c}$ o žyvu ne ja] e/o il suo doppio hanno raggiunto, tuttavia, uno stadio superiore del processo di immobilizzazione, ritrovandosi privi delle gambe che al diavolo di Vertep erano compenetrate nella terra. All'ottavo verso si assiste al passaggio alla seconda persona singolare, dopo che l'utilizzo della prima persona nei primi tre versi aveva lasciato il posto a un riferimento indefinito a ciascuna delle tre persone singolari nei quattro versi successivi, rendendo le caratterizzazioni in essi contenute ascrivibili tanto alla sfera dell'io, quanto a quella dell'egli, il doppio. Il consueto “tu" stusiano, nel quale l'unità dell'io e la sua biforcazione nel momento della riflessione sul sé si trovano a coincidere, sancisce così l'inscindibilità del soggetto e del doppio e, dunque, la riunificazione di un'identità apparentemente scissa. L'identità tra i due è confermata dalla caratterizzazione del "tu" come "pezzo di dolore", ricorrente con frequenza nell'immaginario stusiano. L'inconsistenza di questa figura, privata sin dalla nascita della corporalità, si concretizza nel suo accostamento a una "bambolina muta", una "marionetta", chiaramente memore della situazione lirica di Vertep. In un crescendo di caratterizzazioni di chiara matrice espressionista, il "tu", nuovamente in bilico tra corporalità e inconsistenza, vede sigillata, con un paradosso solo apparente, la propria unitarietà dalla constatazione della propria morte. Quest'ultima si trova a perdere misticamente la propria contrapposizione alla nascita, sancendo il supera-

pende nell'oscura oscurità. / Tu, nato, ti sei solo impoverito, / non hai raggiunto il corpo. Non sei arrivato / alla tua carne. Solo di passaggio / tra i mondi-in-mezzo, ti muovi appena in fondo / a un'esistenza estranea. / Cento notti / davanti e cento notti indietro, / e tra di loro - una bambolina muta: / bruciata, bianca di dolore-di-sé, / come una macchia dell'inferno, il grido malinconico / dell'universo, un piccolo proiettile di sole, / alienato e disperso dentro al corpo. / La nascita stai ancora ad aspettare, / mentre la morte è già in te da tempo.' 
mento definitivo di ogni illusoria dualità. Ancora una volta, dietro a un apparente trionfo della disgregazione postmodernista si nasconde un raffinato esercizio di stile, a sua volta riconducibile al gusto postmodernista stesso, dal quale emerge il permanere dell'affermazione modernista della soggettività.

La lirica successiva, la quarta della raccolta, funge da cerniera stilistica tra il trittico iniziale e il gruppo di testi seguente:
Порідшала земна тужава твердь, міський мурашник поточив планету.
Міліціонери, фізики, поети
вигадливо майструють власну смерть.
Протрухлий український материк
росте, як гриб. Вже навіть немовлятко
і те обіцяє стати нашим катом
і порубати віковий поріг,
дідівським вимшілий патріотизмом,
де зрідка тільки човгання чобіт
нагадує: іще існує світ
справіку заборонений, як схизма.
Ця твердь земна трухлявіє щодня,
а ми все визначаємось. До суті
доходимо. I, Господом забуті,
вітчизни просимо, як подання ${ }^{90}$.

La tematica nazionale, preannunciata in Vertep nel più ampio contesto della società sovietica, viene qui sviluppata nel senso di una critica allo pseudo-patriottismo ucraino. La menzione della preparazione della propria morte, che funge da collegamento tra [Poridšala zemna tužava tverd'] e [Meni zdajet’sja, ščo žyvu $n e j a]$, è accostabile alla tradizione rilkiana. Il principale interlocutore stusiano, già discusso in precedenza, è una lirica di Das Buch von der Armut und vom Tode (Il libro della povertà e della morte), la terza parte di Das Stunden-Buch (Il libro d'ore, 1904), nella quale inizia a delinearsi il mito rilkiano della propria morte come realizzazione suprema della propria vita:

Oh Herr, gib jedem seinen eignen Tod.

Das Sterben, das aus jenem Leben geht, darin er Liebe hatte, Sinn und Not $^{91}$.

90 Ivi: 156 . 'Si è rarefatta la dura terra, / il formicaio urbano si mangia il pianeta. / Poliziotti, fisici, poeti / preparano abili la propria morte. / Il marcio continente ucraino / cresce come un fungo. Già da infante / promette d'essere il nostro boia / e picconare la soglia secolare, / col patriottismo muffo dei vecchietti, / dove zoccoli che battono soltanto / ricordano: ancora esiste un mondo / da secoli proibito, uno scisma. / La terra è marcia, giorno dopo giorno, / e noi diamo nell'occhio. Giungiamo / al sodo. E, da Dio dimenticati, / chiediamo la patria che ci spetta.'

91 Rilke 1996: I, 236. 'O Signore, dai a ciascuno la propria morte. / Il morire, che vien da quella vita, / in cui ebbe amore, ebbe senso, ebbe bisogno.' 
Significativa in questo senso è, nel testo stusiano, il riferimento ai "poeti", riconducibile alla poetologia rilkiana modernista di Das Stunden-Buch. Nella lirica in questione, tuttavia, l'accostamento dei poeti stessi ai "poliziotti", oltre che connotare i primi come figure repressive nell'ottica di una 'poetologia negativa' della contemporaneità, causa un evidente abbassamento stilistico, ironicamente in contrasto anche con la tonalità elevata del verso successivo. Come nella Waste Land eliotiana, imprescindibile punto di riferimento per quel modernismo europeo non alieno da tentazioni e incursioni nei territori dell'estetica postmoderna, la citazione va a situarsi in una zona di confine. Da una parte, la tradizione che essa rappresenta è sconfessata e desacralizzata dalla contemporaneità. Dall'altra, è proprio la dolorosa sopravvivenza della tradizione stessa a garantire ancora la possibilità della parola poetica ${ }^{92}$. Nel caso del testo stusiano, a prevalere è certamente la costatazione del totale decadimento della poesia in un mondo reso schiavo dalla storia, nel quale i poeti, degradati a poliziotti, preparano la propria morte civica, intellettuale e spirituale, vendendo la propria arte a un deleterio pseudo-patriottismo di maniera. [Poridšala zemna tužava tverd'] si configura dunque metapoeticamente come un manifesto letterario a monito della poesia contemporanea e dell'arte stusiana stessa, a tratti tentata da una politicizzazione a metà tra esercizio di stile e inevitabile cessione ai richiami della storia e della tradizione letteraria, in primo luogo ševčenkiana. Duplice è il significato del "patriottismo" stesso sul quale l'io lirico di questi versi si trova a riflettere. A esso si può riferire tanto la poesia ucraina di argomento patrio orientata al modello del populismo tardo-ottocentesco, quanto la poesia sovietica ufficiale. In questa luce diventa maggiormente comprensibile la prosa volutamente, ostentatamente bassa dei componimenti che seguono, il cui carattere fortemente antipoetico non potrebbe altrimenti trovare una spiegazione convincente.

Il primo di essi è interpretabile nei termini di una stilizzazione di alcuni cliché della cultura sovietica:

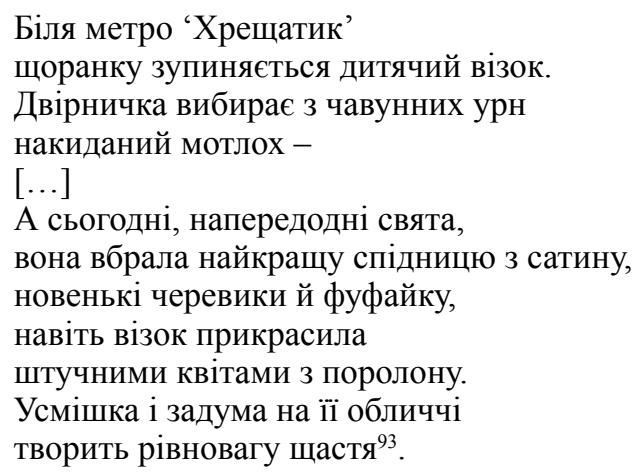

92 Eliot 1969: 75: "These fragments I have shored against my ruins."

93 T I.1, 156. "Vicino al metrò Chreščatyk / si ferma ogni mattina / un passeggino. / La custode tira fuori dai bidoni / l'immondizia - / [...] / Oggi, il giorno prima della festa, / si è messa la gonna di satin più bella, / le scarpe nuove e la giacca nuova, / ha 
La perfetta raffigurazione dell'"allegro cimitero" attraverso la figura della povera donna delle pulizie trova riscontro nelle due poesie successive, ugualmente dominate dall'iperrealistica "antipoesia" della quotidianità sovietica ${ }^{94}$.

A esse fa seguito una breve lirica incentrata su una scena familiare, decisamente distinta rispetto ai testi precedenti dalla tonalità e dal ritmo tradizionali che la contraddistinguono:
Тато молиться Богу, тужить мама. Сестра
уникає порогу,
хоч вернутись пора.
Уникає - радіє, повертає, мовчить.
Повечір'я ще тліє, іще хвірка рипить, іще видно дорогу, іще гусне жура. Тато молиться Богу і ридає сестра ${ }^{95}$.

Emerge qui chiaramente una riflessione metapoetica sul logoramento dei cliché rusticani della tradizione ucraina. Si assiste a un rovesciamento dell'idil-

anche addobbato il passeggino / con fiori finti di poliuretano. / Il sorriso e la pensosità sul suo volto: / ecco l'equilibrio, la felicità.'

94 Tra le fonti di ispirazione dell' "antipoesia" del giovane Stus potrebbe figurare Tadeusz Różewicz (1921-2014), ampiamente tradotto in russo già dal 1963 (si pensi all'antologia Bespokojstvo, con traduzioni a firma di scrittori di primo piano come Boris Sluckij e David Samojlov). Stus, che in una lettera del 1963 cita l'opera di Różewicz come modello di robusta scrittura poetica "realista", tradusse tra gli anni Sessanta e l'inizio degli anni Settanta quattro liriche różewiczane dalla raccolta Twarz trzecia ('Il terzo volto') del 1968 (Śmiech, Talent, Streszczenie and Ciało moje). Si noti la contiguità tra la poetica di [Bilja metro Chreščatyk] e una lirica różewiczana come $W$ świetle dziennym ('Alla luce del giorno') dalla raccolta Zielona róża ('Una rosa verde') del 1961, in: Różewicz 1988: II, 18: "Kiedy bohater dusi / lub pokrywa / bohaterkę pocałunkami / odbiorcy przerzwają ssanie / cukierka / siedzą z rozchylonymi ustami / mają twarze zwrócone / do białego płótna / które wydziela ze siebie / fosforyczny blask // W świetle dziennym / mała i bezbarwna / jest prawdziwa łza / brzydko wygląda / prawdziwa kobieta / co idzie pod murem / i płacze / ma nos zaczerwieniony / rzęsy bez barwy / sklejone / pończochę na lewej nodze / skręconą." 'Quando l'eroe soffoca / o copre / di baci l'eroina / gli spettatori / smettono di succhiar / caramelle / siedono a bocca aperta / con i volti rivolti / alla tela bianca / che emana / un bagliore di fosforo // Alla luce del giorno / piccola e spenta / c'è una lacrima vera / è brutta / la donna vera / che va sotto il muro / e piange / ha il naso rosso / le ciglia spente / attaccate / la calza sinistra / le cade.'

95 T I.1, 158. 'Il papà prega Dio, / triste è la mamma. La sorella / evita la soglia, / ma di tornare è l'ora. / Evita - gioisce / torna - tace. / Si spegne la sera, / stride la porta, / ancora la strada si vede, / ancora è grande la tristezza. / Il papà prega Dio / e piange la sorella.' 
lio ševčenkiano Sadok vyšnevyj kolo chaty ('Il giardino dei ciliegi presso casa'), incentrato sulla sopravvivenza, reale o agognata, dell'istituto familiare, e nello specifico della sua componente femminile, come garanzia della sopravvivenza dell'individuo, dell'umanità e, indirettamente, della nazione. Nell'anti-idillio stusiano l'atemporale armonia dell'ipotesto di Ševčenko si sgretola nella tristezza dei membri della famiglia e nell'incomunicabilità che li divide. La corruzione che segna l'orizzonte assiologico dell'universo lirico di Veselyj cvyntar ha iniziato a penetrare il nucleo sacro della realtà familiare.

Ad accomunare [Poridšala zemna tužava tverd'], [Bilja metro "Chrě̌čatyk”] e [Tato molyt'sja Bohu] è l'assenza dell'io lirico, la cui preponderanza nell'universo poetico stusiano è stata più volte ribadita. In [Poridšala zemna tužava tverd'] esso si era confuso nella prima persona plurale, riferibile sia ai poeti alle prese con la preparazione della propria morte, sia ai "non-cittadini" dell'allegro cimitero. Il suo provvisorio ritorno è al centro della lirica seguente, più volte modificata dallo stesso Stus nel decennio seguente:

На Лисій горі догоряє багаття нічне

і листя осінне на Лисій горі догоряє, а я вже забув, де та Лиса гора, і не знаю, чи Лиса гора впізнала б мене.

Середина жовтня, пора надвечер'їв твоїх, твоїх недовір і невір і осіннього вітру.

І вже половина життя забувається. Гріх

уже забувається. Горе і радість нехитра.

Середина жовтня - твоїх тонкогорлих розлук,

і я вже не знаю, не знаю, не знаю, не знаю,

чи я вже помер, чи живу чи живцем помираю,

бо вже відбринило, відквітло, відгасло, відграло навкруг.

$[\ldots]^{96}$

L'incertezza gnoseologica che segna il rapporto dell'io con se stesso, così come il rapporto del mondo esterno con l'io in funzione di oggetto, non preclude neanche in questo caso la sua pienezza ontologica. Incapace di credere nella realtà di se stesso e del mondo esterno, il soggetto è tuttavia in grado di mantenere l'integrità del proprio sé, la cui unità e coesione è paradossalmente espressa dalla sfiducia e dalla mancanza di punti di riferimenti. Ciò trova conferma nella lirica che segue, la cui secca laconicità contrasta nettamente con il malinconico andamento cantilenante di [Na lysij hori dohorjaje bahattja nične], a conferma

96 Ivi: 159. 'Sul Monte Calvo brucia il falò notturno / e le foglie d'autunno sul Monte Calvo bruciano, / e già non so più, dov'è il Monte Calvo, e non so / se mi riconoscerebbe il Monte Calvo. / Metà di ottobre, l'ora dei tuoi crepuscoli, / delle tue sfiducie e infedeltà e del vento d'autunno. / E già metà della vita si dimentica. Il dolore e la gioia semplice. / Metà ottobre - delle tue separazioni dal collo sottile, / e già non so, non so, non so, non so / se già son morto, se vivo o se muoio vivendo, / perché già più non squilla, non sboccia, non cala, non suona qui intorno. / [...]' 
dell'instancabilità dello Stus sperimentatore stilistico anche in un'opera in cui la concentrazione tematica sembra prevalere rispetto al lavoro sui linguaggi:

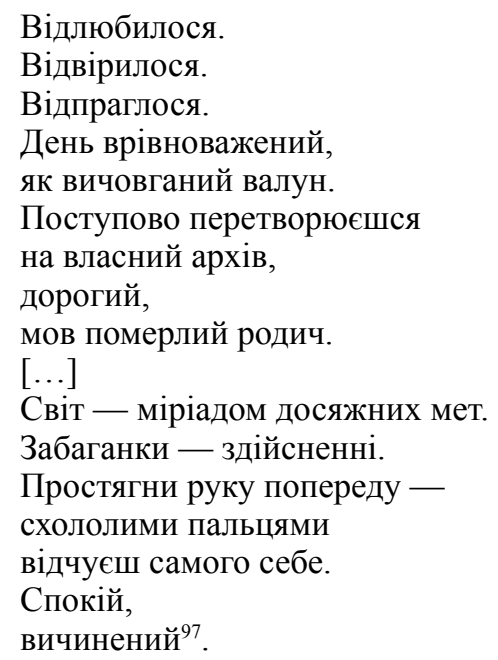

Ricollegandosi al testo precedente attraverso la ripresa di una serie di verbi costruiti a partire dal prefisso vid-, in grado di negare il significato stesso della radice che lo segue, [Vidljubylosja] prospetta all'io la possibilità di un ritrovato dialogo con se stesso e con il mondo esterno. Se, come si è già potuto osservare, la continua, ossessiva ricerca del sé che il soggetto compie è interpretabile come l'essenza profonda della sua natura, in sintonia con la concezione sartriana del1'“essere-per-sé", la dinamica alterna del suo rapporto con il mondo è da leggersi alla luce della constatazione dell'assurdità del mondo stesso, ora vicino e comprensibile, ora distante e inafferrabile ${ }^{98}$. L'io è qui allo stesso tempo aperto a una riconciliazione con se stesso e con la realtà esterna e sterilmente rivolto a un'ipseità viziata, che, come mostra l'immagine dell'archivio del sé, non sembra più coinci-

97 Ibidem. 'Più non si ama. / Più non si crede. / Più non si vuole. / Un giorno equilibrato, / come scoglio lisciato. / Pian piano ti trasformi / nel tuo proprio archivio, / caro mio, / come un parente morto. / [...] / Il mondo - è una miriade di mete raggiungibili. / I capricci - fattibili. / Stendi la mano in avanti - / con le dita fredde / sentirai te stesso. / Calma, sei pronto.'

98 Nella seconda parte della lirica sembrano risuonare una citazione quasi letterale di un brano da L'être et le néant. Cfr. Sartre 1943: 370: "Ainsi le monde, comme corrélatif des possibilités que je suis, apparaît, dès mon surgissement, comme l'esquisse énorme de toutes mes actions possibles. La perception se dépasse naturellement vers l'action ; mieux, elle ne peut se dévoiler que dans et par des projets d'action. Le monde se dévoile comme un ' creux toujours futur', parce que nous sommes toujours futurs à nous-mêmes." Il passo sartriano si inserisce in un'ampia analisi sulla corporalità, ricollegabile, nella lirica stusiana, alla raffigurazione di una percezione sensoriale nei versi antecedenti il distico finale. 
dere con la realtà della vita. Il rapporto del soggetto con se stesso e con il mondo è dunque raffigurato in questi versi sotto il segno di un'estrema indeterminatezza.

Nelle liriche immediatamente successive la rappresentazione del teatro dell'assurdo del mondo, a metà tra contingenza storica e immutabilità ontologica, è nuovamente filtrata attraverso il prisma dell'abbassamento stilistico. In due delle tre liriche che seguono [Vidljubylosja] è presente un riferimento al motivo del cimitero introdotto nel titolo della raccolta. Nel primo caso, all'interno del trittico Mumja ('Mummia'), esso si accompagna a una sarcastica riflessione sulla vanità della natura umana e della storia:

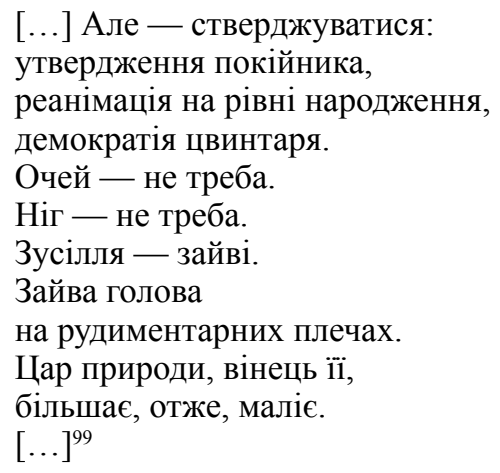

All'identificazione dell'uomo con una mummia si associa il richiamo al diavolo di Vertep, immobilizzato e incapace di agire, privato dell'identità e dell'individualità che lo renderebbero una 'persona'.

All'assenza di tratti caratterizzanti in un essere umano ormai disumanizzato sembra corrispondere un mondo altrettanto inerte e informe:

Попереду нарешті порожнеча

і довгожданна. Вічність пізнаю, даровану годиною лихою.

А білий світ - без кольору і звуку —

ні форми, ні ваги, ани смаку -

розлився безберегою водою.

Цей бенкет смерті в образі життя

щасливого відстрашує і врочить:

устромиш ногу в воду - i помреш ${ }^{100}$.

99 T I.1, 160. '[...] Ma affermarsi: / la conferma del defunto, / la rianimazione a livello della nascita, / la democrazia del cimitero. / Gli occhi - non servono. / Le gambe - non servono. / Gli sforzi - inutili. / Inutile la testa / rudimentali le spalle. / Il re della natura, il suo coronamento, / si fa più grande, cioè, più piccolo. // [...]'

100 Ivi: 163. 'Davanti finalmente il vuoto / tanto atteso. L'eternità conosco, / donatami da un'ora sofferente. / Il mondo è bianco, non ha colore e suono, / non ha forma, peso, gusto - / è straripato come acque senza riva. / Banchetto di morte sotto forma di vita / felice - spaventa e ammalia: / metterai un piede nell'acqua - e morirai.' 
Ridotto a una immagine scolorita di se stesso, il cosmo-mondo si è trasformato in caos, rendendosi letale per l'essere umano. Incontenibile e incomprensibile, la realtà è in grado di distruggere il soggetto, qualora egli tenti di entrare in contatto con essa. All'eliotiana "morte per acqua" che l'io vede come inevitabile nel caso di uno suo ri-avvicinamento al mondo si affianca paradossalmente, a livello della raccolta nel suo complesso, la constatazione dell'identità tra il mondo e l'uomo, uniti 'negativamente' dalla comune carenza di tratti personalizzanti. Il soggetto è contemporaneamente attratto dal vuoto del mondo e consapevole della sua potenza devastatrice. Si ha a che fare, in questo caso, con un testo che supera poeticamente la consueta logica umana, eliminando le differenze tra i contrari e identificando ciò che non è identificabile sulla base della comune mancanza di tratti peculiari. Il mondo è contemporaneamente vuoto e liquido, nulla e pienezza. Ciò è espresso esplicitamente dal rimando all'eternità, incomprensibile per la natura umana, e dalla fusione degli opposti nell'immagine del "banchetto di morte sotto forma di vita". Si noti, inoltre, come la caratterizzazione di questa vita illusoria come "felice" possa aprire una breccia di concreta storicità in un testo segnato da una temporalità complessa $\mathrm{e}$ contraddittoria, nella quale l'eternità convive con il passato di un'ora di sofferenza e con il futuro di una morte inevitabile. Il richiamo alla grottesca falsità della rappresentazione dell'esistenza reale è chiaramente riconducibile al mondo sovietico, in sintonia con l'ispirazione storica alla base della raccolta nel suo complesso.

Nell'insistenza sulla contraddittorietà come elemento cardine del linguaggio poetico e sull'idea del vuoto come superamento della vita verso la morte, [Poperedu narešti porožneča] sembra tradire nuovamente una possibile ispirazione cvetaeviana ${ }^{101}$, nello specifico a proposito di Poema Vozducha. La duplicità dell'attrazione e repulsione per la morte negli universi poetici dei modernisti Cvetaeva e Stus ${ }^{102}$ si rifrange in questo caso nell'accentuazione del carattere inquietante della morte stessa, come privazione piuttosto che liberazione. D'altro canto, l'inconsistenza e la falsità della vita stessa sembrano renderla l'unica risposta a un corto circuito ontologico che riguarda indifferentemente il micro- e il macrocosmo.

Nella lirica successiva si assiste a un repentino ritorno della realtà storica ucraina nella sua concretezza. La dedica "alla memoria di A.H.", ovvero alla scultrice Alla Hors'ka, amica di Stus e degli altri šistdesjatnyky uccisa nel 1970 con buona probabilità a causa della sua vicinanza agli ambienti della Dissiden$\mathrm{za}$, apre un testo in cui il recupero della tematica nazionale ucraina si innesta sul motivo della morte già ampiamente elaborato nelle poesie precedenti:

Ярій, душе. Ярій, а не рідай.

У білій стужі сонце України.

А ти шукай - червону тінь калини

на чорних водах — тінь її шукай,

де горстка нас. Малесенька щопта

101 Sulla complessa dinamica dell'attrazione dell'io lirico cvetaeviano per il vuoto si vedano Zubova 1993 e Bobryševa 2013.

102 Sul tema della morte nella lirica cvetaeviana e della tensione dell'io lirico verso di essa si veda Frejdlin 1994. 
лише для молитов і сподівання.

Усім нам смерть судилася зарання,

бо калинова кров - така ж крута,

вона така ж терпка, як в наших жилах.

У сивій завірюсі голосінь

ці грона болю, що падуть в глибінь,

безсмертною бідою окошились ${ }^{103}$.

Con un linguaggio poetico fortemente tradizionale, incentrato sulla ripresa di uno dei simboli dell'identità ucraina, il viburno, Stus accantona momentaneamente i motivi grotteschi legati all'“allegro cimitero" per concentrarsi sulla rielaborazione di un evento traumatico della storia recente interpretato in chiave profetica. Anche in questo caso, tuttavia, non mancano i punti di contatto con la lirica precedente. Negli ultimi due versi di [Jarij duše. Jarij, a ne rydaj] il dolore che attanaglia la piccola comunità di cui l'io lirico si sente parte è paragonato a una "pena immortale". Sia a livello morfo-sintattico che a livello fonico il sintagma bezsmertnojo bidoju si ricollega al corrispondente sintagma bezberehoju vodoju in [Poperedu narešti porožneča]. La caratterizzazione della pena come "immortale" attua inoltre un'interessante svalutazione semantica dell'aggettivo in questione, rendendolo ossimoricamente latore di un significato negativo. Come nel testo che la precede, anche in questi versi si viene a creare una paradossale interferenza tra la sfera della morte e quella dell'immortalità. L'eternità del male e della sofferenza sembra porsi come ostacolo alla morte liberatrice, anche se quest'ultima è destinata a essere precoce, privando il soggetto della possibilità di agire. La constatazione della pochezza numerica delle anime che il soggetto sente vicine pare essere memore di una nota lirica pasternakiana da Temy $i$ varjacii, [Nas malo, nas možet byt'troe]:

Нас мало. Нас, может быть, трое

Донецких, горючих и адских

Под серой бегущей корою

Дождей, облаков и солдатских

Советов, стихов и дискуссий

О транспорте и об искусстве.

$[\ldots]^{104}$

103 T I.1, 163. 'Erompi, anima. Erompi, ma non piangere. / Nel bianco gelo è il sol dell'Ucraina. / E tu cerca - l'ombra rossa del viburno / sulle acque nere - la sua ombra cerca, / dov'è di noi un pizzico. Un piccolo mucchietto / di preghiere e speranze solamente. / Per noi tutti la morte è precoce, / il sangue del viburno è così rapido, / aspro come ci scorre nelle vene. / Nella bufera grigia dei lamenti / grappoli di dolore cadon profondi, / come pena immortal si son fermati.'

104 Pasternak 2003-2005: I, 189. La lirica di Pasternak era stata ripresa nel 1964 da Andrej Voznesenskij. In [Nas mnogo. Nas možet byt' četvero], dedicata a Bella Achmadulina, il poeta šestidesjatnik concludeva un testo profondamente segnato dal linguaggio lirico neoavanguardista tipico della sua generazione con una nota ottimistica decisamente distante dalla lirica stusiana di sei anni più tarda. Si veda Voznesenskij 1983: I, 136: “Что нам впереди предначертано? / Нас мало, нас может быть четве- 
Riferendosi al "trio futurista" composto da Pasternak stesso, Majakovskij e Nikolaj Aseev ${ }^{105}$, 1 'io lirico pasternakiano profetizza un tardo riconoscimento del merito dei poeti da parte della comunità umana, prendendo così parzialmente le distanze dalla tradizione del Poèt $i$ tolpa puškiniano:

Закружимся вихрем вороньим,

И - мимо! - Вы поздно поймете ${ }^{106}$.

In [Jarij duše. Jarij, a ne rydaj] è invece il discorso nazionale a trovarsi in primo piano. Il sangue che scorre nelle vene dei pochi eletti, destinati alla preghiera e a una speranza disillusa, è dello stesso colore e delle stesse fattezze del sangue che nutre uno dei simboli nazionali ucraini. L'identificazione tra la patria e gli artisti, che ne permettono la sopravvivenza al di là della tragedia storica e della loro conseguente totale contrapposizione al sistema, è completa.

Nelle liriche seguenti viene nuovamente abbandonato il riferimento storico concreto per recuperare l'elaborazione della tematica storica in senso ampio sotto il segno dell'assurdo, da una parte, e di un'attesa, seppur momentanea riconciliazione tra l'io e il mondo, dall'altra.

In [Vony sydjat'za stolom], il cui stile prosastico spicca notevolmente sullo sfondo di [Jarij duše. Jarij, a ne rydaj], la felicità familiare permette al soggetto di abbandonarsi a un fugace recupero della propria fiducia nella realtà:

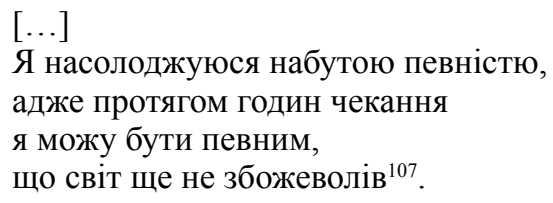

po. / Мы мчимся - а ты божество! / И все-таки нас большинство!” La conoscenza di [Nas mnogo. Nas možet byt'četvero] da parte di Stus risulta altamente probabile. Per una rielaborazione postmoderna di questo motivo nella poesia ucraina, ambiguamente a metà tra rassegnazione e scherzosa riaffermazione della propria identità di poeta, si veda da una lirica di Ihor Rymaruk (1958-2008) dei tardi anni Ottanta, in: Rymaruk 1988: 29: “Щасливець був поет, який писав: 'Нас мало,'— / нас може й не було? // Чиї ж тоді вуста здмухнули пил із неба? / Які ж малі вузли зв’язали рваний час?! / — Така вже благодать, / що вигадать нас треба, / якщо не має нас!" 'Fortunato era il poeta che scrisse: "Siam pochi", - / noi forse non siamo stati? // Le labbra di chi aspirano allora la polvere dal cielo? / Che piccoli nodi han legato il tempo spezzato?! / - Una grazia tale, / che si dovrebbe inventarci, / se non ci fossimo!'

105 Più tardi Pasternak 'incluse' Marina Cvetaeva nella ristretta cerchia, dedicandole una copia di Temy $i$ variacii: “Несравненному поэту Марине Цветаевой, 'донецкой, горючей и адской"'. Si noti la naturale attrattività dell'aggettivo doneckij per Stus.

106 Si veda dalla nota lirica puškiniana, in: Puškin 1949-1950: II, 53: “Подите проч — какое дело / поэту мирному до вас! / В разврате каменейте смело, / Не оживит вас лиры глас!”

107 T I.1, 165. '[...] Mi godo la certezza che ho acquisito, / già, in tre ore d'attesa, / posso essere certo / che il mondo ancora non è impazzito.' 
Questa affermazione dell'io lirico sembra tuttavia contrastare notevolmente con l'assurdità del bozzetto immediatamente seguente:

Сповнений почуттям вдячності, він захотів переповісти мені всю свою історію, але виявилося, що історій нема.

І він мусив був обмежитись самими словами вдячності ${ }^{108}$.

Nella loro laconica, gnomica semplicità questi versi mostrano la vuotezza del mondo di cui l'io lirico si era appena illuso di poter anche solo parzialmente comprendere il senso. È evidente come nell'insieme della poesia stusiana la postmoderna mancanza di una "storia", ricollegabile al vuoto trovato e invocato in [Poperedu narešti porožneča], non escluda e si integri significativamente con l'opposta permanenza di una verità da perseguire e ricercare.

La seconda lirica successiva a [Spovnenyj počuttjam vdjačnosti] presenta un ulteriore capitolo dell'autobiografia artistica dell'autore, introducendo una nuova figura con cui il soggetto stusiano viene "profeticamente" a identificarsi. La dedica alla memoria di M. K. Zerov introduce un testo del tutto coerente con la rappresentazione di sé e del proprio vissuto che l'io lirico stusiano fornisce al lettore dagli anni Sessanta sino a Palimpsesty:

Колеса глухо стукотять, мов хвиля об паром,

стрічай, товарищу Хароне,

з лихом і добром.

Колеса б'ють, колеса б'ють, кудись торують путь.

Уже. Додому не вернуть, додому не вернуть.

$[\ldots]$

Москва, гора Ведмежа, Кем

і попів острів — шлях

за гратами, за вартами,

розбухлий на сльозах.

$[\ldots]$

Рад-соц-конц-таборів союз,

котрий Господь забув,

Диявол тех забув $[\ldots]^{109}$.

108 Ibidem. 'Pieno di gratitudine, / voleva raccontarmi / tutta la storia, / ma venne fuori / che non c'era alcuna storia. / E dovette limitarsi / alla sola gratitudine.'

109 T I.1, 166. 'Sorde sbattono le ruote, / come un'onda sul battello, / incontraci, compagno Caronte, / nel bene e nel male. / Sbattono le ruote, sbattono le ruote, / aprono una strada che va da qualche parte. / Eccoci. A casa non si torna, / a casa non si torna. 
Gli avvenimenti degli ultimi anni della vita di Mykola Zerov, arrestato nel 1935 e morto quarantasettenne due anni più tardi alle isole Solovki, si intersecano sul mito di sé come Poeta ucraino che l'io lirico stusiano sviluppa incessantemente di lirica in lirica e di raccolta in raccolta. Due anni prima della reclusione, Stus fornisce un'ulteriore e convincente ragione per non cedere a una facile lettura in chiave puramente biografica della sua poesia carceraria. L'evocazione delle tappe della via crucis zeroviana riprende elementi tipici della lirica di ispirazione martirologica, come il viaggio, il cammino, qui esplicitamente senza ritorno, e le grate della cella. Negli ultimi versi qui citati l'esplicitazione sarcastica delle circostanze alla base della persecuzione contribuisce all'armonizzazione di [Kolesa hlucho stukotjat'] nel complesso di Veselyj cvyntar, opera intrinsecamente segnata dal riferimento alla storia e da un doloroso riso attraverso le lacrime di gogoliana memoria. Il riferimento a Caronte al terzo verso, un Caronte ormai decaduto a "compagno", è, oltre che un ulteriore tassello della rappresentazione dell'inferno della Storia, un evidente omaggio all'attività di Zerov come traduttore e propagatore della poesia e della cultura classica in Ucraina.

L'innalzamento stilistico operato da [Kolesa hlucho stukotjat'] si ripercuote sulle liriche successive. La prima di esse si ricollega inaspettatamente alla conclusione di [Vony sydjat'za stolom], reintroducendo una nota almeno apparentemente positiva nella raffigurazione del rapporto dell'io lirico con la realtà circostante:

Так явно світ тобі належать став,
Що, вражений дарованим багатством
одного дня, відчув, як святотатство:
блукати лісом, йти між отав,
топтати ряст, аби спізнати в зорі
наближення своїх гріховних прав.
Рушай вперед. І добротою хворий,
розтань росою димною між трав ${ }^{110}$.

Illuminato dalla grazia, il soggetto è giunto alla comprensione del mondo, qui espressa nei termini di un suo "possesso". La concordia con la realtà significa, tuttavia, l'accettazione della natura peccaminosa della propria esistenza. Questa è da leggersi attraverso diversi prismi interpretativi anche in evidente contraddizione tra loro, come sembra esplicitare lo stridente ossimoro "diritti peccaminosi". A un primo livello, la constatazione del possesso del mondo non può che evocare nel soggetto un sentimento di colpa e di peccato, legato alla sproporzione tra la piccolezza del sé e la grandezza del mondo. Questa interpretazione

/ [...] / Mosca, il Monte degli Orsi, Kem' / e l'Isola del Pope - un cammino / oltre le grate, oltre le guardie, / gonfio di lacrime. / [...] / Unione dei campi di concentramento socialisti sovietici, / dimenticata da Dio, / e anche dal demonio. [...]'

110 T I.1, 167. 'È chiaro, ora il mondo t'appartiene, / dai ricchi doni impressionato / hai sentito un giorno come sacrilegio: / vagar nel bosco, andar tra gli sterpi, / nell'erba, per veder nell'aurora / i tuoi peccati, i tuoi diritti venire. / Vai avanti. Di bontà malato, / sciogliti come rugiada, vapore sull'erba.' 
è accettabile solo nel caso di una più precisa definizione del lessema "mondo" introdotto nel primo verso. Non si può non constatare, infatti, una contrapposizione implicita fra il mondo come grottesco "allegro cimitero", sul quale si concentra la raccolta nel suo complesso, e il mondo primordialmente inteso come natura, al centro di questi versi. La possibilità per l'io di comprendere il mondo e di toccarlo con il potere distruttivo della propria fisicità sottintende una duplice caratterizzazione dell'io stesso, corrispondente alla duplicità del mondo stesso. Da una parte il soggetto è identificabile come poeta, come eletto tra gli uomini, elevato e purificato dalla grazia. Dall'altra parte non gli è concessa una completa rimozione dell'umano in sé, dunque della fisicità e della peccaminosità a essa legata. L'esistenza stessa del soggetto in quanto essere umano sembra contraria alla vita della natura e la possibilità della sua comprensione di quest'ultima è dunque messa in dubbio.

L'unica modalità di cui l'io dispone per potersi avvicinare alla natura è l'annullamento di sé e della propria corporalità, ancora una volta ricollegabile al magistero cvetaeviano di opere come Poema vozducha e $S$ morja. Da questo punto di vista [Tak javno svit tobi naležat'stav] sembra configurarsi come una risposta al ciclo Derev'ja, nel quale l'io lirico di Marina Cvetaeva celebra la possibilità di una fuga dal mondo degli umani nel grembo della natura (Cvetaeva 2004: 566):

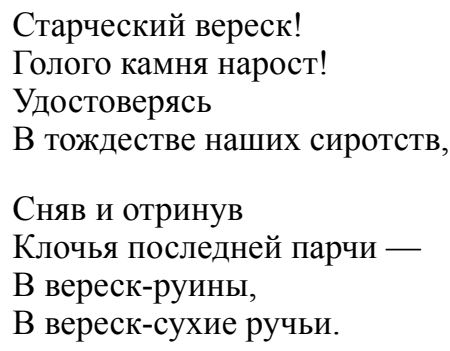

Se in Derev'ja l'avvicinamento tra l'io-poeta e la natura è giustificato dalla loro comunanza ontologica, in [Takjavno svit tobi naležat'stav] è proprio la loro inconciliabile differenza a suggerire a un soggetto enigmaticamente "malato di bontà" la necessità di superare la propria corporalità e, dunque, se stesso come unità ontica. Non è da escludersi, inoltre, che il dissolvimento del soggetto tra le erbe possa serbare la memoria del mito orfico. Lo sparagmos, lo spargimento delle membra del cantore tracio a opera delle menadi, sarebbe qui sottoposto a un'ulteriore rarefazione, che ne accentuerebbe ulteriormente il valore di pegno di fertilità ed eternità della parola poetica. Quest'ultima lettura riabiliterebbe la figura del poeta e la validità della sua missione conoscitiva, in sintonia con la poetologia modernista alla base dell'universo poetico stusiano.

A questo proposito è necessario osservare come questa lirica, e i suoi primi tre versi in particolare, possa suggerire un accostamento a uno dei miti poetici e metapoetici modernisti più cari a Stus, ovvero la filosofia dell'arte rilkiana. Il superamento della volontà di possesso delle cose da parte del soggetto-poeta è conditio sine qua non della vera poesia nella lirica di Rilke della fase mediana 
e matura, sempre più al centro degli interessi artistici e umani del giovane Stus. Nei versi conclusivi del penultimo componimento di Das Stunden-Buch, risalenti al 1903, la figura di Francesco d'Assisi si innesta sul modello orfico, anticipando la poetologia dei due decenni successivi:

Und als er starb, so leicht wie ohne Namen, da war er ausgeteilt: sein Samen rann in Bächen, in den Bäumen sang sein Samen und sah ihn ruhig aus den Blumen an.

Er lag und sang. Und als die Schwestern kamen, da weinten sie um ihren lieben Mann ${ }^{111}$.

Non è da escludere che questi versi possano essere alla base dell'ispirazione della parte finale di [Tak javno svit tobi naležat'stav]. All'origine della parte iniziale della lirica sembra invece trovarsi, come già accennato, il sistema lirico rilkiano maturo nel suo insieme, per il quale si può rimandare in primo luogo a Wendung ('Svolta', 1914):

Denn des Anschauns, siehe, ist eine Grenze.

Und die geschaute Welt

will in der Liebe gedeihn.

Werk des Gesichts ist getan, tue nun Herz-Werk an den Bildern in dir, jenen Gefangenen; denn du überwältigtest sie: aber nun kennst du sie nicht. Siehe, innerer Mann, dein inneres Mädchen, dieses Errungene aus tausend Naturen, dieses erst nur errungene, nie noch geliebte Geschöpf ${ }^{12}$.

La volontà di possesso delle cose del mondo che caratterizza l'artista in quanto uomo deve lasciare spazio a un rapporto di sublimazione interiorizzante, l'unico in grado di salvare le cose dallo scorrere del tempo e della distruzione. Questo processo, identificabile in ultima analisi con la poesia stessa, è espresso dalla metafora del "lavoro del cuore", per la quale la sensibilità poetica stusia-

111 Rilke 1996: I, 252. 'E quando morì, leggero e senza nome / era in ogni luogo: correva il suo seme / nei fiumi, cantava il suo seme nei rami / e lo guardavo, quieto, dai fiori. / Giaceva e cantava. E quando giunsero le sorelle, / piansero per l'uomo che amavano.'

112 Ivi: II, 101. 'Perché al vedere, sai, c'è un limite. / E il mondo veduto / Vuol crescere d'amore. // Il lavoro della vista è compiuto, / fai ora quello del cuore / alle immagini in te, le prigioniere; ché / le hai sopraffatte: ma più non le conosci. / Vedi, o uomo dentro, la fanciulla che è in te, / conquistata da / mille nature, questa / solo ancora conquistata, non / ancora amata creatura.' 
na deve essersi mostrata particolarmente ricettiva. La necessità per l'artista di dischiudere l'invisibile a spese del visibile, inevitabilmente sottomesso alla fugacità del mondo esteriore, sembra trovare riscontro nel sublimarsi del soggetto in rugiada nel verso conclusivo di [Tak javno svit tobi naležat'stav] in risposta ai danni provocati dalla volontà di possesso e dalla fisicità. La complessità della combinazione ipertestuale di questa lirica, per la quale un doppio ipotesto rilkiano si combina con probabili richiami all'opera cvetaeviana è un'eloquente dimostrazione dell'altissimo valore intellettuale dell'esperienza poetica stusiana alla fine degli anni Sessanta.

La lunghissima lirica successiva rimanda invece al secondo testo della raccolta, Vertep, recuperando e rielaborando ampiamente la metafora del mondo come teatro (dell') assurdo:

Ця п’єса почалася вже давно,

і лиш тепер збагнув я: то вистава,

де кожен, власну сутність загубивши,

і дивиться, і грає. Не живе.

Отож мені найщасливіша роль

дісталася в цій незнайомій п'єсі,

в якій я слова жодного не вчив

$[\ldots]^{113}$

Dopo aver brillantemente recitato la parte assegnatagli, l'io lirico scopre di aver recitato la parte di Yorick nello spettacolo "Ščaslyvyj Joryk" ("Il felice Yorick') ${ }^{114}$ davanti a una platea di spettatori privi di personalità e autodeterminazione: "Ми всі однаково щасливі" 115 . Egli non può che rassegnarsi all'idea di essere parte di questa informe comunità, basata sul livellamento delle individualità e sull'ottundimento della facoltà intellettuale:

Так живучи у ролі аж до смерті, вивчай слова забуті: боротьба, народ, любов, несамовитість, зрада, порядність, честь... ${ }^{116}$

113 T I.1, 167. 'Questa pièce è cominciata ormai da tanto, / e solo adesso capisco: è una messinscena, / ognuno, perduta la sua essenza, / ora guarda, ora recita. Non vive. / Ecco che a me la parte più felice / è capitata in questa pièce ignota, / di cui non so nemmeno una parola. / [...]'

$114 \mathrm{Si}$ ricordi, in connessione con [Kolesa hlucho stukotjat'], dalla lirica Poor Yorick! di Mykola Zerov, in: Zerov 1990: I, 40: “І слів марудних, і нудних тирад / В собі відчути пута утяжливі, / Знать, що чуття не здіймуться в припливі, / I буде все, що скажеш ти, невлад." 'Delle pesanti parole e noiose tirate / Sentir in sé le catene che stringono, / Saper che i sentimenti non scorreranno a riva, / E sarà tutto ciò che dici tu sbagliato.'

115 T I.1, 167. 'Siamo tutti ugualmente felici'.

116 Ibidem. 'Vivendo la parte fino alla morte, / impara parole dimenticate: lotta, / popolo, amore, forza, tradimento, / ordine, onore...' 
Nell"“allegro cimitero" della contemporaneità la realtà è negata, ridotta all'esibizione trionfalistica del suo contrario: "Грішник, / хто журиться. A праведний - радіє" "17.

Nella seconda, breve parte del lungo componimento l'io lirico abbandona gli attori/spettatori della pièce in cui si è ritrovato a recitare e si abbandona a un monologo di riflessione, il cui nucleo concettuale è riassunto nell'affermazione seguente, profondamente segnata da venature espressioniste:

Світ

тримається на випадкових рухах,

які його означують. Пітьма

навпомацки у кості грала ${ }^{118}$

La constatazione dell'insanabile assurdità della realtà vanifica la fiducia in una cosmologia razionale, costretta a cedere di fronte all'evidenza della cieca casualità, premessa per il dipanarsi di una storia alienata e alienante.

In sintonia con le liriche precedenti al centro dei testi seguenti è una rielaborazione lirica dei devastanti effetti che l'interazione con la realtà causa alla psiche del soggetto. Le due liriche immediatamente successive a [Cja p"esja počalasja vže davno] sono segnate da una tonalità martirologica contrastante con il rassegnato sarcasmo predominante in Veselyj cvyntar. Nella prima la necessità di ribellarsi all'assurdo e al dolore con la propria azione è fortemente ribadita dal soggetto:

Змагай, знеможений життям, знеможений, змагай.

Минуле вабить вороттям

і врочить і нехай.

А ти, сомнамбуло, змагай, у напівсні живи, де жовті сходяться леви

у присмерковий гай.

$[\ldots]^{119}$

Provato, affaticato e distratto dalle tentazioni di un passato non precisamente definito, l'io si rivela ancora una volta in grado di preservare l'integrità della propria persona. L'unitarietà del soggetto sembra essere garantita e rafforzata dalla lotta, dalle difficoltà che sembrano inizialmente metterne a repentaglio la vita stessa.

Nella lirica seguente si assiste a uno dei vertici del discorso martirologico stusiano:

117 Ibidem. 'Peccatore, / chi è triste. E il giusto - è felice.'

118 Ibidem. 'Il mondo / si regge su movimenti casuali / che lo caratterizzano. Il buio / a tastoni giocava a dadi.'

119 Ivi: 172. 'Battiti, battuto dalla vita, / battuto, battiti. / Il passato lusinga col ritorno / e incanta, e così sia. / E tu, sonnambulo, battiti, / in un semi-sonno vivi, / dove gialli si incontrano i leoni / nel prato del crepuscolo. / [...]' 


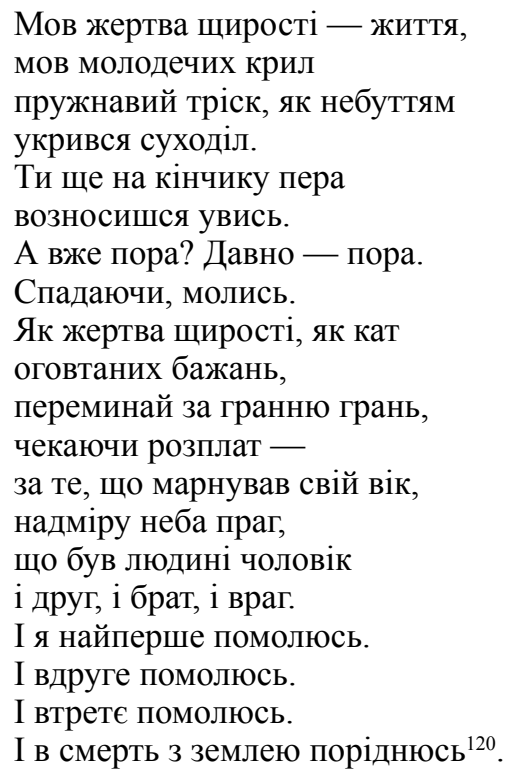

La raffigurazione del macrocosmo del teatro dell'assurdo ha ceduto il posto nuovamente all'analisi del microcosmo dell'io. La natura di quest'ultimo è definitivamente segnata dal primo sostantivo della lirica, la "vittima" (žertva) che sarebbe assurta a simbolo dello žiznetvorčestvo stusiano nell'inscindibilità di vita e arte che avrebbe caratterizzato l'esistenza del poeta secondo la vulgata (cfr. Hundorova 1992). Il vissuto dell'io è qui rappresentato dapprima attraverso il prisma della spazialità, secondo una dinamica di contrapposizione tra un'aspirazione verso l'alto e una ricaduta verso il basso. La volontà del soggetto di innalzarsi al di sopra dell' "allegro cimitero" mediante la poesia, come emerge dalla metafora sineddotica della punta della penna, si scontra così 'tradizionalmente' con la constatazione di una sua inarrestabile caduta. Nuovamente, come già in Zymovi dereva, è ipotizzabile un riferimento al topos rilkiano della caduta come rinascita. Secondo il modello dei versi conclusivi della Decima elegia, infatti, il precipitare dell'io alla terra è inaspettatamente garanzia della possibilità di una riconciliazione con essa. L'apparentamento con la terra, nella sua triplice accezione di patria, suolo latore di vita e sfera ctonia, ricompensa il soggetto degli eccessi compiuti durante l'esistenza, legati all'incomprensione della natura assurda e distruttrice del mondo. Solo la morte può essere possibilità di vita. Si

120 Ibidem. "Vittima della sincerità - la vita, / come di giovani ali / un rumore elastico, come di niente / si è coperta la secca valle. / Ancora sulla punta della penna / ti sollevi verso l'alto. / È già ora? Lo è da tanto. / Cadendo, prega. / Vittima della sincerità, un boia / di sogni ammansiti / smussa uno spigolo dietro l'altro, / attendendo ricompense - / per aver sprecato la tua età, / aver chiesto troppo cielo, / per esser stato uomo, / amico, fratello e nemico. / E per prima cosa prego. / E per seconda prego. / E per terza prego. / E nella morte / della terra sarò consanguineo.' 
notino, ancora una volta, le implicazioni cvetaeviane di una simile concezione. Nel mondo dello "Yorick felice" l'amore umanamente inteso non è ammissibile e praticabile. Le alternative ai sentimenti di un marito, di un amico, di un fratello o di un nemico sono l'ottundimento, come nel caso di [Cja p "jesja počalasja vže davno], e l'eroismo del martire, come nei versi appena discussi.

La speranza in una futura 'conquista della propria morte' sembra però negata nella lirica immediatamente successiva:

У тридцять літ ти тільки народився, аби збагнути: мертвий ти єси у мертвім світі. I нема нікого окруж. Ти тільки сам. I - мрець єси. Хіба що так: недозволений простір живого духу кличе самосмерть подобою життя. $[\ldots]^{121}$

L'identità negativa tra l'io e il mondo postulata nella prima quartina preclude al soggetto stesso ogni possibilità di redenzione. Nei versi successivi viene invece analizzata la genesi di questo stato di paralisi, dalla quale si evince che la morte-invita del soggetto è un fenomeno storico causato dalla frizione tra le aspirazioni dello spirito e la condizione esistenziale dell'“allegro cimitero". Il mantenimento di un'identità sembra non essere (più) sostenibile nel mondo contemporaneo. In evidente contraddizione con l'invito alla resistenza che l'io aveva rivolto a se stesso in [Zmahaj, znemoženyj žyttjam], la lirica sviluppa il filone opposto dell'auto-annullamento:
Поневажаю індивідуальність -
справовікий набуток лихоліть.
Отож бреди назад. І скільки сили
простуй назад. Бо тільки там життя -
ще до народження. Із світу імітацій -
вповзи у кожну з вимішених шкур.
$[\ldots]^{122}$

La fuga dal mondo alla rovescia del presente è immaginabile solo mediante il ritorno a una condizione anteriore allo sviluppo dell'individualità. Allo stesso tempo è invocata la possibilità irreale di un'esistenza alternativa non legata alla scelta, dunque contraria alla natura stessa della vita umana. Come a proposito di numerose altre liriche stusiane, anche in questo caso, al di là delle apparenze, si ha a che fare con un soggetto pre-postmoderno integro e pienamente identico a

121 Ivi: 173. 'A trent'anni sei appena nato / per capire: sei un morto / in un mondo morto. E non c'è nessuno / intorno. Sei solo tu. E sei - morto. / forse è così: lo spazio non concesso / dello spirito vivo chiama la morte-di-sé / sotto forma di vita. / [...]'

122 Ibidem. 'Disprezzo l'individuo - / secolare frutto di anni duri. / Vai dunque indietro. E quanta forza / rivolgi indietro. Perché sola lì è la vita - / prima di nascere. Dal mondo che imita - / striscia in ciascuna delle pelli mutate. / [...]' 
se stesso, in grado di mantenere il controllo sulla propria persona. In crisi è 'solamente' il rapporto tra l'io e la realtà esterna, costante minaccia per un soggetto sottoposto alla pressione distruttiva del mondo. La peculiarità dell'io lirico stusiano è dunque il suo posizionamento al limite dell'abisso, dal quale esso riesce a salvarsi in virtù della capacità po(i)etica. È la parola a garantire la sopravvivenza dell'io come integrità, seppur provata e dilaniata, impedendone il dissolvimento. In ciò è nuovamente possibile individuare un importante punto di contatto tra l'universo poetico stusiano e quello di uno degli autori con cui Stus ha intrattenuto un dialogo artistico particolarmente serio e gravido di ricadute sulla sua stessa opera, ovvero Marina Cvetaeva. Come nella produzione cvetaeviana matura, l'integrità dell'io è messa a repentaglio dal contatto con la realtà esterna che lo circonda, ma la forza che all'io deriva dalla parola ne garantisce una dolente sopravvivenza. È indubbio che rispetto alla poesia genuinamente modernista di Marina Cvetaeva la lirica stusiana mostri un grado di avvicinamento alla postmoderna dissoluzione dell'io decisamente maggiore. Tuttavia, una lettura approfondita del testo stusiano nella sua totalità dimostra come non si giunga affatto a una cancellazione della personalità come microcosmo. È, piuttosto, il gioco intrinsecamente postmoderno con una pluralità di linguaggi, tra i quali viene a spiccare anche quello legato alla foucaultiana eclissi del soggetto, a creare le condizioni per un'errata assimilazione tout court della sensibilità poetica stusiana al discorso artistico e culturale predominante nella cultura occidentale dagli anni Sessanta.

Questa ambiguità si rifrange nelle liriche che seguono [U trydcjat' lit ty til' $k y$ narodyvsja]. Nella prima di esse l'attenzione dell'io lirico rimane concentrata sulla possibilità della propria esistenza come individualità distinta:

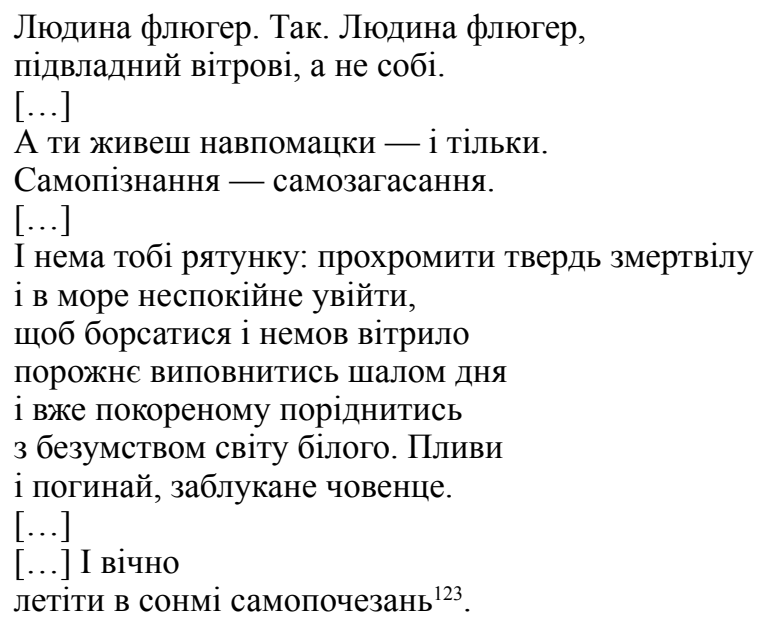

123 Ivi: 174. 'L'uomo è una banderuola. Sì. Una banderuola, / sottomessa al vento, non a se stessa. / [...] / Vivi a tastoni - solo così. / Conoscenza di sé è auto-spegnimento. $/[\ldots] /[\ldots]$ E non c'è per te / salvezza: lacerare la terra pietrificata / e nel mare irrequieto entrare, / per agitarsi e come una vela / vuota riempirsi del furore del giorno / e già 
La conoscenza di sé come conditio sine qua non della persona si scontra nella realtà storica con il bisogno di mettere a tacere l'io come irripetibilità. Il mondo all'incontrario, pura follia, si mostra come l'unica piattaforma possibile per una comunità umana a cui è negata la redenzione. Il prezzo da pagare per una parte in un vertep ormai svuotato del suo valore spirituale è l'effettiva sparizione del proprio io. Gli effetti dell'interesse di Stus per il pensiero esistenzialista da Pascal al Novecento in questo periodo della sua crescita personale e letteraria sono più che evidenti.

Nella lirica seguente la speculazione astratta di [Ljudyna fjuher. Tak. Ljudyna fljuher] assume una nota più personale, mediante l'accentuazione del vissuto emozionale dell'io lirico ${ }^{124}$, aprendo la strada ai riferimenti autobiografici della successiva Vertannja ('Ritorno'):

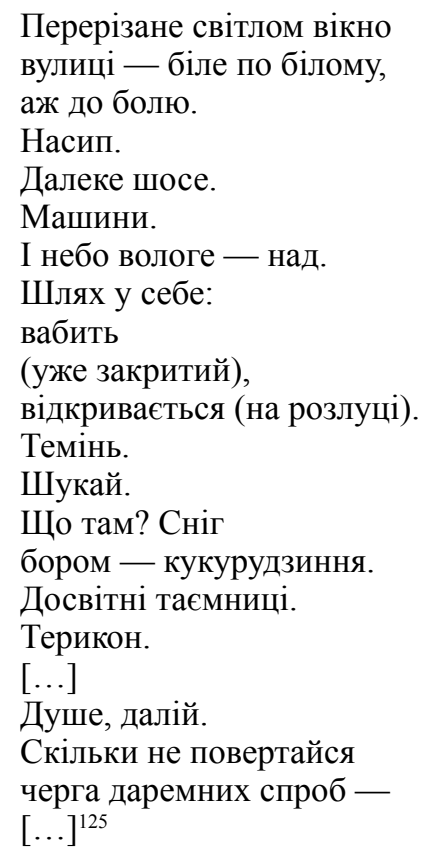

sottomesso legarsi / alla follia del mondo. Naviga / e perisci, barchetta dispersa. / [...]/ [...] E in eterno / vola in una schiera di autosparizioni.'

124 Ibidem: “А все немудре. Доживу / віка, докалічію, / допоки жили не зірву / чи не зламаю шиї." "Non è difficile. Vivrò / fino a che dovrò, sempre più storpio, / finché non mi taglierò le vene / o non mi spezzerò l'osso del collo.'

125 Ivi: 175. 'Fatta a pezzi dalla luce la finestra / sulla strada - bianco su bianco, / fino al dolore. / Un terrapieno. / La strada distante. / Macchine. / E il cielo umido sopra. / Un cammino in sé: / richiama (è già chiuso), / si apre (nella separazione). / Oscurità. / Cerca. / Cosa c'è lì? Neve / nel bosco - spighe di granturco. / Misteri prima dell'alba. / Colline del Donbas. / [...] / Avanti, anima. / Per quanto tu possa tornare, / una serie di prove invano. $-/[\ldots]$ ' 
Nella skovorodiana coincidenza tra il ritorno a casa e il cammino interiore (cfr. Bartolini 2010: 75-90) il soggetto è confrontato con la postmoderna consapevolezza della difficoltà e della vanità di entrambi. La finestra, ideale strumento di apertura al mondo esteriore, si ritrova frantumata da una luce accecante, dunque impossibilitata allo svolgimento del suo ruolo di mediatrice tra il microcosmo e il macrocosmo. La rinuncia alla conoscenza di sé come condizione di sopravvivenza nel mondo, che l'io lirico aveva postulato in [Ljudyna fljuher. Tak. Ljudyna fjuher], è fonte di dolore per un soggetto umanisticamente votato al cammino interiore e inevitabilmente posto di fronte al crollo degli ideali di una tradizione di cui vorrebbe sentirsi erede. La frammentazione della realtà e lo sbarramento del percorso verso di sé introducono nuovamente innegabili venature postmoderne all'interno di un'opera, come si è visto, ancora strenuamente ancorata al retaggio modernista.

La contrapposizione fra il mondo e l'io può assumere tonalità ancora più violente:

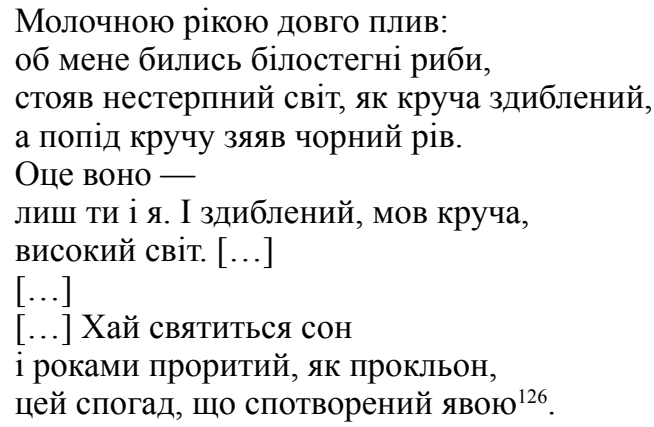

Nel suo consueto sdoppiamento tra i poli opposti ma complementari dell'io e del tu, il soggetto si trova a fronteggiare l'ostilità di un mondo dalle fattezze mostruose in completa solitudine. La dualità intrinseca alla natura del soggetto si esplicita anche a livello temporale, oltre che spaziale, attraverso la contrapposizione tra il ricordo autentico, sepolto da anni e maledetto in quanto fonte inesauribile di dolore, e la sua trasfigurazione a opera della realtà che lo ha corrotto. La fiducia nella seppur remota possibilità di redenzione dell'io grazie alla riscoperta del ricordo autentico riconferma l'assunto modernista di fondo alla base dell'universo poetico stusiano. Il sogno, intimamente connesso con il ricordo, è antidoto al potere logorante e disumanizzante della realtà, possibilità di dialogo con un'ipostasi del sé non corrotta dalla storia, precedente al rovesciamento assiologico dell'“allegro cimitero". Sembra così rafforzarsi una concezione storicistica

126 Ivi: 176. "In un fiume latteo ho nuotato a lungo: / mi colpivan pesci bianchi, / il mondo insopportabile, come una riva ritto, / sotto la riva nere le fauci di un abisso. / Eccolo. Eccolo è lui. È lui - / solo tu ed io. E ritto, come una riva, / l'alto mondo. [...] / [...] / [...] Santo sia il sogno / e da anni scavato, come un improperio, / questo ricordo, dalla veglia sfigurato.' 
della condizione esistenziale dell'io. Il male non sarebbe radice ontologica, ma solamente errore temporale. Una simile concezione sembra essere pienamente in linea con il millenarismo ševčenkiano alla base della tradizione letteraria e filosofica della moderna civiltà ucraina. Ciò non esclude, beninteso, la possibilità che questo assunto conviva con il suo contrario, ovvero con una radicale e assoluta negazione della possibilità del bene, come sembra emergere da altre liriche nel complesso dell'opera stusiana.

Le poesie che seguono tornano a focalizzarsi sul macrocosmo. La descrizione sarcastica della realtà sovietica ${ }^{127}$, elaborata anche attraverso un utilizzo della lingua in chiave neo-avanguardista, si alterna nelle cinque liriche successive a [Moločnoju rikoju dovho plyv] a note di disperazione per il doloroso permanere di un principio di umanità nelle marionette che popolano l'universo grottesco della contemporaneità:

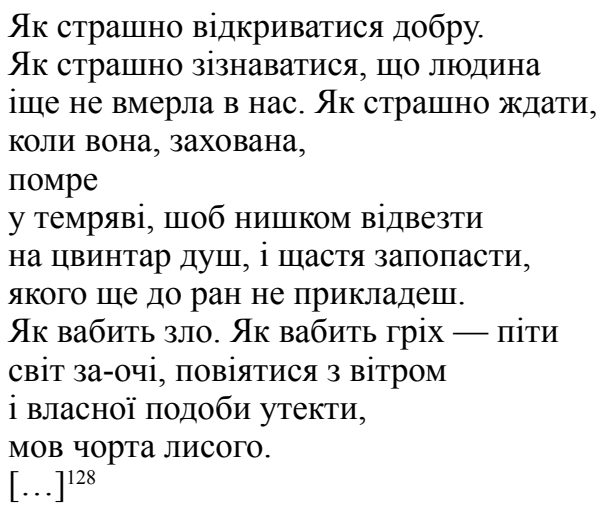

È qui ribadito il persistere dell'individualità come resistenza alla nullificazione della persona, causata dalla pressione distruttiva del mondo. Il linguaggio è allo stesso tempo colloquiale e speculativo, segnato da frequenti ripetizioni e parallelismi sintattici. La tentazione a cedere, percepita come peccato, è una minaccia costante per il superstite, ancora in grado di salvaguardare la propria

127 Ibidem: “Рятуючись од сумнівів, / б’ю телеграму собі самому: / вчасколивесьрадянськийнарод / івсепрогресивнелюдствоготується / гіднозустрітичерговийз “іздкпрс / бажаю тобі великих успіхів, / щиро заздрю, / що ось уже тридцять років / ти живеш у найщасливішій у світі країні. / [...]” 'Salvandomi dai dubbi, / batto un telegramma a me stesso: / nelmomentoincuituttoilpopolosovietico / etuttal'umanitàprogressistasiprepara / afesteggiarecomesidevel'ennesimocongressodelpcus / ti auguro grandi successi, / ti invidio sinceramente, ché da trent'anni / vivi nel paese più felice al mondo. / [...]'

128 Ivi: 177. 'Com'è terribile aprirsi al bene. / Com'è terribile confessare: l'uomo / non è morto ancora in noi. E aspettare / che, nascosto, muoia, / nel buio, per portarlo di nascosto / al cimitero delle anime, e trovar la felicità / che sulle ferite ormai non metti. / Come attira il male. Come attira il peccato - andarsene / dal mondo, librarsi col vento / e fuggire il proprio sembiante, / come il demonio. / [...]' 
integrità morale ed esistenziale. La configurazione verbale del testo, tuttavia, lascia intravedere la futura sconfitta dell'io, destinato ad aumentare le file del "cimitero delle anime".

La morte-in-vita del soggetto è non a caso al centro della terza lirica successiva a [Jak strašno vidkryvatysja dobru]:

Утрачені останні сподівання.

Нарешті — вільний, вільний, вільний ти.

Тож приспішись, йдучи в самовигнання:

безжально спалюй дорогі листи,

і вірші спалюй, душу спалюй, спалюй

свій найчистіший, горній біль — пали.

$[\ldots]^{129}$

Ribadendo la propria identità di poeta, l'io ne mette in risalto l'assoluta incompatibilità con l'ordinamento delle cose nella realtà contemporanea. L'essere poeta risulta altresì intimamente connesso con la capacità di provare dolore, innalzandosi così al di sopra dell'appiattimento psicofisico imposto all'umanità disumana degli inerti compagni del soggetto.

Nelle liriche seguenti si continua ad assistere all'ormai consueta alternanza tra la fiducia nella possibilità di conservare la propria eccezionalità di poeta e il cedimento all'omologazione nella massa. A questa duplicità corrisponde la variabilità della forma espressiva, con veri e propri smottamenti stilistici tra un linguaggio legato al registro elevato della lirica tradizionale e il gioco con il lessico della contemporaneità e i repentini abbassamenti di registro a esso connessi (cfr. Ševel'ov 1987). Non mancano, inoltre, riferimenti di ispirazione autobiografica alle reali vicende dell'autore.

Tra le ultime liriche della raccolta spiccano alcuni dei testi più noti e antologizzati dell'intera opera stusiana, più tardi ripresi all'interno dell'ampio corpus di Palimpsesty. In [U c'omu poli, syn'omu, jak l'on] il principio ermetico funge da ipnotica visualizzazione e resa auditiva della solitudine del soggetto in un mondo di ombre:

У цьому полі, синьому, як льон, де тільки ти і ні душі навколо, уздрів і скляк: блукало в тому полі сто тіней. В полі, синьому, як льон. А в цьому полі, синьому, як льон, судилося тобі самому бути, аби спізнати долі, як покути у цьому полі, синьому, як льон. $[\ldots]$

129 Ivi: 178. 'Perse le ultime speranze. / Sei finalmente - libero, libero, libero. / E allora affrettati, corri in esilio: / brucia spietato le care lettere, / e i versi brucia, l'anima brucia, brucia / il tuo più puro, l'alto tuo dolore - brucia. / [...]' 


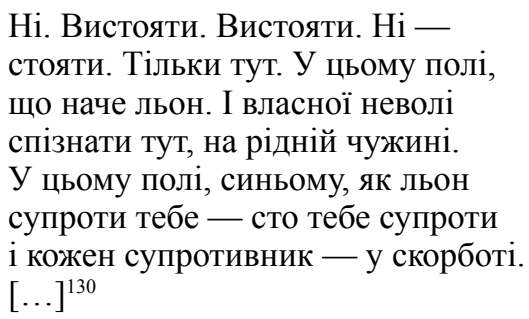

L'orientamento della lirica sulla ripetizione ossessiva contribuisce a rendere a livello del significante la condizione di astrazione del soggetto a livello del significato. Mediante un linguaggio venato di ascendenze simboliste ed espressioniste, che recupera elementi fondamentali dell'immaginario poetico stusiano, quali il fascino per il numerale "cento" e l'inquietante onnipresenza delle ombre, viene ripresa l'immagine di un io eroicamente votato alla lotta e alla contrapposizione. Il terreno socio-politico in cui affonda le sue radici anche questa lirica non solo non esaurisce l'interpretazione, ma può essere considerato come una delle diverse componenti della sua totalità semantica. La natura profondamente ermetica e astratta della rappresentazione lirica induce a considerare l'atto di resistenza del soggetto in esso raffigurato come una dichiarazione poetologica di allontanamento dalla comunità umana verso l'isolamento della parola. Anche in relazione all'appartenenza di questi versi al macrotesto fortemente coeso di Veselyj cvyntar, la prigionia dell'io si rivela allo stesso tempo dolorosa impossibilità di sfuggire all'ispirazione e inevitabile constatazione del proprio non recidibile attaccamento alla sfera umana, degradata a massa informe in un oscuro cimitero di anime defunte. Il progressivo distaccamento del soggetto dalla concretezza materiale, a cui, ben inteso, non può mai far seguito una completa rarefazione, sembra confermato dal distico conclusivo:

\section{Здичавів дух і не впізнає тіла, у цьому полі, синьому, як льон ${ }^{131}$.}

Che, almeno in questo caso, la consueta ridna čužyna stusiana possa con buone probabilità essere letta in riferimento alla devastante, alienante azione della parola poetica su di un soggetto dolorosamente incapace di integrarsi nel consorzio umano sembra confermato anche dalla storia del testo. Più tardi signi-

130 Ivi: 184 . 'In questo campo, azzurro come il lino, / dove solo tu sei e un'anima non c'è attorno, / ho visto, trasalendo: vagavano nel campo / cento anime. Nel campo, azzurro come il lino. / E in questo campo, azzurro come il lino, / ti è toccato esser solo, / per conoscer la sorte, e l'espiazione / in questo campo, azzurro come il lino. / [...] / No. Resistere. Resistere. No - / stare. Solo qui. In questo campo, / che è come il lino. E la mia prigionia / conoscer qui, in terra straniera e patria. / In questo campo, azzurro come il lino / contro di te - cento contro di te / e ciascuno in lotta con te - è a lutto. / [...]'

131 Ibidem. 'S'è fatto selvatico lo spirito, non riconosce il corpo, / in questo campo, azzurro come il lino.' 
ficativamente ricollocata in Palimpsesty, [U c'omu poli, syn'omu, jak l'on] risale a un periodo della biografia stusiana antecedente al reale imprigionamento dell'autore ed è dunque da inquadrarsi nel filone della prigionia 'ideale', letteraria, fondamentale nell'universo poetico di Stus e riconducibile, come si è visto, a tradizioni ben distanti tra di loro come quelle ševčenkiana e cvetaeviana.

Accostabile a [U c'omu poli, syn'omu, jak l'on] per ispirazione, imagery e fortuna è [Sto dzerkal sprjamovano na mene]:

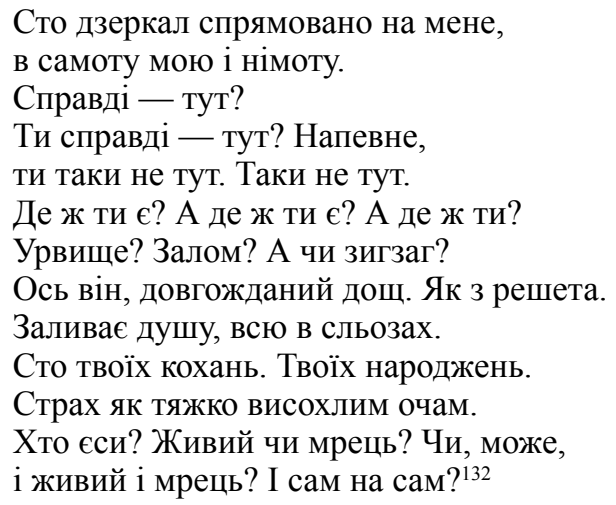

La concentrazione dell'io lirico su se stesso, cardine dell'universo poetico stusiano nel suo complesso, rende difficoltosa la localizzazione spaziale di un'entità prevalentemente autonoma e autotelica. Nell'ottica dell'assottigliamento fisico e della sublimazione che caratterizzano sempre maggiormente il soggetto stusiano dai tardi anni Sessanta in poi, la nascita e la morte si mostrano interscambiabili, private della rigida contrapposizione che le contraddistingue nella 'normalità' della vita umana. L'impossibilità di una definizione ontologica unitaria e definitiva è allo stesso tempo, tuttavia, un inatteso punto di contatto tra l'io e la massa dell'"allegro cimitero", per la quale, in Vertep, era stata affermata la mancanza di una chiara distinzione tra persone e ombre. A caratterizzare profondamente il soggetto è, dunque, la capacità introspettiva, il cammino gnoseologico e ontologico in sé, qui raffigurato nei termini di un'ossessione autoreferenziale contemporaneamente garanzia di identità e unitarietà e pegno della sua dolorosa alienazione da una realtà estranea e nemica. L'incerto posizionamento spaziale dell'io è legato all'evocazione di situazioni-limite, quali l'abisso, tipiche dell'immaginario stusiano, concrete visualizzazioni tanto delle caverne interiori del soggetto stesso, quanto delle insormontabili difficoltà relative a una

132 Ivi: 193 . 'Cento specchi proiettati su di me, / sulla mia solitudine e mutezza. / Veramente - qui? Sei veramente - qui? Certo, / non è qui che sei. Non è qui. / Dov'è che sei? Ma dov'è che sei? Ma dove? / Un precipizio? Un tornante? O uno zigzag? / Eccola, la pioggia tanto attesa. A catinelle. / Bagna l'anima, l'anima in lacrime. / Cento tue morti. Cento tue nascite. / È terribile per gli occhi secchi. / Chi sei? Un vivo o un morto? O, forse / sia vivo che morto? / E tutto solo?' 
sua seppur temporanea stabilizzazione in un mondo a lui ostile. La pioggia redentrice, di possibile derivazione pasternakiana e ryl's'kiana ${ }^{133}$, è un'inaspettata apparizione dell'elemento naturale in veste salvifica, componente alquanto rara nell' economia dell'immaginario di Veselyj cvyntar, basato essenzialmente sulla contrapposizione a livello umano tra l'io e la folla e l'io e la storia.

Legata a [U c'omu poli, syn'omu, jak l'on] e a [Sto dzerkal sprjamovano na mene] è inoltre la celeberrima [V meni uže narodžujet'sja Boh]:

\author{
В мені уже народжується Бог \\ i напівпам'ятний, напівзабутий, \\ немов і не в мені, а скраю смерті, \\ куди живому зась - мій внук і прадід \\ пережидає, заки я помру. \\ Я з ним удвох живу. Удвох існую, \\ коли нікого. І гримить біда, \\ мов канонада. Він опорятунок, \\ я ж білоусто мовлю: порятуй, \\ мій Господи. Опорятуй на мить, \\ а далий я, оговтаний, врятую \\ себе самого сам. Самого - сам. \\ Він хоче поза мене вийти. Прагне, \\ рятуючи, донищити мене, \\ аби на протязі, на буряних вітрах \\ я вийшов сам із себе, наче шабля \\ виходить 3 піхов. Хоче вийти геть, \\ щоб згасла свічка болю. \\ Щоб тьма покорення мене порятувала, \\ інобуттям. Іножиттям. Найменням \\ уже невласним: ось він, той загал, \\ яким кермує той шалений бог, \\ котрий в мені воліє народитись. \\ (а я ще тую свічку посвічу, \\ аби мені не смеркло передчасно. \\ Пресвітлої години свічка чорна - \\ неначе перемога крадькома) $)^{134}$.
}

133 Molto frequente è l'evocazione della pioggia nella lirica giovanile di Maksym Ryl's'kyj. Si vedano, in particolare, alcuni versi di una sua lirica del 1925 dal titolo Došč ('Pioggia'), in cui la pioggia, come in [Sto dzerkal sprjamovano na mene], è "tanto attesa” (dovhoždanyj), in: Ryl's'kyj 2005: 190: “Благодатний, довгожданий, / Дивним сяйвом осіянний, / Золотий вечірній гість / Впав бадьоро, свіжо, дзвінко / На закурені будинки / Зголоднілих передмість. / Відкривай гарячі груди, Мати земле!” 'Vivificante, a lungo attesa, / Splendente di un bagliore prodigioso, / Ospite dorato della sera, / Cadde con fragore, fresca e risuonante / Sui palazzi polverosi / In periferie affamate. / Apri il caldo seno, Madre terra!'

134 T I.1, 195. 'Dentro di me sta già nascendo Dio, / mezzo noto, mezzo scordato, / come non dentro di me, al bordo della morte, / dove non vanno i vivi - un avo mio, un nipote / sta in attesa finché non morirò. / Io e lui viviamo in due. In due esisto, / quando 
Il consueto sdoppiamento dell'io è qui esplicitamente legato al superamento della temporalità razionale. La nascita del Dio all'interno del soggetto, probabilmente ispirata a una lirica di Bohdan-Ihor Antonyč ${ }^{135}$, non esclude infatti una già avviata convivenza di quest'ultimo con una figura che è contemporaneamente più adulta e più giovane di lui. La vittoria della totalità sul potere limitante $\mathrm{e}$ soffocante delle opposizioni logiche usuali, così come, a un livello ancora più evidente, la complessa relazione simbiotica del soggetto con Dio ${ }^{136}$, rimandano nuovamente al prototipo del rilkiano Das Buch vom mönchischen Leben, la prima parte dello Stunden-Buch, con cui il poeta praghese si affermò definitivamente come una delle massime voci liriche nell'Europa del primo Novecento. Come in [V meni uže narodžujet'sja Boh], anche in Das Buch vom mönchischen Leben l'io lirico e Dio sono uniti da un rapporto di parentela totalizzante:

Du bist der Wald der Widersprüche.

Ich darf dich wiegen wie ein Kind, und doch vollziehen sich deine Flüche, die über Völkern furchtbar sind ${ }^{137}$.

So bin ich nur als Kind erwacht, so sicher im Vertraun nach jeder Angst und jeder Nacht

dich wieder anzuschaun ${ }^{138}$.

non c'è nessuno. E tuona la disgrazia, / come un cannone. Lui è la salvezza. / Io dico, con le labbra bianche: / salvami, mio Signore. Salvami per un attimo, / e poi io, ormai calmo, salverò / me stesso. Me stesso salverò. / Vuole uscire da me. Cerca, / salvandomi, di distruggermi, / perché nella corrente, nei venti tempestosi / io esca da me stesso, come una sciabola / esce dalla guaina. Vuole andare via, / perché si spenga la candela di dolore. Perché l'oscurità / della sottomissione salvi me, / con un'altra esistenza. Un'altra vita. Un nome / ormai non mio: eccola, la massa, / governata da quel dio impazzito, / che ama nascere dentro di me. / (e io quella candela accenderò, / perché per me si spenga non precoce. / Di ora chiarissima candela nera - / come vittoria di soppiatto).'

135 È probabile un richiamo ai due versi conclusivi di Gloria in excelsis di Bohdan Ihor Antonyč (1932). Si veda l'ultima quartina della lirica nella sua interezza: Antonyč 2012: 89: “Хай грає пісня серед герця, / бо це найбільша з перемог. / У жолобі мойого серця / сьогодні народився Бог." “Che suoni forte il canto, / perché questa è la grande vittoria. / Nella mangiatoia del mio cuore / è nato oggi Dio.' Il motivo della vittoria (peremoha) nelle rispettive conclusioni delle due liriche, alquanto diverse per tonalità, sembra confermarne il legame genetico.

136 Sull'ampiezza e la complessità della tematica religiosa nella multiformità delle sue realizzazioni nella poesia di area slava dei primi decenni del secondo Novecento si vedano, tra gli altri, von Zitzewitz 2012, Łucewicz 2008, Šmidt 2007, Kukulin 2011a: 391-393 e, per quanto riguarda la poesia ucraina nello specifico, Černenko 1988.

137 Rilke 1996: I, 182. 'Sei tu la selva dei contrari, / ti tengo in grembo come un bimbo, / ma delle tue maledizioni / hanno timore tutte le genti.'

138 Ivi: 194. 'Solo come fanciullo sono desto, / sicuro e fiducioso / dopo ogni notte, dopo ogni ansia / che ti rivedrò.' 
In entrambi i testi è altresì raffigurata la convivenza dell'io e di Dio:
Du, Nachbar Gott, wenn ich dich manchesmal
in langer Nacht mit hartem Klopfen störe, -
so ists, weil ich dich selten atmen höre und weiß: Du bist allein im Saal ${ }^{139}$.

Tuttavia, gli elementi in comune con il possibile ipotesto rilkiano sono sottoposti da Stus a una decisa rivalutazione in chiave negativa. Il Dio intrinseco al soggetto, impossibilitato a esistere senza di lui e allo stesso tempo fonte di energia vitale, mette ora a repentaglio il soggetto stesso cercando di abbandonarlo. Identificabile nell'arte e nel suo potere metamorfico e metaforico, il simbiotico Dio rilkiano si è trasformato in una forza nemica, incapace di garantire all'io il supporto necessario nella sua resistenza contro la pressione della realtà esterna. Nel complesso di Veselyj cvyntar, ciò non esclude la validità dell'identificazione tra il Dio e l'arte che emerge dal testo rilkiano: come in altre liriche della raccolta, l'arte e l'ispirazione poetica sono la causa del distacco del soggetto lirico dal mondo, ponendolo in una situazione di isolamento e precarietà. Nella seconda parte della lirica, tuttavia, il dio, ora definito "folle", è messo in collegamento con la massa che il soggetto rifugge, assumendo una caratterizzazione completamente opposta alla precedente. Questa ambivalenza, concreta realizzazione della sovraccitata "selva delle contraddizioni" nel modello rilkiano (Wald der Widersprüche), rispecchia l'ambiguo rapporto dell' io lirico con la propria natura di poeta, dunque di emarginato, in Veselyj cvyntar. È significativo, a questo proposito, che la raccolta non presenti alcuna lirica interamente ascrivibile al filone poetologico, in evidente contrapposizione con l'importanza assunta dalla figura del poeta e dalla sua esaltazione all'interno di Zymovi dereva.

Si vedano, infine, due liriche connesse con Vertannja, in cui si è potuta riscontrare l'effettiva preponderanza di una weltanschauung inconfondibilmente postmodernista in un'opera e in un sistema poetico ascrivibili, come si è visto, a un orientamento prevalentemente modernista. La prima delle due liriche in esame riprende con chiarezza il motivo del ritorno a casa e gli spunti autobiografici di Vertannja, rifacendosi anche alla lirica di apertura della raccolta:

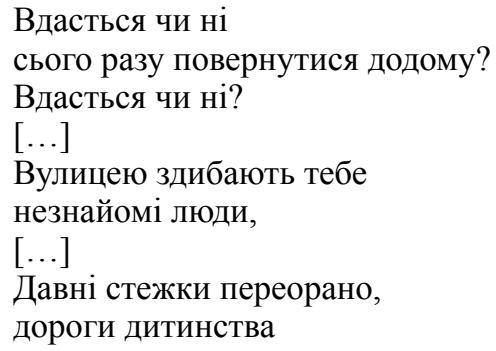

139 Ivi: 159. 'O Signore, o mio vicino, quando a volte / ti sveglio la notte bussando, / lo faccio non sentendo il tuo respiro / e sapendoti solo nella sala.' 


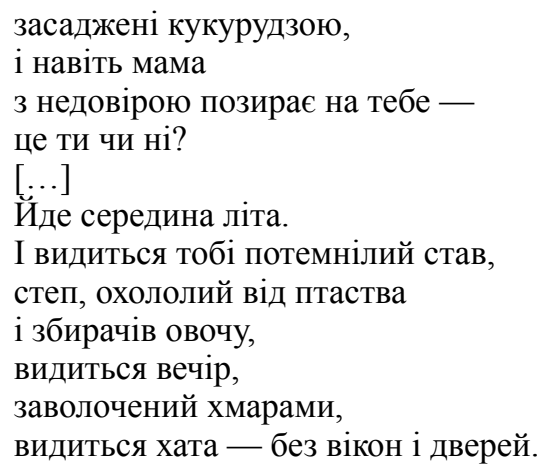

Іде середина літа $^{140}$.

Le difficoltà incontrate dal soggetto nel tortuoso percorso verso di sé, nucleo tematico di Vertannja, sono qui 'esteriorizzate'. La realtà visibile si trova ora a coincidere con l'universo interiore dell'io, riproponendo l'identità negativa tra macrocosmo e microcosmo più volte raffigurata nel corso dell'opera. La conoscenza di sé appare negata, precludendo dunque una realizzazione sul piano ontico del potenziale che il soggetto nasconde in sé. La casa, ancora una volta metafora dell'io, è surrealisticamente sbarrata, privata delle porte e delle finestre che ne consentirebbero l'accesso da parte del proprietario. La figura della madre, ševčenkiano simbolo di identità, continuità e umanità, si ritrova qui nei panni di una figura diffidente, sostanzialmente nemica ${ }^{141}$. La fusione

140 T I.1, 187. 'Si riuscirà o no / questa volta a tornare a casa? / Si riuscirà o no? / [...] / I vecchi sentieri sono arati, / le strade dell'infanzia / seminate di granturco / e anche la mamma / con sospetto ti guarda - / sei tu o non sei tu? / [...] / È la metà dell'estate. / E si intravede il pozzo annerito, / la steppa, fredda degli uccelli / e dei lavoratori nei campi, / si vede la sera, / avvolta dalle nuvole, / si vede la casetta - senza finestre e senza porte - / È la metà dell'estate.'

141 Si può ipotizzare un dialogo tra la lirica in questione e l'incipit di uno dei romanzi più amati da Stus, L'Étranger di Albert Camus. La notizia della morte della madre in una calda giornata presumibilmente estiva (Camus 1983: I, 31: "J'ai pris l'autobus à deux heures. Il faisait très chaud") e il breve viaggio in autobus verso l'ospizio dove la donna è mancata portano Meursault, il protagonista, a riflettere sul proprio distaccamento dalla madre stessa, interpretabile come una perdita del legame tra sé e il proprio passato, dunque tra sé e la propria identità: ivi: 32: "Quand elle était à la maison, maman passait son temps à me suivre des yeux en silence. Dans les premiers jours où elle était à l'asile, elle pleurait souvent. Mais c'était à cause de l'habitude. Au bout de quelques mois, elle aurait pleuré si on l'avait retirée de l'asile. Toujours à cause de l'habitude. C'est un peu pour cela que dans la dernière année je n'y suis presque plus allé. Et aussi parce que cela me prenait mon dimanche - sans compter l'effort pour aller à l'autobus, prendre des tickets et faire deux heures de route." Anche Meursault, come l'io lirico stusiano, è di sovente costretto a dubitare della propria identità e necessita di prove, non sempre fortunate, per accertarsi della sua realtà: ivi: 89: "Ce jour-là, après le départ du gardien, je me suis regardé dans ma gamelle de fer. Il m'a semblé que mon 
anch'essa ševčenkiana delle sfere spaziali ed esistenziali della patria e della terra straniera, ostile all'esiliato, fondamentale nell'immaginario stusiano nel suo complesso, si innesta in questi versi in una visione incontestabilmente postmoderna di totale disorientamento interno ed esterno. Notevole, in questo senso, è il contrasto tra l'impostazione semantica del testo nel suo insieme e il sostrato 'tradizionale' della caratterizzazione spazio-temporale dell'azione lirica, concretizzato nell'insistenza sulla stagione estiva, dunque sul trionfo della vita, e sui dettagli della realtà rurale riprodotti con minuziosità. Lo smottamento tra l'io, la sua percezione di se stesso e la realtà non potrebbe essere più completo. Questo senso di smarrimento assoluto è ribadito ancora più apertamente nella lirica conclusiva dell'ideale trittico rappresentato da Vertannja e dalle due liriche in questione:

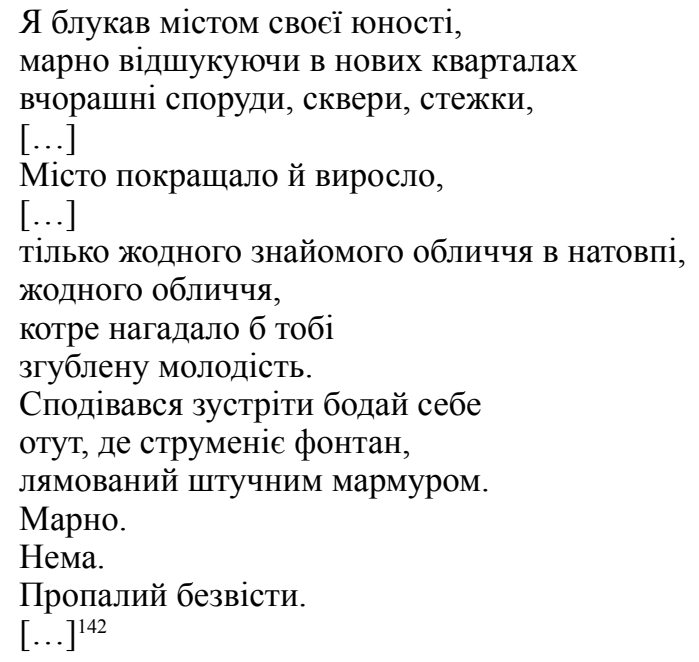

La fusione del topos del vagabondaggio alla ricerca di sé e della tradizione otto-novecentesca della poesia urbana nella figura del flâneur è alla base dell'ispirazione di questi versi. Anche in questo caso è lecito parlare di identità negativa tra una realtà esterna apparentemente florida e un soggetto apparentemente identico a se stesso. Dietro la patina trionfale di una città in crescita si nasconde infatti una massa senza volto, priva di caratterizzazioni individuali, immersa in un ambiente illusorio e inconsistente, come rivela il dettaglio del marmo artificiale che decora la fontana. Allo stesso tempo, l'utilizzo del pronome personale di

image restait sérieuse alors même que j'essayais de lui sourire. Je l'ai agitée devant moi. J'ai souri et elle a gardé le même air sévère et triste."

142 T I.1, 193. "Vagavo nella città di quand'ero giovane, / cercando invano nei nuovi quartieri / i palazzi di ieri, le piazze, i sentieri, / [...] / La città è più bella, è cresciuta, / [...] / ma nessun volto noto nella folla, / nessun volto, / che ti ricordi / la perduta giovinezza. / Speravo di incontrare almeno me / qui, dove scroscia la fontana, / con la sua lamina di marmo finto. / Invano. Non c'è. / È disperso. / [...]' 
prima persona all'inizio del testo in connessione con un verbo al tempo passato garantisce, visualizza la sopravvivenza dell'io al di là dell'andamento tematico della lirica, creando un cortocircuito semantico non inusuale nell'insieme dell'universo poetico di Veselyj cvyntar, riconducibile, anche in questo caso, alla tensione di fondo tra un'istanza disgregante di matrice postmodernista e l'assunto modernista alla base dell'opera.

La 'modernità' di [Ja blukav mistom svojeji junosti] risulta ben evidente, ad esempio, da un confronto con Misto molodosti ('La città della gioventù') del 1958, una lirica incentrata sulla stessa tematica a firma di Vasyl' Mysyk (19071983), longevo classico vivente della poesia ucraina sovietica, molto apprezzato dallo stesso Stus ${ }^{143}$ :

Ми тут росли і виростали

В цьому бентежному краю.

Тепер дивлюся на квартали -

I жодного не пізнаю.

Неначе й річка тихше ллється,

і помутніли небеса,

і надто гордою здається

будинків смілива краса.

Але під вітами чинара

У вересневій темноті

Закохана самотня пара

іде так само як тоді.

I шелестять неспішні кроки

В сухому місті... Тільки це

й зосталося. О роки, роки,

Як одмініли ви лице!

Старого міста! По бульвару

Якою бурею пройшли!

Все одмінили! Тільки пару

не одмінили. Не змогли ${ }^{144}$.

143 Si veda dalla lettera alla moglie del 15-03-1983, in: T VI.1, 433: “Дуже шкода за В. Мисиком (щойно читав некролог). Як я шанував цього поета!” 'Мі spiace molto per V. Mysyk (ho appena letto il necrologio). Come ammiravo questo poeta!'

144 Mysyk 1983: 87. 'Qui siam cresciuti e diventati adulti. / In questo paese travagliato. / Adesso sto guardando i quartieri. / E non ne riconosco nessuno. // Come se il fiume scorresse più piano / e il cielo fosse più scuro, / e sembra anche troppo fiera / l'ardita bellezza dei palazzi. // Ma sotto i rami del platano / nel buio di settembre / una coppia solitaria e innamorata / cammina come camminava ai tempi. // E frusciano i passi lenti / tra le foglie secche... Solo questo / è rimasto. O anni, anni, / come avete cambiato il volto // della vecchia città! Sul viale / come una tempesta siete passati! / Tutto avete cambiato! Solo la coppia / non avete cambiato. Non siete riusciti.' 
Se la lirica stusiana è aperta da un pronome di prima persona singolare, che sancisce l'unicità dell'io e la sua integrità, il soggetto di [My tut rosly $i$ vyrostaly] si concepisce innanzitutto come parte di una non specificata collettività. Mentre gli aspetti 'esteriori' della vita umana appaiono inevitabilmente sottomessi alla storia, la natura profonda dell'umanità, ciò che in ultima analisi è più importante, sembra essere al riparo dagli sconvolgimenti della temporalità. La coppia innamorata che l'io lirico vede camminare per il viale della "vecchia città" gli ricorda, infatti, i dolci anni della giovinezza, garantendogli in questo modo la certezza di una continuità con il proprio passato.

Il legame tra la lirica stusiana e il possibile ipotesto mysykiano sembra confermato dalla caratterizzazione delle rispettive città, entrambe almeno esteriormente cresciute e abbellitesi. La semantica profonda delle due poesie, è però molto diversa, se non addirittura opposta. Nel caso della poesia di Mysyk, la visita si conclude con una sostanziale autoaffermazione, che, in sintonia con la dichiarazione di appartenenza all'umanità nel suo insieme nel primo verso, si traduce in una lode della comunità degli uomini. La lirica stusiana, al contrario, raffigurando l'incomunicabilità tra gli esseri umani, sancisce l'impossibilità per il singolo di riconoscersi in se stesso. 


\section{Capitolo quinto. La poesia della maturità}

\section{1. Čas tvorčosti / Dichtenszeit}

\subsection{Le liriche originali}

Con Čas tvorčosti / Dichtenszeit il percorso artistico di Stus giunge alla maturazione. Allo stesso tempo, la biografia del poeta comincia a giocare un ruolo non secondario nell'ispirazione e nella composizione delle liriche. La scrittura delle oltre trecento liriche della raccolta, alle quali si sommano più di centoventi traduzioni da Goethe che possono essere a loro volta essere considerate parte integrante dell'opera stessa, è infatti direttamente connessa con l'arresto di Stus, avvenuto a Kiev il 12 gennaio 1972. In carcerazione preventiva fino al settembre dello stesso anno, quando sarebbe stato condannato a cinque anni di reclusione e tre anni di confino, Stus inizia la scrittura del nuovo ciclo poetico con una consapevole ed evidente impostazione diaristica. La maggior parte delle liriche reca infatti l'indicazione della data di scrittura in calce al testo, anche se la composizione dell'opera non rispetta necessariamente l'ordine cronologico delle singole poesie. Le date d'inizio e di conclusione del lavoro alla raccolta sono il 12 gennaio e il 30 settembre del 1972. I curatori di entrambe le edizioni delle opere stusiane si sono basati non solo sulla fonte testuale primaria, ovvero il quaderno su cui Stus lavorò in cella, ma anche sulle lettere dell'anno successivo nelle quali il poeta copiò per i familiari parte delle liriche della raccolta apportando alcune modifiche (ZT III, 693-695). Rispetto a $T, Z T$ presenta aggiustamenti cronologici e testuali dovuti all'avanzamento del lavoro filologico sull'opera stusiana nel suo insieme. È evidente come la vicenda testuale di Čas tvorčosti / Dichtenszeit presenti nel complesso un grado di difficoltà decisamente minore rispetto alle opere precedenti e successive, come si può evincere dalla consultazione dell'apparato critico di $Z T$, molto meno consistente rispetto agli apparati relativi alle altre raccolte, Palimpsesty e Zymovi dereva in primo luogo. L'intimo legame tra le vicende esterne e le condizioni della scrittura della raccolta sembrano averne determinato l'unicità nell'insieme della poesia stusiana e la sostanziale unitarietà di ispirazione e testualità. Come ha scritto Marharyta Jehorčenko, "è forse proprio Cas tvorčosti, più di ogni altra raccolta di Stus, ad aver bisogno dell' 'in- 
trusione' della biografia, che non può essere ignorata da chi voglia quanto meno avvicinarsi alla comprensione del poeta"'. Che Čas tvorčosti / Dichtenszeit sia da considerarsi come un'opera 'compiuta' è confermato anche dall'annotazione dell'autore sul frontespizio del manoscritto: "Finis coronat opus - 30.9.1972".

Particolarmente significativa è a questo proposito la possibilità di considerare l'opera divisa in due parti, resa evidente dallo stesso raddoppiamento del titolo in tedesco e in ucraino. Le traduzioni da Goethe che, secondo una più che condivisibile opinione dei curatori di entrambe le raccolte, costituiscono la seconda parte della raccolta, si trovano così a rapportarsi specularmente agli originali stusiani, ampliando notevolmente la gamma stilistica e tematica dell'opera e mettendo al contempo in discussione la possibilità di una sua lettura in chiave prevalentemente diaristica. All'epigrafe in calce alla parte originale della raccolta fa eco un'annotazione quasi identica a conclusione delle traduzioni goethiane: "Finis coronat opus! 18.10.72.".

Nel corpus di Čas tvorčosti / Dichtenszeit sono state inoltre inserite, in versioni leggermente diverse rispetto ai testi originali, anche alcune liriche provenienti dalle raccolte precedenti ${ }^{2}$. Ciò rende necessaria una dose ancora maggiore di cautela nei confronti della possibilità di una lettura autobiografica della raccolta. Numerosi componimenti di Čas tvorčosti / Dichtenszeit sono poi stati inseriti e ricontestualizzati in Palimpsesty.

Non si può sostenere che a Čas tvorčosti / Dichtenszeit sia estranea una componente narrativa, come mostra la lirica di apertura, la celeberrima [Meni zorja sijala nyni vranci]:

Мені зоря сіяла нині вранці, устромлена в вікно. І благодать така ясна лягла мені на душу смирену, що я збагнув блаженно: ота зоря - то тільки скалок болю, щовічністю протятий, мов огнем. Ота зоря - вістунка твого шляху, хреста і долі - ніби вічна мати, вивищена до неба (від землі на відстань справедливості), прощає тобі хвилину розпачу, дає наснагу віри, що далекий всесвіт почув твій тьмяний клич, але озвався прихованим бажанням співчуття та іскрою високої незгоди: бо жити — то не є долання меж,

1 Jehorčenko 2004: 131: “Можливо, саме 'Час творчості', як ніяка інша збірка Стуса, потребує ‘втручання’ біографії, котра не може не бути врахована, коли ми хочемо бодай наблизитись до розуміння поета."

2 Si tratta di [Tak javno svit tobi naležat'stav], [Ja marno včyv hramatyku kochannja] e [Berezy - navt'oky. Trava napnulas']. L'ultima lirica, originariamente parte di Kruhovert', sarà discussa nel corso di questo capitolo. 


\begin{abstract}
а навикання і самособою-
наповнення.

Лиш мати - вміє жити, аби світитися, немов зоря ${ }^{3}$.
\end{abstract}

Il valore programmatico di questa lirica, descrizione di un'epifania tanto esistenziale quanto poetologica, sembra consentirne sia un'interpretazione in chiave biografica, sia una lettura 'assoluta', non necessariamente connessa alla vicenda personale dell'autore. L'indicazione della data in calce alla poesia, come si è osservato elemento comune a molte delle liriche della raccolta, induce a non trascurare il sostrato biografico del testo. La localizzazione del soggetto nei primi versi della lirica evidenzia la contrapposizione tra lo spazio interno in cui egli si trova e lo spazio esterno dal quale, attraverso una finestra, la grazia può fluire su di lui. La rinascita dell'io è dunque inscindibile dall'azione di un agente esterno, simbolizzato da una stella, a sua volta identificata, ancora una volta, con un "pezzo di dolore". Che il dolore sia attributo innanzitutto del soggetto stesso è evidente, anche in riferimento alla costante presenza di questo elemento nell'immaginario stusiano delle opere precedenti a Čas tvorčosti / Dichtenszeit. L'accostamento della stella al dolore, nella poesia stusiana sineddoche del soggetto, sembra così annullare ogni differenza tra la sfera esterna del mondo e la sfera interna dell'io. La conseguenza primaria di questo accomunamento del macrocosmo al microcosmo nel segno della sofferenza, che testimonia un importante recupero della sensibilità espressionistica ben rappresentata nella fase iniziale della poesia stusiana, è una conferma della validità di un'interpretazione che privilegi l'analisi del vissuto interno dell'io lirico al di là delle cause esterne e storiche che lo hanno influenzato. Se tutto è dolore, la realtà esterna perde di autonomia rispetto all'universo interiore del soggetto che ingloba la totalità delle cose con la forza incontenibile della propria sofferenza. Il mondo si fa io, dopo che l'io si è fatto dolore "eterno". Si assiste dunque a un'epoché della storia, messa a tacere dall'ingigantirsi dell'interiorità di un soggetto assurto a Dio. Gli attributi cristologici dell'io di [Meni zorja sijala nyni vranci], crocifisso, momentaneamente disperato di fronte alle apparenti avversità del destino, Figlio di una Madre assunta in cielo, sono palesi. Sullo sfondo della madre postmodernamente incapace di riconoscere il figlio di una delle ultime liriche di Veselyj cvyntar, la 'protagonista femminile' di questi ver-

ZT III, 7. 'Una stella mi è brillata la mattina, / dentro la finestra. E la grazia / sull'anima in pace si è posata / chiara, nella beatitudine ho compreso: / la stella è solo un pezzo di dolore, / come di fuoco eterno penetrato. / Messaggero del tuo cammino è la stella, / della croce e del destino - come madre eterna, / al cielo elevata. (dalla terra / alla distanza della giustizia), perdona / a te la disperazione d'un attimo, dà / la forza della fede, che l'universo lontano / abbia sentito il grido tuo spento, abbia risposto / con un fioco desiderio di pietà / e una scintilla di alta indignazione: / vivere non è passare $\mathrm{i}$ limiti, / ma imparare e riempirsi / di se stessi. / Solo la madre - sa vivere, / per accendersi, come una stella.' 
si segna un deciso ritorno alla tradizione, non da ultimo ševčenkiana ${ }^{4}$. Quello della Madre è un modello di perfezione irraggiungibile, come dichiara il distico finale della lirica. Il suo insegnamento, tuttavia, sembra coincidere con l'atteggiamento del soggetto nei confronti di se stesso e del mondo che egli sta inglobando. L'esortazione della Madre al Figlio si identifica con la cura del proprio io, nel dispiegamento della capacità di accrescere il proprio spazio interiore fino a farlo coincidere con il Tutto. La vita è un "riempimento di se stessi", un interminabile accrescimento dell'io nel percorso del proprio destino, inscindibile dalla croce che lo caratterizza in primo luogo. Nell'infinitezza del cammino da compiere verso lo riempimento di sé e dell'universo con la propria natura l'io arriva a cogliere la disponibilità dell'universo stesso a essere colmato. Esso appare dapprima "distante" (dalekyj vsesvit), ma inaspettatamente non privo di disponibilità nei confronti dell'azione totalizzante del soggetto. Il riempimentodi-sé è un processo infinito, coincidente con il Golgota della realizzazione della propria natura. Rispetto all'incertezza dell'io nei confronti di se stesso e della propria missione, predominante nell'impianto semantico di Veselyj cvyntar, Čas tvorčosti / Dichtenszeit sembra dunque segnare un importante passo avanti nel cammino interiore dell'io lirico stusiano, non più insicuro circa la necessità del processo di conoscenza di sé e della realizzazione ontologica del percorso gnoseologico nel proprio io.

Si può dunque parlare di rinascita dell'io. Le due tradizioni che confluiscono in questa palingenesi sono, da una parte, quella goethiano-pasternakiana della rigenerazione etico-estetica del soggetto, dall'altra quella puškinianocvetaeviana dell'illuminazione dell'io-poeta da parte di un'ispirazione artistica connotata religiosamente. Si noti, inoltre, come nell'accettazione del cammino destinatogli che il soggetto di [Meni zorja sijala nyni vranci] dichiara di aver compiuto sia l'aspetto passivo dell'assunzione della grazia a prevalere su un'eventuale volontà di azione, fatta salva la consapevolezza da parte dell'io della propria eccezionalità.

Le liriche immediatamente seguenti riprendono e rielaborano i motivi fondamentali di [Meni zorja sijala nyni vranci]. Nella seconda poesia della raccolta è ribadito, infatti, l'avvicinamento dell'io al cielo, dunque la fusione tra l'io e l'universo:

$4 \quad$ Sulla persistenza del motivo sacrale della Madre nella poesia ucraina del Novecento si veda, ad esempio, una delle prime liriche (1947) di Oleh Zujevs'kyj (da Rubčak indicato, si ricordi, come possibile antecedente di Stus), ancora riconducibili alla prima fase classicistica di un poeta dell'Emigrazione che avrebbe in seguito sperimentato ancora più profondamente con una sensibilità ermetico-surrealista. Zujevs'kyj 1992: 46: "Полохливо, розбіглись ниви, / наче їм ця весна чужа. / I незміряна щедрість зливи / Прошуміла до них, мов жаль... // Та цього ані раз не взяти / Нашим серцем хоч би й хотів. / I тому підвелася Мати — / Рятівниця усіх світів." 'Agitati corsero i campi, / Come se la primavera non conoscessero. / E il generoso dar dell'acquazzone / Si fece sentire, come il tedio... // E questo mai lo coglierai / Anche se col cuore lo vorresti. / E per questo si levò la Madre - / Lei che sa salvare tutti i mondi.' 
Яке блаженство - радісно себе пуститися, неначе човен берега.

Не нарікай і не шкодуй, сердего: тобі все ближче небо голубе.

$[\ldots]^{5}$

Il momentaneo distacco tra il soggetto e se stesso annunciato dal distico iniziale viene così compensato dall'allargamento della sfera dell'io alla totalità delle cose, qui metonimicamente rappresentata dal cielo. La lettura in chiave 'affermativa' di questi versi qui proposta, alla luce del significato globale della raccolta, non esclude un'interpretazione di segno opposto, incentrata sulla scissione del soggetto e sul conseguente avvicinarsi della sua fine. Da questo punto di vista [Jake blaženstvo - radisno sebe] rappresenterebbe un'immediata ricaduta dell'io nell'incertezza ontologica dopo l'annuncio della sua ricomposizione in [Meni zorja sijala nyni vranci].

La rinascita del soggetto è invece esplicitamente dichiarata nell'incipit della terza lirica della raccolta, che reca la stessa data di composizione di [Meni zorja sijala nyni vranci]:

Оце твоє народження нове -

в онові тіла і в онові духу.

I запізнавши погляду і слуху

нового, я відчув, що хтось живе

в моєму тілі. Нишком вижидає

мене із мене.

Вабить повсякчас,

$[\ldots]$

Це він для тебе обживав ці мури,

і ще тебе не знаючи? Це він

шукає шпари у твоїй натурі,

аби солодкий близити загін?

Геть одійди, почваро, і не смій

ні кроку ближче. Згинь, гидка почваро!

Але ж - нестерпна - безневинна кара,

хоч ти сказись, хоч ти збожеволій ${ }^{6}$.

5 ZT III, 8. 'Che beatitudine - abbandonare con gioia / me stesso, come una nave la riva. / Non lamentarti, non rimpiangere, poveraccio: / ti è sempre più vicino il cielo azzurro. / [...]'

6 Ivi: 9. 'Ecco, questa è la tua nuova nascita - / in un nuovo corpo, in un nuovo spirito. / Conosciuti lo sguardo e l'udito / nuovi, ho sentito che c'è qualcuno / nel corpo mio. Di soppiatto attende / che esca da me stesso. Sempre lusinga, / [...] / 亡̀ lui che ha preparato per te i muri, / senza ancora conoscerti. È lui / che cerca crepe in te, / avvicinando dolce la rovina? / Vattene via, mostro, non osare / un passo avanti. Sparisci, orrido mostro! / Ma è insopportabile - l'ingiusta punizione, / o ti rovini, o diventi un matto.' 
Alla decisa affermazione del totale rinnovamento di sé che l'io lirico effettua nel distico iniziale si contrappongono nettamente i versi successivi, attraverso la ripresa dei motivi di [V meni uže narodžujet'sja Boh] da Veselyj cvyntar. Il doppio del soggetto, nel quale si condensano le forze avverse al cammino interiore, perde significativamente ogni rilkiano attributo divino per trasformarsi in una figura mostruosa, in sintonia con il consolidamento della volontà del soggetto di portare avanti il proprio percorso, annunciata come grazia celeste in [Meni zorja sijala nyni vranci]. Il rifiuto della morte si trova a coesistere con una sua indiretta evocazione a causa dell'insopportabilità della via crucis toccata in sorte all'io lirico. L'apparente crisi onto-assiologica che caratterizzava il soggetto prima della discesa della grazia è in realtà da interpretarsi come parte integrante del suo tormentato cammino interiore, dunque piena attuazione del riempimento-disé annunciato nella lirica iniziale dell'opera. Che la strada intrapresa dal soggetto sia fruttuosa sembra confermato dal distico conclusivo della poesia seguente:

Як серце зростає просторе!

Сльоза побиває сльозу!

L'ascesa del cuore a totalità del mondo si sta compiendo e il dolore a cui il soggetto non può sfuggire è parte integrante del cammino intrapreso.

I dettagli concreti dell'esistenza materiale dell'io incarcerato sono al centro della lirica successiva:

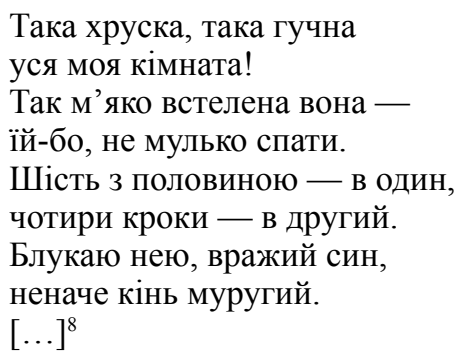

Identificandosi con il mondo interiore dell'io lirico, la stanza di quest'ultimo si eleva al di sopra della materialità per consentirgli il cammino in sé ormai definitivamente intrapreso. L'angusta spazialità esteriore sembra sublimarsi in vastità interiore, luogo delle peregrinazioni di un soggetto libero ed esuberante. Allo stesso tempo, è messa in risalto la fragilità di questo spazio intimo dolorosamente conquistato, così come il risvolto uditivo del cammino, nel quale si può leggere una metafora della parola poetica in quanto realizzazione della conoscenza di sé da parte del soggetto. La caratterizzazione negativa che l'io dà di sé

7 Ivi: 10. 'Spazioso sta crescendo il cuore! / Una lacrima batte un'altra.'

8 Ivi: 11. 'Così fragile, così fragorosa / è tutta la mia camera! / Il letto è così morbido, / eh sì, si dorme in pace. / Sei e mezzo da una parte, / dall'altra quattro passi. / Maledetto, vago in lei / come un cavallo nero. / [...]' 
nel frammento citato getta inoltre un'ombra di angoscia su uno 'scenario lirico' a prima vista positivo, contribuendo alla sua ambiguità semantica.

L'inscindibile nesso tra il cammino interiore e la poesia, già postulato dal titolo stesso della raccolta, è riaffermato nella lirica successiva, tra le più celebri dell'intera produzione stusiana e tra le più citate dai fautori di un'interpretazione di quest'ultima in chiave patriottica:

Як добре те, що смерті не боюсь я, і не питаю, чи тяжкий мій хрест.

Що вам, богове, низько не клонюся в передчутті недовідомих верств.

Що жив-любив і не набрався скверни ненависті, прокльону, каяття.

Народе мій, до тебе я ще верну

і в смерті обернуся до життя

своїм стражденним і незлим обличчям,

як син, тобі доземно поклонюсь

і чесно гляну в чесні твої вічі,

і чесними сльозами обіллюсь.

Так хочеться пожити хоч годинку, коли моя розвіється біда.

Хай прийдуть в гості Леся Українка, Франко, Шевченко і Сковорода.

Та вже! Мовчи! Заблуканий у пущі, уже не ремствуй, прозирай у глиб, у суще, що розпукнеться в грядуще і ружею заквітне коло шиб9.

Pur non estranea alla tradizione della poesia politica, [Jak dobre te, ščo smerti ne bojus' ja] può essere letta anche nei termini di un inno dell'io lirico a se stesso e, soprattutto, alla propria identità di poeta. L'auspicato, anzi predetto ritorno del poeta al popolo, espresso in termini liberi da connotazioni storico-politiche, è ricollegabile alla tradizione dell'Exegi monumentum aere perennius ${ }^{10}$. Consapevole dei rischi di uno snaturamento della propria parola poetica, il soggetto, me-

9 Ivi: 13 . 'È bene che non temo io la morte / e non chiedo se è pesante la mia croce. / Che a voi, oh Dei, basso non mi inchino, / un lungo cammino presentendo. / Che ho vissuto, amato senza macchia, / odio, male, pentimenti. / Popolo mio, da te io tornerò, / e nella morte conquisterò la vita, / col volto mio buono e sofferente, / come un figlio, a terra mi inchinerò / e negli occhi onesti tuoi guarderò, / e lacrime amare verserò. / Ancora un'oretta vivere vorrei, / mentre svanirà la mia disgrazia. / Che vengano da me Lesja Ukrajinka, / Franko, Ševčenko e Skovoroda. / Ma basta! Taci! Perso dentro il bosco, / più non lamentarti, guarda nel profondo, / in ciò che è vero, in ciò che sboccerà, / e come rosa fiorirà sui vetri.'

10 Sulla fortuna dell'Exegi monumentum nella letteratura ucraina cfr. Sodomora 2006: 11-39. A proposito della sua presenza nella tradizione russa si veda Lachmann 1987. 
diante una sorta di palinodia interna, invita se stesso nella parte finale della lirica a concentrarsi sull'essenziale, su ciò che fiorirà colorando i vetri della finestra del carcere, materiale e ideale, in cui si trova rinchiuso, ovvero la poesia stessa. Non a caso il rimprovero rivolto a se stesso segue immediatamente l'evocazione dei quattro numi tutelari delle lettere patrie. Se c'è un significato nazionale in questa lirica, esso riguarda innanzitutto la sfera della letteratura e della cultura e, metapoeticamente, il ruolo di questa lirica nella tradizione nazionale. L'assenza di scrittori stranieri tra gli autori nominati come sodali dell'io lirico-poeta è l'omaggio di Stus alla propria identità di poeta ucraino, nell'ambito di una raccolta 'pluriculturale', come segnala al lettore il suo stesso titolo. L'eternità del lascito di un io lirico contemporaneamente prometeico e umilmente umano è dunque inscindibile dalla natura di scrittore dell'io stesso, che sembra posizionarsi nella storia della letteratura ucraina come quinto vate. Si noti, inoltre, come l'io lirico inviti i grandi maestri della tradizione ucraina a visitarlo nella cella, invece di immaginare un proprio pellegrinaggio verso di loro. L'importanza del proprio contributo alla causa della cultura nazionale fa sì che il soggetto si senta pienamente allo stesso livello di chi l'ha preceduto.

Nelle liriche successive trovano tuttavia espressione tentennamenti e impeti di sfiducia del soggetto circa la propria capacità di proseguire nel percorso scelto $^{11}$, così come dolorosi ricordi della vita precedente, anteriore alla scelta individuale e individualista del cammino in sé verso la parola ${ }^{12}$. La tematica della poesia e dell'ispirazione poetica si mostra sempre più centrale, in sintonia con il titolo della raccolta $\mathrm{e}$ in contrasto con la scarsità di liriche metapoetiche e poetologiche in Veselyj cvyntar:
$[\ldots]$
Отак і прокидається уміння
накликати натхнення, що жене
од тебе всі найсолодші мрії
і каже: віщий образ назирай -
де ані радості, ані надії.
То - твій правдивий край. Ото - твій край ${ }^{13}$.

La natura ideale del poeta si configura come opposta alle consuetudini dell'umanità. L'ispirazione è la negazione delle più intime manifestazioni umane, qua-

11 ZT III, 14: 'Оце тобі про славу і огуддя. / Оце воно, життя. Оце - воно.” 'Ed eccoti la gloria e la corona. / Eccola, è la vita. Eccola. È lei.'

12 Ivi: 16: “Лише в ночному снінні є питомий / знак, що там десь $є$ син і там $\epsilon$ ти, / моя голубко вижурена, люба, / ти за межею, за ріллею, там, / куди, аби я волю дав чуттям, / на ліктях зміг би доповзти." 'Solo di notte, nel sonno il segno / inconfondibile: il figlio, te, / colomba mia triste, amore mio, / sei oltre il confine, oltre il campo, là, / dove, per dar spazio ai sentimenti, / potrei sui gomiti strisciare.'

13 Ivi: 17. '[...] / E di nuovo sai / chiamar l'ispirazione, che toglie / a te ogni sogno più dolce / per dirti: l'orizzonte saggio guarda, / dove non c'è allegria, né speranza. / Il tuo vero paese. Il tuo paese.' 
li il sogno e la speranza. L'astrazione assoluta e l'ascetismo che si richiedono al poeta nello sprofondamento in sé e nella conseguente esplicitazione dell'ispirazione non concedono alcuna ricaduta nella sentimentalità.

L'identificazione assoluta dell'io lirico con la figura ideale del poeta è ribadita in altre tre liriche composte nei giorni immediatamente successivi:

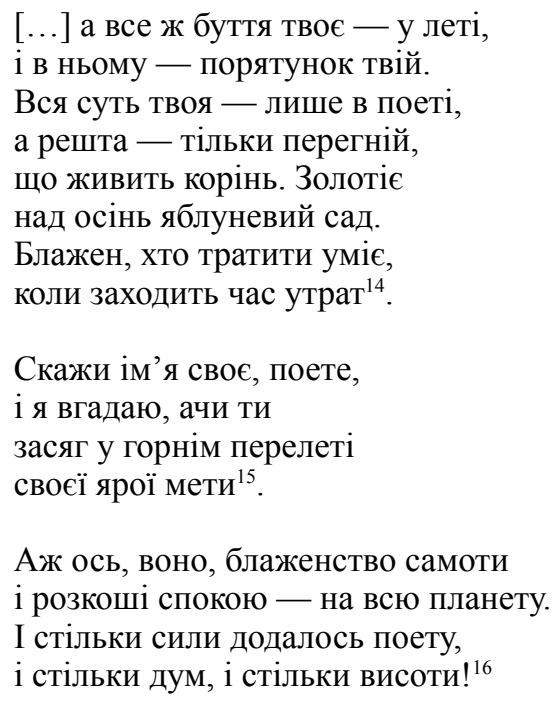

Elemento primario dell'essenza del poeta è, sulla scia della poetologia romantico-simbolista, la capacità di elevarsi al di sopra della terrestrità. Come emerge dal terzo brano citato, tuttavia, il raggiungimento del proprio zenit è un obiettivo da perseguire con alacrità, assolutamente non garantito dalla mera capacità di esercitare l'attività poetica. L'aspetto più significativo delle considerazioni poetologiche dei frammenti citati è, tuttavia, da ricercarsi nel primo di essi, nel nesso postulato tra l'essenza del poeta e "il resto". Tutto ciò che non rientra nella poesia risulta di primaria importanza per il poeta, come mostra chiaramente l'immagine dell'humus che nutre le radici. Il vissuto strettamente umano del poeta-uomo, dunque, non può essere né negato né rifiutato, ma coltivato come parte fondamentale del processo di ispirazione. È ben evidente in questi versi l'intrinseca contraddittorietà della poetologia stusiana, scissa tra due opposte e ineludibili tensioni: da una parte, la moderna e postmoderna volontà di separare la parola poetica dal sentimento umano; dall'altra, l'attaccamento alla tradizione 'umanistica' di una poesia in

14 Ivi: 21. '[...] eppure è nel volo l'essere tuo, / in esso la salvezza tua. / La tua essenza è nel poeta, / e il resto soltanto concime, / che nutre le radici. Splende / d'oro in autunno il frutteto dei meli. / Beato chi sa perdere / nell'ora delle perdite.'

15 Ivi: 25. 'Dì il nome tuo, o poeta, / e io indovinerò se / nell'alto volo hai raggiunto / la meta tua suprema.'

16 Ivi: 27. 'Eccola, beata è la solitudine / e il lusso della pace sul pianeta. / E tanta forza ha avuto il poeta, / tanti pensieri e così tanta altezza.' 
primo luogo espressione della verità dell'esperienza. Il motivo dell'innalzamento in volo del poeta introdotto nelle liriche esaminate, ora come marcia trionfale, ora come definitivo annullamento di sé, risulta centrale in molti dei testi di Čas tvorčosti / Dichtenszeit composti nei primi tre mesi della stesura della raccolta ${ }^{17}$.

Come già anticipato, anche alla tematica amorosa e famigliare spetta un posto di primo piano nell'universo poetico di Čas tvorčosti / Dichtenszeit. Il rapporto tra l'io lirico e la donna amata sembra a tratti raffigurato sulla base del modello di Orfeo ed Euridice:
$[\ldots]$
Мов на антоновім огні, не чув нічого я й не бачив в останньому зусіллі зміг збагнути: Все. Тебе я трачу, от тільки заверну за рі ${ }^{18}$.

È per un errore del 'personaggio' maschile, altrove connotato come poeta, che l'amore è destinato a finire. La necessità della separazione è d'altro canto scritta nel destino e la sua certezza non può che essere accettata con fermezza e dolorosa rassegnazione dal soggetto. Si veda, a questo proposito la conclusione di un'altra lirica rivolta alla donna amata composta nello stesso giorno:

\author{
Як, скажи, до тебе я вернуся? \\ Сном? Явою? Мертвим чи живцем? \\ I до кого словом обронюся \\ зболеним? Перед чиїм лицем \\ я тобі повідаю про долю - \\ ту, що, ніби зашпори, зайшла \\ в душу. Але кожну — славословлю. \\ Ти страждала? Отже, ти жила ${ }^{19}$.
}

17 Ivi: 87: "I знай: твоє спасіння - тільки в леті, / а твій спочинок - то вельможна смерть, / яке щасливому не по кишені." “E sappi: la salvezza tua è nel volo, / e il tuo riposo - la maestosa morte, / che un fortunato non si può permettere.' Ivi: 91: “Нема мені спину. Тож зносся до зір. / Внизу Україна, немов водовир. / Та, мертвий, тепер ти іiі не почув." 'Non posso fermarmi, sali alle stelle. / Sotto l'Ucraina, come un mulinello. / Ma tu sei morto, ora non la senti.’ Ivi: 99: “Єси поет, запраглий неба, / во віки і віки — поет!' 'Sei un poeta, hai voluto il cielo, / nei secoli dei secoli - poeta!” Ivi: 104: “Життя - неначе не було, / а тільки краєм перейшло / по бездоріжжю. Свого лету — / ти так, здається, й не почав." 'La vita - come non ci fosse / stata, passando al bordo di una / via sterrata. Tu, il volo tuo / è come non l'avessi mai iniziato.'

18 Ivi: 29. 'Come se avessi una cancrena / senza sentire, non vedendo / riuscii a capire nell'ultimo sforzo / che era la fine, ti stavo perdendo, / non appena avrei girato l'angolo.'

19 Ivi: 31. 'Come farò, dimmi, a tornar da te? / Nel sonno? Nella veglia? Vivo o morto? / E a chi rivolgersi con la parola / dolente? E davanti a quale volto / raccontarti del destino - / che, come uno spillo, è entrato / nell'anima. Ma - io lo benedico. / Hai sofferto? Vuol dire che hai vissuto.' 
L'ipotesi di un ritorno del soggetto alla donna, avanzata nel primo dei versi citati, sembra essere abbandonata nello svolgimento della lirica. L'attenzione si sposta, infatti, dal rapporto dei due amanti alla natura del loro destino, identificabile nel dolore stesso. Nei due versi conclusivi la sofferenza arriva ad assimilarsi alla vita tout court e la scelta esistenziale del soggetto è quella di una totale accettazione della vita nella sua essenza di dolore. La benedizione del destino, dunque del dolore e della vita nella sua totalità, si configura così, in riferimento alla fondamentale tematica poetologica predominante, come conditio sine qua non della parola. Allo stesso tempo, in riferimento alla concezione del vissuto umano come nutrimento della poesia precedentemente analizzata, è necessario evidenziare l'irrinunciabilità dell'esperienza amorosa e del dolore a essa intrinsecamente legato come ossigeno del fuoco poetico.

Che quello del poeta sia un cammino verso l'alto è frequentemente ribadito dall'io lirico:

Крізь сотні сумнівів я йду до тебе,
добро і правдо віку. Через сто
зневір. Моя душа, запрагла неба,
всерозкриленна, держить путь на стовп
веселого вогню, що осіянний
одним твоїм бажанням - аж туди,
де не ступали ще людські сліди,
з щовба на щовб аж за смертельні грані
людських дерзань, за чорну порожнечу,
де вже нема ні горя, ні біди,
і врочить порив: не спиняйся, іди.
То шлях правдивий. Ти - його предтеча ${ }^{20}$.

La potenza del soggetto, la sua capacità di superare le difficoltà intrinseche ed estrinseche è al centro della lirica, definibile nei termini di un'apoteosi dell'io ${ }^{21}$. La sua sacralità, evidenziata dal riferimento a Giovanni Battista, il Predecessore (predteča) per eccellenza, lo eleva al di sopra dell'umanità, dunque al di là dei sentimenti, in evidente contrasto con quanto affermato nelle liriche precedentemente citate e di quest'ultima, come è bene sottolineare, contemporanee. L'io afferma di volersi spingere in uno spazio assolutamente altro, (ancora) non descrivibile con il linguaggio, più distante e oscuro del "nero vuoto" della sofferenza. Una lettura di questi versi in chiave metapoetica, in riferimento a un'ulteriore radicalizzazione del linguaggio ermetico stusiano

20 Ivi: 34. 'Tra cento dubbi vengo a te, / o verità del tempo. Tra cento / miscredenze. Chiede il cielo / l'anima, tutta alata, persegue la colonna / di fuoco vivo, illuminata / del tuo solo desiderio, andiamo lì, / dove non c'è traccia umana, / di cima in cima, oltre i confini / mortali del coraggio, il nero vuoto / dove non c'è dolore, né disgrazia, / e ammalia l'impeto: non fermarti, vai. / Giusto è il cammino. Tu - il suo precursore.'

21 Jurij Ševel'ov ha sottolineato il carattere "dichiarativo-profetico" di questi versi, chiaramente segnati dall'esperienza filosofica esistenzialista. Cfr. Ševel'ov 1987: 375. 
in Čas tvorčosti / Dichtenszeit, così come nella più tarda raccolta Palimpesty, risulta pienamente giustificata. Se in [Kriz' sotni sumniviv ja jdu do tebe] a imporsi è l'eroicità del soggetto, nella lirica successiva è l'aspetto tragico del dono poetico a risultare in primo piano:

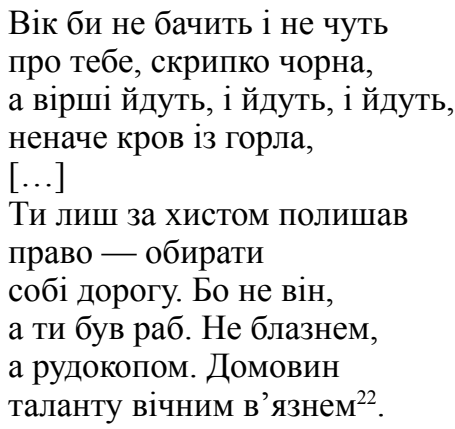

Mediante un nuovo riferimento alla pasternakiana [O znal by ja, čto tak byvaet] è tematizzato il potenziale letale dell'attività poetica, responsabile dell'allontanamento del poeta dall'alveo della vita umana. L'identificazione del soggetto, inequivocabilmente un poeta, con un prigioniero, significativa nel caso di una poesia squisitamente 'carceraria' come quella di Čas tvorčosti / Dichtenszeit, è anticipata da una sua caratterizzazione come "minatore". È ipotizzabile a questo proposito un accostamento all'incipit del poemetto rilkiano Orpheus. Eurydike. Hermes, che Stus avrebbe tradotto pochi anni più tardi:

Das war der Seelen wunderliches Bergwerk.

Wie stille Silbererze gingen sie als Adern durch sein Dunkel. $[\ldots]^{23}$

La metonimia rilkiana della miniera per gli inferi, in cui Orfeo tenta invano, accompagnato da Ermes, di riconquistare Euridice, è ricollegabile all'immagine stusiana del poeta-minatore prigioniero della propria ispirazione. La successiva esplicita identificazione del talento con una tomba, dunque della poesia con la morte, risulta altrettanto riconducibile al sottotesto orfico che permea l'intera raccolta.

In una delle ultime liriche del gennaio 1972 è indirettamente tematizzata la necessità per il poeta di astenersi dalla maledizione della propria sorte, motivo fondamentale in Čas tvorčosti / Dichtenszeit e, successivamente, in Palimpsesty:

22 ZT III, 35. 'Non sentirti, non vederti / nero violino, / e vanno i versi, e vanno, e vanno, / come sangue dalla gola, / [...] / Solo per il talento hai lasciato / il diritto di sceglierti / la strada. Non è lui, / sei tu lo schiavo. Non un buffone, / ma un minatore. Delle tombe / del talento eterno prigioniero.'

23 Rilke 1996: I, 500. 'Era delle anime la miniera portentosa. / Come quieto argento andavano, / vene nella tenebra.' 

[...] I в хапливий сон
угнався гострий, ніби ніж, прокльон, і провертається в душі розверстій,
бо він - найбільший ворог мій - спішить
моєю кров'ю лезо окропить,
щоб став і ти такий, як треба, - черствий ${ }^{24}$.

La paradossale, contraddittoria immagine della maledizione, dunque dell'incapacità di accettare in sé la sofferenza, come un coltello conficcato nell'anima rivela una chiara matrice espressionista ${ }^{25}$. Allo stesso tempo, l'esortazione indiretta che il soggetto rivolge a se stesso a saper accogliere il dolore è ricollegabile, ancora una volta, alla lezione della poesia matura di Rilke. Elemento probabilmente cardine del sistema poetico rilkiano degli anni Venti, l'accettazione affermativa (Bejahung) del reale nella sua inscindibile unitarietà di sofferenza e felicità ${ }^{26}$ inizia a porsi come imperativo categorico, seppur instabile e doloroso, del soggetto stusiano. Nella nona delle Duineser Elegien, tradotte da Stus nei mesi precedenti all'arresto, si assiste a un esplicito richiamo dell'io lirico alla necessità della lode, diretta conseguenza dell'accettazione della realtà:

\author{
Preise dem Engel die Welt, nicht die unsägliche, $i \mathrm{hm}$ \\ kannst du nicht großtun mit herrlich Erfühltem; im Weltall, \\ wo er fühlender fühlt, bist du ein Neuling, drum zeig \\ ihm das Einfache, das, von Geschlecht zu Geschlechten gestaltet, \\ als ein Unsriges lebt neben der Hand und im Blick. \\ Sag ihm die Dinge. [...] \\ [...] \\ [...] Und diese, von Hingang \\ lebenden Dinge verstehn, daß du sie rühmst; vergänglich, \\ traun sie ein Rettendes uns, den Vergänglichsten, $\mathrm{zu}^{27}$.
}

24 ZT III, 41. '[...] E nel sonno frettoloso / si è infilata, tagliente, una maledizione, / e si rigira nell'anima aperta, / è il mio maggior nemico, s'affretta / a bagnar la lama col mio sangue, / perché tu diventi, come devi, arido.'

25 Si veda, ad esempio, l'ultima strofa di Der Wanderer ('Il viandante') di Albert Ehrenstein (1886-1950), in: Pinthus 1990: 71: “'Töte dich!' spricht mein Messer zu mir. / Im Kote liege ich; / Hoch über mir, in Karossen befahren / Meine Feinde den Mondregenbogen". "Ucciditi!" - mi dice il mio coltello. / Tra feci giaccio; / Sopra di me cavalcano in carrozza / L'arcobaleno i miei nemici.'

26 Sulla scia del pensiero di Paul de Man e della Decostruzione, Gerhard Ammelburger ha evidenziato il carattere retorico, mediato della lode nella tarda poesia rilkiana, premessa a un'esaltazione del reale che superi la dialettica di positività e negativa per farsi lode apodittica, irrazionale, incomprensibile. Cfr. Ammelburger 1995.

27 Rilke 1996: II, 228. 'Loda all'angelo il mondo, non l'indicibile, lui / non puoi sorprenderlo sentendo il sublime. Nell'universo / dove sente sentendo di più, sei un novellino, mostragli / ciò che è semplice, che va di stirpe in stirpe, / che è nostro, negli occhi e nella mano. / Digli le cose. / [...] / E queste cose, che vivono / di morte, lodale, effimere / si affidano a noi, ancora più effimeri.' 
Ancora più evidente e vicina all'universo poetico stusiano risulta l'esaltazione della lode nei Sonette an Orpheus. Si veda dall'ottavo sonetto della prima parte:

Nur im Raum der Rühmung darf die Klage

gehn, die Nymphe des geweinten Quells, wachend über unserm Niederschlage,

daß er klar sei an demselben Fels,

der die Tore trägt und die Altäre ${ }^{28}$.

Rispetto alle conquiste dell'io lirico rilkiano delle Elegien e, in misura ancora maggiore, dei Sonette ${ }^{29}$, l'io lirico di Čas tvorčosti / Dichtenszeit si trova ancora a lottare per la vittoria sulla disperazione e l'accettazione di ciò che potrebbe superficialmente apparire come il Male. La maledizione che egli riconosce indirettamente come il contrario dell'ideale Lamentazione rilkiana (Klage), parte integrante della Lode nell'essenza a-logica della poesia, è un nemico non ancora completamente sconfitto. Il rischio che la maledizione comporta è il silenzio della parola poetica, qui raffigurato metaforicamente nei termini dell'aridità.

In una delle liriche seguenti sembra essere ribadita, in contrasto con i testi poetologici precedentemente analizzati, la necessità dell'io di rimanere sulla terra, dunque di accettarla:

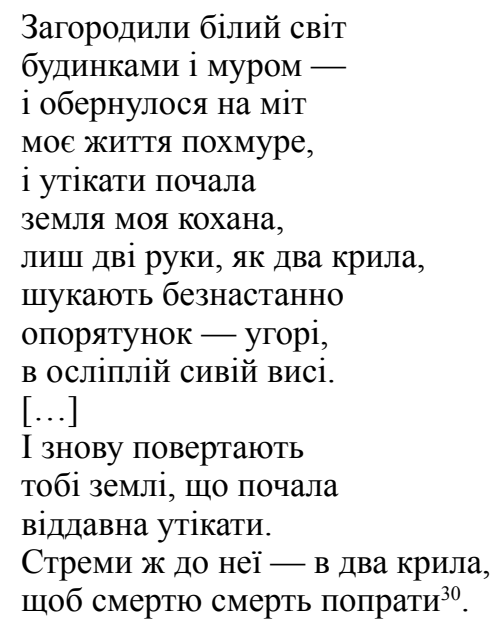

28 Ivi: 244 . 'Solo nella lode può il lamento / andare, ninfa della fonte pianta, / vigile sulla nostra sconfitta, / che sia chiaro alla stessa roccia, // che le porte regge, e gli altari.'

29 La critica recente sembra concorde nell'osservazione delle sostanziali differenze tra i due opera magna della tarda poesia rilkiana. È ormai assodato il carattere più unitario e coeso dei Sonette, nei quali la Rühmung del reale sembra definitivamente compiuta. Cfr. Engel 2004: 405 e Gerok-Reiter 1996. Si tengano comunque in considerazione le osservazioni di Ammelburger sovraccitate.

30 ZT III, 48. 'Han recintato il mondo / con muri e palazzi - / e mito è diventata / la cupa vita mia, / e a fuggire ha cominciato / la terra mia amata, / solo due braccia - due 
Il distacco dalla terra, imputato a una causa indipendente dalla volontà del soggetto, è all'origine della rarefazione di un io alla disperata ricerca di un appiglio in una realtà altra. Il ritorno alla terra, anch'esso frutto di un atto non compiuto dall'io, disperso nell'altitudine di un universo astratto, è qui accolto come una possibilità di salvezza. [Zahorodyly bilyj svit] sembrerebbe dunque decisamente distante da una lirica come [Skažy im "ja svoje, poete]. A un'analisi più attenta, tuttavia, si nota come in entrambi i testi sia ugualmente tematizzata la necessità di uno spostamento, la ricerca di una dimensione altra, raggiungibile esclusivamente con le proprie ali, dunque con strumenti non accessibili all'essere umano. In questo senso, sia l'invito all'abbandono della terra che quello apparentemente contrario del ritorno a essa possono essere ricondotti alla medesima radice, il mito modernista del Poeta al centro di Čas tvorčosti / Dichtenszeit.

In un'altra lirica, in sintonia con l'immagine del Poeta alato, il soggetto si rivolge a se stesso come a un angelo:

Ти, янголе, закинутий у пекло, настачене собі за власний прогріх цю понадмірну відданість шляхам будучих літ - уже спізнав чекання, коли ж відслоняться тобі світи, занадто добре знані, ще до твого народження? Ти, янголе, спізнав кінець путі? $[\ldots]$

$[\ldots]$

I при початку тих часів блаженних ти став, зніяковілий, і утрата болить тобі обабоки - ти, янголе припнутий гострожалими списами до тіла власного, — хреста подоба втрачаеш право самоуникання, самопереростання скрайніх меж і розминувшись із самим собою, ти почезаеш у невзгоді вчинків (чужих чинінь) - як вічна колотнеча з народження заблуклої душі, не названої власною ще і досі. $[\ldots]^{31}$

ali, / cercan senza sosta / la salvezza - in cima, / nell'alto grigio, che è ormai cieco. / [...] / Ti hanno ridato / la terra, che a lungo a fuggire / aveva cominciato. / Corri da lei - di ali ne hai due, / per calpestar la morte con la morte.'

31 ZT III, 54-55. 'Tu, angelo, gettato nell'inferno, / dato a te stesso per colpa tua - / la troppa attenzione ai cammini / degli anni a venire - già sai l'attesa, / quando si apriranno i mondi / già troppo noti a te prima che tu / nascessi? Angelo, hai riconosciuto / la fine del percorso? [...] / [...] / E all'inizio di quei beati tempi / ti ergevi, sofferente, e la perdita / fa male a tutte due le parti - angelo, / stretto da lance dalla punta acuta / al proprio corpo - l'aspetto di una croce - / perdi il diritto ad evitar te stesso, / di crescer 
È, in realtà, con un angelo caduto che il soggetto identifica se stesso. Novello Lucifero, ha peccato nell'eccessiva dedizione al cammino intrapreso, o più esattamente, secondo il testo della lirica, ai "cammini". La reale natura di questi ultimi può solo essere ipotizzata. Se, da una parte, l'insistenza sulla propria colpa e sui cammini intrapresi potrebbero spingere a immaginare che essi altro non siano che una metafora per l'egotismo dell'io lirico, eccessivamente assorbito dalla propria natura, la sua logorante attesa dell'agognata apertura dei mondi come castigo sembra inficiare questa supposizione. Il suo errore sembra racchiudersi, al contrario, in un'esagerata volontà di contatto con i mondi esterni che ora possono soltanto essere desiderati. Il prezzo che l'io lirico deve pagare per la sua colpa è, dunque, un totale e dolorosissimo ripiegamento su se stesso, come, a livello macrotestuale, ben si evince dalla raccolta nel suo insieme. L'assimilazione del soggetto a Lucifero nel verso iniziale non impedisce il suo successivo accostamento a Cristo sulla croce. La condanna a un'(eterna) chiusura in e su se stesso non esclude, allo stesso tempo, l'impossibilità, in questo contesto paradossale, di una vera comprensione di sé, impossibilità espressa dalla perdita del "diritto ad evitare [s]e stesso" e a fuoriuscire dai propri angusti confini. Tuttavia, pur non potendo sfuggire a se stesso, l'io è allo stesso tempo condannato alla sparizione. Alla radice della sua rovina sembrano trovarsi tanto fattori esterni, quali la dipendenza da azioni altrui in contrasto tra loro, tanto moventi interni, riconducibili all'incapacità di rendere realmente 'propria' la propria anima. A dipanarsi sotto gli occhi del lettore è una descrizione metapoetica di una lirica condannata alla costante, ossessiva auto-tematizzazione del soggetto e alla concomitante, paradossale negazione della possibilità di quest'ultimo di conoscere ed esprimere se stesso mediante la poesia.

Il motivo angelico è ripreso in una lirica di pochi giorni posteriore:

Цей спертий запах смерти, наче спирт,
геть виповнив кімнати синім чадом
душі, своїм притьмареним свічадом,
і обсідає душу, мов упир.
На чорному папері білі літери
просипані, мов янголи ясні,
котрі щепочуть: на марудься в сні,
з похмурого чола завжди витри,
бо ти єси за нею, потойбіч
людського остраху і сподівання.
До узголів'я клониться світання
у кілька поминальних ярих свіч ${ }^{32}$.

fuori dai limiti estremi / e non riuscendo a incontrar te stesso / scompari nel dolore delle azioni / (gli atti altrui) - eterna lotta / della nascita di un'anima smarrita, / che ancora oggi non sai chiamare tua. / [...]'

32 Ivi: 64. 'Forte odore di morte, come spirito, / riempie la stanza di fumo blu / dell'anima, il suo oscurato specchio, / e assedia l'anima, come un vampiro. / Sulla carta nera bianche lettere, / come angeli chiari, / sussurrano: nel sogno non soffrire, / dalla 
In uno stato intermedio tra la vita e la morte, l'io lirico è messo a confronto con la sua stessa anima. Se nella lirica precedentemente analizzata se ne era postulata l'irraggiungibilità, essa appare ora come lo "specchio oscurato" del soggetto. Allo stesso tempo ne è affermato il nesso con la morte. Il soggetto si ritrova immerso in una realtà capovolta, simbolizzata dalla sua scrittura a lettere bianche su fogli neri. In conseguenza di ciò la sua esistenza ha abbandonato $\mathrm{i}$ sentimenti umani per traghettarsi "al di là", in uno spazio che non è ancora morte, ma non è più vita ${ }^{33}$. La fusione tra la vita e la morte e il raggiungimento di una nuova dimensione in cui esse hanno perso l'opposizione che le divide tradizionalmente sono visualizzati nel distico finale, nel quale un raggio di luce memore dell'Annunciazione si posa sul cuscino dell'io lirico sotto forma di candele mortuarie. L'io, allo stesso tempo vivo e morto, è messo in grado di comprendere la propria situazione dalle lettere bianche da lui vergate sulla carta nera, ovvero dalla propria poesia.

In una lirica di pochi giorni successiva, la scrittura poetica, 'professionalmente' identificata come "lavoro", sembra aver integralmente preso il posto del soggetto:
I заступила мене робота, і вибрала весь порив молодий, і цілий всесвіт вималів до столу письмового, паперу і пера.
$[\ldots]$
$[\ldots]$ я жити прагнув од дитинства - косити сіно чи садити сад, копати картоплі чи прокидати од хати сніг, під зорями нічними самотньому блукати, щоб себе до себе повертати - між землею і небом. А не зміг. Прости мене, поєзіє, розлучнице-ворожко ${ }^{34}$.

Contrapponendo alla poesia l'agognata 'vita materiale', descritta con un abbassamento di registro atipico in Čas tvorčosti / Dichtenszeit, l'io lirico non manca di mettere in evidenza la propria unicità di poeta, scisso tra il cielo e la terra $\mathrm{e}$

fronte cupa la tristezza scaccia, / perché sei oltre lei, al di là / della paura, della speranza. / Al capezzale s'inchina l'aurora / in chiare, funebri candele.'

33 In una lirica precedente (ivi: 57) l'io lirico aveva esclamato: 'O порожнечо душ / і порожнечо життєіснування / на півдороги між життям і смертю” ('O vuoti delle anime / e vuoto dell'esistenza-della-vita / a metà strada tra vita e morte').

34 Ivi: 73. 'Ed è così che mi oscurò il lavoro, / e mi ha portato via la forza giovane, / e tutto l'universo ha reso un tavolo, / dove scrivere, con solo carta e penna. / [...] / [...] sin dall'infanzia volevo vivere, / falciare il fieno, piantar le piante, / scavar patate, dal tetto di casa / togliere la neve, sotto le stelle / di notte vagare solo, ridando / me stesso a me stesso - tra la terra / e il cielo. E non ho saputo. Perdonami, / poesia, tu che separi e che sai predire.' 
dunque condannato alla sofferenza. Impossibilitato a trovare se stesso, costretto a un infinito, solipsistico cammino interiore, il soggetto riconosce il potere distruttivo della poesia nei confronti della sua appartenenza al genere umano, fino ad arrendersi all'inevitabilità della propria inguaribile dipendenza dalla poesia stessa. Se nei primi versi della lirica la stessa esistenza dell'io sembra annullata dalla poesia, la sua esistenza e la sua unitarietà risultano indirettamente ribadite nella parte finale. Nell'immagine della camminata solitaria del soggetto alla ricerca di se stesso è possibile ipotizzare un richiamo alla conclusione della rilkiana Elegie an Marina Zwetajewa-Efron:

Auch in abnehmender Frist, auch in den Wochen der Wendung niemand verhülfe uns je wieder zum Vollsein, als der einsame eigene Gang über der schlaflosen Landschaft ${ }^{35}$.

La possibilità del raggiungimento della pienezza del sé, evocata e auspicata nell' "undicesima" elegia rilkiana (cfr. Por 2009), è (postmodernamente) negata in [I zastupyla het' mene robota].

È interessante osservare, a questo proposito, come la stessa tematica sia rivisitata e modificata in una lirica posteriore di circa tre settimane:
[...] Не смій померти! Стань перед кінцем
цього кривавого прокляття - долі.
Наприостанку в себе повернись,
щоб провернуть немилосердне лезо
оцих напасте-злигодне-поезій,
а вже тоді - хоч і за вітром війсь ${ }^{36}$.

In un impeto di volontà di autoconservazione, il soggetto percepisce la paradossale necessità di ribellarsi alla poesia, sottraendosi alla sua infausta onnipotenza. Solo così, apparentemente, egli potrà finalmente ritornare a se stesso, ritrovando quell'umanità perduta dopo aver scelto di dedicarsi esclusivamente alla parola.

La complessità della raffigurazione spaziale dell'imprevedibile percorso del poeta $^{37}$ è tematizzata in una delle liriche successive:

35 Rilke 1996: II, 404-405. 'Anche nel tempo cadente, anche se viene la svolta / nulla ci porta ad esser completi / come andare da soli sulla terra che è insonne.' Le stelle del solitario paesaggio stusiano si ritrovano nei versi di apertura dell'elegia rilkiana. Cfr. ibidem: "O Die Verluste ins all, Marina, die stürzenden Sterne! / Wir vermehren es nicht, wohin wir uns werfen, zu welchem Sterne hinzu!" 'O il perder nel tutto, Marina, le stelle cadenti! / Ché non l'aumentiamo, se anche ci lanciamo, qualunque sia la stella!'

36 ZT III, 96. 'Non osar morire! Ergiti di fronte alla fine / del sanguinoso male che è il destino. / Ritorna alla fine a te stesso, / per rivoltare l'impietosa lama / di queste disgrazie-sventure-poesie, / e allora, poi, puoi pur volar nel vento.'

37 Si pensi ancora a Poety di Marina Cvetaeva. 
І враз він уривається — твій шлях, де таємничі злети і падіння.

Це дивна смерть зоветься воскресінням, лиш хай життя обернеться на прах.

Знекрилений, ти чуєш дужий змах крила — і закипіла прірва синя!

Який високий злет! Яке падіння!

Не доберу, що захват, а що жах.

$\mathrm{Hi}$, він не уривається. Дарма.

$[\ldots]^{38}$

La natura del cammino che il soggetto ha intrapreso, e che è condannato a non poter abbandonare, sembra tradursi nel superamento dei contrari che regolano la consueta logica umana. Esso è dunque radicalmente opposto all'esistenza terrena nella sua accezione tradizionale. Le dinamiche spaziali solo apparentemente contrapposte dell'innalzamento e della caduta si rivelano coincidenti. Alla vittoria sulla spazialità corrisponde la perdita della distinzione tra entusiasmo e terrore e l'ingresso nella sfera del sublime. La morte altro non è che la resurrezione e la mancanza di ali non compromette la possibilità di un volo nell'abisso celeste. Nel contesto poetologico della raccolta nel suo insieme, a proposito della necessità per il soggetto di farsi cenere è ipotizzabile un riferimento a Balkon, una lirica cvetaeviana del 1922 (Cvetaeva 2004: 554):
Ах, с откровенного отвеса -
Вниз - чтобы в прах и в смоль!
Земной любови недовесок
Слезой солить - доколь?
Балкон. Сквозь сонные ливни
Смоль поцелуев злых.
И ненависти неизбывной
Вздох: выдышаться в стих!
$[\ldots]$

Rispetto al presunto ipotesto cvetaeviano, a [I vraz vin uryvajet'sja - tvij šljach], come alla poesia stusiana in generale, è tendenzialmente estraneo il motivo del rifiuto dell'amore terreno, drammaticamente centrale all'universo poetico dell'autrice di Posle Rossii. Comune ai due testi è, invece, l'invocazione della "morte-nella-poesia" come abbandono della terrestrità. In entrambi le ceneri (prach) simbolizzano l'agognata condizione del poeta libero dalle costrizioni della corporalità e della razionalità.

38 ZT III, 109. 'E si spezza all'improvviso - il tuo cammino, / di misteriosi voli e cadute. / Questa strana morte è resurrezione, / ché la vita si risolva in polvere. / Di ali privato, senti il forte slancio / dell'ala - e si agita l'abisso blu! / Che volo in alto! E che caduta! / Che cosa è impeto? Cos'è terrore? / No, non si interrompe. È tutto invano. / $[\ldots]$ ' 
I motivi di [I vraz vin uryvajet’sja - tvij šljach] vengono ripresi tre giorni più tardi in una lirica molto simile, con una maggiore accentuazione del significato poetologico della morte:

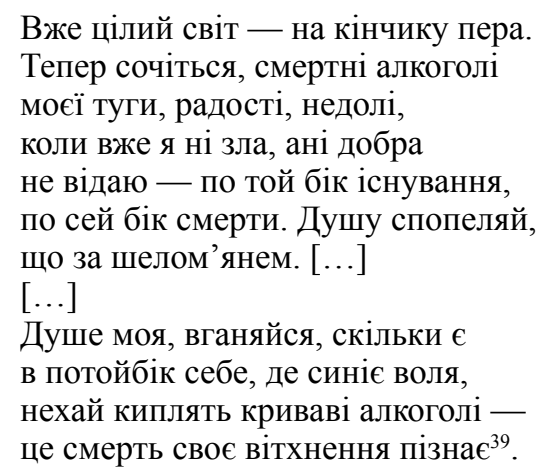

Nella morte provocata dall'abbandono all'ispirazione poetica, l'esistenza terrena e l'esistenza ultraterrena cessano di trovarsi in opposizione, così come il bene e il male dell'etica consueta. La componente ultraterrena della realtà ontica/ ontologica del poeta, tuttavia, sembra avere il sopravvento sui resti di terrestrità che ancora caratterizzano il soggetto. L'anima brucia, mettendosi così in grado di raggiungere la piena libertà, possibile solamente nell'azzurro dell'aldilà. Nel testo, profondamente segnato da una imagery di natura espressionista, è dunque presente un'evidente contraddizione tra l'annunciato superamento dell'opposizione tra i due regni dell'esistenza e la successiva invocazione della realtà ultraterrena. Questo apparente smottamento semantico altro non è, a un livello più profondo di lettura, che una realizzazione metapoetica delle possibilità conoscitive della poesia stessa, capace di superare le anguste limitazioni del linguaggio e della logica umana.

Che il cammino in questione sia un cammino "del cuore" è esplicitato da una lirica composta tre giorni più tardi:
Дороги серця - як дороги долі, що заступили всі земні путі.
Тепер буремній укорись сваволі, котра провадить у новім житті, де почезають всі орієнтири, де тільки небо, і земля, і ти.
Тепер своїм дерзанням освяти,

39 ZT III, 116. 'Il mondo - sulla punta della penna. / Adesso sgorga, alcool mortale, / della tristezza, gioia, malasorte, / già più non conosco né il bene, né il male - / dall'altra parte dell'esistenza, / da questa parte della morte. L'anima / brucia, già oltre all'altura. $[\ldots] /[\ldots]$ / Anima mia, in corsa, finché / c'è di te nell'aldilà, dov'è blu / la libertà, ribolla l'alcool rosso - / la morte conosce la sua ispirazione.' Stus sembra trarre la parola šelom ’ja (altura, collina), non riportata dai dizionari della lingua ucraina, dallo Slovo o polku Igoreve (cfr. Olifirenko 2003: 85). 


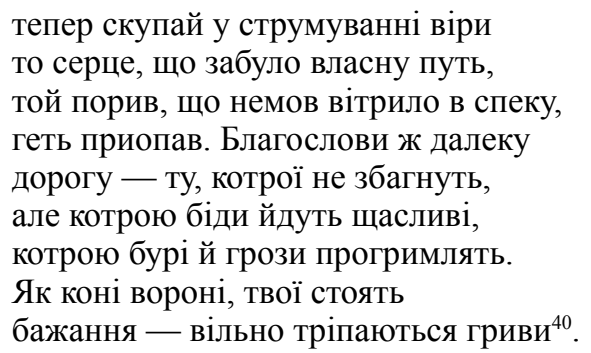

La palingenesi dell'io è frutto dell'abbandono alla volontà del cuore. Quest'ultima è dapprima posta in opposizione alla terra e alle sue strade, per poi ritrovarsi in sintonia con essa. Ricollegandosi ancora esplicitamente a una tradizione cardiocentrica in cui confluiscono i più importanti modelli poetici di Stus, questi versi mostrano la tensione dell'io lirico stusiano verso un'ulteriore epoché della razionalità. Il tumultuoso cammino lungo le vie del cuore, tuttavia, sembra inaspettatamente preludere a una riconciliazione delle sfere del dionisiaco e dell'apollineo, così come della terra e del cielo. Nella vita nova della poesia, il soggetto, ontologicamente scisso tra i due opposti poli, potrebbe ritrovarsi in una rinnovata sintonia con entrambi. L'utopia di un mondo coincidente con il cuore, al centro di questa lirica, si configura nell'universo poetico stusiano al fianco e alla pari del suo contrario, la constatazione dell'impossibilità di giungere alla conclusione del percorso e di spezzare le catene che legano il soggetto alla disperazione e alla sua causa primaria, la razionalità. Il motivo del cuore, già ampiamente rappresentato nelle liriche e nelle raccolte giovanili, si conferma dunque fondamentale anche nelle opere della maturità.

In una poesia dell'inizio di aprile, dunque più tarda di circa due settimane, in sintonia con la metafora teatrale di Veselyj cvyntar, il cuore risulta il "protagonista del dramma infinito" della tragedia in cui è coinvolto l'io lirico:
$[\ldots]$
Народжений, щоб стати за офіру оцій недовідомості смеркальній, ти знаеш: дійова особа - серце в цій героїчній драмі без кінця ${ }^{41}$.

40 Ivi: 122 . 'Le strade del cuore - come il destino, / le vie della terra hanno bloccato. / Piegati ora all'arbitrio furente, / che ti conduce in una vita nuova, / dove più non son riferimenti, / c'è solo il cielo, la terra e tu. / Santifica ora col tuo osare, / bagna nello scorrer della fede / il cuore, dimentico del cammino, / l'impeto, come vela nell'arsura / caduta giù. Benedici la strada / distante - che non si può comprendere, / su cui van felici le disgrazie, / su cui rimbombano tempeste e tuoni. / Come cavalli neri stanno i tuoi / desideri - liberi strappano le briglie.'

41 Ivi: 138. '[...] / Nato, per diventare vittima / dell'oscuro incomprensibil, / sai: personaggio è il cuore / in questo dramma eroico senza fine.' 
Lo stesso tema è ripreso in una lirica non datata, presumibilmente risalente alla settimana successiva:

Планета серця, трагедійний зал опукою підноситься в узвишшя. $[\ldots]^{42}$

Principale interlocutore di Stus in questi versi è la quarta delle Duineser Elegien rilkiane:

Wer saß nicht bang vor seines Herzens Vorhang?

Der schlug sich auf: die Szenerie war Abschied.

$[\ldots]$

Ich bleib dennoch. Es giebt immer Zuschaun ${ }^{43}$.

La scissione dell'io e della sua conoscenza auto-speculativa, fondamentale nell'universo poetico stusiano, giunge qui al suo culmine. Il carattere infinito dello spettacolo del cuore nei versi del poeta ucraino trova piena corrispondenza nell'ipotesto rilkiano.

Nel distico conclusivo di una lirica della fine di maggio si assiste invece a un allargamento dello spazio cardiaco dal mondo interiore dell'io lirico, chiaramente connotato come poeta, all' "uomo" in generale:

[...] Бо простір серця

людині визначено 3 правіків ${ }^{44}$.

Come nella poesia pasternakiana, anche nell'universo poetico di Stus si assiste, infatti, a un'incerta e variabile definizione dello status ontologico del poeta. Più spesso quest'ultimo è distinto dall'uomo, superiore, dotato di capacità e peculiarità precluse agli esseri umani. Meno frequentemente, come in questo caso e nella prosa di Dvoje sliv čytačevi, il dono del poeta, identificabile con il cuore stesso, sembra essere accessibile a chiunque voglia e sappia accoglierlo.

La rinascita del soggetto a una vita autentica, ovvero il compimento del cammino assegnatogli dalla sorte, può trovarsi a coincidere con l'abbandono della terra:

[...] Мені відкрилася галактична бездна.

Я ж зорянею штольнею лечу

i, вигоряючи, свій шлях значу,

хоч згадую тебе - i серцем мерзну.

'У тебе в надрах визріває безум,

42 Ivi: 152 . 'Pianeta del cuore, la sala tragedie / al volo si solleva sull'altura. / [...]'

43 Rilke 1996: II, 211. 'Che non siede con pena alle quinte del cuore? / Si sono aperte: la scena è il congedo. / [...] / Ma rimango. C'è sempre da guardare.' Nelle lettere ai familiari degli ultimi anni Stus avrebbe richiesto con insistenza l'invio del testo di questa elegia, evidentemente molto vicina alla sua sensibilità.

${ }^{44}$ ZT III, 213. '[...] Perché lo spazio del cuore / all'uomo è dato da secoli.' 
о земле-мамо!' - скільки сил кричу.

I тут, як Фенікс, що зродився з пеплу, мені душа вертається із пекла ${ }^{45}$.

La distruzione dell'io, inevitabile conseguenza della sua fuga dalla terra, si rivela premessa alla sua rigenerazione. Il distacco dalla realtà terrestre di un soggetto in grado di riconoscere un percorso nello spazio apparentemente terrificante della realtà stellare è motivato dalla follia della terra stessa, madre, o meglio matrigna, sia del poeta, che della pazzia. Quest'ultima, infatti, è raffigurata come un feto in sviluppo nelle viscere della terra.

In una lirica composta solamente tre giorni dopo, al contrario, non sembra esserci alcuna distinzione tra la realtà terrestre e la realtà stellare:

Усе - у народженні, усе - у плоті й крові.

Долає смерть одне живе життя.

Те, що колись, поставши із любови, ані про спин, ані про вороття не відає. Оновлення планети у смерті смерті, в радості чинінь.

Отак і ти постанеш, знов, поете, 3 майбутнього високих благостинь, коли навчишся бачити і любити, радити веснам, першому зелу. Лише збагни, людина - небожитель, не відданий ані добру, ані злу, лише живому — тому, що у русі шукає, прагне, твориться, кишить. Квітуй же сподіванням, бо в окрузі усе запрагло тлін свій пережить, аби себе подовжити у леті годин, зірок, галактик і систем. Благословенна ж будь, моя плането, благословенний серця вічний щем, благословенні зорі над водою, і райдужне суцвіття по дощі, і кроплене живлющою росою бажання невгамовної душі, і усміх матері, і плач дитини, і птахи вільної високий лет, бо існування зоряні години підносять нас угору і вперед ${ }^{46}$.

45 Ivi: 126. 'Mi si è aperto un abisso galattico. / Volo in un cunicolo di stelle / e, bruciando, segno il mio cammino, / anche se ti ricordo - e gela il cuore. / 'Matura in te la tua follia, / oh terra-mamma!' - grido a piena voce. / Come la Fenice, rinata dalla cenere, / l'anima mia ritorna dall'inferno.'

46 Ivi: 132. 'Tutto è nella nascita, nel sangue e nella carne. / È solo la vita a vincer la morte. / Ciò che un tempo, venendo dall'amore, / né delle soste, né dei ritorni. / sa. La 
La capacità di comprendere l'esistenza e l'esistente nella totalità delle sue apparenti contraddizioni è la chiave dell'immortalità. Come nella poesia filosofica del tardo Rilke e nel tardo Pasternak, soprattutto in Doktor Z Zivago ${ }^{47}$, non c'è distinzione tra la vita e la morte. La vita stessa, se vissuta come essa merita, come attuazione del cammino che a ciascuno è assegnato, priva la morte del suo potere distruttivo. Tra il microcosmo dell'uomo e il macrocosmo della terra non vi è, allo stesso modo, alcuna differenza. Il rinnovamento spirituale del singolo è preludio e realizzazione del "rinnovamento del pianeta" nella sua interezza. Anche questi versi, tuttavia, pongono al lettore lo stesso dilemma già incontrato a più riprese in Čas tvorčosti / Dichtenzseit: chi è l'io lirico? Chi è oggetto e soggetto della sua meditazione e dei suoi ammonimenti? Al settimo verso l'invito di chiara matrice rilkiana a imparare a vedere e ad amare ${ }^{48}$, è rivolto dall'io lirico al poeta, dunque, primariamente, a se stesso. Quattro versi più tardi, al contrario, è la persona tout court a essere identificata con un abitante del cielo, in una realtà in cui ogni distinzione tra il mondo celeste e il mondo terrestre

rinascita del pianeta - / la morte della morte, la gioia delle azioni. / E ti ergerai di nuovo tu, poeta, / dal futuro delle alte grazie, / quando imparerai a vedere e amare, / le primavere, il primo verde. / Comprendi: l'uomo abita il cielo, / né al bene, né al male è legato, / ma a ciò che è vivo, a ciò che è in movimento, / che cerca, vuole, crea e ribolle. / Fiorisci di speranza, intorno a te / tutto vuol superare la cenere, / per prolungare se stessi nel volo / di ore, stelle, galassie e sistemi. / Sii benedetto, mio pianeta, / benedetto l'eterno dolore del cuore, / benedette le stelle sull'acqua, / e, di vivida rugiada bagnato, / il desiderio dell'anima non paga, / il sorriso della madre, il pianto del bambino, / l'alto volo dell'uccello libero, / perché le ore stellari della vita / ci elevano nell'alto, ci elevano in avanti.'

47 Si pensi alle pagine dedicate all'approssimarsi della morte di Anna Ivanovna e alle riflessioni che da questo scaturiscono in Jurij Živago, fondamentali non da ultimo per la definizione della sua filosofia dell'arte: Pasternak 2003-2005: IV, 69: "Не о чем беспокоиться. Смерти нет. Смерть не по нашей части. А вот вы сказали: талант, это другое дело, это наше, это открыто нам. А талант - в высшем широчайшем понятии есть дар жизни. Смерти не будет, говорит Иоанн Богослов, и вы послушайте простоту его аргументации. Смерти не будет, потому что прежнее прошло. Это почти так: смерти не будет, потому что это видали, это старо и надоело, а теперь требуется новое, а новое есть жизнь вечная.” Cfr. anche ivi: 91: “Сейчас как никогда ему было ясно, что искусство всегда, не переставая, занято двумя вещами. Оно неотступно размышляет о смерти и неотступно творит этим жизнь. Большое, истинное искусство, то, которое называется Откровением Иоанна, и то, которое его дописывает."

48 Si ricordi uno dei più noti brani del romanzo rilkiano Die Aufzeichnungen des Malte Laurids Brigge (I quaderni di Malte Laurids Brigge), in: Rilke 1996: III, 456: "Ich lerne sehen. Ich weiß nicht, woran es liegt, es geht alles tiefer in mich ein und bleibt nicht an der Stelle stehen, wo es sonst immer zu Ende war. Ich habe ein Inneres, von dem ich nicht wußte. Alles geht jetzt dorthin. Ich weiß nicht, was dort geschieht." 'Imparo a vedere. Non so da cosa dipenda, ma sento che tutto mi entra nel profondo, che tutto si muove dentro di me, mentre prima, invece, le cose si fermavano in un determinato punto e rimanevano lì. Ho un mondo interiore che ignoravo. Va a finire tutto lì. Non so bene che cosa vi succeda.' 
è annullata. In conformità con i modelli di Rilke e Pasternak, l'oscillazione tra l'umanizzazione della figura del poeta e il distacco dal genere umano a essa contrapposto si conferma nuovamente un tratto fondamentale dell'universo poetico stusiano maturo. Non meno significativa, a proposito del dialogo di Stus con gli artisti che lo hanno maggiormente interessato e influenzato, è la questione del ruolo del fattore esterno della grazia nella palingenesi del soggetto. In [Use - v narodženni, use - u ploti j krovi] il superamento da parte dell'io dello stato di stallo spirituale precedente alla rigenerazione sembra essere consentito unicamente da un'illuminazione divina proveniente dall'alto. Nel modello rilkiano a cui sembra riferirsi il nono verso, al contrario, la spinta dapprima a imparare a vedere, per poi saper amare, è interamente frutto della volontà del soggetto. È invece il sostrato pasternakiano a mostrarsi di primaria importanza nella descrizione della terra che il soggetto deve imparare ad amare. L'immagine di un mondo in continua metamorfosi, letteralmente brulicante di vita, è riconducibile all'immaginario di Sestra moja - žizn'. Anche nella descrizione del proprio rapporto con la terra, tuttavia, l'io lirico di [Use - v narodženni, use - u ploti $j$ krovi] mostra le profonde contraddizioni insite nella sua dichiarazione di amore per le cose della terra. Nell'inno al creato che conclude la lirica si assiste infatti a un'interessante dinamica spaziale, segnata da un'iniziale catabasi dalle stelle alla terra, mediante una pioggia ancora di inconfondibile pasternakiana memoria, a sua volta seguita da una nuova anabasi verso le stelle. Quest'ultima era stata anticipata dal "libero volo dell'uccello", elemento fondamentale dell'immaginario di Rilke dalla poesia degli anni Dieci ai capolavori degli anni Venti. L'ultimo verso di [Use - v narodženni, use - u ploti $j$ krovi] ribadisce così il motivo cvetaeviano della fuga dalla terra, predominante in Ćas tvorčosti / Dichtenszeit. In questa lirica, tuttavia, la lode della terra viene postulata come conditio sine qua non della possibilità di un suo successivo abbandono verso le stelle, verso quel cielo che dell'uomo (o solamente del poeta?) è la vera patria.

In una lirica della fine di maggio, più tarda dunque di circa due mesi, si assiste a un completo ribaltamento della prospettiva di [Use - v narodženni, use $-u$ ploti $j$ krovi], accompagnato dal recupero di alcuni importanti elementi dell' $i$ magery del testo appena analizzato:

Дорога самовтечі, непідвладна моїм бажанням, рине, як вода.

I я спливаю не за течією, але всупір — неначе в горловину пролитих криків. Ніби повертаюсь до давнього народження (моє перейдене життя - то простір смерті).

Протипотік - запраг гори, як горя без світу, спогадів і навіть снів. Я ніби закоркований. Неначе лиш улягаю силі рабування і самознищую буремний дух. Малію, обертаючись на тугу, 
пряму, як смерть, і чорну, ніби смерть.

Пролита цятка болю, я шукаю

утраченої грудки самосну,

іще не розпочатої. I марно:

бо ж самопроминання - твій преділ ${ }^{49}$.

L'acqua, che in [Use - v narodženni, use - u ploti j krovi] santificava e rivitalizzava i desideri dell'anima, è qui accostata alla strada che porta alla perdita di sé, opposta agli stessi desideri. La rinascita non è più rigenerazione, ma riproposizione di una vita che è morte. Ogni speranza di una vittoria su quest'ultima è negata dalla sua onnipresenza. Il movimento è negato al soggetto, "tappato" nella schiavitù dell'autodistruzione. Non c'è possibilità di ascesa al cielo, come lascia presumere l'accostamento della montagna al dolore (“"запраг гори, як гоpя"), di origine ševčenkiana e cvetaeviana ${ }^{50}$, sulla base della paronomasia tra i due termini in ucraino, così come in russo. La trasformazione dell'io in un "grumo", già presente nella poesia giovanile e destinato a rimpicciolirsi ulteriormente, si accompagna al recupero della sensibilità espressionista.

La disposizione del soggetto in uno spazio astratto, centrale agli ultimi testi analizzati, si alterna in Čas tvorčosti / Dichtenszeit alla sua rappresentazione tra le quattro mura della cella carceraria, già discussa a proposito della lirica iniziale:

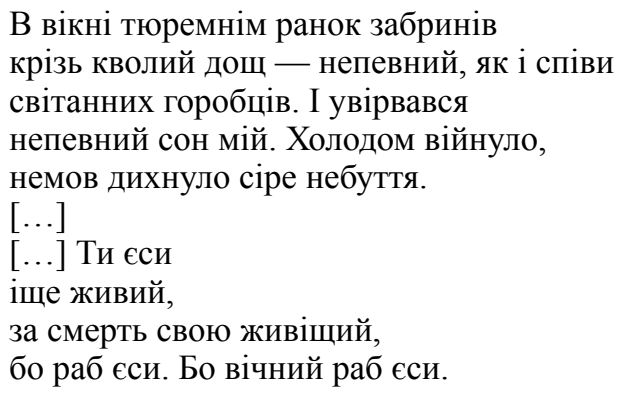

49 ZT III, 195. 'Strada della fuga di sé, non risponde / ai miei desideri, scorre come l'acqua. / E io navigo per la corrente, / ma contro - come in una gola / di grida rovesciate. Come tornassi / alla vecchia nascita (la mia / vita trascorsa - è spazio di morte). / Controcorrente - voglia di montagna, di dolore - / senza luce, ricordi, neanche sogni. / Sono come tappato. Come solo / alle catene sottomesso, / distruggendo il mio spirito in tumulto. / Mi faccio piccolo, divento tristezza, / dritta come morte, nera come morte. / Un segno di dolore alla ricerca / del grumo perduto del sogno-di-sé, / non ancora iniziato. E invano: / perché lo sfuggirti - è il tuo destino.'

50 Si veda dal poemetto Kavkaz, in: Ševčenko 2003: 343: “За горами гори, хмарою повиті, / Засіяні горем, кровію политі” (Brogi, Pachlovksa 2015: 227: "Monti su monti nelle nuvole avvolti, / Seminati di dolore, di sangue irrorati') e dall'incipit del Poema gory, in: Cvetaeva 1997-1998: III.1, 60: “Вздрогнешь — и горы с плеч, / И душа - горе́. / Дай мне о го́ре спеть: / О моей горе́!,” nonché dalla conclusione della seconda lirica del già citato trittico Sivilla, in: Cvetaeva 2004: 562: “Горе горе́! Под тольщей / Век, в прозорливых тьмах / Глиняные осколки / Царств и дорожный прах.” 
Життя і смерть лежать на рівновагих спокійних шалях - тільки доторкнися куди захочеш - i неспокій серця вгадає стежку — вгору ачи вниз. $[\ldots]^{51}$

Fondamentale per l'ispirazione alla base di questi versi si rivela nuovamente un linguaggio di matrice esistenzialista. Il freddo che colpisce l'io lirico dalla finestra è infatti assimilato a un "grigio non-essere", probabilmente memore del néant sartriano, imprescindibile dall'esistenza umana nel suo complesso. Alla filosofia di L'être et le néant è altresì riconducibile la quartina finale, incentrata sulla scelta di vita che il cuore inquieto dell'io lirico si appresta a compiere. Il motivo esistenzialista, eminentemente sartriano della schiavitù dell'uomo dalla libertà è qui tradotto spazialmente nei termini della dinamica ora di contrapposizione, ora di fusione tra le sfere dell'alto e del basso tipiche dell'immaginario della raccolta.

Più distante dal modello sartriano sembra invece essere la riflessione sulla vita e la morte. Se nella sua summa filosofica l'autore de La nausée, contrapponendosi esplicitamente al sistema di pensiero heideggeriano e a Rilke, rifiuta nettamente l'idea della morte come suprema realizzazione del progetto del singolo, il soggetto stusiano si raffigura in questi versi nell'atto di soppesare due opzioni della stessa portata. Si tenga ben presente, tuttavia, che i concetti di vita e morte, all'interno di un sistema prettamente lirico e non filosofico come quello dell'arte di Stus, sono naturalmente complementari, altamente contraddittori e passibili di continui smottamenti semantici, rivalutazioni e ripensamenti. Degno di nota nel contesto dell'interpretazione di questa lirica è evidente l'utilizzo poetico di termini e motivi della filosofia esistenzialista, a testimonianza del continuo interesse di Stus per questa pagina della storia culturale europea, piuttosto che di una loro improbabile riproposizione in termini di coerenza e sistematicità concettuale.

In una lirica dell'inizio di maggio i motivi dell'attesa e della libertà, anch'essi di origine esistenzialista, sono connessi all'onnipresente tematica poetologica:

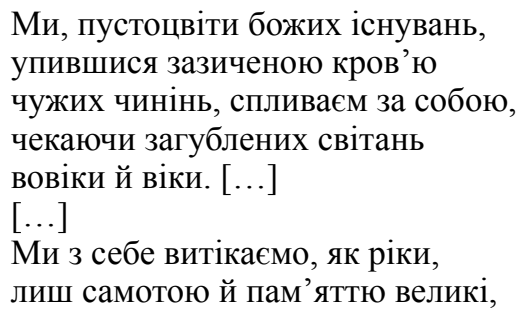

51 ZT III, 208. 'Nella finestra del carcere il mattino risuona, / tra la pioggia esile - incerto, come i canti / dei passeri all'alba. E si è spezzato/ l'incerto sogno mio. Tirava aria fredda, / come soffiasse grigio il nulla. / [...] / [... Sei / ancora vivo, più della tua morte, / perché sei schiavo. Sei eterno schiavo. / Vita e morte hanno lo stesso peso, / giacciono tranquille - puoi toccarle - / dove vuoi - e l'inquietudine del cuore / indovinerà il sentiero - verso l'alto o verso il basso. / [...]' 
встромляємось між скелями двома, аби ріка пливла, а ми стояли і несобою самострумували.

Поезіє, покаро із покар, моєї волі вікова в'язнице! $[\ldots]^{52}$.

Il primo e principale problema nell'interpretazione globale della lirica è posto, ancora una volta, dal pronome personale con cui essa si apre. Se la lettura dei soli primi versi potrebbe indurre a un'identificazione del "noi" con la comunità degli esseri umani in generale, la seconda parte del testo spinge a propendere per un approccio poetologico. In netta opposizione all'esaltazione della figura del poeta al centro di diverse liriche della raccolta, [My, pustocvity božych isnuvan'] presenta i poeti come turgeneviani "uomini superflui", sì caratterizzati da un'origine divina, ma sterili, improduttivi, condannati all'inanità. Particolare rilievo spetta alla dipendenza del poeta da modelli esterni. La storia della poesia si viene così a configurare come un meccanismo autotelico basato sulla continua ripetizione da parte di vampiri assettati del sangue dei loro predecessori, a loro volta assassini dei poeti che li hanno preceduti. La letteratura come palinsesto è dunque sottoposta a un'impietosa (auto)critica. Il fare poesia è posto in contrapposizione alla libertà, in quanto incontrastabile dipendenza da un sistema pre-esistente e ineludibile. Essa è la negazione dell'azione, della possibilità di un cambiamento in sé e nel mondo circostante. Per questo motivo la poesia è cella carceraria, venendo così a coincidere, nel contesto della raccolta, con la realtà dell'io lirico nel suo complesso.

Due liriche di pochi giorni più tarde si ricollegano, in modo diverso, al tema di [My, pustocvity božych isnuvan']. Nella prima di esse il soggetto esorta se stesso a un paradossale abbandono del percorso poetico:
Рушай убік, де справжній край душі,
де ще нема ні стежки, ані сліду.
Себе самого обійди, сновидо,
і мерву спогадів розворуши.
[...]
Як тяжко, вік навчаючись, не вміти
знайти між плетива правдивий шлях!
Куди спроваджує тебе політ -
нерозпізнаний, та грудний і рідний?
Коли впаду я, тихий і погідний,
і в смерті скрем'янію на граніт ${ }^{53}$.

52 Ivi: 229. 'Noi, sterili fiori di vite divine, / ebbri di sangue preso in prestito, / di azioni altrui, nuotiamo dietro a noi, / aspettando le perdute aurore / nei secoli dei secoli. [...] / [...] / Sgorghiamo da noi stessi, come fiumi, / solo di solitudine e memoria grandi, / infiliamo noi stessi tra due rocce, / così che il fiume scorra e noi restiamo / e scorriamo di noi non con noi stessi. / Poesia, castigo dei castighi, / della mia libertà cella secolare! / [...]'

53 Ivi: 233. 'Spostati a lato, nel vero regno dell'anima, / ove non vi sono né tracce, né sentieri. / Devia da te stesso, tu sonnambulo, / smuovi la paglia dei ricordi. / [...] / 
La possibilità di ritrovare "il vero regno dell'anima" è connessa all'abbandono del sentiero dato, ovvero della poesia, impensabile al di fuori del solco della tradizione. Per poter riconquistare se stesso il poeta-sonnambulo è costretto a fuoriuscire da sé, dal proprio essere interamente soggiogato dalla poesia, per perseguire il ricordo messo a tacere. Il nuovo sentiero, l'autentico cammino di un io slegato dalla servitù della parola, tuttavia, si rivela mortale. Il motivo del volo è qui rivalutato 'negativamente'. Da metafora dell'estasi poetica esso si trasforma nel suo contrario, assumendo una nuova connotazione mortifera. Non sembra esserci via d'uscita per un soggetto condannato alla poesia. La fedeltà nei suoi confronti equivale a un'eterna reclusione, mentre una vittoria su di essa equivale alla morte. Il motivo poeto-tanatologico svidzins'kiano e cvetaeviano del granito ${ }^{54}$, con il quale si conclude [Rušaj ubik, de spravžnij kraj duši], ritorna nella medesima posizione, ma con un significato ben diverso, nell'altra lirica in questione:

\author{
[...] Покам'янила віку струмування \\ припливів і відпливів череда. \\ Така пустеля опадає світ, \\ умовклий, перетлілий і оспалий, \\ і лиш рядки, що на папері стали, \\ карбують день-у-день твердий граніт ${ }^{55}$.
}

Non è da escludere che i primi due versi citati si ricolleghino al motivo (bloomiano) della tradizione letteraria e della fatale dipendenza del soggetto poeta

Duro è dopo lungo studio non saper / trovar la retta via tra i garbugli! / Dove ti sta portando il volo - / non conosciuto, ma vicino e tuo? / Dove cadrò, tranquillo e silenzioso, / impietrito nella morte sul granito?'

$54 \mathrm{Si}$ veda da [Nastane den' mij sumnyj] ([Giungerà il giorno mio triste]) in: Svidzins'kyj 2004: I, 109: “І погаснеш для мене / Ти, пристрасний світе, / Ненадивляний світе, / Бурхотливий, п’янкий. / Не буду як лист деревний, / Нi як травинка, позбавлена слова, / А буду як сонний граніт / Над гомоном вод неспокійних. / Замкнуся в мовчанні важкім. / Зіллюся з невиразною мислю / В великім усім... / Буду як сонний граніт.” 'E ti spegnerai per me, / O mondo di passioni, / O mondo che non ho ammirato fino in fondo, / fragoroso e inebriante. / Non sarò come la foglia di un albero, / Né come il filo d'erba privo di parola, / Ma come il granito che dorme / Sul brusio delle acque irrequiete. / Mi chiuderò in un silenzio pesante. / Mi fonderò con un pensiero non detto / Nel grande tutto... / Sarò come il granito che dorme'. Per quanto riguarda il possibile sostrato cvetaeviano, si pensi ancora a Balkon, già discussa a proposito di [I vraz vin uryvajet’sja - tvij šljach]: “[...] И ненависти неизбывной / Вздох: Выдышаться в стих! // [...] // Дабы с гранитного надбровья / Взмыв - выдышаться в смерть!" Il motivo del granito è significativo, con un'ampia gamma di connotazioni, anche negli universi poetici di altri scrittori importanti per il palinsesto letterario stusiano, come, tra gli altri, Ivan Franko, Osip Mandel'štam e lo stesso Pasternak.

55 ZT III, 235. '[...] Ha impietrito la corrente del secolo / la serie di maree alte e basse. / Questo deserto assedia il mondo, / ammutolito, incenerito, apatico / e solo i versi, erti sulla carta, / il granito incidono di giorno in giorno.' 
da essa, come sembrerebbe indicare il recupero dell'imagery legata all'acqua. Tuttavia, il dono poetico è qui rivalutato come unica possibilità di espressione, e dunque di affermazione dell'io in un mondo irrigidito. L'incisione dei versi sulla dura pietra di quest'ultimo si contrappone al silenzio dilagante, all'inaridimento di un universo spersonalizzato. L'insistenza del soggetto sulla quotidianità della scrittura rispecchia metapoeticamente la composizione di Čas tvorčosti / Dichtenszeit, come si è visto, l'unica raccolta stusiana a poter esser accostata, sia pure con grande prudenza, al genere della lirica diaristica.

La sfera semantica del liquido ritorna nelle due liriche successive nuovamente in riferimento alla morte:

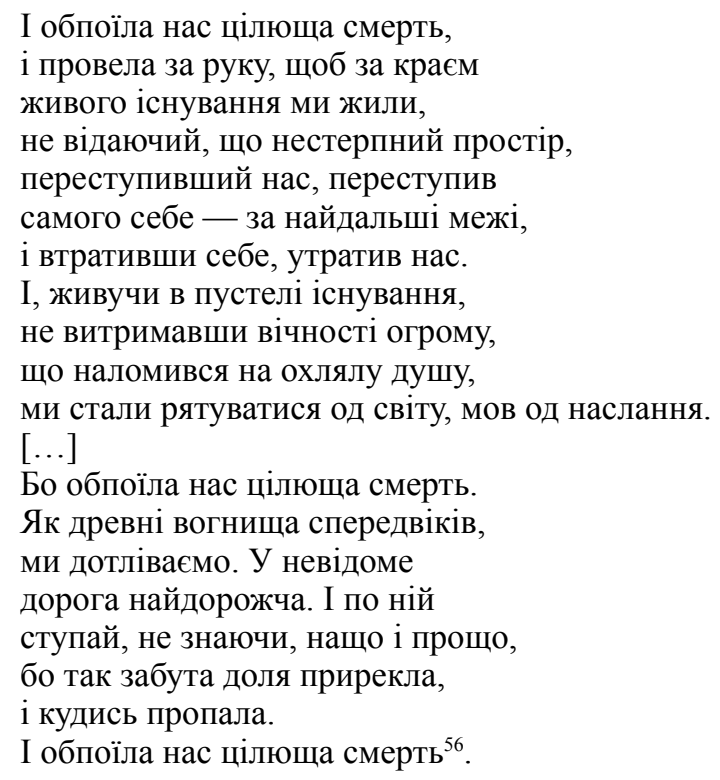

In un universo paradossale, in cui la morte appare ai viventi come speranza di vita, l'inebriante pozione che essa offre non è sufficiente per salvare gli uomini dalla forza distruttiva della vita. L'eternità, non più salvezza dalla fugacità e dalla provvisorietà dell'esistenza sulla terra, si è fatta oppressione. L'anima, ridotta a un'esile carcassa, è costretta a una vana fuga dal mondo nella speranza di sfug-

56 Ivi: 236 ' $E$ ci ha ubriacati la morte che rigenera, / e ci ha presi per mano, per vivere / oltre al limite dell' esistenza viva, / non sapendo che, insopportabile, / lo spazio, passatici, aveva passato / se stesso - oltre i confini più estremi / e, perdutosi, aveva perso noi. / E, vivi nel deserto dell'esistere, / non sopportando la massa dell'eterno, / infrantosi sull'anima insecchita, / iniziammo a salvarci dal mondo, / come dal maligno. / [...] / E ci ha ubriacati la morte che rigenera. / Come antichi roghi secolari / finiamo di bruciare. Nell'ignoto / la strada più cara. E lungo di essa / vai, non sapendo perché e percome, / perché così predisse la sorte obliata, / e si pronunciò e scomparve. / E ci ha ubriacati la morte che rigenera.' 
gire a se stessa. La strada che conduce lontano dal mondo, dal "deserto dell'esistenza", è una strada verso l'ignoto, lungo la quale il soggetto sembra essere accompagnato dalla morte e dalla bevanda inebriante e curativa che essa gli offre.

Nella lirica seguente, intitolata Na nezabud' - družyni ('Per non dimenticare alla moglie') la coppa mortale viene promessa anche alla compagna dell'io lirico:

Зустрінемося нині уночі, коли засну я. І зі сну в сніння твоє самотнє прийду, з туги синій.

Зустрінемося нині уночі.

Лише не жур мене і не клени, що я, мов янгол із крилом підбитим, сколошкав сон твій, люба, й пригнітив.

Але не жур мене і не клени.

І разом розтроюдимо біду

і будем пити смертні алкоголі.

Там, де чотири вітри бродять в полі, чекай мене, кохана, я прийду ${ }^{57}$.

Nel passaggio da una lirica ermetico-espressionista a una lirica amorosa, la sintassi poetica subisce evidenti trasformazioni. Abbandonata la complessa ipotassi di [I obpojila nas ciljušča smert'], il messaggio dell'io lirico alla donna amata si fa piano, apparentemente spontaneo e non costruito, nonostante un'analisi della sua fattura fonica, marcata da frequenti allitterazioni, ne riveli il carattere profondamente poetico. Alla semplificazione della costruzione linguistica corrisponde una maggiore linearità semantica. In opposizione all'invito a intraprendere l'oscuro cammino indicato da una sorte dimenticata nella lirica precedente, l'io lirico di Na nezabud'-družyni è certo della possibilità di una morte comune con la donna. L'elisir fatale è ora realmente salvifica. Si noti, nel verso conclusivo, un'inattesa, ma possibile reminiscenza di Ždi menja, i ja vernus' di Konstantin Simonov, una delle più celebri poesie sovietiche, di argomento tanto amoroso quanto politico.

Come in Veselyj cvyntar, anche in Čas tvorčosti / Dichtenszeit la contrapposizione tra l'io e il mondo non esclude una loro identità negativa:

[...] Бо ти єси уламок цілоти, як вискалок безмежного мовчання, існуеш тільки, як сліпе свічадо, що віддзеркалює вселенську смерть, подобу галактичної стихії.

57 Ivi: 237. 'Ci incontreremo ora di notte, / quando mi addormenterò io. E dal sonno nel sogno / tuo solitario arriverò, dalla tristezza azzurra. / Ci incontreremo ora di notte. / Solo non rimproverarmi, non maledirmi, / ché io, come un angelo dall'ala spezzata, / ho turbato il tuo sonno, amore, e l'ho oppresso. / Solo non rimproverarmi, non maledirmi. / E insieme chiameremo la disgrazia / e berremo l'alcool della morte. / Lì, dove vagano nel campo i quattro venti, / aspettami, amore, arriverò.' 


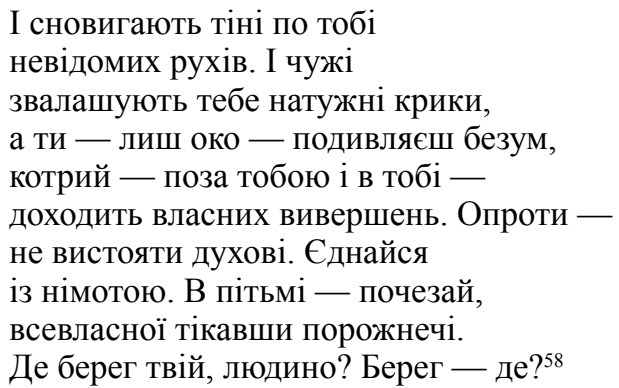

L'impotenza del soggetto altro non è che il riflesso dell'aberrazione dell'essere nella sua universalità. Non c'è reale differenza ontologica tra il soggetto $\mathrm{e}$ il folle mondo di cui egli è parte integrante. La sua peculiarità consiste, tuttavia, nella capacità di riflettere il male. Il tetro ermetismo di gran parte della lirica stusiana di Čas tvorčosti / Dichtenszeit, così come di alcuni dei più tardi Palimpsesty, sembra allora trovare una spiegazione metapoetica nell'assurdità della realtà che essa rifrange. "Occhio" e "specchio" del tutto, il poeta riproduce solamente "la morte universale" che lo penetra e lo avvolge. La frequente imperscrutabilità della poesia matura di Stus è qui dunque 'realistica' raffigurazione di una realtà capovolta, distorta, intimamente malata. In ciò risiede l'essenza profonda dell'espressionismo stusiano, che, da semplice filone stilistico nella poesia giovanile, della quale rappresenta un'importante componente, diventa Poesia tout court. Nell'abisso del caos in cui l'io lirico e il mondo sono precipitati inizia a farsi pressante la ricerca di una riva (bereh), non a caso uno degli elementi fondamentali dell'immaginario di Palimpsesty e, in misura minore, di Čas tvorčosti $/$ Dichtenszeit. La possibilità di salvezza sembra venire anche in questo caso dalla dissoluzione del sé, e dunque del tutto, nell'oscurità del nulla e del silenzio. La parola poetica, dolorosa ma incontenibile, si rivela così coincidente con l'esistenza stessa, il cui impossibile annullamento è l'oggetto chimerico della disperata ricerca del soggetto.

La rarefazione della fisicità del soggetto è centrale a molto liriche della maturità stusiana:

Живи у душах інших, як вампір,

бо вже давно немає в тебе тіла.

Таким бо таланом нагородила

тебе земля, де спокій твій і мир.

В цій порожнечі смерті - твій зупин,

58 Ivi: 245-246. '[...] Perché sei uno scarto dell'intero, / un digrigno del silenzio sconfinato, / esisti solo come specchio cieco, / che rispecchia la morte universale, / sembiante della forza galattica. / E vagano le ombre su di te / di movimenti sconosciuti. Estranee / ti castrano grida in tensione, / e tu - solo occhio - guardi la pazzia, / che, oltre te così come in te, / giunge al compimento. Non può / poi lo spirito resistere. Unisciti / al silenzio. Nell'oscuro sparisci, / fuggendo il vuoto tuo universale. / Dov'è la riva tua, uomo? Dov'è, la riva?' 


\begin{abstract}
це смерть твоя, голодна існуванням.
Живи ж у ній. Живи своїм конанням

і нескінченністю оцих хвилин, подоланий і винищений ними,

бо ти віднині їхній раб єси.

Відбитих душ відбитої краси

тепер шукай очима навісними ${ }^{59}$.
\end{abstract}

La negazione della morte come salvezza e pegno di resurrezione, come in numerose altre liriche di Čas tvorčosti / Dichtenszeit, significa per il soggetto cattiva infinità. La sua morte, "avida di vita", rifiuta se stessa, negando all'io la possibilità di trovare pace. È così accantonata la cristologia introdotta all'inizio dell'opera, almeno per quanto riguarda l'esito trionfante e salvifico della vicenda di Cristo. A rimanere, e a essere destinata all'eternità, è solo la croce. Anche di questi versi, tuttavia, è possibile una lettura in chiave poetologica. Essi sembrano infatti ricollegarsi ai motivi di [My, pustocvity božych isnuvan'], precedentemente analizzata, proseguendo nella dichiarazione di una poetica postmoderna in essa annunciata.

Di impostazione completamente opposta è invece la terzultima lirica della raccolta, datata 30 settembre:

Пахло весною і прілею глицею, пахла галявина, геть одвологла, пахло губами твоїми гіркими, пахло розлукою передчуття. $[\ldots]$

Тільки бо грішний про святощі знає, тільки бо грішному стати святим, тільки межу заступивши, відчуєш, тільки упавши пізнаєш себе ${ }^{60}$.

Dopo un'appassionata rievocazione della prima notte di nozze, l'io lirico afferma la validità del proprio cammino, non alieno dal peccato, ma proprio per questo umanamente votato alla santificazione e alla conoscenza. Quest'ultima, intesa nello specifico come conoscenza di sé, skovorodianamente propedeutica

59 Ivi: 320 . 'Vivi in anime altrui, come un vampiro, / perché da tanto più non hai un tuo corpo. / Con un destino così t'ha premiato / la terra, dov'è la calma e la pace tua. / In questo vuoto di morte è il tuo ritiro, / è la tua morte, che ha fame d'esistenza. / Vivi in lei. Vivi della tua fine / e dell'infinito di questi attimi, / da loro sconfitto e abbattuto, / perché da adesso sei loro schiavo. / Di anime battute la bellezza riflessa / cerca ora con occhi impazziti.'

60 Ivi: 364. 'Odorava di primavera e foglie umide, / odorava di radura nel disgelo, / odorava delle tue labbra amare, / odorava presentendo il distacco. / [...] // Perché solo il peccatore sa la santità, / perché solo il peccatore può diventare santo, / solo superando il limite sentirai, / solo cadendo conoscerai te stesso.' 
alla conoscenza del tutto, è inscindibile dal superamento degli angusti confini che l'io tende a imporre a se stesso. In un'ottica tanto olistica quanto teleologica, [Pachlo vesnoju i priloju hlyceju] postula il tormentato percorso dell'io, la via crucis che egli sembra compiere senza la speranza di una redenzione, come via d'accesso alla beatitudine. Si noti, ancora una volta, il sottotesto rilkiano della caduta come rinascita nell'ultimo verso.

Rispetto alle raccolte degli anni Sessanta, Čas tvorčosti / Dichtenszeit si distingue dunque notevolmente per uniformità tematica e stilistica. La quasi totalità delle oltre trecento poesie che compongono la parte 'originale' dell'opera è definibile nei termini di una continua rielaborazione del materiale linguistico-tematico che si è presentato e discusso. Su questo sfondo spiccano le pochissime, nonché parziali digressioni dalla linea dominante, incentrata sulle peregrinazioni dell'io lirico nei propri vissuti e la riflessione sul proprio rapporto con la poesia e la realtà.

Si vedano, a questo proposito, alcuni versi di Skyt Manjavs 'kyj ('Il monastero di Manjavy') dell'inizio di luglio:

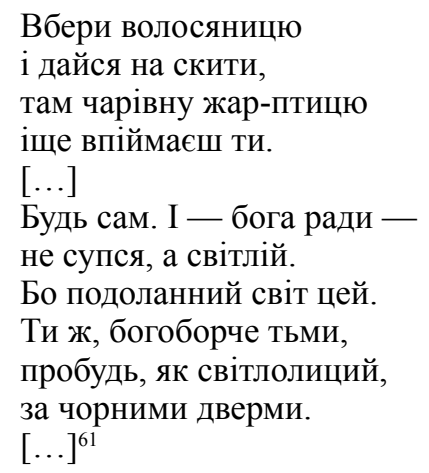

Si potrebbero definire Skyt Manjavs 'kyj come un Rollengedicht in fieri, ovvero una poesia in cui l'identificazione tra l'io lirico e un determinato personaggio non viene postulata dall'inizio del testo, ma costruita nello svolgimento della lirica stessa. Evidente è inoltre la vicinanza del protagonista di questi versi all'io lirico attorno al quale si sviluppa la raccolta nel suo complesso. Nella prima quartina il soggetto indossa la maschera di un monaco ${ }^{62}$, nei panni del quale il compimento del cammino interiore verso la realizzazione della propria natura si presenta più facilmente realizzabile. Non allontanandosi dunque dalla 'narrazione' di Čas tvorčosti / Dichtenszeit nel suo insieme, Skyt Manjavs 'kyj ne offre

61 Ivi: 266. 'Indossa un saio, / in monastero vai, / l'uccello di fuoco / vi ritroverai. / [...] / Sì te stesso. E - per Dio - / non t'aggrottare, ma risplendi. / Si può vincere questo mondo. / Tu, che il dio della tenebra lotti, / rimani dietro alle porte nere. / [...]'

62 Un accostamento di questi versi al monaco slavo orientale protagonista del rilkiano Stunden-Buch, più volte citato in precedenza, sembra in questo caso da escludersi. 
una modalità di svolgimento differente, arricchendola di una sfaccettatura nuova mediante il travestimento dell'io lirico sotto le spoglie di un 'altro'. In questo senso risalta anche l'utilizzo di una misura breve, il trimetro giambico, già presente in altre liriche della raccolta, ma decisamente meno rappresentato a livello quantitativo della tetrapodia e, soprattutto, della pentapodia giambica, lo schema metrico predominante nelle liriche originali di una raccolta modernisticamente 'classica' come Čas tvorčosti / Dichtenszeit.

Più difficilmente accostabile alla tradizione del Rollengedicht, a causa dell'utilizzo della terza persona, è invece [Zapachlo soncem, voskom i zelom], composta alla metà di luglio:

Запахло сонцем, воском і зелом.

В мосянжне колихання передліта летить бджола, любов'ю обігріта, мов янгол із наламаним крилом.

$[\ldots]$

[...] Мала,

вона пойметься ярим золотом сонця

і схочеться їй віщих таємниць запричаститися, припавши ниць до утлого кульбабиного лонця ${ }^{63}$.

Ricollegandosi all'antica e ricchissima tradizione della poesia sulle api, ben rappresentata tanto nella tradizione ucraina che in quella russa ${ }^{64}$, questi versi, intrisi di acmeistica eleganza e classicità, non prevedono la presenza di un io lirico direttamente o indirettamente al centro del testo, venendo così a costituire un unicum all'interno di Čas tvorčosti / Dichtenszeit. Per l'io lirico stesso, assente ma tuttavia indirettamente presente nel contesto della raccolta, l'ape si presenta come un utopico modello da imitare. Con la sua capacità di "partecipare dei più alti misteri” dell'universo abbassandosi sull'esile stelo di un soffione, seguendo dunque

63 ZT III, 282. 'Odorò di sole, cera ed erbe. / Ondeggia d'ottone la prima estate, / vola un'ape, d'amore scaldata, / come un angelo dall'ala incrinata. / [...] / [...] Piccola, / la prenderà l'oro chiaro del sole / e vorrà lei dei più alti misteri / partecipare, precipitando / sul debole grembo del soffione.'

64 Si ricordino nella tradizione ucraina la favola Pčela $i$ šeršen' di Skovoroda e la lirica Bdžola ('L'ape') di Bohdan-Ihor Antonyč. Per quanto riguarda la letteratura russa si vedano, tra le numerose liriche incentrate sullo stesso motivo, Pčela di Jakov Polonskij, accostabile al filone della poesia "apicola" di memoria classica, Pčëly di Afanasij Fet, incentrata sulle vicissitudini interiori dell'io lirico, [Ne ty l' povedala podrugam pčelam] di Vjačeslav Ivanov e Čerepacha di Mandel'štam, entrambe basate su una rilettura in chiave poetologica del motivo apicolo, nonché la favola in versi sovietica Pčela di Dem'jan Bednyj. Per un'erudita disamina del motivo dell'ape nel modernismo russo, con particolare riferimento a Mandel'štam, cfr. Hansen-Löve 1993: 136-148. In area tedesca si pensi a [Die Bienen fallen in den dünnen Röcken] ('[Cadono le api nelle sottili vesti]') dell'espressionista Georg Heym e Thema und Variation ('Tema e variazione') di Ingeborg Bachmann. 
nient'altro che il proprio istinto e la propria natura, l'ape riesce a portare a termine il compito che il soggetto assegna a se stesso nella tragica consapevolezza della sua irrealizzabilità. Il ripiegamento dell'io su se stesso ampiamente descritto nell'opera è l'esatto opposto del volo armonioso dell'insetto, nel quale il confine tra l'interiorità e il mondo esteriore è felicemente annullato. Alla base dell'ispirazione di [Zapachlo soncem, voskom izelom] è ipotizzabile, anche alla luce della genealogia poetica del motivo dell'ape precedentemente ricostruita, la presenza di un velato ipotesto rilkiano. Si tratta dell'ottava delle Duineser Elegien, in cui alla chiusura dell'uomo su se stesso è contrapposta l' "apertura" dell'animale, la "creatura" ${ }^{65}$. Nonostante i versi rilkiani in questione evochino una zanzara, e non un' ape, la presenza della parola "grembo" nel testo rilkiano induce a non escludere questa ipotesi:

O Seligkeit der kleinen Kreatur,

der immer bleibt im Schooße, der sie austrug;

o Glück der Mücke, die noch innen hüpft,

selbst wenn sie Hochzeit hat: denn Schooß ist Alles ${ }^{66}$.

In una versione precedente di [Zapachlo soncem, voskom i zelom], inoltre, il grembo evocato nell'ultimo verso appartiene significativamente all'insetto stesso: “до тужної землі припавши лонцем" 67 . A unire i due testi è la radicale contrapposizione tra l'uomo e l'insetto, nonché la raffigurazione dell'inaspettata superiorità di quest'ultimo, più tradizionalmente l'ape in Stus, più avanguardisticamente il moscerino in Rilke, sulla limitatezza dell'uomo.

In una lirica precedente, composta alla metà di aprile, si assiste a una modalità differente di utilizzo di un motivo animale. Se l'ape di [Zapachlo soncem, voskom i zelom] è difficilmente identificabile con l'io lirico, per il quale funge piuttosto

65 Rilke 1996: II, 224: "Mit allen Augen sieht die Kreatur / das Offene. Nur unsre Augen sind / wie umgekehrt und ganz um sie gestellt / als Fallen, rings um ihren freien Ausgang." 'Con tutti gli occhi vede la creatura / l'aperto. Solo i nostri sono / come girati, rivolti ad essa, / trappole, attorno al suo libero uscire.'

66 Ivi: 225 . 'O beatitudine della creatura, / che sempre sta nel grembo da cui nacque: / che gioia la zanzara, che dentro salta, / anche per le nozze: perché tutto è grembo.' Si pensi anche a un passo della lettera di Rilke al traduttore polacco Witold von Hulewicz del 13 novembre 1925, una delle più note dell'epistolario rilkiano, costruito sulla metafora pindarico-platonica delle api come poeti. Cfr. Rilke 1987: III, 898: "Wir sind die Bienen des Unsichtbaren. Nous butinons éperdument le miel du visible, pour l'accumuler dans la grande ruche d'or de l'Invisible. Die 'Elegien' zeigen uns an diesem Werke, am Werke dieser fortwährenden Umsetzungen des geliebten Sichtbaren und Greifbaren in die unsichtbare Schwingung und Erregtheit unserer Natur, die neue Schwingungszahlen einführt in die Schwingungs-Sphären des Universums." La citazione nel testo rilkiano è da Maeterlinck. 'Siamo le api dell'invisibile. Nous butinons éperdument le miel du visible, pour l'accumuler dans la grande ruche d'or de l'Invisible. Le Elegie ci mostrano questo lavoro, il lavoro della continua trasposizione di ciò che amiamo, vediamo e tocchiamo nell'invisibile oscillazione e nell'eccitamento della nostra natura, che apporta nuove frequenze nell'universo.'

67 ZT III, 643: 'sulla terra triste cadendo col piccolo grembo.' 
da irraggiungibile modello di perfezione, le due cicogne di [Vertajut'žuravli na vetchi hnizda] sono evidentemente una metafora per il soggetto e la sua amata:

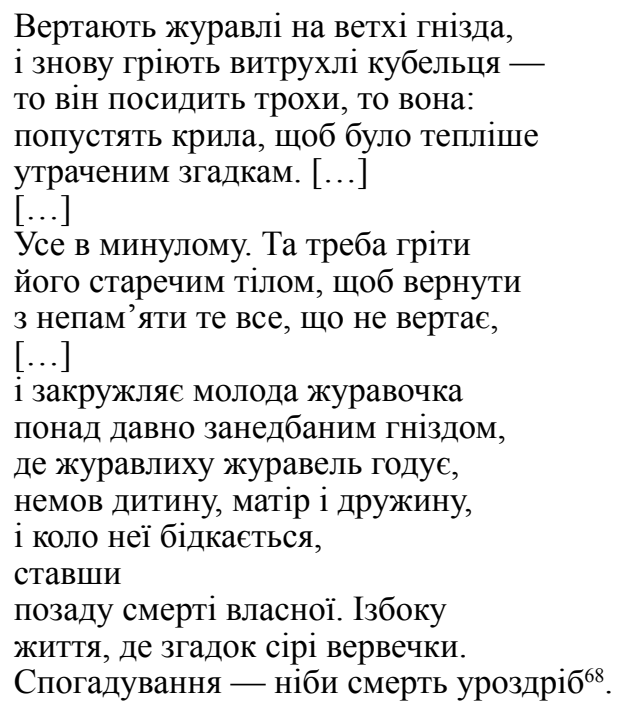

Venendo a occupare anche in questo caso il proprio posto in una tradizione poetica piuttosto consolidata ${ }^{69}$, questi versi si inseriscono agevolmente nel filone amoroso di Čas tvorčosti / Dichtenszeit, classicamente incentrato sulla dolorosità del ricordo e sull'onnipresenza della morte anche in ciò che dovrebbe costituirne la negazione.

Di due giorni precedente a [Vertajut'žuravli na vetchi hnizda] è un Rollengedicht, incentrato sul nume tutelare delle lettere ucraine. In Ševčenko. Doroha do Ors 'ka ('Ševčenko. Strada verso Orsk'), memore della poesia del primo Stus, il grado di identificazione dell'io lirico, assente ma implicito, con il protagonista è decisamente elevato:

68 Ivi: 164-165. 'Tornano le cicogne ai vecchi nidi, / di nuovo scaldano le vecchie foglie - / ora è lui che siede un po', ora lei: / allargano le ali per scaldare / i ricordi persi. $[\ldots] /[\ldots]$ / È tutto nel passato. Va scaldato / col corpo vecchio per far ritornare / alla memoria quello che non torna, / [...] / vola in cerchio la piccola cicogna / sul nido ormai da tempo abbandonato, / dove è lui che nutre lei, / bambina, madre, moglie, / e attorno a lei si strugge, dietro / alla propria morte. Sta al lato / della vita, dei mucchi grigi dei ricordi. / Rimembranza - morte che si sparge.'

69 Si ricordino, per quanto riguarda la poesia ucraina, Žuravli di Ivan Franko, [Ključamy klyčut' žuravli] di Volodymyr Svidzins'kyj, Žuravli di Bohdan Lepkyj (1872-1941), piuttosto vicina alla sensibilità poetica stusiana, la quasi prosastica Žuravli di Maksym Ryl's'kyj, nonché Žuravli vysoki prolitajut'di Jevhen Hucalo (1937-1995), contemporaneo di Stus. Nella tradizione russa si pensi almeno alla ballata Ivikovy žuravli di Žukovskij da Schiller e a Žuravli di Nikolaj Zabolockij, poeta amato da Stus, nonché alla celebre traduzione russa (1968) di Žuravli del poeta daghestano di lingua avara Rasul Gamzatov (1923-2003). 
І закривавились твої сліди

по сніжних кучугурах. Скільки ока -

все далина: порожня і глибока.

А ти - іди. А ти - іди. А - йди.

$[\ldots]$

Був битий шлях — ще вчора. А тепер

весь виднокрай зотлів, а люд - помер,

а вітер видув, а сніги встелили,

а заздрісні боги благословили.

Цей навіжений, цей скажений степ

на ве́сну бугилою поросте ${ }^{70}$.

Il cammino solitario del poeta, ormai lontano da un'umanità consumatasi, è infine ripreso in una poesia di tre mesi più tardi:

Берези - навтьоки. Трава напнулась.

Згинаються тополі в три дуги,

і спересердя хмари хтось прогупує,

і гнівно ляскають білясті батоги.

$[\ldots]$

Та в'юниться, немов батіг, їздовий:

— Рушай, гроза, під райдужну веселку ${ }^{71}$.

In entrambe le liriche, sorprendentemente più vicine alla sensibilità dello Stus degli anni Sessanta e in netto contrasto con la poetica predominante nella raccolta $^{72}$, la descrizione di una natura ora spoglia ora selvaggia, non contaminata dalla civiltà, si accompagna alla raffigurazione del viaggio del viandante, alla ricerca di un equilibrio che solamente il ritiro dal consorzio degli uomini può almeno temporaneamente garantirgli. Il singolo e il paesaggio si rivelano co-protagonisti di brevi narrazioni liriche piuttosto stridenti nel panorama di Čas tvorčosti / Dichtenszeit, a dimostrazione dell'impossibilità di ricondurre integralmente $\mathrm{a}$ un unico denominatore stilistico e tematico anche la raccolta più unitaria nel complesso della poesia stusiana.

In un'opera in cui, come si è potuto osservare, la presenza pasternakiana, pur non assente, è meno forte che nei versi del periodo giovanile, spiccano due evidenti rielaborazioni di materiale poetico dell'autore di Živago. Si veda il primo

70 ZT III, 156. 'Si sono insanguinate le tue tracce / sui cumuli di neve. L'occhio vede / vuota e profonda la pianura. E tu - va. E tu - va. Va. / [...] / Era battuto il cammino - già ieri. E ora / bruciato è l'orizzonte, morta la gente, / soffiato il vento, sparse le nevi, / e gli dei invidiosi hanno benedetto. / Questa steppa matta, impazzita / si coprirà di cerfoglio a primavera.'

${ }_{71}$ Ibidem. 'Betulle - in fuga. L'erba s'è fatta rigida. / Si piegano i pioppi in tre archi, / e irato le nuvole qualcuno colpisce, / e con rabbia sbattono le biancastre fruste. / [...] / E s'attorciglia, come frusta, il cocchiere: / Vattene, tempesta, sotto all'arcobaleno allegro.'

72 [Berezy-navt'oky. Trava napnulas'] risale infatti al periodo di Kruhovert'. Il suo reinserimento in Čas tvorčosti / Dichtenszeit non può mancare di sorprendere il lettore. 
di essi, la conclusione di una lirica incentrata sulla tipica auto-rappresentazione dell'io lirico nello spazio soffocante della cella carceraria:
Підноситься душа моя розквітла, запрагла йти у всезнищенну синь. Яка це ера? І яка пора?
Один, чекавший судної години, вслухаюсь із живої домовини, як галасує вічна дітвора ${ }^{73}$.

Il riferimento pasternakiano in questione è la quinta strofa della celeberrima Pro èti stichi da Sestra moja - žizn'(Pasternak 2003-2005: I, 115):
В каше, ладонью заслонясь,
Сквозь фортку крикну детворе:
Какое милые у нас
Тысячелетье на дворе?

La situazione del soggetto pasternakiano è capovolta. Se quest'ultimo è estaticamente immerso nel vortice della vita nell'inebriante sfrenatezza di ogni sua possibile manifestazione, tanto da dimenticarsi della sua localizzazione temporale, all'io lirico stusiano è concesso solamente di librarsi con l'anima nella fragilità di uno spazio destinato alla rovina, mentre il corpo è costretto a restare nella tomba ossimoricamente viva della realtà. Gli si contrappone, al di là del muro esplicitamente evocato nel secondo verso della lirica ${ }^{74}$, la vita degli uomini, qui espressa per sineddoche dal rumore dei bambini che giocano. E dunque la memoria lessicale a tradire l'origine pasternakiana di questi versi e il loro ribaltamento semantico.

Il secondo caso di esplicito dialogo con la tradizione di Pasternak è più complesso, in quanto si basa sul recupero di almeno due brani del poeta russo:

Кажи, акторе, де твої лаштунки?

І роль твоя скінчилась. Де ж твій кін?

$[\ldots]$

Кажи, акторе, що то за прокляття, поезія, найбільша із оман, котра бере нас у любовний бран, аби потому 'ддати на розп'яття? ${ }^{75}$

73 ZT III, 287. 'Si solleva in fiore l'anima mia, / avida di azzurro da distruggere. / Che era è? E che stagione? / Solo, aspettando l'ora del giudizio, / ascolto da questa viva tomba / quel rumore eterno dei bambini.'

74 Ibidem: "По той бік муру гуркотять машини." 'Dall'altra parte del muro tubano le macchine.'

75 Ivi: 343. 'Di', attore, dove sono le tue quinte? / La tua parte è finita. Dov'è la tua scena? / [...] / Dì, attore, che maledizione è, / la poesia, la più grande illusione, / che ci imprigiona, come l'amore, / per darci poi alla crocifissione.' 
Gli ipotesti coinvolti sono ancora una volta Gamlet, dagli Stichotvorenija Jurija Živago, e [O, znal by ja, čto tak byvaet] da Vtoroe roždenie, entrambe già incontrate come possibili fonti di ispirazione per Stus nelle raccolte precedenti. Se in Gamlet l'uscita dell'attore sulla scena è ancora possibile (Pasternak 20032005: IV, 515: “Гул затих. Я вышел на подмостки”) e il proprio destino, seppur temporaneamente rinnegato, è definito e riconosciuto da un Cristo ritrovatosi su un moderno palcoscenico (ibidem:“Если только можно, Авва Отче, / Чашу эту мимо пронеси. // Я люблю твой замысел упрямый / И играть согласен эту роль. / Но сейчас идет другая драма, / И на этот раз меня уволь”), in [Каžy, aktore, de tvoji laštunky] l'isolamento di un soggetto ormai non in grado di mostrare $\mathrm{a}$ un pubblico il proprio percorso di sofferenza risulta ancora più marcato. La solitudine dell'Amleto-Cristo pasternakiano (ibidem: “Я один, все тонет в фарисейство") ѐ così amplificata nell'impossibilità stessa di uno spazio comunicativo. Ciò non esclude, tuttavia, l'inevitabilità della crocifissione. Quest'ultima è posta direttamente in connessione con la poesia, mettendo così in evidenza il collegamento tra le due liriche di Pasternak in questione. In [O, znal by ja, čto tak byvaet] il poeta è infatti paragonato all'attore (ivi: II, 80: “О знал бы я, что так бывает, / Когда пускался за дебют, / Что строчки с кровью - убивают, / Нахлынут горлом и убьют") e per entrambi l'afflato emozionale nella dedizione alla parola è latore di rovina. La tragicità della sua sorte, tuttavia, non è priva di un significato profondo, grazie al quale il suo vissuto di dolore risulta intimamente legato al destino del suo tempo (ibidem):

Когда строку диктует чувство,

Оно на сцену шлет раба,

И тут кончается искусство,

И дышат почва и судьба.

Se ciò sia sostenibile anche a proposito di [Kažy, aktore, de tvoji laštunky] è incerto. L'indubbio nichilismo della lirica si scontra infatti con l'affermarsi di un senso nella raccolta nel suo complesso, ponendo all'attenzione del lettore il frequente problema del contrasto tra il microtesto del singolo componimento e i macrotesti delle raccolte stusiane, segnate da tensioni semantiche e, come si è visto, in certi casi stilistiche molto forti.

L'esemplare contrasto tra [Žyvy u dušach inšych, jak vampir] e [Pachlo vesnoju i priloju hlyceju] ben evidenzia la profonda dualità che distingue la raccolta nel suo significato complessivo, scissa tra una nichilistica elaborazione poetica del trauma e la proclamazione della sublime finalità del dolore. D'altro canto, queste due tendenze giungono a una fusione nella coerenza di una testualità profondamente unitaria, raramente segnata dai bruschi sbalzi stilistici e tematici che contraddistinguevano le opere precedenti, nonché, in parte, i futuri Palimpsesty. L'assoluta concentrazione della parola poetica sull'io, nella complessa totalità del suo rapporto con se stesso e con la realtà circostante, mostra l'intrinseca omogeneità dell'ispirazione alla base della raccolta del 1972. L'autoritratto dell'io lirico è dinamico, imprevedibile nella molteplicità delle sue continue trasformazioni, 
il che conferisce alla lirica di Čas tvorčosti / Dichtenszeit un afflato epico unico nell'insieme del lascito poetico stusiano. La vicenda dell'io che in essa è ossessivamente raffigurata offre infatti alla raccolta del 1972 una tensione narrativa che priva parzialmente ogni singola lirica della sua autonomia per farne un maestoso affresco dell'interiorità di un io. Allo stesso tempo, secondo il suggerimento fornito al lettore dal titolo dell'opera stesso, non si può sottovalutare la dimensione metapoetica del testo. Senza accantonare la possibilità di una lettura della raccolta come 'storia di un'anima', questo approccio mette in risalto la riflessione sulla scrittura poetica come componente essenziale dello scrivere stusiano, soprattutto del periodo maturo. La divisione dell'opera in due parti, una composta da liriche 'originali' e una da traduzioni da Goethe, testimonia della necessità di non appiattirne l'interpretazione concentrandosi esclusivamente sulla narrazione dei vissuti dell'io. L'incorporazione della parola goethiana, dei suoi stilemi e dei suoi motivi all'interno del testo stusiano, così come la contemporaneità del lavoro dell' autore alle proprie liriche e alle versioni da Goethe, dimostrano come sia proprio la concreta riflessione metapoetica a costituire il significato profondo di Ćas tvorčosti / Dichtenszeit. Stus sembra celebrarvi l'onnipotenza della propria penna, in grado di spaziare dalla luminosa mistica di [Meni zorja sijala nyni vranci] al cupo ermetismo espressionista di [I obpojila nas ciljušča smert'], fino all'amplia gamma stilistico-tematica dei testi goethiani, senza per questo venire meno all'intento unitario sotteso all'opera nel suo complesso.

Che Goethe, inoltre, funga da modello di irraggiungibile perfezione per l'io lirico della prima parte di Čas tvorčosti / Dichtenszeit è esplicitamente dichiarato in una lirica di maggio, che sembra confermare la tesi secondo la quale le traduzioni da Goethe costituiscono il secondo capitolo della raccolta, complementare nella sua differenza alla parte 'originale':

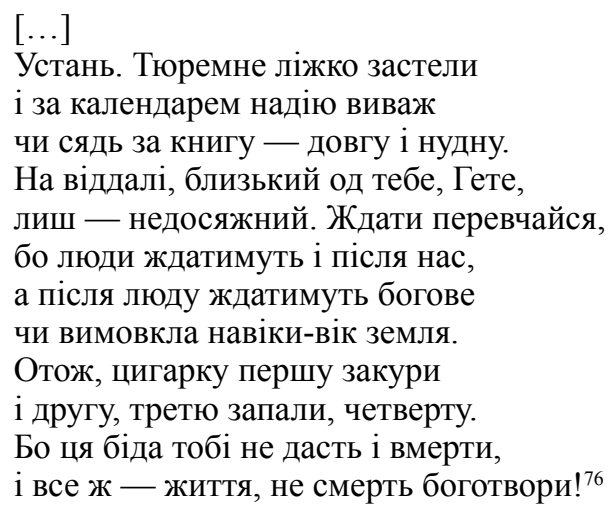

76 ZT III, 203. 'Alzati. Prepara il letto della cella / e misura la speranza al calendario / o prendi un libro - lungo e noioso. / Più in là, vicino a te, c'è Goethe, / - irraggiungibile. Impara ad aspettare, / si aspetterà anche dopo di noi, / e dopo aspetteranno anche gli dei, / finché per sempre non tacerà la terra. / Ecco, fuma la prima sigaretta / e anche la seconda, terza e quarta. / Questo male non ti farà morire, / ma adora la vita, e non la morte!' 
Tanto vicino, quanto irrimediabilmente lontano, Goethe indica all'io lirico la necessità di concentrare le proprie forze sulla celebrazione della vita. Questo compito potrà essere effettivamente portato a termine solamente attraverso le traduzioni stesse, il cui fondamentale significato per la raccolta nel suo insieme è così metapoeticamente esplicitato.

\subsection{Le traduzioni da Goethe}

L'inaspettata, sorprendente complementarietà delle traduzioni da Goethe al complesso di Čas tvorčosti / Dichtenszeit ne costituisce indubbiamente l'aspetto più interessante. Annotate all'interno di un quadernetto auto-prodotto della stessa fattura di quello destinato alle liriche originali, esse furono rielaborate nei mesi successivi al trasferimento in Mordovia e quindi ricopiate nelle lettere di Stus ai famigliari fino alla fine del 1973 . I curatori di $Z T$ hanno opportunamente deciso di mantenere la numerazione del quadernetto del 1972, proponendo come versione definitiva quella desunta dalle lettere, riportando nell'apparato critico le varianti precedenti, composte nel periodo della carcerazione preventiva. La seconda parte di Čas tvorčosti / Dichtenszeit comprende più di cento liriche, alle quali si aggiungono versioni di opere goethiane di più ampio respiro come le Römische Elegien (Elegie Romane) e i Venezianische Epigramme (Epigrammi veneziani). Spaziando dal giovane Goethe dello Sturm und Drang alla lirica della vecchiaia tra gli anni Venti e gli anni Trenta dell'Ottocento, Stus non lavorò ai testi secondo un ordine cronologico, anche se si può notare una netta preferenza per la prima lirica goethiana nella fase iniziale e un continuo spaziare tra i decenni nella fase successiva.

Il corpus degli originali goethiani e delle relative versioni stusiane è indubbiamente caratterizzato da una notevole varietà stilistica e tematica. A Lieder amorosi del periodo classico si affiancano i grandi inni dello Sturm und Drang, la lirica filosofica dalla fase giovanile alla tarda maturità, la poesia didascalica (Metamorphose der Pflanzen [Metamorfosi delle piante] e Metamorphose der Tiere [Metamorfosi degli animali]), una ballata classica (Der Fischer [Il pescatore]), la poesia scherzosa (Tischlied, [Canzone da tavola]) e numerosi componimenti del West-östlicher Divan (Divano occidentale-orientale). La scelta stusiana delle liriche da tradurre sembra così guidata da un duplice intento. Da una parte, soprattutto per quanto riguarda i primi testi tradotti, ma non solo, si possono notare diversi punti di contatto tra la poesia goethiana e i motivi centrali all'opera stusiana matura stessa, come la tematica poetologica e la riflessione sulle possibilità e i "limiti" dell'operare umano. Dall'altra, Stus sembra perseguire la più ampia gamma di temi e forme all'interno dell' $O$ pus lirico goethiano ${ }^{77}$, mettendo alla prova e arricchendo la propria penna in

77 Per una sintetica ed efficace visione d'insieme del percorso lirico goethiano si veda Wünsch 1998. Basandosi prevalentemente sulla costruzione del soggetto 
un periodo, come si è potuto osservare, all'insegna dell'uniformità per quanto riguarda la produzione originale, in netto contrasto con l'instancabile sperimentazione stilistica degli anni Sessanta. Riflettendo sulla selezione dei testi tradotti, si ha l'impressione che Stus abbia volontariamente escluso alcuni testi a lui più immediatamente vicini per dare spazio a generi e tematiche più distanti dalla sua sensibilità. L'insieme testuale delle traduzioni goethiane segna così la fusione dello Stus poeta con uno Stus propriamente traduttore, non direttamente influenzato dal proprio universo poetico nella scelta delle opere su cui lavorare. L'analisi verterà sulle liriche tradotte più vicine alla poesia stusiana originale, nonché su alcune interessanti divergenze tra gli originali e le traduzioni, sintomi di un inevitabile adattamento del testo di partenza all'universo poetico del traduttore.

Fondamentale si rivela per il poeta-traduttore il rispetto delle caratteristiche formali del testo di partenza. La conservazione dello schema metrico e della configurazione delle rime è una costante delle traduzioni stusiane da Goethe, mentre si osservano naturali divergenze a livello ritmico e occasionali incongruenze a livello strofico. Nel periodo successivo alla condanna e all'arrivo in Mordovia, Stus si dedicò inoltre allo studio della metrica classica per adattare le traduzioni delle Römische Elegien alla metrica goethiana originale, basata su modelli latini (cfr. Althaus 1994). Solo la prima delle Römische Elegien si è conservata nella versione rivisitata del 1973.

Der Besuch (La visita, 1788), la prima delle liriche goethiane scelte da Stus, è una poesia amorosa basata su modelli classici, in primo luogo properziani, incentrata sul topos dell'amante che visita in segreto la stanza dell'amata, addormentatasi sul divano durante il lavoro a maglia. La versione stusiana, che riprende la pentapodia trocaica goethiana, si distingue dall'originale nella scelta del modo verbale su cui si regge il nocciolo semantico della lirica stessa. Se nel testo di Goethe (Goethe 2000: I, 237) si assiste a un racconto all'indicativo (wollt', hab', offf'), in Vidvidyny la narrazione lirica è resa potenziale

e del suo rapporto con la realtà, la studiosa ha suddiviso la storia della poesia di Goethe in quattro fasi, segnate rispettivamente dal titanismo dello Sturm und Drang, dal classicismo, dal superamento del classicismo e dalla vecchiaia. L'ultimo dei tre macro-periodi è indubbiamente il più complesso e variegato, difficilmente riconducibile a un denominatore comune. Per un approccio di sintesi alla lirica di Goethe si veda anche Zagari 1991. Lo studioso italiano ha messo in evidenza la complementarietà di una moderna e modernistica messa in discussione dell'equilibrio tra soggetto e oggetto e del premoderno e umanistico mantenimento di questo equilibrio nell'universo poetico goethiano. Walter Müller-Seidel ha invece studiato il percorso dialettico della lirica di Goethe, mostrando come, partendo dalla fresca individualità dello Sturm und Drang, si giunga, mediante un progressivo avanzamento della componente tragica - e dunque teatrale - a scapito della componente lirica, a una "rassicurante" universalità, unico rimedio contro la vecchiaia e l'avvicinarsi della fine. Cfr. Müller-Seidel 1990. Il corpus di traduzioni goethiane di Stus riflette efficacemente il percorso della lirica di Goethe nella sua interezza. 
dall'utilizzo del congiuntivo/condizionale. Si vedano le rispettive prime strofe dei due testi:

Meine Liebste wollt' ich heute beschleichen,

Aber ihre Türe war verschlossen.

Hab' ich doch den Schlüssel in der Tasche!

Öffn' ich leise die geliebte Türe!

Я б прокрався до своєї любки, тільки ж замкнені у неї двері.

Ох, коли б то мав ключа в кишені, аби стиха увійти до хати ${ }^{78}$.

Nel passaggio dall'oggettività dell'indicativo in Goethe all'ipoteticità ottativa del congiuntivo/condizionale, il carattere vitalistico e trionfante del testo originale è sostituito dal mesto lamento di un amante privato della possibilità di incontrare l'amata. Questa contrapposizione sembra essere apparentemente superata dalla coincidenza delle rispettive strofe finali, nelle quali viene annunciato l'incontro serale con la donna, che ricompenserà abbondantemente l'amato per non averla svegliata in occasione della visita notturna:

Seh' ich diese Nacht den Engel wieder,

$\mathrm{O}$, wie freut sie sich, vergilt mir doppelt

Dieses Opfer meiner zarten Liebe (Goethe 2000: I, 239).

Стріну янгола я, ледве смеркне.

I вона сторицею віддячить

за офіри ніжного кохання ${ }^{79}$.

Se nel testo goethiano, tuttavia, si parla di un nuovo incontro, come indica la particella verbale wieder (nuovamente) alla fine del primo verso, la conclusione di Vidvidyny postula un appuntamento che alla luce delle strofe precedenti assume un carattere dimesso, quasi fantasmagorico, ben lontano dalla trionfale energia vitale e dalla sicurezza di sé che caratterizzano l'io lirico goethiano. Vidvidyny, allontanandosi così notevolmente dall'originale, si inserisce perfettamente nel macrotesto di Čas tvorčosti / Dichtenszeit. Da una parte, essa sembra ricollegarsi a una lirica come [Na nezabud'-družyni]; dall'altra, l'immagine della donna addormentata potrebbe essere messa in connessione con un componimento dell'inizio di febbraio, non esente da suggestioni ševčenkiane:

Спить жона, золотими ножами

пообкладувана,

78 ZT III, 369. 'M'intrufolerei dalla mia amata, / ma chiusa è la sua porta. / Oh, se avessi la chiave in tasca, / per entrare di soppiatto in casa.'

79 Ivi: 372. 'Incontrerò l'angelo, appena farà scuro. / E cento volte mi ricompenserà / per il sacrificio dell'amore dolce.' 
на зажурену схожа маму.

$[\ldots]$

Чи ти перекинешся в мене, як я вже не буду собою, ачи відшукаєш хоч в смерті моє охололе плече? ${ }^{80}$

Il convegno amoroso post mortem descritto in [Spyt'žona, zolotymy nožamy] potrebbe così aver agito da catalizzatore dell'attenzione di Stus nella scelta di Der Besuch come prima lirica su cui cimentarsi come traduttore e delle conseguenti scelte effettuate nella traduzione, dal momento che Stus ricevette in cella i primi due tomi delle opere goethiane pochi giorni dopo la scrittura di questa lirica ${ }^{81}$.

Nella seconda traduzione stusiana da Goethe, Prysvjata ('Dedica'), gli elementi comuni all'universo poetico di Čas tvorčosti / Dichtenszeit sono ancora più evidenti. Composta nel 1784, Zueignung fu scelta da Goethe tre anni più tardi come testo introduttivo del primo tomo delle sue Schriften. La stessa sorte toccò alla lirica circa trent'anni più tardi, a testimonianza del significato peculiare di Zueignung per l'opera goethiana giovanile. Esaltazione dell'essenza del poeta, nonché giustificazione della 'poesia' di fronte alla 'verità' e alle generazioni a venire (cfr. Kaufmann 2011: 169-208), Zueignung si mostra assolutamente congeniale alla poetologia stusiana matura. La raffigurazione del dialogo del poeta immerso nella natura con la musa, che gli fa dono del "velo della poesia [tessuto] dalla mano della verità" (ivi: 153: "Der Dichtung Schleier aus der Hand der Wahrheit"), subisce tuttavia nella versione stusiana una notevole 'cristianizzazione'. Nella quarta ottava di entrambe le liriche alla pagana espressione goethiana ein göttlich Weib ('una donna divina') corrisponde infatti un'inconfondibile bohomatir. Nella sesta ottava di Prysvjata è introdotto un vocativo assente nell'originale di Goethe, altrettanto univocamente legato alla Madre di Dio. Questa innovazione si inserisce inoltre nel contesto di un'amplificazione della semantica cristiana e più in generale metafisica che riguarda la seconda parte dell'ottava in questione nella sua interezza. Si vedano entrambi i passi:

Du hast mir wie mit himmlischem Gefieder

Am heißen Tag die Stirne sanft gekühlt;

du schenktest mir der Erde beste Gaben,

Und jedes Glück will ich durch dich nur haben!

У літню спеку ти мені, мов сину,

чоло студила, пресвята жоно,

усі земні дари я брав од тебе,

все щастя, що зазнав, - спадало 3 неба ${ }^{82}$.

80 Ivi: 102 . 'Dorme mia moglie, di coltelli d'oro / ricoperta, / simile alla madre che ora è triste. / [...] / Ti getterai in me, quando già non sarò più me stesso, / o cercherai almeno nella morte la mia fredda spalla?'

81 Cfr. ivi: 714. L'edizione utilizzata da Stus è probabilmente quella in dodici tomi edita nella RDT (Aufbau-Verlag, Berlin-Weimar) nel 1966. La lirica goethiana vi è presentata in ordine cronologico.

82 Ivi: 373 . 'Nel caldo estivo tu a me, come a un figlio / la fronte rinfrescavi, o santa donna, / da te i doni terrestri tutti ebbi, / dal cielo ebbi la felicità.' 
Se in Zueignung la felicità del poeta è e sarà esclusivamente dono di una musa pagana, le gioie che l'io di Prysvjata ha conosciuto, e di esse si parla significativamente solo al passato, sono chiaramente dono della grazia divina. Nel testo goethiano il riferimento al cielo è inoltre attenuato dal suo trovarsi all'interno di un paragone ("wie mit himmlischem Gefieder"). Completamente aliena a quest'ultimo è inoltre la rappresentazione del rapporto tra la dea e il poeta nei termini di una relazione tra madre e figlio, foriera di implicazioni cristologiche a livello della raffigurazione del soggetto. Prysvjata sembra così passibile di un accostamento al testo di apertura di Ćas tvorčosti / Dichtenszeit, [Meni zorja sijala nyni vranci], a sua volta assimilabile a Zueignung in quanto lirica introduttiva con un evidente valore programmatico. Si noti come la generale cristianizzazione del testo spicchi palesemente anche nel distico finale delle rispettive settime strofe:

Ich muß mein Glück nur mit mir selbst genießen,

Dein holdes Licht verdecken und verschließen.

Хай сяєво твоє благословенне

3 довірою світитиме до мене ${ }^{83}$.

La luce "dolce" (holdes Licht) emanata dalla dea goethiana si trasforma in un bagliore "benedetto" (sjajevo blahoslovenne), pienamente coerente con il carattere cristiano della divinità femminile nell'interpretazione di Stus.

$\mathrm{Al}$ di là di queste evidenti e fondamentali differenze, i due testi condividono alcuni motivi alla base di entrambi gli universi poetici, come la complessa dialettica tra umanità e divinità nella definizione della natura del poeta. L'oscillazione tra l'elogio della propria capacità di innalzarsi al di sopra dei consueti "limiti dell'umanità", per riprendere un noto titolo goethiano di cui si avrà modo di parlare in seguito, e la consapevolezza della necessità di rimanere uomo tra gli uomini segnano profondamente l'opera di entrambi gli scrittori (cfr. Goethe 2000: I, 562). L'ammonimento della musa a questo proposito in Zueignung è tradotto fedelmente in Prysvjata:

So glaubst du dich schon Übermensch genug,

Versäumst die Pflicht des Mannes zu erfüllen!

Wie viel bist du von andern unterschieden?

Erkenne dich, leb' mit der Welt in Frieden.

Хіба ж для тебе збав уже нема

i ти вже непорушний, як колона?

Хіба ж ти не такий, як інші? Годі,

пізнай себе й зі світом будь у згоді ${ }^{84}$.

83 Ibidem. 'Che il bagliore tuo benedetto / nella fiducia risplenda su di me.'

84 Ivi: 374 . 'Che forse tu difetti più non hai, / invincibile come una colonna? / Che forse non sei proprio come gli altri? / Conosci te stesso e stai col mondo in pace.' 
Aggirando il goethiano Übermensch, forse troppo univocamente legato a Nietzsche per un orecchio novecentesco, Stus recupera nuovamente l'archetipo del monumentum aere perennius (“і ти вже непорушний, як колона?”), per poi metterlo in discussione in sintonia con il modello di Zueignung. La conoscenza di sé si traduce qui, dunque, nel riconoscimento della propria completa appartenenza al genere umano. Nei primi due versi dell'ottava conclusiva, infine, in cui Stus riprende senza significative variazioni il testo goethiano, risuonano motivi tipici dell'universo poetico stusiano:

Хай вам не буде спину, юні друзі, коли тяжкий тягар подовжить шлях ${ }^{85}$.

L'apostrofe ai posteri di gusto tardo-illuministico e (pre)romantico con cui si concludono Zueignung e Prysvjata sembra inoltre passibile di una lettura in senso politico non da escludersi nel testo goethiano, ma altamente probabile nel caso di Stus, poeta 'puro' ma allo stesso tempo compartecipe della tradizione ucraina di una poesia inevitabilmente e profondamente venata di significati storico-sociali.

Il secondo dei due celeberrimi Wandrers Nachtlied[er] goethiani, noto come Ein Gleiches (Uno stesso) in quanto riprende il titolo e la tematica del precedente Inno del viandante notturno, pur mostrando le oggettive difficoltà del traduttore alle prese con un testo dall'estrema sinteticità, ineguagliabile nella sua efficacia espressiva ${ }^{86}$, offre un ottimo esempio di 'appropriazione' della poesia di Goethe all'interno dell'universo poetico stusiano. In conformità con il raddoppiamento goethiano della stessa tematica in due componimenti differenti, anche Stus propone due versioni distinte di uno stesso Ničnyj spiv blukača $([A]$ e $[B])$. Le rispettive conclusioni delle due traduzioni stusiane offrono la possibilità di una reinterpretazione della tematica della morte rispetto alla poesia originale di Čas tvorčosti / Dichtenszeit, all'interno della quale il motivo della fiducia nell'imminente arrivo della fine è negato dall'ossessiva evocazione dell'impossibilità di trovare la quiete in una dinamica di cattiva infinità ${ }^{87}$. Il distico finale della versione $[A]$ è simile all'originale goethiano nella laconicità della sua sintassi paratattica:

Зажди 3 хвилину -

і ти впокоїш дух ${ }^{88}$.

85 Ivi: 375 . 'Non fermatevi, o giovani amici, / se il pesante fardello allunga la via.'

86 Goethe 2000: I, 142: "Über allen Gipfeln / Ist Ruh, / In allen Wipfeln / Spürest du / Kaum einen Hauch; / Die Vögelein schweigen im Walde. / Warte nur, balde / Ruhest du auch." "Sopra ogni vetta / È quiete, / In ogni fronda / Senti / Appena un soffio; / Gli uccelli tacciono nel bosco. / Aspetta, presto / Riposerai anche tu.'

87 Su Ein Gleiches come trionfo della soggettività - in quanto accettazione di una sua componente costitutiva e ineluttabile quale la finitezza - cfr. Eldridge 2011. Per un'interpretazione generale della lirica si rimanda a Schober 1986.

${ }_{88}$ ZT III, 379. 'Attendi un istante / e calmerai lo spirito.' 
Più complessa sintatticamente e dunque più distante dal testo tedesco è invece la versione $[B]$ :

Зажди, допоки

усе довкола смеркне,

тоді вже і сам спочинь ${ }^{89}$.

I due passi sembrano poter essere messi in connessione con un unico passo della raccolta:

Отак і ти схолонеш, пане-брате,

коли в благословенну ввійдеш смерть ${ }^{90}$.

Il secondo Wandrers Nachtlied si rivela dunque notevolmente distante dall'universo poetico stusiano, al quale può tuttavia offrire l'occasione di una rivalutazione di un tema fondamentale per esso, quale la morte e la lotta dell'io lirico per la sua agognata conquista.

La stessa tematica è ripresa nella prima quartina di Do misjacja ('Alla luna'), traduzione della seconda versione (Spätere Fassung) della goethiana An den Mond, pubblicata per la prima volta nel 1789 , la cui data di composizione è incerta:

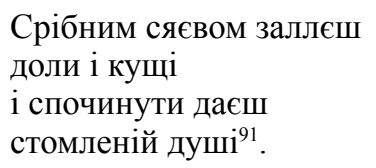

Accostabili alla poesia più tipicamente stusiana sono anche le due strofe conclusive:
Хто од світу одвернувсь,
зла не мавши, - свят,
хто ж до себе пригорнув
любого стократ,
хто подалі од людей,
їх не зовучи,
лабіринтами грудей
бродить уночі 92 .

89 Ibidem. 'Attendi finché / tutt'intorno si farà scuro / e allora riposa tu stesso.'

90 Ivi: 185 . 'E ti raffredderai anche tu, fratello, / quando entrerai nella morte benedetta.'

91 Ivi: 383 . 'Col bagliore della luna riempirai / valli e arbusti / e riposare farai / l'anima stanca.'

92 Ibidem. 'Chi il mondo ha abbandonato / non nel rancore è santo, / chi a sé più volte ha stretto / un amico caro, / chi distante dalla gente, / non volendola chiamare, / nei labirinti del petto / vaga nella notte.' 
Si tratta in entrambi i casi di due rese completamente aderenti all'originale goethiano: il motivo della solitudine dell'artista e del cammino interiore nei meandri del proprio cuore, vicini alla sensibilità poetica stusiana, non hanno reso necessario alcun intervento sostanziale rispetto al testo di partenza.

Accostando l'assimilazione del genio umano alla divinità, da una parte, e l'esortazione a non misurarsi con la forza superiore dei celesti, dall'altra, la poesia goethiana si rivela decisamente affine a Stus. Alla traduzione di Grenzen der Menschheit (Limiti dell'umanità) del 1780 circa fa infatti immediatamente seguito il Wanderers Sturmlied di circa otto anni prima ${ }^{93}$. Se quest'ultimo è inquadrabile nel periodo dello Sturm und Drang goethiano, il primo dei due testimonia invece del passaggio a una fase artistica più matura ${ }^{94}$. Interessante è il contrasto tra Meži ljudstva e una delle più celebri liriche di Čas tvorčosti / Dichtenszeit, [Jak dobre te, ščo smerti ne bojus'ja]. Se nella seconda l'io lirico celebra se stesso in quanto pari agli dei, davanti ai quali non sente l'obbligo di inchinarsi, a imporsi in Meži ljudstva è il riconoscimento della necessità per l'uomo, e dunque anche per il poeta, di non sollevarsi al livello degli dei e di non sfidarli nella loro inarrivabile potenza:

Бо не осміє

смертний з богами

стати на прю 95 .

L'inferiorità degli uomini rispetto agli dei è tuttavia compensata dall'onnipotenza del genere umano sulla terra, di cui è padrone assoluto:
А як упреться
він, твердокостий,
в цю добродайну
землю тривку -
рівних до нього
в світі не знайдеш,
міццю він з дуба
або з вина ${ }^{96}$.

L'io lirico di Pisnja blukal'cja pid čas buri, in conformità con l'originale goethiano, celebra invece la propria seppur parziale (cfr. Windrich 2012: 157) compartecipazione alla forza degli dei:

Ось вода, а ось і твердь $є$, ось і син - води і тверді,

\footnotetext{
93 Sulla complessa datazione della lirica cfr. Windrich 2012: 150.

94 Su Grenzen der Menschheit come cerniera tra lo Sturm und Drang e la classicità goethiana cfr. Titzmann 1998.

95 ZT III, 385. 'Perché non oserà / il mortale con gli dei / scendere a lotta.'

96 Ibidem. 'Come penetrerà / con le forti ossa / nella terra generosa, / nella terra eterna - / simili a lui / non ce n’è al mondo, / è come la quercia, / è come il vino.'
} 
а над ними я блукаю, богорівний ${ }^{97}$.

In Zustrič i proščannja, versione ucraina di Willkommen und Abschied (Benvenuto e addio) del 1771, tra le liriche più note e più rappresentative dello Sturm und Drang (cfr. Brandt 1991: 38-41), sembra essere invece una particolarità lessicale ad aver probabilmente attratto l'attenzione di Stus traduttore. Nella descrizione della notte in cui il cavaliere decide improvvisamente di affrontare l'oscurità e i suoi pericoli per correre tra le braccia dell'amata, il linguaggio di Goethe si rivela particolarmente affine all'immaginario stusiano (Goethe 2000: I, 28):

Schon stand im Nebelkleid die Eiche,

ein aufgetürmter Riese, da,

Wo Finsternis aus dem Gesträuche

Mit hundert schwarzen Augen sah.

Nella versione di Stus spicca l'aggettivo stookyj:

В імлу вгорнувшись, дуб високий

у небо велетом стримів

i, причаївшись, смерк стоокий

за ним дивився 3 чагарів ${ }^{98}$.

Poetismo riportato nei dizionari della lingua ucraina standard, a differenza di diversi hapax e neologismi stusiani costruiti similmente e con la stessa radice, questo aggettivo risulta indubbiamente 'tipico' per il linguaggio poetico di Stus, avvicinando la lirica goethiana in questione alla sua sensibilità poetica.

Nella lirica che segue, Podorožujučy Harcem uzymku, traduzione della celebre Harzreise im Winter (Viaggio invernale nello Harz) della fine degli anni Settanta ${ }^{99}$, diversi sono i punti di contatto tra gli immaginari dei due poeti. Centrale al testo è la tradizionale metafora della strada, fondamentale, come si è più volte osservato, nell'universo poetico stusiano:

[...] Бо лиш господь

накреслив кожному

свою дорогу,

${ }_{97}$ ZT III, 387. 'Ecco l'acqua, ed ecco la terra, / ed ecco il figlio - dell'acqua e della terra, / su di loro io cammino / come un dio.'

98 Ivi: 394. 'Stretta nella nebbia un'alta quercia / si alzava al cielo come un gigante / e, nascostosi, il crepuscolo / la guardava dagli arbusti.'

99 Harzreise im Winter è considerata una dei momenti più complessi dell'opera poetica goethiana, di cui rappresenta di conseguenza un campo privilegiato di riflessione critica. Gli studiosi ne ha messo in risalto, tra i vari aspetti, ora la complessa simbologia spaziale (Riedel 2003), fondata sulla cosmogonia binaria degli inferi e del cielo, ora il rapporto con la tradizione petrarchesca (Mandelarzt 2006), ora gli evidenti risvolti poetologici nel passaggio dallo Sturm und Drang alla maturità (Schmidt 1983 e Kaufmann 2011: 105-168). 


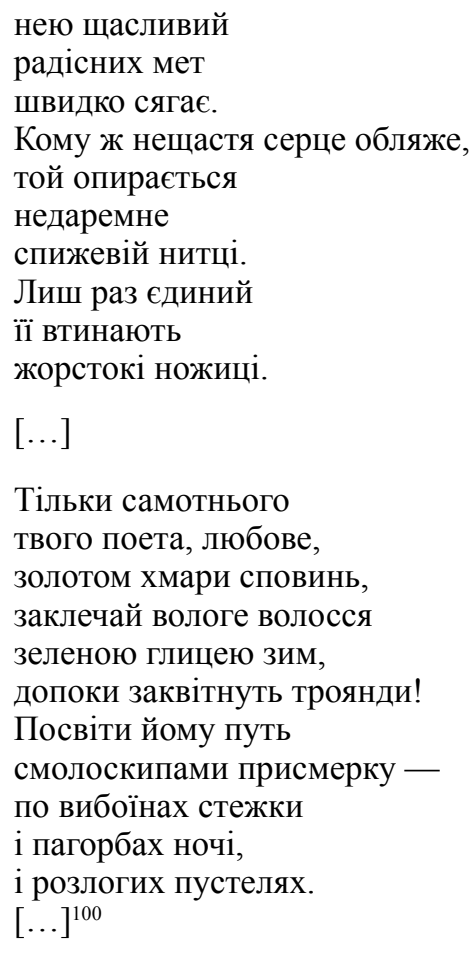

Nella prima delle strofe citate, corrispondente alla seconda del testo, la proclamazione della fedeltà al cammino destinato al singolo è passibile di collegamenti con numerosissime ricorrenze testuali nell'insieme dell'opera stusiana. Nella seconda parte della strofa Stus si discosta dall'originale goethiano, accentuando il carattere passivo e ricettivo dell'uomo colpito dalla disgrazia. Si veda da Harzreise im Winter:

Wem aber Unglück

Das Herz zusammenzog,

Er sträubt vergebens

Sich gegen die Schranken

Des ehernen Fadens.

Den die doch bittre Schere

Nur einmal löst ${ }^{101}$.

100 ZT III, 396-398 passim. 'Perché solo il signore / ha segnato a ciascuno / la sua strada, / chi è felice su di lei / le allegre mete / rapido raggiunge. / Ma a chi la sfortuna / il cuore stringe, / si attiene / non per caso / al filo di bronzo. / Solo una volta / lo tagliano / crudeli forbici. // [...] // Solo il solitario / tuo poeta, o amore, / dell'oro della nube avvolgi, / gli umidi capelli intreccia / delle verdi foglie dell'inverno, / finché non fioriranno le rose! / Illuminagli la via / con le fiaccole del crepuscolo - / sulle buche del cammino / e le alture della notte, / e gli ampli deserti. / [...]'

101 Goethe 2000: I, 50. 'A chi sfortuna / Il cuore ha stretto / Si rizza invano / Contro le sbarre / Del fil di ferro. / Che poi l'amara forbice / Solo una volta taglia.' 
La rassegnazione dell'uomo nel testo stusiano, accostabile a molti passaggi di Čas tvorčosti / Dichtenszeit, si discosta notevolmente dall'inutile ribellione dell'individuo contro le inderogabili decisioni della sorte in Harzreise im Winter. La piena maturità dell'io lirico 'adulto' della raccolta stusiana sembra qui distaccarsi dalla giovanile vitalità dello Sturm und Drang che contraddistingue la poesia goethiana degli anni Settanta e, in parte, dei primi anni Ottanta. Nella descrizione dell'accidentato cammino che attende il poeta nel percorso della vita Podorožujučy Harcem uzymku non si discosta invece dall'originale, fornendo un ottimo esempio di complementarietà tra gli immaginari poetici dei due autori.

La conclusione dell' inno goethiano Ganymed del $1774^{102}$, nell'originale come nella traduzione stusiana Hanimed, è invece in parte avvicinabile alla poetologia trionfante che trova posto nelle liriche di Čas tvorčosti / Dichtenszeit dei primi mesi, in parallelo, come si è osservato, alla raffigurazione dell'ineludibile tragicità di un vicolo cieco esistenziale:

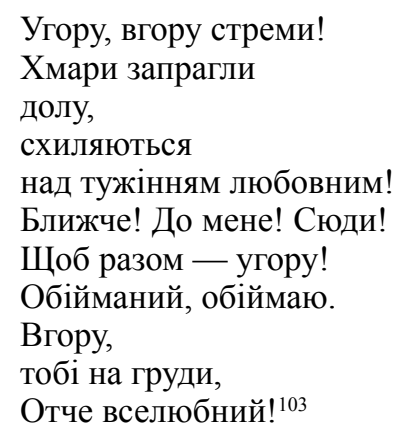

L'aspirazione verso l'alto del Ganimede goethiano si mostra tuttavia decisamente differente dalla trasfigurazione dell'io lirico stusiano in liriche come [Blažen, chto tratyty umije]. Nel superamento dell'apparente contrapposizione tra il gesto passivo dell' accoglimento delle nuvole, scese per accompagnarlo verso il cielo, e l'impeto attivo verso l'alto, Ganimede corona idealmente la propria perfezione. Il soggetto stusiano, al contrario, ricerca in un chimerico volo solitario verso l'ignoto dei cieli la fuga dall'orrore dell'esistenza sulla terra, dove poter realizzare liberamente la propria natura di poeta.

Vera e propria "logodicea"104 è la conclusione di An Werther ( $A$ Werther), prima lirica della Trilogie der Leidenschaft (Trilogia della passione), capolavo-

Sul motivo del cuore nella poesia goethiana e sulle sue fonti si vedano Rüdiger 1990 e Košenina 2013.

102 Sulla complessa vicenda testuale dell'inno goethiano e sui molteplici problemi interpretativi da essa derivanti cfr. Weber 2007.

103 ZT III, 403-404. 'Verso l'alto, verso l'alto affrettati! / Le nuvole si spingono / in basso, tendono / all'amore che soffre, / più vicino! A me! Qui! / Insieme - verso l'alto! / Abbracciato, abbraccio. / Verso l'alto, / nel tuo petto, / o Padre che tutto ami!' 104 Sulla logodicea come principio cardine della lirica stusiana cfr. Kisel'ova 2010. 
ro della poesia goethiana della vecchiaia. La rassegnata, sorridente saggezza del Goethe anziano sembra adattarsi alla penna di Stus non meno dell'appassionata lirica giovanile:

Та вабить шлях, котрого не збагнуть: по лабіринтах серця - наша путь.

І ми, твоїх пильнуючи доріг, колись на смертний станемо поріг. Який зворушливий поета спів, що смерть своїм натхненням одмінив. Тому, хто знав це горе і розпуку, дай, боже, повісти про власну муку ${ }^{105}$.

La metafora del cuore come groviglio di strade da percorrere nell'infinito cammino della conoscenza di sé e del mondo si presenta a Stus traduttore come un'immagine spontaneamente assimilabile al proprio linguaggio poetico. La concretizzazione delle goethiane "passioni" ("Dann zog uns wieder ungewisse Bahn / Der Leidenschaften labyrintisch an") ${ }^{106}$ nel "cuore" (serce) di Do Vertera è inoltre giustificata dal "labirinto del petto" di An den Mond, tradotto letteralmente con la sola modificazione del numero come “лабіринтами грудей". La connessione stabilita in An Werther tra la poesia e la sofferenza è del tutto coerente con l'universo poetico stusiano, all'interno del quale, tuttavia, la raffigurazione della morte è 'novecentescamente' più complessa che nel caso di Goethe, dove essa figura come un nemico da combattere con la forza dell'ispirazione. Ciò spiega, probabilmente, l'omissione nella traduzione stusiana dell'aggettivo halbverschuldet (semicolpevole) presente nel testo originale in riferimento al poeta:

Verstrickt in solche Qualen, halbverschuldet, Geb' ihm ein Gott zu sagen, was er duldet ${ }^{107}$.

Se il vero poeta è immune dalla tentazione del suicidio, a differenza del Werther evocato dal titolo della lirica, il solo pensiero del tradimento della vita appare all'io lirico goethiano come una "colpa". In Do Vertera, al contrario, sono le sofferenze che la fedeltà alla vita comporta a imporsi in primo piano. Un confronto dei rispettivi distici finali mostra infatti la ricorrenza nella versione stusiana di ben tre sostantivi considerabili come sinonimi legati alla sfera del dolore (hore,

105 ZT III, 432. 'E chiama il cammino, incomprensibile. / Nei labirinti del cuore la via. / E noi, seguendo le tue strade, / staremo alla soglia della morte. / È commuovente il canto del poeta, / che, ispirato, cancella la morte. / Chi dolore e disperazione conosce / canti, o Dio, la propria sofferenza.'

106 Goethe 2000: I, 381. 'E ancora ci chiamò il cammino incerto / delle passioni come un labirinto.' soffre.'

107 Ibidem. 'In tali tormenti costretto, colpevole, / un dio gli lasci dire quanto 
rozpuka, muka), mentre nel testo tedesco appare solamente una volta il sostantivo Qualen (torture), accompagnato dal più blando verbo dulden (sopportare).

La seconda parte della Trilogie der Leidenschaft, la lunga Elegie, fu definita da Wilhelm von Humboldt come la più bella e più perfetta tra le poesie goethiane (cfr. Goethe 2000: I, 761). Tradotta da Stus come Marijenbads' $k a$ Elehija, la lirica è accostabile all'universo poetico stusiano in diversi punti. L'epigrafe al testo, autocitazione dalla tragedia Torquato Tasso, nonché chiaramente collegata alla conclusione della precedente An Werther, è un'apoteosi della figura del poeta:

Коли людину біль онімував, дав бог мені сказати, як я мучусь ${ }^{108}$.

La parola poetica vi è raffigurata come vittoria sul dolore, eterno compagno dell'io lirico stusiano. La narrazione dell'incontro del soggetto goethiano con la donna amata, al centro dell'elegia ${ }^{109}$, rappresenta di per sé un tema vicino alla poesia stusiana degli anni della reclusione e dell'esilio, ricca di liriche incentrate su immaginari (e nella seconda parte degli anni Settanta anche reali, se si accetta la validità di un'ispirazione, come anche nel caso dell'originale goethiano, non da ultimo autobiografica; cfr. Oberlin 2006) ritrovamenti con la compagna di vita. Anche in questo caso è nella strofa finale che si concentrano tanto gli elementi del testo interessanti ai fini di una comparazione degli universi lirici dei due poeti, quanto le divergenze nella traduzione rispetto all'originale:

Усесвіт у мені, я в ньому зник без сліду,

адже ж я був улюбленець богів, котрі на мене насилали біди, я ж радощами й горем багатів. Тепер боги мені склепили губи, підносять вгору й віддають погубі ${ }^{110}$.

Rispetto all'originale di Goethe ("Sie drängten mich zum gabeseligen Munde, / Sie trennen mich, und richten mich zu Grunde") ${ }^{111}$, in cui il punto di vista è quello trionfante del passato, la versione stusiana accentua nel penultimo verso la tragi-

108 ZT III, 433. 'Quando il dolore ha ammutolito l'uomo, / dio mi ha lasciato dire quanto soffro.'

109 È stata messa in evidenza, anche in riferimento al titolo della trilogia, la centralità del motivo amoroso, fondamentale nella seconda lirica del ciclo e dunque, in un'ottica trinaria e dialettica, al ciclo nella sua totalità. Cfr. Wünsch 1991: 179-180. L'elegia di Marienbad si configurerebbe inoltre come una poetologia negativa della sofferenza amorosa. Lo sgorgare della parola sarebbe possibile solo in una situazione di distacco dall'amata e, dunque, di dolore. Cfr. Mayer 1986.

110 ZT III, 438. 'È l'universo in me, in lui scomparso, / io, degli dei allora il favorito, / che mandavano disgrazie su di me, / sempre più ricco di gioie e di dolore. / Adesso mi han chiuso gli dei la bocca, / mi sollevano, mi danno alla rovina."

111 Goethe 2000: I, 385. 'Mi spinsero alla bocca generosa, / Mi lacerano, mi spingono giù a terra.' 
cità del presente, in cui il poeta si trova paradossalmente privo della possibilità di sfuggire al proprio dolore grazie alla parola. Nell'ultimo verso, invece, è la divergenza nella rappresentazione spaziale della rovina del soggetto a imporsi all'attenzione del lettore. Se nell'Elegie goethiana la perdizione dell'io è legata alla terra, in quanto raffigurata mediante l'espressione "zu Grunde (zugrunde) richten", nella quale emerge il suolo come superficie concreta contro l'io si schiaccia (rispetto al fraseologizzato "zugrunde"), nella traduzione ucraina il 'decadimento' del soggetto è legato al suo sollevarsi verso il cielo. In ciò la conclusione di Marijenbads ' $k a$ Elehija si ricollega alla complessa e contraddittoria spazialità della lirica stusiana nel suo complesso. Se l'elevazione al di sopra della terra è sinonimo della capacità poetica, essa significa contemporaneamente la morte del soggetto in quanto conclusione della vicenda umana e ingresso in una dimensione altra. Nell'ottica 'goethiana' del testo in questione, tuttavia, l'ascesa in quanto abbandono della vita nel mondo è messa esplicitamente e univocamente in connessione con la rovina $(p o h u b a)$. Si assiste dunque a una rivalutazione nei termini del linguaggio di Stus di un assunto prettamente goethiano, ovvero della necessità per il poeta di incarnare la totalità della vita nell'interezza delle sue manifestazioni terrestri. Non a caso, infatti, lo schiacciamento del soggetto è preceduto dalla sua lacerazione, ovvero dalla perdita della propria integrità di anima e corpo, astrazione e concretezza.

Un ulteriore elemento di interesse nella versione stusiana dell'elegia è dato dalla parte iniziale dell'ottava strofa, dove nelle pieghe del testo sono riconoscibili evidenti consonanze con brani della parte originale di Čas tvorčosti / Dichtenszeit:

Задосить миті, щоб тривку подобу впіймати в мерехтливому видінні.

Старе, вернись, аби одну особу

я відрізнити міг у миготінні

забутих лиць. [...] $]^{112}$

Al di là della non piena coincidenza semantica tra la traduzione e i versi goethiani, a colpire in questo caso è la consonanza di questa strofa nel suo complesso con la parte centrale di una lirica stusiana di fine luglio:

Сосна росте із ночі. Долілиць подоба янгольського парашута, неначе мрія, прогріх і покута у мерехтінні найдорожчих лиць ${ }^{113}$.

Pur non avendo dati concreti sulla datazione delle versioni da Goethe, la loro sequenza induce a ritenere che il lavoro alla Marijenbads 'ka Elehija sia anterio-

112 ZT III, 434. 'Basta un momento per catturare / ciò ch'è durevole e appena luccica. / Vecchio mio, ritorna, ch'io possa / distinguere una persona che balena / tra visi nell'oblio. [...]'

113 Ivi: 293. 'Sorge il pino della notte a testa in giù - / sembra un paracadute d'angelo, / come un sogno, un peccato, un pentimento / nel balenare dei visi più cari.' 
re a luglio e che sia stata dunque la traduzione a influenzare la lirica 'originale'. In quest'ultima, reminiscenze lessicali dell'elegia si ritrovano sparsi nel tessuto verbale di versi quasi adiacenti, fianco a fianco a elementi del linguaggio tecnico come il "paracadute", piuttosto insoliti nel contesto di Čas tvorčosti / Dichtenszeit.

Anche la terza e ultima parte della trilogia sembra trovare una collocazione adeguata nello spazio poetico di Stus. Omyrennja, traduzione letterale di Aussöhnung ('Riconciliazione'), anticipa nel titolo il suo significato di dialettico superamento della crisi descritta in Do Vertera e Marijenbads' ka Elehija. Come si è avuto modo di osservare a proposito delle liriche originali di Čas tvorčosti / Dichtenszeit, la disperazione convive nella raccolta con la fiducia nella propria forza di poeta e nell'azione salvifica della grazia, la cui discesa è stata descritta nella programmatica lirica di apertura [Meni duša sijala nyni vranci]. Si veda, anche in questo caso, l'ultima delle tre strofe della traduzione stusiana:

І раптом від душі відляже туга:

ти ще живий, ще серце в грудях б'ється, що, музикою впившись, хай недуге, а щиро дякує, гучить, сміється.

Тож хай повік святиться це чудове подвійне щастя — музики й любові ${ }^{114}$.

L'inattesa rigenerazione, frutto di un'epifania suscitata dall'arte, è rara nell'universo poetico stusiano, all'interno del quale il potere ristoratore della parola poetica è riservato al soggetto attivo, al poeta. Tuttavia, tanto dall'originale goethiano ("Und so das Herz erleichtert merkt behende, / Daß es noch lebt und schlägt und möchte schlagen, / Zum reinsten Dank der überreichen Spende / Sich selbst erwidernd willig darzutragen" ${ }^{115}$ quanto dalla versione ucraina emerge la possibilità di un'interpretazione del cuore come principio creatore, dapprima ricettore di un impulso poetico, quindi suo (ri)produttore. In Omyrennja è accentuata, rispetto all'originale, la presenza del soggetto, nella terza strofa come nelle parti precedenti. Se in Aussöhnung, infatti, la riflessione lirica è costruita interamente sulla terza persona, la traduzione stusiana fa più volte ricorso alla prima $\mathrm{e}$ alla seconda persona, in sintonia con l'impostazione egocentrica e auto-dialogica della poesia di Stus nel suo insieme. Tirando le somme della riflessione sul ruolo della traduzione della Trilogie der Leidenschaft nel complesso dell'opera di Stus, risulta evidente come il trittico goethiano possa trovare agilmente una collocazione a fianco delle poesie originali, perdendo tuttavia l'impostazione dialettica che lo caratterizza nel profondo. Non a caso, infatti, le tre versioni stusiane non sono raccolte sotto forma di ciclo, ma disposte autonomamente una dopo l'altra,

114 Ivi: 439. 'Di scatto la tristezza lascia l'anima: / sei vivo, ancora batte il cuore in petto, / imbevuto di musica, malato, / ringrazia sincero, risuona, ride. / Santa sia sempre la meravigliosa / doppia felicità: musica e amore.'

115 Goethe 2000: I, 386. 'E così il cuore, svelto, nota con sollievo / che ancora vive, batte e vuole battere, / fortemente grato alla ricca offerta / pronto a offrir se stesso in ricompensa.' 
seppur nel rispetto della successione dell'originale. La poesia di Stus, nell'alternanza di disperazione e trionfo, sconfitta di fronte al male e rinascita mediante la parola che caratterizza la vicenda dell'io lirico suo protagonista, è modernamente estranea a qualsivoglia andamento dialettico, per sua natura estraneo alla sensibilità artistica modernista. Gli opposti convivono in essa fianco a fianco ponendo una seria sfida alla razionalità, in sintonia con l'essenza stessa della poesia.

Alla traduzione della Trilogie der Leidenschaft fa seguito dopo due liriche amorose la versione di Urworte. Orphisch (Parole primordiali. Orfiche), altro capolavoro dell'opera goethiana matura ${ }^{116}$. Breve ciclo composto di cinque ottave, recanti rispettivamente un titolo in greco e in tedesco, Urworte. Orphisch mostra un andamento dialettico che lo avvicina alla trilogia appena discussa. Nella rappresentazione del Demone, del Caso, dell'Amore, della Necessità e della Speranza, il ciclo tratteggia nuovamente un inno all'individualità e al potenziale creatore dell'uomo assolutamente non estraneo alla poesia stusiana. La tragica, modernistica raffigurazione della dolorosa lotta dell'individuo per il mantenimento del proprio io al centro della lirica matura di Stus non può che distinguersi tuttavia nettamente dal trionfante impeto vitale che vena la poesia goethiana dallo Sturm und Drang alla vecchiaia. Come nella Trilogie der Leidenschaft, a sigillare l'accidentata ricerca del soggetto

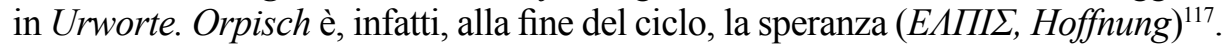

Nel primo dei cinque brevi componimenti, $\triangle A I M \Omega N$, Dämon, sono contemporaneamente proclamate l'indivisibilità dell'io e la necessità per l'io stesso di rimanere fedele alla propria natura. Si veda dalla traduzione stusiana, Praslova. Orfične:

Коли в той день, як світ тобі відкрився,

пораннє сонце зорі привітало,

ти скільки сили до життя пустився,

законів світу пильнувавши стало.

Тож бережи себе, яким зродився -

так, як пророки й відьми наказали.

I сила, й час не владні над тобою,

ти - форма, в ній нуртує дух розвою118.

Rispetto all'originale, nella versione ucraina appare affievolito l'imperativo assoluto dell'identità (si veda il quinto verso della lirica goethiana: "So mußt du

116 Per un'ampia introduzione a Urworte. Orphisch si veda Buck 1996. Lo studioso ha insistito sulla centralità dell'idea di metamorfosi per la costituzione concettuale del ciclo, così come di tutta l'opera goethiana matura.

117 Goethe 2000: I, 360. La critica più recente, in contrasto con le interpretazioni tradizionali del ciclo, non ha tuttavia mancato di mettere in evidenza come la battaglia per l'individuo nel tardo Goethe non sia esente da fatica e contraddizioni. Cfr. Kristiansen 2008.

118 ZT III, 443. 'Quand'in quel giorno il mondo ti si aprì / e il primo sole salutò l'aurora, / quanta forza mettesti nella vita, / le leggi del mondo sempre seguendo. / Conserva te stesso, come sei nato - / come ordinarono profeti e streghe. / La forza e il tempo non ti hanno in pugno, / sei forma. In te è lo spirito che cresce.' 
sein, dir kannst du nicht entfliehen") ${ }^{119}$, ma non per questo perde di efficacia la portata dell'affermazione della soggettività come valore assoluto, fondamentale sia nel classico universo poetico goethiano, sia nel moderno universo poetico stusiano. A porsi come elemento di rottura tra i due sistemi è tuttavia l'idea di "legge", in questi versi elemento regolatore della compartecipazione dell'io al mondo. Rispetto al testo di Goethe, in cui non viene esplicitamente stabilito un legame tra la legge e il mondo ("Nach dem Gesetz, wonach du angetreten") ${ }^{120}$, la versione stusiana sembra accentuare ulteriormente l'hegeliana razionalità del reale di Urworte. Orphisch (“законів світу пильнувавши стало”), che si mostra dunque estremamente distante dal 'teatro dell' assurdo' fondamentale e paradossalmente fondante nell'opera stusiana da Veselyj cvyntar in poi. Attraverso le imprevedibilità del Caso, il conforto dell' Amore e le pressioni della Necessità, attori di primo piano delle tragedie e delle (poche) tragicommedie della poesia stusiana, il percorso della vita dell'uomo è coronato nell'ottica del testo goethiano dalla Speranza:

Колись одхилить брама, вкрай обридла, рубіж, де мури пролягли грубезні.

Та брама - скелі давньої страшидло.

Спадає з нас ярмо, і путо чезне.

А ти, хто має в бурі й хмари сідла, знеси нас на крили над синю бездну.

Вона, що зворушає всі запони, змахне крилом, і відстаюить еони ${ }^{121}$.

Il sostantivo nadija (speranza), così come il suo sinonimo spodivannja, costituisce una significativa ricorrenza testuale nel corpus di Čas tvorčosti / Dichtenszeit ${ }^{122}$, figurando nella maggior parte dei casi come un'illusione da combattere e superare nel cammino verso la morte.

Anche nell'immaginario stusiano la speranza risiede nei cieli, ma il suo effetto sull'uomo è ora distruttivo, ora inefficace:

$[\ldots]$

Уже слабих од надміру надії, котра грудками падає з небес, і нас донищує. [...] $]^{123}$

119 Goethe 2000: I, 359. 'Così hai da essere, / Da te non puoi sfuggire.'

120 Ibidem. 'Per la legge a cui aderisti.'

121 ZT III, 444. 'Aprirà un giorno il cancello, ormai vecchia, / il confine, dove spessi sono i muri. / Il cancello - della rocca spauracchio. / Cade da noi il giogo, e le catene. / Tu, che in nuvole e tempesta hai la sella, / sollevaci sopra l'abisso blu. / Lei sa smuovere tutti gli ostacoli, / muove un'ala - e indietro gli eoni.'

122 Si registrano nella parte originale della raccolta circa cinquanta ricorrenze per il campo semantico della speranza, con una leggera prevalenza del sostantivo spodivannja sul sinonimo nadija.

123 ZT III, 67. '[...] / già deboli d'eccesso di speranze, / che cade dal cielo come a mucchi / e ci distrugge. [...]' 
Se nell'ultimo componimento di Urworte. Orphisch essa risulta in grado di sollevare l'uomo al di sopra dell'abisso, nella poesia originale di Čas tvorčosti / Dichtenszeit la sua identificazione con l'effimera benedizione divina sull'io lirico la condanna all'impotenza. L'uomo è condannato ad affogare nell'incomprensibilità dell'abisso:

Благословенна днино, ти скінчилась.

[...]

Розтанеш. І розмиешся. Немов

світання зірка в галактичній бездні

чи досвітку рожева хоругов

Ти лиш надія наших двох народжень.

Намарна спроба. Проблиском надій

постала 3 висі. $[\ldots]^{124}$

In questa lirica dell'inizio di luglio, probabilmente precedente alla traduzione di Urworte. Orphisch, il paradigma goethiano si mostra ribaltato, negato. Al-

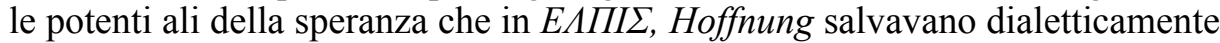
l'uomo dalla tirannia della necessità e dall'imprevedibilità del caso si contrappone così in [Blahoslovenna dnyno, ty skinčylas'] la sua lacerazione, il suo fluttuare tra l'illusione e la consapevolezza dell'incurabilità della propria dualità.

Particolarmente significativa nel contesto stusiano risulta la traduzione di Vermächtnis (Lascito), summa della poesia filosofica goethiana matura:

Ніщо не згине, що існує!

Бо вічне шлях свій ним торує.

Буття щасливий ти єси!

Буття ж бо вічне. I закони

живому стали для ослони,

щоб цілий світ зажив краси.

Віддавна правда нам постала,

високих духом поєднала:

пильнуй же правди, що в віках!

Подякуй, смертний, мудрій волі,

що сонце замикає в колі

і зорям визначає шлях.

А до єства звернись свого -

і там $€$ вісь і знак дороги,

святий для тебе заповіт,

котрого жоден не зламає,

хто про своє сумління дбає,

124 Ivi: 277. 'Giornata benedetta, sei finita. / [...] / Ti perderai! Sparirai! Scomparirai! / Ti squaglierai. Scorrerai via. Come / stella d'aurora nel galattico abisso / o rosa di stendardi del mattino. / Solo speranza delle nostre nascite. / Vana prova. Un lampo di speranze / venuto dall'alto. [...]' 
немов про сонце власних літ.
$[\ldots]$
I як справіку в творчій тиші писали твори наймиліші співці зневіри й сподівань, так ти існуй в чудовнім хисті, бо провіщати душі чисті - найбажаніше 3 покликань ${ }^{125}$.

Contemporaneamente in sintonia e in opposizione alla poesia originale di Čas tvorčosti / Dichtenszeit, questi versi sembrano portare a compimento una delle due tendenze che segnano la poesia stusiana matura nella loro inscindibilità. Seppur meno rilevante da un punto di vista quantitativo, infatti, l'aspirazione centripeta non smette di costituire una componente di primo piano nell'auto-caratterizzazione e ricerca di sé dell'io lirico indiscutibilmente al centro dell'opera di Stus degli anni Settanta. Paradossalmente in parallelo all'impulso centrifugo, ovvero alla narrazione del proprio consumarsi e al richiamo spasmodico di una morte consolatoria che tarda ad arrivare, l'affermazione di se stesso si rivela principio fondamentale dell'auto-rappresentazione del soggetto. L'identificazione goethiana della verità che ciascuno deve perseguire con il proprio essere, realizzata in un testo dal significato esplicitamente programmatico, si ritrova così a integrarsi agevolmente nel macrotesto stusiano, al di là delle moltissime ed evidenti differenze che separano i due universi poetici. La validità dell'accidentato cammino interiore descritto dal soggetto in Čas tvorčosti / Dichtenszeit trova legittimazione e conferma in un testo che della raccolta potrebbe essere epigrafe o coronamento. A suggellare la compatibilità del testamento di Goethe con la lirica stusiana è soprattutto l'inscindibile fusione tra la "verità" e la "poesia" che in esso viene proclamata, nel contesto di un'opera il cui significato poetologico è esplicitamente dichiarato dal titolo stesso. La dichiarazione del primato dell'interiorità, nel quale la lezione di Goethe si ritrova inaspettatamente a fondersi con il modello skovorodiano e rilkiano, equivale per l'io lirico di Stus alla constatazione della giustezza del proprio percorso e a una seppur momentanea vittoria sulla disperazione. Quest'ultima, tuttavia, non arriva a negare il valore almeno altrettanto profondo del suo opposto, il nulla. Al crocevia tra apoteosi

125 Ivi: 553-554. 'Niente perisce di ciò che esiste! / L'eterno in lui ha il suo cammino. / Nell'essere sei tu felice. / L'essere è eterno. E le leggi / ai vivi sono sostegno / perché il mondo si riempia di bellezza. // Da tempo è in noi la verità, / gli alti di spirito ha unito: / segui la verità nei secoli! / Ringrazia, o mortale, la saggia volontà / che il sole chiude in un cerchio / e alle stelle indica il cammino. // Rivolgiti alla tua essenza - / lì è l'asse, il segnale del cammino, / la legge per te sacra / che nessuno mai infrangerà, / chi bada alla propria coscienza, / come al sole dei propri anni. // [...]// Da secoli creando in silenzio / scrivono le opere migliori / cantori di sfiducia e di speranze, / vivi anche tu nello stupendo dono / ché alle anime pure predire / è la più dolce delle vocazioni.' 
del sé e sua distruzione, all'io stusiano maturo non è concesso alcun definitivo trionfo sul Dolore. L'unica costante per esso è la necessità di esistere guardandosi dentro, in un alternarsi di elevazioni e sprofondamenti che non può conoscere per definizione lo scioglimento di una triade dialettica.

Il linguaggio delle traduzioni stusiane da Goethe, infine, può serbare memoria della poesia precedente a Čas tvorčosti / Dichtenszeit, come nel caso di Za čarkoju ('Davanti a una coppa'):

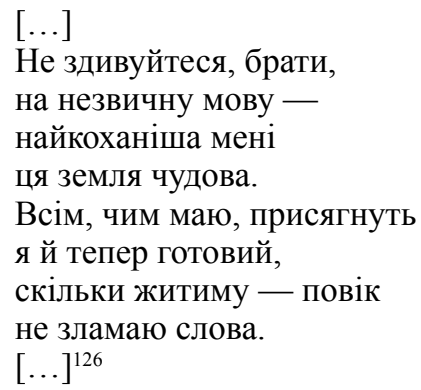

Il riferimento è a [Prysmerkovi sutinky opaly] da Zymovi dereva, precedentemente discussa anche a proposito del suo intertesto pasternakiano. Non è certamente da escludere un ruolo di Tischlied come possibile ipotesto della lirica del 1967 in combinazione con Gamlet dalle Poesie di Jurij Živago. A imporsi in questo caso all'attenzione del lettore è il forte contrasto tra questi versi e la poesia di Čas tvorčosti / Dichtenszeit nel suo complesso, testimone della repentina evoluzione e cristallizzazione della lirica stusiana nel lasso di tempo relativamente breve trascorso tra il 1967 e il 1972.

\section{Palimpsesty}

Palimpsesty è stata più volte identificata con l'opera stusiana tout court, fino a stravolgere il percorso poetico di Stus, rendendolo ingiustamente auctor unius libri. Oltre che per evidenti motivi di trasmissione testuale, questo errore può trovare una giustificazione a posteriori nel carattere di summa intrinseco all'opera, nella quale versi originali si affiancano a riprese e riproposizioni di componimenti e spunti precedenti. Lo stesso titolo Palimpsesty ${ }^{127}$ crea in realtà non

126 Ivi: 451. '[...] Non sorprendetevi, fratelli, / del linguaggio strano, / più amata di tutti per me / è questa terra stupenda. / Tutto ciò che ho a lei / dedicherò, / fino a quando vivrò, / questa parola non infrangerò. [...]'

127 Jurko Pokal'čuk (1941-2008), scrittore e amico di Stus in gioventù, ha indicato in un verso di García Lorca, poeta su cui i due giovani letterati avevano sperimentato le loro abilità di traduttori nei primi anni Sessanta, la possibile origine del titolo dell'opus magnum stusiano. Cfr. Pokal'čuk 1991: 133. Mykola Il'nyc'kyj ha invece 
pochi problemi agli studiosi dell'opera di Stus, dal momento che con esso ci si può riferire a due opere sostanzialmente differenti, alle quali la critica si riferisce con i nomi Mahadans'ka versija e Kyjivs 'ka versija. La prima è la raccolta composta da Stus tra il 1977 e il 1979 durante il confino nella Kolyma, frutto di un'intensa rielaborazione e selezione del materiale poetico di più di un decennio. La seconda versione, più lunga, fu invece concepita a Kiev tra il 1979 e il 1980, alla vigilia della seconda, fatale condanna. Allo stato attuale dei lavori, la Mahadans'ka versija comprende duecentonovanta liriche e non prevede alcuna divisione in sezioni. Più complessa è invece la questione dell'edizione della Kyjivs 'ka versija, di cui il quinto tomo di $Z T$ rappresenta oggi ossimoricamente "il corpus incompiuto più completo" (ZT: V, 3). Frutto di un lungo e complicato lavoro d'archivio, il quinto tomo di $Z T$ presenta un apparato critico più ampio rispetto a $T$, dove per la prima volta era stato presentato il corpus kieviano di $\mathrm{Pa}$ limpsesty. Quest'ultimo consiste di circa trecentosessanta liriche, divise in due parti, di cui la seconda è numericamente maggiore di circa trenta componimenti. A causa dell'interruzione dei lavori a $Z T$ non ha ancora visto la luce la ricostruzione della terza parte dell'opera, prevista da Stus ma non realizzata a causa della nuova condanna e del conseguente arresto. Per il momento, il lettore dispone solamente di circa ottantacinque liriche pubblicate in $T$ come presunta terza parte dell'opera, sulla base degli indici alfabetici compilati dall'autore. Stus non riuscì nemmeno ad approntare completamente la seconda sezione, di cui una parte è conservata solamente in minuta. Al periodo tra il 1973 e il 1978 risalgono inoltre oltre circa duecento componimenti non destinati a essere inclusi nella raccolta.

Si farà in seguito riferimento alla Kyjivs'ka versija in virtù della sua maggiore ampiezza e della cronologia della sua seppur parziale composizione, nella consapevolezza della necessità di uno studio approfondito delle divergenze nelle due versioni. Fondamentale nell'ideazione e nella concretizzazione di Palimpsesty è la ripresa e ricontestualizzazione di numerose liriche di Čas tvorčosti / Dichtenszeit e Veselyj cvyntar, spesso in una versione divergente dall'originale. Al momento la Kyjivs 'ka versija comprende circa ottantacinque liriche da Čas tvorčosti / Dichtenszeit e sedici da Veselyj cvyntar. Ciò è plausibilmente da ricondurre all'incertezza dell'autore sulle sorti delle due raccolte precedenti, da lui ritenute con buona probabilità perdute per sempre. Alquanto inferiore è il numero delle liriche non originali nella Mahadans 'ka versija. La seconda parte della Kyjivs 'ka versija, infatti, è inaugurata da dieci liriche da Veselyj cvyntar e si conclude con cinquanta liriche da Čas tvorčosti / Dichtenszeit. Evidente nell'economia della Kyjivs 'ka versija risulta la ripetizione di circa trenta componimenti

ricordato come Palimpsest sia anche il titolo di una poesia di Petro Karmans'kyj (18781956), fondamentale esponente del primo Modernismo ucraino, sicuramente nota a Stus. Come nota Halyna Kolodkevyč, anche Mykola Voronyj (1871-1938), contemporaneo di Karmans'kyj e a lui vicino per sensibilità estetica, compose una lirica intitolata Palimpsest, nella quale è l'anima dell'io lirico a essere assimilata a un palinsesto: “Цe душа моя — той палімпсест” (Voronyj 1996: 120 - 'È l'anima mia quel palinsesto'). Cfr. Kolodkevyč 2015: 41. 
in entrambe le parti, nonché all'interno della stessa parte, anche per più di una volta. È difficile stabilire se ciò sia da attribuirsi a una consapevole scelta artistica di Stus o all'interruzione della preparazione dell'opera in seguito alla condanna e all'arresto, anche se la seconda ipotesi sembra non priva di fondamento.

A distinguere nettamente la Kyjivs' $k a$ versija dalla Mahadans 'ka versija è, inoltre, la diversa disposizione delle liriche, nel contesto di un'opera in cui la disposizione stessa, messo da parte il principio cronologico centrale a Čas tvorčosti / Dichtenszeit, si ritrova a giocare un ruolo di primo piano. Nella sua (almeno progettata) suddivisione in tre sezioni e nell'importanza che in essa vengono ad assumere i legami semantici tra le liriche contigue ${ }^{128}$, la Kyjivs ' $k a$ versija di Palimpsesty risulta strutturalmente accostabile a Zymovi dereva, ugualmente tripartita, di cui non riprende, tuttavia, alcun singolo testo ${ }^{129}$.

La raccolta è introdotta da due epigrafi. La prima è un'autocitazione da una delle liriche di Palimpsesty:

Благословляю твою сваволю дорого долі, дорого болю ${ }^{130}$.

La seconda mira a creare un nesso profondo tra l'autore implicito e l'io lirico:

У новій збірці — вірші, написані між 1971-77 роками. В ній — мої болі й радощі, мрії й передуми, спогади й сніння, образки життя ${ }^{131}$.

La benedizione del duro cammino imposto al soggetto dalla sorte sembra caratterizzare la raccolta nel segno della tarda opera rilkiana, nella quale la lode dell'esistente in ogni sua manifestazione, come nella Neunte Elegie, si impone come elemento centrale del sistema poetico. Nell'implicito avvicinamento della concezione generale della raccolta ai presupposti fondamentali dell'universo poetico del Rilke maturo, l'io lirico di Palimpsesty ne marca tuttavia immediatamente le differenze. L'atteggiamento del destino nei confronti dell'uomo è infatti definito come "arbitrio", introducendo così una connotazione chiaramente negativa nella caratterizzazione dei rapporti tra l'individuo e la propria sorte, difficilmente accostabile all'assoluta "affermatività" (Bejahung) del tardo Rilke. L'annotazione al lettore, invece, sembra proporre una chiave di lettura dell'opera sostanzialmente discordante dal suo effettivo contenuto, predisponendone una semplicistica interpretazione in chiave autobiografica e definendo come "scenette

128 Nell'apparato del quinto tomo di ZT Dmytro Stus parla a più riprese di poetyčni zroščennja ('agglomerati poetici'). Nell'analisi di Zymovi dereva si è ampiamente mostrata l'importanza dello stesso principio compositivo.

129 Si ricordi l'edizione all'estero di Zymovi dereva nel 1970. Ciò metteva in secondo piano, probabilmente, la necessità di fissare nuovamente sulla carta e preservare i testi della grande summa dell'opera giovanile.

130 ZT V, 5. 'Benedetto il tuo arbitrio, / o strada del destino, o strada del dolore.'

131 Ibidem. 'Nella nuova raccolta - i versi scritti tra il 1971 e il 1977. I miei dolori e le mie gioie, i desideri e i ripensamenti, i ricordi e i sogni, scenette di vita.' 
di vita" un ampio e variegato corpus costituito in buona parte da liriche ermetiche, nelle quali, dunque, la ricostruzione del significato passa attraverso un lungo e difficoltoso processo di svisceramento del significante, del suo complesso tessuto fonico-semantico, e dei suoi risvolti culturali e intertestuali ${ }^{132}$. Sembra dunque essere l'autore implicito stesso ad anticipare e favorire quell'approccio riduttivistico a Palimpsesty ed ergo all'opera di Stus nel suo insieme che a tutt'oggi non ha purtroppo smesso di costituire il nocciolo dello stusoznavstvo ucraino.

La lunga lirica di apertura della Kyjivs 'ka versija, databile alla seconda metà degli anni Settanta $(\mathrm{ZT}: \mathrm{V}, 665)$, è una perfetta esemplificazione della poesia ermetica stusiana dei tardi Palimpsesty, in evidente contrasto con l'annotazione in calce appena discussa:

Гойдається вечора зламана віть, як костур сліпого, що тичеться в простір осінньої невіді. Жалощів брості коцюрблються в снінні - а дерево спить. [...]

Гойдається вечора зламана віть, і синню тяжкою в осінній пожежі мій дух басаманить. Кінчилися стежі: нам світ не належить - бовваном стоїть. Шалена вогненна дорога кипить. Взялась кушпелою - обвітрені крони всю душу обрушать у довгі полони і згадкою - вечора зламана віть. Тугий небокрай, погорбатілий з люті гірких дорікань. О піддайся покуті самотності! (Господи, дай мені жить!) Удай, що обтято дорогу. Що спить душа, розколошкана в смертній оркані високих наближень. На серця екрані гойдається вечора зламана віть. [...]

Тепер, недоріко, подайсь за водою (а нишком послухай: чи всесвіт не спить?)

Усесвіт - не спить. Він ворушиться, вовтузиться, тузаний хвацько під боки мороками спогадів. Луняться кроки, це, Господи, сяєво. Це - торжество: надій, проминань, і наближень, і навертань у своє, у забуте й дочасне.

$[\ldots]$

Це довге кружляння — над світом і під

132 Per un'approfondita discussione sul significato del temine poesia ermetica nell'ampiezza dei significati che questo termine ha assunto nel Novecento si rimanda a Waldschmidt 2011: 13-41. 


\begin{abstract}
кошлатими хмарами, під багряними торосами замірів. Господи, з ними нехай порідниться навернений рід отой, що принишк попід товщею неб залізних, із пластику, шкла і бетону. Надибую пісню, ловлю їй до тону шовкового голосу (зацний погреб). Поорана чорна дорога кипить нема ні знаку - од прадавнього шляху. Сподоб мене, Боже, високого краху! Вільготно гойдається зламана віть ${ }^{133}$.
\end{abstract}

Nella scissione tra la tendenza a una raffigurazione pura, slegata dalla mimesi razionale, e la sottomissione del dettaglio alla creazione di un quadro di insieme ricomponibile solo a una lettura profonda, [Hojdajet'sja večora zlamana vit'] è a buon diritto definibile come una lirica programmatica ${ }^{134}$. L'identificazione di se stesso con un ramo spezzato che il soggetto sviluppa nella prima parte della lirica induce a considerarne il primo dei rilkiani Sonette an Orpheus come probabile ipotesto:

Da stieg ein Baum! O reine Übersteigung!

O Orpheus singt! O hoher Baum im Ohr! ${ }^{135}$

Parte di un tutto a cui non è più in grado di apportare un proprio contributo (l'albero che dorme), l'io lirico del primo "palinsesto" stusiano si rivela dun-

133 Ivi: 7: 'Dondola il ramo rotto della sera, / come bastone d'un cieco nello spazio / ignoto dell'autunno. Della tristezza i germogli / si piegano nel sonno - e dorme l'albero. / [...] / Dondola il ramo rotto della sera, / e di pesante blu nell'incendio d'autunno / si macchia lo spirito. Finiti i sentieri: / non c'appartiene il mondo - è un idolo. / Matta ribolle la strada infuocata. / È un vortice. I rami nel vento / l'anima tutta spingono in lunghe prigionie, / e col ricordo - il ramo rotto della sera. / E il sole - tuo, verticale, ribolle. / Teso l'orizzonte, ingobbito dell'ira / di amari rimproveri. Cedi all'espiazione / della solitudine! (Signore, fammi vivere!) / Fingi che sia interrotta la strada. Che dorma / l'anima, dall'uragano scossa / di ciò che alto si avvicina. Sullo schermo del cuore / dondola il ramo rotto della sera. / [...] / Adesso, incapace, cerca l'acqua / (e di soppiatto ascolta: non dorme - l'universo?). / L'universo - non dorme. Si muove, si / agita, spinto con forza sui fianchi / dai bui ricordi. Risuonano i passi / è, Signore, bagliore. È trionfo: / speranze, irradiamenti, avvicinarsi, / ritorni in ciò ch'è proprio, che fu, precoce. / [...] / Questo muoversi in cerchio - sul mondo e sotto / le nubi arruffate, i purpurei / massi degli intenti. Dio, con loro / che si unisca questa stirpe convertita, / impietrita sotto la massa dei cieli - / di ferro, plastica, vetro e cemento. / Trovo un canto, cerco per il suo tono / una serica voce (nobili esequie). / Arata la nera strada ribolle / non vi son segni del cammino antico. / Concedimi, Dio, un'alta rovina! / Umido si agita il ramo rotto.'

134 Così essa è piuttosto frettolosamente definita nei commenti di $Z T$, in riferimento alla "filosofia stusiana dello stoicismo" (ivi: 665).

135 Rilke 1996: II, 241. 'Vi salì un albero. O puro, o alto trapasso! / Orfeo canto! $\mathrm{O}$ alto albero nell'orecchio!' 
que un Orfeo caduto, impotente, fossilizzato: non più un albero, ma solamente un ramo inerte ${ }^{136}$. Sbattuto dai colpi d'aria di un cielo terribilmente blu, egli è confrontato all'incomprensibilità di un mondo impenetrabile e minaccioso. Nella seconda parte del testo, tuttavia, dopo che l'io lirico è riuscito a imporre a se stesso la ricerca di un nutrimento, l'universo (vsesvit, Weltall) si rivela a lui vicino, vittima delle stesse sofferenze e ugualmente sottomesso al potere lacerante del ricordo. Come in diverse liriche di Zymovi dereva, Veselyj cvyntar e Čas tvorčosti / Dichtenszeit, si assiste dunque a un'identificazione negativa dell'io lirico e del mondo all'insegna del dolore e dell'imperfezione. Alla raffigurazione del tormento dell'universo fa tuttavia seguito un inaspettato tripudio di gioia e di speranza nel segno del riavvicinamento dell'io alla propria perduta identità. Alla luce dell'accostamento del soggetto a un Orfeo postmodernamente decaduto sembra a questo proposito sostenibile una lettura della lirica in chiave poetologica. La luce trionfale che irradia il soggetto e l'universo è la (ritrovata) capacità poetica. Un'interpretazione in questo senso trova inoltre giustificazione nella scelta di porre [Hojdajets'ja večora zlamana vit'] in apertura della raccolta, in sintonia con la luce stellare che aveva illuminato l'io lirico all'inizio di Čas tvorčosti / Dichtenszeit. La parola poetica è ciò che è "proprio", "scordato" e inaspettatamente "precoce". La tematica poetologica è dunque ripresa nella parte conclusiva della lirica, con un possibile ulteriore riferimento ai Sonette an Orpheus:

Einzig das Lied überm Land heiligt und feiert ${ }^{137}$.

Nella quartina finale, tuttavia, la speranza di una rinascita, portata con sé dal ritorno dell'ispirazione, è nuovamente accantonata nel buio di una strada priva di ogni punto di riferimento. Al soggetto non resta che evocare il dio che gli è stato interlocutore per tutto il corso della lirica affinché quest'ultimo gli conceda la grazia di una fine, in netta contrapposizione alla sete di vita precedentemente espressa al dio stesso. La morte, in sintonia con la poetologia implicitamente sviluppata nei versi antecedenti, è "alta", degna della sofferenza di un novello, seppur decaduto Orfeo. Accostabile all'universo poetico dei Sonette an Orpheus è altresì l'inaspettato abbassamento nei meandri della materialità della vita moderna nella descrizione dei cieli che opprimono la stirpe. Come in [Hojdajet'sja večora zlamana vit'] l'evocazione di plastica, vetro e cemento si staglia stridente sullo sfondo dell'atemporalità della situazione dell'io lirico, così nei sonetti rilkiani il dialogo con il cantore tracio è a tratti imprevedibilmente rivolto all'affermarsi della modernità:

136 Di possibile memoria, inoltre, svidzins'kiana. Si veda Svidzins'kyj 2004: I, 143: “Ще осінь, поломениста квітка, / Гойдає зламаним стеблом. / Ще не роздерте вітром / Вогке тепло. / І руки в тебе теплі ще, / Коли зіходимось надвечір, / I шерхлий осокір / Над нами ржаво крекче.” “Ancora l'autunno, fiore infiammato, / Muove un ramo rotto. / Ancora non strappato dal vento / Il caldo umido. / E le tue mani sono ancora calde, / Quando ci riuniamo la sera, / E il pioppo ruvido / geme rugginoso.'

137 Rilke 1996: II, 250. 'Solo il canto sulla landa / celebra e santifica.' 
Sieh, die Maschine:

wie sie sich wälzt und rächt

und uns entstellt und schwächt ${ }^{138}$.

Un diretto accostamento di questi versi con la descrizione stusiana dell'effetto opprimente della materia sull'uomo non sembra da escludersi. Al modello rilkiano, ora corretto in chiave avanguardistica, sembra inoltre da ricondursi "lo schermo del cuore" alla metà del testo, come già in Čas tvorčosti / Dichtenszeit.

La ripetizione del primo verso e le sue variazioni contribuiscono al dipanarsi di una lirica inconsueta nel panorama dell'opera stusiana che aveva preceduto Palimpsesty, una lirica scissa tra referenzialità e pura astrazione, nella quale la possibilità di ricostruire un andamento narrativo, come si è appena cercato di mostrare, non esclude per il lettore l'opportunità di abbandonarsi alla musica del testo, accantonandone almeno parzialmente la significazione. Anche il ritmo anfibrachico, decisamente raro nel repertorio del poeta, contribuisce a conferire a [Hojdajet 'sja večora zlamana vit'] un posto particolare tra i capolavori di Stus, senza per questo negarne l' 'esemplarità' come introduzione all'ermetismo di Palimpsesty. Nell'inafferrabilità del loro ondeggiamento tra l'innalzarsi del canto trionfante e lo sprofondamento nell'angoscia questi versi tradiscono le intense frequentazioni dello Stus degli anni Settanta con la lirica rilkiana matura.

Netto è il contrasto tra la maestosità dei lunghi versi anfibrachici e l'immaginario ermetico di [Hojdajet'sja večora zlamana vit'] e la secchezza del trimetro giambico della lirica immediatamente successiva nella Kyjivs'ka versija, accostabile all'universo poetico di Veselyj cvyntar. Non a caso a essa fanno seguito due liriche della raccolta del 1970. Nella sua scarsità di tropi e nell'apparente semplicità che la contraddistingue, [Ja tak i ne zbahnuv], la cui prima testimonianza risale al 1974, ben mostra come Palimpsesty, come anticipato dal titolo e a differenza di Čas tvorčosti / Dichtenszeit, sia un'opera scissa tra tensioni diverse, più difficilmente classificabile sotto un'etichetta tematico-stilistica unitaria:
Я так і не збагнув
і досі ще не знаю, чи світ мене минає
чи я його минув.
Днедавне завзялось у снінні чарувати.
Та й знакомиті дати
мені проставив хтось!
Світ повен сподівань,

138 Ivi: 249. 'Guarda, la macchina: / come si agita, come si vendica, / ci sfigura, ci indebolisce.' La "macchina" è tematizzata in due sonetti (XVIII della Prima parte, qui citato, e X della Seconda), mentre nel XIX della seconda parte l'io lirico riflette sull'effetto logorante dell'economia moderna per l'uomo. 
мов став, що ні схлюпнеться.

І царство - не минеться

без клятв і без карань ${ }^{139}$.

Nonostante le evidenti differenze stilistiche, tuttavia, le due liriche sono accomunate dalla stessa tensione verso l'astrazione e da una simile opacizzazione semantica. La seconda lirica risulta inaspettatamente più oscura della prima, nonostante l'innegabile semplicità della sua struttura e della sua imagery. In essa la riflessione sul rapporto tra il soggetto e il mondo, come si è visto tematica centrale della lirica stusiana, è complicata dall'ambiguità della rappresentazione del mondo stesso, dapprima intrinsecamente estraneo all'io lirico, poi avvicinabile, comprensibile e portatore di speranza. Nel suo insieme [Ja tak i ne zbahnuv] sembra sottrarsi a un'interpretazione razionale complessiva, anticipando una tendenza comune a numerose liriche della raccolta. La prima quartina, spiazzante nella semplicità e nell'impoetica chiarezza che la contraddistinguono, si presta così a un'interpretazione metapoetica: come il mondo e il rapporto della soggettività con esso, anche la lirica sfugge a una comprensione assoluta e definitiva, rimandando a un continuo bisogno interpretativo, destinato a una frustrante, dolorosa, ma produttiva insaziabilità.

Se paragonata a Čas tvorčosti / Dichtenszeit, con cui condivide numerose poesie, il tormentato rapporto tra lo sfondo biografico dell'autore e la vicenda esistenziale dell'io lirico, nonché, parzialmente, il periodo di gestazione e scrittura, Palimpsesty si rivela un'opera più complessa, sfaccettata e difficilmente sintetizzabile. Se nella raccolta del 1972-1973 l'assoluta concentrazione del soggetto su se stesso, messa ancora più in evidenza dalla sua auto-raffigurazione spaziale nell'angusto microcosmo della cella carceraria, contribuisce al formarsi di una narrazione lirica coerente e altamente unitaria, la summa poetica stusiana dei secondi anni Settanta si rivela in confronto alquanto centrifuga, non da ultimo per la sua tormentata vicenda testuale. L'ulteriore ermetizzazione del linguaggio e un ampliamento, o ri-posizionamento della prospettiva, ora rivolta nuovamente non soltanto sul sé, ne fanno un testo di più ampio respiro. L'attenzione del soggetto, oltre che su stesso e sulla continua rielaborazione del proprio io, così come sul vissuto amoroso e sul mito dell'Ucraina, si disperde a più riprese nei labirinti di una parola ermetica in cammino verso la liberazione dalla rigorosa aderenza alla razionalità della mimesis.

Da una delle liriche iniziali della prima parte emerge con chiarezza la nuova possibilità di una poesia non necessariamente incentrata sull'io:

Пливуть видіння, пагорбами криті,

а за горою - паділ і байрак.

Цвітуть волошки в золотому житі,

139 ZT V, 9. 'Capito non ho ancora / e ancora non lo so, / se è il mondo che mi evita / o io che l'ho evitato. / L'antico si è messo / a incantare nel sonno. / E date importanti / qualcuno mi ha assegnato! / Il mondo è pieno di speranze, / come uno stagno che neanche schizza. / E questo regno passerà / senza castighi e giuramenti.' 


\begin{abstract}
а цей смарагдом луки сяє мак.
I таємнича мавка білорука

ступає - ніби вічністю пливе.

Кружляє мак. А над смарагдом луки

уже нависло небо гробове ${ }^{140}$.
\end{abstract}

Evidente è l'innovazione di questi versi nel contesto dell'egocentrismo della tarda lirica di Stus. L'epoché dell'io nel testo si declina nella sua riduzione a puro occhio e a pura voce, al di là della cortina della rappresentazione. A imporsi al centro della scena sono le visioni stesse, che la retina del soggetto si limita a registrare e, in due casi, a interpretare metaforicamente (lo smeraldo del prato, il flusso dell'eternità). L'imagery oscilla tra l'atemporale idillio folclorico di una natura incantata, in cui la bellezza è al servizio della vita dell'uomo (i fiordalisi nel grano) e il mito promette eternità, e la minaccia di un cielo ostile connotato espressionisticamente ${ }^{141}$.

L'ampliamento della visione dell'io al di fuori dei confini della propria anima era stata anticipato in crescendo nelle liriche precedenti. A [Ja tak $i$ ne zbahnuv] fanno infatti seguito la programmatica [Sto dzerkal sprjamovano na mene] e [Cej stav povisplenyj, osinnij, čornyj stav], entrambe da Veselyj cvyntar. Come si ricorderà, quest'ultima si conclude con un distico di ispirazione esistenzialista, nel quale viene tematizzata la comunanza tra l'inquietante, espressionistico paesaggio naturale descritto nelle tre quartine precedenti $\mathrm{e}$ l'anima inquieta del soggetto:

Неприхищений, а чуєш, чуєш протяг у душі?

La lirica successiva riprende la domanda conclusiva di [Cej stav povisplenyj, osinnij, čornyj stav] per fornire una risposta che allarga la prospettiva dell'io dalla propria anima alla realtà esterna:

Здається, чую: лопають каштани,
жовтозелену викидають брость
і зовсім поруч - київське весняне
пахуче небо гуком налилось.
Здається, бачу: рвуться буйні трави,
де вже відговорили всі струмки,

140 Ivi: 13. 'Nuotano visioni, di poggi coperte, / e dietro alla montagna - valle e bosco. / Fiordalisi in fiore nel grano d'oro, / e sullo smeraldo del prato splendono i papaveri. / E una misteriosa ninfa dalle bianche mani / incede - come nuotasse nell'eternità. / Si muovono i papaveri. E sullo smeraldo del prato / già incombe il cielo tombale.'

${ }^{141}$ Si veda la strofa conclusiva di Die Stadt der Qual ('La città del tormento') di Georg Heym, in: Heym 2006: 138: "Ich bin der Leib von ausgehölter Qual. / In meinen Achseln rotes Feuer hängt. / Ich bäume mich, und schreie manchmal laut, / In schwarzer Himmel Grabe ausgerenkt." 'Sono il corpo del tormento eroso. / Nelle mie ascelle il rosso fuoco. / Mi ergo e urlo ad alta voce / Nella tomba dei cieli neri.' 
а Україна, Лебединя, Слава

за сином назирає з-під руки.

$[\ldots]^{142}$

La descrizione dell'improvviso trionfo della primavera, connotato come un'inarrestabile estasi sensuale, introduce condensandoli nello spazio di pochi versi i motivi tradizionali che si ripetono con frequenza in Palimpsesty, ovvero l'Ucraina, la famiglia e la natura nell'inarrestabilità del suo eterno mutare. L'atteggiamento ricettivo del soggetto è qui direttamente tematizzato, mentre nella successiva [Plyvut'vydinnja, pahorbamy kryti] il suo occhio è solo implicitamente presente, a dimostrazione del riaffermarsi in Palimpsesty di una poesia non necessariamente incentrata sull'io lirico, accanto, ben inteso, all'epopea dell'anima e della sua ispirazione artistica che il lettore di Stus conosce da Ćas tvorčosti / Dichtenszeit. Le connessioni tra le prime sei liriche della prima parte di Palimpsesty sono ben rappresentative dei meccanismi alla base del funzionamento della raccolta nel suo insieme. Come Zymovi dereva, infatti, il capolavoro stusiano è costruito in parte sull'accostamento di gruppi di liriche unite da una tematica comune, oppure da un simile atteggiamento dell'io lirico. Questo meccanismo di composizione, che giustifica e motiva il riutilizzo di testi precedentemente inclusi in altre raccolte, garantisce all'opera un prisma tematico più ampio e differenziato rispetto all'universo monistico di Čas tvorčosti / Dichtenszeit.

Che in Palimpsesty lo spazio dell'io lirico sia più difficilmente scindibile dalla realtà circostante è dimostrabile sulla base di numerose poesie. Si veda la nota [Jaka nesterpna ridna čužyna]:

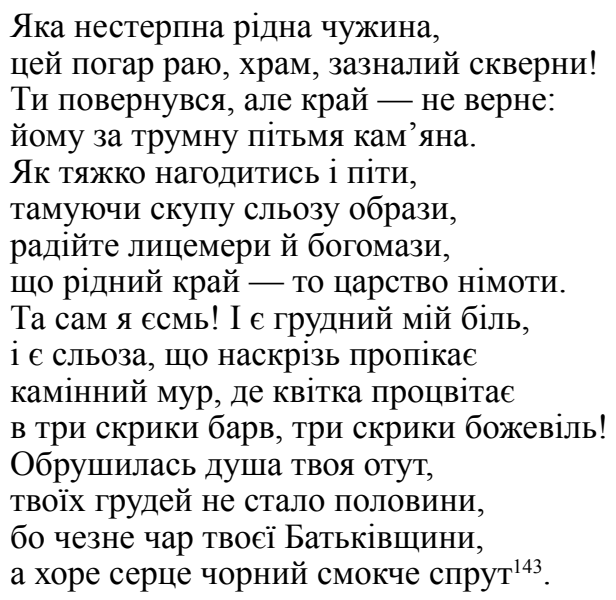

${ }^{142} \mathrm{ZT} \mathrm{V}, 12$. 'Mi sembra di sentire: sbocciano i castagni, / crescono germogli giallo-verdi, / e proprio accanto, primaverile, il cielo / odoroso di Kiev risuona. / Mi sembra di vedere: irrompono le erbe, / dove già parlano i torrenti, / e l'Ucraina, cigno, gloria, / il figlio guarda da sotto le mani. / [...]'

143 Ivi: 20 . 'Mi è straniera la terra natia, / paradiso bruciato, tempio profanato! / Sei tornato, non tornerà - il paese: / ha per lapide tenebre di pietra. / Difficile apprestarsi e 
Ricollegandosi tanto alla tradizione ševčenkiana, quanto alla sensibilità espressionista, questi versi postulano inizialmente una totale contrapposizione tra l'io e il mondo. Come in Veselyj cvyntar, quest'ultimo tende a identificarsi con la patria. Nella raccolta del 1970, tuttavia, l'interesse sperimentale per il linguaggio delle Avanguardie e gli spunti postmoderni attenuavano il pathos romantico, qui nuovamente in primo piano. L'invettiva dell'io lirico contro i responsabili del declino morale della terra natia, che difficilmente non risulterà anacronistica al lettore occidentale nel contesto della cultura poetica degli anni Settanta, introduce dapprima una sua decisa auto-affermazione, destinata a subire nella quartina finale del testo un brusco ripensamento. La sostanziale identificazione dell' io lirico lacerato con la patria che ha perduto perché essa stessa sta scomparendo, sottoposta a un processo di snaturamento morale e intellettuale, mostra l'impossibilità di scindere il singolo e la comunità di cui egli è - o vorrebbe essere - parte. L'io non è ora concepibile senza il mondo, in un contesto in cui quest'ultimo si riduce agli stretti confini della patria. Il decadimento della patria causa ipso facto la consunzione del soggetto. Nel passaggio da un'iniziale contrapposizione tra l'io e il mondo a una loro identificazione negativa si assiste all'immagine del disgregarsi della realtà nel suo insieme.

La lirica successiva, già elaborata in un due versioni in Čas tvorčosti / Dichtenszeit, presenta una simile compenetrazione tra l'uomo e la realtà sotto il segno del dolore e dello sfacelo:

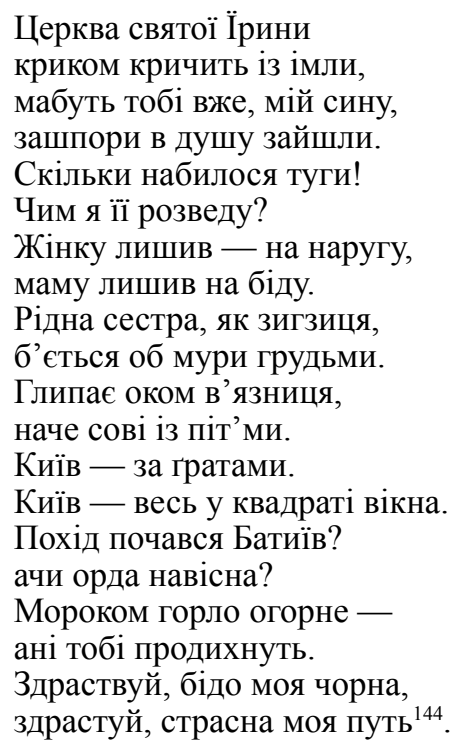

ripartire, / fermando dell'offesa le lacrime avare, / gioite, voi ipocriti e bigotti, / la patria è ora il regno delle tenebre. / Ma io sono! Ed è il mio dolore in seno / e una lacrima brucia per intero / il muro di pietra, dove sboccia un fiore / in tre grida di colori e di follia! / È rovinata qui l'anima tua, / metà del petto tuo più non è, / perché della Patria scompare l'incanto / e il cuore risucchia una nera piovra.'

144 Ivi: 21. 'La chiesa di Santa Irina / dalla nebbia grida gridando, / forse a te, figlio mio, / il gelo è entrato nell'anima. / Quanta tristezza c'è! / Come fare a dissiparla? / La 
La "carne dell'anima" lacerata che in [Jaka nesterpna ridna čužyna] tormentava il soggetto, privato dell'appartenenza a una patria che potesse riconoscere come sua, è ora quella del figlio ${ }^{145}$, presente in numerose liriche di Čas tvorčosti / Dichtenszeit e Palimpsesty. La patria scomparsa è qui rappresentata per sineddoche e metafora dalla chiesa di Santa Irina, distrutta da Batu Khan alla metà del Duecento ${ }^{146}$. L'impotenza del soggetto, macchiatosi delle atroci sofferenze che infligge alle donne a lui vicine, lo rende accostabile a un Cristo condannato alla croce, senza che si profili tuttavia la speranza di una resurrezione. L'io lirico e la realtà sono nuovamente uniti nella condanna a un inarrestabile decadimento. Rispetto a entrambe le versioni del testo incluse nella raccolta precedente (ZT III, 88, 329), questa nuova redazione, in conformità con la generale tendenza a una maggiore compenetrazione tra l'io e il mondo nel passaggio da Čas tvorčosti / Dichtenszeit a Palimpsesty, accentua l'identificazione tra il soggetto e Kiev, specularmente disposti ai due lati della finestra sbarrata della cella carceraria: il tredicesimo e il quattordicesimo verso del testo di Palimpsesty erano infatti assenti nelle due varianti antecedenti.

La più tarda e più lunga delle due versioni della lirica incluse in Čas tvorčosti / Dichtenszeit non manca di inserire il vissuto dell'io nel quadro complessivo della tragicità della vicenda umana, arrivando anche ad attribuire la croce all'umanità nel suo insieme:

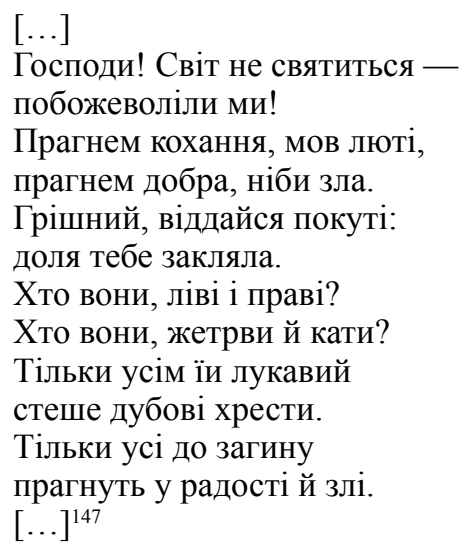

moglie ho lasciato al disprezzo, / la mamma ho lasciato in disgrazia. / Come un cuculo la sorella / sbatte il petto al muro. / Si guarda attorno la cella / come civetta al buio. / Kiev - oltre le grate, / nel quadrato di una finestra. / È iniziato l'attacco di Batu? / Cosa fa l'orda guerriera? / Si chiude la gola di tenebra - / non potrai più respirare. / Salve, disgrazia mia nera, / salute, oh mia via crucis.'

145 A proposito dell'immagine del gelo che trafigge l'anima, in questo caso dell'amata, si ricordi [Jak, skažy, do tebe ja vernusja] da Čas tvorčosti / Dichtenszeit.

146 Dopo la rimozione delle rovine alla metà dell'Ottocento e la costruzione al loro posto di una cappella, ogni traccia dell'antica chiesa fu eliminata all'inizio degli anni Trenta.

147 Ivi: 329. '[...] / Signore! Il mondo non è santo - / qui siamo tutti impazziti! / Chiediamo amore come rabbia, / chiediamo il bene, come il male. / Pentiti, peccatore: 
Non esenti da venature pubblicistiche che li rendono insoliti e piuttosto stridenti nel contesto di Čas tvorčosti / Dichtenszeit, questi versi ben mostrano come anche alla raccolta del 1972 non sia aliena una componente 'universalizzante', che pone la via crucis del soggetto nel più ampio quadro della sofferenza intrinseca alla vita dell'uomo sulla terra. Tuttavia, in sintonia con quanto è già stato osservato in precedenza a proposito delle somiglianze e divergenze tra le due uniche opere superstiti dello Stus maturo, non si può non notare come l'assimilazione tra il dolore dell'io lirico e la condanna al male inferta dalla sorte a tutto il consorzio umano nella versione di [Cerkva svjatoji Jiryny] dell'agosto del 1972 sia da leggersi alla luce dell'esplorazione del sé che permea ogni fibra di Čas tvorčosti / Dichtenszeit, condizionandone il carattere in ultima analisi centripeto e monologico. Riattualizzata nello 'spazio aperto' di Palimpsesty, in mancanza di un centro di gravità semantico ben definito, la lirica riacquista autonomia, facendosi tassello di un mosaico testuale variegato e imprevedibile.

Nella polifonicità delle sue singole liriche, l'universo di Palimpsesty sembra poter essere suddiviso con un buon grado di approssimazione in due macrofiloni, identificabili nell'ermetismo di una poesia pura, astratta dal referente, da una parte, e nella narrazione lirica del vissuto dell'anima nel contesto della realtà, dall'altra ${ }^{148}$. L'interazione tra queste due tipologie liriche è riconducibile ora al formarsi di brevi cicli poetici, ora all'accostamento di componimenti anche ben diversi tra loro. L'individuazione di queste due tendenze principali non esclude, naturalmente, che esse possano compenetrarsi all'interno dei singoli componimenti, che vengono così nuovamente a costituirsi come terreni di giustapposizione tra linguaggi artistici differenti.

Nella lirica ermetica di Palimpsesty il principio musicale tende a prendere il sopravvento sulla referenzialità. Esemplare dello Stus ermetico, nel quale ben si delineano lo scontrarsi e l'amalgamarsi tra il principio astratto e la narratività, si può considerare questa lirica:

У німій, нібі смерть, порожнечі свічад пересохла імла шеребершить, мов пісок, і високий, як зойк, тонкогорлий співак став ширяти над тілом своїм.

Дух підноситься д’горі. У зашморзі бід аж зайшовся кривий од волання борлак, аж огранням дзеркал заросилася кров! Ніч зсідається, наче кришталь.

\footnotetext{
/ la sorte ti ha incantato. / Chi sono, di destra o sinistra? / Chi sono, vittime e boia? / A tutti loro il maligno / piallerà croci di rovere. / Tutti soltanto la fine / chiedono in gioia e dolore. / [...]'

148 Jurij Ševel'ov ha individuato in Palimpsesty "due maniere stilistiche:" il poetismo da una parte e una fusione di espressionismo e surrealismo dall'altra. Oltre a esse, Ševel'ov considera separatamente la poesia ermetica e la prosa in versi. Cfr. Ševel'ov 1987: 384-394 passim.
} 
Начувайсь, навіжена, скажена душе!

Бо вдивляння, вслухання, зненацька уб'ють!

І зверескнула нервів утрата струна,

і зверескнув пугкий напівсон кришталю,

і зверескнула пустка свічад ${ }^{149}$.

La sovrapposizione dell'elemento areferenziale sulla rappresentazione domina la prima quartina della lirica, scissa tra un distico iniziale semanticamente opaco e due versi conclusivi nuovamente raffigurativi. Il rifiuto della specularità semantica del segno è paradossalmente espresso dall'immagine metapoetica del muto vuoto degli specchi. Non potendo riflettere la realtà davanti alla quale sono posti, essi riflettono all'infinito il loro nulla. La nebbia ossimoricamente rinsecchita che colma il divario materiale tra essi è sinesteticamente messa in connessione con la sfera acustica, che nel sordo fruscio accostabile a quello della sabbia ripete a un altro livello sensoriale la stessa muta autoreferenzialità degli specchi. In questo universo in sé conchiuso penetra all'improvviso il grido tremendo del cantore, scisso nella dualità di voce e corpo. L'ingresso nel quadro astratto dei primi due versi di un elemento narrativo ben definito, la cui azione è temporalmente marcata da un verbo incoativo, stravolge l'economia del testo, ora conteso da due tensioni in opposizione. Il consueto motivo stusiano-cvetaeviano del distaccamento dello spirito del poeta dalle pastoie della materialità e del suo innalzamento nello spazio libero dei cieli cede il passo a una raffigurazione di ispirazione espressionista ${ }^{150}$ del ferimento del corpo del cantore. Il vuoto degli specchi si è ora macchiato di sangue e l'integrità psicofisica del poeta è ricostituita negativamente nella doppia lacerazione del corpo e dell'anima. L'ipotesto pasternakiano relativo alla fatalità della poesia, già più volte incontrato in Zymovi dereva e Čas tvorčosti / Dichtenszeit, ritorna nell'ispirazione di questi versi nuovamente incentrati sugli effetti devastanti dell'atteggiamento del poeta verso il mondo. In un'inscindibile fusione delle sfere sensoriali della vista e dell'udito la terzina conclusiva raffigura la distruzione del tutto, in un quadro in cui i muti

$149 \mathrm{ZT} \mathrm{V}, 23$. 'In un muto, come morte, vuoto di specchi / la nebbia rinsecchita fruscia come sabbia / e alto, come un grido, il cantore dalla gola fine / si è librato al di sopra del suo corpo. / Lo spirito in alto si solleva. Nel cappio di disgrazie / si è fatto stretto e storto il gozzo dalle grida, / imperlate di sangue le tacche degli specchi! / La notte come cristallo raggrumata. / Stai all'erta, anima impazzita, anima rabbiosa! / Lo sguardo, l'ascolto - ammazzano di colpo! / E gridò la corda tagliata dei nervi, / e gridò il terribile torpore del cristallo, / e gridò il deserto degli specchi.'

150 Si veda, ad esempio, la seconda parte del dittico Der fliegende Holländer ('L'olandese volante') di Georg Heym, in: Heym 2006: 34: "Dicht grüßt der Dichter, düsteres Phantom, / Den durch die Nacht der Liebe Schatten führt, / Im unterirdischen ungeheurn Dom, / Wo schwarzer Sturm die Kirchenlampe schürt, / Die lautlos flackert, ein zerstörtes Herz, / Von Qual durchlöchert, und die Trauer krankt / Im Tode noch in seinem schwarzen Erz. / [...]". 'Intenso saluta il poeta, oscuro fantasma, / Che nella notte l'ombra dell'amore ha condotto, / Nel prodigioso duomo sotterraneo, / Dove scuote nera la tempesta la luce della chiesa, / che zitta luccica, un cuore distrutto, / di tormento lacerato, e il lutto addolora / ancora, nella morte, nella sua nera linfa.' 
specchi del primo verso si sono identificati con la figura del poeta, segnando il passaggio da una lirica metapoetica a una propriamente poetologica. Le loro nature risultano infatti apparentate nella comune reazione negativa al contatto con la realtà esterna. L'ascolto e la visione del mondo, in un universo in cui i sensi sono ormai inscindibili, sono fatali per chi, come lo specchio e il poeta, può resistere solamente nell'immobilità e nell'isolamento di un mortuario manto di nebbia.

L'accostamento del cantore orfico allo specchio è un'ulteriore reminiscenza della poesia matura di Rilke. Nella seconda delle Duineser Elegien gli angeli, ontologicamente irraggiungibili per l'essere umano, sono paragonati a specchi che richiamano a sé la bellezza da loro effluita, dunque auto-referenziali e opachi per l'osservatore esterno:

Spiegel: die die entströmte eigene Schönheit wiederschöpfen zurück in das eigene Antlitz ${ }^{151}$.

L'autosufficienza degli angeli-specchi rilkiani, dolorosa per l'uomo, si è persa nella poesia stusiana, dove l'isolamento del poeta nello specchio del proprio io è causa di sofferenza. All'infrangersi dello specchio non sembra tuttavia seguire una sua liberazione ${ }^{152}$.

L'apertura a ciò che sta al di là di sé è latrice di sofferenza e devastazione. Un'interpretazione generale del testo sembra oscillare tra la constatazione di una poetologia tragica, votata alla chiusura del poeta nell'angusto spazio del proprio io, e la messa in primo piano della componente areferenziale del testo. È evidente come i due livelli si compenetrino profondamente, fornendo un ottimo esempio della tendenza dello Stus maturo a una lirica ermetica allo stesso tempo astratta e referenziale, nella quale il dissolvimento della realtà razionalmente intesa si fonde con l'imprescindibile raffigurazione degli elementi costitutivi dell'universo poetico stusiano, come, in questo caso, il mito orfico del poeta lacerato.

A [U nimij, niby smert', porožneči svičad] può essere accostata una lirica costruita sugli stessi principi, disposta nella Kyjivs 'ka versija nella seconda posizione successiva:

Стань і вдивляйся: скільки тих облич довкола виду твого, ніби німби, так сумовито виграють на дримбу, хоч Господа на допомогу клич.

151 Rilke 1996: II, 205. 'Specchi: che la propria bellezza defluita / ricreano nel proprio volto.'

152 Un altro riferimento ancora più evidente al brano rilkiano in questione è da ricercarsi nei primi versi di una lirica della terza parte di Palimpsesty, in: T III.2, 69: "Ми нібито обернені свічаддя - / єдину власну душу світлимо / i сяйво фокусуємо на серце - / щоб спопелити чи нагріти? Морок / росте і тьмяне дзеркало світліє, / мов дрібка сяйва, встромлена у ніч. / [...]" 'Siamo come specchi rivoltati - / la sola nostra anima illuminiamo / e il bagliore rivolgiamo al cuore - / per incenerirlo o riscaldarlo? La tenebra / cresce e opaco lo specchio riluce, / come frammento di bagliore infilato nella notte.' 


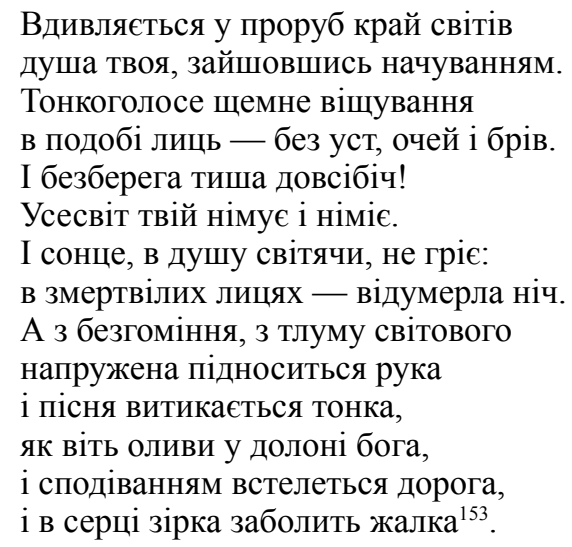

Come in [U nimij, niby smert', porožneči svičad], un'iniziale definizione dello spazio lirico in senso astratto si sviluppa in una raffigurazione dell'attività sensoriale di un'anima ormai liberatasi della materialità del corpo, nel paradossale silenzio di un universo in cui la vita sembra essersi assimilata alla morte. In entrambi i testi i versi conclusivi rappresentano metapoeticamente l'emergere della parola dal dolore, ricorrendo tuttavia a scelte stilistiche opposte. Nel primo caso la poesia è un violento grido di ispirazione espressionistica assimilato a un cristallo che si spezza. In [Stan'i vdyvljajsja: skil'ky tych oblyç], al contrario, la flebile voce che si staglia sulla mutezza di una realtà atrofizzata sembra farsi portatrice di una tenue speranza di rinnovamento. Anche in questo caso sembra ipotizzabile un riferimento al Diciannovesimo sonetto della prima parte dei Sonette an Orpheus, già evocato a proposito di [Hojdajet'sja večora zlamana vit'].

$\mathrm{Nel}$ contesto di un'interpretazione globale di Palimpsesty, l'unica opera parzialmente accessibile al lettore negli anni Ottanta insieme a Zymovi dereva, Bohdan Rubčak ha dialetticamente interpretato [Stan' $i$ vdyvljajsja: skil'ky tych oblyč] come la conclusione del percorso della poesia stusiana verso la riconciliazione con la realtà e la "vittoria sull'abisso" (Rubčak 1987: 351). Che una lettura di questa tipo, incentrata sul valore metapoetico e poetologico del canto come risposta alla finitezza, alla storia e alla sofferenza, sia valida per la lirica in questione è assolutamente evidente. Meno convincente è invece una sua trasposizione dialettica a riguardo della poesia stusiana matura nel suo insieme. Come si può evincere dalla lettura delle liriche di Palimpsesty finora discusse, la sofferenza, l'impotenza e la disperazione dell'io coesistono nella raccolta con la sua

153 ZT V, 25. 'Alzati e guarda: quanti di quei volti / intorno ai tuoi occhi, come aureole, / suonano la drymba con tristezza, / che chiameresti Dio in aiuto. / Guarda nel foro ai confini del mondo / l'anima tua, mettendosi in ascolto. / Acuta, dolente profezia, / come volti senz'occhi e senza bocca. / Tutt'intorno sconfinato silenzio! / Il tuo mondo ammutolisce, tace. / Il sole splende, ma non scalda l'anima: / muore la notte - su volti che si spengono. / Ed ecco, dal silenzio della folla / tesa una mano si solleva / e un canto s'innalza acuto, / come ramo d'ulivo nel palmo di dio, / e la strada si stende alla speranza, / e fa male nel cuore una stella pungente.' 
affermazione e il suo trionfo, inscindibili dalla sua natura di poeta. Un'interpretazione che privilegi soltanto uno dei due aspetti della raffigurazione di sé da parte del soggetto in Palimpsesty ne semplificherebbe la ricchezza e la complessità.

A questo proposito resta da notare come nella lirica in questione risulti piuttosto problematica una definizione dei rapporti tra il soggetto e la realtà, nello specifico l'elemento umano che si staglia sul fondo del nebbioso e inerte universo in cui l'io si ritrova immerso. Esso sembra caratterizzato da un'assoluta omologazione e spersonalizzazione, rispetto alle quali contrasta nettamente la seppur indefinita figura del cantore, inizialmente smaterializzato come pura anima, quindi ridotto per sineddoche alla mano che si solleva, identificandosi così interamente con il canto. Una distinzione netta tra lo spazio del soggetto e l'umanità è in realtà complicata dall'attribuzione alla seconda di uno strumento musicale, dunque del dono artistico, mentre è incerto a chi si riferisca la "dolente profezia, / come volti senz'occhi e senza bocca". Accordabile tendenzialmente all'io lirico e alla sua anima in ascolto, essa sembra riguardare anche la massa degli uomini in virtù del riferimento a una serie di sembianti umani trasfigurati. Trova dunque conferma in questa lirica l'ambiguità nella rappresentazione del posto dell'io nel consorzio umano che segna la poesia stusiana dalle origini alla maturità.

Il motivo della poesia come resurrezione, in netto contrasto con la rielaborazione della tematica pasternakiana da [O znal by ja, čto tak byvaet] più volte incontrata in diverse liriche delle raccolte precedenti, permea anche un testo di chiara ispirazione ševčenkiana:

Посоловів од співу сад, од солов'їв і од надсад.

І од самотньої свічі, і од жалких зірок вночі.

У небі місяц горовий скидається, як пульс живий. Ущухлим світлом сяють вишні опонічні. Допіру лив високий дощ. I все невтішні мої передуми будив.

Я двері прочинив з веранди, де кострубатий вертоград, собі не в силі дати лад, пильнує перший сон троянди. Свіча затріпотіла - й світло, мов голуба, пустила в лет, і вірш твій вирвався без титла, і дух твій вирвався з тенет, бо надто кругле небо краю, і кругла саду ліпота, бо мати дивиться свята. Я в ній - смеркаю і світаю ${ }^{154}$.

154 Ivi: 37. 'Si è intorpidito dal canto il giardino, / dagli usignoli e dalle fatiche. / E dalla candela solitaria, / e dalle tristi stelle nella notte. / Nel cielo la luna montagnosa 
Tra le liriche stusiane con un più ampio corpus di varianti ${ }^{155}$, [Posoloviv od spivu sad] è innanzitutto un dialogo con una delle più celebri poesie ševčenkiane, [Sadok vyšnevyj kolo chaty] dal ciclo V kazemati (Nella casamatta, 1847):

Садок вишневий коло хати,

Хрущі над вишнями гудуть,

Плугатарі з плугами йдуть,

Співають ідучи дівчата,

А матері вечерять ждуть.

Сем'я вечеря коло хати,

Вечірня зіронька встає,

Дочка вечерять подає,

А мати хоче научати,

Так соловейко не дає.

Поклала мати коло хати

Маленьких діточок своїх;

Сама заснула коло їх.

Затихло все, тілько дівчата,

Та соловейко не затих ${ }^{156}$.

/ si scuote come un polso che batte forte. / Di luce fievole brillano i ciliegi, / della notte. È appena caduta / forte la pioggia. E tutti i miei tristi / ripensamenti ha risvegliato. / Ho aperto la porta della veranda, / dove il ruvido giardino / che un ordine non sa darsi, / sorveglia il primo sonno della rosa. / La candela si è messa a tremare - e la luce, / come un colombo, / ha messo in volo, / e il tuo verso è libero dai segni / e il tuo spirito lo è dalle catene, / perché è troppo tondo il cielo qui, / e tonda è la bellezza del giardino, / perché la madre è santa quando guarda. / In lei mi ottenebro e riluco.'

155 Ivi: 476-479. Sulle varianti della lirica cfr. Kolodkevyč 2015: 174-188.

156 Ševčenko 2003: I, 17-18. Traduzione italiania in Brogi, Pachlovska 2015: 161: "Giardino di ciliegi attorno a casa, / Maggiolini ronzano tutt'intorno, / Gli aratori con l'aratro vanno, / Cantano, tornando, le fanciulle, / Le madri aspettan per la cena. // La famiglia cena presso casa, / Stella serotina in cielo, / La figlia serve al desco, / Ammaestrarla vorrìa la madre, / Ma canta forte l'usignuolo. // A dormire stende dentro casa, / La madre i piccolini, / Nel sonno cade assieme a loro. / Or tutto tace, ma non s'acquetan / Le fanciulle e l'usignolo." La più nota e diretta rielaborazione dell'idillio ševčenkiano, dal titolo Vyšni ('Ciliegie'), appartiene alla penna di Bohdan-Ihor Antonyč. Si veda Antonyč 2012: 222: “Антонич був хрущем і жив колись на вишнях, / на вишнях тих, що їх оспівував Шевченко. / Моя країно зоряна, біблійна й пишна, / квітчаста батьківщино вишні й соловейка! // Де вечори з євангелії, де світанки, / де небо сонцем привалило білі села, / цвітуть надхненні вишні кучеряво й п'янко, / як за Шевченка, знову поять пісню хмелем." "Antonyč era un maggiolino e viveva un tempo sui ciliegi, / su quei ciliegi cantati da Ševčenko. / Paese mio stellato, biblico e sontuoso, / patria fiorita del ciliegio e l'usignolo! // Dove sono le sere del vangelo, dove le albe, / dove il cielo inonda di sole i bianchi villaggi / fioriscono potenti i ciliegi ricci e inebrianti, / come ai tempi di Ševčenko irrorano di luppolo il canto.' 
Dell'idillio composto da Ševčenko durante la reclusione a Pietroburgo nel 1847 Stus riprende evidentemente i motivi del giardino conquistato dal canto dell'usignolo, dei ciliegi e delle stelle che lo adornano, e della figura mitizzata della madre che vi irradia saggezza e santità. L'imagery di ševčenkiana memoria si innesta in una lirica ancora una volta incentrata sul motivo poetologico dell'ispirazione, scisso, come per numerosi componimenti di Palimpsesty, tra raffigurazione e astrazione. Lo sprigionarsi della parola è connesso con l'apertura della porta di casa da parte dell'io lirico e con il conseguente contatto tra il suo mondo interiore, espresso dalla metafora skovorodiana della casa, e il giardino, tratteggiato, come si è visto, in senso evidentemente ševčenkiano. La seppur cauta apertura dell'io alla realtà esteriore, e, nello specifico, a un'esteriorità per definizione mediata tra la sfera del sé e ciò che di sconosciuto e minaccioso sta al di là - come il giardino -, potrebbe dunque essere letta metapoeticamente nei termini di una moderata dichiarazione di adesione alla tradizione ševčenkiana. La quartina iniziale, tuttavia, può essere interpretata anche in senso opposto, come un'ironica affermazione di distanza dal modello di Ševčenko: questo sembra suggerire l'immagine del giardino indebolito dall'instancabile canto dell'usignolo e dalla tristezza delle stelle nel cielo ${ }^{157}$.

Allo stesso tempo non è difficile notare come il giardino stesso ${ }^{158}$, connotato con il termine aulico di origine slavoecclesiastica vertohrad, al di là degli attributi ševčenkiani che lo caratterizzano dal primo all'ultimo verso e da un probabile riferimento alla raccolta poetica Sad božestvennych pesnej di Skovoroda, sia assimilabile alla tradizione pasternakiana, come suggerisce Jurij Ševel'ov (Ševel'ov 1987: 390). La sua natura antropomorfa lo avvicina infatti al giardino di Plačuščij sad da Sestra moja - žizn' (Pasternak 2003-2005: I, 117):

Ужасный! Капнет и вслушается,
Всё он ли один на свете,
Мнет ветку в окне, как кружевце,
Или есть свидетель.
Но давится внятно от тягости,
Отеков, земля ноздревая,
И слышно: далеко, как в августе,
Полуночь в полях назревает. [...]

Anche il motivo della pioggia scrosciante e delle preoccupazioni che si risvegliano con essa potrebbero rimandare a un ipotesto pasternakiano, ossia Vtoraja ballada da Vtoroe roždenie (ivi: II, 61):

157 Che in [Posoloviv od spivu sad] si parli di "stelle" al plurale, in contrapposizione all'unica "stella" di [Sadok vyšnevyj kolo chaty], si potrebbe spiegare in riferimento a una possibile autocitazione nel quarto verso. Si ricordi l'ultimo verso di [Stan" i vdyvljajsja: skil 'ky tych oblyč]: "i в сериі зірка заболить жалка."

158 Cfr. Savčuk 2010: 232. Sulla fortuna del termine vertograd nella poesia russa dell'Età d'Argento, imprescindibile punto di riferimento per Stus, si veda Razumovskaja 2010 . 
Ревет фагот. Гудит набат.

На даче спят под шум без плоти,

Под ровный шум на ровной ноте,

Под ветра яростный надсад.

Льет дождь, он хлынул с час назад.

$[\ldots]$

Я просыпаюсь. Я объят

открывшимся. Я на учете.

Я на земле, где вы живете,

И ваши тополя кипят.

$[\ldots]$

Льет дождь. Я вижу сон: я взят

Обратно в ад, где всё в комплоте, И женщин в детстве мучат тети,

А в браке дети теребят.

$[\ldots]$

Si consideri, inoltre, che una delle varianti del testo è racchiusa in un quaderno contenente alcune delle traduzioni stusiane della poesia di Rilke. Sebbene il significato metapoetico di quest'ultima sia meno esplicito che nella versione entrata nella raccolta ${ }^{159}$ e la lirica in questione non figuri tra i testi tradotti da Stus, si può tuttavia ipotizzare un riferimento al testo di apertura del rilkiano Buch der Bilder (Libro delle immagini, 1902), dal titolo programmatico Eingang (Ingresso):

Wer du auch seist: am Abend tritt hinaus

aus deiner Stube, drin du alles weißt;

als letztes vor der Ferne liegt dein Haus: wer du auch seist.

Mit deinen Augen, welche müde kaum

von der verbrauchten Schwelle sich befrein,

hebst du ganz langsam einen schwarzen Baum

und stellst ihn vor dem Himmel: schlank, allein.

Und hast die Welt gemacht. Und sie ist groß

und wie ein Wort, das noch im Schweigen reift.

Und wie dein Wille ihren Sinn begreift,

lassen sie deine Augen zärtlich los... ${ }^{160}$

159 ZT V, 477: “Я двері прочинив - i світло, / мов голуба, пустив у лет / і зір замерехтіли титла." 'Но aperto la porta - e la luce / come un colombo ho liberato in volo / e delle stelle son balenati i segni.'

160 Rilke 1996: I, 257. 'Chiunque tu sia. La sera esci / dalla tua stanza, la conosci bene; / al confine del mondo è la tua casa, chiunque tu sia. / Con i tuoi occhi, della soglia stanchi, / che se ne liberano a fatica, / alzi pian piano un albero nero: / davanti al cielo è solo, è snello. / E hai fatto così il mondo: Guarda, è grosso, / sembra una parola che matura nel silenzio. / E mentre il tuo volere afferra il senso, / abbandonan pian piano gli occhi tuoi...' 
Il nesso tra l'apertura del sé al mondo e lo sgorgare dell'ispirazione poetica che vi è descritto sembra costituire un significativo precedente per la poetologia di [Posoloviv od spivu sad]. Che la conclusione di un testo così profondamente segnato dal dialogo con alcune delle diverse tradizioni ${ }^{161}$ che maggiormente hanno accompagnato il percorso poetico stusiano si incentri su un'immagine di chiara derivazione ševčenkiana è probabilmente da considerarsi nei termini di una dichiarazione di adesione alla scuola poetica nazionale in primis, al di là dell'ironico distanziamento dal modello di Śevčenko individuato a proposito della prima quartina. È altrettanto evidente come la ricchezza intertestuale della lirica nel suo insieme, perfetto esempio di palinsesto poetico, ben dimostri l'impossibilità di considerare separatamente e gerarchicamente i diversi elementi all'origine della sua ispirazione, da ricercarsi piuttosto proprio nella complessa giustapposizione e rielaborazione degli stimoli dei diversi modelli a cui essa si rifà. Altrettanto costitutivo della lirica è la compenetrazione tra l'elemento figurativo e narrativo, incentrato sull'originarsi dell'ispirazione nel poeta in seguito alla sua apertura alla realtà esterna, il piano metapoetico relativo allo svelamento delle tradizioni letterarie alla base del testo e alla loro rielaborazione e combinazione, e il gioco areferenziale con il significante, evidente soprattutto nei primi versi.

La lirica che segue [Posoloviv od spivu sad] mostra una simile fusione tra astrazione e figuralità, in sintonia con la tendenza prevalente nella raccolta nel suo insieme:

Іди в кубельце спогаду - зогрійся!
Хай зашпори від серця відійдуть.
I терплячи покару, покорися
і поцурайся навертати путь
до зустрічі. Хай пам'ять відбігає,
як кров тобі з обличчя відійшла.
Вже погорою голос сновигає,
згубивши рідні контури села.
3 крайокраю, з цієї високості,
пади, згорнувши крила, до долин,
де ясмину набрякли ярі брості
і склеплено повіки білих стін.
У пустці цій - метелики чотири
усілись по кутках - і тугу тьмять.
Кохана спить. У ярому потирі-
вино кохання і вино проклять ${ }^{162}$.

161 La rima сад/надсад all'inizio della lirica può inoltre ricordare al lettore la rima надсада/сада nella prima strofa di Roždestvenskij roman di Iosif Brodskij (1962): Brodskij 2011: I, 115: “Плывет в тоске необъяснимой / среди кирпичного надсада / ночной кораблик негасимый / из Александровского сада [...]” Non sono attestate testimonianze dirette della conoscenza di Brodskij da parte di Stus, la quale risulta, tuttavia, molto probabile.

162 ZT V, 38. 'Va' nella tana del ricordo - scaldati! / Che esca il gelo dal cuore, / sopporta la condanna, sottomettiti / e rinuncia a rivolgere il cammino / all'incontro. Scappi la memoria, / come ha lasciato il tuo volto il sangue. / E già nell'alto vaga ormai la voce, / perduto ciò che avevo del villaggio. / Oltre al confine, da questa altitudine / 
Rielaborando una tematica fondamentale per tutta la poesia stusiana matura quale la memoria, questi versi ne mettono in evidenza il carattere duplice, ossia l'inscindibilità del sollievo dal dolore nell'emergere del ricordo alla coscienza dell'io lirico. Il ricordo è dapprima assimilato a una tana, dove il soggetto può trovare riparo e calore, liberandosi del gelo che aveva assediato il suo cuore ${ }^{163}$. Improvvisamente, tuttavia, in concomitanza con l'enjambement che unisce la prima e la seconda quartina, la memoria viene rifiutata. Invocandone l'abbandono, il soggetto ritrova la propria capacità poetica. La voce è messa in grado di raggiungere le massime altitudini del cielo, perché l'io lirico possa dunque lasciarsi cadere nel profondo di una natura primordiale, dopo aver riacquistato una paradossale unitarietà psicofisica e conosciuto il creato nella totalità del suo spazio. In questa nuova dimensione, sottratta alle costrizioni della razionalità, è finalmente possibile l'incontro con l'amata, messo in dubbio nei versi precedenti. Esso avviene, tuttavia, all'insegna della maledizione, sulla quale la lirica giunge alla conclusione. La complessa architettura spaziotemporale di [Idy v kubel'ce spohadu-zohrijsja!], in cui, ancora una volta, figuratività razionale ed ermetismo si fondono inscindibilmente, è accostabile alla poesia rilkiana matura. La comunicazione tra la sfera dell'interiorità, ovvero la memoria e il cuore, e la realtà esterna nella sua totalità di cielo e terra sembrano raffigurare la compenetrazione del micocosmo e del macrocosmo, in sintonia con una tendenza caratterizzante per Palimpsesty nel suo complesso, in parziale contrapposizione al ripiegamento dell'io nello spazio del sé che plasma maggiormente Ćas tvorčosti / Dichtenszeit.

Ciò è particolarmente evidente nella lirica immediatamente successiva a [Idy v kubel'ce spohadu-zohrijsja!]:
Верни до мене, пам'яте моя!
Нехай на серце ляже ваготою
моя земля з рахманною журбою,
хай сходить співом горло солов'я
в гаю нічному. Пам'яте, верни
із черебця, із липня жаротою.
Хай яблука осіннього достою
в мої червонобокі виснуть сни.
Нехай Дніпра уроча течія
бодай у сні, у маячні струмує.
I я гукну. I край мене почує.
Верни до мене, пам'яте моя ${ }^{164}$.

cadi, chiudi le ali, giù nella valle, / dove sboccia chiaro il gelsomino / e son chiuse le palpebre dei bianchi muri. / In questo deserto - quattro farfalle / sedute agli angoli oscuran la tristezza. / Dorme l'amata - nel chiaro calice / il vino dell'amore, di maledizioni.' 163 Si ricordino a questo proposito [Cerkva svjatoji Jiryny] e [Jak, skažy, do tebe ja vernusja?] da Čas tvorčosti / Dichtenszeit.

${ }_{164}$ ZT V, 39. 'Ritorna da me, memoria mia! / Che sul cuore si adagi come un peso / la terra mia con mite tristezza, / che scenda con il canto la gola dell'usignolo / sul prato notturno. Ritorna, memoria, / col calore del timo e di luglio. / Che di mela autunnale in abbondanza / vi sia nei miei sogni dai fianchi rossi. / Che la corrente ammaliante del 
Il cuore dell'io lirico è pronto ad accogliere su di sé la terra, segnata dalla stessa tristezza che lo caratterizza usualmente. Nella conclusione della lirica la terra arriva a identificarsi con l'Ucraina, irraggiungibile nella vita reale e conoscibile solamente nell' astrazione del sogno e del delirio. La memoria, la terra e la patria diventano così sinonimi della stessa identità del soggetto, la cui capacità poetica, anticipata dall'evocazione dell'usignolo, è resa possibile dalla loro seppur momentanea e illusoria presenza. Il riferimento alla mela potrebbe recare traccia del Tredicesimo sonetto della Prima parte dei rilkiani Sonette an Orpheus, dove essa, esplicitamente in connessione con la terra, esprime metapoeticamente il ruolo dell'esperienza sensoriale nello scaturire dell'ispirazione ${ }^{165}$. L'immagine del poeta che emerge da questi versi è indubbiamente quella del vate nazionale, la cui attività profetica, tuttavia, può essere auspicata solamente nell'ambito dell'irrealtà e del sogno.

Il carattere ambiguo del ricordo, insostituibile stimolo per la parola e inesauribile fonte di dolore, tende ad associarsi ripetutamente con il motivo messianico:

Геть спогади - сперед очей.

Із лиць - жалі, із уст -

колючі присмерки ночей

у цей сорокопуст.

Як став - то вплав,

як брід - то вслід,

як мур — то хоч нурця,

пройдімо лабіринтом бід

до свого реченця,

де щонайвища з нагород

і найчесніша — мста

за наш прихід і наш ісход

під тягарем хреста ${ }^{166}$.

Le lacerazioni della memoria sulla carne dell'io lirico lo inducono a invocare la fuga dal ricordo, che si rivela immediatamente impossibile. Dopo la prima quartina, infatti, si assiste al viaggio del soggetto nel tortuoso percorso della rimembranza, che si trova a coincidere con un "labirinto di disgrazie". Il discorso martirologico, annunciato implicitamente sin dall' incipit di questa breve, oscura poesia in versi giambici di diversa lunghezza, si concretizza nella conclusione, ulteriore tassello della cristologia poetica dello Stus maturo. Si noti come

Dnepr / almeno in sogno, nel delirio scorra. / E io parlerò. E il paese sentirà. / Ritorna da me, memoria mia!'

165 Rilke 1996: II, 247: "Voller Apfel, Birne und Banane, Stachelbeere...Alles dieses spricht / Tod und Leben in den Mund... Ich ahne..." 'Mela, pera, banana, uva spina... Tutto ciò dice / vita e morte nella bocca... Mi sento...'

166 ZT V, 16. 'Via i ricordi - d'in fronte agli occhi. / Dai volti - dolori, dalle labbra - / il crepuscolo pungente delle notti / in questo rimembrare. / Se è uno stagno - a nuoto, / se è un guado - al seguito, / se è un muro - almeno un tuffo, / nel labirinto dei mali / verso il termine, / dove la più alta ricompensa / e la più onesta - è la vendetta / per il nostro arrivo e il nostro esodo / sotto il fardello della croce.' 
la descrizione dello spazio della memoria recuperi due elementi caratterizzanti dell'universo lirico stusiano da Veselyj cvyntar in poi, quali lo stagno e il muro.

L'incontro tra l'io lirico e la donna amata descritto nel verso conclusivo di [Idy v kubel'ce spohadu - zohrijsja] può essere letto alla luce del modello orfico che caratterizza buona parte della lirica amorosa di Čas tvorčosti / Dichtenszeit e Palimpsesty. Si veda, a questo proposito, uno dei testi più celebri della poesia d'amore di Stus, componente fondamentale della sua opera matura:

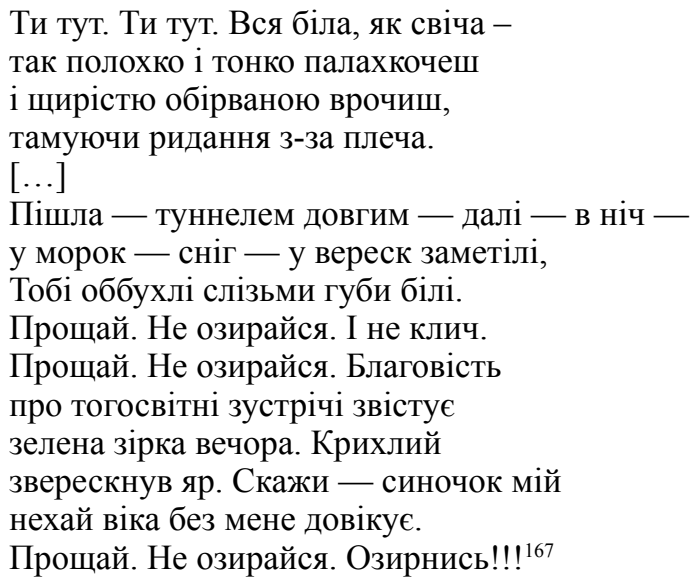

L'onirico incontro tra il soggetto e la donna amata, identificata con un'immagine molto produttiva nell'immaginario di Palimpsesty quale la candela, rivela nella conclusione della lirica il modello orfico a cui esso è ispirato. Nella prospettiva rovesciata del mito di Orfeo elaborata negli ultimi versi del testo, Stus tradisce un riferimento incrociato alla poesia rilkiana e cvetaeviana ${ }^{168}$. Il verbo ozyratysja/ozyrnutysja, con il quale l'io lirico invita la donna dapprima a non girarsi dalla sua parte per poi contraddirsi nella parola conclusiva dell'ultimo verso, si riscontra infatti anche nel penultimo verso della traduzione stusiana

167 Ivi: 31. 'Sei qui. Sei qui. Bianca come una candela - / paurosamente bruci, così sottile / e incanta la tua vicinanza lacerata, / mentre trattieni dietro alle spalle il pianto. / [...] / Sei andata per un lungo tunnel nella notte / nel buio, nella neve di una tempesta urlante, / si son gonfiate di lacrime le labbra bianche. / Addio. Non guardare. E non chiamare. / Addio. Non guardare. La buona novella / degli incontri nell'aldilà annuncia / la stella verde della sera. Fragile / ha gridato il fosso. Dì - che il figlio mio / senza di me la vita sua trascorra. / Addio. Non guardare indietro. Guarda!!!'

168 Nella poesia ucraina si ricordi il tradizionale Plač Evridiky ('Il pianto di Euridice', 1973-74) di Leonid Pervomajs'kyj, tra le ultime liriche del celebre poeta sovietico, dunque contemporanea della lirica stusiana, in: Pervomajs'kyj 1985: I, 454: "He треба, Орфею, не треба було, / А ти озирнувся - навіщо? / Ти знав це, ти відав, що в цьому все зло / I кара для мене найвища! // [...]" 'Non dovevi, Orfeo, non dovevi, / ma ti sei girato - perché? / Sapevi, lo sapevi che era il male, / e per me la più alta punizione! // [...]' 
del poemetto rilkiano Orpheus. Eurydike. Hermes, già citato a proposito di Čas tvorčosti / Dichtenszeit:

\author{
І коли \\ бог зупинив іiї і з болем мовив: \\ 'Він озирнувся!' - не збагнула мови, \\ і тільки запитала стиха 'хто'?
}

Se nel capolavoro dei Neue Gedichte e nella sua versione ucraina è il cantore a girarsi verso Euridice, in conformità con la tradizione del mito, in [Ty tut. Ty tut. Vsja bila, jak sviča -] è Orfeo a proiettare sulla figura femminile, che ha compiuto il viaggio negli inferi alla ricerca dell'amato, la possibilità di contravvenire al dettato delle divinità ctonie. Ciò avviene, tuttavia, nella consapevolezza della precarietà dell'incontro, al quale viene contrapposta la speranza di un nuovo convegno ultraterreno. Una chiara distinzione tra il regno infernale e la terra viene così messa da parte in un richiamo a una realtà trascendente compiuto in un contesto, quale quello in cui si colloca l'io lirico, che annulla nel buio e nel gelo di un nero spazio liminale i confini tra la vita terrena e l'aldilà. L'invito dell'io lirico alla donna a non girarsi potrebbe essere letto al di fuori della cornice mitica, come un semplice suggerimento per alleviare il comune dolore della separazione, se non fosse marcato dalla sua successiva negazione alla fine della lirica.

La volontà di vanificare l'incontro mostra l'influenza nella concezione di [Ty tut. Ty tut. Vsja bila, jak sviča -] di due distinti ipotesti cvetaeviani, EvridikaOrfeju e Rano eščë - ne byt'!, entrambe raccolte in Posle Rossii. In Evridika Orfeju (Cvetaeva 2004: 596) è la donna a invitare il cantore tracio a rinunciare all'idea di riportarla sulla terra:

Для тех, отженивших последних клочья

Покрова (ни уст, ни ланит!...)

$\mathrm{O}$, не превышение ли полномочий

Орфей, исходящий в Аид?

$[\ldots]$

Уплочено же - вспомяни мои крики! -

За этот последний простор.

Не надо Орфею сходить к Эвридике

И братьям тревожить сестер.

L'inaspettata esortazione finale del soggetto alla figura femminile nella lirica di Stus sembra collocarsi nello stesso orizzonte. L'io lirico, ormai assorbito nella dimensione degli inferi, ritiene impossibile il proprio ritorno nella realtà degli uomini e, di conseguenza, rifiuta l'amore terreno. Il richiamo opposto a un

169 T IV, 67. 'E quando / dio la fermò e disse con dolore: / 'Si è girato!' - lei non comprese / e solo chiese piano "Chi?", 
possibile ricongiungimento degli amanti nel mondo ultraterreno è invece al centro di Rano ešče - ne byt' (ivi: 621):

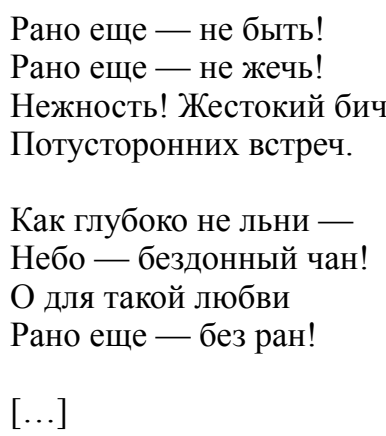

In [Ty tut. Ty tut. Vsja bila, jak sviča -] si assiste dunque alla complessa fusione di due ipotesti dello stesso autore, Marina Cvetaeva, nei quali vengono rispettivamente elaborate due concezioni dell'amore terreno e ultraterreno in opposizione tra loro, e alla loro sovrapposizione sull'ipotesto di un altro autore, Rilke, a sua volta fondamentale per la poesia della stessa Cvetaeva.

L'impossibilità dell'amore per l'io lirico di Palimpsesty può assumere la forma di una dolorosa identificazione della donna amata con il mondo stesso:

Ти підійшла — а я тебе не ждав.

Не сподівайся, що аж так нагально, знаку ані подавши - все відтрутиш, щоб заступити всесвіт мій цілий.

Так, світ тобою став. Ти - стала світом

чужим, як ти. Німим, як ти. Як ти -

непроханим. Та чую - жаль обох вас

уникнути — чи брата чи сестри ${ }^{170}$.

La donna e il mondo si avvicinano sino a fondersi nell'inaccessibilità della loro natura e della loro presenza per il soggetto, contemporaneamente immerso in essi e irrimediabilmente distante. La mutezza che accomuna il mondo e la figura femminile concretizza la loro incapacità a entrare in relazione con l'io, qui rinchiuso nella prigione di un'individualità non più in grado di un contatto con ciò che sta al di fuori. La congruenza di questi versi con la tematica orfica dell'amore impossibile nella separazione dei due amanti tra il mondo terreno e l'aldilà sviluppata nelle liriche precedenti, così come la produttività di questa separazione per il canto poetico, è evidente. Altrettanto manifesta è l'inadeguatezza di

170 ZT V, 75. 'Ti sei avvicinata - e io non t'aspettavo. / Non sperare che, così determinata, / senza dare un cenno, tutto scaccerai / per occupare tutto il mio universo. / Sì, il mondo è ora te. Tu - sei il mondo / estraneo, come te. Muto, come te. Come te / non richiesto. E sento: il vostro dolore / evitare, di fratello o di sorella.' 
una lettura semplicistica del motivo amoroso come consolazione dai mali della storia, non infrequente nella critica.

Si noti, inoltre, come le due liriche in esame sembrino richiamarsi a una poesia amorosa "tradizionale" dello šistdesjatnyk Mykola Vinhranovs'kyj del 1960, dal titolo Tost ('Brindisi'):

Ти тут! Ти тут! Кохана, ти як світ, -

Початок і кінець твій загубився...

Багряною півчарою схилився

В вологих сонцетінях небозвід;

$[\ldots]$

За свято засинання й просинання,

За довші крила нашим літакам.

I за прощання! Вип’ю за прощання -

Прощання ще не зраджувало нам ${ }^{171}$.

La memoria del testo di Vinhranovs'kyj, da Stus indubbiamente conosciuto, si rifrange dunque su due testi, entrambi influenzati nello specifico dal suo primo verso. L'incipit di [Ty tut. Ty tut. Vsja bila, jak sviča -] riprende chiaramente il brano corrispondente nell'ipotesto vinhranovs'kiano, per riconnettersi dunque alla strutturazione di quest'ultimo nella parte conclusiva, recuperando il motivo dell'addio degli amanti. Il secondo emistichio del primo verso di [Ty tut! Ty tut! Kochana, ty jak svit, -], incentrato sull'identificazione della figura femminile con il mondo intero sulla base del suo straordinario significato per l'io lirico, si riflette negativamente in [Ty pidijšla - a ja tebe ne ždav] alla luce della valenza tendenzialmente ostile che spetta al mondo nell'universo poetico di Stus, nonché, in primo luogo, dell'esplicita caratterizzazione di quest'ultimo in questi versi.

Sullo sfondo della relativa reticenza dell'io lirico stusiano per quanto riguarda la sfera dell'amore fisico, il lettore non può mancare di notare un lungo componimento della terza parte di Palimpsesty, capolavoro di poesia erotica per un autore poco incline a questo genere:

Цей спалах туги над імлою літ поєднує розкрижені дороги в сліпучім снінні. Довге і веселе було вертання — в очужілий гурт.

$[\ldots]$

Вглядайся. Впізнавай. I не кажи,

171 Vinhranovs'kyj 2013: 125. 'Sei qui! Sei qui! Mia amata, come il mondo, - / Si son persi la tua fine ed il tuo inizio... / Come un boccale di porpora è piegato / in umidi chiaroscuri l'orizzonte; // [...] // Per la festa del dormir e del destarsi, / Per ali più lunghe ai nostri aerei. / E per l'addio. Berrò io per l'addio - / L'addio ancora mai non ci ha tradito.' 


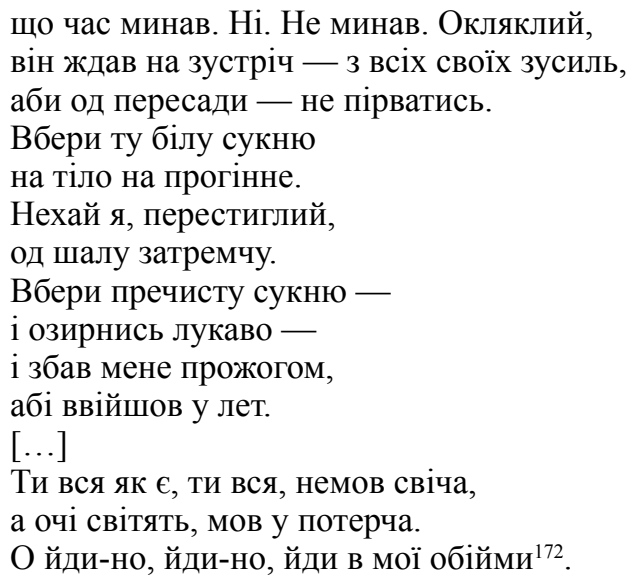

L'invito alla donna a rivolgere il proprio sguardo malizioso (“ozyrnys' lukavo") segna il suo ricongiungimento con l'io lirico dopo la separazione sancita in [Ty tut. Ty tut. Vsia bila, jak sviča-]. La consueta tensione del soggetto verso l'alto, il suo irrefrenabile desiderio di spiccare il volo, è ora legata al compimento dell'atto amoroso. Il potenziale salvifico della figura femminile è esplicitato inoltre dal suo accostamento a una candela, frequente ed evidente simbolo di illuminazione ed epifania nella poesia non solo stusiana. Da un punto di vista pragmatico, il verso conclusivo della lirica, nel quale l'invito a indossare l'abito bianco cede il posto a un più deciso richiamo alla donna ad avvicinarsi, segna il compimento del rituale del corteggiamento svolto mediante la parola poetica stessa. Il silenzio che segue idealmente alla conclusione del testo, nel momento del congiungimento dei

172 T III.2, 92-93. 'Lampo di dolore sulla nebbia degli anni, / riunisce le strade rischiarate / in un sonno accecante. Lungo e allegro / fu il ritorno - in un cenacolo ora estraneo. / [...] / Guarda. Riconosci. E non dire / che il tempo è passato. No. Non è passato. Intorpidito, / aspettava l'incontro - con tutti i suoi sforzi / per non strapparsi - per l'esagerazione. / Metti quel vestito bianco / sul corpo spalancato. / Perché io, più che maturo, / mi ecciti, mi agiti. / Metti quel bel vestito - / e guarda indietro con malizia - / e finiscimi di furia, / così che spicchi il volo. / Sei tutta come sei, sei come una candela, / e splendono gli occhi come a un bambino. / Vieni, Vieni qui, vieni tra le mie braccia.' Il forte dislivello tematico e stilistico tra la parte iniziale del testo, di cui è qui citata la prima quartina, e le strofe successive trova una spiegazione plausibile anche nella vicenda testuale della lirica. [Cej spalach tuhy nad imloju lit] è infatti un palinsesto di diversi frammenti composti in vari anni. Una variante della seconda metà della lirica, a partire dal verso "Vbery tu bilu suknju" è inclusa nella prima parte di Palimpsesty (ZT V, 283). La versione qui citata, dalla "terza parte" dell'opera, si avvicina maggiormente alla variante riportata nell'apparato critico di $Z T$ (ivi: 605), pur non coincidendo con essa. L'apparato critico di $Z T$ data questa versione intermedia ai secondi anni Settanta ed è dunque lecito supporre una datazione simile per i versi qui citati, tradotti e commentati. L'eterogeneità del testo è segnalata graficamente mediante una spaziatura iniziale che distingue i versi centrali, a partire da "Vbery tu bilu suknju", dalla parte iniziale e dalla parte finale. 
due amanti, esplicita al lettore con un atto illocutorio il potere perlocutorio della lirica nei confronti dell'interlocutore diretto del soggetto, mostrando ancora una volta l'alto grado di metariflessività intrinseco a gran parte della poesia di Stus.

Se in [Ty tut. Ty tut. Vsja bila, jak sviča -] l'io lirico dichiara implicitamente l'impossibilità della propria liberazione dagli inferi, la lotta per l'anabasi dal mondo infernale e la fiducia nella rinascita non sono estranee ad altri testi. Si veda a questo proposito [Cej bereh zustričej - i ne zbahneš], tra i capolavori dello Stus ermetico:

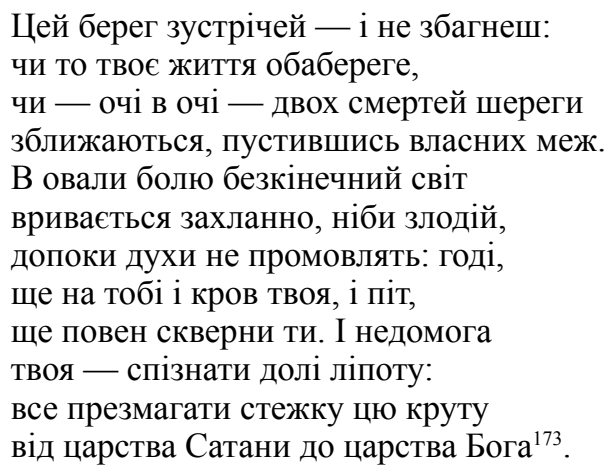

Nella dualità che caratterizza l'immagine della riva, frequente nell'immaginario dello Stus maturo, si condensa esemplarmente l'impossibilità di ridurre a uno schema razionale l'universo lirico di Palimpsesty, al cui interno l'astrazione della parola poetica dal legame univoco con il referente arriva a giocare un ruolo di primo piano. Pur ricorrendo due volte in due versi successivi, dapprima come sostantivo e poi come morfema di un aggettivo neologismo, la riva stusiana viene ad assumere un valore semantico astratto, intrinsecamente poetico. Alla sua sostanziale desemantizzazione fa eco la prima quartina nel suo complesso, per la quale non è più possibile alcun tipo di parafrasi. Sullo sfondo dell'ermetismo dei primi quattro versi, la prosecuzione della lirica in chiave tradizionale non può che suscitare nel lettore una sensazione di straniamento, anche se, come si è già avuto modo di osservare, l'accostamento di brani ermetici e brani narrativi è una componente fondamentale della poetica di Palimpsesty. A dipanarsi negli otto versi rimanenti è la descrizione di un'ascesi e di un'ascensione, mediante le quali l'io lirico potrà porre fine alla pressione del mondo su di sé, spianando la propria strada verso la divinità. Il mondo terreno, non a caso "infinito", e il regno di Satana si rivelano dunque equivalenti, uniti nella comune distanza da Dio a cui si trova a essere almeno temporaneamente condannato anche il soggetto stesso. La sua puri-

173 ZT V, 94. 'Questa riva è d'incontri - e non capisci / se sia la tua vita sulle due rive, / se - occhi negli occhi - / le schiere di due morti / si avvicinino, perduti i confini. / In ovali di dolore il mondo infinito / si getta avidamente, come un ladro, / finché gli spiriti non diranno: no, / ancora su di te è sangue, e sudore, / d'impurità sei pieno ancora. E tua / condanna è della sorte conoscere il bello: / sempre compier quest'erto cammino / dal regno di Satana al regno di Dio.' 
ficazione si accompagna tradizionalmente al distacco dell'anima dal fardello della corporalità, che lo costringe a rimanere oppresso nella morsa del mondo. Come più volte ribadito, il motivo stusiano dell'agognata dematerializzazione dell'io è accostabile al corrispondente paradigma nell'universo poetico cvetaeviano.

Il mondo degli uomini, come si è appena potuto osservare, si identifica con l'inferno stesso. La sua opposizione al polo della divinità è al centro di una lirica di chiara ascendenza ševčenkiana:

Немає Господа на цій землі:

не стерпів Бог - сперед очей тікає,

аби не бачити нелюдських кривд,

диявольских тортур і окрутенств.

В краю потворнім є потворний бог -

почвар володар і владика люті

скаженої - йому нема відради

за цю єдину: все трощити впень

і нівечити, і помалу неба

додолу попускати, або світ

безнебим став. Вітчизною щалених

катованих катів. Пан-Бог - помер ${ }^{174}$.

L'idea dell'assenza e della fuga di Dio, così centrale all'immaginario di Ševčenko ${ }^{175}$, si accompagna specularmente all'apparizione sulla terra di una divinità ostile, identificabile in ultima analisi con l'uomo stesso. Il sostrato ševčenkiano si trova così a fondersi con la lezione dell'Espressionismo tedesco, altrettanto fondamentale, come si è notato a più riprese, nella genealogia poetica stusiana. Il precedente più diretto è, in questo caso, Der Gott der Stadt (Il dio della città) di Georg Heym, uno dei testi canonici della cultura letteraria di lingua tedesca del primo Novecento. L'ultima strofa della lirica di Heym sembra anticipare perfettamente il mostruoso dio assassino e cannibale di [Nemaje Hospoda na cij zemli]:

Er streckt ins Dunkel seine Fleischerfaust.

Er schüttelt sie. Ein Meer von Feuer jagt

174 Ivi: 109 . 'Non c'è Signore su questa terra: / Non la sopporta Dio - è fuggito / per non vedere disumane offese, / atrocità e diaboliche torture. / In un paese mostruoso è un dio mostruoso - / sovrano degli orridi, principe di folle / malvagità, altra gioia non conosce / che questa: ogni cosa distruggere / e annientare, abbassare poco a poco / il cielo, così che il mondo / rimanga senza cielo. Patria di pazzi / torturatori-torturati. Il Signore-Iddio è morto.'

$175 \mathrm{Si}$ può inoltre intravedere in questi versi un rovesciamento delle affermazioni della massa umana ignorante e decaduta nel Poslanije ševčenkiano, in Ševčenko: 2003: I, 350: “'І ми не ми, і я не я, / I все те бачив, і все знаю, / Нема ні пекла, ані раю, / Немає й бога тілько я!'” 'Е noi non siamo noi, e io non sono io, / E tutto ho visto e tutto so, / Non c'è inferno e paradiso, / E dio non c'è, ci sono solo io.' Sul dio ševčenkiano cfr. Brogi Bercoff 2007: 123-127 passim. 
Durch eine Straße. Und der Glutqualm braust

und frisst sie auf, bis spät der Morgen tagt ${ }^{176}$.

La caratterizzazione stusiana del dio si spinge tuttavia al di là del possibile ipotesto heymiano. Se in quest'ultimo la furia devastante dell'inquietante protagonista della lirica sembra essere momentaneamente placata dal risvegliarsi del giorno sulla città, in [Nemaje Hospoda na cij zemli] ciò è reso impossibile dall'eliminazione del cielo. L'universo nella sua totalità è stato assorbito dal mondo, che si è fatto sinonimo della totalità delle cose. Non c'è dunque alcuna via di fuga dal Male che l'uomo quotidianamente infligge a se stesso, come esplicitamente dichiarato nell'ultimo verso della lirica. Ulteriore esempio di palinsesto, ossia di confluenza e rielaborazione di più tradizioni poetiche nell'alveo di una singola entità testuale ${ }^{177}$, a sua volta parte del corpus per sua natura aperto della raccolta, [Nemaje Hospoda na cij zemli] mostra efficacemente l'ampiezza stilistica di Palimpsesty, che sembra dunque rifarsi in parte all'esperienza dello Stus giovanile, in contrapposizione alla relativa monologicità di Ćas tvorčosti / Dichtenszeit.

Se la terra è ormai privata della rigenerante presenza della divinità, all'io lirico è a tratti concesso un contatto con essa:

\author{
Звелася длань Господня \\ і кетяг піднесла \\ над зорі великодні \\ без ліку і числа. \\ Ця синь зазолотіла, \\ це золото сумне, \\ пірвавши душу з тіла, \\ об'яснили мене. \\ Голосить снігавиця, \\ колючий хрипне дріт, \\ а золота жар-птиця \\ пускається в зеніт ${ }^{178}$.
}

176 Heym: 2006, 14-15. 'Stende nel buio il suo pugno assassino. / Lo scuote, disperde un mare di fumo / Lungo la strada. E il fumo la invade / E la divora, finché non è mattino.'

177 Si ricordi un'altra evidente rielaborazione del Gott der Stadt heymiano nella poesia ucraina, Kinec'svitu ('La fine del mondo') di Antonyč, dall'ultima raccolta antonyčana Rotaciji ('Rotazioni', 1936), in: Antonyč 2012: 241-242: “Мов бура плахта, хмара круків / сідає на дахах бриластих, / і місяць, звівши сині руки, / немов пророк, став місто клясти. // [...] // Гримить підземний лоскіт здаля, / вдаряє в мури буря дзвонів, / і місто котиться в провалля / під лопіт крил і мегафонів." 'Come bruna stoffa nuvola di corvi / siede sui tetti di pietra, / e la luna, con le braccia conserte, / come un profeta maledice la città. // [...] // Tuona da lontano il fragore sotterraneo, / colpisce i muri uragano di suoni, / la città sprofonda nell'abisso, / sotto i colpi di ali e di megafoni.'

$178 Z \mathrm{~T} \mathrm{~V}, 17$. 'S'è sollevata la mano di Dio / e una corona di fiori ha alzato / sulle stelle della Pasqua / infinite e innumerevoli. / Questo azzurro dorato, / quest'oro triste, 
Lontano dal mondo degli uomini, libero dalla propria corporalità, il soggetto è irradiato dalla luce stellare, avvolto dal bagliore divino che lo sottrae alle leggi del mondo, simbolizzate dalla costrizione delle cifre. Con un procedimento non insolito nella poesia di Palimpsesty, la situazione lirica della prima quartina si ritrova completamente ribaltata nei versi successivi. Alla realtà mistica configuratasi nel primo verso si contrappone ora nuovamente l'inverno della vita sulla terra, dietro al quale, anche in riferimento al filo spinato che accompagna rauco lo sfuriare della tempesta di neve, sembra lecito intravedere un richiamo all'esperienza biografica dell'autore, rinchiuso in un campo in Mordovia ${ }^{179}$. Nell'ultimo verso si assiste invece nuovamente alla vittoria della realtà invisibile sulla materialità dell'esistenza umana, ovvero alla fuga dell'io lirico, nei panni dell'Uccello di fuoco, nell'azzurro dei cieli. Anche in questo caso, dunque, la tendenza ermetica non sembra scindibile dal richiamo alla concretezza della narrazione lirica. La fusione del blu e dell'oro come raffigurazione del raggiungimento di una dimensione nuova, oltre che ovvio richiamo alla simbologia nazionale ucraina, sembra rifarsi all'esperienza poetica simbolista, in primo luogo alla raccolta Zoloto v lazuri di Andrej Belyj (1903), interamente permeata di immagine coloristiche e sinestetiche incentrate sull'avvicinamento e la fusione di realtà e tonalità opposte. Si pensi alle prime due strofe della lirica iniziale della raccolta, prima parte del trittico Bal'montu:
В золотистой дали
облака, как рубины, -
облака, как рубины, прошли,
как тяжелые, красные, льдины.
Но зеркальную гладь
пелена из туманов закрыла,
и душа неземную печать
тех огней сохранила ${ }^{180}$.

Allo stesso tempo, in virtù di comuni ricorrenze lessicali e di una simile contrapposizione tra la dolorosa sterilità della vita sulla terra e il potere rigenerante

\footnotetext{
/ che l'anima dal corpo ha strappato, / mi hanno illuminato. / Schiamazza la bufera, / punge rauco il fildiferro, / ma d'oro l'uccello di fuoco / si spinge verso il cielo.'

179 La lirica risale al 1974. Cfr. ivi: 667.

180 Belyj 2006: I, 79. Ma si veda anche, per quanto riguarda la letteratura ucraina, una lirica di Jevhen Malanjuk (1897-1968), il più noto poeta dell'emigrazione ucraina del periodo interbellico, possibile punto di riferimento per Stus come modello di poeta allo stesso tempo puro e politico, in: Malanjuk 1992: 56: “А дні пливуть — мелодія в блакить, / а дні дзвенять, як золото в лазурі, / І вічністю триває кожна мить, / I в спокої втопились давні бурі." 'Scorrono i giorni - melodia nell'azzurro, / risuonano i giorni come oro in azzurro, / E ogni attimo è come eternità, / E nella pace affondano le antiche bufere.'
} 
della trascendenza, non sembra da escludersi un riferimento al sonetto Dante di Mykola Zerov (1921):

Сагою дивною, без демена і числа, Ми пропливали вдвох, 一я й чарівник Вергілій.

Як бронза він різьбивсь - i до далеких ліній

Ріка незнана нас, гойдаючи, несла.

Латаття там плелось без ліку і числа,

На світ займалося в пустелі златохвилій;

Я поглядом тонув у тій наплаві білій,

А слухом - у речах небесного посла.

Я чув: 'Ці лілії, що упояють чаром,

Далеко від землі, від valle lacrimarum,

Зросли тут завісом потужньої руки;

Далекі від тривог і від земної сварки,

Колишуться і снять, одвічні двійники

Сонетів і канцон майбутнього Петрарки ${ }^{181}$.

Comune a entrambi i possibili ipotesti è il motivo poetologico della liberazione del cantore dalle pastoie dell'esistenza umana grazie alla parola, sia per quanto riguarda [Zvelasja dlan'Hospodnja], sia nel più ampio contesto dell'opera stusiana matura. La tradizione simbolista e post-simbolista si innesta così nel complesso palinsesto della poesia stusiana, qui chiaramente marcata dalla realtà dell'esperienza umana dell'autore.

Un immaginario simile è al centro di un'altra lirica della prima parte di $\mathrm{Pa}$ limpsesty, testimone della vicinanza dello Stus maturo alla sensibilità simbolista:

Той образ, що в відслонах мерехтить, повторюють дзеркалами дзеркала.

Це в прискалках душа твоя жахтить, ледь народженна ачи з мертвих встала.

Вона збирає в стосики тонкі

усі твої розсипані відбитки,

мов золоті, з поховань скіфських, злитки

на поза всякий час і всі віки.

У синіх вітражах, б'ючи, як млість, вже золота спалахує подоба,

181 Zerov 1990: I, 66. 'In un fiume portentoso, senza timone e cifra / Navigavam in due - io e lo stregon Virgilio. / Come bronzo si stagliava e a linee lontane / Il fiume sconosciuto, cullando, ci portava. / Attorcigliavansi ninfee a non finire / Salendo verso il mondo nel deserto d'onde d'oro; / Lo sguardo mio affondò in quel bianco veleggio, / L'udito mio nei suoni del console celeste. // Udii: "Questi gigli, che inebriano d'incanto, / Distante dalle terra, la valle lacrimarum, / Crebbero qui nel gesto di una mano forte; // Distanti dalle cure, dalla discordia in terra / Si dondolano e sognano, come eterni doppi / Di sonetti e di canzoni del Petrarca che verrà.", 
i біла пучка тягнеться до лоба,
і серце покріпляє благовість,
о милосердний Господи! Знова
душа постала 3 тліну всежива! ${ }^{182}$

Il trionfo dell'anima sulla temporalità ne sancisce una caratterizzazione ambigua, a metà tra evanescenza e corporalità. Nonostante la sua paradossale fisicità sia dapprima ridotta a una serie di sottili fascette di riflessi, l'anima si accompagna a una fronte, sineddoche della facoltà intellettuale, e a un cuore. La paradossale corporalità dell'anima è inoltre contemporaneamente indebolita e confermata dall'infinito riflettersi della sua luce negli specchi, in un contesto, come emerge dal primo verso della lirica, marcatamente teatrale. La tenue consistenza materiale dell'anima è altresì accostata alla pesantezza dei lingotti d'oro di un antico tesoro, complicandone ulteriormente la raffigurazione in bilico tra inconsistenza e concretezza. Come in [Zvelasja dlan' Hospodnja] la tonalità cromatica dell'oro si accompagna al blu, qui legato all'arte delle vetrate, scisse, come l'anima stessa, tra trascendenza e materialità. Evidente è il (ri)consolidamento dell'identità dell'io, capace di resistere all'azione logorante del tempo e della storia e di imporsi sulla loro sostanziale impotenza di fronte alla trascendenza. Anche in questo caso, infatti, la vittoria del soggetto sulle forze a lui avverse non sarebbe possibile senza l'azione redentrice della divinità, in grado di confortare e rafforzare il cuore, simbolo di unità dell'io.

Come già anticipato, tuttavia, a colpire l'attenzione del lettore è il dialogo con la tradizione simbolista che permea il testo a ogni suo livello, a cominciare dalla sua eccezionale musicalità e dai contrasti cromatici che ne caratterizzano l'imagery, segnata dalla vivida fiamma dell'anima che arde, da una parte, e dalla rarefazione della foschia intorno alle vetrate del tempio, dall'altra. Il superamento della contrapposizione tra concretezza materiale e dematerializzazione con cui l'anima, non senza l'imprescindibile contributo della grazia celeste, riesce a garantire la propria continuità è di per sé riconducibile alla lezione del Simbolismo, probabilmente filtrata attraverso il prisma della poetica del Rilke maturo: la trascendenza delle cose in una dimensione altra, slegata dalle costrizioni e dalle limitazioni della terrestrità, non esclude la conservazione del valore e dell'identità della cosa stessa, ora arricchita di un significato più ampio rispetto a ciò che permette di vedere lo sterile approccio della consuetudine.

In [Toj obraz, ščo v vidslonach merechtyt'] la coesione dell'anima è anticipata dal riflettersi della sua immagine in un numero imprecisato di specchi, sulla cui superficie risplende inarrestabile la sagoma nervosa della sua fiamma. Ė il testo stesso a rivelare esplicitamente il dialogo con la tradizione simbolista avvicinando l'oro dell'anima che brucia di energia alle sepolture degli Sciti, evidente omaggio alla po-

182 ZT V, 74. 'Quell'immagine riluce nelle quinte, / ripetuta, rifratta dagli specchi. / È l'anima tua che brucia nelle rocce, / appena nata, o forse dai morti risorta. / Raccoglie in fascette sottili / tutti i tuoi sparsi riflessi, / come lingotti d'oro in tombe scite, / per oltre ogni tempo e ogni secolo. / In vetrate blu, battendo come nebbia, / già s'infiamma un sembiante dorato, / e un batuffolo bianco si spinge alla fronte / e il cuore rafforza la buona novella, / o Signore misericordioso! Ancora / l'anima salva si è alzata dalle ceneri.' 
esia blokiana. In una lettera del gennaio 1976, non a caso, Stus scrive alla moglie della sua riscoperta della lirica di Aleksandr Blok dopo quattro anni "di separazione", nonché dell'inaspettata constatazione di motivi ed elementi comuni tra l'esperienza artistica e umana del massimo poeta simbolista russo e la propria. Tra i testi che Stus cita non manca il poemetto Skify del 1918, indubbiamente distante dalla sensibilità stusiana da un punto di vista 'concettuale'183. Passibile di un accostamento all'opera blokiana è inoltre la teatralità insita alla rappresentazione delle peripezie dell'anima in [Toj obraz, ščo v vidslonach merechtyt']. Le quinte teatrali attraverso le quali riluce l'anima riflessa negli specchi sembrano costituire un rovesciamento del palcoscenico tragicomico su cui si svolgevano le assurde vicende dell'umanità contemporanea in Veselyj cvyntar, segnando dunque una rivalutazione delle possibilità ontologiche della teatralità. Il palcoscenico, oltre che metafora dello svolgimento degli avvenimenti storici nella falsità e nella vuotezza che li caratterizza, può essere luogo di piena liberazione del cuore dalle catene della terra e di accoglimento della grazia.

In alcune liriche il soggetto di Palimpsesty appare nei panni di uno spettatore di una scena sulla quale il proprio cuore diventa soggetto e protagonista di un'azione teatrale, un'immagine di derivazione rilkiana che Stus aveva già sperimentato in Čas tvorčosti / Dichtenszeit e nella poesia giovanile:

Сповільнено твій час прозрінь.

Пора ненависті заходить.

І трудно серце колобродить -

на нього налячає тінь.

Надходить час нових чинінь.

А так здалось - лихий нас водить.

Як довго доля нас не вродить!

I падає на серце тінь.

Не жди жалоб, не жди молінь.

Хто нас горожами городить?

Хто, Боже, нас зі світу зводить?

На серце налягає тінь.

Сповільнена пора прозрінь -

зловісна тінь перед тобою

йде назирці. Черга видінь

кривавою укрита млою.

183 Si ricordi la ripetuta ricorrenza degli Scizia come simbolo dell'oppressione e della schiavitù nei Neofity ševčenkiani, in: Ševčenko 2003: II, 249: "На хресті / стремглав повисіли святого / Того апостола Петра. / А неофітів в Сіракузи / В кайданах одвезли. И син / Алкід, твоя дитина, / Єдиная твоя родина, / Любов єдиная твоя, / Гниє в неволі, в кайданах. / А ти, прескорбная, не знаєш, / Де він конає пропадає! / Ідеш шукать його в Сибір / Чи теє... В Скіфію... I ти... / I чи одна ти? Божа мати!" Brogi, Pachlovska 2015: 303: "Sulla croce / A capo in giù appesero / L'apostolo Pietro. / E i neofiti a Siracusa / In catene portarono. E il figlio / Alcide, il tuo bambino, / Unico tua famiglia, / Unico amore tuo, / Langue prigioniero in catene. / E tu, dolorosa, non sai / Dove agonizza, dove perisce! / In Siberia lo vai a cercare / O forse... nella Scizia... E tu... / Ma forse che sei sola? Madre divina!" 


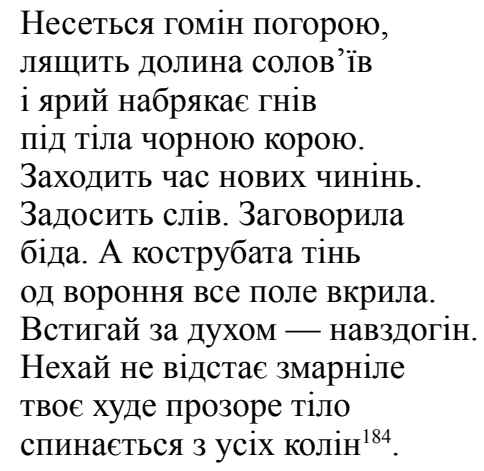

La narrazione lirica delle vicende del cuore, annunciata dalla prima quartina, sembra allargarsi nei versi successivi a una pluralità non meglio identificata, come mostra il generico pronome di prima persona plurale che compare per la prima volta al settimo verso. Non è ad ogni modo possibile determinare univocamente se dietro al "noi" in questione, in costante alternanza con la seconda persona singolare, sia da scorgersi un riferimento all'umanità nel suo insieme oppure un rimando a una scissione dell'io. La scena che come in un teatro si delinea davanti allo sguardo tanto dell'io lirico quanto del lettore/spettatore è estremamente caotica. L'attacco dell'odio alla psiche del soggetto, annunciato nei primi due versi, ne causa un rallentamento della capacità visiva che sembra rispecchiarsi poetologicamente nell'affastellarsi di immagini e avvenimenti nel corso del testo. A fare da contrappeso allo scatenarsi degli eventi e all'incapacità di organizzare il materiale visivo da parte del soggetto è la ripetizione, con elementi di variazione, del motivo dell'ombra che si posa sul cuore. Il panorama che attanaglia lo sguardo indebolito dell'io è a tratti caratterizzato espressionisticamente e, nel suo complesso, votato alla raffigurazione di un mondo oppressivo e soffocante. Consapevole del proprio stato di soggezione all'odio e all'effetto devastante di quest'ultimo, l'io esorta ripetutamente se stesso all'azione. Nella quartina finale quest'ultima si concretizza nella necessità di stare al passo con lo spirito, combattendo così gli effetti deleteri dell' attacco del maligno. La causa primaria della condizione di confusione e smarrimento che affligge il soggetto, oppure la comunità di cui egli si ritiene parte, è da identificarsi nel distacco dal mondo. La volontà di mantenersi in sintonia con lo spi-

184 ZT V, 122. 'Più lento è il tempo delle tue visioni. / Avanza il tempo dell'odio. / E con fatica il cuore vaga - / si posa su di esso un'ombra. / S'avvicina il tempo di nuove azioni. / E sembrò che il maligno ci guidasse. / Da quanto la sorte non ci genera! / Cala sul cuore un'ombra. / Non attendere lutti, non attender preghiere. / Chi ci recinge di recinti? / Chi, oh Dio, dal mondo ci allontana? / Sul cuore si posa un'ombra. / Più lento è il momento delle tue visioni - / sinistra un'ombra davanti a te / si muove al seguito. Una serie di visioni / è coperta di foschia insanguinata. / Si trascina in salita un brusio, / vocia la valle degli usignoli, / e forte esplode la rabbia / sotto la nera corteccia del corpo. / Avanza il tempo di nuove azioni. / Basta parole. Ha preso voce / la disgrazia. E un'ombra arruffata / delle cornacchie ha coperto tutto il campo. / Stai al passo con lo spirito - dietro a lui. / Che non rimanga indietro smunto / il corpo tuo esile e trasparente, / si solleva da ogni ginocchio.' 
rito espressa nella conclusione della lirica sembra dunque poter essere accomunata a una riconciliazione con il mondo, a un riavvicinamento a esso, in contrasto con la volontà di un distacco da esso espressa, come si è potuto osservare, in numerose liriche. Lo spazio altro dal mondo in cui il soggetto si ritrova paradossalmente a osservare l'oscuramento del proprio cuore e il rallentamento del proprio occhio è caratterizzato come inospitale e nemico, oscuro e frastornante. Un tentativo di ricostruzione della vicenda lirica non mette beninteso in discussione il carattere volutamente complesso del testo, scisso tra innalzamenti e abbassamenti prosastici.

Il doloroso distacco dell'io dal mondo raffigurato in [Spovil'neno tvij čas prozrin'] può configurarsi anche in senso nazionale:

Ще вруняться горді Славутові кручі, ще синіс річки замріяна гладь, та вже проминув тебе птахом летючим твій час, твій останній. Попереду — падь.

[...]

Розкрилені висі твої пронеслися попереду прірва. I ока не мруж.

Ти бачиш розхрестя дороги? Молися, бо ще ти не воїн і ще ти не муж.

Ревуть пароплави, гудуть паровози, i аероплани прокреслюють слід. Чіпляйся за кручу, як терен колючий, чіпляйся за небо, як яблуні цвіт.

Бо вже ослонився безокрай чужинний, бо вже чужинецький ощирився край. Прощай, Україно, моя Україно, чужа Україно, навіки прощай ${ }^{185}$.

In versi in cui all'enfasi romantica della descrizione delle rive dello Dnipro, topos per eccellenza delle lettere ucraine, si alterna una fascinazione per la macchina di memoria futurista, l'io lirico raffigura la liminalità della propria situazione al confine tra il definitivo abbandono di qualcosa che risulta intimo e connaturato alla sua essenza, la patria, e l'ingresso nella dimensione inquietante di uno spazio straniero. Entrando in contatto con quest'ultimo e perdendo il sostegno dell'Ucraina, che, come emerge dal distico iniziale, è indifferente ai destini del suo cantore, il soggetto giungerà alla fase definitiva della propria ma-

185 Ivi: 115 . 'Ancora inverdiranno i fieri pendii del divino Dnipro, / ancora si farà blu la sognante superficie del fiume, / e già ti ha passato a volo di uccello / il tempo tuo, l'ultimo. Dinnanzi a te - l'abisso. / [...] / Le altezze tue alate sono passate, / ti sta dinnanzi il precipizio. E non chiudere gli occhi. / Vedi il bivio della strada? Prega / perché ancora non sei guerriero, ancora non sei uomo. / Ruggiscono i battelli, ronzano le locomotive, / e gli aeroplani arabescano tracce. / Attaccati ai pendii, una spina che punge, / attaccati al cielo, come il fiore del melo. / Ché già si è coperto lo sconfine straniero, / già è digrignato lo straniero confine. / Addio, Ucraina, oh mia Ucraina, / straniera Ucraina, per sempre addio.' 
turazione. Il raggiungimento della pienezza del sé, qui identificata nella bellicosità, sembra dunque inscindibile dall'esperienza del dolore e dello straniamento.

La rappresentazione dell'Ucraina come terra madre fattasi straniera, lontana, irraggiungibile è naturalmente da ricondursi alla tradizione di Ševčenko. Evidente è in questi versi sia la memoria della poesia ševčenkiana della fase pietroburghese, nella prima metà degli anni Quaranta, sia l'influenza della lirica del confino (1848-1857). Si veda dal già citato poema Son:
Царю! Царю!
I бог не розлучить
Нас $з$ тобою. Кайданами
Скований зо мною
Навіки-віки. Тяжко мені
Витать над Невою.
України далекої,
Може, вже немає.
Полетів би, подивився,
так бог не пускає $\epsilon^{186}$.

Ancora più vicina a Palimpsesty per quanto riguarda il motivo dell'Ucraina sembra essere la poesia ševčenkiana degli anni del confino in Asia centrale:
Заросли шляхи тернами
На тую країну,
Мабуть, я ії навіки,
Навіки покинув ${ }^{187}$.

Anche l'immagine dell'Ucraina contemporaneamente natia e straniera è di origine ševčenkiana:

В неволі виріс між чужими,

$\mathrm{I}$, не оплаканий своїми,

В неволі плачучи, умру,

I все з собою заберу,

Малого сліду не покину

На нашій славній Україні,

На нашій — не своій землі ${ }^{188}$.

186 Ševčenko 2003: I, 275. Brogi, Pachlovska 2015: 217: "Zar! O zar! / Ormai nemmeno Dio te da me / dividerà. Nei secoli in catene / A me tu sei legato. È infinita pena / Sulla neve librarsi. / L'Ucraina lontana / Forse già più non c'è. / Vorrei volar laggiù, guardare, / Ma Dio non lo concede."

187 Ševčenko 2003: II, 191. 'Si son riempiti di spine i sentieri / Verso quel paese, / Forse per sempre, / Per sempre l'ho lasciato.'

188 Ivi: 13. 'In schiavitù son cresciuto fra estranea gente / E, senza il pianto dei miei cari, / Morirò piangendo in schiavitù. / E tutto porterò via con me, / Né lascerò di me traccia alcuna / Nell'Ucraina nostra imperitura, / Sulla terra nostra, non più nostra.' 
Come nella lirica di Ševčenko, la raffigurazione dell'allontanamento dall'Ucraina si accompagna nella poesia stusiana all'incontenibile desiderio di poterla nuovamente raggiungere:

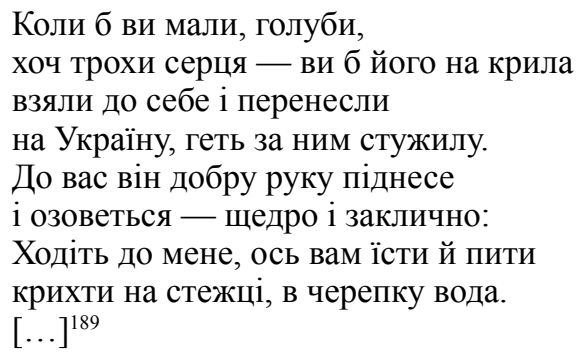

Aggiungendo un nuovo tassello alla propria auto-rappresentazione, l'io lirico di [Koly b vy maly, holuby] si riaggancia alla tradizione ševčenkiana dei versi conclusivi dell'appena citata [Zarosly šljachy ternamy]:

О господи!

Дай мені хоч глянуть

На народ отой убитий,

На тую Україну! ${ }^{190}$

Si noti inoltre come la ripresa del motivo degli uccelli alla finestra, ben rappresentato nella lirica carceraria di Čas tvorčosti / Dichtenszeit, sembri nuovamente ricollegare l'io stusiano di questi versi al mito di San Francesco. Mediatore tra Stus e il testo francescano può essere stato lo Stunden-Buch rilkiano, nel quale Francesco d'Assisi è modello per l'io lirico della seconda parte, Das Buch von der Armut und vom Tode (cfr. Stahl 2006-2007).

La diversità del linguaggio poetico di [Koly b vy maly, holuby] dalle numerose declinazioni del paradigma ermetico individuate nelle liriche precedenti ben testimonia dell'amplissima gamma di procedimenti, motivi, stili e riferimenti intertestuali che caratterizzano il capolavoro di Stus, non riconducibile a una definizione univoca e sistematizzante. L'immagine disarmantemente umana di un io lirico rassegnato che dialoga con gli animali va a sommarsi alle altre, numerose sue raffigurazioni, ora sotto le spoglie di Orfeo, ora guerriero, ora amante stordito dagli eventi. Si arricchisce così di nuovi colori la già variegata tavolozza con cui il soggetto dipinge se stesso, conferendo ulteriore complessità a un universo

189 ZT V, 129. 'Se voi, se voi aveste, o colombi, / almeno un po' di cuore - sulle ali / lo mettereste e lo portereste / in Ucraina, che di lui ha nostalgia. / Buona la mano per voi alzerà / e vi dirà, generoso e invitante: / Venite da me a bere e mangiare, / briciole sul sentiero, nella scodella acqua. / [...]'

190 Ševčenko 2003: II, 191. 'O Signore! / Fammi almeno guardare / Quel popolo ucciso, / Guardar l'Ucraina.' 
poetico ancora innegabilmente incentrato, pur nella notevole varietà delle sue modalità espressive e dei suoi significati, sulla rappresentazione del sé.

La rielaborazione poetica del vissuto dell'io può basarsi, come si è visto, sul ricordo, ora invocato ora rifiutato, sulla visione, come nel caso di molte liriche ermetiche di Palimpsesty, nonché sul sogno. Si vedano, a proposito di quest'ultima forma di conoscenza di sé, alcuni brani di una lunga lirica segnata a tratti da un interessante abbassamento del registro linguistico:

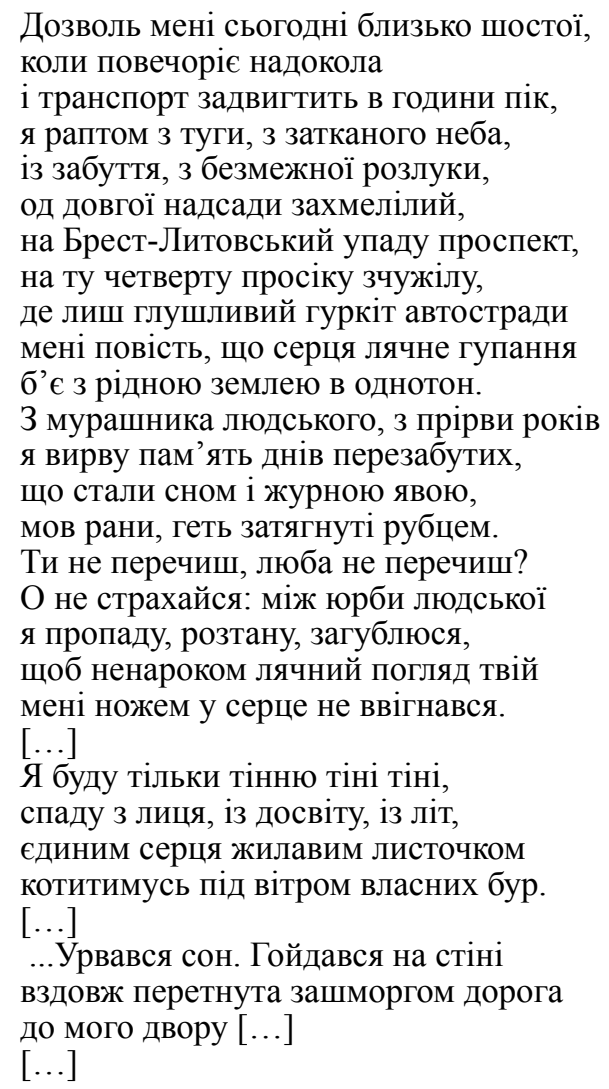

Померти на дорозі повертання занадто солодко, аби Господь нам не поклав у долі узголів' ${ }^{191}$.

191 ZT V, 146. 'Permettimi oggi intorno alle sei, / quando tutto intorno si fa sera / e il traffico freme all'ora di punta, / dal nulla, dal dolore e dal cielo coperto / l'oblio e la distanza senza fine, / dalla lunga tensione inebriato, / di cadere sul Prospekt Brest-Lytovs'kyj, / su quella quarta corsia alienata, / dove il rombo assordante della strada / solo mi dirà che batte impaurito il cuore / all'unisono con la terra natia. / Dal formicaio umano e l'abisso degli anni / strapperò la memoria dei giorni obliati, / che sono sogno e triste realtà, / come ferite, come cicatrici. / Non sei contraria, amore, non sei contraria? / Oh, non ti spaven- 
In versi in cui si incontrano e si intrecciano tradizioni diverse tra loro come la poesia urbana e la lirica amorosa, il soggetto sceglie di mettersi nuovamente a nudo davanti al lettore, privando la propria parola di filtri ermetici e diversioni dalla narrazione principale. La prima parte della lirica, che occupa all'incirca cinque sesti del testo, è la spassionata, quasi masochistica, iperrealistica raffigurazione del ritorno del soggetto nella città da cui è stato allontanato, Kiev, più spesso presentata nella poesia stusiana matura nella veste aulica dei suoi monumenti secolari e nella peculiare fusione di storia e natura che ne caratterizza il tessuto urbano. A prevalere qui, come nel primo Stus, è la città contemporanea, novecentesca, caotica e polverosa, con la quale, tuttavia, l'io lirico ricerca una sintonia espressa da una parte nei termini tradizionali dell'amore "per la terra patria", dall'altra mediante l'immagine di memoria futurista del rombo delle macchine allineato al battere del proprio cuore. Si preannuncia in questo modo un affascinante accostamento di elementi linguistico-culturali tradizionali e sensibilità avanguardista, pienamente giustificata, oltre che dalla natura profonda di Palimpsesty, dalla logica totalizzante e trasgressiva del sogno. La tematizzazione della memoria, come si è visto elemento importante della riflessione lirica di Palimpsesty, si concretizza qui nella similitudine della ferita e della cicatrice, che si configurano a loro volta come un tassello dell'ambigua e contraddittoria rappresentazione del corpo del soggetto, ancora una volta scisso tra concretezza e dematerializzazione. Nella ripresa del dialogo con la donna amata, dopo la lunga descrizione dello spazio urbano e del proprio incontro con esso, l'io lirico tende ad accentuare la propria inconsistenza fisica, paragonandosi di frequente a un'ombra, sino a recuperare la formula "l'ombra di un'ombra di un'ombra" già ricorrente nella poesia stusiana giovanile.

Il progressivo assottigliamento del soggetto nell'avvicinarsi alla donna amata sembra anticipare l'impossibilità dell'incontro, anche se il lettore non è ancora informato del carattere onirico della narrazione, che si rivela solo nel momento, qui non citato, in cui il soggetto giunge davanti alla porta della casa, definita come "la porta del paradiso" (rajs 'ku bramu, ibidem) e assiste alla riunione della donna con il figlio. La descrizione del ritorno dell'io lirico alla realtà dopo l'interruzione dell'idillio illusorio, nel quale l'irrealtà del suo ricongiungimento con la famiglia era insita nell'immaterialità dell'uomo, segna la fine della lunga prima parte del testo. Gli aforistici tre versi finali ne segnano il valore universale, evidenziato anche dall'utilizzo della prima persona plurale. L'improvviso spezzamento della dimensione onirica, denunciata solo nell'attimo della sua interruzione, non sembra priva di risvolti metapoetici. La breve narrazione del ritorno del soggetto alla realtà che ha dovuto abbandonare per l'arbitrio della sorte, a cui egli, nella prima delle due epigrafi anteposte alla raccolta, ha dichiarato di concedersi, è infat-

tare, tra la folla / sparirò, mi scioglierò, mi perderò, / perché per sbaglio il tuo tremendo sguardo / non mi entri nel cuore come un coltello. / [...] / Sarò solo l'ombra di un'ombra di un'ombra, / senza volto, esperienza, senz'anni, / della sola foglia venosa del cuore / mi muoverò al vento delle mie tempeste. / [...] / ...S'è interrotto il sogno. Pendeva al muro / come annodata per il lungo la strada / al mio cortile. [...] / [...] // Morire sulla strada del ritorno - / è troppo dolce perché il Signore / non ci metta nella sorte un capezzale.' 
ti indipendente dalla lunga raffigurazione del sogno, che si rivela come tale solo a posteriori. Il brusco cambio di prospettiva da pura narrazione lirica, alla quale non è estranea la dimensione del fantastico e dell'irreale, allo svelamento del suo carattere onirico tout court complica notevolmente il significato del testo, arricchendolo di elementi di riflessione sul valore stesso della poesia, in grado di creare un mondo realistico e di smascherarsi da sé. Quello che viene così a crearsi è un gioco di specchi metariflessivo che conferisce al testo un valore gnoseologico aggiunto, al di là dell'esplorazione del sé che l'io lirico vi attua come di consueto.

Nella rappresentazione di un'esistenza libera dalle costrizioni imposte dalla sorte il vissuto del soggetto di Palimpsesty oscilla di frequente tra sogno e ricordo, senza che, come nel caso di [Dozvol'meni s'ohodni blyz'ko šostoji], il confine tra le due esperienze sia chiaramente marcato:

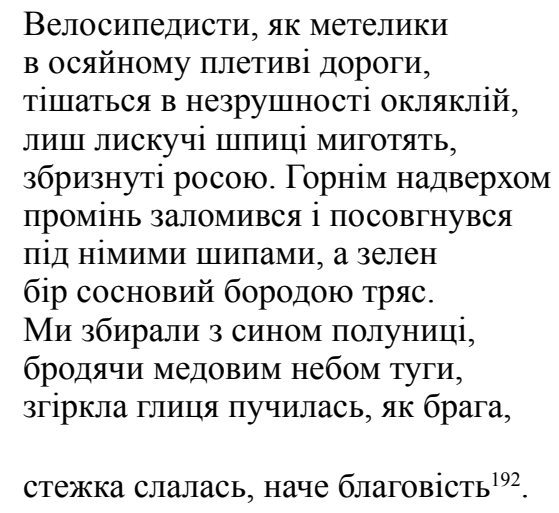

Nelle prime due quartine la presenza dell'io è ridotta all'occhio in cui filtrano le immagini riprodotte e rielaborate nel testo. Il quadro d'insieme è contemporaneamente nitido e sfocato, come in un dipinto impressionista. La concentrazione sui dettagli, come il riflesso dei raggi delle biciclette irrorati di rugiada, sembra testimoniare di una logica onirica, così come la similitudine iniziale tra i ciclisti e le farfalle. Più vicina al linguaggio delle fiabe è invece la metafora della barba della pineta, con la quale si conclude la prima parte della poesia. L'apparente passaggio a una narrazione lirica lineare, momentaneamente annunciato dal primo verso della terza quartina, è nuovamente sconfessato nel distico conclusivo, segnato da brusche similitudini e passaggi dal livello microscopico a quello panoramico. Dall'ultimo verso emerge tuttavia un'apertura teleologica a una futura realtà extratestuale che sembra costituire il principale elemento di contatto tra [Velosypedysty, jak metelyky] e la raccolta nel suo complesso. Pur non escludendo

192 ZT V, 214. 'I ciclisti, come farfalle, / nell'intreccio luminoso della strada, / son felici nell'immobile fermezza, / solo risplendono i raggi scintillanti, / imperlati di rugiada. Dall'alto / un raggio s'è infranto e s'è disposto / sotto le ruote mute, e verde / la pineta ha scosso la barba. / Raccoglievamo io e mio figlio fragole, / vagando nel cielo di miele triste, / marcio il pino è gonfio come corda, / il sentiero disteso un vangelo.' 
la presenza dell'io lirico, questi versi sembrano oscillare tra la rielaborazione del motivo famigliare ben rappresentato in Palimpsesty, da una parte, e il puro gioco con il linguaggio e le possibilità di rappresentazione visuale che esso offre, dall'altra, aggiungendo un ulteriore tassello al ricchissimo panorama testuale dell'opera, difficilmente riconducibile a una tensione tematico-stilistico totalizzante.

$\mathrm{Al}$ crocevia di differenti suggestioni stilistiche è una lirica dal chiaro sostrato biografico, legata al difficile viaggio compiuto da Stus nel 1978 dalla regione di Magadan, dove stava scontando gli ultimi mesi del confino, a Donec'k, per congedarsi dal padre gravemente malato:

\author{
Сьогодні прощальна пора настигає - \\ і від суходолу зірветься літак. \\ Але й з-поза хмар небезпека чигає - \\ то ледь відстає, то вперед забігає. \\ Отож, начувайся: рушаємо вспак. \\ Таксі. Шурхотіння. Пронозистий вітер \\ і далеч, урубана в обрій мечем - \\ тих ієратичних незначених літер \\ нервовий скоропис — як сіверкий щем \\ Пронозистий вітер. Таксі. Шурхотіння. \\ Заплакані вікна. Всевікна твої. \\ Готуйся до злету. Кінець животінню. \\ На тебе чатують світи-галаї. \\ $[\ldots]$ \\ Викружуй, таксисте, ми вже на екрані. \\ Це аеропорт, це аеропорт! \\ Чи то ж тобі в честь, навіжений талане, - \\ такий велелюдний позаду ескорт! \\ Як пси, зовсібіч оступають сексоти, \\ і кожен очима буравить тебе. \\ Вокзал. Коридори німі, як комплоти. \\ А небо в вікні - наче біль голубе. \\ Тож - в неба провалля, в бездоння, бездолий \\ нагірний, невірний, западистий рай, \\ всебідий, всегнівний, всещедрий, всекволий. \\ А що під крилом твоїм. Кара, карай! \\ У небо, у надвищ, за хмари за чорні \\ До сонця, Ікаре, спрямовуй свій лет! \\ Нарівні зі смертю - ми вже непоборні. \\ Нарівні зі смертю - сягаємо мет. \\ $[\ldots]$ \\ Коли ж нас поймає, долає знемога - \\ підноситься пісня — і віща й щемка! ${ }^{193}$
}

193 Ivi: 163. 'Ecco arrivare l'ora dell'addio - / e dalla terra si strapperà l'aeroplano. / Ma da oltre le nuvole il pericolo incombe, / ora s'alza appena, ora corre in avanti. / Allora, sta' all'erta, muoviamoci indietro. / Taxi. Fruscio. Vento impiccione, / l'orizzonte di spada lacerato - / di quelle ieratiche lettere / il corsivo nervoso - dolore che penetra. / Vento impiccione. Taxi. Fruscio. / Finestre che piangono. Le tue pan-finestre. / Preparati 
Nella preparazione al viaggio le diverse emozioni che si susseguono e si scontrano nel cuore dell'io lirico sembrano riflettersi a livello formale mediante una continua alternanza di modelli ritmico-sintattici. Nella prima quartina non vi è frizione tra la sintassi e lo schema metrico-ritmico. L'andamento 'classico' delle proposizioni introduce gradualmente il lettore alla vicenda lirica e ai suoi risvolti sul vissuto interiore del soggetto. Dal quinto verso, nel quale un lessico di militaresca memoria sembra rispecchiarsi nella scansione marcatamente staccata delle parole, che rimarrà dunque predominante sino alla fine del testo, si assiste allo stravolgimento del delicato equilibrio della strofa di apertura. Le frasi si modificano, ora spezzandosi, ora dilatandosi al di là del limite del verso e del confine della strofa, che smentisce l'attesa di una quartina derivata dai primi quattro versi. Nel caso di una lirica legata a un episodio della biografia dell'autore, è lecito ricollegare la tensione così magistralmente ricreata nel testo con gli strumenti della lingua alle difficoltà che hanno accompagnato il viaggio di Stus in Ucraina. I riferimenti agli agenti segreti sulla strada verso l'aeroporto rispecchiano la realtà della grottesca sorveglianza da parte delle autorità sovietiche sul poeta nel corso del viaggio, che egli poté effettuare solamente dopo estenuanti richieste e scontati rifiuti. L'avvicinarsi del volo e il momentaneo distacco dalla terra causano un'ulteriore rarefazione della dizione poetica, che giunge a concretizzarsi in versi completamente ellittici del verbo e dalla cadenza marziale. La pointe del testo esplicita infine il discorso metapoetico sotteso alla lirica nella sua interezza. Ricollegandosi alla conclusione di [Stan'i vdyvljajsja: skil'ky tych oblyč], l'io lirico di [S'ohodni proščal'na pora nastyhaje -] ribadisce una concezione della poesia come frutto della sofferenza e vittoria su di essa, nonché strumento di conoscenza. La sperimentazione stilistica che costituisce il tessuto della lirica, si conferma dunque come la realizzazione linguistica di un doloroso percorso di esplorazione interiore. Interrogandosi sui possibili ipotesti di questo testo, che, pur nell'esplicitazione di un paradigma metapoetico fondante per tutta l'opera stusiana matura, mostra un utilizzo delle possibilità del linguaggio poetico piuttosto insolito, a porsi come potenziale referente privilegiato è ancora una volta la tradizione cvetaeviana. I versi centrali di [S'ohodni proščal'na pora nastyhaje-], nei quali si realizza momentaneamente il volo reale e metaforico dell'io al di sopra della terra e delle sue minacce, si mostrano tipologicamente apparentati alla poesia cvetaeviana dei secondi anni Venti. L'accostamento di neologismi basati sulla stessa radice, la riduzione della componente verbale e la generale rivalutazione del valore iconico della singola parola al di là della costruzione sintattica accomunano in questa lirica la sperimentazione di Stus al linguaggio poetico maturo di Marina

al volo. Non vegeti più. / Ti sorvegliano mondi lontani. / [...] / Svolta, tassista, siam già sullo schermo. / Ecco l'aeroporto, è lì l'aeroporto! / Che sia in tuo onore, talento impazzito, / una scorta al seguito di tale entità? / Agenti segreti da tutte le parti, / ti fissano immobili, cani rabbiosi. / Stazione, corridoi muti come complotti. / E il cielo nella finestra è blu come il male. / Nell'abisso del cielo, nel precipizio, senza destino / montano, incerto paradiso che si infossa, / di sventure, rabbie, doni e debolezze. / Che hai sotto l'ala? / Castigo - castiga. / In cielo, l'altissimo, nere le nubi, / al sole dirigi, o Icaro, il volo! / Al pari con la morte - siam invincibili, / al pari con la morte - conquistiamo le vette. / [...] / Quando fatica ci prende, ci stende, / si solleva il canto - veggente, dolente.' 
Cvetaeva (cfr. Bilovus 2004: 62). Il nesso tra la figura e la scrittura cvetaeviana e gli avvenimenti all'origine dell'ispirazione di [S'ohodni proščal'na pora nastyhaje -] è confermato inoltre dall'epistolario stusiano ${ }^{194}$.

Come già nella poesia anteriore a Palimpsesty, il modello della poesia cvetaeviana matura rivive in alcune liriche del capolavoro di Stus:

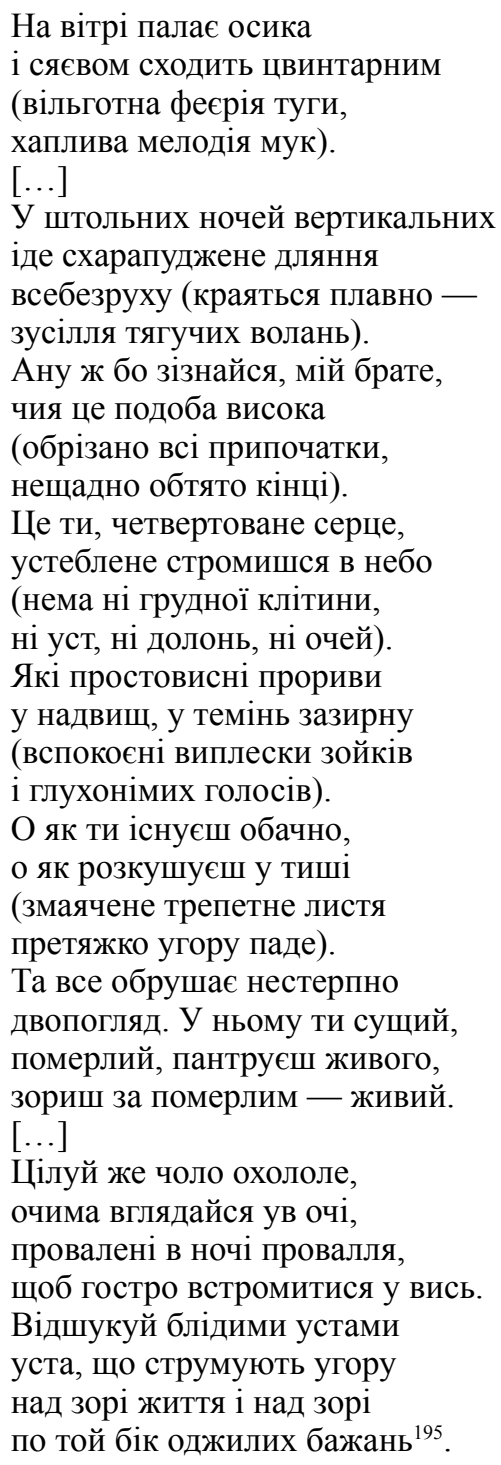

194 Si veda dalla già citata lettera ai familiari del 4-03-1984, in: T VI.1, 461.

195 ZT V, 140. 'Al vento il tremolo brucia / splendendo come un cimitero / (l'umida fiaba della tristezza, / la rapida melodia dei dolori. / [...] / Nei cunicoli delle notti 
Nell'imagery visionaria di [Na vitri palaje osyka], ripetuta nella seconda parte di Palimpsesty con alcune marginali differenze (ivi: 257), l'espressionismo stusiano sembra raggiungere il suo apogeo. L'identificazione fra l'albero del primo verso, il cuore dell'io lirico e la propria totalità psicofisica sconvolta dalla tensione verso l'alto si inserisce in un quadro profondamente inquietante, nel quale le predominanti suggestioni visive si fondono, come spesso nella poesia di Stus, con altrettanto minacciosi elementi uditivi. La terra è caratterizzata ex negativo come ciò da cui il soggetto ricerca ossessivamente la fuga nel movimento verticale. Il suo incontenibile slancio al di sopra di ciò che altro non è che dolore e immobilità è coerentemente accompagnato da un'ossimorica, pesante caduta verso l'alto delle foglie dell'albero. A rallentare e trattenere l'elevazione dell'io lirico nell'infinito della verticalità sembra essere la sua stessa doppia natura. Contemporaneamente vivo e morto, egli è condannato a fluttuare in uno spazio intermedio tra la terra e il cielo, tra la l'inerzia della morte-in-vita nella dimensione orizzontale dell'esistenza umana e la libertà assoluta della vita-in-morte nell'altezza irraggiungibile di una dimensione opposta. L'intrinseca contraddittorietà dell'essenza del soggetto è altresì espressa, anche in questo caso, dalla sua ambigua corporalità. Privo di cassa toracica, labbra, mani e occhi, nient'altro che cuore, nella penultima quartina della lirica l'io esorta se stesso a baciare la propria fronte raffreddatasi e a guardarsi negli occhi. In questa riunificazione del soggetto con se stesso sembra racchiudersi infine il pegno della sua auspicata elevazione al cielo, come dichiarato nell'ultima strofa. Il legame tra la ritrovata integrità dell'io lirico e la sua improbabile, eternamente auspicata liberazione sembra tuttavia alludere all'impossibilità di questo evento e alla conseguente condanna dell'io alla prigionia. A riassumere esemplarmente la natura alogica della sua fisicità sono le voci sordomute che, in uno dei passi più oscuri della lirica, sembrano contribuire alla sua reclusione, anche se la loro attribuzione al soggetto stesso non è univoca.

Come già anticipato, la raffigurazione del soggetto nella complessità della sua scissione tra la terra e il cielo e dell'altrettanto ambiguo smaterializzarsi del suo corpo sembrano rivelare un'ispirazione cvetaeviana. Un possibile prototipo dell'io lirico di [Na vitri palaje osyka] è infatti da ricercarsi nuovamente nella Sibilla cvetaeviana del trittico Sivilla da Posle Rossii, già incontrata tra le fonti di ispirazioni dello Stus di Zymovi dereva. Quintessenza del poeta, o del poeta al femminile, la Sibilla di Marina Cvetaeva condivide con l'io lirico di [Na vitri

verticali / va il protrarsi spaventato / della grande immobilità (si tagliano lenti / gli sforzi degli urli prolungati. / Ma ammettilo, fratello, / di chi è quest'alto sembiante / (tagliate le radici, / impietosamente mozzate le punte). / Sei tu, cuore torturato, / impalato, ti innalzi al cielo / (non c'è petto, / né bocca, né mani, né occhi). / Come son erti gli assalti / nell'alto, nel buio iperuranio / calmatisi gli schizzi delle grida / e delle voci sordomute). / Oh, come vivi con cautela, / come mangi nel silenzio / (allucinate foglie balenanti / cadono pesanti verso l'alto). / E insopportabile demolisce / il doppio sguardo. In esso tu esisti, / morto, il vivo sorvegli, / fissi il morto - da vivo. / [...] / Bacia la fronte fredda / con gli occhi guarda negli occhi, / inabissati nell'abisso della notte, / per infilarti acuto nell'alto. / Cerca con labbra pallide / labbra che puntino in alto / sopra le stelle della vita e sopra le stelle / dall'altra parte dei vecchi desideri.' 
palaje osyka] la tendenza a farsi albero nel processo di de-umanizzazione che accompagna inevitabilmente la vita del poeta (Cvetaeva 2004: 561):

Сивилла — выжжена, сивилла: ствол.

Все птицы вымерли, но бог вошел.

$[\ldots]$

Сивилла: выбыла, сивилла: зев

Доли и гибели! - Древо меж дев.

La trasformazione in un albero, o meglio in un nudo e rinsecchito tronco, è funzionale all'incontenibile tensione verso l'alto che caratterizza la natura del poeta cretaeviano e stusiano (ibidem):

Час не стареющий, так в седость трав

Бренная девственность, пещерой став

Дивному голосу...

— Так в звездный вихрь

Сивилла: выбывшая из живых.

Si noti come nel testo di Stus il soggetto miri a spingersi addirittura al di là delle stelle, superando la Sibilla nella volontà di allontanarsi dalle costrizioni della terrestrità. Con l'io lirico di [Na vitri palaje osyka] la Sibilla di Marina Cvetaeva ha inoltre in comune un'ossimorica "voce sordomuta" solo apparentemente impossibile (ibidem):

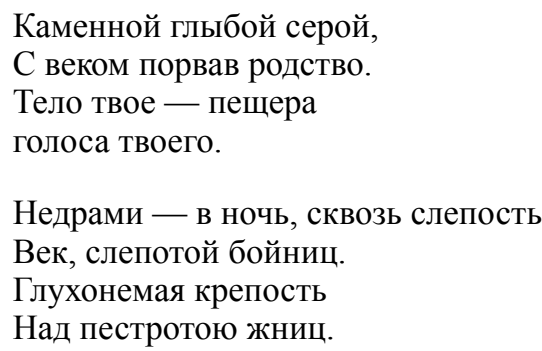

Nella differenza ontologica che distingue la sua voce da quella degli esseri umani e nella sua conseguente incapacità di comunicare con loro, il poeta cvetaeviano e stusiano non può che risultare sordomuto, pur essendo, al contrario, ricettore e latore della verità: “Сивилла: вещая! Сивилла: свод!” (ibidem). Si ricordi la definizione del canto del poeta come "veggente" (ucr. viščyj, rus. veščij) in [S'ohodni proščal'na pora nastyhaje], vicina a [Na vitri palaje osyka] per il comune dialogo con la poesia di Marina Cvetaeva, nel primo caso a livello stilistico e nel secondo a livello tematico. Comune a entrambe è inoltre la rappresentazione del poeta nel suo inarrestabile distacco dalla realtà terrena. 
Al 'testo cvetaeviano' di Palimpsesty è accostabile una lunga lirica della seconda parte dell'opera dal carattere fortemente sperimentale:

Сто чорних псів прогавкало. Сто псів.

А дощ — i дощ. Геть небо заступила

блідава мла. І виє в сотню пащ:

Пу-гу-гу-гу. Гуль-гуль. Пу-гу-гу-гу.

Ти ще - ось-ось. Допіру-но ступив

за всемежу. Старечою ходою

із костуром - іще бриниш мені

всеобрієм. І світ мені - скричалий.

Як я летів! Як нісся! Як сто крил

моїх відрослих - заважали лету.

Ку-ку-гуль-гуль-куку-пугу-пугу.

Гуль-гуль-ку-ку-пугу — перелітало

в зигзиче, шаре, голубе - гуль-гуль

i бралось смертним смерком. Пуги-гулі!

І опадалі мертві солов'ї

обабіч літака — як змерзлі сльози.

$[\ldots]$

Мій хорий орлику, мій хо-

(як ходорами, заходили

всі коридори!). Тилик-тилик -

лунає музика сліпа.

Вона причаєна. Глуха.

Гучить бо в себе. І прямує

туди, де все глухонімує, де вічна хата без верха чи то літує, то зимує.

$[\ldots]$

Два дальніх берега. Два - між.

А посередині струмує

ріка життя. Упрост прямує

червона барка. В барці криж.

Наглянь! Я ж здалека лечу!

невже про те, щоб проминути?

Зболіле серце в кригу вкуте.

Стою. І свічкою свічу.

О боже, зглянься! Я ж лечу

з самого запотойбік-світу!

О відверни іiі неситу. 
Стою. 3 усіх очей кричу.

То сон був. Тільки сон. [...]

$[\ldots]$

[...] А мама - де?

А де - Марія?

Вітчизна — де? І горілиць

упав. Зажданий мій, зажди!

Ще буде - мати і Вітчизна.

О трута, трутонька, трутизна

пече уста. Подай води.

$[\ldots]^{196}$

La vicinanza di [Sto čornych psiv prohavkalo. Sto psiv] alla poetica cvetaeviana è stata notata anche da Dmytro Stus nel commento al quinto tomo di $Z T$. Nei centosessanta versi di questa lirica, come [S'ohodni proščal'na pora nastyhaje] ispirata dal viaggio del 1978 al capezzale del padre malato, il figlio del poeta ha visto, "similmente al Poema konca di M. Cvetaeva", una "reinterpretazione panoramica di suoni, avvenimenti, narrazioni e addirittura oggetti, purificati dal loro significato quotidiano, come se messi in secondo piano dalla grave situazione dell'addio. A dominare qui è la lingua delle allusioni, dei gesti, dei suoni, che acquistano un significato simbolico solo nell'istante dell'addio per sempre" ${ }^{197}$. Nell'opera cvetaeviana l'utilizzo della lingua poetica come strumento di ripro-

196 Ivi: 350 . 'Cento cani neri abbaiarono. Cento cani. // E pioggia - e pioggia. Ha rimpiazzato il cielo / una nebbia pallida. E ululan cento fauci: / Pu-hu-hu-hu. Hul'-hul'. Pu-hu-hu-hu. // Ancora tu - eccoti, eccoti. Appena passato / oltre il confine dei confini. Andatura da vecchio / col bastone - ancora mi risuoni / nel pan-orizzonte. / E il mondo a me - gridante. // Come volavo! Come andavo! Come le cent'ali / mie ricresciute - disturbavano il volo. / Ku-ku-hul'-hul'-kuku-puhu-puhu. / Hul'-hul'-ku-ku-puhu - volo / in ciò che è cuculo, grigio, azzurro - hul'-hul' / e s'è fatto tenebra mortale. Puhu-hul'! / E cadevano morti gli usignoli / ai due lati dell'aereo - come lacrime ghiacciate. // [...] // Aquilotto mio malato, mio ma- / (Come tremando son partiti / i corridoi tutti!). Tylyktylyk - / risuona la musica cieca. / È strozzata. Sorda. / Suona in se stessa. È diretta / là, dove tutto si fa sordomuto, / dove l'eterna casa senza cima - / ora passa l'estate, ora sverna. // [...] // Due rive lontane. Due - in mezzo. / E al centro - scorre / il fiume della vita. Prosegue dritta / una barca rossa. Nella barca - una croce. // Guarda bene! È da lontano che volo! / Davvero si tratta di passare poi oltre? / Il cuore dolente è infitto nel ghiaccio. / Sto in piedi. E splendo come una candela. / Oh, Dio, non guardar così! Sono in volo / dal mondo proprio dall'altra parte! / Oh girala, l'insaziabile. / Sto in piedi. Grido da tutti gli occhi. // Era un sogno. Solo un sogno. [...]/ [...]// [...] E la mamma - dov'è? E dov'è Maria? / La patria - dov'è? E a pancia in su / son caduto. T'ho così aspettato, aspetta! / Ci saranno - la madre e la Patria. / O, il veleno, il piccolo veleno, venefico veleno / brucia le labbra. Dammi acqua. / [...]'

197 Ivi: 725: “В цьому вірші, подібно до 'Поэмы конца' М. Цвєтаєвої, наявне панорамне переосмислення звуків, подій, сюжетів і навіть предметів, очищених від щоденного значення, ніби підміненого значеннями високої ситуації прощання. 
duzione di suoni parzialmente slegati dalla rappresentazione, è riscontrabile, ad esempio, nel pometto Pereuločki del 1922: “А-ю-рай, / А-ю-рей, / Об-ми-рай / Сне-го-вей” (Cvetaeva 2004: 531). La critica cvetaeviana ha osservato la vicinanza di una poesia di questo tipo all'estetica delle avanguardie, nello specifico alla zaum' di Aleksej Kručënych ${ }^{198}$. Espressione più radicale del futurismo russo nella sua volontà di liberare il linguaggio dalla schiavitù della referenzialità, l'opera di Kručënych, decisamente più opaca e 'trasgressiva' della contemporanea poesia di Velimir Chlebnikov o, per quanto riguarda la letteratura ucraina, di Mychajl' Semenko (1892-1937), sembra costituire un antecedente della sperimentazione stusiana nella parte iniziale di [Sto čornych psiv prohavkalo. Sto psiv], insolita e straordinaria pur nel contesto dell'insaziabile volontà di sperimentazione dello Stus di Zymovi dereva e Palimpsesty. Tuttavia, l'appartenenza della lirica al 'ciclo cvetaeviano' di Palimpsesty, giustificata dal sostrato biografico alla base della sua ispirazione, inducono a ritenere innanzitutto l'opera di Marina Cvetaeva come il principale punto di riferimento per questi versi. Il moderato utilizzo cvetaeviano della zaum ' in chiave altamente emozionale come strumento di espressione di esplosivi sentimenti non altrimenti riproducibili sembra accostabile alle prime strofe della lirica stusiana in questione, dietro alle quali si celano analoghe emozioni, seppur più esplicitamente raffigurate in [S'ohodni proščal'na pora nastyhaje]. In [Sto čornych psiv prohavkalo. Sto psiv] l'utilizzo del linguaggio transmentale nella parte iniziale della lirica si accompagna ad apparenti negazioni della logica consueta: la ricrescita delle ali (evidentemente cadute o mozzate in precedenza) rende più difficoltoso il volo del poeta. Questa affermazione incomprensibile trova una giustificazione alcuni versi più tardi, quando l'io lirico afferma di trovarsi a bordo di un aeroplano. Se, da una parte, la ricrescita delle ali potrebbe essere letta nei termini di una rinnovata ispirazione poetica, quest'ultima sembra essere poi negata dalla caduta e dalla morte degli usignoli alla fine della strofa, vanificando ogni tentativo di interpretazione di questi versi in chiava razionale. Ciò conferma, dunque, la loro prossimità all'estetica delle avanguardie. La rarefazione degli elementi riconducibili alla zaum' nelle strofe successive si accompagna alla comparsa di motivi tradizionali, come la patria, la madre e la sorella, accomunate nella loro irraggiungibilità e riconducibili all'immaginario ševčenkiano, così come il volo che si rivela un sogno. [Sto čornych psiv prohavkalo. Sto psiv] si mostra dunque come una complessa costruzione testuale in cui il controllo delle emozioni mediante la stringatezza e l'iconicità di un linguaggio di origine avanguardistica si fonde con l'interesse per la fusione sperimentale di diverse tradizioni, inclusa quella conservatrice del modello ševčenkiano, fornendo un ulteriore, brillante esempio di palinsesto poetico tardo-stusiano.

Тут домінує мова натяків, жестів, звуків, що набувають символічного значення лише у хвилину навік прощання.”

198 Si veda Ciepiela 2009: 327: "In the first stanza quoted here, and elsewhere in the poem, the text devolves into pure vocalization." 
Il sogno del ritorno a casa può essere raffigurato con una strumentazione stilistica di segno opposto, come nel caso di [Vsja v žuželyci, porosi, vuhilli]:

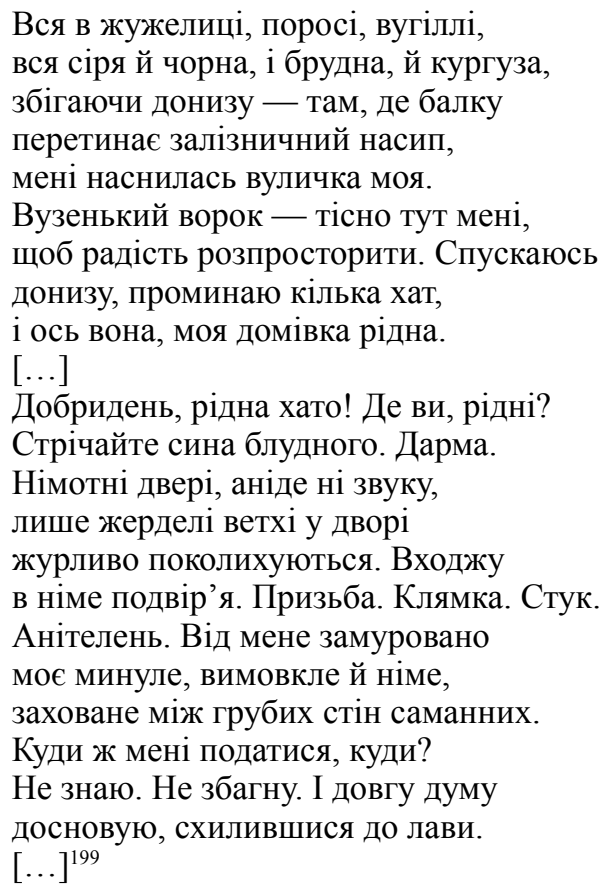

Come in [Ja blukav mistom svojeji junosti] da Veselyj cvyntar, reinserita nella seconda parte di Palimpsesty (ivi: 201), il ritorno a casa, in questi versi esplicitamente legato alla dimensione onirica, è causa di smarrimento esistenziale. La negazione del contatto con il proprio passato significa l'impossibilità di (ri) conoscere se stessi e di avere di conseguenza fiducia nel proprio futuro. Se nella lirica cronologicamente anteriore, tuttavia, il motivo tanto modernista quanto postmodernista della perdita dell'identità e dell'assoluta solitudine dell'uomo davanti a se stesso e al mondo si accompagnava a un linguaggio poetico marcatamente a-poetico, assimilabile a una narrazione in prosa solo graficamente definibile come poesia, in [Vsja vžuželyci, porosi, vuhilli] si assiste a una ten-

199 ZT V, 246. 'Tutta fuliggine, polvere e carbone, / tutta grigia, nera, sporca e monca, / correndo verso il basso - lì, dove attraversa / il fosso il terrapieno della ferrovia, / mi è apparsa in sogno la mia viuzza. / Un piccolo sacco - non c'è posto qui / per dare spazio alla gioia. Scendo / giù, passo qualche casa, / ed eccola, la mia casetta natia. / [...] / Buongiorno, casa natia! Dove siete, cari? / La porta muta, tutto in silenzio, / solo i vecchi albicocchi in giardino / ondeggiano tristi. Entro / nel cortile. Il fossato. Il catenaccio. Busso. / Nessuno. È murato da me / il mio passato, muto e azzittito, / nascosto tra grezze mura di mattone. / Dove devo andare, dove? / Non so. Non capisco. E il lungo canto / terminerò appoggiato alla panchina. / [...]' 
sione alquanto maggiore sia tra la tematica e la sua realizzazione formale, sia tra le diverse parti del testo. La lirica dei tardi anni Sessanta riassume se stessa nel distico iniziale (“Я блукав містом своєї юності, / марно вишукуючи в нових кварталах"), in cui la perdita di ogni illusione è sobriamente messa di fronte al lettore con una secchezza riconducibile a una sensibilità di marca postmodernista. In questi versi, al contrario, le aspettative create dalla prima strofe sono ribaltate dal successivo svolgimento del testo. Con un linguaggio contemporaneamente familiare e poetico, in cui l'evocazione di aspetti bassi della realtà materiale è strutturata mediante un evidente parallelismo, i primi cinque versi sembrano infondere nel lettore la speranza di un sereno ricongiungimento dell'io lirico con il suo ambiente natio. Questa nota apparentemente positiva è al contempo confermata e relativizzata dalla situazione onirica, che ne mette in risalto l'irrealtà, permettendo tuttavia che in essa si realizzi un evento sereno impossibile nella vita reale. Si noti, dunque, come anche in questi versi si sviluppi la riflessione metapoetica stusiana sul rapporto tra poesia, sogno e ricordo, fondamentale per la poetica di Palimpsesty. A distinguere l'incipit di [Vsja $v \check{z} u z ̌ e l y c i$, porosi, vuhilli] dalla corrispondente sezione di [Ja blukav mistom svojeji junosti] è inoltre la sua versificazione tradizionale. La consueta pentapodia giambica non consente alcuna anticipazione sul significato del testo a differenza del verso libero di [Ja blukav mistom svojeji junosti], grazie al quale, in combinazione con un lessico chiaramente legato al topos della modernità urbana, può essere facilmente anticipato l'abbandono dell'illusione di un'identità inalienabile tipico della sensibilità novecentesca. Anche l'atmosfera rusticana e di possibile derivazione ševčenkiana che segna la descrizione della "viuzza" a cui l'io lirico ha potuto fare ritorno tiene inizialmente il testo a debita distanza dallo scivolamento nella disperazione che ne caratterizzerà la lunga seconda parte. La seconda strofa, seppur non priva di espliciti accenni a un iniziale disagio del soggetto, non smette di insistere sul carattere dichiaratamente familiare dell'ambientazione. Il successivo riconoscimento della propria estraneità a ciò che in passato era parte di sé e dell'assoluta solitudine che questa estraneità comporta si realizzano nel testo mediante una notevole rarefazione della sintassi, che sembra presagire il silenzio della disillusione.

Si noti, inoltre, come nel commento di $Z T$ venga sottolineata la collocazione di questa lirica tra testi risalenti alla seconda metà degli anni Settanta, in virtù della sua vicinanza al filone donec'kiano legato al viaggio per congedarsi dal padre malato, nonostante essa risalga con buona probabilità al 1972 (ivi: 709).

Tra gli spazi che costellano la geografia poetica di Palimpsesty un posto di primo piano non può che spettare alla Kolyma, luogo di residenza forzata di Stus negli ultimi anni della prima condanna. L'immagine della Magadanskaja oblast', la regione dei lager del GULag per eccellenza, è nella poesia stusiana inaspettatamente meno univoca di quanto ci si potrebbe aspettare. Nei trimetri poliritmici di [Oj ty, hore holodne,] la tradizionale invocazione della patria lontana si accompagna a un'indiretta maledizione dell'inospitale estremo nordest della Russia: 


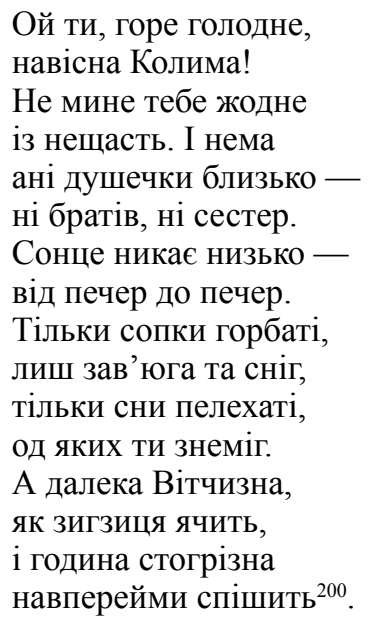

Recuperando elementi tipici della tradizione ševčenkiana ormai diventati parte integrante dell'universo lirico stusiano, quali la solitudine, l'esilio e la desolazione della terra straniera, questi versi risentono della lezione di Ševčenko anche per quanto riguarda la stilizzazione della poesia folclorica. Ciò che all'apparenza si mostra come un'assoluta contrapposizione tra la dolente terra natia, agognata e irraggiungibile, e gli odiati luoghi del confino, si rivela a uno sguardo più attento il suo contrario. L'Ucraina e la Kolyma sono infatti accomunate dalla stessa sofferenza e dalla stessa sottomissione a una sorte crudele e incomprensibile, parti diverse di uno stesso mondo egualmente disumanizzato.

Le inospitali terre ghiacciate dell'estremo settentrione possono tuttavia suscitare nell'io lirico un inatteso senso di tenerezza e di comunione:

Колимські конвалії - будьте для Валі, достійтесь для Валі - рожеві огні.

Пробачте, у вас забагато печалі, пробачте, красуні, ви надто сумні.

Моя чужаниця - то ваша, то рідна земля, на якій ви, цнотливі, зросли, на завтра хай видасться днина погідна, аби ми, нівроку, здорові були.

Бо завтра ж ми підем стрічати кохану журливу журавку — таку ж, як і ви.

Про свято я іскру болгарську дістану і викину клопоти всі з голови ${ }^{201}$.

200 Ivi: 341. 'Dolore affamato, / odiata Kolyma! / Passano da te tutte / le infelicità! / Intorno a me nessuno, / fratello né sorella. / Il sole vaga basso, / da una grotta all'altra. / Nient'altro che colline, / solo bufere e neve, / confusi sono i sogni / che ti hanno addormentato. / Ma la lontana Patria / come una gazza geme, / e l'ora minacciosa / a giungere s'affretta.' 201 Ivi: 253. 'Mughetti della Kolyma - siate per Valja, / resistete per Valja - oh fuochi rosa. / Scusate, troppa è la tristezza, / scusate, bellissimi, troppo è il dolore. / La terra 
La lirica risale con ogni probabilità al 1977, quando la moglie di Stus, Valentyna Popeljuch, poté trascorrere un mese al fianco del marito al confino. L'esortazione a sbocciare e a conservarsi che l'io lirico rivolge ai mughetti e, presumibilmente, ai loro frutti negli spazi dolenti e dolorosi della Kolyma sembra nascondere implicazioni metapoetiche e poetologiche. Associato, tra le sue molteplici connotazioni, alle lacrime di Maria sotto la croce, il mughetto, un motivo presente in tutte le tradizioni poetiche vicine a Stus ${ }^{202}$, potrebbe alludere alla poesia stusiana stessa, generata dal dolore e dalla separazione, così come, più indirettamente, alla donna e al suo pianto sotto l'ideale croce dell'io lirico, al quale, come si è già osservato, non sono estranei attributi cristologici. Nel suo insieme il testo è infatti scisso tra l'atemporale liricità dei primi sei versi, incentrati sul collegamento tra la freschezza dei mughetti e la figura femminile, e la spiccata quotidianità della seconda parte, segnata dall'insistenza sulla contingenza temporale e dall'abbassamento del registro lessicale all'ultimo verso. A imporsi alla percezione del lettore è, nel contesto di Palimpsesty, il quadro di un temporaneo, provvisorio rischiaramento dell'anima e del paesaggio in cui essa è immersa.

La tradizione del Rollengedicht, già riscontrata nella poesia stusiana giovanile e in Čas tvorčosti / Dichtenszeit, non manca di trovare spazio anche nell'ampio progetto di Palimpsesty. Tra le liriche più celebri della raccolta figurano infatti le cinque parti di Treny M.H. Černyševs'koho ('I lamenti di M. G. Černyševskij'), due delle quali sarebbero state riproposte autonomamente nella seconda parte dell'opera. Il ciclo, probabilmente composto in diversi momenti attorno alla metà degli anni Settanta, si inserisce nel filone di poesie come Kostomarov u Saratovi da Zymovi dereva e le raffigurazioni di Ševčenko e Skovoroda sparse in tutta la lirica stusiana dagli esordi sino a Palimpsesty. Sullo sfondo di questi testi, l'interesse precipuo dei Treny risiede nella scelta come loro eroe di un personaggio estraneo alla storia culturale ucraina, anche se simpatizzante della sua causa, nonché figura di culto nel pantheon sovietico. Si noti, tuttavia, come a Černyševskij avesse dedicato un sonetto Mykola Zerov nel 1933, molto vicino alla sensibilità poetica di Stus ${ }^{203}$. L'identificazione tra l'io lirico stusiano e il Černyševskij

straniera è per voi patria, / la vostra, in cui virtuosi siete cresciuti, / ché sia domani un giorno di sole, / ché siamo, speriamo, in buona salute. / Domani l'amata andremo a incontrare / la triste cicogna, che soffre con voi. / Avrò per la festa anche uno spumante / e i pensieri dalla testa scaccerò.'

202 Il motivo del mughetto non è infatti estraneo alla storia della poesia ucraina (Lesja Ukrajinka, Konvalija), russa (Fet, [O pervyj landyš, iz-pod snega], Pasternak, Landyši) e occidentale (Ungaretti, Mughetto — si ricordi il documentato interesse di Stus per la poesia ermetica italiana), anche se non sembra possibile stabilire nessi intertestuali tra queste liriche e [Kolyms'ki konvaliji - bud'te dlja Vali,], spiazzante nell'accostamento di universalità e tragica situazionalità che la contraddistingue.

203 Zerov 1990: 92: “Поглядала ніч і волохатий сполох / Над безвістю засніжених долин. / Як терпне серце! Скільки літ один / Німує він у нетрях захололих! // Він згадує: між друзів ясночолих / Кипить розмова; від привітних стін 
dell'esilio dopo la condanna del 1864 , apertamente dichiarata dal poeta in una lettera alla moglie del $1977^{204}$, è pienamente in linea con il testo carcerario della poesia di Stus, come si è osservato parte integrante del suo universo poetico fin dagli anni precedenti alla detenzione e al confino. Un affascinante caso, dunque, di sincretismo tra la tradizione storica e letteraria prettamente ucraina, inevitabilmente inserita nel discorso culturale sovietico, e le mitologie eroiche di quest'ultimo, per il quale la componente russa non può che essere fondamentale.

La quartina iniziale delle prima delle cinque parti del ciclo segna immediatamente la tonalità grave e il pathos romantico che non abbandoneranno il testo fino all'ultimo verso:

Народе мій, коли тобі проститься крик передсмертний і тяжка сльоза розхстріляних, замучених, забитих по соловках, сибірах, магаданах? 205

Sin dal primo verso, che riprende una lirica dei primi anni Sessanta inserita in Delo № 13 / BE1339, la dimensione dell’io si fa sineddoche di una collettività

/ Спливає світло: і немовби дзвін, / Він кличе все живе, він б'є на сполох. // Суд і заслання... Мука самоти... / О як у сяйві небо розкололось! / А тиша мертва i нема мети. // Враз бубонці: далеко рипнув полоз, / I кріз сніжок, здається, чути голос: / 'Ще не покаявся? Не виправився ти?'” 'Notte polare e angoscia arruffata, / Sull'ignoto delle valli innevate. / Si raggela il cuore! Da anni solo / E muto negli anfratti ormai di gelo! // Ricorda lui: gli amici rischiarati / Conversano; tra mura accoglienti / Scorre la luce e come una campana / Richiama all'allarme ciò che è vivo. // Processo e esilio... Star soli nella cura... / Il cielo che si è infranto nel bagliore! / Morto è il silenzio e già non c'è scopo. // Repentini i sonagli: stride la slitta / E tra le nevi par esser una voce: / "Non sei pentito? Migliore già non sei?",

204 Dalla lettera alla moglie del 20-12-1977, in: T VI.1, 292: “Колись Чернишевський писав - із в'язниці Петропавлівської - до дружини: ми 3 тобою, наше життя - належить історії. Тому будьмо гідні своєї долі - i не нарікаймо на неї - долю. Думаю, що наше з Тобою життя теж стало часточкою історії нашого народу." "Scrisse a suo tempo Černyševskij alla moglie dalla fortezza di Pietro e Paolo: la nostra vita appartiene alla storia. Quindi dobbiamo essere degni della nostra sorte e non lamentarcene. Penso che anche la nostra vita sia diventata una piccola parte della storia del nostro popolo.' Si veda anche un passo della lettera alla moglie del 26-06-1978, in: ivi: 314: “Сіли в Якутську. Знову я відчув подих часів Чернишевського: кілька будівель на площі залишилося від тих часів. Може, i незлих будівель, навіть мальованих, проте кожна промовляє: я бачила Миколу Гавриловича, тут вибував Павло Грабовський." 'Siamo atterrati a Jakutsk. Hо sentito di nuovo l'aria dei tempi di Černyševskij: sulla piazza è rimasto qualche palazzo di quell'epoca. Dei palazzi non male, anche, ma mi sembra che ognuno dica: ho visto Nikolaj Gavrilovič, qui ha abitato Pavlo Hrabovs'kyj.' Pavlo Hrabovs'kyj (1864-1902) è entrato nella storia culturale ucraina come scrittore, pubblicista e attivista politico.

205 ZT V, 89-92. 'Popolo mio, quando saranno a te perdonati / il grido di morte e la lacrima greve / di fucilati, torturati e uccisi / A Magadan-Siberia-Solovki?' 
unita dal dolore e dalla repressione. Si nota inoltre un'inaspettata discrepanza tra due poli provvisoriamente opposti: il "popolo" (narod) - elemento sacro dell'etica e dell'estetica tanto dello šistdesjatnyctvo, quanto della cultura sovietica - e la massa senza nome delle vittime della tirannia imperiale. A fungere da oggetto dell'invocazione è nella seconda strofa lo stato:
Державо напівсонця-напівтьми, ти крутишся у гадину, відколи тобою неспокутний трусить гріх і докори сумління дух потворять ${ }^{206}$.

L'amoralità che governa la vita della nazione è alla base della sua decadenza morale, causa del suo futuro disgregarsi. È interessante osservare come le accuse mosse dall'io lirico dei Treny siano accostabili al lessico dei consueti dialoghi dell'io lirico della poesia stusiana con se stesso:
[...] Це божевілля пориву, ця рвань
всеперелетів - з пекла до раю,
це надвисання в смерть, оця жага
розтлінного весь білий світ розтлити
і все товкти, товкти зболілу жертву,
щоб вирвати прощення за свої
жахливі окрутенства — то занадто
позначене по душах і хребтах ${ }^{207}$.

In un macabro crescendo di orrore e crudeltà, a svilupparsi sotto gli occhi del lettore avvezzo alla poesia stusiana è un allargamento della prospettiva che ha riguardato sinora l'io lirico e la sua tormentata interiorità, da una parte, e il dio crudele che ne causa le sofferenze, dall'altra, a una dimensione universale in cui la statualità arriva a coincidere con il tutto. La patologica instabilità, l'irrefrenabile e inquietante slancio che sballotta l'anima dall'inferno della quotidianità a un illusorio paradiso e la comunanza con la morte sono infatti caratteristiche che l'io lirico della poesia stusiana ha più volte attribuito a se stesso. La tendenza all'accanimento sulle sofferenze della propria vittima è invece una peculiarità del "dio mostruoso" protagonista di [Nemaje Hospoda na cij zemli -], con cui la quarta strofa di [Narode mij, koly tobi prostyt'sja] condivide anche elementi lessicali e particolarità sintattiche. Si tratta dunque di un'evidente caso d'identità negativa, tra l'io lirico, il dio crudele che governa il mondo di [Nemaje Hospoda na cij zemli -] e il mondo stesso, ridottosi alle anguste dimensioni di uno stato

206 Ibidem. 'Stato di semisole e semitenebra, / ti attorcigli come serpe fin da che / ti scuote il peccato inespiato / e la coscienza rimprovera e snatura lo spirito.'

207 Ibidem. '[...] Questa follia dell'impeto, strappo / dei voli universali - dall'inferno al cielo, / ondeggiamenti nella morte, sete / del corrotto di corrompere il mondo intero / e tutto schiacciare, la vittima dolente schiacciare, / per estorcere il perdono per i propri / terribili obbrobri - questo è troppo / evidente in anime e schiene.' 
che si è fatto paradossalmente universo. La lirica si chiude in tono profetico, con un'ambigua e inquietante evocazione di oscuri, minacciosi presagi:

Тота сльоза тебе іспопелить

і лютий зойк завруниться стожало

ланами й луками. I ти збагнеш

обнавіснілу всенищивність роду.

Володарю своєї смерти, доля -

всепам'ятна, всечула, всевидюща -

нічого не забуде, ні простить ${ }^{208}$.

La retorica poesia pubblicistica dei primi versi ha così (ri)ceduto il posto al visionario espressionismo dello Stus apocalittico. La rovina che l'io lirico prospetta al suo interlocutore, dietro al quale sembra lecito scorgere ancora il popolo e lo stato nella loro identificazione, si inserisce nel quadro di una dimensione totalizzante sottoposta al controllo della sorte e della sua spietatezza. Quest'ultima è garante di vendetta nei confronti della corruzione che il popolo come entità ha lasciato propagarsi nella propria carne. Interlocutore dell'io lirico in questi versi potrebbe tuttavia essere l'io stesso, secondo la tendenza dominante nella poesia di Stus. Ciò potrebbe trovare conferma nel secondo componimento del ciclo, nel quale il linguaggio di Černyševskij si trova ad assomigliare sempre di più al linguaggio consueto dell'io lirico stusiano:

\section{$[\ldots]$ \\ Німі, нерозпізнанні вже уста, серця студені, тьмою взяті очі і шкарубкі долоні, де вже доль не розпізнаєш лінії.}

То рештки

душі твоєї, що напівжива.

О болю болю болю болю мій!

Куди мені податися, щоб тільки

не трудити роз'ятреної рани,

не дерти серця криком навісним?

$[\ldots]^{209}$

Il ritratto della folla completamente de-individualizzata che appare agli occhi 'di Černyševskij' incarcerato è anche in questo caso non dissimile dalle consuete raffigurazioni delle visioni dell'io lirico stusiano maturo e dalla sua inconsistenza fisica. Si pensi, ad esempio, a [Stan' $i$ vdyvljajsja: skil'ky tych oblyč] e a [Na

208 Ivi: 89 . 'Quella lacrima ti incenerirà / e l'urlo malvagio che tutto punge sboccerà / nei campi e nei prati. E tu capirai / della stirpe il folle distruggere. / Signora della sua morte, la sorte - / tutto ricorda, sente e vede - / nulla dimentica, nulla perdona.'

209 Ivi: 90. '[...] Mute, ormai irriconoscibili labbra, / cuori freddi, occhi presi dal buio / e mani ruvide, dalle linee del destino / irriconoscibili. Sono i resti / dell'anima tua, che è mezza morta. / O dolore del dolore del dolore del dolore! / Dove mettermi, per solo non / lacerare la ferita aperta, / non strappare il cuore col grido di pazzia? / [...]' 
vitri palaje osyka]. L'identificazione tra l'umanità, l'io lirico del Rollengedicht e il soggetto della poesia stusiana trova dunque un'ulteriore conferma. Il singolo pensante e sofferente è accomunato alla moltitudine dalla stessa corporalità negata. A differenziare notevolmente l'io lirico dalla massa, tuttavia, è la raffigurazione del cuore. Se i "cuori” della folla, significativamente al plurale, sono "freddi", incapaci ormai di provare emozioni e di ribellarsi, il Cuore del soggetto è allo stremo delle forze, sul punto di lacerarsi per la tensione che lo estenua. Nelle tre parti rimanenti l'io si fa utopico portavoce di una collettività apparentemente risvegliatasi, pronta ad ascoltare il suo grido di vendetta. Se la terza lirica è pervasa da un'imagery marcatamente ermetica nel contesto di una romantica poesia civile ${ }^{210}$, la quarta assume la tonalità marziale di un canto di guerra:
$[\ldots]$
Дай нам серця неприкаяні, дай стрепіхатий стогнів, душ смолоскипи розмаяні між чужинецьких вогнів.
Пориве, пориве, пориве, разом пірвемося в лет.
Бач - розсвітається зориво.
Хай і на смерть, а - вперед. $[\ldots]^{211}$

A catturare primariamente l'attenzione del lettore è in questi versi il passaggio dalla prima persona singolare alla prima persona plurale, nell'ambito di un lessico militareggiante di futuristica memoria. L'io appare ora dissolto nella comunità virile di un gruppo risvegliatosi all'azione e bisognoso del supporto di un dio veterotestamentario. Il Cuore del soggetto è finalmente assimilato ai cuori della pluralità, a differenza che nella prima lirica riscaldatisi e assetati di azioni. Le prospettive di battaglia e di vittoria dell'io e dei suoi compagni guerrieri raggiungono una dimensione cosmica, spingendosi insaziabilmente in avanti e verso l'alto. Questa prospettiva trionfale è tuttavia nuovamente infranta e riportata alla realtà nella quinta e ultima lirica del ciclo:

Зрадлива, звадждена Вітчизна в серці дзвонить

і там росте, нам пригнітивши дух.

Ви, нею марячи, зазнайте скрух і скрух, і най вас Бог, і най вас Бог боронить.

$[\ldots]$

210 Ibidem: 'Чотири вітри — полощуть душу. / У синій вазі — стеблина яра. / У вирві шалу, світ-завірюсі / чорніє безум хитай-води. / [...]” 'Quattro venti - sciacquano l'anima. / Nel vaso blu - un giovane stelo. / Nel burrone dell'impeto, nel mondobufera / nereggia la follia dell'acqua-oscilla. [...]'

211 Ivi: 91. '[...] Dacci cuori irrequieti, / dacci arruffati lamenti, / fiaccole ariose d'anime / tra fuochi stranieri. / Impeto, impeto, impeto, / insieme spiccheremo il volo. / Guarda - risplende una vampa. / Siam pronti alla morte - avanti. / [...]' 
Щедрує вам безсмертя щедрий вечір

в новій Вітчизні - по громадді спроб.

Отож, не ремствуйте, що вам на лоб

поклав Господь свій світлий перст нищівний ${ }^{212}$.

Sulla nota della contrapposizione tra la falsa patria del presente e l'immortalità della patria futura, frutto di lotte e tentativi, si chiude un ciclo di liriche solo apparentemente lineare. I repentini cambi di prospettiva nella raffigurazione dei rapporti tra l'io e i suoi compatrioti, a loro volta probabile sineddoche dell'umanità, rendono più complesso il quadro di una poesia che nella sua prima quartina sembrerebbe presentarsi come semplice pubblicistica. Di particolare interesse si rivela anche la sperimentazione formale dei Treny M.H. Cernyševs'koho. La frequente pentapodia giambica dello Stus maturo si trova a cedere il posto al trimetro dattilico nella quarta lirica, mentre nella terza il verso è diviso in due emistichi, consistenti di due dipodie giambiche con clausola femminile. Nella lirica conclusiva, inoltre, la pentapodia giambica si alterna all'esapodia. L'accostamento di pathos romantico, imagery espressionista e tentazioni ermetiche segna un testo in cui, al di là della più semplice pubblicistica dei primi versi, sembra lecito riconoscere una summa del linguaggio poetico stusiano maturo.

Accostabile alla tradizione del Rollengedicht è probabilmente anche $\mathrm{Za} \mathrm{li-}$ topysom Samovydcja ('Dalla Cronaca del Testimone'):

Украдене сонце зизить схарапудженим оком, мов кінь навіжений, що чує під серцем ножа, за хмарами хмари, за димом пожарищ - високо зоріє на пустку давно збайдужіле божа. Стенаються в герці скажені сини України, той з ордами бродить, а той накликає москву, заллялися кров'ю всі очі пророчі. 3 руїни підводиться мати — в годину сю грозову: $[\ldots]$

А де Україна? Все далі, все далі, все далі.

Шляхи поростають дрімучим терпким полином. $[\ldots]^{213}$

212 Ivi: 92 . 'Traditrice, discordiosa la Patria chiama nel cuore / e lì cresce, opprimendoci lo spirito. / Voi, sognandola, molto soffrirete, / e ché Dio vi protegga, ché Dio vi protegga. / [...] / Canti per voi l'immortalità la sera generosa / nella nuova Patria dopo una massa di prove. / Non lamentatevi, dunque, che sulla fronte / il Signore vi ha messo il dito suo chiaro e devastante.'

213 Ivi: 51. 'Il sole rubato guarda di sbieco con l'occhio impaurito, / un cavallo imbizzarrito, un coltello sotto al cuore, / nubi dietro alle nubi, fumo davanti agli incendi - nell'alto / illumina il deserto un piccolo dio ormai indifferente. / Accorrono alla battaglia furiosi i figli dell'Ucraina, / chi vaga con le orde, chi invoca mosca, / si innaffiano di sangue gli occhi veggenti. Dalla rovina / si solleva una madre - nell'ora fatale: / [...] / E dov'è l'Ucraina? Più in là, più in là, sempre più in là. / I sentieri si riempiono di amaro, addormentato assenzio. / [...]' 
I ventiquattro versi della lirica stusiana, ispirati con buona probabilità dalla ripubblicazione a Kiev nel 1971 del settecentesco Litopys samovydcja ('Cronaca del testimone'), una delle più significative fonti storiche sull'Ucraina della seconda metà del Seicento, sono una stilizzazione del folclore legato all'epopea cosacca. Allontanandosi decisamente dalla relativa rigorosità storica della cronaca, testimonianza della tormentata età di Bohdan Chmel'nyc'kyj e dei fatali decenni successivi, Za litopysom samovydcja si rivela piuttosto un'esaltazione dell'immaginazione poetica, come risulta dalla barocca similitudine del distico iniziale, nonché del colorito tradizionale ucraino. Si può parlare in questo caso di Rollengedicht in relazione all'implicito io lirico del testo, dietro al quale si può scorgere l'anonimo autore della cronaca. Ciò non esclude, tuttavia, la possibilità, nell'ottica della raccolta nel suo complesso, di attribuire la narrazione lirica alla consueta voce della poesia stusiana. In ciascuno dei due casi la questione dell'io è complicata dall'evocazione della tradizionale figura della madre, a cui poco prima della metà del testo l'io lirico non esplicitato cede la parola. Nei versi rimanenti l'attribuzione della parola al discorso diretto della madre o all'io lirico implicito non è immediatamente ricavabile dal testo e può essere solamente ipotizzato. Oltre che una pittoresca rielaborazione del materiale derivato dalla memoria storica cosacca, nuovamente divenuta fonte di sopravvivenza identitaria per l'Ucraina sovietizzata, secondo una tendenza ben rappresentata nella poesia dello šistdesjatnyctvo, le pentapodie anapestiche di Za litopysom samovydcja si rivelano una raffinata costruzione testuale in grado di meditare e far meditare sulla natura della parola poetica. L'indeterminatezza relativa alla natura dell'io lirico si innesta infatti sulla riflessione metaletteraria introdotta dal titolo stesso della poesia, che esplicita il rimando a un'opera letteraria e storica a sua volta anonima.

Si osservi, infine, come nel laboratorio di Palimpsesty trovi posto anche la rielaborazione poetica del linguaggio della filosofia esistenzialista:

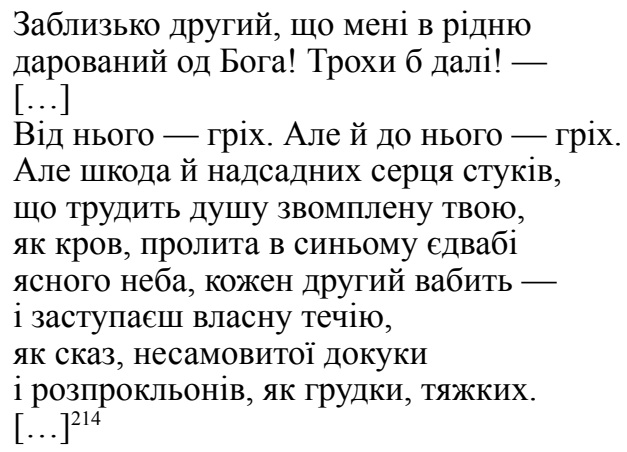

214 Ivi: 305 . 'Troppo vicino l'altro, che a me in famiglia / è stato da Dio donato! Un po' più in là! - / Da lui è peccato. Ma anche a lui è peccato. / Ma peccato per i battiti tesi del cuore, / che stancano l'anima tua perdutasi, / come sangue versato nella seta blu / del chiaro cielo, ogni altro attira - / e coprendo la propria corrente, / come rabbia, di straordinarie seccature / e stramaledizioni, come grumi, pesanti.' 
L'aforisma sartriano "L'enfer c'est les autres" da Huis clos si presta in questi versi a una prosastica sperimentazione su motivi centrali alla filosofia dell'esistenzialismo sia ateo che religioso, riconducibili alla poetica di Veselyj cvyntar. Pur nella loro consonanza con forme e tematiche tipiche della produzione dell'autore nel suo complesso, questi versi contemporaneamente lirici e a-poetici, lontani da qualsivoglia forma di ermetismo, forniscono un'ulteriore dimostrazione della necessità di non costringere il capolavoro stusiano nelle anguste maglie di una definizione univoca. 



\section{Capitolo sesto. Modernismo e intertestualità modernista nell'universo poetico stusiano}

L'ampiezza del percorso artistico stusiano nel suo dialogo con molteplici tradizioni e nella sua varietà stilistica e tematica rende molto difficoltosa una schematizzazione sia delle fonti che l'hanno ispirato, sia della sua collocazione nel contesto della storia della poesia del Novecento ucraina ed europea. Come si è ampiamente avuto modo di osservare, la lirica di Stus si mostra in ogni sua fase restia a generalizzazioni ed etichette troppo stringenti, mostrandosi costantemente segnata da uno spiccato sperimentalismo e da una profonda tensione auto-riflessiva e metapoetica. Lo studio della produzione stusiana nel suo sviluppo dai tardi anni Cinquanta alla fine degli anni Settanta non può così prescindere dal riconoscimento dell'inadeguatezza scientifica di rigide definizioni che non tengano conto della natura tendenzialmente 'centrifuga' dell'universo lirico di un autore instancabilmente votato a mettere in discussione il proprio fare poetico. A proposito di ciascuna delle quattro raccolte della fase mediana e matura della produzione stusiana, Zymovi dereva, Veselyj cvyntar, Čas tvorčosti / Dichtenszeit e Palimpsesty, lo studioso si trova a confrontarsi con la necessità di ricercare una caratterizzazione valida per la sua natura stilistica, tematica e compositiva in grado di non obliterarne allo stesso tempo l'estrema molteplicità di tensioni interne.

A complicare ulteriormente la ricerca di una sintesi contribuisce anche la presenza di elementi fondamentali della lirica matura già nella fase giovanile e la speculare persistenza di retaggi tipici della poesia dei primi anni nei capolavori del periodo della detenzione e dell'esilio. La sopravvivenza in Palimpsesty del motivo della patria nelle sue diverse declinazioni e l'anticipazione dell'auto-esplorazione dell'io lirico nella poesia giovanile sono le manifestazioni più evidenti dell'unitarietà dell'opera stusiana nel suo complesso, così come la ricollocazione in Palimpsesty di numerosi componimenti dalle raccolte precedenti. Pur nelle profonde differenze che segnano la sua evoluzione, non sempre dettate esclusivamente dal fattore cronologico, come ben dimostra la sostanziale contemporaneità di due raccolte alquanto diverse tra loro come Zymovi dereva e Veselyj cvyntar, l'arte di Stus è espressione di una volontà creatrice sempre coerente con se stessa.

Se al centro di Zymovi dereva è la sperimentazione stilistica in sé, il che si traduce in una complessità di linguaggi che non avrà uguali nell'insieme dell'opera di Stus, Čas tvorčosti / Dichtenszeit si dimostra, al contrario, l'apice del 
monologismo stusiano, pur nella sua divisione tra la prima parte 'originale' e la seconda parte 'goethiana'. Tra questi due estremi si collocano le esperienze molto diverse tra loro di Veselyj cvyntar e Palimpsesty. Se nella prima gli sbalzi formali e tematici sono votati alla raffigurazione della grottesca assurdità del1'“allegro cimitero" all'interno e all'esterno dell'umanità, nell'anima del singolo come nella storia, a imporsi nell'ultima raccolta è la tensione tra il principio centripeto della concentrazione del soggetto su di sé e la forza centrifuga della realtà nella sua incomprensibile totalità.

Il tentativo di una necessaria riflessione conclusiva si profila dunque come un cammino tortuoso. La principale aporia ermeneutica, ancora una volta, sembra derivare in primo luogo dal contrasto tra un'ispirazione artistica compatta e totalizzante e la policromia delle sue realizzazioni nelle diverse raccolte. Ė l' "uno" o è il "molteplice" a imporsi in ultima analisi nella poesia stusiana e in una sua adeguata interpretazione? Non è difficile comprendere come dietro a questa domanda si celi il più ampio problema del posizionamento dell'opera di Stus nella storia della poesia novecentesca ucraina ed europea.

Come si è ripetutamente osservato, la lirica stusiana dalla seconda metà degli anni Sessanta in poi non è esente da ripetute incursioni in territori ascrivibili alla sensibilità postmodernista. La momentanea perdita del controllo sul sé da parte dell'io e la disgregazione di quest'ultimo riscontrabili in alcune liriche della maturità possono essere ricondotti a una sorta di inconsapevole anticipazione di un Postmodernismo ancora ben lontano dall'imporsi come tendenza culturale e letteraria dominante in Ucraina, così come in Russia (cfr. Dornblüth 1999). È tuttavia possibile considerare gli spunti postmodernisti dell'universo lirico stusiano come un elemento determinante e costitutivo della sua fattezza? In sintonia con un'osservazione di Tamara Hundorova precedentemente discussa, sembra opportuno contestualizzare le anticipazioni postmoderniste di Stus nell'ambito di una poetica che, nella complessità delle sue tensioni e ispirazioni, si conferma riconducibile alla tradizione del Modernismo europeo.

La molteplicità dei linguaggi che costituiscono la poetica stusiana, gli spostamenti del focus dal microcosmo della soggettività al macrocosmo della realtà esterna e le momentanee manifestazioni di disgregazione risultano, a una visione d'insieme, sottoposte a un principio aggregante identificabile nell'io lirico. A cambiare, nelle singole raccolte, è il grado di esplicitazione di questo imprescindibile fattore. Se si sceglie di accettare la validità euristica di un'ottica teleologica, inoltre, non è difficile notare come la lirica stusiana degli anni Settanta sia decisamente più marcata in senso soggettivo rispetto alle prove precedenti, radunate nelle due raccolte dei tardi anni Sessanta, nonostante il de-centramento di Palimpsesty rispetto a Čas tvorčosti / Dichtenszeit. Il peso del principio accentrante della soggettività in Palimpsesty è tuttavia maggiormente accentuato che in entrambe le raccolte dei tardi anni Sessanta. Il percorso artistico di Stus si mostrerebbe dunque come un cammino di relativa accentuazione di ciò che lo rende, in ultima analisi, assimilabile all'estetica modernista sin dai suoi inizi. L'aspetto più assimilabile al Postmodernismo dell'estetica stusiana, oltre alle numerose, ma temporanee 'incursioni' nel campo del disgregamento della sogget- 
tività che si sono osservate, è invece da vedersi probabilmente nell'insaziabile volontà di sperimentazione stilistica della sua poesia ${ }^{1}$.

Come ha scritto Dirk von Petersdorff, "la letteratura moderna parla continuamente della seduzione dell'auto-idolatria - e della caduta in un senso di colpa fondamentale, che vede il percorso della soggettività come errore primario" L'ambiguità dell'universo poetico stusiano, scisso tra narcisistica autocontemplazione e il richiamo alla funzione profetica del bardo della tradizione poetica ucraina, sembra porsi esattamente all'insegna di questo dilemma.

L'esperienza poetica di Stus è assimilabile alla sensibilità modernista anche per la strenua difesa dell'autonomia dell'arte che in essa si realizza ${ }^{3}$. Configurandosi come una decisa negazione di una concezione ideologica dell'arte come strumento di lotta socio-politica, la poesia stusiana prende le distanze sia, naturalmente, dall'estetica del realismo socialista, sia dalla tradizione populista con cui una cospicua parte della letteratura ucraina si era fatta dalla fine dell'Ottocento portatrice della volontà di indipendenza di una nazione privata di una statualità. Il ruolo politico di Stus come paladino della causa ucraina e vittima di conseguenza del totalitarismo sovietico non deve dunque essere confuso con la 'naturale' apoliticità della sua poesia, sì promotrice della lotta nazionale, ma in quanto alta e consapevole realizzazione del suo pieno potenziale culturale.

Si può riflettere sull'applicabilità alla poesia stusiana dell'idea della "fine dell'estetica della responsabilità" discussa da Walter Koschmal a proposito della letteratura russa e polacca del tardo Novecento. Secondo lo studioso tedesco,

l'estetica della responsabilità presuppone uno scopo, un'utopia, un'unitarietà di senso degna di essere perseguita, nei cui confronti un soggetto identico a se stesso e spinto da una fede messianica si sente obbligato e responsabile 4 .

L'estetica della responsabilità, fondamentale per le culture dell'Europa orientale nell'età del Romanticismo e del Realismo, sarebbe stata messa in crisi dal Modernismo e in seguito definitivamente accantonata dal Postmodernismo. La poesia di Stus, al contrario dell'operato pubblico del suo autore, si mostra libera

1 Sul Postmodernismo come pastiche stilistico si veda Koslowski 1986: 2.

2 Petersdorff 2005: 11: "Immer wieder spricht die moderne Literatur von der Verlockung der Selbstvergötterung - und dem Absturz in ein fundamentales Schuldbewusstsein, das die Subjektwerdung als Urfehler ansieht."

3 Sulla possibilità di una lettura postmodernista della difesa dell'arte nel Novecento, in continuità con la lezione del Modernismo, si veda Ziegler 1991: 7: “And it is this playfulness and narcissism which stand out in the eye of the general public as the distinctive features of postmodernism, rather than its courageous and moving attempt to replace metaphysics with aesthetics - the attempt that we find both in the parents of postmodernism and their true offspring [...]."

4 Koschmal 1996: 26: "Die Verantwortungsästhetik setzt ein Ziel voraus, eine Utopie, ein erstrebenswertes Sinnganzes, dem gegenüber sich ein mit sich selbst identisches, von messianischem Glauben getragenes Subjekt verantwortungsvoll verpflichtet weiß." 
dall'obbligo di una responsabilità esterna nei confronti della contingenza storica, ma inconfondibilmente e modernisticamente legata a un'idea di responsabilità interna nei confronti dell'arte stessa e del suo valore, ancora immune dalla desacralizzazione di quest'ultima propagata e realizzata dal Postmodernismo.

Il Modernismo stusiano si riflette nel profondo dialogo che la sua lirica intrattiene con l'opera di scrittori ascrivibili alla stessa sensibilità, nel più ampio contesto di una tavolozza intertestuale composta di elementi modernisti, classici e romantici. Pur rivelandosi decisivo e dominante, il sostrato modernista del palinsesto stusiano si tinge con frequenza di venature pre-moderniste, come mostra l'imprescindibilità delle tradizioni di Ševčenko, Goethe e Skovoroda nella sua definizione.

Due dei tre poeti nei confronti dei quali Stus dichiarò la propria massima vicinanza, Rilke e Pasternak, sono tra i massimi rappresentanti delle tendenze moderniste delle rispettive letterature. Ė altresì emersa l'importanza del costante dialogo di Stus con la poesia di Marina Cvetaeva, l'altro membro dell'ideale terzetto di poeti modernisti legati umanamente e artisticamente da un rapporto epistolare e da un intenso reciproco interesse per le rispettive produzioni poetiche.

Qualunque riflessione sulla portata del dialogo tra Stus e la tradizione pasternakiana dovrà necessariamente confrontarsi con l'affermazione del poeta in Dvoje sliv čytačevi a proposito di una propria "liberazione" da un amore per Pasternak da lui ritenuto "esagerato" verso la metà degli anni Sessanta. È effettivamente riscontrabile un affievolimento della presenza pasternakiana nella poesia di Stus della fase mediana e matura, ovvero dai tardi anni Sessanta in avanti? Si è osservato come il modello pasternakiano risulti determinante per la costruzione dell'universo poetico di Kruhovert', la prima raccolta stusiana, composta negli anni della massima influenza dell'autore di Doktor Živago sul giovane poeta ucraino, secondo le parole di quest'ultimo. È prevalentemente il giovane Pasternak di Sestra moja - žizn' a riflettersi nella produzione del primo Stus. Accostandosi e fondendosi significativamente con la coeva e affine tradizione del primo Tyčyna, la poesia pasternakiana giovanile è un punto di riferimento imprescindibile per la costruzione di un io lirico votato a un'estatica fusione con la realtà circostante nell'irrefrenabile vitalità di quest'ultima. La prevalenza dell'elemento naturale, con cui l'universo poetico di Kruhovert' tende maggiormente a identificarsi, relegando in secondo piano la dimensione storica, si dimostra irresistibile forza di attrazione e fonte di energia. Per l'io lirico del primo Stus, così come per quello del primo Pasternak, la compenetrazione tra il sé e la natura non è percepita come causa di un possibile disgregamento di un'entità, l'io stesso, che proprio dall'interazione con il macrocosmo in cui è immersa ricava stimolo e legittimazione. Si è notato inoltre come in Kruhovert'siano riscontrabili i germogli della poetologia stusiana. In relazione a quest'ultima si assiste a un ampliamento dei riferimenti al modello pasternakiano. Il dialogo con la poesia del Pasternak maturo di Vtoroe roždenie identificato nella lirica stusiana Slovo, incentrata sulla problematicità dell'essenza del poeta al di là dell'estasi derivante dall'ispirazione e dalla fusione con la natura, mostra tanto la complessità dell'universo poetico stusiano già a partire dai suoi esordi, quanto l'impossibilità di una definizione 
univoca della presenza pasternakiana nella poesia giovanile. L'oggettiva prevalenza tra le fonti di Kruhovert' della produzione pasternakiana degli anni Dieci, nella quale il contatto tra l'io lirico e il mondo si realizza gioiosamente e spontaneamente, rispetto alla più eterogenea poesia dei decenni a venire, segnata dallo scontro del soggetto con la storia, appare tuttavia in sintonia con il vitalismo dominante nel primo Stus.

La pervasività della presenza pasternakiana in Kruhovert' si stempera nella multiformità del ben più ampio progetto poetico di Zymovi dereva. Da sostanziale pilastro del primo esperimento, l'importanza della poesia di Pasternak si riduce nella nuova raccolta a una serie di intertesti non in grado di imporsi come elemento fondamentale e fondante. Ciò appare giustificato dalla concezione artistica alla base di Zymovi dereva, ovvero dalla supremazia della sperimentazione stilistica sulla sintesi. Questo non esclude, tuttavia, la persistenza, anche significativa, del riferimento stusiano a un modello, quello pasternakiano, probabilmente imprescindibile nello spazio letterario sovietico degli anni Sessanta. Nelle liriche riconducibili alla sensibilità artistica delle Avanguardie non mancano, come si è potuto osservare, probabili convergenze con la produzione pasternakiana maggiormente segnata dalle giovanili frequentazioni del poeta russo con il Futurismo. È tuttavia il dolente Pasternak senile dei versi di Doktor Živago a mostrarsi sempre più affine alla sensibilità di Stus, ancora aperta alle più disparate suggestioni stilistiche e tematiche, ma ben lontana ormai dal monismo vitalistico predominante in Kruhovert'.

Decisamente ridotto si rivela il ruolo della poesia pasternakiana nell'ispirazione alla base di Veselyj cvyntar. La relativa unitarietà tematica della raccolta, riconducibile in buona parte alla raffigurazione dell'Assurdo nel micro- e nel macrocosmo, sembra concedere ben poco spazio sia all'irrefrenabile scambio tra il soggetto e la natura del giovane Pasternak, sia alla malinconica rassegnazione della sua lirica più matura. Ciò non esclude la presenza di alcuni evidenti intertesti, a dimostrazione di un'inestinguibile, seppur rarefatta continuità nel rapporto poetico tra Stus e Pasternak.

Poco marcata a livello quantitativo, ma non per questo irrilevante, si mostra la presenza di Pasternak in Čas tvorčosti / Dichtenszeit. L'importanza della tematica poetologica nella raccolta del 1972 si riflette non da ultimo nel rifrangersi della complessa poetologia pasternakiana tra le sue pagine. Come già in Zymovi dereva e Kruhovert', Stus fa sua la lezione di [O znal by ja, čto tak byvaet] e Gamlet, mettendo in risalto la tragicità intrinseca all'essenza del poeta. L'inscindibile legame tra la poesia e la morte non esclude, tuttavia, il nesso tra la poesia stessa e la rigenerazione del soggetto, liberatosi grazie alla parola poetica da una rigida contrapposizione tra la morte e la vita. La filosofia dell'arte di Doktor Živago, incentrata sul superamento della morte grazie alla parola e preannunciata dall'estatica fusione tra l'io e la realtà circostante in Sestra moja - žizn ${ }^{\prime 5}$, si rispecchia nell'idea di rinascita che permea Čas tvorčosti / Dichtenszeit nel suo complesso.

$5 \quad$ Sull'unitarietà dell'opera pasternakiana cfr. Fateeva 2003. 
In Palimpsesty, infine, il modello pasternakiano va a costituire solamente una delle diverse componenti che plasmano l'ampio e affascinante palinsesto poetico stusiano, all'interno del quale tradizioni, linguaggi e suggestioni stilistico-tematiche diverse si affiancano nella formazione di un quadro per sua natura non riconducibile a un singolo denominatore, fatto salvo il mantenimento del principio di soggettività come fondamentale fattore strutturale.

La dichiarazione di Stus a proposito del "suo superamento" di un amore per Pasternak da lui giudicato a posteriori come "eccessivo" sembra dunque riflettersi in un'effettiva riduzione della presenza pasternakiana dai tardi anni Sessanta in poi. Ciò non significa in alcun modo un rifiuto della tradizione poetica di Pasternak in toto. Le problematicità della filosofia dell'arte pasternakiana si ritrovano amplificate nell'universo poetico di Stus. Se nell'opera di Pasternak dai tardi anni Venti in poi il mantenimento di un rapporto di equilibrio e reciproco arricchimento tra il soggetto e il mondo è reso più difficoltoso dalla storia, ma non per questo messo in discussione, nella lirica stusiana da Zymovi dereva in poi si assiste a un quadro decisamente più complesso. La relazione tra l'io lirico e la realtà non si lascia ricondurre a una definizione unitaria. L'astrazione del primo da un mondo avvertito come entità nemica si alterna sia a momenti di riconciliazione, sia al riconoscimento di un'identità negativa tra i due poli, basata sulla loro compartecipazione al caos. In questa sostanziale differenza è probabilmente da scorgere un'importante discrepanza tra il 'fiducioso' modernismo pasternakiano e il più complesso tardo modernismo stusiano.

La componente 'negativa' nella concezione stusiana del rapporto tra l'io e il mondo è un fondamentale elemento di comunanza tra l'universo poetico di Stus e quello di Marina Cvetaeva. La parabola della presenza cvetaeviana nella poesia di Stus mostra un andamento diverso rispetto al caso di Pasternak. Assente dalla produzione degli esordi e soltanto menzionata di sfuggita in una lettera del 1964, la poesia cvetaeviana, non meno imprescindibile della tradizione pasternakiana per la poesia sovietica underground degli anni Sessanta e Settanta, si dimostra un modello determinante per la definizione dell'io lirico stusiano maturo e per la sua auto-caratterizzazione come poeta. La frequenza delle citazioni cvetaeviane nelle lettere di Stus degli ultimi anni è invece una possibile conferma della sua importanza nella lirica stusiana matura, nonostante l'autore di Palimpsesty non abbia mai esplicitamente riconosciuto a Cvetaeva un ruolo importante nella propria formazione poetica. Gli intertesti cvetaeviani nell'opera di Stus, come si è visto, sono stati generalmente ignorati dalla critica.

L'analisi condotta sembra avere fornito chiare prove di come la tendenza del soggetto stusiano all'astrazione dal mondo, alla smaterializzazione e alla fuga in una dimensione altra, riscontrabile frequentemente da Zymovi dereva in poi, possa essere posta in connessione con la tradizione cvetaeviana. È evidente, inoltre, come al centro degli universi poetici di entrambi si imponga la figura stessa dell'io lirico. Esso è costante oggetto di auto-esplorazione e arri- 
va non di rado a identificarsi con il tutto, assumendo a tratti un carattere marcatamente ipertrofico.

A imporsi tra le possibili fonti di Stus sono innanzitutto, come si è potuto osservare, le liriche cvetaeviane apertamente incentrate sulla figura del Poeta, come, tra le altre, il trittico Poety, il trittico Sivilla, nonché Emigrant e Balkon. La contrapposizione ontologica tra il poeta e il mondo degli uomini, fondamentale per la definizione dell'universo poetico cvetaeviano maturo, si riflette nella poesia stusiana senza tuttavia risultare determinante. L'espressione della superiorità del Poeta sull'uomo, frequente in Čas tvorčosti / Dichtenszeit, si alterna paradossalmente con il suo contrario, il riconoscimento della proprio umanità, venendo a comporre una rappresentazione poetologica complessa, contraddittoria e refrattaria a una definizione univoca. La componente orfica cvetaeviana sembra così fondersi con una tradizione di taglio opposto, riconducibile sia all'autorità di Pasternak, sia al modello di Ševčenko, entrambi portatori di una visione 'umanistica' del Poeta come uomo.

Si è altresì notato come la forte tendenza del linguaggio poetico cvetaeviano maturo alla sperimentazione avanguardista possa aver influenzato stilisticamente alcune liriche di Palimpsesty. Il linguaggio poetico stusiano rimane, ciò nonostante, decisamente più legato a una tendenza opposta a quella delle Avanguardie storiche, distinguendosi per una predilezione per forme versificatorie tradizionali e mantenendo, rispetto al modello cvetaeviano, una configurazione artistica accostabile a un'idea di atemporale 'classicità'. Ciò vale, beninteso, per lo Stus degli anni Settanta in misura molto maggiore che per l'instancabile sperimentalismo delle prime raccolte.

Ponendosi come fattore decisivo della conformazione dell'universo poetico stusiano maturo dalla metà degli anni Sessanta per tutto il decennio seguente, 1'opera di Marina Cvetaeva, alquanto sottovalutata nello stusoznavstvo, si rivela dunque uno degli elementi cardine della biografia letteraria di Stus e la chiave alla comprensione di un aspetto essenziale della sua lirica, quale la poetologia.

Sostanzialmente assente dai versi giovanili, nei quali essa è forse riscontrabile come fonte della metafora e sineddoche del cuore unitamente al modello skovorodiano e ševčenkiano, la presenza rilkiana inizia timidamente a manifestarsi in Zymovi dereva.

È tuttavia in Veselyj cvyntar, composta in concomitanza con la prima fase di lavoro alla traduzione delle Duineser Elegien, che Rilke si impone definitivamente come elemento irrinunciabile dell'ispirazione stusiana. Nell'ampiezza del suo percorso, la poesia rilkiana si riflette quasi integralmente in Veselyj cvyntar arrivando a comprendere sia la raffinata lirica poetologica giovanile di Das Buch vom mönschischen Leben, prima parte di Das Stunden-Buch, sia il complesso costrutto filosofico delle Duineser Elegien, sia la produzione della fase mediana. Il dialogo tra l'io lirico e il suo Dio - interpretabile come l'arte stessa - del Buch vom mönchischen Leben, trionfo Jugendstil del giovane Rilke sicuro della propria ispirazione e della propria capacità di plasmare a suo piacimento la materia verbale, si mescola liberamente in Veselyj cvyntar con la poesia della crisi del Rilke 
degli anni Dieci. Quest'ultima è segnata dalla messa in discussione della poetica dei Neue Gedichte, nei quali un io lirico saturo dell'auto-referenzialità su cui era fondato Das Buch vom mönchischen Leben aveva trovato una via d'uscita in una descrizione fenomenologica delle cose del mondo, raggiungendo un precario equilibrio tra la propria sfera e la realtà circostante ${ }^{6}$. Il superamento della fenomenologia e la necessità di un "lavoro del cuore" (Herzwerk), di un' eternizzante interiorizzazione dell' universo, risultano chiaramente affini all'universo poetico di Stus, così come la poesia del Rilke maturo delle Duineser Elegien, incentrate su un'ermetica raffigurazione della complessità della condition humaine.

Il percorso artistico di Rilke, instancabilmente venato di svolte e modificazioni poetiche e poetologiche, si mostra dunque per lo Stus di Veselyj cvyntar come un repertorio di temi e immagini da cui attingere e a cui ispirarsi al di là delle profonde divergenze che lo riguardano al suo interno. Non può che sorprendere, inoltre, come le reminiscenze rilkiane si armonizzino tra loro e con le altre 'voci' nell'insieme di una raccolta nel suo complesso decisamente diversa dalla poesia di Rilke. La raffigurazione dell'assurdo e del grottesco del mondo e dell'anima, non di rado affidata a un'estrema prosaizzazione della lingua, è effettivamente molto distante dall'universo poetico di Rilke. Tuttavia, gli elementi rilkiani di Veselyj cvyntar riescono a fondersi con motivi e stilemi di natura anche opposta in una totalità artistica, come si è già osservato, sorprendentemente omogenea nonostante l'estrema differenziazione delle sue componenti.

In Čas tvorčosti / Dichtenszeit è il significato profondo della poesia rilkiana matura a configurarsi come pilastro concettuale della raccolta. L'accettazione e la glorificazione dell'esistente, o almeno la consapevolezza della loro necessità, si impongono infatti all'io lirico come l'unica possibilità di dominio sulla realtà e sulla sorte. L'inclusione della lamentazione nella lode è l'obiettivo poetologico che il soggetto assegna a se stesso secondo il modello del Rilke delle Duineser Elegien e dei Sonette an Orpheus. Le difficoltà legate alla realizzazione di questo ambizioso programma etico-estetico vengono direttamente tematizzate nella raccolta stusiana del 1972, così come nelle elegie rilkiane. Da questo punto di vista è evidente come le Elegien risultino più vicine all'universo poetico stusiano rispetto ai Sonette, nei quali il superamento dell'autonomia ontologica della "Lamentazione" e il trionfo della Lode si mostrano ormai pienamente realizzati.

Non dissimile è la presenza di Rilke in Palimpsesty. La vana ricerca dell'ideale rilkiano di un'assoluta Bejahung si scontra con la consapevolezza dell'ineluttabilità della negazione. Non mancano altresì evidenti rimandi a liriche rilkiane precedenti agli anni Venti, come il poemetto Orpheus. Eurydike. Hermes, anticipazione della tematica orfica più ampiamente sviluppata nei Sonette di circa un ventennio più tardi.

Almeno sin da Veselyj cvyntar la poesia rilkiana si conferma, dunque, come un punto di riferimento imprescindibile per Stus. Il tentativo della ripresa da parte dello Stus degli anni Settanta del presupposto poetologico di fondo del Ril-

$6 \quad$ Per una lettura più approfondita del percorso poetico rilkiano qui abbozzato si veda, tra gli altri, Eckel 1994. 
ke maturo, ovvero di una sconfitta della precarietà e della sofferenza dell'uomo mediante l'azione vivificante e taumaturgica della parola poetica, è un'eloquente testimonianza del profondo legame tra i percorsi artistici dei due poeti. A ciò si sommano le numerose somiglianze a livello di imagery, altrettanto passibili di una lettura in chiave poetologica, come la frequente riduzione della figura umana al cuore e l'insistenza sulla solitudine del soggetto, in Stus prevalentemente situazione storica ed esistenziale, in Rilke conditio sine qua non dell'essenza del poeta.

Le profonde differenze che dividono i due universi poetici non devono tuttavia essere dimenticate. La poetologia rilkiana è incentrata, come si è già evidenziato, sull'obiettivo del raggiungimento di un equilibrio tra l'io lirico e l'universo. L'evoluzione della poesia di Rilke è così l'esplicitazione stessa di questo percorso, che sfocia, nella sua ultima fase, nel superamento della contrapposizione tra le cose del mondo e il soggetto. Questa narrazione, identificabile come il trionfo dell'estetica modernista alla conclusione di un travagliato percorso metapoeti$\mathrm{co}$, non è da ritrovarsi nella lirica stusiana. In quest'ultima si assiste infatti a una chiusura dell'io lirico in se stesso che non lascia spazio a una penetrazione della realtà esterna nella sfera del sé, assurta a dimensioni che la confondono a tratti con la totalità. Se nell'arte rilkiana, grazie alla poesia e al suo potenziale salvifi$\mathrm{co}$, si delinea il coronamento di un iter di riavvicinamento tra la sfera del soggetto e ciò che sta al di fuori di esso, a verificarsi nell'opera stusiana è, al contrario, un processo di alienazione. L'obiettivo dell'accettazione e della lode che l'io lirico persegue mediante la parola poetica non è rivolto alla realtà esterna, la cui assurdità è stata definitivamente sancita nella fase di Veselyj cvyntar, ma votato autoreferenzialmente alla dimensione dell'io e alla sua difficoltosa salvaguardia.

Le divergenze tra il posizionamento dell'io lirico stusiano e il modello rilkiano non si limitano al rapporto con la realtà esterna. In Rilke, come si è già osservato, il soggetto è artefice della propria solitudine, senza la quale non ritiene possibile la totale devozione alla parola poetica. In Stus, al contrario, essa è doloroso frutto delle circostanze, nonché inevitabile condizione esistenziale del mondo contemporaneo. Nel suo universo poetico si distinguono, tuttavia, due entità 'tradizionali' in grado di fungere da polo di attrazione per l'io lirico immerso nella sua solitudine, ovvero la donna amata e la patria. Nonostante la poesia amorosa stusiana si riveli decisamente poco uniforme, lacerata da spinte contrastanti e refrattaria a una definizione univoca, il permanere del legame amoroso come forza contrapposta alla chiusura dell'io in se stesso è evidente.

Ancora più complessa è la dinamica dei rapporti tra l'io lirico e la sua appartenenza etnico-nazionale. Elemento completamente estraneo all'universo poetico cosmopolita e individualista di Rilke, non assente negli immaginari di Cvetaeva e Pasternak, la patria si rivela nella poesia di Stus l'imprescindibile sostrato di una tradizione che all'isolamento modernista del singolo pensante contrappone l'ideale umanistico di una comunità fondata sulla condivisione. Ora maledetta, ora intensamente evocata e ricercata, l'immagine stusiana della patria è fattore costituente dell' 'ucrainicità' della sua poesia, componente di primo piano del versante 'tradizionale' del suo contributo alla storia della lirica novecentesca europea. La persistenza di un sofferto e contraddittorio mito patrio nell'opera di Stus non 
inficia, ben inteso, la contemporanea e predominante presenza del mitologema a essa opposto, ovvero l'esaltazione di un'apolide individualità modernista. La co-esistenza di questi due filoni, seppur quantitativamente impari, è un'ulteriore dimostrazione dell'onnicomprensività dell'universo lirico stusiano, in grado di accogliere in sé spunti postmoderni e retaggi pre-modernisti nell'ampio contenitore di un'estetica intrinsecamente modernista.

A proposito dei rapporti tra Stus e la letteratura di lingua tedesca, si è osservato come, oltre al profondo e pervasivo dialogo con la poesia rilkiana, spicchino tra le sue fonti due tradizioni molto distanti tra loro, ovvero l'opera goethiana e la lirica dell'Espressionismo. Definito da Stus come il suo poeta per eccellenza, l'autore del West-Östlicher Divan assurge a doppio dell'io lirico in Čas tvorčosti / Dichtenszeit, mostrandosi insuperato modello di armonia nel momento di massima concentrazione del soggetto su se stesso nella storia della poesia stusiana. Il cammino interiore in direzione del proprio destino, dell'accettazione di sé e della capacità di lodare la sorte mediante la parola poetica, come si è visto intimamente legato al modello rilkiano, sembra così incorporare in sé l'estatico equilibrio tra individualità e totalità, fisicità e corporalità, eternità e fugacità rappresentato dall'esperienza artistica goethiana. Non è d'altro canto difficile notare come la natura del rapporto tra gli universi poetici di Stus e Goethe diverga sensibilmente dal dialogo tra Stus e la poesia modernista nelle sue varie declinazioni. L'intrinseca classicità della poesia di Goethe non può che rappresentare per Stus un irraggiungibile modello di perfezione, irrecuperabile, tuttavia, nel tortuoso percorso della modernità. È per questo motivo che il posto di Goethe nel palinsesto stusiano è esplicitamente marcato e sostanzialmente limitato a Čas tvorčosti / Dichtenszeit. L'incorporazione della lezione artistica goethiana non può che essere per la poesia di Stus un evento momentaneo e circoscritto, al contempo interiorizzato e distanziato.

Diverso è il caso dell'espressionismo di Stus. Pur non sempre ugualmente intensi e frequenti nell'insieme del suo percorso poetico, immagini e stilemi riconducibili alla tradizione dell'Espressionismo tedesco inducono a ipotizzarne una profonda conoscenza da parte di Stus sin dagli anni degli esordi letterari. A risultare particolarmente vicina alla sensibilità stusiana è la cupa poesia del primo Espressionismo legata ai nomi di Georg Heym e Georg Trakl e ancora esente dall'intensa politicizzazione che l'avrebbe segnato negli anni della Prima guerra mondiale. L'universo poetico stusiano sembra inoltre riprendere e sviluppare uno dei presupposti di fondo dell'estetica espressionista, ovvero la centralità del principio soggettivo, il dolore derivante dalla consapevolezza della sua precarietà nel mondo, la paura della sua possibile lacerazione e la conseguente esplosione di immagini oscure e apocalittiche ${ }^{7}$. L'alternanza di disperazione e trionfalismo,

$7 \quad$ Secondo Richard Hinton Thomas, la lirica espressionista è lo spazio di ribellione di un io indebolito che cerca disperatamente di riconquistare la forza perduta, opponendosi strenuamente allo scioglimento del sé nella pluralità. Cfr. Hinton Thomas 1969: 23-24. Il critico arriva a parlare di "autofaga ossessione dell'Io" ("selbstverzehrende 
rassegnazione e bellicosità che caratterizza il vissuto dell'io lirico nella grandiosità del suo svelarsi di fronte agli occhi del lettore è un indubbio punto di contatto tra l'universo poetico di Stus e i suoi predecessori nella poesia tedesca del primo Novecento. Lo stesso dicasi per l'impossibilità di recidere completamente i legami tra la poesia e la sfera politica, che, pur non rappresentando un elemento centrale dei rispettivi sistemi poetici di Stus e degli espressionisti tedeschi, ne plasma a tratti l'ispirazione e la tematica, come nel caso, innanzitutto, di diverse liriche di Veselyj cvyntar e di Palimpsesty.

Esemplare realizzazione del paradigma soggettivista del Modernismo ${ }^{8}$, l'E- $^{\prime}$ spressionismo tedesco sembra rivelarsi in ultima analisi una delle componenti più significative della genealogia letteraria stusiana. Non è tuttavia possibile stabilire con certezza il grado dell'effettiva presenza della tradizione espressionista tra le fonti di Stus, potendo di conseguenza distinguere l'evidente affinità da un'eventuale, nonché probabile derivazione. La sua notevole dimestichezza con la letteratura tedesca e la diffusione della poesia espressionista nella storia culturale sovietica lasciano sicuramente propendere per l'ipotesi di una diretta conoscenza da parte di Stus della tradizione espressionista.

Ichbesessenheit", 36), definizione adattabile alla descrizione dell'universo poetico di Čas tvorčosti / Dichtenszeit e Palimpsesty. Helmut Motekat ha osservato l'intersezione dell'io e del mondo nella potente, violenta 'espressione' dell'io stesso e della sua sofferenza, risultante in un rafforzamento della centralità del principio soggettivo nell'universo poetico espressionista. Cfr. Motekat 1976. Si ricordino, inoltre, le significative accuse di soggettivismo lanciate da Lukács all'Espressionismo.

8 La spinosa questione della collocazione dell'Espressionismo nel panorama culturale e letterario del Novecento europeo è ampiamente dibattuta dalla critica. Cfr. Murphy 1999: 3: "For although expressionism has been labeled the 'historical modernist movement par excellence' besides its modernist characteristics - such as its shift from transparent, realist representations of a common world, towards abstraction, obscurity, and the investigation of subjectivity and the unconscious - it also shares many of those key features, in particular the revolutionary, counter-discursive and anti-institutional functions, by which Bürger defines the historical avant-garde.” 



\section{Riflessioni conclusive}

La lettura portata avanti in queste pagine e le conclusioni che se ne sono tratte non esauriscono certamente le molteplici problematicità che la poesia di Stus, complessa e intellettuale, allo stesso tempo unitaria e multiforme, paradossalmente centripeta e centrifuga, pone al lettore e allo studioso. Si è cercato di fornire una visione d'insieme del variegato mosaico intertestuale della raffinata arte stusiana sullo sfondo di una descrizione generale della sua opera poetica secondo il principio cronologico, ancora mancante nel panorama critico. Parallelamente si è potuta fornire una prima risposta all'interrogativo circa il rapporto di Stus con i suoi modelli letterari privilegiati, ora da lui apertamente riconosciuti, come Pasternak e Rilke, ora 'necessari', come Ševčenko, ora in parte celati, come Cvetaeva e - probabilmente - gli Espressionisti tedeschi. Si è visto come l'intertestualità stusiana trascenda le frontiere delle letterature nazionali, pur nutrendosi in modo privilegiato di ipotesti provenienti dalle tradizioni a lui vicine, ossia ucraina e russa, e dall' "affinità elettiva" del poeta con la cultura di lingua tedesca. Si è anche messo in evidenza come l'opera stusiana nel suo complesso, e Palimpsesty in particolare, sia puntellata da numerosi e variegati spunti intertestuali che spaziano dalla lirica 'tradizionale' del Novecento ucraino, al Simbolismo russo, all'Esistenzialismo francese e tedesco.

La discussione dei rapporti dialogici tra la lirica stusiana e la poesia russa, in particolare l'opera di Boris Pasternak e Marina Cvetaeva, nonché la frequenza e la natura delle dichiarazioni di Stus a questo proposito nel suo epistolario, ha dimostrato come la forte dedizione di Stus alla causa nazionale ucraina non significhi in alcun caso un suo rifiuto della tradizione letteraria russa.

L'analisi del percorso poetico stusiano nella sua interezza qui condotta ha inoltre mostrato il progressivo accentuarsi degli spunti modernisti presenti sin dagli esordi della produzione del poeta. La maturazione artistica dai primi versi a cavallo tra gli anni Cinquanta e Sessanta ai due capolavori della maturità, Čas tvorčosti / Dichtenszeit e Palimpsesty, si configura come il singolare coronamento di uno sviluppo multiforme all'insegna dell'unitarietà. Si è potuto ampiamente apprezzare come il modernismo stusiano si arricchisca di variegate sperimentazioni stilistiche, più evidenti nella fase giovanile e mediana dell'opera, nonché di incursioni nella sensibilità postmodernista.

Tra gli aspetti da approfondire con maggiore urgenza spicca il versante metrico-ritmico della lirica di Stus e l'ambito della versificazione in generale, fon- 
damentali per uno studio più completo del suo rapporto con la tradizione poetica. A questo proposito restano anche da indagare più da vicino il suo dialogo con la poesia ucraina degli anni Venta e Trenta, in particolare con Mykola Zerov, Volodymyr Svidzins'kyj e Bohdan-Ihor Antonyč. Anche una discussione dell'esistenzialismo stusiano, al crocevia tra poesia, filosofia e 'cultura' nel senso più ampio del termine, rimane un desideratum, con l'obiettivo di giungere a una sistematizzazione dei numerosi rimandi al pensiero esistenzialista che si sono incontrati nell'analisi testuale.

A un livello più ampio si delinea inoltre la necessità di uno studio che inquadri con maggiore approfondimento l'esperienza del modernismo stusiano nella storia della poesia del secondo Novecento, in Ucraina e non solo, riflettendo sulla natura profonda dell'arte modernista dopo l'età del Modernismo storico. La domanda che bisognerà porsi riguarda il livello di maggiore o minore unicità che caratterizza la poetica modernista di Stus nel contesto - non solo ucraino del suo tempo. Un'indagine di questo tipo permetterebbe di ridefinire la parabola modernista nella storia della letteratura ucraina novecentesca, contribuendo a metterne in luce la complessità e la ricchezza ancora in gran parte sconosciute e misconosciute, nonché ridefinendo l'esperienza dello šistdesjatnyctvo letterario. Ciò contribuirebbe anche a una significativa ridiscussione della storia del Modernismo occidentale e della sua sopravvivenza nel dopoguerra, secondo una parabola interpretativa che ha preso piede negli ultimi anni (cfr. tra gli altri Zima 2001 e Žitenev 2012), senza riuscire ancora a imporsi come passaggio imprescindibile nella storia culturale del secolo scorso. 


\section{Bibliografia}

\section{OPERE DI VASYL' STUS}

$T:$

$Z T$ :

Stus 2000b:

Stus 2008a:
V. Stus, Tvory: u čotyr'och tomach, šesty knyhach, L'viv, Prosvita, 1994-1998.

V. Stus, Zibrannja tvoriv: $u$ dvanadcjaty tomach, Kyjiv, Fakt, 2007-2009.

V. Stus, Iz konspektiv 1970-ch rokiv, "Slovo i čas", 2000, 9, pp. 45-51.

V. Stus, Lev Tolstoj jak javyšče, “Kyjivs'ka Rus"”, 2008, 5, pp. 8-34.

\section{LETTERATURA PRIMARIA}

Antonyč 2012:

B. I. Antonyč, Vybrani tvory, Kyjiv, Smoloskyp, 2012.

Belyj 2006:

Brecht 1988:

Brodskij 2011:

Bunin 1987:

Camus 1983:

Cvetaeva 1990:

Cvetaeva 1997-1998:
A. Belyj, Stichotvorenija i poemy, Sankt-PeterburgMoskva, Akademičeskij proekt, 2006.

B. Brecht, Werke: Große kommentierte Berliner und Frankfurter Ausgabe, Aufbau-Suhrkamp, BerlinWeimar-Frankfurt a.M., 1988.

I. Brodskij, Stichotvorenija i poemy, Sankt-Peterburg, Akademičeskij proekt, 2011.

I. Bunin, Sobranie sočinenij: v šesti tomach, Moskva, Chudožestvennaja literatura, 1987.

A. Camus, Euvres complètes, Paris, Éditions du Club de l'Hônnet Homme, 1983.

M. Cvetaeva, Stichotvorenija i poemy, Leningrad, Sovetskij pisatel', 1990.

M. Cvetaeva, Sobranie sočinenij: v semi tomach, Moskva, Ellis Lak, 1997-1998. 
Cvetaeva 2004:

Drač 1962:

Eliot 1969:

Franko 1951:

Goethe 2000:

Heym 2006:

Kostenko 1969:

Majakovskij 1968:

Malanjuk 1992:

Mandel’štam 1993-1997:

Mysyk 1983:

Pasternak 2003-2005:

Pervomajs'kyj 1985:

Pinthus 1990:

Puškin 1949-1950:

Rilke 1987:

Rilke 1996:

Różewicz 1988:

Ryl's'kyj 2005:

Rymaruk 1988:

Sartre 1943:
M. Cvetaeva, Knigi stichov, Moskva, Ellis Lak, 2004.

I. Drač, Sonjašnyk: poeziji, Kyjiv, Deržavne vydavnyctvo chudožn'oji literatury, 1962.

T. S. Eliot, The Complete Poems and Plays, London, Faber and Faber, 1969.

I. Franko, Vybrani poeziji, Kyjiv, Deržavne vydavnyctvo chudožn'oji literatury, 1951.

J. W. Goethe, Werke: Hamburger Ausgabe in 14 Bänden, München, DTV, 2000.

G. Heym, Werke, Stuttgart, Reclam, 2006.

L. Kostenko, Poeziji, Baltimore-Paris-Toronto, Smoloskyp, 1969.

V. Majakovskij, Sobranie sočinenij v vos'mi tomach, Moskva, Pravda, 1968.

Je. Malanjuk, Poeziji, Kyjiv, Ukrajins'kyj pys'mennyk, 1992.

O. Mandel'štam, Sobranie sočinenij: v četyrech tomach, Moskva, Art-Biznes-Centr, 1993-1997.

V. Mysyk, Tvory v dvoch tomach, Kyjiv, Dnipro, 1983.

B. Pasternak, Polnoe sobranie sočinenij: v odinnadcati tomach: s priloženijami, Moskva, Slovo, 2003-2005.

L. Pervomajs'kyj, Tvory v semy tomach, Kyjiv, Dnipro, 1985.

K. Pinthus (a cura di), Menschheitsdämmerung: Ein Dokument des Expressionismus, Berlin, Rohwolt, 1990 (1920).

A. Puškin, Polnoe sobranie sočinenij: v šesti tomach, Moskva, Chudožestvennaja literatura, 1949-1950.

R. M. Rilke, Briefe, Frankfurt a.M., Insel, 1987.

R. M. Rilke, Werke: Kommentierte Ausgabe in vier Bänden, Frankfurt a.M.-Leipzig, Insel, 1996.

T. Różewicz, Poezja, Kraków, Wydawnictwo Literackie, 1988.

M. Ryl's'kyj, Liryka, Kyjiv, Kyjivs'ka pravda, 2005.

I. Rymaruk, Uprodovž snihopadu: poeziji, Kyjiv, Molod', 1988.

J. P. Sartre, L'être et le néant : essai d'ontologie phénoménologique, Paris, Gallimard, 1943. 
Ševčenko 2003:

T. Ševčenko, Zibrannja tvoriv u šesty tomach, Kyjiv, Naukova dumka, 2003.

Sinčenko, Stus, Finberg 2018: O. Sinčenko, D. Stus, L. Finberg (a cura di), Dysydenty: Antolohija tekstiv, Kyjiv, Duch i litera, 2018.

Skovoroda 2011:

H. Skovoroda, Povna akademična zbirka tvoriv, Edmonton-Toronto-Charkiv, Vydavnyctvo Kanads'koho Instytutu Ukrajins'kych studij-Majdan, 2011.

Svidzins'kyj 2004:

V. Svidzins'kyj, Tvory u dvoch tomach, Kyjiv, Krytyka, 2004.

Symonenko 2012:

V. Symonenko, Vybrani tvory, Kyjiv, Smoloskyp, 2012.

Trakl 2012:

G. Trakl, Das dichterische Werk, München, DTV, 2012.

Tyčyna 1971:

P. Tyčyna, Vybrani tvory, Kyjiv, Dnipro, 1971.

Vinhranovs'kyj 2013:

M. Vinhranovs'kyj, Vybrani tvory, Kyjiv, Smoloskyp, 2013.

Voronyj 1996:

Voznesenskij 1983:

M. Voronyj, Poeziji, pereklady, krytyka, publicystyka, Kyjiv, Naukova dumka, 1996.

A. Voznesenskij, Sobranie sočinenij: v trech tomach, Moskva, Chudožestvennaja literatura, 1983.

Zerov 1990:

M. Zerov, Tvory v dvoch tomach, Kyjiv, Dnipro, 1990.

Zujevs'kyj 1992:

O. Zujevs'kyj, Vybrane: poeziji, pereklady, Kyjiv, Dnipro, 1992.

\section{LETTERATURA CRITICA}

Admoni 1962:

V. Admoni, Poezija Rajnera Marii Ril'ke, "Voprosy literatury", 1962, 12, pp. 138-158.

Althaus 1994:

T. Althaus, Lyrik der Klassik: Goethes »Römische Elegien «, in: Id., S. Matuschek, Interpretationen zur neueren deutschen Literaturgeschichte, Münster, Lit, 1994, pp. 43-70.

Ammelburger 1995:

G. Ammelburger, Bejahungen: Zur Rhetorik des Rühmens bei Rainer Maria Rilke, Würzburg, Königshausen \& Neumann, 1995.

Autant-Mathieu 1999:

M.-C. Autant-Mathieu, Brecht au pays $d u$ " grand ordre ", "Théâtre/Public", 1999, 148-149, pp. 65-74.

Babenko 2006:

V. Babenko, Tradyciji i novatorstvo filosofos'kosvitohljadnych aspektiv tvorčosti $V$. Stusa, "Moloda nacija", 2006, 1, pp. 13-43.

Bachtin 2000:

M. Bachtin, Sobranie sočinenij, Moskva, Russkie slovari, 2000 . 
Baevskij 2011:

Bak 1995:

Bakuła 1999:

Barabanova 2008:

Bartolini 2005:

Bartolini 2010:

Bartolini 2012:

Becker, Kiesel 2007:

Bedryk 1993:

Belentschikow 1994:

Bellezza (in stampa):

Berdychovs'ka 2004:

Berehuljak 1992:

Bertens 1986:
V. Baevskij, Puškinsko-pasternakovskaja kul'turnaja paradigma, Moskva, Jazyki slavjanskoj kul'tury, 2011.

D. Bak, Slovo v lirike Vasilja Stusa, “Grani”, 1995, 177, pp. 19-26.

B. Bakuła, Skrzydło Dedala: Szkice, rozmowy o poezji $i$ kulturze ukraińskiej lat 50.-90. XX wieku, Poznań, WiS, 1999.

O. Barabanova, Poetyka pejzažu Vasylja Stusa, “Aktual’ni problemy ukrajins'koji literatury i fol'kloru”, 2008, 12, pp. 315-322.

M. G. Bartolini, Marina Cvetaeva's “Poety”. An Analysis, “eSamizdat”, III, 2005, 1, pp. 57-70.

M. G. Bartolini, "Introspice mare pectoris tui": Ascendenze neoplatoniche nella produzione dialogica di H.S. Skovoroda (1722-1794), Firenze, Firenze University Press, 2010.

M. G. Bartolini, “Nello stretto triangolo della notte...": Jurij Tarnavs 'kyj, il Gruppo di New York e la poesia della Diaspora ucraina negli USA, Roma, Lithos, 2012.

S. Becker, H. Kiesel, Literarische Moderne: Begriff und Phänomen, in: Id., Literarische Moderne: Begriff und Phänomen, Berlin-New York, De Gruyter, 2007, pp. 9-35.

Ju. Bedryk, Vasyl'Stus: Problema spryjmannja, Kyjiv, Fotovideoservis, 1993.

V. Belentschikow, Rußland und die deutschen Expressionisten 1910-1925: Zur Geschichte der deutschrussischen Literaturbeziehungen 1910-1925: Zweiter Teil: Lyrik, Frankfurt a.M. et al., Peter Lang, 1994.

S. A. Bellezza, The Shore of Expectations: A Study on the Culture of the Ukrainian Shistdesiatnyky, 1953-1973, Edmonton, Canadian Institute of Ukrainian Studies Press, in stampa.

B. Berdychovs'ka, Šistdesjatnyky - bunt pokolinnja, in: Ead., O. Hnatjuk, Bunt pokolinnja: Rozmovy $z$ ukrajins 'kymy intelektualamy, Kyjiv, Duch i litera, 2004, pp. 10-31 (Bunt pokolenia, Lublin, UMCS, 2000).

A. Berehuljak, Rolja pam "jati u zberihanni identyčnosty ta poetyčnoho «ja», in: M. Pavlyšyn (a cura di), Stus jak tekst, Melbourne, Monash University - Slavic Section, 1992, pp. 53-62.

H. Bertens, The Postmodern Weltanschauung and its Relation with Modernism: An Introductory Survey, 
Bertens 1995:

Bila 2007:

Bila 2008:

Bila 2010:

Bilovus 2004:

Bobryševa 2013:

Bogomolov 1972:

Bojčuk 1993:

Bojčuk 2000:

Bojko-Blochyn 1981: in: D. Fokkema, H. Bertens (a cura di), Approaching Postmodernism: Papers presented at a Workshop on Postmodernism, 21-23 September 1984, University of Utrecht, Amsterdam-Philadelphia, John Benjamins, 1986, pp. 9-51.

H. Bertens, The Idea of the Postmodern: A History, London-New York, Routledge, 1995.

A. Bila, Skovorodynivs 'kyj kod u dyskursi šistdesjatnyctva (na materiali tvorčosti V. Stusa), in: Hryhorij Skovorodaduchovnyj orijentyr dlja sučasnosti, Kyjiv, 2007, pp. 23-33.

A. Bila, Liryka V. Stusa i problema postsymvolizmu, "Aktual'ni problemy ukrajins'koji literatury i fol'kloru", 2008, 12, pp. 57-64.

A. Bila, Postmodernists'kyj kontekst "Palimpsestiv" V. Stusa, "Aktual'ni problemy ukrajins'koji literatury i fol'kloru”, 2010, 15, pp. 117-123.

L. Bilovus, Teorija intertekstual'nosti jak modus novatorstva u tvorčych fenomenach Vasylja Stusa ta Ivana Svitlyčnoho, Ternopil', Pidručnyky i posibnyky, 2004.

I. Bobryševa, Semantičeskoe pole "pustota" v idiolekte M.I. Cvetaevoj: avtoreferat dissertacii na soiskanie učënoj stepeni kandidata filologičeskich nauk, Rostovna-Donu, Južnyj Federal'nyj Universitet, 2013.

A. Bogomolov (a cura di), Sovremennaja buržuaznaja filosofija, Moskva, Izdatel'stvo Moskovskogo Universiteta, 1972.

B. Bojčuk, «Stus jak tekst», uporjadnyk Marko Pavlyšyn, statti, 91 storinky, v-vo Universytet im. Monaša, viddil Slavistyky, Melborn, 1992, "Svito-vyd", 1993, 3, pp. 115-117.

B. Bojčuk, Zatemnena storona misjacja, "Krytyka", IV, 2000, 10, pp. 27-28.

J. Bojko-Blochyn, Goethe und die ukrainische Literatur, in: H.-B. Harder, H. Rothe (a cura di), Goethe und die Welt der Slawen: Vorträge der 1. internationalen Konferenz des „Slawenkomitees“, im Goethe-Museum Düsseldorf: 18.-22. September 1979, Gießen, Wilhelm Schmitz, 1981, pp. 213-228.

Bondarenko, Bondarenko 1996: A. Bondarenko, Ju. Bondarenko, Vykorystannja poeziji šistdesjatnykiv dlja stanovlennja svitohljadu učniv. (Tvory Liny Kostenko, Vasylja Stusa, Ivana Svitlyčnoho), "Dyvoslovo", 1996, 11, pp. 52-55. 
Bordukova 1998:

Böschenstein 1990:

Brandt 1991:

Brodsky 1983:

Brogi Bercoff 2007:

Brogi Bercoff 2011:

Brogi Bercoff 2012:
N. Bordukova, Pro misce H. Skovorody u tvorčosti Vasylja Stusa, “Aktual'ni problemy ukrajins'koji literatury i fol'kloru", 1998, 2, pp. 35-40.

B. Böschenstein, Das Ich und seine Teile: Überlegungen zum anthropologischen Gehalt einiger lyrischer Texte, in: G. Buhr, F. A. Kittler, H. Turk (a cura di), Das Subjekt der Dichtung: Festschrift für Gerhard Kaiser, Würzburg, Königshausen \& Neumann, 1990, pp. 73-98.

H. Brandt, Goethes Sesenheimer Gedichte als lyrischer Neubeginn, "Goethe-Jahrbuch", 1991, 108, pp. 31-46.

P. P. Brodsky, The Russians'Rilke: Reception as a Mirror of Literary Reality, "Germano-Slavica”, IV, 1983, 3, pp. 143-150.

G. Brogi Bercoff, La poesia di Taras Ševčenko. Prove di lettura, "Studi slavistici", 2007, 4, pp. 117-141.

G. Brogi Bercoff, Owls and Dogs: Lexical and Symbolic Semantics in the Poetry of Taras Sevčenko, in: K. Marciniak (a cura di), Birthday Beasts' Book: Where Human Roads Cross Animal Trails: Cultural Studies in Honour of Jerzy Axer, Warszawa, Artes Liberales, 2011, pp. 31-39.

G. Brogi Bercoff, Il "Poslanije” di Taras Ševčenko tra slavismo, nazione e profetismo, in: G. Carpi, L. Fleishman, B. Sulpasso (a cura di), Venok. Studia Slavica Stefano Garzonio Sexagenario oblata. In Honor of Stefano Garzonio, Stanford, Stanford University Press, 2012, pp. 155-175.

Brogi Bercoff, Pachlovska 2015: G. Brogi Bercoff, O. Pachlovska, Taras Ševčenko. Dalle carceri zariste al Pantheon ucraino, MilanoFirenze, Le Monnier Università, 2015.

Brogi Bercoff, Pavlyshyn, Plokhy 2017: $\quad$ G. Brogi Bercoff, M. Pavlyshyn, S. Plokhy (a cura di), Ukraine and Europe: Cultural Encounters and Negotiations, Toronto-Buffalo-London, Toronto University Press, 2017.

Brojtman 1997: $\quad$ S. Brojtman, Russkaja lirika XIX-načala XXveka v svete istoričeskoj poetiki: sub"jektno-obraznaja struktura, Moskva, RGGU, 1997.

Buck 1996:

T. Buck, Goethes „,Urworte. Orphisch“, Frankfurt a.M. et al., Peter Lang, 1996.

Burdorf 2017: $\quad$ D. Burdorf, The I and the Others. Articulations of Personality and Communication Structures in the Lyric, "Journal of Literary Theory", XI, 2017, 1, pp. 22-31.

Burjankyk 1993: N. Burjanyk, Sviča i svičado v poeziji Vasylja Stusa, "Slovo i čas", 1993, 11, pp. 51-57. 
Burjanyk 1997:

Calinescu 1987:

Cavenagh 2009:

Černenko 1988:

Charpa 1985:

Chejfec 1983:

Chernetsky 2007:

Chernetsky 2011:

Ciepiela 2009:

Clark 2013:

Coenen-Mennemeier 2004:

Compagnon 1998:

Čorna 1999:

Čubrakova 2012:
N. Burjanyk, Incarceration and Death, The Poetry of Vasyl'Stus, PhD dissertation, University of Alberta, 1997.

M. Calinescu, Five Faces of Modernity: Modernism Avant-Garde - Decadence - Kitsch - Postmodernism, Durham, Duke University Press, 1987.

C. Cavenagh, Lyric Poetry and Modern Politics: Russia, Poland, and the West, New Haven-London, Yale University Press, 2009.

O. Černenko, Nove duchovne svitovidčuvannja v poezijach ukrajins 'kych dysydentiv, "Sučasnist", 1988, 2, pp. 16-30.

U. Charpa, Das poetische Ich - persona per quam, "Poetica", 1985, 17, pp. 149-169.

M. Chejfec, Ukrainskie siluety, München, Sučasnist', 1983.

V. Chernetsky, Mapping Postcommunist Cultures: Russia and Ukraine in the Context of Globalization, MontrealLondon-Ithaca, McGill-Queen's University Press, 2007.

V. Chernetsky, Nation and Translation: Literary Translation and the Shaping of Modern Ukrainian Culture, in: B. J. Baer (a cura di), Contexts, Subtexts and Pretexts: Literary Translation in Eastern Europe and Russia, Amsterdam-Philadelphia, John Benjamins, 2011, pp. 33-53.

C. Ciepiela, Cvetaeva's Lyricism and Kručenych's 'Zaum', "Russian Literature", LXV, 2009, 1-3, pp. 321-228.

K. Clark, "Wait for me and I shall return": The Early Thaw as a Reprise of Late Thirties Culture?, in: D. Kozlov, E. Gilburd (a cura di ), Soviet Society and Culture during the 1950s and 1960s, Toronto-Buffalo-London, University of Toronto Press, 2013, pp. 85-108.

B. Coenen-Mennemeier, Das lyrische Du: Funktionen und Variationen einer poetischen Sprechsituation, Frankfurt a.M. et al., Peter Lang, 2004.

A. Compagnon, Le démon de la théorie : Littérature et sens commun, Paris, Seuil, 1998.

M. Čorna, Do pytannja “estetyky straždannja” u poeziji Vasylja Stusa, "Svito-vyd”, 1999, 4, pp. 92-98.

Z. Čubrakova, Poezija nemeckogo ekspressionizma $v$ vosprijatii B. Pasternaka. Kommunikativnye problemy perevodnogo teksta, “Tekst. Kniga. Knigoizdanie”, 2012, 2, pp. 12-25. 
Culler 1988:

Culler 2015:

Djurčinov 1979:

Dmytrenko 2007:

Dornblüth 1999:

Dorošenko 2016:

Dreyfus 2006:

Dudarenko 2009:

Dzjuba 2003:

Dzjuba 2008:

Eckel 1994:

Eldridge 2011:

El'nickaja 1994:
J. Culler, The Modern Lyric: Generic Continuity and Critical Practice, in: C. Koelb, S. Noakes (a cura di), The Comparative Perspective on Literature: Approaches to Theory and Practice, Ithaca-London, Cornell University Press, 1988, pp. 284-299.

J. Culler, Theory of the Lyric, Cambridge (Mass.)-London, Harvard University Press, 2015.

M. Djurčinov, Antinomija «romantizm - realizm》v poetike Pasternaka, in: M. Aucouturier (a cura di), Boris Pasternak 1890-1960: Colloque de Cérisy-la-Salle (1114 septembre 1975), Paris, Institut d'Études Slaves, 1979, pp. 95-103.

M. Dmytrenko, Budivnyčyj tajemnyčoho chramu Mykola Vorobjov: Poezija sorokalittja, in: M. Vorobjov, Bez kory: vybrane (1964-2007 rr.), Kyjiv, Mykola Dmytrenko, 2007, pp. 626-629.

G. Dornblüth, Poststalinizm - Postavangardizm: Das Subjekt und die Welt der Objekte in der postmodernen frühen Lyrik Andrej Voznesenskijs, München, Otto Sagner, 1999.

O. Dorošenko, Vasyl'Stus, Charkiv, Folio, 2016.

H. L. Dreyfus, The Roots of Existentialism, in: Id., M. A. Wrathall (a cura di), A Companion to Phenomenology and Existentialism, Malden-Oxford-Carlton, Blackwell Publishing, 2006, pp. 137-161.

L. Dudarenko, Poetyčna Kyjivs'ka škola: idejni ta estetyčni parametry, Kyjiv, Neopalyma kupyna, 2009.

I. Dzjuba, Sviča u kam 'janij pit'mi, in: V. Stus, Palimpsest: Vybrane, Kyjiv, Fakt, 2003 (1991), pp. 7-32.

I. Dzjuba, Volja, in: N. Čamata (a cura di), Temy i motyvy poeziji Tarasa Ševčenka, Kyjiv, Naukova dumka, 2008, pp. 76-85.

W. Eckel, Wendung: Zum Prozeß der poetischen Reflexion im Werk Rilkes, Würzburg, Königshausen \& Neumann, 1994.

R. Eldridge, Narrative Reharsal, Expression, and Goethe's "Wandrers Nachtlied II", in: N. Carroll, J. Gibson (a cura di), Narrative, Emotion, and Insight, University Park, The Pennsylvania State University Press, 2011, pp. 109-130.

S. El'nickaja, Dve "bessonnicy” Mariny Cvetaevoj, in: V. Schweitzer et al. (a cura di), Marina Tsvetaeva: One Hundred Years: Papers from the Tsvetaeva Centenary 
Engel 2004:

Erlich 1959:

Eshelman 1997:

Eysteinsson 1990:

Eysteinsson, Liska 2007:

Fateeva 2003:

Finnin 2011:

Finnin 2014:

Flaker 1979:

Flejšman 1979:

Fokkema, Bertens 1986:

France 1979:

Frank 1962:
Symposium: Amherst College, Amherst, Massachusetts, 1992, Oakland, Berkeley Slavic specialties, 1994, pp. 91-110.

M. Engel (a cura di), Rilke-Handbuch: Leben - WerkWirkung, Stuttgart, Wissenschaftliche Buchgesellschaft, 2004.

V. Erlich, The Concept of the Poet in Pasternak, "The Slavonic and East European Review", XXXVII, 1959, 89, pp. 325-335.

R. Eshelman, Early Soviet Postmodernism, Frankfurt a.M. et al., Peter Lang, 1997.

A. Eysteinsson, The Concept of Modernism, IthacaLondon, Cornell University Press, 1990.

A. Eysteinsson, V. Liska (a cura di), Modernism, Amsterdam-Philadelphia, John Benjamins, 2007.

N. Fateeva, Proza poeta: Kniga o Pasternake, Moskva, NLO, 2003.

R. Finnin, Nationalism and the Lyric, or How Taras Shevchenko speaks to Compatriots Deads, Living, and Unborn, "The Slavonic and East European Review", LXXXIX, 2011, 1, pp. 29-55.

R. Finnin, A Divided Ukraine: Europe's Most Dangerous Idea, 27-03-2014 <http://www.crassh.cam.ac.uk/blog/ post/a-divided-ukraine-europes-most-dangerous-idea $>$ (ultimo accesso: 20-04-2018)

A. Flaker, Symbolism or Modernism in Slavic Literatures?, "Russian Literature", VII, 1979, 4, pp. 329-348.

1. Flejšman, Fragmenty «futurističeskoj» biografii Pasternaka, "Slavica Hierosolymitana", 1979, 4, pp. 79-113.

D. Fokkema, H. Bertens, Approaching Postmodernism: Papers presented at a Workshop on Postmodernism, 21 23 September 1984, University of Utrecht, AmsterdamPhiladelphia, John Benjamins, 1986.

P. France, Pasternak et le romantisme, in: M. Aucouturier (a cura di), Boris Pasternak 1890-1960: Colloque de Cérisy-la-Salle (11-14 septembre 1975), Paris, Institut d'Études Slaves, 1979, pp. 81-92.

V. S. Frank, Vodjanoj znak: Poetičeskoe mirovozzrenie Pasternaka, in: Sbornik statej, posvjaščënnych tvorčestvu Borisa Leonidoviča Pasternaka, Mjunchen, Institut po izučeniju SSSR, 1962, pp. 240-252. 
Frejdlin 1994:

Fuchs 2009:

Fülleborn 1988:

Gasparov 1995:

Genette 1982:

Gerok-Reiter 1996:

Ginzburg 1987:

Gladkova, Mnuchin 1982:

Gorelik 2011:

Görner 2002:

Grabher 1989:

Grabowicz 1982:

Grabowicz 1992:
Ju. Frejdlin, Tema smerti v poetičeskom tvorčestve Mariny Cvetaevoj, in: V. Schweitzer et al. (a cura di), Marina Tsvetaeva: One Hundred Years: Papers from the Tsvetaeva Centenary Symposium: Amherst College, Amherst, Massachusetts, 1992, Oakland, Berkeley Slavic specialties, 1994, pp. 249-261.

B. A. Fuchs, Poetologie elegischen Sprechens: Das lyrische Ich und der Engel in Rilkes „Duineser Elegien “, Würzburg, Königshausen \& Neumann, 2009.

U. Fülleborn, Einleitung, in: Id., M. Engel (a cura di), Das neuzeitliche Ich in der Literatur des 18. und 20. Jahrhunderts: Zur Dialektik der Moderne: Ein internationales Symposion, München, Wilhelm Fink, 1988, pp. 9-27.

M. Gasparov, "Poema vozducha" Mariny Cvetaevoj: opyt interpretacii, in: Id., Izbrannye stat' $i$, Moskva, NLO, 1995, pp. 261-274.

G. Genette, Palimpsestes : La littérature au second degré, Paris, Seuil, 1982.

A. Gerok-Reiter, Wink und Wandlung: Komposition und Poetik in Rilkes "Sonette an Orpheus", Tübingen, Niemeyer, 1996.

L. Ginzburg, Literatura v poiskach real'nosti: stat'i, esse, zametki, Leningrad, Sovetskij pisatel', 1987.

T. Gladkova, L. Mnuchin, Bibliographie des æuvres de Marina Tsvetaeva, Paris, Institut d'Études Slaves, 1982.

L. Gorelik, Mif o tvorčestve v proze i stichach Borisa Pasternaka, Moskva, RGGU, 2011.

R. Görner, “Denken des Herzens”. Zugänge zu einem Motiv in Rilkes Werk, "Blätter der Rilke-Gesellschaft", 2002, 24, pp. 147-164.

G. M. Grabher, Das lyrische Du: Du-Vergessenheit und Möglichkeiten der Du-Bestimmung in der amerikanischen Dichtung, Heidelberg, Carl Winter, 1989.

G. G. Grabowicz, The Poet as Mythmaker: a Study of Symbolic Meaning in Taras Ševčenko, Cambridge (Mass.), Harvard University Press, 1982.

G. G. Grabowicz, Ukrainian-Russian Literary Relations in the Nineteenth Century: A Formulation of the Problem, in: P. J. Potichnyj et al. (a cura di), Ukraine and Russia in Their Historical Encounter, Edmonton, CIUS Press, 1992, pp. 214-244. 
Grabowicz 1995:

Grinberg 1966:

Grübel 1987:

Gudz' 1994:

Habermas 1981:

Hamburger 1977:

Hansen-Löve 1993:

Harmaš 1991:

Hassan 1987:

Hasty 1996:

Herrnstein-Smith 1971:

Hillebrandt et al. 2017:

Hinton Thomas 1969:

Hnatjuk 2012:
G. G. Grabowicz, Ukrainian Studies: Framing the Contexts, "Slavic Review", LIV, 1995, 3, pp. 674-690.

I. Grinberg, Žizn', mysl', obraz, "Voprosy literatury", 1966, 3, pp. 16-26.

R. Grübel, The Personal Pragmatic Institutions of Poetic Discourse, in: I. M. Zavala, T. A. Van Dijk, M. Díaz-Diocaretz (a cura di), Approaches to Discourse, Poetics and Psychiatry, Amsterdam-Philadelphia, John Benjamins, pp. 149-170.

Ju. Gudz', Dopovnennja do statusiv movčannja, "Svitovyd", III, 1994, 1, pp. 65-75.

J. Habermas, Modernity versus Postmodernity, "New German Critique", 1981, 22, pp. 3-14.

K. Hamburger, Die Logik der Dichtung, Frankfurt a.M.Berlin-Wien, Ullstein, 1977 (1957).

A. A. Hansen-Löve, Mandel'shtam's Thanatopoetics, in: R. Vroon, J. E. Malmstad (a cura di), Readings in Russian Modernism: to Honor Vladimir Fedorovich Markov, Moskva, Nauka, 1993, pp. 121-157.

H. Harmaš, Červone i čorne: poezija-dolja Vasylja Stusa, "Slovo i čas", 1991, 5, pp. 20-25.

I. Hassan, Pluralism in Postmodern Perspective, in: M. Calinescu, D. Fokkema (a cura di), Exploring Postmodernism: Selected Papers Presented at a Workshop on Postmodernism at the XIth International Comparative Literature Congress, Paris, 20-24 August 1985, Amsterdam-Philadelphia, John Benjamins, 1987, pp. 17-39.

O. P. Hasty, Tsvetaeva's Orphic Journeys in the Worlds of the Word, Evanston, Northwestern University Press, 1996.

B. Herrnstein-Smith, Poetry as Fiction, "New Literary History", II, 1971, 2, pp. 259-281.

C. Hillebrandt et al., Theories of Lyric, "Journal of Literary Theory", XI, 2017, 1, pp. 1-11.

R. Hinton Thomas, Das Ich und die Welt: Expressionismus und Gesellschaft, in: W. Rothe (a cura di), Expressionismus als Literatur: Gesammelte Studien, Bern-München, Francke, 1969, pp. 19-36.

O. Hnatjuk, Šistdesjatnyky. Doli ta roli, in: Ead., Miž literaturoju i politykoju: Eseji ta interpretaciji, Kyjiv, Duch i litera, 2012, pp. 6-43. 
Hodunok 2011:

Holub 2012:

Hrabovyč 1976:

Hryzun 2011:

Hühn 2005:

Huk 1992:

Hundorova 1992:

Hundorova 2004:

Hundorova 2008:

Hundorova 2009:

Hundorova 2013:

Huyssen 1984:

Il'nyc'kyj 1990:

Il'nyc'kyj 1996:

Il'nyc'kyj 1999:

Ilnytzkyj 2003:
P. Hodunok, Hermenevtyka indyvida u zbirci $V$. Stusa "Veselyj cvyntar" ta v tekstach M. Chvyl'ovoho: porivnjal'nyj analiz, "Naukovi zapysky. Serija 'Filolohična",, 2011, 21, pp. 132-141.

O. Holub (a cura di), Poezija iz-za grat: Antolohija, Kyjiv, Smoloskyp, 2012.

H. Hrabovyč, Serhij Jefremov jak istoryk ukrajins 'koho pys'menstva, "Sučasnist"”, 1976, 10, pp. 52-61.

A. Hryzun, Poezija bahatoznačnych pidtekstiv: (ukrajins'ka sugestyvna liryka XX st.): monohrafija, Sumy, Universytets'ka knyha, 2011.

P. Hühn, Plotting the Lyric: Forms of Narration in Poetry, in: E. Müller-Zettelmann, M. Rubik (a cura di), Theory into Poetry: New Approaches to Lyric, Amsterdam-New York, Rodopi, 2005, pp. 139-172.

B. Huk, Uwagi o stanie badań nad twórczościa Wasyla Stusa, "Slavia Orientalis", XLI, 1992, 1, pp. 67-77.

T. Hundorova, Fenomen Stusovoho «žertvoslova», in: M. Pavlyšyn (a cura di), Stus jak tekst, Melbourne, Monash University - Slavic Section, 1992, pp. 1-29.

T. Hundorova, Šistdesjatnyctvo: metafora, im "ja, dim, in: M. Kocjubyns'ka, Moji obriji: Tom 1, Kyjiv, Duch i litera, 2004, pp. 4-10.

T. Hundorova, Kitč i literatura: travestiji, Kyjiv, Fakt, 2008.

T. Hundorova, ProJAvlennja slova: Dyskursija rann'oho ukrajins 'koho modernizmu, Kyjiv, Krytyka, 2009 (1997).

T. Hundorova, Pisljačornobyl's'ka biblioteka: Ukrajins 'kyj literaturnyj postmodernizm, Kyjiv, Krytyka, 2013 (2005).

A. Huyssen, Mapping the Postmodern, "New German Critique", 1984, 33, pp. 5-52.

M. Il'nyc'kyj, Palimpsesty Vasylja Stusa, "Vitčyzna", 1990, 3, pp. 14-16.

M. Il'nyc'kyj, Literaturni tradyciji poeziji “poza tradyciji", "Sučasnist", 1996, 10, pp. 113-128.

M. Il'nyc'kyj, “Iz zachidnoji perspektyvy... ”: Nad knyhoju Marka Pavlyšyna "Kanon ta ikonostas”, Kyjiv, 1997, “Kur”jer Kryvbasu”, 1999, 1, pp. 164-173.

O. S. Ilnytzkyj, Modeling Culture in the Empire: Ukrainian Modernism and the Death of the All-Russian Idea, in: A. Kappeler et al. (a cura di), Culture, Nation, 
Ilnytzkyj, Hawrysch 2001:

Iščenko 2015:

Iser 1966:

Ivanyšyn 2012:

Ivaško 1994:

Jakobson 1935:

Jakobson 1981:

Jakuševa 2004:

Jastrubec'ka 2004:

Jastrubec'ka 2011:

Jastrubec'ka 2013:

Jastrubec'ka 2014:

Jehorčenko 2002:

Jehorčenko 2004:

Jehorčenko 2008a: and Identity: The Ukrainian-Russian Encounter (16001945), Edmonton-Toronto, CIUS, pp. 298-324.

O. S. Ilnytzkyj, G, Hawrysch, A Concordance to the Poetic Works of Taras Shevchenko, New York, Shevchenko Scientific Society, 2001.

Je. Iščenko, Ekzystencijni koncepty chudožn'oji svidomosti V. Stusa: monohrafija, Kyjiv, Kyjivs'kyj Universytet, 2015.

W. Iser (a cura di), Immanente Ästhetik: Ästhetische Reflexion: Lyrik als Paradigma der Moderne: Kolloquium Köln 1964: Vorlagen und Verhandlungen, München, Wilhelm Fink, 1966.

P. Ivanyšyn, Krytyka i metakrytyka jak osmyslennja literaturnosti, Kyjiv, Akademvydav, 2012.

V. Ivaško, Mif pro Vasylja Stusa jak dzerkalo šistdesjatnykiv, "Svito-vyd", III, 1994, 4, pp. 104-121.

R. Jakobson, Randbemerkungen zur Prosa des Dichters Pasternak, "Slavische Rundschau”, 1935, 7, pp. 357-374.

R. Jakobson, $O$ "Stichach, socinennych noč'ju vo vremja bessonnicy", in: Id., Selected Writings: III: Poetry of Grammar and Grammar of Poetry, The Hague-ParisNew York, Mouton, 1981, pp. 378-387.

G. Jakuševa (a cura di), Gëte v russkoj kul'ture XX veka, Moskva, Nauka, 2004.

H. Jastrubec'ka, Koncept “Ukrajina” v poezotvorčosti Vasylja Stusa, "Slovo i čas", 2004, 10, pp. 37-44.

H. Jastrubec'ka, Tezaurus V. Stusa kriz' pryzmu mistyčnoho, "Naukovi zapysky. Serija "Filolohična", 2011, 21, pp. 374-383.

H. Jastrubec'ka, Dynamika ukrajins 'koho literaturnoho ekspresionizmu: Monohrafija, Luc'k, Tverdynja, 2013.

H. Jastrubec'ka, Tvorčist' Vasylja Stus i sučasna svidomist', "Dyvoslovo", 2014, 7-8, pp. 64-67.

M. Jehorčenko, Motyv hricha v poeziji Vasylja Stusa, "Naukovi zapysky Nacional'noho Universytetu 'KyjivoMohyljans'ka Akademija': Filolohični nauky”, 2002, 72, pp. 18-23.

M. Jehorčenko, Čas tvorčosty Vasylja Stusa, "Sučasnist", 2004, 2, pp. 131-145.

M. Jehorčenko, Funkcija “pasternakivs'koho tekstu” u tvorčosti Vasylja Stusa, "Aktual'ni problemy ukrajins'koji literatury i fol'kloru”, 2008, 12, pp. 83-87. 
Jehorčenko 2008b:

Jones 2013:

Kanapa 1953:

Karpušin 1967:

Kas'janov 1995:

Kaufmann 2011:

Kermode 1968:

Kisel'ova 2010:

Kocjubyns'ka 1991:

Kolodkevyč 2015:
Kastberger 2000:

Kološuk 2011:

M. Jehorčenko, Problema tvorčosti u Vasylja Stus ta Maryny Cvjetajevoji, "Mandrivec", 2008, 2, pp. 63-66.

P. Jones, The Personal and the Political: Opposition to the Thaw and the Politics of Literary Identity in the 1950s and 1960s, in: D. Kozlov, E. Gilburd (a cura di), Soviet Society and Culture during the 1950s and 1960s, Toronto-Buffalo-London, University of Toronto Press, 2013, pp. 231-265.

J. Kanapa, Ekzistencializm - vrag gumanizma, in: M. Cebenko (a cura di), Francuzskie kommunisty v bor'be za progressivnuju ideologiju: Sbornik sokraščënych perevodov s francuzskogo, Moskva, Izdatel'stvo inostrannoj literatury, 1953, pp. 185-214.

V. Karpušin, Koncepcija ličnosti u Al'bera Kamju, "Voprosy filosofii", 1967, 2, pp. 128-136.

H. Kas'janov, Nezhodni: ukrajins 'ka intelihencija $v$ rusi oporu 1960-80-ch rokiv, Kyjiv, Lybid', 1995.

$\mathrm{K}$. Kastberger, Ist die Postmoderne die bessere Avantgarde?, in: K. Bartsch (a cura di), Avantgarde und Traditionalismus: Kein Widerspruch in der Postmoderne?, Innsbruck-Wien-München, StudienVerlag, 2000, pp. 13-24.

S. Kaufmann, ,Schöpft des Dichters reine Hand ... “: Studien zu Goethes poetologischer Lyrik, Heidelberg, Winter, 2011.

F. Kermode, Continuities, London, Routledge \& Kegan Paul, 1968.

L. Kisel'ova, Lohodiceja ukrajins 'koho modernizmu: Tyčyna, Svidzins'kyj, Os'mačka, in: V. Morenec', M. Tkačuk (a cura di), Ljudyna v časi (filosofs 'ki aspekty ukrajins'koji literatury XX-XXI st.), Kyjiv, NaUKMA, 2010.

Kliems, Raßloff, Zajac 2006: A. Kliems, U. Raßloff, P. Zajac (a cura di), Spätmoderne: Lyrik des 20. Jahrhunderts in Ost-Mittel-Europa, Berlin, Frank\&Timme, 2006.

M. Kocjubyns'ka, Fenomen Stusa, "Sučasnist'”, 1991, 9, pp. 26-35.

H. Kolodkevyč, Variatyvnist'poetičnoho myslennja Vasylja Stusa: Monohrafija, Kyjiv, Kyjivs'kyj Mižnarodnyj Universytet, 2015.

N. Kološuk, Dysydent'ski poetyčni poslannja 1970-ch rokiv u porivnjal'nomu aspekti (tjuremno-tabirni virši $V$. Stusa ta "Nizvidky z ljubov"ju, nadcjatoho kvitnepada..." 
Korniejenko 1996:

Korniejenko 1998:

Kordun 1997:

Koschmal 1996:

Košenina 2013:

Koslowski 1986:

Kovaliv 1989:

Kozlov 2013:

Kraan 1991:

Kraljuk 2010:

Kravčenko 2002:

Kravčenko 2003:

Kravčenko 2005:
J. Brods 'koho), "Naukovi zapysky. Serija 'Filolohična'", 2011, 21, pp. 235-246.

A. Korniejenko (a cura di), Poezja Wasyla Stusa, Kraków, Universitas, 1996.

A. Korniejenko, Ukraińskimodernizm: próba periodyzacji procesu historycznoliterackiego, Kraków, Universitas, 1998.

V. Kordun, Kyjivs 'ka škola poeziji-ščo ce take?,"Svitovyd", VI, 1997, 1-2, pp. 7-19.

W. Koschmal, Ende der Verantwortungsästhetik?, in: J.-U. Peters, G. Ritz (a cura di), Enttabuisierung: Essays zur russischen und polnischen Gegenwartsliteratur, Bern et al., Peter Lang, 1996, pp. 19-43.

A. Košenina, »Wie schlägt dein Herz«: Goethes Kardiopoetik, in: C. Rohde, T. Valk (a cura di), Goethes Liebeslyrik: Semantiken der Leidenschaft um 1800, Berlin-New York, Walter de Gruyter, 2013, pp. 67-85.

P. Koslowski, Die Baustellen der Postmoderne Wider den Vollendungszwang der Moderne: Statt einer Einleitung, in: Id., R. Spaemann, R. Löw (a cura di), Moderne oder Postmoderne?: Zur Signatur des gegenwärtigen Zeitalters, Weinheim, Acta Humaniora, 1986, pp. 1-16.

Ju. Kovaliv, Z odnoho džerela, in: V. Dončyk (a cura di), Dialektyka chudožn'oho pošuku: literaturnyj proces 60 80-ch rokiv, Kyjiv, Naukova dumka, 1989, pp. 81-107.

D. Kozlov, The Readers of Novyi Mir: Coming to Terms with the Stalinist Past, Cambridge (Mass.)-London, Harvard University Press, 2013.

M. Kraan, Towards a Model of Lyric Communication: Some Historical and Theoretical Remarks, "Russian Literature", XXX, 1991, pp. 199-230.

P. Kraljuk, «...benket smerti v obrazi žyttja»: Vasyl'Stus jakfilosof-ekzystencialist, 22-10-2010, <http://www.day. kiev.ua/uk/article/cuspilstvo/benket-smerti-v-obrazizhittya $>$ (ultimo accesso: 20-04-2018).

L. Kravčenko (a cura di), Rajner Marija Ril'kej Ukrajina, Drohobyč, Kolo, 2002.

L. Kravčenko, Rajner Marija Ril'ke i Vasyl'Stus: osoblyvosti poetyky, "Slovo i čas", 2003, 9, pp. 35-43.

L. Kravčenko (a cura di), R. M. Ril'ke j Ukrajina: naukovi studiji ta pereklady z R.M. Ril'ke, Drohobyč, Kolo, 2005. 
Kravčenko 2008:

Krings 2005:

Kristiansen 2008:

Kubijovyč 1993:

Kukulin 2011a:

Kukulin 2011b:

Kulcsár-Szábo 2016:

Kulyk 2008:

Kuz'menko 2002:

Kuznecova 2002:

Kyryčenko 2016:

Lachmann 1987:

Lavrent'eva 2010:

Levin 1976:
L. Kravčenko, Vasyl'Stus - interpretator poeziji R.M. Ril'ke: Monohrafija, Drohobyč, Kolo, 2008.

M. Krings, Selbstentwürfe: Zur Poetik des Ich bei Valéry, Rilke, Celan und Beckett, Bern, Francke, 2005.

B. Kristiansen, Zum Verhältnis von Selbstsein und Miteinandersein in Goethes Urworte. Orphisch, "Goethe Yearbook", 2008, 15, pp. 131-159.

V. Kubijovyč et al. (a cura di), Encyclopedia of Ukraine: 3: $L-P f$, Toronto, University of Toronto Press, 1993.

I. Kukulin, Die Wiedergeburt religiöser Bildersprache in der russischen Lyrik Anfang des 21. Jahrhunderts, "Zeitschrift für slavische Philologie”, 2011, 68, pp. 377-420.

I. Kukulin, "Razočarovanie vistorii” kak sociokul turnyj diagnoz 1960-1970-ch godov: Andrej Sinjavskij i Arkadij Belinkov, "Studi slavistici", 2011, 8, pp. 113-136.

Z. Kulcsár-Szábo, Bakhtin and Lyric Poetry, "The Dostoevsky Journal: A Comparative Literature Review", XVII, 2016, pp. 44-64.

A. Kulyk, Moji zustriči z Vasylem Stusom i joho students 'kymy tovaryšamy, "Kyjivs'ka Rus", , 2008, 5, pp. 37-48.

O. Kuz'menko, Chudožnja interpretacija dijsnosti v poezijach V. Holoborod'ka ta V. Stusa: 1960-ch-počatku 1970-ch, "Vitčyzna", 2002, 3-4, pp. 138-143.

A. Kuznecova, Cvetaeva i Gëte: (Nebol'šoj etjud na neob"jatnuju temu), in: V. Lossky, J. De Proyart (a cura di), Marina Tsvétaeva et la France : Nouveautés et Inédits, Paris-Moskva, Institut d'Études Slaves-Russkij put', 2002, pp. 170-177.

S. Kyryčenko, Ptach pidnebesnyj: Spohady pro Vasylja Stusa, Kyjiv, Smoloskyp, 2016.

R. Lachmann, Imitatio und Intertextualität: Drei russische Versionen von Horaz' Exegi monumentum, "Poetica", 1987, 19, pp. 195-229.

N. Lavrent'eva, I.V. Gëte i Boris Pasternak (k probleme russko-nemeckich literaturnych svjazej), Rjazan', Rjazanskij Oblastnoj Institut razvitija obrazovanija, 2010.

S. R. Levin, Concerning What Kind of Speech a Poem Is, in: T. A. van Dijk (a cura di), Pragmatics of Language and Literature, Amsterdam-Oxford, North Holland, 1976, pp. 141-160. 
Levin 1989:

Locher 1981:

Łucewicz 2008:

Makarčuk 1992:

Makaryk, Tkacz 2010:

Malen'kyj 2004:

Mandelarzt 2006:

Marinčak 2013:

Marinelli 2002:

Marszałek 2006:

Mason 1958:

Mayenowa 1979:

Mayer 1986:
Ju. Levin, Lirika s kommunikativnoj točki zrenija, in: Id., Izbrannye trudy: Poetika - Semiotika, Moskva, Jazyki russkoj kul'tury, 1998 (1971), pp. 464-480.

J. P. Locher, Ist Boris Pasternak ein Dichter der Avantgarde?, in: H. Riggenbach (a cura di), Colloquium Slavicum Basiliense: Gedenkschrift für Hildegard Schröder, Bern-Frankfurt a.M. Las Vegas, Peter Lang, 1981, pp. 407-441.

L. Łucewicz, Religioznye intencii russkogo poetičeskogo andegraunda 50-60-ch gg., "Przegląd rusycystyczny", 2008, 1, pp. 51-73.

V. Makarčuk, "Vid junych lit do junoho zmužninnja» (Rannja liryka Vasylja Stusa), "Slovo i čas", 1992, 8, pp. 64-69.

I. R. Makaryk, V. Tkacz (a cura di), Modernism in Kyiv: Kiev, КИЇВ, КИЕВ, КІЈÓW,קיע: Jubilant Experimentation, Toronto-Buffalo-London, University of Toronto Press, 2010.

I. Malen'kyj, Kosmolohija ljuds 'koji osobystosty i duch $u$ vzajemoviddzerkalenych vsesvitach Vasylja Stusa, "Sučasnist"”, 2004, 1, pp. 120-137.

M. Mandelarzt, "Harzreise im Winter". Goethes Antwort auf Petrarca und die Naturgeschichte der Kultur, "Goethe-Jahrbuch", 2006, 123, pp. 86-99.

V. Marinčak, Poezija Vasylja Stusa i christianskaja aksiologija, "Toronto Slavic Quarterly", 2013, 43, pp. 67-101.

L. Marinelli, La porta senza chiave: Appunti sparsi sull'Io lirico nella poesia polacca contemporanea tra testimonianza, confessione e sfida (Miłosz, Herbert, Szymborska), "Critica del testo", V, 2002, 1, pp. 239-263.

M. Marszałek, Imagination, Konstruktion und Mythographie. Bohdan-Ihor Antonyč und die ukrainische Spätmoderne, in: A. Kliems, U. Raßloff, P. Zajac (a cura di), Spätmoderne: Lyrik des 20. Jahrhunderts in OstMittel-Europa, Berlin, Frank\&Timme, 2006, pp. 211-223.

E. C. Mason, Rilke und Goethe, Köln-Graz, Böhlau, 1958.

M. R. Mayenowa, Poetyka teoretyczna. Zagadnienia języka, Wroclaw et al., Zakład narodowy imienia Ossolińskich, 1979.

M. Mayer, Dichten zwischen Paradies und Hölle: Anmerkungen zur poetologischen Struktur von Goethes 
McHale 1986:

Mel'nyk 1990:

Mel'nyk 2000:

Michajlov, Čudakov 1960:

Michajlova 2015:

Michajlova 2017:

Morenec' 1989:

Morenec' 1998:

Morenec' 2002:

Morenec' 2013:

Moskalec' 1999:

Motekat 1976:
Elegie von Marienbad, "Zeitschrift für deutsche Philologie", CV, 1986, 2, pp. 234-256.

B. McHale, Change of Dominant from Modernist to Postmodernist Writing, in: D. W. Fokkema, H. Bertens (a cura di), Approaching Postmodernism: Papers presented at a Workshop on Postmodernism, 21-23 September 1984, University of Utrecht, Amsterdam-Philadelphia, John Benjamins, 1986, pp. 53-79.

Ja. Mel'nyk, "Vmeni uže narodžujet'sja Boh", "Vitčyzna", 1990, 10, pp. 157-161.

V. Mel'nyk, Metalinhvistyčna problema dvoholossja ta dialohičnych vidnosyn u poeziji V. Stusa, "Slovo i čas", 2000, 9, pp. 32-36.

O. Michajlov, S. Čudakov, Zametki o poezii 1959 goda, "Voprosy literatury", 1960, 4, pp. 36-62.

T. Michajlova, Stichotvorenie M. Cvetaevoj v perevode V. Stusa kak transljacija idei žizni B. Pasternaka, in: O. Palamarčuk (a cura di), Komparatyvni doslidžennja slov"jans 'kych mov i literatur pam"jati akademika Leonida Bulachovs 'koho, Kyjiv, 2015, pp. 336-342.

T. Michajlova, Vasyl'Stus kak perevodčik russkoj literatury, in: M. Dąbrowska, P. Głuszkowski, K. RomanRawska (a cura di), Literatura $i$ władza: Zwiazki na gruncie rosyjskim $w$ XVIII-XXI wieku, Warszawa, Instytut Rusycystyki UW, 2017, pp. 213-226.

V. Morenec', Poezija tr'och desjatylit': harmonija $i$ superečnosti, in: V. Dončyk (a cura di), Dialektyka chudožn'oho pošuku: literaturnyj proces 60-80-ch rokiv, Kyjiv, Naukova dumka, 1989, pp. 21-80.

V. Morenec', Do pytannja modernosti liryky Vasylja Stusa: (Chudožn'o-filosofs 'ki aspekty indyvidual'noho stylju), "Naukovi zapysky Nacional'noho Universytetu 'Kyjivo-Mohyljans'ka Akademija'”, 1998, 4, pp. 97-105.

V. Morenec', Nacional'ni šljachy poetyčnoho modernu peršoji polovyny XX st.: Ukrajina i Pol'šča, Kyjiv, Vydavnyctvo Solomiji Pavlyčko "Osnovy", 2002.

V. Morenec', U svobodi, in: M. Hryhoriv (a cura di), Kyjivs'ka poetyčna škola: Antolohija: Vybrane, Kyjiv, Presa Ukrajiny, 2013, pp. 7-17.

K. Moskalec', Strasti po vitčyzni: Lyst do mandrivnyka na Schid, "Krytyka", III, 1999, 6, pp. 4-14.

H. Motekat, Das Experiment des deutschen Expressionismus, in: H. G. Rötzer (a cura di), Begriffsbestimmung des 
Możejko 2007:

Müller-Seidel 1990:

Müller-Zettelmann 2005:

Murphy 1999:

Mychajlova 2016:

Myšanyč 2001:

Nachlik 2008:

Najenko 1998:

Najenko 2008:

Najenko 2010:

Nalyvajko 1991: literarischen Expressionismus, Darmstadt, Wissenschaftliche Buchgesellschaft, 1976, pp. 327-364 (Id., Experiment und Tradition. Vom Wesen der Dichtung im 20. Jahrhundert, Frankfurt a.M.-Bonn, Athenäum, 1962, pp. 79-109).

E. Możejko, Tracing the Modernist Paradigm: Terminologies of Modernism, in: A. Eysteinsson, V. Liska (a cura di), Modernism, Amsterdam-Philadelphia, John Benjamins, 2007, I, pp. 11-33.

W. Müller-Seidel, Lyrik, Tragik und Individualität in Goethes später Dichtung, in: G. Buhr, F. A. Kittler, H. Turk (a cura di), Das Subjekt der Dichtung: Festschrift für Gerhard Kaiser, Würzburg, Königshausen \& Neumann, 1990, pp. 498-518.

E. Müller-Zettelmann, "A Frenzied Oscillation”: Auto-Reflexivity in the Lyric, in: Ead., M. Rubik (a cura di), Theory into Poetry: New Approaches to Lyric, Amsterdam-New York, Rodopi, 2005, pp. 125-145.

Müller-Zettelmann, Rubik 2005: $\quad$ E. Müller-Zettelmann, M. Rubik, Introduction, in: Eaed. (a cura di), Theory into Poetry: New Approaches to Lyric, Amsterdam-New York, Rodopi, 2005, pp. 7-17.

R. Murphy, Theorizing the Avant-Garde: Modernism, Expressionism, and the Problem of Postmodernity, Cambridge, Cambridge University Press, 1999.

T. Mychajlova, Vasyl'Stus i rosijs 'ka literatura: formy transformaciji poetyčnoji tradyciji: dysertacija na zdobuttja naukovoho stupenja kandydata filolohičnych nauk, Kyjiv, Nacional'na Akademija Nauk Ukrajiny, Instytut Literatury im. T. H. Ševčenka, 2016.

S. Myšanyč, Narodnopoetyčna stychija v tvorčosti Vasylja Stusa, “Aktual'ni problemy ukrajins'koji literatury i fol'kloru”, 2001, 6, pp. 39-94.

Je. Nachlik, Dolja, in: N. Čamata (a cura di), Temy $i$ motyvy poeziji Tarasa Ševčenka, Kyjiv, Naukova dumka, 2008, pp. 162-184.

M. Najenko, Vasyl'Stus - “ostannijpoet”: ujakij šerenzi?, "Krynycja”, 1998, 1-6, pp. 53-56.

M. Najenko, Vasyl'Stus: pisljamodernyj tekst $i$ postmodernyj kontekst, “Aktual'ni problemy ukrajins'koji literatury i fol'kloru”, 2008, 12, pp. 39-56.

M. Najenko, Istorija ukrajins 'koho literaturoznavstva $i$ krytyky: Navčal'nyj posibnyk, Kyjiv, Akademia, 2010.

D. Nalyvajko, Vasyl'Stus - perekladač, "Vsesvit", 1991, 1, pp. 183-185. 
Nalyvajko 1995:

Narivskaja 2011:

Nesvit 2007:

Nesvit 2010:

Novičenko 1961:

Oberlin 2006:

Obertas 2010:

Olifirenko 2003:

Onikijenko 2001:

Oomen 1975:

Orač 1993:
D. Nalyvajko, Rainer Maria Rilke und die Ukraine als komplexes Problem, in: W. Kraus, D. Zatons'kyj (a cura di), Von Taras Ševčenko bis Joseph Roth: UkrainischÖsterreichische Literaturbeziehungen, Bern et al., Peter Lang, 1995, pp. 49-59.

V. Narivskaja, Kul'turnaja samoidentičnost' kak neobchodimost' žiznedejatel 'nosti: fenomen Vasilija Stusa, "Polilog: Studia neofilologiczne", 2011, 1, pp. 97-110.

“...Narode mij, do tebe ja šče vernu...”. Juvilejna včena rada Instytutu literatury im. Ševčenka NAN Ukrajiny, prysvjačena 70-littju Vasylja Stusa, "Slovo i čas", 2008, 3, pp. 3-11.

M. Naydan, Ukrainian Avant-garde Poetry Today: Bu$B a-B u$ and Others, "Slavic and East European Journal", L, 2006, 3, pp. 452-468.

S. Nesvit, Problema avtors'koho samovyražennja $u$ zbirci V. Stusa «Zymovi dereva», "Aktual'ni problemy ukrajins'koji literatury i fol'kloru”, 2007, 11, pp. 114-125.

S. Nesvit, Zbirka V. Stusa „Kruhovert'”: kody samorealizaciji, “Aktual'ni problemy ukrajins'koji literatury i fol'kloru”, 2010, 15, pp. 307-315.

L. Novičenko, Kniga živaja, sporjaščaja, "Voprosy literatury", 1961, 5, pp. 215-222.

G. Oberlin, »Doch tückisch harrt das Lebewohl zuletzt". Psychische Tiefenstrukturen und Bewußtseinsschichten in Goethes Marienbader »Elegie», "Goethe-Jahrbuch", 2006, 123, pp. 135-151.

O. Obertas, Ukrajins 'kyj samvydav: literaturna krytyka ta publicystyka (1960-i - počatok 1970-ch rokiv): monohrafija, Kyjiv, Smoloskyp, 2010.

L. Olifirenko, Slovnyk poetyčnoji movy Vasylja Stusa: (ridkovžyvani slova ta individual'no-avtors ' $k i$ novotvory), Kyjiv, Abrys, 2003.

I. Onikijenko, Filosofs'ke osmyslennja času u viršach V. Stusa i J.-V. Gete, “Aktual'ni problemy ukrajins'koji literatury i fol'kloru”, 2001, 6, pp. 186-192.

U. Oomen, On Some Elements of Poetic Communication, "Georgetown University Working Papers on Languages and Linguistics”, 1975, 11, pp. 60-68.

O. Orač (a cura di), “Ne vidljubyv svoju tryvohu rannju...”, Kyjiv, Ukrajins'kyj pys'mennyk, 1993. 
Ovsijenko 2007:

Ovsijenko 2013:

Pachl'ovs'ka 2000:

Parisi 2014:

Pastuch 2010:

Pavlova 1962:

Pavlychko 1996:

Pavlyčko 1999:

Pavlyšyn 1992a:

Pavlyšyn 1992b:

Pavlyshyn 2010:

Pen 1994:
Pachlovska 2017:

V. Ovsijenko, Vasyl'Stus u viddzerkalennjach: Spohady Vasylja Ovsijenka pro Vasylja Stusa, Poltava, RIK, 2007.

V. Ovsijenko (a cura di), Vasyl'Stus: Poet i Hromadjanyn: Knyha spohadiv to rozdumiv, Kyjiv, Klio, 2013.

O. Pachl'ovs'ka, Ukrajins'ki šistdesjatnyky: filosofija buntu, "Sučasnist", 2000, 4, pp. 65-84.

O. Pachlovska, The Poetry of the Sixtiers and Europe: Between Culture and Politics, in: G. Brogi Bercoff, M. Pavlyshyn, S. Plokhy (a cura di), Ukraine and Europe: Cultural Encounters and Negotiations, Toronto-BuffaloLondon, University of Toronto Press, 2017, pp. 390-413.

V. Parisi, Il lettore eccedente: Edizioni periodiche del samizdat sovietico, 1956-1990, Bologna, il Mulino, 2014.

T. Pastuch, Kyjivs 'ka škola ta jiji otočennja: (moderni styl'ovi tečiji ukrajins 'koji poeziji 1960-90-ch rokiv), L'viv, LNU imeni Ivana Franka, 2010.

N. Pavlova, Ekspressionizm i realizm, "Voprosy literatury", 1961, 5, pp. 120-141.

S. Pavlychko, Modernism vs. Populism in Fin de Siècle Ukrainian Literature: A Case of Gender Conflict, in: P. Chester, S.E.S. Forrester (a cura di), Engendering Slavic Literatures, Bloomington-Indianapolis, Indiana University Press, 1996, pp. 83-104.

S. Pavlyčko, Dyskurs modernizmu v ukrajins'kij literatury, Kyjiv, Lybid', 1999 (1997).

M. Pavlyšyn (a cura di), Stus jaktekst, Melbourne, Monash University - Slavic Section, 1992.

M. Pavlyšyn, Kvadratura kruha: prolohomeny do ocinky Vasylja Stusa, in: Id. (a cura di), Stus jak tekst, Melbourne, Monash University - Slavic Section, 1992, pp. 31-52.

M. Pavlyshyn, Martyrology and Literary Scholarship: The Case of Vasyl Stus, "Slavic and East European Journal", LIV, 2010, 4, pp. 585-606.

D. Pen, Dvojničestvo v russkoj sovetskoj lirike 19601980-ch, "Voprosy literatury"; 1994, 2, pp. 3-29.

Pesonen, Chejnonen, Obatnin 1996: $\quad$ P. Pejsonen, Ju. Chejnonen, G. Obatnin (a cura di), Studia russica helsingiensia et tartuensia $V$ : Modernizm i postmodernizm v russkoj literature $i$ kul'ture, Helsinki, Helsinki University Press, 1996.

Pestova 2004:

N. Pestova, Nemeckojazyčnyj ekspressionizm vosveščenii rossijskoj germanistiki, in: N. Pavlova (a cura di), 
Petersdorff 2005:

Pidhirnyj 2002:

Pidhirnyj 2003:

Pljušč 1987:

Pljušč 1991:

Pohorjelova 2010:

Pokal'čuk 1991:

Poliščuk 2011a:

Poliščuk 2011b:

Polivanov, Charer 1995:

Poljuha 2011:
Russkaja germanistika: Ežegodnik Rossijskogo sojuza germanistov: Tom I, Moskva, Jazyki slavjanskoj kul'tury, 2004, pp. 163-174.

D. von Petersdorff, Fliehfkräfte der Moderne: Zur IchKonstitution in der Lyrik des frühen 20. Jahrhunderts, Tübingen, Max Niemeyer, 2005.

B. Pidhirnyj (a cura di), Necenzurnyj Stus: Knyha u 2-ch častynach: Častyna 1, Ternopil', Pidručnyky i posibnyky, 2002.

B. Pidhirnyj (a cura di), Necenzurnyj Stus: Knyha u 2-ch častynach: Častyna 2, Ternopil', Pidručnyky i posibnyky, 2002.

L. Pljušč, Vbystvo poeta Vasylja Stusa, in: O. Zinkevyč, M. Francuženko (a cura di), Vasyl'Stus: v žytti, tvorčosti, spohadach ta ocinkach sučasnykiv, BaltimoreToronto, Ukrajins'ke Vydavnyctvo «Smoloskyp» im. V. Symonenka, 1987, pp. 285-301.

L. Pljušč, «Vil'hotno hojdajets ’ja zlamana vit'...», “Slovo i čas", 1991, 11, pp. 38-47.

O. Pohorjelova, Hermetyčna tradycija u liryci V. Stusa, “Aktual'ni problemy ukrajins'koji literatury i fol'kloru", 2010, 14, pp. 159-169.

Ju. Pokal'čuk, Vasyl' Stus i moje pokolinnja, "Dzvin", 1991, 7, pp. 131-137.

Ja. Poliščuk, Vasyl'Stus, šistdesjantyky i ukrajins'ka ideja, "Ivan Ohijenko i sučasna nauka ta osvita: naukovyj zbirnyk: serija istoryčna i filolohična", 2011, 8, pp. 222-229.

Ja. Poliščuk, Vasyl' Stus i ukrajins'kyj okcydentalizm, "Naukovi zapysky: Serija 'Filolohična'”, 2011, 21, pp. 273-285.

K. Polivanov, K. Charer, Zabytye perevody Borisa Pasternaka iz poezii nemeckogo ekspressionizma, in: K. Harer, H. Schaller (a cura di), Festschrift für Hans-Bernd Harder zum 60. Geburtstag, München, Otto Sagner, 1995, pp. 339-399.

V. Poljuha, Problema buttja ljudyny u tvorčosti Vasylja Stusa: ekzystencyjnyj vymir: avtoreferat dysertaciji na zdobuttja naukovoho stupenja kandydata filosofs ' $k y c h$ nauk, Kyjiv, Nacjonal'na Akademija pedahohičnych nauk Ukrajiny, 2011. 
Por 2009:

Possamai 2000:

Pott 2004:

Prosalova 2008:

Punina 2008:

Punina 2012:

Pustova 1998:

Pylypiuk 2002a:

Pylypiuk 2002b:

Rajbedjuk 2010a:

Rajbedjuk 2010b:

Rajbedjuk 2012:

Raryc'kyj 2002:
P. Por, Rilkes Zwetajewa-Elegie: Eine ars poetica der metaelegischen Schöpfung?, "Modern Austrian Literature”, XLII, 2009, 1, pp. 23-40.

D. Possamai, Che cos'è il postmodernismo russo?: Cinque percorsi interpretativi, Padova, il Poligrafo, 2000.

S. Pott, Poetiken: Poetologische Lyrik, Poetik und Ästhetik von Novalis bis Rilke, Berlin-New York, Walter de Gruyter, 2004.

V. Prosalova, Recepcija V. Stusa: postradjans'ka $i$ diasporna interpretaciji, "Aktual'ni problemy ukrajins'koji literatury i fol'kloru”, 2008, 12, pp. 255-267.

O. Punina, "Try masky..." (Substrat "teatral'noho dijstva" $i$ nadsubstratna konfiguracija v poezijach zbirky Vasylja Stusa "Veselyj cvyntar"), “Aktual'ni problemy ukrajins'koji literatury i fol'kloru”, 2008, 12, pp. 334-351.

O. Punina, "Za čytannjam Jasunari Kavabaty" Vasylja Stusa: dosvid osjajannja, "Slovo i čas", 2012, 5, pp. 50-57.

F. Pustova, Dejaki osoblyvosti pejzažnoji liryky $V$. Stusa: (zb. "Zymovi dereva»), "Aktual'ni problemy ukrajins'koji literatury i fol'kloru”, 1998, 2, pp. 66-72.

N. Pylypiuk, Vasyl'Stus, Mysticism, and the Great Narcissus, in: P. D. Morris (a cura di), A World of Slavic Literatures: Essays in Comparative Slavic Literatures in Honor of Edward Mozejko, Bloomington, Slavica, 2002, pp. 173-210.

N. Pylypiuk, Meditations on Stained Glass: Kholodny, Kalynets, Stus, "Journal of Ukrainian Studies", XXVII, 2002, 1-2, pp. 195-214.

H. Rajbedjuk, Paradygma tila v problemnomu poli chudožn'oji antropolohiji V. Stusa, "Istoryko-literaturnyj žurnal", 2010, 17, pp. 178-187.

H. Rajbedjuk, Eksplicytni formy intertekstual'nosti $u$ tvorčosti ukrajins 'kych poetiv-dysydentiv, "Aktual'ni problemy ukrajins'koji literatury i fol'kloru”, 2010, 15, pp. 243-253.

H. Rajbedjuk, Vyvčennja tvorčosti ukrajins 'kych poetivdysydentiv: Navčal'no-metodyčnyj posibnyk, Izmajil, RVV IDHU, 2012.

O. Raryc'kyj, Poezija herojičnoho čynu: Vasyl' Stus: evoljucija chudožn'oho myslennja, Chmel'nyc'kyj, Prosvita, 2002. 
Razumovskaja 2010:

Riedel 2003:

Rjabčuk 1999:

Rosins'ka 2010:

Rötzer 1976:

Rubčak 1980:

Rubčak 1987:

Rubin 1963:

Rüdiger 1990:

Rudnyc'kyj 1987:

Sakovec' 2011:

Sarževs'kyj 1992:

Savčak 1992:
A. Razumovskaja, Vertograd v poezii Serebrjanogo veka, "Russkaja reč",, 2010, 1, pp. 14-21.

W. Riedel, Bergbesteigung/Hadesfahrt. Topik und Symbolik der „Harzreise im Winter", "GoetheJahrbuch", 2003, 120, pp. 58-71.

M. Rjabčuk, ,,Nebiž Ril'ke” i ,, Syn Tarasa”, "Krytyka”, III, 1999, 6, pp. 14-19.

O. Rosins'ka, Symvolika poeziji V. Stusa: Monohrafija, Donec'k, Noulidž, 2010.

H. G. Rötzer, Einleitung, in: Id., Begriffsbestimmung des literarischen Expressionismus, Darmstadt, Wissenschaftliche Buchgesellschaft, 1976, pp. 1-16.

B. Rubčak, Shevchenko's Profiles and Masks: Ironic Roles of the Self in Kobzar, in: G. S. N. Luckyj (a cura di), Shevchenko and His Critics. 1861-1980, Toronto-BuffaloLondon, University of Toronto Press, 1980, pp. 395-429.

B. Rubčak, Peremoha nad prirvoju: Pro poeziju Vasylja Stusa, in: O. Zinkevyč, M. Francuženko (a cura di), Vasyl' Stus: v žytti, tvorčosti, spohadach ta ocinkach sučasnykiv, Baltimore-Toronto, Ukrajins'ke Vydavnyctvo «Smoloskyp» im. V. Symonenka, 1987, pp. 315-351 ("Sučasnist", 1983, 10, pp. 52-83).

B. Rubin, Uroki odnoj poetičeskoj biografii: (Zametki o lirike Evg. Evtušenko), "Voprosy literatury", 1963, 2, pp. 17-45.

H. Rüdiger, Die Metapher vom Herzen in der Literatur, in: Id., Goethe und Europa: Essays und Aufsätze 19441983, Berlin-New York, De Gruyter, pp. 117-159.

L. Rudnyc'kyj, Vasyl'Stus i nimec'ka literatura: Vidnošennja poeta do Gete i Ril'ke, in: O. Zinkevyč, M. Francuženko (a cura di), Vasyl'Stus: v žytti, tvorčosti, spohadach ta ocinkach sučasnykiv, BaltimoreToronto, Ukrajins'ke Vydavnyctvo «Smoloskyp» im. V. Symonenka, 1987, pp. 352-367.

S. Sakovec', Chaos ta kosmos jak elementy kosmohoničnoho mifu Vasylja Stusa, "Naukovi zapysky. Serija "filolohična"”, 2011, 21, pp. 325-333.

S. Sarževs'kyj, Praktyka duchovnoho tryvannja v poeziji Vasylja Stusa, in: M. Pavlyšyn (a cura di), Stus jak tekst, Melbourne, Monash University - Slavic Section, 1992, pp. 63-77.

P. Savčak, Poetyka vidpovidal'nosty i vidpovidal'nist 'krytyky: dekanonizacija tvorčoji osobystosty i tvorčosty Vasylja 
Savčuk 2010:

Schlaffer 1995:

Schmid 1986:

Schmidt 1983:

Schneider 1961:

Schober 1986:

Schönert 1999:

Schwartz 1997:

Schwarz 2000:

Seemann 1984:
Stusa, in: M. Pavlyšyn (a cura di), Stus jak tekst, Melbourne, Monash University - Slavic Section, 1992, pp. 79-91.

H. Savčuk, Semantyčnyj pik poeziji V. Stusa «Posoloviv od spivu sad...», "Visnyk Charkivs'koho Nacional'noho Universytetu. Serija: Filolohija”, 2010, 910, pp. 231-234.

H. Schlaffer, Die Aneignung von Gedichten: Grammatisches, rhetorisches und pragmatisches Ich in der Lyrik, "Poetica", 1995, 27, pp. 38-55.

H. Schmid, Postmodernism in Russian Drama: Vampilov, Amalrik, Aksënov, in: D. W. Fokkema, H. Bertens (a cura di), Approaching Postmodernism: Papers presented at a Workshop on Postmodernism, 21-23 September 1984, University of Utrecht, Amsterdam-Philadelphia, John Benjamins, 1986, pp. 157-184.

J. Schmidt, Goethes Bestimmung der dichterischen Existenz im Übergang zur Klassik: "Harzreise im Winter", "Deutsche Vierteljahrsschrift für Literaturwissenschaft und Geistesgeschichte", LVII, 1983, 4, pp. 613-635.

K. L. Schneider, Der bildhafte Ausdruck in den Dichtungen Georg Heyms, Georg Trakls und Ernst Stadlers: Studien zum lyrischen Sprachstil des deutschen Expressionismus, Heidelberg, Carl Winter, 1961 (1954).

R. Schober, Wanderers Nachtlied von Johann Wolfgang Goethe: Ein Gedicht, seine Entstehung und Nachwirkung, in: J. Riesz, P. Boerner, B. Scholz (a cura di), Sensus communis: Contemporary Trends in Comparative Literature: Panorama de la situation actuelle en Littérature Comparée, Tübingen, Narr, 1986, pp. 343-356.

J. Schönert, Empirischer Autor, Implizierter Autor und Lyrisches Ich, in: F. Jannidis et al. (a cura di), Rückkehr des Autors: Zur Erneuerung eines umstrittenen Begriffs, Tübingen, Max Niemeyer, 1999, pp. 289-294.

S. Schwartz, The Postmodernity of Modernism, in: H. Witemeyer (a cura di), The Future of Modernism, Ann Arbor, The University of Michigan Press, 1997, pp. 9-31.

E. Schwarz, Das verschluckte Schluchzen. Poesie und Politik bei Rainer Maria Rilke, in: Id., "Ich bin kein Freund allgemeiner Urteile über ganze Völker": Essays über österreichische, deutsche und jüdische Literatur, Berlin, Erich Schmidt, 2000, pp. 176-194.

K. D. Seemann, Die Kommunikationsstruktur im lyrischen Gedicht, in: J. R. Döring-Smirnov, P. Rehder, W. Schmid (a cura di), Text Symbol Weltmodell: Johannes Holthusen 
zum 60. Geburtstag, München, Otto Sagner, 1984, pp. 533-554.

Seemann 1988:

Ševel'ov 1987:

Shallcross, Nycz 2011:

Shkandrij 2001:

Sheppard 1993:

Simonek 1992:

Šistdesjatnyctvo jak javyšče, joho vytoky j naslidky 1997: $\quad$ Šistdesjatnyctvo jak javyšče, joho vytoky j naslidky, "Slovo i čas", 1997, 8, pp. 40-55.

Skovoroda Online Concordance: $\quad<$ http://www.artsrn.ualberta.ca/skovoroda/> (ultimo accesso: 20-04-2018)

Slavutych 1983:

Y. Slavutych, Einheit der Seelen: Die Poesie von Vasyl' Stus, "Jahrbuch der Ukrainekunde", 1983, pp. 207-220.

Šmidt 2007:

V. Šmidt, Religioznyj i molitvennyj motiv v poezii poètovuznikov GULAGa, "Slavia Orientalis", LVI, 2007, 2, pp. 203-211.

Šmilo 2006:

H. Šmilo, Imennyky-okazionalizmy v poeziji V. Stusa, "Moloda nacija", 2006, 1, pp. 206-228.

Smirnov 1985:
I. Smirnov, Poroždenie interteksta: (elementy interkestual'nogo analiza s primerami iz tvorčestva B. L. Pasternaka), "Wiener Slawistischer Almanach", Sonderband 17, Wien, 1985. 
Smirnova 2013:

Sodomora 2006:

Solovej 1999:

Solovej 2008:

Solovej 2009:

Solovej 2011:

Solovej, Punina 2016a:

Solovej, Punina 2016b:

Spanos 1976:

Stahl 2006/2007:

Stahl 2017:

Steiner 1991:

Stephens 1982:
E. Smirnova, Pole dlja manevrov? Filosofskie perevody $v$ SSSR v 1970-e gg. (na primere francuzskoj filosofii), in: AAVV, Konstruiruja «sovetskoe»?: Političeskoe soznanie, povsednevnye praktiki, novye identičnosti: Materialy naučnoj konferencii studentov $i$ aspirantov: 19-20 aprelja 2013 goda, Sankt-Peterburg, SanktPeterburg, Izdatel'stvo Evropejskogo Universiteta v Sankt-Peterburge, 2013, pp. 124-130.

A. Sodomora, Studiji odnoho virša, L'viv, Litopys, 2006.

E. Solovej, Ukrajins 'ka filosofs 'ka liryka, Kyjiv, Junivers, 1999.

O. Solovej, Zbirka Vasylja Stusa "Veselyj cvyntar" $i$ pytannja styl'ovoji dynamiky, "Aktual'ni problemy ukrajins'koji literatury i fol'kloru”, 2008, 12, pp. 279-294.

O. Solovej, Modusy chudožn'oji prozy Vasylja Stusa: (travmatyčnyj dosvid ljudyny ta etyka oporu literatury), "Aktual'ni problemy ukrajins'koji literatury i fol'kloru", 2009, 13, pp. 322-333.

E. Solovej, «Jaka nesterpna ridna čužyna!». (Imaholohični aspekty poeziji Vasylja Stusa), "Literaturna komparatyvistyka”, IV, 2011, 1, pp. 214-251.

O. Solovej, O. Punina, Stusoznavči zošyty: Zošyt peršyj, Vinnycja, Prostir literatury, 2016.

O. Solovej, O. Punina, Stusoznavči zošyty: Zošyt druhyj, Vinnycja, Prostir literatury, 2016.

W. Spanos, Heidegger, Kierkegaard and the Hermeneutic Circle: Towards a Postmodern Theory of Interpretation as Dis-closure, "boundary 2", IV, 1976, 2, pp. 455-488.

A. Stahl, Rilkes Franz von Assisi: Spuren, Kontekst, Ethik, "Blätter der Rilke-Gesellschaft", 2006-2007, 27-28, pp. 32-48.

H. Stahl, Towards a Historical Typology of the Subject in Lyric Poetry, "Journal of Literary Theory", XI, 2017, 1, pp. 125-135.

J. Steiner, Rilke und Goethe, "Blätter der RilkeGesellschaft", 1991, 18, pp. 23-35.

A. Stephens, Überlegungen zum lyrischen Ich, in: T. Elm, G. Hemmerich (a cura di), Zur Geschichtlichkeit der Moderne: Der Begriff der literarischen Moderne in Theorie und Deutung: Ulrich Fülleborn zum 60. Geburtstag, München, Wilhelm Fink, 1982, pp. 53-67. 
Stock 2005:

Stricha 2006:

Stus 1992:

Stus 2000a:

Stus 2005:

Stus 2008b:

Stusivs 'ki čytannja 1998:

Šum 1970:

Surikova 2013:

Svjato 2007:

Syvokin' 2001:

Tarnašyns'ka 2008a:

Tarnašyns'ka 2008b:

Tarnašyns'ka 2010:
U. B. C. Stock, The Ethics of the Poet: Marina Tsvetaeva's Art in the Light of Conscience, London, Modern Humanities Research Association, 2005.

M. Stricha, Ukrajins'kyj chudožnij pereklad: miž literaturoju i nacijetvorennjam, Kyjiv, Fakt, 2006.

D. Stus, Žyttja i tvorčist' Vasylja Stusa, Kyjiv, Fotovideoservis, 1992.

D. Stus, Berehamy konspektiv V. Stusa, "Slovo i čas", 2000, 9, pp. 42-44.

D. Stus, Vasyl'Stus: žyttja jak tvorčist', Kyjiv, Fakt, 2005.

D. Stus, Dialoh iz tekstom, “Kyjivs'ka Rus"”, 2008, 5, pp. 35-36.

Stusivs 'ki čytannja, "Slovo i čas”, 1998, 6, pp. 17-28.

A. Šum, Poezija Vasylja Stusa, in: V. Stus, Zymovi dereva: perša zbirka poezij, Bruxelles (?), Literatura i mystectvo, 1970, pp. 1-8.

O. Surikova, Russkij samizdat 1960-1980-ch godov: Sud'ba poezii modernistov i ee tradicii. Moskovskie tvorčeskie ob"edinenija i periodičeskie izdanija: avtoreferat dissertacii na soiskanie učënoj stepeni kandidata filologičeskich nauk, Moskva, Moskovskij Gosudarstvennyj Universitet imeni M. V. Lomonosova, 2013.

R. Svjato, Problema literaturnych pokolin': “period bezčassja” $i$ ukrajins'ka poezija 70-ch rokiv XX st., "Naukovi zapysky Nacional'noho Universytetu 'KyjivoMohyljans'ka Akademija'”, 2007, 72, pp. 67-73.

H. Syvokin', Vasyl'Stus i Ševčenko, “Dyvoslovo”, 2001, 10, pp. 5-6.

L. Tarnašyns'ka, Prezumpcija docil'nosti: Abrys sučasnoji literaturoznavčoji konceptolohiji, Kyjiv, KyjivoMohyljans'ka Akademija, 2008.

L. Tarnašyns'ka, Imperatvy ščyrosti v chudožn'oestetyčnij paradyhmi Ivana Franka ta joho interpretacija Vasylem Stusom, in: Ead., Prezumpcija docil'nosti: Abrys sučasnoji literaturoznavčoji konceptolohiji, Kyjiv, Kyjivo-Mohyljans'ka Akademija, 2008, pp. 71-83.

L. Tarnašyns'ka, Ukrajins'ke šistdesjatnyctvo: profili na tli pokolinnja: (Istoryko-literaturnyj ta poetykal'nyj aspekty), Kyjiv, Smoloskyp, 2010. 
Tarnašyns'ka 2013:

Tarnavs'kyj 1987:

Tarnavs'kyj 2000:

Titzmann 1998:

Tromly 2009:

Ulbrechtová 2009:

Uškalov 2014:

Vasyl'čenko-Kaverina 2011:

Venclova 1994:

Veretelnyk 2016:

Virolajnen 2005:

Vitins 1977:
L. Tarnašyns'ka, Dyskurs doby: dyskurs šistdesjatnyctva $v$ ukrajins'kij literaturi XX stolittja, Kyjiv, Akademperiodyka, 2013.

O. Tarnavs'kyj, Znajomstvo z poetom Vasylem Stusom, in: O. Zinkevyč, M. Francuženko (a cura di), Vasyl' Stus: v žytti, tvorčosti, spohadach ta ocinkach sučasnykiv, Baltimore-Toronto, Ukrajins'ke Vydavnyctvo «Smoloskyp» im. V. Symonenka, 1987, pp. 302-314 (Al'manach UNS, Jersey City, 1983, pp. 134-147).

Ju. Tarnavs'kyj, Temna storona misjacja, "Krytyka”, IV, 2000, 7-8, pp. 4-10.

M. Titzmann, Vom »Sturm und Drang« zur »Klassik«: »Grenzen der Menschheit« und "Das Göttliche« - Lyrik als Schnittpunkt der Diskurse, "Jahrbuch der deutschen Schillergesellschaft", 1998, 42, pp. 42-63.

B. Tromly, An Unlikely National Revival: Soviet Higher Learning and the Ukrainian "Sixtiers," 1953-65, "The Russian Review”, 2009, 68, pp. 607-622.

H. Ulbrechtová: Ruská poezie druhé poloviny 20. stoleti: Úvahy o teorii, literární historii a filozofii, Praha, Slovanský ústav AV ČR, 2009.

L. Uškalov, Moja ševčenkivs 'ka encyklopedija: iz dosvidu samopiznannja, Charkiv, Majdan, 2014.

N. Vasyl'čenko-Kaverina, Muzyčni motyvy v perekladach Vasylja Stusa ta jich uposlidžennja u joho oryhinal'nij tvorčosti, "Mandrivec", 2011, 2, pp. 78-82.

T. Venclova, Poema gory $i$ Poema konca Mariny Cvetaevoj kak Vetchij Zavet i Novyj Zavet, in: V. Schweitzer et al. (a cura di), Marina Tsvetaeva: One Hundred Years: Papers from the Tsvetaeva Centenary Symposium: Amherst College, Amherst, Massachusetts, 1992, Oakland, Berkeley Slavic specialties, 1994, pp. 147-161.

R. Veretelnyk, Found in Translation: Vasyl Stus and Rudyard Kipling's "If", "Kyiv-Mohyla Humanities Journal”, 2016, 3, pp. 161-186.

M. Virolajnen: Poterjannoe «Ja»: o poetičeskom samosoznanii Zolotogo i Serebrjanogo veka, in: N. Buks (a cura di), Semiotika bezumija, Pariž-Moskva, Sorbonna-Russkij institut, 2005, pp. 85-94.

I. Vitins, Escape from Earth: A Study of Tsvetaeva's Elsewheres, "Slavic Review", XXXVI, 1977, 4, pp. 644-657. 
Vivat 2003:

Vivat 2008:

Voljans'ka 1987:

Waldschmidt 2011:

Walisch 2012

Waters 2003:

Weber 2007:

Weststeijn 2000:

Windrich 2012:

Woldan 2002:

Wolf 2005:
H. Vivat, Chudožni osoblyvosti ta providni motyvy poetyčnoji tvorčosti Vasylja Stusa, Odesa, Studija "Negocijant", 2003.

H. Vivat, Ivan Franko i Vasyl Stus: Frankivs 'ki motyvy $v$ poeziji Vasylja Stusa, "Dyvoslovo", 2008, 1, pp. 44-48.

L. Voljans'ka, "Proščaj, Ukrajino, moja Ukrajino, čuža Ukrajino, naviky proščaj!"”, in: O. Zinkevyč, M. Francuženko (a cura di), Vasyl'Stus: v žytti, tvorčosti, spohadach ta ocinkach sučasnykiv, BaltimoreToronto, Ukrajins'ke Vydavnyctvo «Smoloskyp» im. V. Symonenka, 1987, pp. 402-423 ("Naše žyttja", 1985, 10, pp. 2-122).

C. Waldschmidt, “Dunkles zu sagen”: Deutschsprachige hermetische Lyrik im 20. Jahrhundert, Heidelberg, Winter, 2011.

R. Walisch, "Daß wir nicht sehr verläßlich zu Haus sind in der gedeuteten Welt": Untersuchung zur Thematik der gedeuteten Welt in Rilkes "Die Aufzeichnungen des Malte Laurids Brigge”, "Duineser Elegien" und spätester Lyrik, Würzburg, Königshausen \& Neumann, 2012.

W. Waters, Poetry's Touch: On Lyric Address, IthacaLondon, Cornell University Press, 2003.

C. Weber, Goethes Ganymed und der Sündenfall der Ästhetik, "Deutsche Vierteljahrsschrift für Literaturwissenschaft und Geistesgeschichte", LXXXI, 2007, 3, pp. 317-345.

W. G, Weststeijn, The Subject in Modern Russian Poetry, in: Id., W. Van Reijen (a cura di), Subjectivity, Amsterdam-Atlanta, Rodopi, 2000, pp. 169-192.

J. Windrich, Götter im Zwielicht. Zur Hymnendichtung des jungen Goethe, "Poetica", XLIV, 2012, 1-2, pp. 143-179.

A. Woldan, Dichtung als Alternative zur Unterdrückung. Zur Lyrik von Vasyl'Stus, in: M. Zybura (a cura di), Geist und Macht: Schriftsteller und Staat im Mitteleuropa des ,,kurzen Jahrhunderts” 1914-1991, Dresden, Thelem, 2002, pp. 373-383.

W. Wolf, The Lyric: Problems of Definition and a Proposal for Reconceptualisation, in: E. Müller-Zettelmann, M. Rubik (a cura di), Theory into Poetry: New Approaches to Lyric, Amsterdam-New York, Rodopi, 2005, pp. 21-56. 
Wrathall, Dreyfus 2006:

Wünsch 1991:

Wünsch 1998:

Yekelchyk 2015:

Zabuzhko 1995:

Zagari 1991:

Zahorujko 2012:

Zahrebel'na 2006:

Zalambani 2009:

Žakkar 2013:

Zarec'kyj 1995:
M. A. Wrathall, H. L. Dreyfus, A Brief Introduction to Phenomenology and Existentialism, in: Id. (a cura di), A Companion to Phenomenology and Existentialism, Malden-Oxford-Carlton, Blackwell Publishing, 2006, pp. 1-6.

M. Wünsch, Zeichen - Bedeutung - Sinn: Zu den Problemen der späten Lyrik Goethes am Beispiel der „, Trilogie der Leidenschaft “, "Goethe-Jahrbuch”, 1991, 108, pp. 179-190.

M. Wünsch, Das lyrische Werk Johann Wolfgang von Goethes, in: D. Jöns, D. Lohmeier (a cura di), Festschrift für Erich Trunz zum 90. Geburtstag: Vierzehn Beiträge zur deutschen Literaturgeschichte, Neumünster, Wachholtz, 1998, pp. 75-90.

S. Yekelchyk, The Early 1960s as a Cultural Space: a Microhistory of Ukraine's Generation of Cultural Rebels, "Nationalities Papers", XLIII, 2015, 1, pp. 45-62.

O. Zabuzhko, Reinventing the Poet in Modern Ukrainian Culture, "Slavic and East European Journal", XXXIX, 1995, 2, pp. 270-275.

L. Zagari, Der Lyriker Goethe: Der erste der Modernen, der letzte der Vormodernen, "Goethe-Jahrbuch", 1991, 108, pp. 117-127.

N. Zahorujko, Literaturoznavča koncepcija Ivana Svitlyčnoho ta literaturna krytyka: (na materiali epistoljarnoji spadščyny dysydenta), "Slovo i čas", 2012, 5, pp. 57-67.

N. Zahrebel'na, Sam na sam iz soboju: vnutrišnij sub"jektnyj synkretyzm u poeziji V. Stusa, "Moloda nacija", 2006, 1, pp. 70-79.

M. Zalambani, Censura, istituzioni e politica letteraria in URSS (1964-1985), Firenze, Firenze University Press, 2009.

Ž.-F. Žakkar, "Antimoderny» v strane sovetov: ot avangarda $k$ andegraundu, in: Id., V. Fridli, J. Cherl't (a cura di), "Vtoraja kul'tura»: neoficial'naja poezija Leningrada v 1970-1980-e gody: Materialy meždunarodnoj konferencii (Ženeva, 1-3 marta 2012 g.), Sankt-Peterburg, Rostok, 2013, pp. 18-29.

O. Zarec'kyj, Ukrajins 'ki šistdesjatnyky i chruščovs 'ka vidlyha v etnokul 'turnomu prostori CPCP, "Sučasnist", 1995, 4, pp. 113-125. 
Zav'jalov 2013:

Zborovs'ka 2009a:

Zborovs'ka 2009b:

Zelinsky 1974:

Zelinsky 1975:

Ziegler 1993:

Zima 2001:

Žirmunskij 1937:

Žitenev 2012:

von Zitzewitz 2012:

Zholkovsky 1988:

Žolkovskij 2011:
S. Zav'jalov, Retromodernizm v leningradskoj poezii 1970-ch godov, in: Ž.-F. Žakkar, V. Fridli, J. Cherl't (a cura di), "Vtoraja kul'tura»: neoficial'naja poezija Leningrada v 1970-1980-e gody: Materialy meždunarodnoj konferencii (Ženeva, 1-3 marta 2012 g.), Sankt-Peterburg, Rostok, 2013, pp. 30-52.

N. Zborovs'ka, Vasyl'Stus i sakramental'nist': mason cy chrystyjanyn?, "Kur”jer Kryvbasu”, 2009, 230-231, pp. 311-324.

N. Zborovs'ka, Vasyl' Stus: do istoriji problemnoho tlumačennja, "Dyvoslovo", 2009, 5, pp. 40-46.

B. Zelinsky, Definitionen der Poesie bei Pasternak, "Zeitschrift für slavische Philologie", XXXVII, 1974, 2, pp. 275-290.

B. Zelinsky, Selbstdefinitionen der Poesie bei Pasternak, "Zeitschrift für slavische Philologie", XXXVIII, 1975, 2, pp. 268-278.

H. Ziegler, The End of Postmodernism: New Directions, in: Ead. (a cura di), The End of Postmodernism: New Directions: Proceedings of the First Stuttgart Seminar in Cultural Studies 04. 08.-18. 08. 1991, Stuttgart, M\&P, 1993, pp. 5-10.

P. V. Zima, Das literarische Subjekt: Zwischen Spätmoderne und Postmoderne, Tübingen-Basel, A. Francke, 2001.

Zinkevyč, Francuženko 1987: O.Zinkevyč, M. Francuženko(a cura di), Vasyl'Stus: vžytti, tvorčosti, spohadach ta ocinkach sučasnykiv, BaltimoreToronto, Ukrajins'ke Vydavnyctvo «Smoloskyp» im. V. Symonenka, 1987.

V. Žirmunskij, Gete v russkoj literature, Leningrad, Chudožestvennaja literatura, 1937.

A. Žitenev, Poezija neomodernizma, Sankt-Peterburg, Inapress, 2012.

J. von Zitzewitz, Viktor Krivulin and Aleksandr Mironov: The Quest for Sacred Language in 1970s Russian Poetry, “Modern Language Review”, CVII, 2012, 3, pp. 872-893.

A. Zholkovsky, Intertextuality, Its Content and Discontents, "Slavic Review", XLVII, 1988, 4, pp. 726-729.

A. Žolkovskij, Poetičeskij mir Pasternaka, in: Id., Poetika Pasternaka: Invarianty, struktury, interteksty, Moskva, NLO, 2011, pp. 10-24. 
Žovtani 2007:

Zubova 1993:

Zubova 2002:

Žulyns'kyj 1990:

Zyla 1989:

Žylin 2008:
R. Žovtani, Nimec 'kyj ekspresionizm vocinci Jurija Klena, “Visnyk Kyjivs'koho Nacional'noho Universytetu imeni Tarasa Ševčenka: Literaturoznavstvo - movoznavstvo fol'klorystyka", 2007, 18, pp. 8-11.

L. Zubova, “Mesto pusto” v poezii Mariny Cvetaevoj, in: V. Polukhina, J. Andrew, R. Reid (a cura di), Literary Tradition and Practice in Russian Culture: Papers from an International Conference on the Occasion of the Seventieth Birthday of Yuri Mikhailovich Lotman: Russian Culture: Structure and Tradition: 2-6 July 1992, Keele University, United Kingdom, Amsterdam-Atlanta, Rodopi, 1993, pp. 177-189.

L. Zubova, Nebo Mariny Cvetaevoj: slovo v kontekste tvorčestva, in: V. Lossky, J. De Proyart (a cura di), Marina Tsvétaeva et la France : Nouveautés et Inédits, Paris-Moskva, Institut d'Études Slaves-Russkij put', 2002, pp. 42-54.

M. Žulyns'kyj, Iz zabuttja-v bezsmertja (Storinky pryzabutoji spadščyny), Kyjiv, Dnipro, 1990.

W. Zyla, Johann Wolfgang Goethe in der ukrainischen Literatur, München, Ukrainische Freie Universität, 1989.

M. Žylin, Vzajemodija viršovoho i prozovoho rytmiv $u$ literaturno-krytyčnych stattjach Vasylja Stusa, "Aktual'ni problemy ukrajins'koji literatury i fol'kloru”, 2008, 12, pp. 323-333. 



\section{Abstract \\ The Poetry of Vasyl' Stus: Modernism and Intertextuality in Late Soviet Ukraine}

This book explores the poetry of Vasyl' Stus (1938-1985), a major Ukrainian writer and intellectual of the second half of the $20^{\text {th }}$ century. The volume aims to present the evolution of Stus' poetic oeuvre from his beginnings in the late 1950s up to his mature poetry of the 1970s. Moreover, it analyses the complex intertextual network of Stus' dialogue with German, Russian and Ukrainian literature and puts these intertextual relations in the context of the history of modernist poetry. The first chapter includes a brief sketch of Stus' biography, a discussion of the cultural setting of his human and artistic growth, as well as a critical survey of secondary literature on Stus' life and work. Stus' move to Kyiv at the beginning of the 1960s coincides with the final phase of the Thaw. The historical and literary specificity of the Ukrainian šistdesjatnyctvo, which promoted a fundamental and manifold renewal of Ukrainian culture in the Soviet framework, is at the core of the chapter. The history of Stus' reception shows how his complex and highly intellectual modernist literary legacy has not been hitherto aptly studied. The second chapter deals with Stus' literary essays and letters, with particular attention to his frequent remarks on literature. Stus' dissatisfaction with several trends in the development of Ukrainian literature clearly shows his willingness to contribute actively to its modernisation. His many observations on the poetry of Rainer Maria Rilke, Boris Pasternak and other writers confirm his deep interest in their work and justify the search for intertextual links with them in his own production. The third chapter analyses Stus' juvenilia, which include his first literary endeavours, his early collections Delo №13 / BE1339 and Kruhovert', and his ungathered poems of the 1960s. Stus' early productions shows the strivings of a young and talented poet in search of his own poetic voice among several stylistic and thematic influences, among which his dialogue with his most important literary models is already recognisable. The fourth chapter focuses on Zymovi dereva and Veselyj cvyntar, Stus' collections of the late 1960s. The strong differences in inspiration and style between the two collections, composed after Stus' first with clash with the Soviet authorities in 1965, are a demonstration of the striking variety of Stus' art in its central period and of the relative independence of Stus' poetics from his biography. The fifth chapter offers an analysis of Stus' masterpieces, Čas tvorčosti / Dichtenszeit and Palimpsesty, both composed in the 1970s after Stus' first arrest in 1972. The study of the differences 
and similarities between the two collections provides a key to understanding the complexity of Stus' mature modernist art. The sixth and last chapter discusses Stus' modernist poetics in the context of the history of European and Ukrainian poetry of the $20^{\text {th }}$ century. This implies a synthesis of the intertextual connections analysed in the preceding chapters, with the aim of identifying the main features of Stus' dialogue with his preferred interlocutors, such as Rilke, Pasternak, Goethe, Cvetaeva and Ševčenko. 


\section{BiblioteCA DI StUdI SLAVISTICI}

1. Nicoletta Marcialis, Introduzione alla lingua paleoslava, 2005

2. Ettore Gherbezza, Dei delitti e delle pene nella traduzione di Michail M. Ščerbatov, 2007

3. Gabriele Mazzitelli, Slavica biblioteconomica, 2007

4. Maria Grazia Bartolini, Giovanna Brogi Bercoff (a cura di), Kiev e Leopoli: il "testo" culturale, 2007

5. Maria Bidovec, Raccontare la Slovenia. Narratività ed echi della cultura popolare in Die Ehre Dess Hertzogthums Crain di J.W. Valvasor, 2008

6. Maria Cristina Bragone, Alfavitar radi učenija malych detej. Un abbecedario nella Russia del Seicento, 2008

7. Alberto Alberti, Stefano Garzonio, Nicoletta Marcialis, Bianca Sulpasso (a cura di), Contributi italiani al XIV Congresso Internazionale degli Slavisti (Ohrid, 10-16 settembre 2008), 2008

8. Maria Di Salvo, Giovanna Moracci, Giovanna Siedina (a cura di), Nel mondo degli Slavi. Incontri e dialoghi tra culture. Studi in onore di Giovanna Brogi Bercoff, 2008

9. Francesca Romoli, Predicatori nelle terre slavo-orientali (XI-XIII sec.). Retorica e strategie comunicative, 2009

10. Maria Zalambani, Censura, istituzioni e politica letteraria in URSS (1964-1985), 2009

11. Maria Chiara Ferro, Santità e agiografia al femminile. Forme letterarie, tipologie e modelli nel mondo slavo orientale (X-XVII sec.), 2010

12. Evel Gasparini, Il matriarcato slavo. Antropologia culturale dei Protoslavi, 2010

13. Maria Grazia Bartolini, "Introspice mare pectoris tui". Ascendenze neoplatoniche nella produzione dialogica di H.S. Skovoroda (1722-1794), 2010

14. Alberto Alberti, Ivan Aleksandăr (1331-1371). Splendore e tramonto del secondo impero bulgaro, 2010

15. Paola Pinelli (a cura di), Firenze e Dubrovnik all'epoca di Marino Darsa (1508-1567). Atti della giornata di studi - Firenze, 31 gennaio 2009, 2010

16. Francesco Caccamo, Pavel Helan, Massimo Tria (a cura di), Primavera di Praga, risveglio europeo, 2011

17. Maria Di Salvo, Italia, Russia e mondo slavo. Studi filologici e letterari, 2011

18. Massimo Tria, Karel Teige fra Cecoslovacchia, URSS ed Europa. Avanguardia, utopia e lotta politica, 2012

19. Marcello Garzaniti, Alberto Alberti, Monica Perotto, Bianca Sulpasso (a cura di), Contributi italiani al XV Congresso Internazionale degli Slavisti (Minsk, 20-27 agosto 2013), 2013

20. Persida Lazarević Di Giacomo, Sanja Roić (a cura di), Cronotopi slavi. Studi in onore di Marija Mitrović, 2013

21. Danilo Facca, Valentina Lepri (edited by), Polish Culture in the Renaissance, 2013 
22. Giovanna Moracci, Alberto Alberti (a cura di), Linee di confine. Separazioni e processi di integrazione nello spazio culturale slavo, 2013

23. Marina Ciccarini, Nicoletta Marcialis, Giorgio Ziffer (a cura di), Kesarevo Kesarju. Scritti in onore di Cesare G. De Michelis, 2014

24. Anna Bonola, Paola Cotta Ramusino, Liana Goletiani (a cura di), Studi italiani di linguistica slava. Strutture, uso e acquisizione, 2014

25. Giovanna Siedina (edited by), Latinitas in the Polish Crown and the Grand Duchy of Lithuania. Its Impact on the Development of Identities, 2014

26. Alberto Alberti, Marcello Garzaniti, Stefano Garzonio (a cura di), Contributi italiani al XIII Congresso Internazionale degli Slavisti (Ljubljana, 15-21 agosto 2003), 2014

27. Maria Zalambani, L'istituzione del matrimonio in Tolstoj. Felicità familiare, Anna Karenina, La sonata a Kreutzer, 2015

28. Sara Dickinson, Laura Salmon (edited by), Melancholic Identities, Toska and Reflective Nostalgia. Case Studies from Russian and Russian-Jewish Culture, 2015

29. Luigi Magarotto, La conquista del Caucaso nella letteratura russa dell'Ottocento. Puškin, Lermontov, Tolstoj, 2015

30. Claudia Pieralli, Il pensiero estetico di Nikolaj Evreinov tra teatralità e 'poetica della rivelazione', 2015

31. Valentina Benigni, Lucyna Gebert, Julija Nikolaeva (a cura di), Le lingue slave tra struttura e uso, 2016

32. Gabriele Mazzitelli, Le pubblicazioni dell'Istituto per l'Europa orientale. Catalogo storico (1921-1944), 2016

33. Luisa Ruvoletto, I prefissi verbali nella Povest'vremennych let. Per un'analisi del processo di formazione dell'aspetto verbale in russo, 2016

34. Alberto Alberti, Maria Chiara Ferro, Francesca Romoli (a cura di), Mosty mostite. Studi in onore di Marcello Garzaniti, 2016

35. Pina Napolitano, Osip Mandel'štam: i quaderni di Mosca, 2017

36. Claudia Pieralli, Claire Delaunay, Eugène Priadko, Russia, Oriente slavo e Occidente europeo. Fratture e integrazioni nella storia e nella civiltà letteraria, 2017

37. Alessandro Farsetti, Una voce parigina nel Futurismo russo: la poesia di Ivan Aksenov, 2017

38. Giovanna Siedina, Horace in the Kyiv Mohylanian Poetics $\left(17^{\text {th }}\right.$-First Half of the $18^{\text {th }}$ Century). Poetic Theory, Metrics, Lyric Poetry, 2017

39. Rosanna Benacchio, Alessio Muro, Svetlana Slavkova (edited by), The Role of Prefixes in the Formation of Aspectuality. Issues of Grammaticalization, 2017

40. Maria Chiara Ferro, Laura Salmon, Giorgio Ziffer (a cura di), Contributi italiani al XVI Congresso Internazionale degli Slavisti. Belgrado, 20-27 agosto 2018, 2018 

